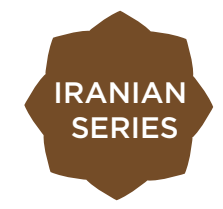

\title{
LOCAL PORTRAITURE
}

THROUGH THE LENS OF THE 19TH CENTURY IRANIAN PHOTOGRAPHERS

\author{
Carmen Pérez González
}

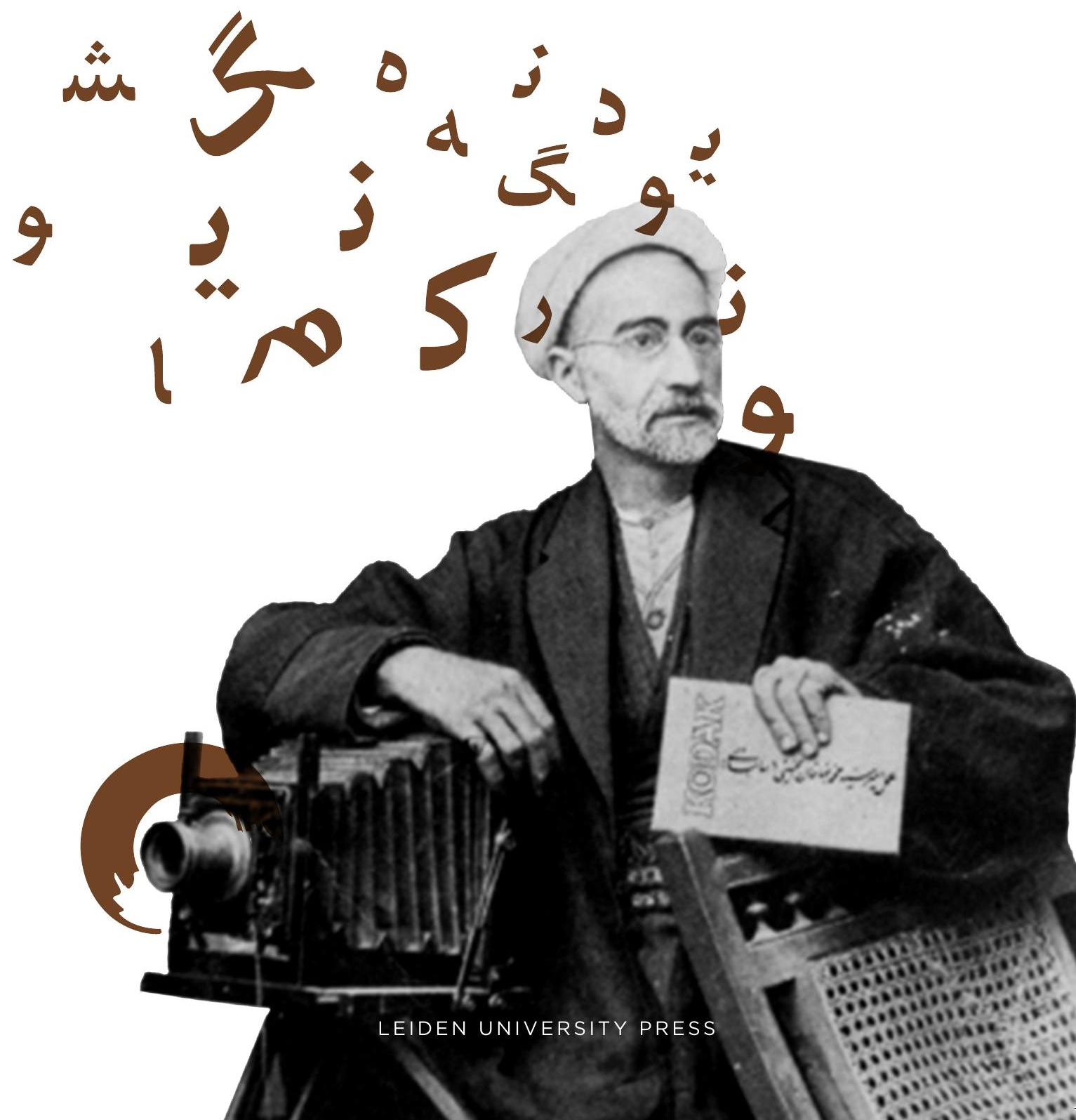




\section{Local Portraiture}




\section{Iranian Studies Series}

The Iranian Studies Series publishes high-quality scholarship on various aspects of Iranian civilisation, covering both contemporary and classical cultures of the Persian cultural area. The contemporary Persian-speaking area includes Iran, Afghanistan, Tajikistan, and Central Asia, while classical societies using Persian as a literary and cultural language were located in Anatolia, Caucasus, Central Asia and the Indo-Pakistani subcontinent. The objective of the series is to foster studies of the literary, historical, religious and linguistic products in Iranian languages. In addition to research monographs and reference works, the series publishes English-Persian critical text-editions of important texts. The series intends to publish resources and original research and make them accessible to a wide audience.

\section{Chief Editor:}

A.A. Seyed-Gohrab (Leiden University)

\section{Advisory Board of ISS:}

F. Abdullaeva (University of Cambridge)

G.R. van den Berg (Leiden University)

D.P. Brookshaw (Standford University)

J.T.P. de Bruijn (Leiden University)

N. Chalisova (Russian State University of Moscow)

D. Davis (Ohio State University)

F.D. Lewis (University of Chicago)

L. Lewisohn (University of Exeter)

S. McGlinn (Unaffiliated)

Ch. Melville (University of Cambridge)

D. Meneghini (University of Venice)

N. Pourjavady (University of Tehran)

Ch. van Ruymbeke (University of Cambridge)

S. Sharma (Boston University)

K. Talattof (University of Arizona)

Z. Vesel (CNRS, Paris)

R. Zipoli (University of Venice) 


\section{Local Portraiture}

Through the Lens of the 19th-Century

Iranian Photographers

Carmen Pérez González

Leiden University Press 
Cover design: Tarek Atrissi Design

Layout: The DocWorkers, Almere

ISBN 9789087281564

e-ISBN 9789400600775

e-ISBN 9789400600782 (ePUB)

NUR $630 / 652$

(C) Carmen Pérez González / Leiden University Press, 2012

All rights reserved. Without limiting the rights under copyright reserved above, no part of this book may be reproduced, stored in or introduced into a retrieval system, or transmitted, in any form or by any means (electronic, mechanical, photocopying, recording or otherwise) without the written permission of both the copyright owner and the author of the book. 
For my family: Luna, Mitra, Mani and Ali-Reza Darvish

For my teachers: Prof. dr. Kitty Zijlmans, Dr. Helen Westgeest and Prof. dr. Just Jan Witkam

To the memory of the Iranian photographer Bahman Jalali (Tehran, 1949-2010) and to his wife Rana Javadi 



\section{Table of Contents}

$\begin{array}{lr}\text { Foreword } & 9\end{array}$

Acknowledgments 13

Acknowledgments for the images 17

$\begin{array}{ll}\text { Introduction } & 19\end{array}$

Brief Introduction to the History of Photography in Iran 27

1 Visual Laterality: The Relationship between the Direction of Writing and Composition $\quad 41$

1.1 Definition of visual laterality $\quad 42$

1.2 Nineteenth-century Iranian portrait photography 45

1.3 Visual brain and visual perception in art 55

1.4 Asymmetries of the photographic space:

1.5 Reading habits versus aesthetic preferences:

A neurological approach $\quad 62$

2 The Written Image: Text and Photography 71

2.1 Persian calligraphy and type of scripts 71

2.2 Text and nineteenth-century Iranian portrait studio photography: Type of script versus content and meaning of the inscription

3 Pose, Gesture and Objects Held by the Sitter 105

3.1 Gesture, posture and pose 105

3.2 Pose and gesture in the Persian painting tradition 112

3.3 Pose and objects held by the sitter in nineteenth-century Iranian portrait photography

4 Arrangement of Space 131

4.1 Spatial characteristics of Persian miniature painting 131

4.2 The use of space in Persian miniature painting 140

4.3 The use of space in nineteenth-century photography in Iran 146

5 Interactions between Western and Iranian Photography 155

5.1 Schema of positions in portrait photography 155

5.2 Western photographers versus local sitters:

Photographing the Other 157

5.3 Interaction between Western and Iranian photographers 165

5.4 Hybridity versus Appropriation 178 
Conclusion

Afterword

193

Bibliography

195

Appendix: Photo Chronology

209

About the author

215

Index

217

Photos 


\section{Foreword}

When Carmen Pérez González asked me to write a foreword to this book, I readily accepted. Carmen had just successfully completed her doctoral dissertation at Leiden University, the Netherlands, and was awarded her $\mathrm{PhD}$ on 2 February 2010. What started a good four years ago, when Carmen Pérez knocked on our door presenting her ideas for a dissertation, grew into an important and very interesting $\mathrm{PhD}$ thesis which has now resulted in this book containing a comparative visual analysis of nineteenthcentury Iranian portrait photography and Persian painting.

How does a Spanish woman with a Masters in Astrophysics from Barcelona University end up studying for a $\mathrm{PhD}$ comparing the photography and painting of Iran in Leiden? Her interest in photography was already there but, after two-and-a-half years traveling overland from Turkey to China, she returned home a skilled photographer with over sixty rolls of film. A catalogue for a solo exhibition on the often hard physical labor performed by women in Asia followed, as well as a study in Fine Arts (Photography) at Barcelona University. The choice of Iran was fuelled by her knowledge and love of the country, its language and culture, which she had come to know well through her Iranian husband. Her coming to Leiden was understandable because Leiden University houses an impressive collection of photographs and teaches in this field, as well as being renowned for its expertise in Middle Eastern studies. The decisive factor in her choice of subject matter was, however, the fact that the history of photography in Iran, especially the early period, had been largely overlooked by Western photography historians. Moreover, besides the wellknown Western photographers (including Ernst Hoeltzer of Germany) who have worked in Iran since the early days of photography, she also discovered a wealth of Iranian photographers, all with their own idiosyncrasies.

It was precisely the specificity of cultural backgrounds and practices that caught her interest. In order to fully understand the cultural embeddedness of practices used in photography and composition, she undertook a comparative analysis with the rich tradition of Persian painting. Through an indepth comparative visual analysis of nineteenth-century portrait photography and Persian (miniature) painting Carmen Pérez arrived at, and substantiated, the insight that aesthetic preferences correlate with socio-cultural habits and practices in writing, reading and looking. She also revealed the nature of this relationship. The direction of writing, for instance, proved to be one of the culturally defined elements in a photograph. Whereas in the West pictures are "read" from left to right (the direction of writing of all Western languages), Carmen Pérez' analysis shows that the opposite in fact 
applies in Iran/Persia, where Farsi is written from right to left. Consequently, Iranian photographers produce "mirror images" of those made by Western photographers. This is supported by studies in the field of visual laterality in neuropsychology and perception psychology, which are crucial in building a theoretical framework for exploring this phenomenon. Furthermore, she made discoveries regarding spatial arrangement, poses and attributes, and the use of text within the space of the image, the latter underscoring the importance of poetry, not only in former Persia but in modern Iran too.

The corpus of work grew over the years, and the photographs now number in their thousands. Each time we met, Carmen Pérez proudly showed us yet another stack of photos, albums and books, ardently collected with the aid of numerous friends and colleagues, who purchased books in Iran and elsewhere. The collection is still growing in both size and importance. The numbers reveal the great interest in photography among nineteenthcentury Iranian photographers, the quality their skill; but Carmen Pérez' analysis has also shown how deeply compositional solutions are rooted in the cultural traditions of Persia.

This study is intermedial, intercultural and interdisciplinary. It brings together various mediums (photography, miniature painting, texts), cultures (Western European and Middle Eastern), and theoretical perspectives (visual analysis, neuroscience, art history and history of photography). In this respect it is as important to photographic studies as it is to the field of study we refer to at Leiden University as World Art Studies. This research is a study of indigenous, culture-bound artistic practices, which we are anxious to learn about, and a study of growing interculturalization over the course of time. This process of artistic exchange between disparate contexts involves diffusion or migration of cultural traits back and forth, illustrated in this case by the changing habits in studio portrait photography inspired by Western practices.

To summarize what makes this book important: First, it is a valuable contribution to the study of the history of photography and the field of World Art Studies, as well as to the history and culture of Iran. Secondly, it is built on a large and partly unknown corpus of photographs, and on an interdisciplinary, comparative approach. It convincingly shows the importance of visual analysis, of deep looking. And lastly, it provides a model for comparative analysis of visual material that can be applied to other cultures and contexts. In this respect, the study not only uncovers the cultural conditioning in the creation of images of a particular country, it also elaborates a model for investigating and comparing corpuses of photographs and paintings produced in disparate cultures around the world. This book is an important contribution to the understanding of both cultural particularities and communalities. It is my profound hope that it will prompt a great deal 
of discussion on the issue of intercultural exchange and will further open up the field of comparative research within and between cultures.

Kitty Zijlmans

Professor of Contemporary Art History and Theory

Leiden University 



\section{Acknowledgments}

There are many people who have contributed in different ways to this research. I am indebted to several Iranian photo historians who have helped me to acquire the material required to start this research project. They bought books for me in Iran and sent them to me in Spain or Germany through Iranian friends traveling back and forth to Iran, or they themselves brought them to me. Rana Javadi has been aware of my research since the very first moment, when in 2003 I went to Iran to start collecting books on the topic. She has helped me ever since, continuously, not only in practical things like getting books for me, but also on a personal level, continuously supporting me and encouraging my research. She has my deepest respect, admiration, and gratitude.

Mohammad Rezā Tahmāsbpur has been extremely helpful and kind to me in the last two years of my $\mathrm{PhD}$ thesis' research, helping me to get recently published books in Iran and answering every question I posed to him by e-mail. Dr Rezā Sheikh has been a wonderful colleague, always encouraging me to keep on my research path, especially in the last two years of post-doctoral research. I had the honor to meet Prof. dr. Iraj Afshar personally on the day of my PhD thesis defense (February 2010), as he was part of the defense committee. Unfortunately, he passed away just a year after that date. There are other scholars to whom I am thankful, since their books were an inspiration and a valuable source of information to me throughout my research (and all of them acted, without knowing it, as my invisible and most respected teachers): among them, the late Yahyā Zokā, Prof. dr. Sheila Blair, Dr. Layla Diba, Prof. dr. Robert Hillenbrand, Prof. dr. Oleg Grabar, and Dr. Charhyar Adle, all of them referenced several times throughout the book. To Corien Vuurman I am thankful for suggesting me to contact one of my three supervisors when I was lost looking for someone somewhere who might have interest in my research.

My dissertation was a higly cooperative and satisfactory work between my supervisors in Leiden and myself. I came to Leiden with an interesting corpus of photographs and paintings and some hypotheses and intuitions, but thanks to the guidance of my three supervisors the dissertation achieved the theoretical depth that was required. Prof. dr. Kitty Zijlmans and Dr. Helen Westgeest have worked hard to pinpoint the best of my research and have guided me and inspired me since I started working with them. To Helen Westgeest I am especially indebted for her ideas on the chapter of the arrangement of the space, and to Kitty Zijlmans for her remarks 
throughout the whole dissertation and especially on the chapter about the interaction of Western and Iranian photography. Prof. dr. Just Jan Witkam was also a fundamental member of the team of supervisors and his remarks and corrections on the chapter devoted to text and photography were very important. Further, I am honored that he translated some of the texts found in the photographs selected for that chapter.

After I finished writing my dissertation in the summer of 2009, I kept researching and testing my different research hypotheses, and in this new phase the help and guidance of the neurologist Prof. dr. Chris McManus (for chapter 1) and the Islamic art historian Prof. dr. Sheila Blair (for chapter 2) have been fundamental.

Kausar Turabi and Dr. Evan Siegel have been very helpful with their corrections of this manuscript written in English, not my mother language. Mina Zand Siegel has kindly helped me with the translation of a long poem found on one of the photographs and has helped me with editing the manuscript.

Dolors Tapias and Manolo Laguillo were the supervisors of my research during the two year PhD course that I took at the Faculty of Fine Arts at Barcelona University in order to get my ABC (All But Dissertation), that allowed me to start my PhD Thesis a couple of years later at the Faculty of Art History at Leiden University. They both helped me in different ways to start my research. Dolors has been one of the most generous teachers that I have ever had, and Manolo was probably the only one in Barcelona University who properly understood the importance of making an in-depth study of the visual-laterality hypothesis.

My family has been extremely important in making me strong enough to persevere in my research. Ali-Reza Darvish has been part of the whole delivery process of this book and the three kids that came to this world in the years that I wrote my dissertation: Luna, who was born in Barcelona the year that I started thinking about this research, in 2004 and Mitra and Mani, who decided to come to this world together, in Cologne, in the Summer of 2007. I also thank the support given to me by good friends of mine: Pilar Lombardo, Kausar Turabi, Sandra Garabello and Eduardo Yáñez, Zari Ashena and Sharhyar Ahadi, Ana Briongos and Toni Alsina, Yael Langella (who spoke 10 languages, among them Hebrew, Arabic and Russian, and whose wisdom, integrity and kindness keep guiding me) and Uwe Geest, Elmar Seibel, Shirin Farahi, Mardi and Nushin Bahadori, Soheila Mirzai, Laura Morala Forte, Eduardo de Francisco Jiménez, José Miguel Espí Huerta, Patricia Cantó, Mónica Solé, and my aunt Angelita Pérez Campos.

Lastly, and most important, I would like to thank my publishers, the Iranian Studies Series (Leiden University Press), especially Asghar Seyed Gohrab, Yvonne Twisk and Chantal Nicolaes. I am grateful also to ICAS 
and its director Paul van der Velde, for the ICAS Prize that they awarded me for my dissertation and for their generous help to print this book.

Cologne, January 2012

Transliteration note:

I wish to thank Dr. Asghar Seyed Gohrab for applying systematically through my manuscript the transliteration schema. An ideal transliteration system for Persian does not exist and there are various systems of transliterations used by different encyclopedia, journals, libraries, etc. For the sake of consistency and uniformity, a transliteration system is used in this book to transcribe the Arabo-Persian script involving a minimum of diacritical signs: only the long vowel /a/ is indicated with $\bar{a}$. The compound words consisting of a noun and a suffix such as akkāsbāshi is written as one word. The initial hamze and the letter eyn at the beginning and at the end of a word is not transcribed, only in the middle of the words the eyn and hamze are indicated. The Persian ezafe is written as -e after consonants and -ye after vowels. 



\section{Acknowledgments for the images}

I would like to thank the Leiden University Institute of Cultural Disciplines for a generous grant to help to finance the costs of the highquality resolution files and reproduction fees of the images printed in this book.

For granting me permission for the reproduction of the photographs and paintings printed in this book, I would like to thank the following individuals and institutions: Juan José Díaz Prósper (Valencia, Spain); Prof. dr. Iraj Afshar (Tehran, Iran); Parisa Damandan (Tehran, Iran); Andrew Halle (Anahita Gallery, Santa Fe, USA); Yokoyama Matsusaburo; Mansour Sane (Shiraz, Iran); Family Collection (Tokyo, Japan); Bahman Bayani (Tehran, Iran); Collection of Prinze Sadruddin Agha Khān (Geneva, Switzerland); Golestān Palace Library (Tehran, Iran); Stephanie Roy Barath and the Alkazi Collection of Photography (New Delhi, India); Princeton University Library (Princeton, USA); Arthur M. Sackler Gallery (Washington, USA); British Library (London, UK); British Museum (London, UK); Oriental and Indian Office Library Collections (London, UK); Museé des Arts Décoratifs (Paris, France); Museé National de Versailles (Paris, France); The Israel Museum (Jerusalem, Israel); National Library (Cairo, Egypt); Royal Asiatic Society (London, UK); Special Collections, Fine Arts Library, Harvard University (Boston, USA); Harvard University Museums (Boston, USA); Museu de la Ciencia i la Técnica de Catalunya (Barcelona, Spain); Leiden University Library (Leiden, the Netherlands); Museum of Ethnology in Leiden (Leiden, the Netherlands); Museum für Volkerkunde in Vienna (Vienna, Austria); Museum für Ostasiatische Kunst (Cologne, Germany); Museum of Ethnology in Berlin (Berlin, Germany); Staatliche Museen (Berlin, Germany); Museum of Ethnology in Zürich (Zürich, Switzerland); The Metropolitan Museum of Art (New York, USA); State Heritage Museum (St Petersburg, Russia); National Library in Vienna (Vienna, Austria); Brooklyn Museum of Art (New York, USA); the Royal Hause Archive (The Hague, the Netherlands); Archive of the Institute for Iranian Contemporary Historical Studies (Tehran, Iran); Topkapi Sarayi (Istanbul, Turkey); Istanbul Museum of Islamic Art (Istanbul, Turkey); and the Photo-Museum Tábor (Tábor, Czech Republic).

I want to thank Ms Khadijeh Mohammadi Nameghi for her generous help with getting me high-resolution files of photographs kept in Iran. 



\section{INTRODUCTION}

\section{Field of research}

The field of research of my book is nineteenth-century Iranian portrait photography. The origin and motivation of this choice lies in my own work as photographer in Asia. After a two and a half years of travel from Turkey to China by land, I came back to Spain in the Summer of 2001 with around sixty rolls of films, mostly black and white, and I published several portfolios and the catalogue of a solo exhibition about the work of women in Asia that opened in the Principe Felipe Museum in Valencia (2002). Many of the photographs showed women doing hard physical work (carrying bricks, breaking stones, etc.) and others performing dailylife tasks like picking up or carrying water, cooking or taking care of children.

I sent the catalogue to an Iranian poet who liked it but remarked that in some of the photographs he could guess that I was a Western photographer. I did not really know what he meant by that, but whatever it was, it concerned me for some time. It motivated me to finish my incipient career as a photographer and to begin a long period of reflection and study whose final result was my dissertation on which this book is based.

Asia has inspired and fascinated me for many years, first as a photographer and later as a researcher. I decided to focus my research on Iran because it is one of the most under-researched Middle Eastern countries by Western photo-historians, specially what concerns local photographers. In this book I undertake a visual analysis of nineteenth-century Iranian portrait photography.

The camera is not just an a-cultural technical device, a non-culture-influenced medium. Culture, or more precisely, the cultural background of the photographer, does play a role in the process of taking a photograph. Photography produces constructions of real life and photographs are cultural productions. Photography is clearly not a mirror of daily life: the fact that images are constructions is especially obvious in nineteenth-century portrait photography. The aim in my dissertation was to analyze photographs in order to show this cultural conditioning in the creation of images. I chose images through the use of fine detail. The corpus of photographs selected for this dissertation constitutes a practical example of photography's construction of the visual world and the goal of this research is to demonstrate that photography is always a construction of reality, regardless of the photographer's nationality. I am specifically interested in exploring 
how indigenous Iranian photographers constructed their own realities in contrast to how foreign photographers constructed Iranian's realities.

Photography and painting both interpret reality. As the British photographer and critic Victor Burgin states,

when photography first emerged into the context of nineteenth century aesthetics, it was initially taken to be an automatic record of reality; then it was argued that it was an expression of an individual; then it was considered to be a "record of a reality through a sensibility" (Burgin 1986: 46).

Susan Sontag stated, "[P]hotographs are as much interpretation of the world as paintings and drawings are". ${ }^{1}$ I myself took the camera and interpreted a reality that was in front of me, no matter how honest my intentions to show "reality" were and how hard I tried to achieve that. With my photographs I showed, like everybody else does, my own reading of the reality that I had in front of me. Significantly, while constructing my own perception of reality, I missed "reality" itself.

As a result of insights into the cultural components in Iranian photography, we may look with different eyes to Western photography in general, which may be more "Western" than we thought.

\section{The state-of-the-art of the discourse}

Both Western and Iranian scholars' research on nineteenth-century Western photography in Iran has been mainly focused on a historical approach. ${ }^{2}$ Most of the publications in the West on nineteenth-century photography in Iran deal with the work of Western photographers. Yet, there was much more photography made by Iranian photographers than we know about in the West and definitely more than by Western photography. Such indigenous work is, indeed, interesting and bears, in some cases, a particular and unique aesthetic. There were more than one hundred Iranian photographers active during the second part of the nineteenth and the beginning of the twentieth century but fewer than thirty Western photographers ${ }^{3}$, and not all of them were professionals: some were amateurs or just took pictures to illustrate their travels. ${ }^{4}$

Several books have been published about nineteenth-century Iranian indigenous photography in Iran: compilations of photographs with an introduction about the history of photography in Iran; monographic books of relevant Iranian photographers active during the nineteenth century; books on photography and photographers in different cities and, rarely, on a particular subject, like the one recently published about the photography of children. ${ }^{5}$ Most of these books on indigenous photography were published in Persian and have not been translated into any other language. Therefore, 
the majority of this material is accessible only to Iranian scholars and to Western scholars fluent in that language.

\section{My position in the field}

As the title of my dissertation suggested ("A Comparative Visual Analysis of Nineteenth-Century Iranian Portrait Studio Photograhy and Persian Painting"), my approach to early Iranian photography is an analytical one based on the visual analysis of photographs taken by Iranian photographers in the nineteenth century. While applying visual analysis, I take into consideration the cultural components of the image.

My research concentrates on a visual analysis of the elements found in nineteenth-century Iranian photography that may have been inherited from the Iranian visual arts tradition, especially from the Iranian painting tradition. The research undertakes a comparative study of the Iranian painting tradition and nineteenth-century Iranian portrait photography. The elements that have been identified and analyzed are:

- Mirror-like composition due to the visual-laterality phenomenon, defined here as the influence of the direction of writing on the composition in works of art, particularly in photography;

- Use of calligraphic inscriptions of text within the photographic space;

- Use of traditional Iranian portraiture poses, such as kneeling, in contrast to sitting or standing;

- The understanding of space in photographic composition: isometrical perspective, vertical composition, grid structure layout and diffuse compositions.

Western elements have been identified as well, but merely as a way of understanding, by way of contrast, the Iranian elements: Victorian pose (frontal, hieratic, static); studio paraphernalia (chairs, backdrops, balustrades, etc); and iconographical elements often borrowed from the Orientalist painting tradition. Finally, I explored the mixed aesthetics present in nineteenth-century Iranian photography due to the appropriation of Western elements. I do not maintain that these elements are exclusive to Iranian culture and/or that they are only found in nineteenth-century Iranian photography. In fact, as we shall see in the course of this book, some of these elements are also to be found in Japanese and Indian photography, albeit with their own peculiarities. This indigenous way of representation differs substantially from Western ones, which makes it important to study it mainly from a comparative visual analysis approach. 


\section{Frames of reference and corpus}

In my research I use an interdisciplinary approach that includes the theory of photography, Islamic art history, neuroscience, post-colonial studies and world art studies. I am constructing a theoretical framework to analyze nineteenth-century photographs in their cultural components. Iranian photography is a case study, but the same study could be undertaken with any other country. The theoretical framework developed here to analyze photographs should work also with other photographic corpuses. Each chapter is guided by a specific theoretical perspective (see further under structure of the book). The photographic material will recur and be analyzed in the various chapters.

The first step in order to undertake this research was to build up a corpus of photographs from which to draw conclusions after pursuing an indepth visual analysis. ${ }^{6}$ In 2003, I started gathering as many published books on Iranian photography as possible with the aim of building up a corpus of photographs that would constitute the material for a starting point for a visual analysis. The process was long and arduous, but I gathered a rich corpus of material to be analyzed. ${ }^{7}$ This corpus consists of around 5,000 portrait photographs (most of them studio portraits, but there are also some outdoor portraits to be found within the corpus). In parallel, I gathered two other corpuses of graphic material: a corpus of paintings (both Persian miniature paintings and Qajar paintings, around 3,000 paintings) and a corpus of Western nineteenth-century portrait photography (around 5,000 photographs). Time and again I went through the three corpuses defined above, visually analyzing them with the aim of establishing groups that could take into consideration each one of the five topics explored in my dissertation: visual laterality, text and photography, pose, space and Western influences.

The Iranian painting tradition includes Persian miniature painting and Qajar painting and, therefore, I will be referring to both traditions recurrently along the book. A comparison will be established between these three, otherwise diverse mediums: Persian miniature painting, Qajar painting and portrait photography (only formally can and will these three different media be compared). Miniatures are part of a sequence in a book. Their size is very small and, therefore, these works are meant to be enjoyed by only one person at a time, a very intimate contemplation. Interestingly, as stated by Susan Sontag and many other theoreticians, photography is, in contrast to Western painting and film, also an object of contemplation, exactly what miniatures are. In contrast with this, Qajar portrait paintings are life-size paintings and are often exposed to the public, mostly on palace walls. Therefore, their reception is collective and open. Photographs can be seen as part of an album and especially in the nineteenth century they were mainly produced with that aim, therefore bearing 
some narrative meaning, or as individual items. What is especially interesting here is that there is no great difference in size between miniature paintings and photographs (in some cases they are even the same size), whereas the difference in size between Western paintings and photographs is huge. ${ }^{8}$

Qajar painting is seen as a worthy successor of the painting of the Timurids (1390-1500) and the Safavids (1501-1722). In portraiture, the Qajar artists went beyond all their predecessors. Whereas Timurid and Safavid painting is confined to manuscripts and albums (inviting an individual and private contemplation), Qajar painting presents itself in a variety of forms (some of them meant for individual contemplation, some other for collective and public contemplation): life-size paintings, painted lacquer, glass, painted enamel and traditional manuscript illustrations and album pictures. As stated by the art historian of Islamic Art Layla S. Diba, "life-size painting of this period was the visual expression of a selfconsciously historizing ruler" (Diba 1998: 45). Nāser al-Din Shah approached the new medium of photography in the same way that his predecessors had approached painting: he consciously utilized imagery to construct a (royal) Persian self-image. This topic has been considered by the leading Iranian photo historian Rezā Sheikh, by Diba and also by the Iranian postcolonialism theorist Ali Behdad. ${ }^{9}$ An important part and production of photography in nineteenth-century Iran was done within the walls of the Golestān Palace in Tehran (Nāser al-Din Shah's residence) and the Dār al-Fonun (Iran's first institution of higher learning based on Western models, that will be properly introduced later on in this book), as we shall see in the brief historical introduction to the history of photography in Iran that follows this introduction. ${ }^{10}$

\section{Structure of the book}

This book is structured in five chapters, according to the five topics mentioned above. In chapter one, the main research question is how the direction of writing and reading of Iranian nineteenth-century photographers influenced the way they composed the photographs that they took. No study of the influence of the direction of script on photographic composition has ever been undertaken. The research is built on visual analysis and is approached from two disciplines: art history and neuroscience.

After studying the photographic material gathered for this research I was able to establish three different groups: linear order (groups of people ordered by height), couples, and people with chairs. The following step was to study the state of the field regarding the visual-laterality phenomenon in neuropsychology and perception psychology to build a theoretical framework in which this phenomenon could be understood. The hypothesis formed by this research is that if pictures are "read" from left to right (the direction of writing of all Western languages), the opposite applies for 
those languages written from right to left (such as Persian). Therefore Iranian photographers would produce 'mirror-images' of those made by Western photographers.

For chapter two, I explored the use and role of calligraphy in the Persian painting tradition and the influence that this has had on nineteenth-century Iranian photography. I analyzed the use and meaning of calligraphic inscriptions or text both within pictorial and photographic space. I established three ways of categorizing the photographs: by elaboration of the script; by content and meaning; and by spatial organization. All of these classifications aim to make a difference between script with a decorative purpose and script with a practical/informative purpose (calligraphy versus plain text).

Chapter three is devoted to the topic of pose. I studied whether the use of the traditional kneeling pose in Persian miniature painting and Qajar portraiture has been inherited by nineteenth-century Iranian portrait photography. Further, I have studied the difference of pose and objects held by men and women in painting and later in photography. In order to achieve this, I have made a thorough visual analysis of the pose and objects held by the sitters both in the Iranian painting tradition and in nineteenth-century Iranian photography. I have identified the typical poses used in nineteenth-century portrait photography in Iran that were mainly inherited from the Persian miniature tradition. I also explored the influence of Western poses on Iranian photo studios such as the changing from a kneeling or squatting position to the sitting position due to the introduction of the chair in the photographer's studio in the same way this happened previously in the painter's studio.

In chapter four, I researched the understanding of space in the Iranian painting tradition and the influence this has had on nineteenth-century Iranian photography. I analyzed the formal use of space both in Persian miniature painting and photography. The main research issues related to the arrangement of space in Persian miniature painting that I am concerned with in this chapter, are topics such as the non-linear perspective approach or the isometrical perspective (also called the parallel perspective) to project a three-dimensional space on a two-dimensional picture plane; the existence of multiple centres of attention (diffuse composition); the grid layout structure; and the vertical composition/vertical perspective. I introduced the kinds of compositions that can be defined due to the arrangement of the elements in the pictorial or photographic space, and explored the ones that could have been peculiar to nineteenth-century Iranian photography as influenced by the Iranian painting tradition.

Chapter five is devoted to the interaction between Western and Iranian photographers. I explored the influence that Western aesthetics in nineteenth-century photography has had on Iranian native portrait photography. The group of indigenous photographers that were more exposed to this 
foreign influence was the court photographers, in contrast to the bazaar or local photographers. I introduced in this section the Western photographers that were active in Iran in the nineteenth century and focused on the ones whose influence on Iranian photographers was more noticeable. How they influenced the aesthetics of local photographers was an important issue. Relevant for the present research was how this influence has changed the four topics explored in the previous chapters: visual laterality, text/calligraphy, pose and space. In order to discuss this, it was essential to know which Iranian photographers were working together with Western photographers.

Depending on the position of the photographer, we can find Iranian photographers whose work perfectly matches that of Western photographers (like some court photographers) and others that have a more indigenous conception and representation in their work (like bazaar photographers). But the majority of them present, with more or less intensity, a hybrid aesthetic in their work.

My final goal in this book is to show through visual analysis of the images that photographs are cultural products and to transcend Edward Said's orientalism by analyzing other constructed realities, those created by indigenous photographers. Next to this, it is fundamental to emphasize the remarkable difference between the Victorian way of representation and other lesser-known peripheral models of representation, such as the Iranian one. ${ }^{11}$ I advocate a place in the global history of photography for those unknown, local photo-histories and for the indigenous photographers that built it up. I address historical modes of representation and the need to achieve intercultural approaches in the study of art in general and of photography in particular. World Art Studies, the disciplinary field that is taking into consideration these matters must be, therefore, a source of inspiration and reference for photo historians. ${ }^{12}$

\section{Notes}

1 The art historian Geoffrey Batchen sees the early photographers as a rebuke both to the modernists and post-modernists views of photography. The modernists see photography as an imprint of nature, a tracing of reality, however crafted and shaped. The post-modernists see it as an ever shifting product of culture, a representation that depends, as the British critic John Tagg put it, "on the institutions and agents which define it and set it to work". Batchen in Burning with Desire: The Conception of Photography steers a middle course between the two positions. He argues that the early photographers were actually deconstructing (in Jacques Derrida's terminology) the opposition between nature and culture, reality and representation, showing them to be false. See Batchen 1997.

2 See: Afshar 1992; Barjesteh 2004 and 1999; Bohrer 1999; Damandan 2004; Scarce 1976: 1-22; Stein 1984: 257-292; Tahmasbpour 2007; Vuurman 2004, 2007 and 2011; Zokā 1997.

3 For a chronology of Western photographers: Vuurman 1995: 24-25. 
4 Most of the Iranian photographers were active in big cities: 47 in Tehran, 13 in Isfahan, 11 in Tabriz, 9 in Shiraz. For Iranian photographers and biographies: Zokā 1997 (in Persian). Also, Afshar 1992 (in Persian). For good insights into historical aspects of Iranian photography, see: Adle 1983: 249-281; and into sociological aspects of Iranian photography, see Sheikh 2004: 231-253.

5 The best sources of information are: Afshar 1992 and Zokā 1997. Further literature: Tahmasbpour 2001 and 2007; Damandan 2001; Jalali 1998, (in Persian); Mahboob \& Nemati 2005, (in Persian); Semsar 2004, (in Persian); Sane 1990, (in Persian) and 2004, (in Persian); Torabi 2003 (in Persian); Sattari 2006 (in Persian).

6 The photographic corpus selected for this research has been collected from all published books about nineteenth-century Iranian photographs, all of them printed in Iran, from the photo-archives in Iran (Palace Golestān, etc), and from private collectors (some of them have their collections online).

7 The photographs printed in the books used while building up the corpus are hosted in several archives in Iran: the biggest and most important one of all photo-archives is the Golestān Palace Library in Tehran, which hosts around 43,000 photographs; the Institute for Iranian Contemporary Historical Studies; Majlis Library; Tehran University Documentation Center; National Documentation Center; National Library; Documentation Center of the Cultural Heritage Organization, all of them in Tehran; archives of Mashhad, Isfahan and Tabriz. Several important private collectors should be mentioned here: Dr Iraj Afshar, Arman Stepanian, Bahman Bayani, Bahman Jalali and Rana Javadi, Mansour Sane (photographs from Shiraz) and Parisa Damandan (photographs from Isfahan), all in Iran, and the Azita Bina and Elmar W. Seibel Collection in Boston, USA.

8 Nevertheless, in recent publications about Western painting-like photographs this is an important issue. Huge formats of photographs by Jeff Wall and the Düsseldorfer Schule (Andrea Gursky, Thomas Struth and Thomas Ruff, among others) are just some wellknown examples. See: Elkins 2007: 129-203.

9 See: Sheikh, 2004: 231-253 and Behdad 2001: 141-152. Layla Diba presented a paper on this topic, "Qajar Photography and its Influence on Modern and Contemporary Persian Painting" at the Qajar Era 2011 conference at St Andrews University, 27-28 August 2011 (her paper will be published in the proceedings of the conference).

10 Iran's first institution of higher learning based on Western models. A special department of photography was opened as early as 1851 .

11 Throughout most of photographic history, these local photo histories have been dismissed or slighted. For instance, in Peter Pollack's Picture History of Photography (1969); Beaumont Newhall's 1982 revision of The History of Photography: From 1839 to the present day; in Masterpieces of Photography, a 1986 compendium of highlights from the George Eastman House Collection; in Mike Weaver's Art of Photography, 1839-1989 (1989); Frizot, Michel, Neue Geschichte der Fotografie, Könneman, 1989; and Naomi Rosenblum's A World History of Photography, there are no references to any of these "peripheral" or "local histories" of photography. Countries like Iran, Syria or Burma have been completely neglected by those global photo-histories and if they have been mentioned at all it always has been through the work of Western photographers in those countries. An exception to this is Mary Warner Marien's book, Photography. A Cultural History, London 2002. This book benefits from two decades of new research into nonWestern photography.

12 Fundamental referents for this topic are: Zijlmans and van Damme, 2008; and Onians 2007. 


\title{
BRIEF INTRODUCTION TO THE HISTORY OF PHOTOGRAPHY IN IRAN
}

\author{
To the memory of Prof. dr. Iraj Afshar (Tehran, 1925-2011)
}

Upon the official request of Mohammad Shah (reigned 1834-1848), two daguerreotype cameras had been sent to the Persian court as early as 1842 , one by the Russian government and the other by the British government. Fate decided that the one sent from Russia would arrive first, in midDecember 1842. The details of this fundamental historical event have been researched in-depth by the leading scholar Chahryar Adle, and as he states,

the Russian set, a present of the Czar, arrived earlier. Nikolai

Pavlov, the young diplomat trained for the purpose, brought it to

Tehran and took the first photograph recorded in Iranian history in presence of Mohammad Shah on the date mentioned. (Adle 2000: 1)

Due to recent research done by Adle, we can conclude that Pavlov took daguerreotypes at court as early as December 1842, so just three years after the announcement of the daguerreotype process in Paris. ${ }^{1}$ Shortly after Pavlov arrived in Iran, the French photographer Jules Richard (1816-1891, later known as Richard Khan) was the first European photographer to work in the Persian court. He arrived in Tehran in 1844 and, after the change of king in 1848, his work expanded from teaching photography at court to teaching photography to Iranian students in the Dār al-Fonun from 1851 onwards, Iran's first institution of higher learning based on Western models, where a special department of photography had been opened. ${ }^{2} \mathrm{He}$ mastered the process of daguerreotype, which was his main teaching subject. Unfortunately, to date only one of his daguerreotypes has been found, hosted at Musèe d'Orsay. ${ }^{3}$

It was under Nāser al-Din Shah (reign 1848-1896) that photography was really developed and different techniques learned and mastered. His interest in photography began when he was very young, devoting time to learning the photographic technique and becoming, later on, a serious and engaged amateur photographer. The Shah decided to bring this new invention close to his servants at court, and several rooms were reserved for photography (known as Akskhāne-ye Mobārake-ye Homāyuni, i.e. "the Royal Photographic Atelier", established within the grounds of the 
Golestan Palace in 1858), as well as at the Dār al-Fonun. This academy was envisioned by Nāser al-Din Shah's prime minister Amir Kabir (18071852) for the training of future military officers and civil servants. As stated by Maryam Ekhtiar and Marika Sardar,

Instruction was conducted in a pattern similar to that of the European academies of fine art, where art was regarded as a scientific and scholarly discipline. Although the Dar al-Funun ultimately altered art education, the age-old master-apprentice system continued to exist and was also important in the field of photography. ${ }^{4}$

The Shah's encouragement of photography in Iran was promoted in two ways: by inspiring his courtiers and actively engaging them in the photographic technique, and by providing Dār al-Fonun with professional photographers as teachers to prepare a solid generation of students that would strengthen the basis of the new invention in Iran. Some were even given the opportunity to refine their skills in government-sponsored training in Europe, in workshops or on courses. It was also thanks to the Shah that several books on photography were translated to be used as teaching material at court or at Dār al-Fonun. According to Yahyā Zokā, in 1859, the first book on photography by an unknown Iranian author was printed, 14 pages long and very small in format $(6 \times 15 \mathrm{~cm})$ (fig. I). It was a handbook to be used as an introduction to the new medium. Zokā and also Iraj Afshar refer to a second book entitled Ketāb-e 'aks by Mohammad Kāzim, printed in $1863 .^{5}$ As argued by the Iranian photo-historian Mohammad Rezā Tahmasbpour, who has been working on this topic in-depth, soon after the first technical books were translated, aesthetic, philosophic and religious debates were to follow. ${ }^{6}$ Both pioneers in the history of Iranian photography, Iraj Afshar and Yahyā Zokā introduced in their books some of those early publications, such as Qavā'ed-e aks va telegrāf (Principles of the Photograph and Telegraph, 1880) and the book Aksiyye-ye hashariyye (1889). These are among the pioneering books on theoretic precepts of photography in Iran.

European professionals were brought to the court and to the Dār alFonun to work as teachers, such as the Austrian August Karl Krziz (18141886, active from 1851-1859 in Iran), and the Italians Fochetti (active in Iran from 1851 onwards), Luigi Pesce (active in Iran from 1851 onwards), Antonio Gianuzzi (active from 1859 onwards) and Luigi Montabone (active in Iran in 1862, died 1877) ${ }^{7}$, and the Frenchman Francois Carlhian (active from 1858 onwards). As remarked by Afshar, among the earliest documents that inform us about the introduction of photography in Iran we find the third volume of the Mer'at al-boldān-e Nāseri written by E'timād al-Saltane (Sāne al-Dowle) in 1863-64. ${ }^{8}$ He says that, 
there are two sources of valuable information about French and Italian photographers in Iran, the former active in the years 1857-60 and the latter dating from 1860-63. For our information about the French photographers, we are indebted to an article by J. Qa'imMaqami based on documents in the French military archives at Vincennes (no. 1673) containing reports by the head of the French military mission in Iran. These mention that in 1857 two photographers named Carlhiée and Blocqueville accompanied the mission. For our information on Italian photographers in Iran, we are indebted to Angelo Piamontese's valuable study, "The Photograph Album of the Italian Diplomatic Mission to Persia (Summer 1862)”. The article deals in a comprehensive manner with the background of the Mission and its members, including the two photographers Luigi Montabone and Pietrobon (Afshar 1992B: 262-263).

Afshar quotes the relevant pages of E'timād al-Saltane's book referring to pioneer European photographers in Iran:

Towards the end of the reign of that pious King and Fighter for the Faith, Muhammad Shah, may the Almightly clothe him in light, Monsieur Richard Khān who at present teaches English and other languages at Dar al-Funun used, with much toil, to take pictures on silver plate. In the early part of the reign of our present Shah, may our souls be sacrificed for him, when the Dar al-Funun was built, Monsieur Krziz, the Austrian artillery instructor, did some photographic experiments on paper. Monseiur Focchetti, the biology teacher, was the first person to use the collodion process at the Tehran College: and Monsieur Carlhian who had accompanied FarrokhKhān Amin al-Dawle from Paris to Tehran in order to propagate the science and methods of photography, made the use of the collodion process widespread (Afshar 1992: 5).

Carlhian then taught the collodion process to Nāser al-Din Shah and to Rezā Akkāsbāshi (1860). There is an album hosted at the Musée National des Arts Asiatiques-Guimet where photographs taken by Carlhian, Pesce and Gianuzzi are shown together with some watercolours collected by the French colonel Victor Francois Brongiart (1809-1968). ${ }^{9}$ He became a teacher at the Dār al-Fonun and did some experiments with cyanotype. ${ }^{10}$ Most probably Āqā Rezā (later Rezā Akkāsbāshi, 1843-1889) learned this technique from him around 1863 and became the first Iranian photographer active in the Persian court. Brongiart was most probably responsible for the introduction of Western props and paraphernalia in the Iranian photographer's studio as well as the typical Victorian poses: frontal and hieratic. Being as he was one of the first Western photographers to work 
as a teacher for Iranian students, he may have been an influential photographer for Iranians, both technically and aesthetically. Āqā Rezā, one of the court's children, became the first qualified photographer to work in the Akskhāne. He was later awarded the title of Akkāsbāshi (Court Photographer), and adopted the name with which he became known as the first professional Iranian court photographer: Rezā Akkāsbāshi. ${ }^{11}$ Already in 1857, Pesce took photographs of ancient cities such as Persepolis, while Gianuzzi took photographs mainly of Mashhad. Both were active in Tehran as well. It was also around this time that Nāser al-Din Shah became actively involved with the new technique and photography became one of his favorite pastimes. Nāser al-Din Shah is considered to be an influential figure in the history of Iranian photography because he was a serious amateur photographer himself, next to the fact that the expansion and development of the technique and art of photography in Iran is indebted to his supporting policies. He photographed everything and anything that belonged to him with overflowing enthusiasm. But his fame in the world of photography, especially outside of Iran, is due to the numerous photographic portraits that he took of his wives. We can recognize the most influential and favorite of his wives by the number of times that they have been depicted, and also because they present a noticeable complicity with the Shah in the way that they have posed: Fātime Sultān Anis al-Dowle (d. 1897) and Zobayde Amine Aghdas (d. 1893). According to the historian Abbas Amanat:

In the later years of his reign' the Shah complained of the stress caused by the rivalry among his wives and their unending demands on him. There were a number of influential wives of peasant background to whom he felt particularly attached. Contrary to princesses and other members of the nobility, these women of low birth better indulged the Shah's undernourished emotional needs. Two of them in particular, Fatima Sultan Anis al-Dawla (d. 1897) and Zubayda Amina Aghdas (d. 1893), brought into the royal harem a certain plebeian mentality and lifestyle - and, in the case of the latter, a degree of vulgarity and homeliness - that appealed to the Shah because of their simplicity (Amanat 1997: 436).

The Qajar prince Malak Ghāsem Mirzā (c.1806-c.1861) was, according to Zokā, the first Iranian photographer to be active in photographic technique and produced some of the earliest examples of court photography in Iran. Zokā argues further that he may have produced earlier daguerreotypes than Richard Khān. ${ }^{12}$

Montabone, who belonged to a family of professional photographers, introduced hand-colored photography in Iran. The photographs taken during his Italian mission were exhibited successfully at the international 
exhibition in Paris in 1867. He produced a well-known album entitled Ricordo del Viaggio in Persia della Missione Italiana 1862. Three copies of the album have been identified: one in the Biblioteca Marciana in Venice, one in the Albumkhāne of the Golestān Palace in Tehran and a third one in the Royal House Archives in the Hague, the Netherlands. ${ }^{13}$ In the words of Tahmasbpour,

the aesthetics and style introduced by Montabone had a profound influence on Iranian photographers working at the imperial court. To date, no earlier examples of colored photographs in the Golestān Palace other than the photographs of Montabone are identified and so we can safely argue that Montabone's photographs mark a revolution in Iranian photography (Tahmasbpour 2007: 17).

Ernst Hoeltzer (1855-1939) and Antoin Sevruguin (late 1830s-1933) are two of the more interesting and prolific photographers that were active in Iran in the last decades of the nineteenth century. They not only stayed longer and lived there for over 30 years, but married Iranian women. Hoeltzer arrived to Iran for the first time in 1871, lived in Iran for over 30 years and married an Armenian woman in Isfahan. ${ }^{14}$ As a residing European photographer in Iran, he produced a remarkable corpus of photographs, specially of Isfahan and the surrounding area. I will analyze his work in chapter 5 .

Sevruguin was born at the Russian embassy in Tehran as the son of a diplomat and lived in Iran for over 30 years as a professional and highly commercial photographer. His work's aesthetics were remarkable. His photography finds itself halfway between staged studio portrait and ethnographic/anthropological documentary photography. Sevruguin's work was very well known by Western travelers and was often used in their travelogues, although he was rarely acknowledged as the photographer. One of the most shocking examples of this is the April 1921 National Geographic Magazine, Modern Persia and its Capital, that I will analyze in chapter 5, where many pictures taken by Sevruguin appeared with another author's name (Faye Fischer). Another well-known journal is Die Welt des Islams by Dr Walter Phillipe Schulz published in 1917 which also contains several uncredited photographs by Sevruguin.

W. Ordén (often spelled M. Hordet) was one of the most mysterious and elusive photographers active in Central Asia at the end of nineteenth century. His work produced in the Khānates of Khiva, Bukhara and Khokand has been published in different books ${ }^{15}$, but to date, it was not known that he also traveled through Persia at the end of the nineteenth century and that he took many photographs there of landscapes, architecture and people. Almost nothing is known of Hordet, except, as mentioned by Vitaly Naumkin, that he traveled in Central Asia between 1885 and $1892 .{ }^{16}$ His 
prints are captioned by writing directly on the negative and sometimes also on the print itself in both French and Russian, but his name is signed using Cyrillic print.

Looking unsuccessfully for the footsteps of the Iranian court photographer Abdollāh Mirzā Qajar (1849-1908) in Austria, I came across the W. Ordén collection of photography hosted by the Museum of Ethnology in Vienna. Being a totally unkown photographer active in the last decade of the nineteenth century in Iran, I will devote some more space to him here in order to properly introduce what I have been able to find so far. The collection comprises 700 photographs from Central Asia and Persia. Next to the collection, there are two letters written in German by the photographer himself and signed "W. Ordén" in which he offers the collection (of photographs taken in Caucassus, Central Asia and Persia, as can be read in the first letter) to the museum stating clearly his conditions. He sent these two letters from St Petersburg. The first one was dated 19 March 1896 (fig. II) and the second one 7 April 1896 (fig. III). So, without a doubt we can date all his photographs hosted in this collection as taken before those dates.

In all the books that printed W. Ordén's photographs taken in Central Asia mentioned above, the photographer is identified as M. Hordet. The accepted transliteration of the photographer's name from Russian seems to have been M. Hordet, but the two letters are signed by "W. Ordén", so both names obviously refer to the same photographer.

W. Ordén's sepia-toned album prints hosted in this collection are in the general range of $16 \times 22 \mathrm{~cm}$ in size and mounted on board. As stated by Kate Fitz Gibbon, "his negative numbering system gives some clue to his prolific nature. Known prints span at least between the numbers 1504 and 1602 , a few are numbered in the 1880 s or 2000 s, and many more appear between 2745 and 2791". ${ }^{17}$ Remarkably, in this collection I have found numbers that go up to 4281 (a photograph taken in Erzurum), so quite a lot higher than was known to date. In particular, the photographs that concern this study, the ones taken in Persia or that depict Persian types, go up to number 3189. The subjects of the photographs include studio portraits (often collages of two, three or four photographs), landscapes (there are several cemeteries), archeological sites and street scenery. There are several photographs of the Golestān Palace (figs. IV and V), of cemeteries of various cities in Iran (figs. VI and VII), a caravanserai in Shiraz (fig. VIII), a tower overlooking the Caspian see in Anzali (fig. IX), and several collages of Persian types, that I shall introduce in chapter 5. So far I have been able to locate two institutional archives and two private collections that hold photographs by Ordén: The Ethnology Museum in Vienna, the KunstKamera in St Petersburg, Anhaita Gallery in Santa Fe, and Elmar Seibel Collection in Boston. I will introduce his work further in chapter 5, 
since he constitutes a new (unkown) name in the history of photography in Iran.

We know of three Western women active in Iran in the Qajar Era, the French archeologist and journalist Jane Dieulafoy (1851-1916, active in 1881-82), the English Isabella Lucy Bishop-Bird (active 1890) and the archeologist Gertrude Lowthian Bell (1868-1926, active in Iran in 1911). Dieulafoy and Bell's travels were inspired and conditioned by their interest in archeological research, whereas that of Bishop-Bird was basically motivated by an interest in traveling and being faced with unknown realities. I will briefly introduce each one of them, as well as a few Iranian female photographers, in chapter 5 .

Aside from the professional European photographers brought to the Persian court on the Shah's request, there were other foreign visitors and travelers to Persia who actively or passively participated in the development of photography in Iran. Western nineteenth-century travelers to Persia came from different interests and cultural backgrounds. There are three categories in which these travelers can be classified according to the motivation that led them to travel: diplomats and travelers on political or military missions; travelers on archeological missions; and tourists (this last group was very small in numbers). Some of these early travelers to Iran wrote and published their studies and memories in the form of books and travelogues. Here it is important to stress the fact that the amount of foreign travelers to Persia was quite insignificant compared to other countries in Asia. A good way to prove this is by comparing the amount of guidebooks published at the end of the nineteenth century in different countries in Asia. If we just consider the most popular British publisher, John Murray's guidebooks, the first guidebook to Persia (as an independent short chapter within the whole guidebook) was published in $1895^{18}$, by which time Murray's guidebook to Japan was in its 5 th edition and to India in its 3rd edition. In the 1854 Murray's guidebook to Turkey (3rd edition) we find just two pages referring to Persia, precisely the route number 60 from Erzurum to Persia. $^{19}$

Scholarly travelers took, bought or commissioned photographs to illustrate their publications. A number of art historians and archeologists commissioned quite extensive photographic surveys, among them the German photographer, Iranologist and writer Franz Stolze (1836-1910) who stayed in Iran from 1874 to 1881 ; the French archeologist and photographer Jacques Jean Marie de Morgan (1857-1924) ${ }^{20}$ who was in Iran in 1897; and the German Friedrich Sarre (1836-1910) who traveled in Iran and Turkestan in 1897-98 and 1899-1900. ${ }^{21}$ Some of these travelers, as in the case of Sarre, used photographs by Sevruguin without crediting him. This was, not surprisingly, very much the norm in the nineteenth century, when copyright issues were unheard of. They concentrated on the landscape, archeological sites and daily life of local people living in small villages. 
Other travelogues are those by the French writer Henry René D'Allemagne (1863-1950) and the Swedish geographer and explorer Sven Hedin (18651952). D'Allemagne's travelogue, Du Khorasan au Pays des Bakhtiaris. Trois mois de voyage en Perse, was published in 1911 in four volumes. Hedin's travelogue $\mathrm{Zu}$ Land nach Indien, published in Leipzig in two volumes in 1910, presents 308 images that include his photographs, watercolors and drawings. At least two of the photographs were probably taken by Sevruguin, since he acknowledges the authorship by another photographer as by an Armenian photographer. ${ }^{22}$

As noted above, the first professional Iranian court photographer was Rezā Akkāsbāshi. He was son of Esmā'il Jadid al-Eslāmi, a well-known court servant and brother of Nāser al-Din Shah's private doctor. He became a court servant while still a child. In 1863, while he was still a servant, the Shah decided that he would be trained as a photographer under the guidance of Carlhian. I will repeatedly come back to this photographer throughout my book since a few of his photographs will be analyzed in the different chapters. Rezā Akkāsbāshi's students, who worked at court or as teachers at Dār al-Fonun, became the first generation of Iranian photographers. For a graphic idea of the amount of court photographers (both nonIranian and Iranian) active during the reigns of Mohammad Shah and Nāser al-Din Shah (both with or without the title Akkāsbāshi), and of the photographers working at Dār al-Fonun, see fig. X.

Ali Khān Amin Hazrat (active from 1873, d. 1888) was the son of the $\bar{A} b d \bar{a} r b \bar{a} s h i$ of Nāser al-Din Shah. As explained to me by Iranian photo historian Rezā Sheikh in e-mail communication (January 2012), "Ābdārbāshi is someone who is in charge of daily refreshments of all sorts, mostly on the liquid side (tea, sharbat...), also light sweets etc, someone who not only took care of the king but also his guests. Their job was extremely important as they also made sure no one poisoned the king, hence very trusted people, very close to the king". In 1876, he became the head of the Akkāskhāne in the Golestān Palace, responsible for training and controling other photographers, such as Mirzā Hoseyn Ali Akkās (active 1877-1889). Album 129, kept at the Golestān Palace, has 70 photographs of different places taken by Ali Khān Amin Hazrat in 1881. From 1882 to 1887, he took the position of his father as the Shah's $\bar{A} b d \bar{a} r b \bar{a} s h i^{23}$ Mirzā Hoseyn Ali Akkās was his most advanced student. He was sent to Europe for further studies in photographic technique. He became Nāser al-Din Shah's private doctor, and the head of the Akkāskhāne for some time. He accompanied the Shah on his second trip to Khorasan and took 76 photographs on the way to Mashhad, 95 photographs in Mashhad and 81 photographs on the way back, now kept in three boxes at the Golestān Palace Library. ${ }^{24}$ The brother of the famous court painter Mohammad Ghaffāri, Kamāl al-Molk (1852-1940), Sāne al-Molk who was himself a painter, used many of his photographs as models for his paintings, an example of 
how photography also influenced Persian painting at the end of the nineteenth century. ${ }^{25} \mathrm{He}$ was undoubtedly one of the most prolific photographers of his time.

Abbās Ali Beyk (active from 1863 onwards) was a student of Rezā Akkāsbāshi as well. He supervised the Akkāskhāne and helped Rezā Akkāsbāshi to develop his photographs. In 1870, the Shah sent him to Arak to take photographs before a planned trip of the Shah with his mother to that land. When he came back to the court, 79 photographs taken by him were printed by Rezā Akkāsbāshi and placed in two identical albums: one for the Shah and one for his mother, both kept at the Golestān Palace. Later on, in 1868, the first studio outside the court was opened and run by Abbās Ali Beik, under the supervision of Rezā Akkāsbāshi. ${ }^{26}$

Yusof Khān Akkās (active from 1892 onwards), a court photographer in the last years of Nāser al-Din Shah's reign, also was granted the $A k k \bar{a} s b \bar{a} s h i$ title. In the Golestān Palace there are three albums (Nos. 109, 110 and 111) with a total of 145 photographs taken by Yusof Khān Akkās between 1894 and $1895 .^{27}$

Mirzā Seyed Ali is no doubt one of the best Iranian photographers of the Qajar Era. His photographs can be found easily among family albums in private collections. He assisted his father, who was himself mostowfi. As explained to me by Sheikh, "mostowfi is like a clerk and accountant combined, they kept track of all kinds of financial transactions, property, selling and buying, also any kind of financial flow in or out of the treasury. They had the ability to keep daily accounts and supply all kinds of reports. Any ruler, provincial, local, or country wide, king and his boys, all had their own mostofi. Mostowfi al-mamālek was the head of all the mostofis". When his father died, he took over his position. There are many photographs with his studio's stamp. In album No. 278, kept at the Golestān Palace, there are many of his photographs. ${ }^{28}$

Manucher Khān Akkās (active around 1882), was active in the last part of the reign of Mozaffar al-Din Mirzā in Tabriz. Zokā explains that in the Golestān Palace there are 83 photographs in two albums (Nos. 434 and 401) that bear Manuchehr Khān's signature. ${ }^{29}$

Mirzā Ahmad Khān Sāne al-Saltane (born 1847), studied medicine at Dār al-Fonun and learnt photography by himself. He was so attracted by it that it later became his profession. Dust Ali Khān Nezām al-Dawle sent him to Europe to study photography, graveure, etc, for 15 months. Upon his return to Iran, he started working at the Akkāskhāne and also at Dār alFonun. He was also actively working theoretically on photographic technique in 1873-1882 and wrote a book about photography entitled Amal-e Akkāsi o Resāla 'i dar Akkāsi, which was presented to Nāser al-Din Shah. Later on (without royal permission or request) he went to Europe and spent over 7 years there. ${ }^{30}$ 
Aghayanz Armeni (active around 1890-1910), was an Armenian photographer, active in the last years of the reign of Nāser al-Din Shah and the first years of Mozaffar al-Din Shah's. He opened a photo studio together with the Iranian photographer Amishu and other colleagues. Several of his photographs are kept at the Palace Golestān Library (albums 285 and 292). There also is an album with forty-eight photographs in the Zokā private collection. $^{31}$ His work follows the aesthetics of pictorialist photography, best represented in the West by Margaret Cameron and in Iran by Antoin Sevruguin. One of his favorite topics was portraits of dervishes using on them the light, atmosphere, composition and pose of the pictorial tradition in photography.

Joseph Papaziant (active from the 1870s onwards) was an Armenian photographer and also a well-known theater actor. In 1875, he opened a studio in Tehran. Due to his outstanding work, the Shah gave him a royal medal (Shir-o Khorshid) that he printed on his card. ${ }^{32}$

Mohammad Hasan Qajar (active during the last years of Nāser al-Din Shah, between 1890 and 1895), worked as a court photographer specializing in military matters. There is a well-known album with photographs of prisoners in Qazvin, most probably a project commissioned by the Shah, taken in 1895 (album No. 334 at Golestān Palace). ${ }^{33}$

Abdollāh Mirzā Qajar attended the Dār al-Fonun and, in 1869, traveled to Europe to study photography. He lived in Paris for one and a half years and in Salzburg for three years. He started his career as a professional photographer immediately on his return from Europe, and was placed in charge of photography in Dār al-Fonun. ${ }^{34}$ Later in the reign of Mozaffar al-Din Shah he became the head of the Imperial Printing Press and his name stamp can be seen at the end of the books printed in that press. ${ }^{35} \mathrm{He}$ is one of the photographers whose work I will present throughout my book. As noted by Afshar, the best source of information about him is his own account (written in 1896-7), which is reproduced in Mr Iqbāl Yaghmā'i's article "The Beginning of the Craft of Photography and Stereotyping in Iran". 36

Amir Khān Jalil al-Dawle Qajar (d. 1888), a prince photographer whose talent has been remarked by Zokā and Adle. In 1896, he took several photographs in Khorasan that were pasted into an album now held at the Golestān Palace (album 438). ${ }^{37}$

Mirzā Jahāngir Khān Akkās (active 1890s to 1910s), worked at the court both with Nāser al-Din Shah in his last years of rule and with Mozaffar alDin Shah. Unfortunately, no specific albums with his photographs have been found so far, and his photographs are hard to find scattered among different collections. ${ }^{38}$

Abd al-Qāsem ebn al-Nuri (active from the 1880s onwards), Mirzā Jahāngir Khān Akkās's father, worked in Nāser al-Din Shah's court. He learned the photographic technique when he was quite young. Several of 
his photographs are kept in albums at the Golestān Palace Library. His work is especially interesting for my research, since he was fond of using inscriptions within the photographic space. He placed his signature within cartouches and in the same way as the illuminators did. Most of the sitters depicted in his photographs are kneeling in the traditional Iranian pose and hold objects borrowed from the Persian painting iconography. ${ }^{39}$ I will come back to him repeatedly, since his work is very interesting for my research, especially concerning the relation of text/calligraphy and image.

Another important Iranian photographer, Ali Khān Vali Hākem (1845/61902), deserves close attention. He was a member of a distinguished Qajar family, his father having had a long career as diplomat and governor. The most important event in his young life occurred when he accompanied his father to St Petersburg in 1855 for several years. During that time, he studied and learned photography. ${ }^{40}$ Ali Khān Vali's photograph album documenting his career as a governor at various places in Azerbaijan (Northwest Persia) between 1873 and 1896, is of virtually unprecedented quality and character. His work will be introduced and analyzed in chapter 5 , since it bears some interesting elements such as the field studio paraphernalia used while taking portraits of people he met during his travels.

In Shiraz, there was a whole family of photographers. Mirzā Hasan Akkāsbāshi (1854-1916) was the first photographer of the family. When he was 16 years old, he emigrated to Bahrain where he met an English photographer who taught him the photographic technique. Four years later he traveled to India and settled in Mumbai for 20 years. There he kept on improving his photographic skills with another English photographer, who was also his student of Persian. He started working as a professional photographer when he was 24 years old. During the last eight years of his stay in Mumbai, he worked as a professional photographer and then returned to Shiraz. In 1894, he opened a studio in Bushehr, the first one to open in Fars province. Later on, he opened a studio in Kazerum and in 1895 , he went back to Shiraz where he did the biggest part of his production as a photographer. ${ }^{41}$ His work, and also that of his family, is interesting for my research, especially due to the use of text within the photographic space, pots of flowers and the understanding of the photographic space in general, as we shall see with examples in the different chapters of this book. Mirzā Mohammad Rezā Akkāsbāshi (1862-1902) was the brother of Mirzā Hasan (1853-1915) and started taking photographs in 1886 . He traveled, like his brother, to Mumbai and learned the retouch technique with the English photographer T.B. Steward. He ran his brother's studio while he was traveling in Irak or in India, where he also worked as professional photographer. ${ }^{42}$ Mirzā Habibollāh Chehrehnegār (1896-1942) was the son of Mirzā Hasan, and Mirzā Fatollāh Cheherhnegār (1877-1932) was his grandson. Both also traveled to India and settled in Mumbai for a while. 
I will, throughout the book, introduce some historical information related to the history of photography in Iran or to the life and work of the photographers considered. This brief historical introduction should be taken as an aid for the general reader to understand the book in its proper historical context. At the end of the book, there is an appendix that will be useful as a chronological guide to historical facts and information about the photographers considered in this book. For further reading in English about the history of photography in Iran, Iraj Afshar's Remarks on the History of Early Photography in Iran remains a good source of information. The best sources in Persian on the history of photography are the classics by Yahyā Zokā and Iraj Afshar. In the last ten years there has been a remarkable increase in research done on Iranian photographers by leading Iranian photohistorians. A detailed bibliography (by Francesca Bonetti, Alberto Prandi and Khadijeh Mohammadi Nameghi) will be published in a special issue of "History of Photography" (HOP) on nineteenth-century and early twentieth-century Iranian photography due in early 2013 (guest editors: Rezā Sheikh and Carmen Pérez González), with all publications in Persian.

\section{NOTES}

1 See: Tahmasbpour 2001: 17. For detailed information about the introduction of the daguerreotype in Iran, see: Adle 1983: 249-280; Adle 1994: 577-578; and Adle 1997: 6-11.

2 See: Ekhtiar, Maryam, Modern Science, Education and Reform in Qajar Iran: The Dār al-Fonun, unpublished $\mathrm{PhD}$ Thesis, New York, 2003, available through UMI; "From Workshop and Bazaar to Academy: Art Training and Production in Qajar Iran", in Diba 1998; "Nasir al-Din Shah and the Dar al-Funun: The Evolution of an Institution", Qajar Art and Society, in Journal of the Society for Iranian Studies, Vol. 34, Nos. 1-4, 2001; "The Shah's Royal Museum: Art Presentation and Authority in Nineteenth Century Iran", in Murraqqa'e Sharqi: Studies in Honor of Peter Chelkowski, AIEP, Republica San Marino, 2007: 83-92.

3 Bonnetti \& Prandi 2010: 23.

4 See: Maryam Ekhtiar and Marika Sardar, "Nineteenth-Century Iran: Art and the Advent of Modernity" in The Time of Art History at http:/www.metmuseum.org/toah/hd/irmd/ hd_irmd.htm

5 For more information about these two books, see: Zokā 1997: 291-293; and Afshar 1992: 11.

6 Tahmasbpour has considered this topic in several articles and books. See, for example: Tahmasbpour 2010 and Tahmasbpour 2001.

7 For a good source of information on the Italian photographers active in Iran in the nineteenth century, see: Bonnetti \& Prandi 2010.

8 As referenced by Afshar: Mer'at al-buldān-e Nāseri, Tehran 1295, iii: 20-1; see Storey PL, i/1, 344, no. 444 (1), ed (2).

9 The album consists of more than 150 photographs and watercolors. For a good analysis of this album, see: Sheikh, Rezā, "The Souvenir Album of Colonel Victor Brongiart, Artillery Attaché at the service of Nāser al-Din Shah, 1852-1856", in Aksnāme (Iranian Photographic Quarterly), Vol. 3, No. 11, Spring/Summer 2003, Tehran: 9-2.

10 The cyanotype process was discovered by John Herschel. A low-cost permanent print made by putting an object (i.e. a drawing or plant specimen) directly in contact with paper 
impregnated with iron salts and potassium ferricyanide, then exposing them to light. The paper turns dark except where the object blocks the light. The resulting image is white on a blue ground. As quoted from Rosenblum 1997: 651.

11 For further information on Rezā Akasbashi, see Zokā 1997: 47-57; and Tahmasbpour 2007.

12 As summarized and translated from Zokā 1997: 8-17. For further information about this photographer, see: Adle 1983.

13 See Vuurman 2004: 23.

14 For a good source of information on Ernst Hoeltzer and a wide selection of his photographs, see Damandan 2004.

15 Naumkin, V., Caught in Time. Great Photographic Archives. Samarkanda. Reading: Garnet Publishing Limited; Naumkin, Vitaly, Caught in Time. Great Photographic Archives. Khiva. Reading: Garnet Publishing Limited; Cagatay, Ergun, Once Upon a Time in Central Asia, Tetrafon, Istanbul 1996; Valeriia Prishchepova, 'Vzgliad so storony: urda, dzhaliap, bacha/A View from the Outside: Urda, Jalap, Bacha' (po fotokollektsiiam MAE RAN 1870-1920 gg.), in Grezy o vostoke. Saint Petersburg: MAE-RAN, 2006; Fitz Gibbon, Kate, 'Emirate and Empire: Photography in Central Asia 1858-1917', in Social Science Research Network (online resource), Sept. 2009: 1-34. I thank Heather S. Sonntag, photo historian expert on $19^{\text {th }}$ century Central Asian phootgraphy for help on locating some of this literature.

16 Naumkin, V. and Nedvestky, A.G.(1997). Bukhara: Caught in Time. Reading: Garnet Publishers: 10 .

17 Fitz Gibbon 2009: 19.

18 Wilson, Sir Charles, A Handbook for Travellers in Asia Minor, Transcaucasia, Persia, etc, London, John Murray Publishers, 1895.

19 The author outlined a route from Tabriz to Tehran, and an alternative one (described as shorter and more picturesque, from Sultaniah to Kasvin): see, Handbook for Travelers to Turkey, describing Constantinople, European Turkey, Asia Minor, Armenia, and Mesopotamia, London, John Murray Publisher, 1854: 270-271.

20 There are 351 photographs taken by Morgan in his first assignment in Iran organized in four albums at the Palace Golestān Library: Nos. 1397, 1398, 1399, 1400. I thank Ms Khadijeh Mohammadi Nameghi for this information.

21 Sarre, F. (1910), Iranische Felsreliefs. Berlin.

22 Hedin, S. (1910), Zu Land nach Indien, 2 volumes, Leipzig: S.A. Brockhaus.

23 As summarized and translated from Zokā 1997: 79-82.

24 As summarized and translated from Zokā 1997: 83-85.

25 For an insightful study of this famous family of painters, see: Diba, L. S., 'The Qajar Court Painter Yahya Ghaffari: His Life and Time', in Hillenbrand 2000: 83-96.

26 As summarized and translated from Zokā 1997: 58-59.

27 As summarized and translated from Zokā 1997: 125-127.

28 As summarized and translated from Zokā 1997: 121-124.

29 As summarized and translated from Zokā 1997: 193-196.

30 As summarized and translated from Zokā 1997: 75-78.

31 As summarized and translated from Zokā 1997: 197-205.

32 As summarized and translated from Zokā 1997: 62-65.

33 As summarized and translated from Zokā 1997: 119-120.

34 As summarized and translated from Zokā 1997: 98-108.

35 Afshar 1992: 9.

36 Afshar 1992: 8.

37 As summarized and translated from Zokā 1997: 128-134.

38 As summarized and translated from Zokā 1997: 135.

39 As summarized and translated from Zokā 1997: 117-118. 
40 As summarized and translated from Zokā 1997: 66-74.

41 As summarized and translated from Persian from the book: Sane 1990: 9-12.

42 As summarized and translated from Sane 1990: 13-14. 


\title{
1 VISUAL LATERALITY: THE RELATION- SHIP BETWEEN THE DIRECTION OF WRITING AND COMPOSITION
}

To the memory of Yael Langella (Paris, 1953 - Lisbon, 2007)

\begin{abstract}
If one observes the movements of a human being in possession of a camera (or of a camera in possession of a human being), the impression given is of someone lying in wait. This is the ancient act of stalking which goes back to the Paleolithic hunter in the tundra. Yet photographers are not pursuing their game in the open savanna but in the jungle of cultural objects, and their tracks can be traced through this artificial forest. The acts of resistance on the part of culture, the cultural conditioning of things, can be seen in the act of photography, and this can, in theory, be read off from photographs themselves.
\end{abstract}

Vilém Flusser (Flusser 2000: 33)

If right and left had not been relegated to the traffic regulations or to the terrestrial and celestial ceremonial, Science and Philosophy would have known how to use them fittingly.

Silvio Ceccato ${ }^{\mathrm{I}}$

The main research question of this chapter is whether, and if so, how the direction of writing and reading of Iranian nineteenth-century photographers influenced the composition of the studio photographs of this period. To understand the relation between the two, I have defined groups of photographs to show different ways of composition due to the different reading habits (left-to-right on the one hand, right- to-left on the other). This research is built on visual analysis and from two frames of reference: art history and neuroscience. First, I will define the phenomenon of visual laterality, then I will introduce the photographic corpus identified as showing the effect of the phenomenon of visual laterality. I will finish the chapter with a historical survey of the main conclusions and results found both in the fields of art history and neuroscience that support the main hypothesis of this chapter. It is important to note that the art-historical literature 
that relates to this phenomenon belongs mainly to the first half of the twentieth-century, whereas the literature in the field of neuroscience is recent, mostly produced in the last fifteen years. This apparent gap in the art-history literature can be explained by the fact that in the field of neuroscience an important group of scholars focused their research on answering and giving an appropriate theoretical framework to the questions posed by some art historians several decades ago, though in a very discrete way. The most recent literature in this field has an interdisciplinary approach.

\subsection{Definition of visual laterality}

Scripts can be written in many directions. The Japanese scripts specialist Akira Nakanishi has elaborated nine models (fig. 1a) to summarize the different directions of scripts. Ancient Phoenician and Aramaic scripts were written in (a) only; the descendants of these scripts, Arabic, Hebrew, Persian, Urdu, and others, are now written in the same way, i.e., from right to left, the opposite direction of all Western languages (b). The neurologist Chris McManus has made a schema of the evolution of the direction of the script in the different languages (fig. 1b), which is very helpful to understand the remarkable number of languages written today with a right-to-left (leftwards) script. ${ }^{2}$

Would this remarkable difference in the writing direction used by different cultures in any way affect the composition in works of art, and in particular in the photographic image, since the direction of writing and reading is exactly the opposite in these two groups of languages? The area of research of this study is Iran in the nineteenth-century and the material of study is photography. The language in question is Persian. My conclusions will be directly connected to photography. Is there a difference in composition between the photographs made by Westerners and by Iranians resulting from this? In other words, I want to know if photographs show evidence of visual laterality, and visual laterality is defined here as the conditioning of the composition of the image by the direction of writing.

How does visual laterality manifest itself, if at all? One of the topics that is fundamental to understanding visual laterality is to know and define its relation with laterality caused by handedness ${ }^{3}$ and hemisphere specialization, in other words, if there is a relationship between left and right in pictorial and photographic space and left and right in the brain. In this particular case, the condition of the composition of the photographic image. My hypothesis is that the fact that Persian is written from right to left implies a production of mirror images to those produced by Western photographers. For the purposes of this discussion a mirror image is understood to be a reflection with respect to the human's plane of symmetry, that is, a left-right mirror image.

Asymmetries of the pictorial space could arise from asymmetries of the brain or from cultural conventions. The psychologists Charles G. Gross 
and Marc H. Bornstein suggest that both contribute to the anisotropy ${ }^{4}$ of art but in different ways. ${ }^{5}$ I will start this research with the second cause of anisotropy of the photographic space, the cultural convention due to the direction of writing of different scripts. Aestheticians have frequently asserted that left and right in a picture are absolutes. The Swiss art historian Heinrich Wölfflin (1864-1945) called attention to the fact that pictures change appearance and lose meaning when turned into their mirror images. He realized that this happens because pictures are "read" from the left to the right, and naturally the sequence changes when the picture is inverted. ${ }^{6}$ Wölfflin noted that the direction of the diagonal that runs from bottom left to top right is seen as ascending, the other as descending. Any pictorial object looks heavier at its right side. ${ }^{7}$ Therefore, my hypothesis is that, if the only condition for that rule of composition is that the pictures are "read" from left to right (like the direction of writing of all Western languages), then the opposite applies to the rest of the languages, i.e. those written from right to left (like Persian): Iranian photographers produce mirror-like images to those made by Western photographers. We can see Wölfflin's thoughts summarized in fig. $2 \mathrm{a}$, where the final point of the scanning path (bottom right) is the heaviest point of the image (painting or photograph). Thus, Western artists would avoid placing an object there and would place it in the bottom left where it does not have such weight as in the symmetrical point. In fig. $2 b$ you can see the Persian (Arabic, Urdu, etc.) version where the final point of the path (bottom left) is the one to be avoided by Iranian artists. We can clearly see that both figures are mirror-reversed images of each other:

The art historian Mercedes Gaffron carried Wölfflin's investigation further. According to her,

the observer experiences a picture as if he was facing its left side. He is subjectively identified with the left, and whatever appears in that part of the picture assumes the greatest importance. (Gaffron 1950: 312)

This agrees with the art historian Alexander Dean's observation of the socalled stage areas of the theater:

as a curtain rises at the beginning of an act, the audience can be seen to look to its left first. The left side of the stage is considered the strong one. In a group of two or three actors, the ones on the left dominate the scene. (Dean 1946)

In Chinese theater, on the other hand, the important positions are to the audience's right. It is interesting to know whether this can be extrapolated to photographs. 
As stated by the art historian Rudolf Arnheim,

it will be evident that when the observer experiences facing the left side, a second and asymmetrically located center is created in the picture at that side. Just like the center of the frame, this subjective center carries importance and can be expected to influence the composition accordingly. A contrapuntal relationship between the two centers results. (Arnheim 1965: 23)

Like the area around the center of the frame, the area of the subjective center is able to carry more weight. There is, then, a curious difference between being "important" and central, at the left, and being heavy and conspicuous at the right, in the words of Arnheim. The same could have been said by an Iranian researcher writing about composition in Iran. Only he would talk about a curious difference between being "important" and central, at the right, and being heavy and conspicuous, at the left. Concluding these observations on the right-left phenomenon Wölfflin reminds his readers that he has described, but not explained it, and he adds: "Apparently it has deep roots, roots that reach down to the nethermost foundations of our sensuous nature" (Wölfflin 1941: 90). At present the most common explanation runs along empiricist lines. The reading of pictures from left to right is a habit taken over from reading the books. ${ }^{8}$

Like Gaffron, the art historian Theodora Haak describes a European tendency of compositions where the movement enters the picture from the left, and where the left side shows more clarity and distinction, while the right leaves more room for the play of imagination. She explains this tendency by a preponderance of right-eyedness. However, in a later work, considering the opposed direction of movement in East Asiatic art, she abandons this theory and assumes that a fundamental difference in mental structure must be the cause of the directional contrast in Western and Eastern art. ${ }^{9}$ In contrast to European pictures, Theodora Haak found out that in the pictorial representations of Eastern Asia one finds a marked direction of movement from right to left. It manifests itself with particular distinctiveness in the so-called makimono, the long scroll, which must be observed while being unrolled uninterruptedly from right to left on the floor. $^{10}$

There is some empirical evidence to support what some art critics have said about a picture that loses something of value when mirror reversed. As described by the scholar Martin Gardner in his interesting book The New Ambidextrous Universe. Symmetry and Asymmetry from Mirror Reflections to Superstrings, David B. Eisendrath Jr, a New York photographer (he does not mention when), prepared a set of 50 scenic photographs so that each picture had two reproductions, one a mirror image of the other. The pairs were shown one at a time to various viewers who were asked to 
designate which one of each pair they liked best. Scenes that had an overall left-right symmetry were chosen as often in one form or the other, but if the scene showed a composition with strong asymmetry, there was about 75 percent agreement among subjects on the choice of one picture over its mirror twin. All these viewers read from left to right. When the same pictures were shown to viewers who read only Hebrew, which goes from right to left, there was a tendency to prefer the mirror reversals of those pictures that had been preferred by left-to-right readers. ${ }^{11}$ Further, Gross and Bornstein ask themselves, if, as aestheticians say,

mirror reversal changes the meaning of a painting, why have so many artists, from Raphael and Rembrandt to Munch, remained apparently indifferent to the reversal of their originals when reproduced as prints or tapestries? And why, conversely, did a few, such as Dürer and Van Gogh, take great care to etch originals in their mirror image? (Gross \& Bornstein 1978: 34).

They point out that, in fact, objective studies (meaning here, based on statistics) involving a number of observers and different paintings have lent little support to the generality of the claims of art historians, that mirrorreversing paintings consistently changes the content or tone of the original. A possible explanation for the failure of experimental psychologists to find the perceptual differences between paintings and their mirror images claimed by aestheticians might be, as Gross and Bornstein suggest, that the psychological experiments involved collections of both symmetrically and asymmetrically organized compositions. In contrast, aestheticians exemplify their point with highly asymmetrical paintings, with marked perspective and lighting differences between the two sides that clearly do alter on reversal.

In sum, the visual-laterality hypothesis is supported by the ideas of classic art historians and aestheticians such as Arnheim and Wölfflin. Their theories have not been contradicted since then and their ideas are still valid in the field of art history and provide an appropriate theoretical background for my research.

\subsection{Nineteenth-century Iranian portrait photography}

I have organized the photographs in three different groups according to their type of composition: the first group, linear order, consists of images in which a group of sitters have been depicted arranged by their height; the second group, couples, consists of images in which a couple has been depicted, one sitter sitting and the other standing; and the third group, chairs, a sitter is depicted standing and resting one of her/his hands on the chair. 


\section{Linear order}

The first group of studio portraits of groups is where people depicted are organized by their height. This group was established after finding a group photograph that depicts five Iranian children (fig. 3), the image responsible for the whole classification that will be shown here. If we compare figures 3, 4, 5, 6 and 7 made by Iranian photographers and figures 8, 9, 10, 11 and 12 made by Western photographers, we can clearly see that some are mirror images of the others. The first photograph (fig. 3), made by an anonymous Iranian photographer, shows a group of Bakhtiyari ${ }^{12}$ children, who posed in height order, from smallest to tallest, if we read it in the Iranian way, but from tallest to smallest if we read it in the Western way. From the clothing the children are wearing, it seems that they were court children. The names have been identified as (right-to-left) Afrasiyāb, Bahman, Shatar, Seifollah and Sohrab. Another photograph (fig. 4), made by Iranian photographer Rezā Akkāsbāshi, shows Prince Firouz Mirzā's children, from right to left: the infant Prince Abd al-Hoseyn (Farmān Farmā), Princess Ma'sume (Esmat al-Saltane), Princess Sorush al-Saltane (Hazrat-e Owliyā) and Princess Malek-Tāj (Najm al-Saltane). ${ }^{13}$ The photograph was taken around 1860. Taken most probably by Rezā Akkāsbāshi (Tahmāsbpur 2001: 152), the next image (fig. 5) presents the sons of Mohandes-e Mamālek in Tehran, ordered again by height, standing on a Persian carpet and performing a military salute. These three images are the clearest photos showing the difference in composition on the basis of visual laterality. The next photograph of this group (fig. 6), also taken by Rezā Akkāsbāshi around 1866, shows this tendency as well. It depicts two men sitting (Ismail and Asad al-Khān if we start with the one at the right of the image) and one standing at the left side of the photograph (Nāser alManushi). The last one (fig. 7) can be seen as two groups of people organized by height: the first one on the back row is formed by four men and one boy; the second one on the front row is composed of four children also organized by height. Its author is an unknown Iranian photographer.

Direction in composition is one of the two factors that determine balance, weight being the other one. This first group of pictures is particularly interesting as far as the direction of the image is concerned, but it also shows clearly what Wölfflin said about the ascending-descending diagonal. He said that the direction of the diagonal that runs from bottom left to top right is seen as ascending, the other one as descending, which is what is happening in the Western photographs that we present here and which demonstrate exactly the opposite (opposite meaning here "mirror-like" compositions) to what happens in the Iranian photographs.

The first photograph of this group of Western photographs (fig. 8), taken by the Czech photographer Ignác Schächtl in Tábor (Czech Republic) around 1900, presents a group of children that are organized by height like 
the ones shown before, but in this case the order mirrors the first ones. The same is true for a family portrait (fig. 9), taken by Czech photographer Josef Jindrich Sechtl in Bozejov (Czech Republic) in 1911 and which presents the Novak Family. The composition of these two images is a mirrorreversed version of figures 3, 4 and 5 . The same happens with a photograph of a group of Khiva women with their children (fig. 10), taken by Ordén not later than 1886. The next photograph (fig. 11), a daguerreotype made by the French photographer E. Lorichon in Spain around 1850. A family portrait by the Spanish photographer Julio Derrey (fig. 12) taken around 1890 is mirror-like image of figure 7.

\section{Couples}

The second group, the couples, is actually a smaller version of the first group. In this kind of photographs, a couple is depicted and one person is always sitting, the other one standing up. We can compare figs. 13, 14, 15 and 16 made by Iranian photographers with figs. 17, 18, 19 and 20 made by Western photographers. The Western photographs are mirror-like images of the Iranian ones. The one who is sitting is usually the person of highest social rank, the older one, or in the case of children, the smallest child (figs. 13, 17). In the photographs taken by Iranian photographers, the chair is, in the majority of the cases, placed at the bottom right side of the picture, i.e. avoiding the heaviest weight point, in Iranian composition (see figure $2 \mathrm{~b}$ ). However, in the photographs taken by Western photographers, the chair is almost always placed at the bottom left side of the picture, avoiding the heaviest weight point (in a Western composition). I found one portrait that deserves a more detailed observation since the two men depicted are actually one and the same person (fig. 14); the photograph is an interesting double-exposure picture of one of the sons of Bahā al-Molk taken by Rezā Akkāsbāshi. ${ }^{14}$ In this case hierarchy plays no role.

There is another difference between Western and Iranian studio portrait photography in the way couples or groups of people are composed and arranged. In Western photography we can find many examples of studio portrait photographs of couples formed by a man and a woman. As photography historian William C. Darrah states,

among the more abundant surviving carte de visite portraits are those of newly married couples and husband and wife at various ages. The most striking convention is the almost universally used pose of the husband seated and the wife standing, with one hand on her husband's shoulder. (Darrah 1981: 36).

In contrast to this, only rarely do you find studio portrait photographs of couples composed of man and wife in Iranian photography in the 
nineteenth century. There are portraits of a man (the Shah) with several of his wives, but those are relatively rare too. According to Iranian historian Guity Nashat,

with the exception of rulers and wealthy individuals, most marriages were monogamous. Polygamous marriages within the well-to-do were rare but were not unheard of: men took second wives when their first wives reached menopause. However, the prospect of sharing a husband with another woman was a threat hanging over the heads of many wives. ${ }^{15}$

What we can find prolifically in Iranian photography is portraits of two men, normally one sitting depending as a sign of respectfulness (the older one normally is sitting) or hierarchical reasons (normally the socially highest rank is sitting).

In this group of couples, we can also identify a subgroup of mothers and fathers holding a child on their lap. It already has been demonstrated by groups of neurologists ${ }^{16}$ that in most of the photographs of parents holding children on their lap, the babies or children are sitting on the left part of their parent's bodies. This bias direction is well established, but why it is to the left, remains unclear. Among several explanations proposed, the handedness explanation posits that most people, being right-handed, hold the child on the left side to keep their right dominant hand free for other tasks related to infant care. ${ }^{17}$ The heartbeat explanation posits that the heartbeat, being more detectible on the holder's left side, makes the left hold more soothing for the infant. ${ }^{18}$ The attention explanation credits the bias to the selective activation in the holder of right-hemisphere-lateralised perceptual, emotional and intentional systems, which predispose a left hold by directing the holder's attention to the left. ${ }^{19}$ Nevertheless, even if this basic directional effect is well established, many details are still uncorroborated, uncertain or inconsistent across studies, and further research is needed.

I have collected some of these photographs, both nineteenth-century Iranian and Western, and I have analyzed them from a formal point of view. The compositions of these photographs agree with the results presented by the neurologists only when we consider Western photographs. An important number of the Iranian photographs (figs. 21 and 22) have reversed compositions (mirror-like compositions) compared to the Western ones (figs. 23 and 24). This, again, raises the question of whether the directionality of the script may play a role in this kind of composition. This topic remains open to further and in-depth research. 


\section{Chairs}

The third group, chairs, is a clear example of Wölfflin's hypothesis. The group of photographs that I present here (figs. 25, 26, 27 and 28, taken by Iranian photographers) and 29, 30, 31 and 32 (taken by Western photographers) are just a few of many examples of it. The first photograph of this group (fig. 25) is a very interesting picture as far as the viewpoint of the photograph is concerned. The photographer has lowered his plane in order to fit the child fully within the picture's frame and therefore, the chair has got a very dominant role, almost a majestic one. The child is posing with a lot of charm and in a very natural way. The next photograph (fig. 26) depicts Sultan Ahmad Mirzā Qajar in a very self-conscious pose for a young boy. He is wearing the clothes and regalia typical of court children and he even holds the omnipresent sword of Qajar painting portraiture. Nāser alDin Shah is looking extremely self-conscious and elegant (fig. 27), resting his left hand on the most photographed court chair, the highly carved rococo one in which he immortalized most of his wives. The last image of this group of Iranian photographs (fig. 28) is the one that depicts Hājji Ali Khān E'temād al-Saltane (Minister of Security Affairs and Governor of Golpāyegān and Khānsār). In the Western group of pictures (figs. 29-32) we can once more appreciate the mirror-like effect. In all these Western images, we can notice that the object located on the right side (in this case, the chair) seems to be heavier than the one located at the left side (as Arnheim points out). Is this visual laterality caused only by the choices made by the photographer (conscious or not), or can it also be produced by the person or group of people depicted? The homogeneity in the pose of those depicted in nineteenth-century portraits points to the fact that, most probably, the photographer was the one who arranged the scene in an already established way, before the sitter came, and the sitter would just follow the directions of the photographer.

The three forms of composition that I have defined above, agree with the examples of stimuli used in the aesthetic-preference experiment already proposed and used by the neurologists S. Christman and K. Pinger and later on by Health et al., which consisted of three geometric elements arranged laterally to form a composition: a vertically-oriented solid black rectangle to represent Weight, an outline of a elongated triangle to represent direction and a stippled hat-like shape to represent Interest (fig. 33). ${ }^{20}$

The three basic compositions I have described at the beginning of this section can be identified with some of the examples of stimuli presented by Christman and Pinger. They can be identified as one of the examples of stimuli shown above: 
- linear order and couples, Iranian composition: figures 3, 4, 5, 6, 7, $13,14,15$ and 16 are examples of stimuli " $\mathrm{D}$ " bottom (balanced weight, absent interest, and right-to-left directionality).

- linear order and couples, Western composition: figures 8, 9, 10, 11, 12, $17,18,19$ and 20 are examples of stimuli "D" top (balanced weight, absent interest, and left-to-right directionality).

- mother/father and child on her/his lap, Iranian composition: figures 21 and 22 are examples of stimuli " $D$ " bottom (balanced weight, absent interest, and left-to-right directionality).

- mother/father and child on her/his lap, Western composition: figures 23 and 24 are examples of stimuli " $\mathrm{D}$ " top (balanced weight, absent interest, and right-to-left directionality).

- chairs, Iranian composition: figures 25, 26, 27 and 28 are examples of stimuli " $A$ " top (right-biased weight, left-biased interest, and left-toright directionality).

- chairs, Western composition: figures 29, 30,31 and 32 are examples of stimuli "A" bottom (left-biased weight, right-biased interest, and rightto-left directionality).

Arnheim wrote: "An unbalanced composition looks accidental, transitory, and therefore invalid" (1969). This however depends on whose eyes are looking at that particular artwork. He also wrote that looking at those unbalanced compositions, we get the impression that the process of creation has been suddenly and accidentally frozen somewhere in its course. Since change is needed, the stillness of the work becomes a handicap. ${ }^{21}$ Foreign observers of nineteenth-century Iranian photographs, such as the ones presented above, could wrongly perceive them as not well composed, but this is a judgment based on ignorance of the existence of other possible modes of representation. Actually, that is what happened in India. As the art critic and photo-historian Judith Mara Gutman pointed out, "in the West the great majority often laughed at photographs like these (non-perspective photos), thinking of them as "mistakes". ${ }^{22}$ In 1895, a correspondent for the Practical Photographer, a magazine published in London for the large audiences soaking up information about photography, caught a glimpse of the swell of indigenous photographic activity in India. He found it repulsive, citing "the bazaars that were 'infested' with native photographers who were bringing down the level of photography all over India", as stated by Gutman. ${ }^{23}$

There are, however, exceptions in both cases, in the Western a small percentage, and in the Iranian a larger one. 


\section{Experiment}

After I finished writing my $\mathrm{PhD}$ thesis, I started an experiment to test the validity of the visual-laterality hypothesis. I would like to thank the leading British neuropsychologist Chris McManus here for his support and guidance during this experiment. I digitalized all the photographic material that I had been able to gather through the years devoted to this research from Iran and from Spain. I decided to choose one particular Western country instead of considering the whole Western world, just for reasons of balance. Spain is my homeland, whose photographic heritage I have been neglecting, and this experiment has given me the possibility to learn a lot about the aesthetics of Spanish photographers in the nineteenth century. I classified the photographs precisely in the three compositional groups defined above. My aim with this esperiment was to get statistical data that would definitely support the visual-laterality hypothesis or force a reconsideration of its principles. The results obtained are as follows (Table 1).

\begin{tabular}{|c|c|c|c|c|c|c|c|c|c|}
\hline & \multicolumn{3}{|c|}{ Linear Order } & \multicolumn{3}{|c|}{ Couples } & \multicolumn{3}{|c|}{ Chairs } \\
\hline & LR & $\mathrm{RL}$ & Total & LR & $\mathrm{RL} \quad \mathrm{To}$ & Total & $\mathrm{L}$ & $\mathrm{R} \quad \mathrm{TC}$ & Total \\
\hline IRAN & $\begin{array}{c}3 \\
17 \%\end{array}$ & $\begin{array}{c}14 \\
83 \%\end{array}$ & 17 & $\begin{array}{l}22 \\
24 \%\end{array}$ & $\begin{array}{l}69 \\
76 \%\end{array}$ & 91 & $\begin{array}{c}55 \\
45 \%\end{array}$ & $\begin{array}{c}67 \\
55 \%\end{array}$ & 122 \\
\hline SPAIN & $\begin{array}{l}13 \\
72 \%\end{array}$ & $\begin{array}{l}5 \\
29 \%\end{array}$ & 18 & $\begin{array}{c}54 \\
66 \%\end{array}$ & $\begin{array}{l}28 \\
34 \%\end{array}$ & $6^{82}$ & $\begin{array}{l}109 \\
68 \%\end{array}$ & $\begin{array}{l}51 \\
32 \%\end{array}$ & 6 \\
\hline
\end{tabular}

Table 1 Comparative percentages Iran versus Spain for the groups: Linear Order, Couples and Chairs.

Currently, I am gathering new books published in Iran in the last months that will let me have more material to further confirm the percentages presented in Table 1. This experiment and the interpretation of its results, was published in the academic journal Laterality: Asymmetries of Body, Brain and Cognition. ${ }^{24}$ In this recently published article, I have referenced the latests publications in the field (from June 2009 to January 2011), many of them not used in this book.

\section{Movement and visual laterality}

Up to this point I have only analyzed studio portrait photographs that are static. Now I would like to consider those that also suggest movement to see if writing and reading habits have an influence on directionality 
(direction of movement of the scene). As the psychologist Jerre Levy points out, it may be that those pictures in which movement, implied or potential movement is present, are preferred by Western observers when the movement is from left to right. If so, monolingual readers of Hebrew and Arabic would prefer the opposite versions of such pictures from those preferred by readers of European languages. ${ }^{25}$ Levy carried out an experiment with Western observers to see their preferences for 97 vacation slides or their mirror versions. He found that left- and right-handers differ in their preferences for mirror versions. Serious experiments similar to this have been undertaken by different groups of neurologists around the globe and I will devote some time to them and their results in the section concerned with the neurological approach to the right-left problem.

The next three images taken by unknown Iranian photographers, present a potential movement towards the left, like the direction of writing of the Iranian script. The first image of this group (fig. 34) depicts a man riding a horse and crossing a river. The horse is going from right to left and his position on the bottom left corner stresses the fact that he is moving leftwards. The movement in the river brings to the viewer the feeling that the horse is really having difficulties crossing the river. The next image (fig. 35) is one of the most beautiful images that I have seen in nineteenth-century Iranian photography. Five small children are depicted sitting on a bench with a leftward reclining pose. The last image of this group (fig. 36) depicts a man riding a motorbike in the right-to-left direction. Nevertheless, it is important to stress here that we have to be very cautious with this particular study case, since it is very difficult to prove this directionality in photography. In fact, I believe that this preference on the directionality of the scene is almost impossible to prove in photography. on the contrary, in painting directionality can be clearly proved, especially in Persian miniature painting. To support my hypothesis, I have identified many stone reliefs and paintings of earlier times in Iran. Is there a tendency to show the movement on the right-to-left direction, like the direction of reading and writing in Iran? Further below, I will present some of those paintings and stone reliefs.

Wölfflin remarked:

one could mean that our art - in the sense of our writing - must always have the inclination, to present movement from the left to the right (marching soldiers, running horses). It is certain that the right side of the picture has a different value from the left one. It decides the general tendency of the picture, that is, its movement to the right. (Wölfflin 1941: 83) 
A good example of this is the motion studies of horses by the photographer Eadweard Muybridge (1830-1904). Further, Arnheim points out that,

since the image is read from left to right, the pictorial movement towards the right is perceived as easier, as if it demanded less effort. If, on the contrary, we see a rider crossing the image from right to left, it will seem to be overcoming a greater resistance, using a greater effort, and therefore going more slowly. (Arnheim 1969: 43)

These phenomena can be related (observable when visual representations are compared with their specular images) with the findings of psychologist H. C. Van der Meer in the sense that "spontaneous movements of the head are executed more quickly from left to right than in the opposite direction" (Van der Meer 1958) and that, when experimental subjects are requested to compare the speeds of two locomotions, one from left to right and the other from right to left, they perceive the movement towards the left as faster. As stated by Arnheim,

it is possible to conjecture that the movement towards the left appears as the winner of a greater resistance; it pushes against the current instead of letting itself be taken by it. (Arnheim 1969: 43)

Since Persian is read and written from right to left, the movement of an image, a scene, also will be depicted and read in that direction. After examining and going through a vast number of Iranian paintings and stone reliefs, I can conclude that this is true most of the time. In the majority of cases, in the Iranian paintings and rock reliefs, the horse is running from right to left, whereas in the Western paintings and reliefs the horse would be running in from left to right.

There are many examples of this kind to be found in painting, but I will show here just a few examples of these kinds of works in Iranian art. In Fath Ali Shah Received by Mirzā Rezā Qoli Monshi al-Molk in Sawdasht (fig. 37), the story is happening in the right to left direction. The important figure in the picture is on the left, Fath Ali Shah enthroned on the Sun Throne, is receiving gifts from a vizier, and other men are also waiting to give him some presents. The arrow of reading is clearly in the right-to-left direction. This painting belongs to the manuscript of the Shähanshāhnāme (Book of the King of the Kings) that was donated in 1818 to the Österreichische National Bibliothek.

The Pictorial Cycle of Eight Poetic Subjects was painted by an unknown artist in Shiraz in the mid-eighteenth century; here I have selected one of the eight works that constitute this cycle (fig. 38). Notice that the horse is running towards the left. 
Shirin Presents a Jug of Milk to Farhād (fig. 39) was painted by an unknown artist in Iran in the late fifteenth-early sixteenth century. Here we see that the scene is happening again in the right-to-left direction. Again, the horse is running towards the left side of the picture.

Military Review with Fath Ali Shah and Prince Hoseyn Ali Mirzā (fig. 40), painted by an unknown artist in Shiraz is an interesting example of the right-to-left directionality of the happening of the scene of a ritual encounter of Fath Ali Shah and a prince during a military review. As described by the Islamic art historian Adel T. Adamova,

The prince has fallen to his knees before the Shah and is identified by an inscription above his head with his title, Farmān Farmā (Prince Hoseyn Ali Mirzā, Fath Ali Shah's son who was governor of Shiraz in 1799-1835). Hoseyn Ali Mirzā's three sons appear at the upper left side, with their names (Akbar Mirzā, Shāhrokh Mirzā and Timur Mirzā) inscribed above their heads. (Adamova 1998: 73)

The Shah is mounted on horseback at the center of the picture, dominating the composition and all those around him and the scene is clearly happening in the right-to-left direction. In Fath Ali Shah at the Hunt (fig. 41), we can see again the horse running from the right to the left. This stone relief was executed by Abdollāh Khān in Rayy, circa 1820-30. Next to the main scene, there are other more peripheral scenes that also reveal this leftward directionality (see, for instance, the one happening in the right top corner). These are but a few examples of this phenomenon, and anybody who may open a book about Persian miniature, will be able to gather many examples of the kind that I have just shown. I have also researched miniatures that illustrate Urdu (also right-to-left script) literary texts and I have found the same consistent leftward directionality in the way the scene is happening and in the direction of the depicted horses.

We can easily find contemporary examples of this directionality in Iranian comics, on Iranian websites (especially interesting to see is the mirror-like composition of the design of the websites that have an Iranian section and an English one) and also in Iranian films where the movement of the camera reveals the influence of reading habits on composition and directionality in Iranian cinema. This also supports the visual-laterality hypothesis but it is a new field of research that goes beyond the scope of the present book but that deserves further and in-depth research.

In sum, I can conclude that there is a tendency in nineteenth-century Iranian photographers to produce mirror-like images of those produced by their Western colleagues. This tendency has been proven to be consistent in the three groups of composition that I have analyzed in this chapter: in the group linear order, Iranian photographers tend to organize the group of sitters by height, from the shortest to the tallest in the leftward direction, 
whereas the Western photographers tend to organize the group in the opposite direction; in the group couples, the person that is sitting on the chair in Iranian photographs is normally placed on the right side of the photograph, whereas in the Western photographs he is placed almost always on the left side of the image and this holds true for the third group, chairs, as well. There is also consistency in the leftward directionality of the scene in Persian miniatures, which gives further evidence to the visual-laterality phenomenon.

\subsection{Visual brain and visual perception in art}

Neurologist Semir Zeki's statement that "all visual art is expressed through the brain, whether in conception, execution or appreciation, and no theory of aesthetics that is not substantially based on the activity of the brain is ever likely to be complete, let alone profound" (Zeki 1999: 1), made me aware of the importance of trying to understand what is happening in the brain in relation to visual art. One of my goals in this section is to find out if Zeki's theories can provide new insights into my subject.

The neurologists have learned enough about the visual brain in the last quarter of the last century to be able to say something interesting about visual art, at least at the perceptual level, as Zeki believes. He hopes that with his, in my opinion, highly interesting book Inner Vision. An Exploration of Art and the Brain, "he can contribute to the foundations of a neurology of aesthetics or neuro-aesthetics, and thus for an understanding of the biological basis of aesthetic experience" (Zeki 1999: 2). The neurobiological view that he presents in his book, is that art has an overall function, which is remarkably similar to that of the visual brain and that it is actually an extension of it and therefore obeys the same laws that govern the visual brain. Actually, everything seems to point to this emerging field becoming fundamental in the decades to come since it is a joint effort of art historians and neurologists to try to understand more about the process of production of a work of art and the role the brain and its functions plays in that process. In May 2008, an institution named Neuroaesthetics has been founded in Berlin, notably by leading scholars in both fields, art history and neuroscience. ${ }^{26}$ The recently published book World Art Studies: Exploring Concepts and Approaches ${ }^{27}$, which acknowledges in the first place art as a panhuman phenomenon, constitutes an effort to study art from all times and regions of the world in an integrative manner from a variety of disciplinary perspectives. Especially interesting for my research is the article written by the neuroart-historian John Onians, "Neuroarthistory: Making More Sense of Art"28, in which he explains with examples why a neuroscientific approach is likely to contribute immensely to world art studies. As Onians states, 
if we know something of the factors that might have affected the unconscious mental formation of the makers and viewers of art in a particular place at a particular time, neuroscience helps us to understand how those factors might also have affected the appearance of that art (Onians 2008: 284).

Onians's recently published book Neuroarthistory. From Aristotle and Pliny to Baxandall and Zeki, offers an account of this new field in the human sciences: neuroarthistory. ${ }^{29}$ The number of art historians making use of neuroscience is growing and this helps them to understand and explain better the creative process and the response to art. In the words of Zeki,

vision is an active process, not a passive one that we have long imagined it to be. Even the most elementary kind of vision is an active process. Art is in his opinion also an active process, a search for essentials; it is a creative process whose function constitutes an extension of the function of the visual brain. (Zeki 1999: 7)

Therefore, if we understand the connections of brain and vision, we will be able to understand better how the aesthetical experience is happening.

The most complex organ in the human body is the brain. Since ancient times, the brain's structures and functions have been prodded, observed and experimented on. A major impetus to the study of the physical workings of the brain came in 1791, when the Italian physician and physicist Luigi Galvani (1737-1798) showed that electricity exists as a force within the brain cells. His experiments were later confirmed by the German physician and physiologist Emil Du Bois-Reymond (1818-1896) in 1850, who found that neurons emit pulses of electricity that travel at around $200 \mathrm{mph}$. The Czech anatomist Jan Evangelista Purkinje (1787-1869), in 1838, found that nerve cells consist of two parts: a nucleus similar to other cells and a set of fibbers which emanate from the nucleus - these were later identified as the axons and dendrites. In 1870, the Italian physician Camillo Golgi (18431926) made the observation that there were literally billions of neurons making up the central nervous system and established that the neurons in the brain sent information to the motor nerves and that information from the sensory nerves was sent to the brain for analysis. These initial discoveries paved the way for modern neuroscience, which in recent years has yielded enormous amounts of information about the physical functions of the brain. Yet, very little of the brain's mystery has been unraveled. What is known of its characteristics is due, in large part, to the efforts of biological psychologists such as Roger Sperry (1913-1994) and Michael S. Gazzaniga. One of the brain's most intriguing aspects is its hemispheric specialization. This refers to the division of tasks within the right and left hemispheres of the brain. In humans, the left side of the brain is dominant in language and 
analytical skills; whereas the right side is dominant in spatial tasks, facial recognition, prosody (tonal qualities of speech), and emotion. In addition, the left hemisphere of the brain controls the right side of the body while the right hemisphere controls the left side. Also, normally the right side of the visual field is projected to the left hemisphere of the brain and the left field to the right hemisphere. The right part of the body is controlled by the dominant left half of the brain, and the left part of the body by the right half of the brain. Therefore, the left hand is controlled by the right half of the brain and the right hand by the left half of the brain. See the following diagram of the visual pathways from Ramón y Cajal's classic Textura del sistema nervioso del hombre y de los vertebrados (fig. 42). ${ }^{30}$

In the past thirty years, the evolution of the knowledge of the structure of the brain and its functions has been remarkable. Nowadays, we know that there is a specific part of the cerebral cortex that deals specifically with vision. It is instructive to recall, as Zeki points out, that it is only recently that neurologists accept that the retina connects with only one well-demarcated part of the brain, the primary visual cortex, and that there is therefore a localization for vision in the brain. ${ }^{31}$ See fig. 43 for a diagrammatic representation of the connections between the eye and the brain ${ }^{32}$ and fig. 44 for the division of functions within the visual brain. ${ }^{33}$

But how can brain functionality be related to left-handedness and leftward scripts at all? This has been one of the most disturbing and confusing points in the whole process of trying to understand the visual-laterality phenomenon, but an important one, since it is the linking point to connect my work with previous research in neurology.

In a recent article written by G.D. Schott and J.M. Schott, Mirror Writing, Left-handedness and Leftward Scripts, the authors say that they have found that a particularly high prevalence of left-handed mirror writing has been reported among those whose native languages are traditionally written in a leftward direction, including Chinese, Japanese and Hebrew. They concluded that,

Innate lefthanders and those whose languages are written leftward thus share an unusual facility for left-handed mirror writing, an observation that may have implications for understanding hemisphere specialization in relation to handedness (Schott \& Schott 2004).

I wonder if what is said for mirror writing is also valid for mirror composition (in this case, mirror composition in photography), since in the end, it is a matter of reading and moving the eyes in one direction or the other. And in this sense, I will present the actual situation related to this topic nowadays. In their article, Schott and Schott wrote that they have observed that, 
a surprisingly large number of reported left-handed mirror writers are those whose native languages have traditionally been written and read leftward. This is evident from various individual reports of Japanese and Chinese patients, most of whom mirror-wrote after (usually) left hemispheric vascular lesions, and the polyglot who, following a head injury, selectively mirror-wrote and read Hebrew script, while his normal reading and writing of Polish remained (Schott \& Schott 2004: 1850).

The high prevalence of mirror writing reported in healthy individuals and the patients whose languages are typically written and read from right to left is striking, as we can conclude after reading the above-mentioned article. The authors wrote that this finding cannot be attributed to population differences in handedness. Left-handedness is no more frequent among Asians than Westerners, and right-handedness has predominated in all cultures for at least 5000 years. Both consonantal phonetic (Hebrew) and ideographic (Chinese and Japanese) languages are implicated. This suggests that, although ideographic languages are extensively processed in the right hemisphere, it is less the structure and more the leftward direction of these languages that is important and that drives, or is driven by, the contralateral right hemisphere. ${ }^{34}$ The neurologist J.R. Skoyles goes on to state that it may well be not only the direction of writing itself but also the right hemisphere involvement in the leftward direction of eye movements and the left visual fields that are important. ${ }^{35}$

The neurologists A. Pollatsky and S. Bolozky, did an experiment that showed that eye movements, the covert scanning of letters and mirror-image perception of words, are linked to the two visual fields. Leftward scripts (scanned with leftward eye movements) are read through the visual window extending into the left visual field (rightward ones are read through one extending into the right visual field). ${ }^{36}$ Visual fields and eye movements are also connected to the two cerebral hemispheres. The left visual field is connected to the right hemisphere and the right with the left hemisphere. Also, each hemisphere controls eye movements directed in the opposite direction (the right hemisphere controls leftward eye movements and the left hemisphere rightward ones), so images scanned through the left visual field into the right hemisphere are also reciprocally controlled by this hemisphere. ${ }^{37}$ Further, a group of Japanese neurologists wrote an article as an answer to the one written by Schott and Schott, in which they make a correction regarding the direction of writing in Japanese. ${ }^{38}$ At the moment, neurologists only seem to agree on the fact that further studies in other languages are warranted, and it is especially important to investigate languages that have been variously written in leftward and rightward directions. These studies can be very relevant to further understand how this mirror-like image happens in the photographic image produced by Iranian 
photographers, always assuming that the mirror-writing phenomenon can be identified with the mirror-like image. Actually, in a more recent article written by G.D. Schott, he states that even if many individual cases of acquired mirror writing are reported among Chinese and Japanese people, these findings need to be interpreted with some caution, as the definition of leftwards direction of language is complex, and variables include the direction of the vertical and horizontal lines of script, letters and hieroglyphs, and changes in direction of written language over time ${ }^{39}$, in a clear reference to the corrections made by the group of Japanese neurologists.

Unlike handedness, which appears to be at least to some degree genetically determined, the direction of reading and writing seems to be merely a matter of convention. Around 1500 A.D. there were as many scripts written and read from right to left as there were written and read from left to right. With the expansion of European culture in the centuries that followed, left-to-right scripts came to predominate (see McManus diagram, fig.1b). It is noted by Skoyles, that in those societies in which script direction changed, writing was not important in propagating religious beliefs. In other cultures it has taken on this role, largely through the belief that written religious works contain the "word of God". Since such writings are believed to be holy, it is central to the religion to propagate them unchanged. ${ }^{40}$ Skoyles suggests further that the convention of leftwardness has been preserved due to the central importance of the Torah and the Koran in the Jewish and Arabic societies, dating back to an earlier period when the leftward script, that was used to write them, reflected right hemispheric reading processes.

In sum, accepting that we can assure an intrinsically parallel phenomenon between mirror script and mirror composition in the pictorial or photographic space, I am able to benefit from this research and conclude that not only the direction of writing but also the right hemisphere involvement in the leftward direction of eye movements and the left visual fields are important and play a role in mirror writing and, therefore, on the visuallaterality phenomenon. However, further studies in other languages are warranted.

\subsection{Asymmetries of the photographic space: Brain mechanisms or artistic conventions?}

Asymmetries of photographic space could arise, as already mentioned before, from asymmetries of the brain or from cultural conventions. Both of them seem to contribute to the anisotropy of art but in different ways. One artistic asymmetry that appears to be universal in this way is profile orientation. Portraits are rarely full-face.

One pioneer study made by the neurologists Chris McManus and N.K. Humphrey, found that the majority face leftward in 1,474 painted portraits 
produced in Western Europe between 1500 to the present. ${ }^{41}$ I am not aware of a similar study made with non-Western paintings. But I have so far gone through around 500 Western studio portrait photographs from the nineteenth-century and a higher number of them, indeed, face leftwards. Similarly, with Iranian portraits I found that there are less examples of profile orientation in the leftward direction, but still the bias is dominant on the left direction. The results obtained after pursuing an experiment with Spanish and Iranian portrait photographs are as follows (Table 2).

\begin{tabular}{llll}
\hline & $\mathrm{L}$ & $\mathrm{R}$ & Total \\
\hline IRAN & 229 & 216 & 445 \\
& $52 \%$ & $48 \%$ & \\
\hline SPAIN & 312 & 198 & 510 \\
& $61 \%$ & $39 \%$ &
\end{tabular}

Table 2 Comparative percentages Iran versus Spain for the group: Profile orientation.

The neurologist Hans-Joachim Hufschmidt asserts that eighty percent of right-handers drawing a human profile direct it towards the left. The preference for the left profile direction is traced back to the early Greek period in paintings, drawings, coin portraits, gems, cameos and vase portraits. Fifty thousand objects have been analyzed. A $60 \%$ prevalence of face direction towards the right occurs in cultural centers of the Mediterranean before 600 B.C. Before the early Greek period, the Assyrian, Egyptian and Sumerian cultures faced more profiles to the right. This tendency for the right profile direction can be traced back to Stone Age cave drawings. The profile shift from right to left occurs in the early Greek period and is related to a shift in script and in letter profile at the same time. This profile shift occurs simultaneously with an acceleration of intellectual and cultural development, which also influenced our present culture. ${ }^{42}$

So profile orientation appears to be a function of brain laterality, not direction of reading, suggest Gross and Bernstein. Nevertheless, it is not possible to reach such a conclusion before further experiments are done considering subjects literate in right-to-left scripts. When a face is fixated centrally, the half of the face in the left visual field is processed by the right hemisphere. As stated by the neurologists C. Gilbert and P. Bakan, "face recognition is a right hemisphere function and, when right-handed people look at the two halves of a front view of a face, the half of the face in the left visual field looks much more 'like the person' than the other half" (Gilbert \& Bakan 1973). Thus the tendency for portraits to locate profiles in the left visual field presumably reflects the fact that facial information would be perceived more readily and accurately by the majority of people (i.e. right-handers). Similarly, as shown in fig. 45, it is the 
expression on the half of the face in the left visual field that usually determines the right-handed viewer's impression of it. ${ }^{43}$ Although the faces are enantiomorphic $^{44}$, right-handers tend to see the lower face happier than the upper one, whereas the reverse is true of left-handers.

In contrast to profile orientation, other aspects of visual anisotropy appear to reflect cultural conventions. Wölfflin and others, have suggested that "individuals typically enter a picture at the left foreground and proceed along a specified path or 'glance curve' into the depth of the picture and over to its right-hand side" (Gross \& Bornstein 1978: 36). He points out how this direction scan lends an aesthetic dimension of movement in graphic art:

Movement from left to right in a painting is perceived as easier and faster, while movement from right to left is slower and perceived as having to overcome

resistance. The former signals attack or approach; the latter signals withdrawal. In addition, the diagonal " " " is often associated with ascent and triumph, while "l" is associated with descent and defeat.

(Wölfflin 1949)

Wölfflin believed that the left-to-right glance curve represented a fundamental aesthetic vector. However, the glance curve in Oriental art appears to be in the opposite direction, as I have already shown earlier in this chapter with some examples of Iranian paintings and engravings. Thus the direction of the glance curve in both painting and theater (as we have pointed out above) appears to be a cultural convention, presumably related to the direction of reading, and I believe that the same is true for photography. The form of this path is best represented by the curve shown in figs. 46a and $46 \mathrm{~b}$. Figure $46 \mathrm{~b}$ shows the curve as seen from above; figure 46a shows it as seen in perspective. It begins in the left foreground, penetrates towards the depth, then turns over towards the right. ${ }^{45}$

Gaffron states that,

to follow the glance curve seems to be our natural way of viewing - so natural, in fact, that the process remains unconscious and we become aware of it only by its effects, which cause the above mentioned phenomenal changes on reversal. (Gaffron 1950: 317)

But, as Gross and Bornstein suggest, the term "glance curve" may be a misnomer, since studies of eyes movements across both Eastern and Western pictures do not reveal glance curves in either direction. ${ }^{46}$ They further argue that, 
Rather such studies suggest that the eye roams over a picture in an arbitrary manner, only stopping to rest on salient features. The glance curve may be some kind of covert cognitive scanning with its direction set by reading habits. Or, alternatively, it may reflect a cultural organizing principle implicit in graphic art. (Gross \& Bornstein 1978: 35)

The results of a recent study made by the neurologists W.H. Zangemeister, K. Sherman and L. Stark ${ }^{47}$ seem to demonstrate that those classical studies' conclusions were, indeed, wrong. Scanpaths, the repetitive sequences of saccadic eye movements, occurred when subjects viewed slide projections of both realistic and abstract art, a result that contrasts with previous theories that suggested that the eye moves freely over a picture in an arbitrary manner. This group of researchers explains in the conclusion of their paper,

the eye movement experiments reported here of subjects looking at abstracts paintings have shown that abstract images are viewed by the same top-down, perceptual-cognitive processes that drive active looking or scanpaths in viewing realistic paintings, scenes and objects. (Zangemeister 1995: 1023)

In sum, it seems that the glance curve theory is not accepted, since it contradicts the results found with recent eye-scanning experiments done by neuropsychologists. Asymmetries of the painting and/or photographic space do arise from asymmetries of the brain and from cultural conventions. One artistic asymmetry that appears to be universal is profile orientation. It has been demonstrated that in the majority of Western paintings the face is shown in the leftward direction. A replica of McManus' experiment should be undertaken with paintings done by artists literate in a right-to-left script language.

\subsection{Reading habits versus aesthetic preferences: A neurological approach}

In the previous sections, I have presented a historical survey of the perspective of art historians towards the left-right phenomenon. Next to this, I made an introduction to the main contributions of neurologists to the possible relation of left-handedness with leftwards scripts and also about the phenomenon of mirror writing. Now I will present a historical survey of the positioning of neurologists towards the more concrete topic of reading habits and aesthetic preferences, which links the two relevant fields for this research: art history and neuroscience. 
There is a large corpus of literature on the asymmetrical placing of the preference, in the West, for the center of gravity to the right of the center. This literature, as we shall see shortly, contains a great deal of discussion about why the basic spatial asymmetry occurs in addition to the now rather discredited idea of a glance curve. There are some fundamental studies related to this topic whose conclusions I will introduce chronologically and that are relevant for my own study, since they support my visual-laterality hypothesis. From the middle of the 1970s onwards, this topic became a main issue for scholars in the field of neurology and nowadays it remains an important topic in the field. Much has been achieved and demonstrated, but there are still several obscure points that deserve further study.

Research has demonstrated that there is a significant effect of reading habits on aesthetic preference, with left-to-right readers showing a preference for stimuli with a rightward directionality while right-to-left readers preferred stimuli with a leftward directionality. These findings raise the question of an interaction between cultural factors and cerebral dominance, as we have already pointed out before. For the cerebral dominance part, one pioneer in the field of lateral dominance and aesthetical preference, the American neurologist Jerre Levy, supports the hypothesis that lateral specialization of the cerebral hemispheres affects preferences for one of two mirror symmetric pictures. As stated in the discussion of that paper,

while preferred choices of one group of right-handers predict choices of another group of right-handers, the predictive validity for a group of left-handers is essentially zero. Slightly over $40 \%$ of sinistrals prefer mirror versions of pictures opposite to the choice of the dextral. (Levy 1976: 436)

These observations are similar to those of neurologists Swartz \& Hewitt who found a very small, but significant, majority of right-handers preferred the original versions of famous paintings as compared with their mirror images, while left-handers did not. ${ }^{48}$ Later on, another article was published on this topic by the neurologists Marily Freimuth and Seymour Wapner that contributed to perceptual and aesthetic theory by demonstrating that two factors influence the evaluation of paintings: sequence of figures and exposure time (meaning here, how long the viewer is observing the figure). It concluded that asymmetrical factors are predominantly operative in perception and aesthetic judgments made after brief observations. These asymmetries influence evaluations only for paintings with dominant directional properties measured by lateral organization. With longer exposure time (and this is relevant for my study) other cognitive factors (e.g. conceptual, symbolic analyses) become increasingly influential. ${ }^{49}$ So, cultural conventions became only a factor of importance after longer exposure time. They found that pictures with implied motion from 
left-to-right are preferred to those with implied motion from right-to-left. Further in this line of research, the American neuropsychologist J. Graham Beaumont, argued as a conclusion of an experimental observation that,

lateral asymmetry in preferred picture arrangements is not the result of a counterbalancing of content against perceptual bias, but a consequence of gaze being directed to informative content on the right, leaving more of the secondary content within the left visual field and associated with attentional bias or processes of the right hemisphere. (Beamount 1985: 103)

He further concluded that,

it is therefore the operation of neuropsychological processes related to the peripheral elements of the visual array, those outside central vision, which best explain the association between aesthetic preferences and features of lateral neuropsychological dominance (Beaumont 1985: 112).

In the same year, an article about the subjective balance in pictures was published by the neurologists I.C. McManus, D. Edmodson and J. Rodger, that showed that when pictures used for the experiment showed large differences in balance point, subjects showed smaller differences, unrelated to handedness or eye-dominance ${ }^{50}$, a conclusion which provides no support for the position of Levy (introduced above). Further, the neurologists Marie T. Banich, Wendy Heller and Jerre Levy, taking into consideration Freimuth and Wapner's study, suggested that the preference of slides with apparent motion from right-to-left deserved comment. After pursuing their experiment, they were able to conclude that: first, it appears that left-toright scanning habits induced by reading do not induce preference for asymmetry of motion in their slides, because right-handers preferred slides with right-to-left motion and because the orientation preference of left-handers was unrelated to asymmetry of motion; second, that their findings differ from those of Freimuth and Wapner, who found that preferred slides were judged to have relative motion from left-to-right. ${ }^{51}$ They point out, however, that in Freimuth and Wapner's study, the slides did not have a significant asymmetry of content, implying with this that it may be that right-to-left motion is only preferred where there is a significant asymmetry of content. It has also been reported by Beaumont (unpublished data) that subjects preferred pictures of horses when they were jumping towards the center of the picture. If the horse was placed to the right of center it was preferred when jumping to the left; conversely, if the horse was placed to the left of center, it was preferred when jumping to the right. ${ }^{52}$ 
As we have already seen, observers often prefer orientation of a stimulus over its mirror image and this preference, as stated by neurologists S. Christman and K. Pinger, for left-to-right directionality may represent a fairly deep and pervasive aspect of mental representations and processes. ${ }^{53}$ The neurologists Chatterjee, Maher and Heilman reported that when normal subjects are asked to draw stick figures depicting the thematic roles of agent and patient, they exhibited a consistent bias to place the agent on the left and the patient on the right, thus displaying a left-to-right pattern of causality. ${ }^{54}$ Further, Christman and Pinger state that, in the same way, there is evidence that scanning patterns in visual search proceed rightward from fixation. ${ }^{55}$ Finally, saccadic latency is less for left-to-right movements than for right-to-left.

Collectively, these findings are suggestive of a deep, underlying preference for left-to-right directionality in both perceptual and motor processes. Nevertheless, as stated by Christman and Pinger, an unresolved question concerns the relation between the aforementioned directional biases and the left-to-right scanning involved in reading. That is, do the aforementioned preferences for left-to-right directionality simply reflect the influence of learned preferences arising from left-to-right reading habits, or is there some more fundamental directional bias that underlies all of these phenomena? They finish their reflection stating that future research involving multiple tasks and/or subjects who read right-to-left language will be necessary to address this issue. ${ }^{56}$ This is, indeed, extremely interesting for my research. One of the fundamental studies done at the beginning of the present decade is the one by neurologists Sylvie Chokron and Maria de Agostini. ${ }^{57}$ The aim of that study was to determine the extent to which aesthetic preference, previously attributed to cerebral dominance, may be determined by reading habits. In order to achieve that, they submitted leftto-right (French) and right-to-left (Israeli) readers to a visual aesthetic preference task. Subjects were presented with pairs of object pictures: one with a left-to-right directionality and the other with right-to-left directionality. As they stated in their discussion, "the main finding of the present experiment is an effect of reading habits on aesthetic preference, with subjects preferring the pictures possessing the same directionality as their reading habits" (Chokron \& De Agostini 2000: 48). Therefore, reading habits are able to influence visual preferences and even the way we mentally represent the world. Only three years later, an article about this topic was published by the neurologists Jacqueline Fagard and Riadh Dahmen. ${ }^{58}$ They compared the influences of reading and writing habits on the asymmetry of space perception and the directional tendencies of French and Tunisian right-handers, aged 5, 7 and, 9 years. By comparing two groups of children who use the opposite direction for writing, before and after being taught to read in school, they evaluated the impact of writing direction on these asymmetries. In their conclusion, they state that, 
basic influences appear to be similar in young children with differing reading and writing habits, which becomes obvious after some practice in writing, overrides these more basic influences. When the two influences are compatible (as when left-right writing favours the pre-existing leftward bias and the left-to-right hand bias), the bias appears stronger and earlier. When the two types of influence are opposed (with right-left writing), there is less and sometimes no bias. The lack of a bias in the Tunisian children in two of the three tasks might also reflect the influence of learning French. (Fargard \& Dahmen 2003: 50)

There are some classic studies ${ }^{59}$ on this topic of reading habits that are important to read. This topic remarkably has been addressed in the last decade by a group of neurologists from the American University of Beirut (Lebanon). This group of researchers advocates the need to acknowledge script as a variable when examining hemispheric asymmetries when employing non-linguistic stimuli, as its influence has been demonstrated by their different experiments including right-to-left script users. The neurologists Robin L. Heath, Aida Rouhana and Dana Abi Ghanem, from the American University of Beirut in Lebanon, have performed two research experiments whose results were published in two different papers in $2005 .{ }^{60}$ In the first experiment they selected three groups of subjects: white Americans, bidirectional readers and Arabic readers. They used the asymmetric chimeric faces test (which I introduced in the previous section) and they found that readers of right-to-left scripts showed a mixed or weak rightward bias in judgments of facial affect which supports again the influence of habitual scanning direction to intersect with laterality. ${ }^{61}$ The second experiment was done with the same three groups of subjects as in the first one, plus one more group of illiterates. Their findings showed that biases in aesthetic preference were influenced by script direction and pictorial dimensions. In a laterally balanced composition, participants preferred to begin their scan with the object representing Interest and terminate with the object representing Weight, the direction being determined by the script. In an unbalanced composition, participants tended to fixate on content, whether Interest or Weight, and move in a direction consistent with the script. ${ }^{62}$ Nowadays, according to the results of my investigation, there are at the moment two groups of scholars working on direction of script and aesthetic preferences or perception: Dr J. Vaid at Texas A \& M and her colleagues are working with Urdu script (also right to left). She was doing work with drawing the profiles of human heads. Steve Christman at the University of Toledo is also researching aesthetics and reading direction.

In sum, all the previous studies constitute a solid theoretical basis that supports the visual-laterality hypothesis. A large amount of research in the field of neuropsychology has demonstrated that there is a significant effect 
of reading habits on aesthetic preference, with left-to-right readers showing a preference for stimuli with a rightward directionality while right-to-left readers preferred stimuli with a leftward directionality.

As a conclusion to the research done for this chapter, I can state that the direction of the script is directly related to the composition of works of art. Therefore, the direction of writing is one of the cultural components that constitute a photograph. There is a tendency in nineteenth-century Iranian photographers to produce mirror-like images of those produced by their Western colleagues. This tendency has been proven to be consistent in the three groups of composition that I have analyzed throughout the chapter. The state of the discourse in the field in neurology is, nowadays, still full of unanswered questions and we will have to wait and see how it will develop with time, to test if we can profit from future findings to be able to explain the visual-laterality phenomenon. Different groups of neurologists have concluded, after pursuing statistical experiments, that not only the direction of writing but also the right hemisphere involvement in the leftward direction of eye movements and the left visual fields are important and play a role in mirror writing and, therefore, on the visual-laterality phenomenon. Leading scholars in the field of neuroscience advocate the need to acknowledge script as a variable when examining hemispheric asymmetries, as its influence has been demonstrated by their different experiments including right-to-left script users. The last studies point to the fact that there is an interaction between cultural factors (reading habits) and cerebral dominance when considering the visual-laterality hypothesis. The fact that those studies acknowledge the script as a variable in perceptual lateral asymmetries gives solid theoretical support to my hypothesis from a neuroscientific approach.

In the following chapters I will extend the process of analysis of images to find other cultural components involved in the process of producing a photograph.

\section{Notes}

1 Taken from Fritsch 1964: 7. Silvio Ceccato (1914-1997) was an Italian philosopher and linguist.

2 After McManus 2004: 242-43.

3 Handedness is an atribute of human beings defined by their unequal distribution of fine motor skill between the left and right hands. An individual who is more dexterous with the right hand is called right-handed, and one who is more skilled with the left is said to be left-handed (8-15\%).

4 Anisotropy is the property of being directionally dependent as opposed to isotropy, which means homogeneity in all directions.

5 Gross and Bornstein 1978: 29-38.

6 Wölfflin 1941: 82-96.

7 Further reading of works by other aestheticians about the right-left problem in art: J.W. Schlosser (1930), "Intorno alla lettura dei Quaddri", Critica, XXVIII: 72; Faistauer, A. 
(1926), "Links und Rechts in Bilde", Amicis, Jahrbuch des Oesterr. Galerien; R. Keller, R. (1942), "The Right-Left Problem in Art", Ciba Symposia, Summit, N.J. III: 1139.

8 Arnheim 1965: 50.

9 Gaffron 1950: 315.

10 Keller 1942: 1142.

11 Gardner 2005: 36-37.

12 The Bakhtiari are a group of southwestern Iranians. A small percentage of Bakhtiari are still nomadic pastoralists. They inhabit the provinces of Lorestan, Khuzestan, Chahar Mahal and Bakhtiari and Isfahan.

13 Taken from Barjesteh 2008: 127.

14 Double exposure in the nineteenth century was especially related and used in spirit photography, but there were photographers that were using it just to create funny tricky portraits or scenes, like the one shown here. A very interesting book about this topic is: Henisch \& Henisch (1994), The Photographic Experience 1839-1914: Images and Attitudes. Pennsylvania: Pennsylvania University Press.

15 Nashat 2004: 76.

16 Harris et al. 2007: 64-86.

17 See: Van der Meer and Husby 2006: 263-276.

18 See: Salk 1961: 740-746. See also: Todd and Butterworth 1998: 229-233.

19 See: Harris et al. 2006; Ramón y Cajal 1899.

20 Taken from Christman and Pinger 1997: 159.

21 Arnheim 1969: 12.

22 Gutman 1982: 39.

23 Gutman 1982: 23.

24 Pérez González, C. (2012, online November 2011), "Lateral Organization in NineteenthCentury Studio Photographs is Influenced by the Direction of Writing: A Comparison of Iranian and Spanish Photographs", in Laterality: Asymmetries of Body, Brain and Cognition. Psychology Press: DOI:10.1080/1357650X.2011.586701

25 Levy 1976: 431-445.

26 The art historians Christine Macel, curator at MNAM Centre Pompidou in Paris, the architect Tammo Prinz) and neurologists (Dr Alexander Abbushi, Prof. Karl Einhäupl and Prof. Detle Ganten from the Dept. of Neurosurgery of Universitätsmedizin Berlin; Prof. Ernst Pöppel, director of the Institute of medical Psychology at Ludwig-MaximiliansUniversity Munich; Prof. Semir Zeki, professor of Neuroesthetics at University College London. Website: http://www.association-of neuroesthetics.org/documents/content.php? nav $=\operatorname{lnk} 0200 \&$ use $=\operatorname{con} 0200$

27 Zijlmans and Van Damme 2008.

28 Onians, J. (2008), "Neuroarthistory: Making More Sense of Art", in Zijlmans \& van Damme (eds.), World Art Studies: Exploring Concepts and Approaches: 265-286.

29 Onians 2007.

30 Ramón y Cajal 1899. The labels have been added by Charles G. Gross and Marc H. Bernstein for their article already mentioned above.

31 Zeki 1999: 16.

32 Zeki 1999: 15.

33 Taken from Zeki 1999: 16.

34 Schott and Schott 2004: 1850.

35 Skoyles 1992: 25-26.

36 Pollatsky et al. 1981: 174-180.

37 Skoyles 1992: 1.

38 Tashiro et al. 2005: 834. They point out that, in contrast to Hebrew script, Japanese script (both Kanji and Kana) is traditionally written and read vertically, although the lines are read from right to left. This does not mean Japanese languages are written in a leftward 
direction. Japanese horizontal scripts are written from left to right, the same as alphabetic languages.

39 Schott 2007: 8.

40 Skoyles 1988.

41 McManus and Humphrey 1973.

42 Hufschmidt 1980.

43 Gross and Bronstein 1978: 35.

44 Enantiomorphs is the mathematical term for two things which have contrary shapes. Also the term incongruent counterparts (objects that are perfectly similar in shape except for being mirror images of each other, such as left and right human hands) is widely used in the scientific literature instead of enantiomorphs. Inmanuel Kant was the first great thinker to point out the philosophical significance of such objects. He called them counterparts because they are similar in nearly every way, incongruent because, despite their similarity, one could never be put in the place of the other. Further reading: Van Cleve, J. and Frederick, R.E. (1991), The Philosophy of Right and Left. Incongruent Counterparts and the Nature of Space, Canada.

45 Gaffron 1950: 317.

46 Gross and Bronstein 1978: 35.

47 Zangemeister et al. 1995.

48 Swartz \& Hewitt 1970: 991.

49 Freimuth \& Wapner 1979, 70: 218.

50 McManus et al 1985, 76: 311.

51 Banich et al. 1989: 193.

52 Banich et al. 1989: 194.

53 Christman \& Pinger 1997.

54 See: Chatterjee et al. 1995.

55 Christman \& Pinger 1997: 174.

56 Christman \& Pinger 1997: 174.

57 Chokron \& De Agostini 2000.

58 Fagard \& Dahmen 2003.

59 See: Dreman, S.B. (1974), "Directionality Trends as a Function of Handedness and of Reading and Writing Habits", in American Journal of Psychology, 87 (1): 247-254; Bryden, M.P. (1966), "Left-Right Differences in Tachistoscopic Recognition: Directional Scanning or Cerebral Dominance?", in Perceptual and Motor Skills, 23: 1127-1134; Ghent Braine, L. (1968), "Asymmetries of Pattern Perception Observed in Israelis", in Neuropsicologia, Vol. 6: 73-88; Blount, P., Colmes, J. \& Rodger, H. (1975), "On the Ability to Discriminate Original from Mirror-Image Reproductions of Works of Art", in Perception, Vol. 4: 385-389; Kugelmass, S. \& Lieblich, A. (1979), "Impact of Learning to Read on Directionality in Perception: a Further Cross-Cultural Analysis", in Human Development 22: 406-415;

60 Heath 2005 A, and Heath 2005 B.

61 It must be noted that the same conclusions were already achieved with an experiment done 25 years ago by the neurologists Joytsna Vaid and Maharaj Singh. Perceptions of happy facial affect from asymmetric composite faces presented in free vision were compared in four groups: left-to-right readers (Hindi), right-to-left readers (Arabic and Urdu), left-to-right and right-to-left readers (Hindi/Urdu) and illiterates (Hindi/Urdu). The leftward bias was present in a significant larger proportion of Hindi than Urdu or Arabic readers. These results are taken to reflect an interaction between a cerebral laterality effect and a directional scanning effect in facial affect judgement. See: Vaid, J. \& Singh, M. (1989), "Asymmetries in the Perception of Facial Affect: Is There an Influence of Reading Habits?”, in Neuropsychologia, Vol. 27, No. 10: 1277-1287.

62 Heath 2005 B: 399. 



\title{
2 THE WRITTEN IMAGE: TEXT AND PHOTOGRAPHY
}

\author{
For Mina Zandi Siegel and Evan Siegel
}

\begin{abstract}
Texts were invented in the second millennium BC in order to take the magic out of images, even if their inventors may not have been aware of this; the photograph, the first technical image, was invented in the nineteenth century in order to put texts back under a magic spell, even if its inventors may not have been aware of this. The invention of the photograph is a historical event as equally decisive as the invention of writing. With writing, history in the narrower sense begins as a struggle against idolatry. With photography, "post-history" begins a struggle against textolatry. Vilém Flusser (Flusser 2000: 19)
\end{abstract}

The usage of text/calligraphy in the Persian painting tradition seems to have had some impact on nineteenth-century Iranian photography. However, the relation of this particular phenomenon to photography is somehow more ambiguous than the laterality factor. It needs to be explored as to what end the photographer has used the inscription around the studio photographs, if they are used just as a decorative purpose, or just as plain text to provide some information (where the text is devoid of any stylistic components) or the text bears some symbolic, or hidden hints, or a combination of any of the above. For this purpose a careful reading of the text, its meaning as well as its style analysis, its symbolic significance, or its literary references, both within the pictorial and the photographic space, will be emphasized in this chapter. Towards this end, I will categorize the photographs selected for this chapter according to three different parameters: by the kind of script used to write the inscriptions; by the content or meaning of the text; and by the way in which the text has been implemented in the photographic space.

\subsection{Persian calligraphy and type of scripts}

The Persian word for calligraphy is khosh-nevisi, literally "beautiful writing". Calligraphy, out of all the arts, could be considered one of the most 
typical expressions of the Islamic spirit. The Koran itself has stressed the importance of writing several times. For example, in the earliest Sura ${ }^{1}$, 96/ 3-4, God is described as the Almighty who "taught man with the Pen" and in Sura 68 the oath begins: "Nun! And by the Pen....". The idea of writing, as stated by the scholar in Islamic culture Annemarie Schimmel, "is found everywhere in the Holy Book: the Koran is pre-eternally written on a wellpreserved tablet" (Sura 85/21-22) (Schimmel 1970: 1). Writing is, thus, considered to be of divine origin and the letters are considered the only worthy carriers of holy scriptures and divine revelation. As stated by Schimmel, "every human fate has been written since pre-eternity, and its unchangeability is expressed in the Prophetic tradition qad jaffa'l-qalam "The Pen has already dried up" (Schimmel 1970: 1). As Near Eastern Languages and Civilizations professor Franz Rosenthal points out: "Sacredness became a characteristic element in writing" (Rosenthal 1961: 17). The sixteenth-century Iranian artist and critic Qādi Ahmad suggests the remarkable importance that calligraphy held within the Muslim world:

Through the qalam (pen) existence receives God's orders, from Him the candle of the qalam receives its light. The qalam is a cypress in the garden of knowledge, the shadow of its order is spread over dust (Ahmad 1959).

Most studies of Islamic calligraphy have concentrated on historical questions. The remarkable work of Nabia Abbot, Annemarie Schimmel, Martin Lings, Yasin Safadi and Sheila Blair among others, has created an important body of information concerning certain aspects of this phenomenon. ${ }^{2}$ Islamic Inscriptions by Blair is an important book as referent for the present chapter since it is a rigorous study of the content and function of inscriptions found on monumental arquitecture to all kinds of portable objects.

Focusing on the particular case of Iran, all different kinds of Persian art are characterized by abstraction, sensuous tendencies, harmony and, more than anything else, by its decorative tendency. In Persian calligraphy this is especially true. In the words of the Iranian scholar Ehsan Yarshater,

the obscuring of the main function of an art through indulgence in secondary aspects of it, finds a further example in the development of Persian calligraphy. In its latest stages, the artist is so much enthralled by his elaboration of curves, circles, and flowing lines, that communication of the written word becomes almost an alien thought to him. It is a thrilling experience to look at late cursive Persian calligraphy, with its extraordinary grace and its intricate artistry, but to try to read it is quite a different matter. One might just as well try to solve a recondite riddle (Yarshater 1962: 69). 
Calligraphy was practiced not only by professional calligraphers, but also by princes and nobles. Calligraphers were a fundamental requirement for any self-respecting court, since they instructed the Shah's children in the principles of the art and, at the same time, produced manuscripts for the royal library.

Schimmel explains that, from the very beginning, two different types of writing seem to have existed side by side,

The normal type for correspondence, as found in papyri, was cursive and a forerunner to the later so-called Naskh-style: round and easy to write. For copying the Holy Book, however, another type is used, called $K u f i$, though there should be a distinction between Meccan, Medinan and Kufic proper (Schimmel 1970: 5).

The Islamic calligraphy scholar Nabia Abbott prefers to speak here of "Koranic scripts" in contrast to the normal hand (Abbott 1941: 69).

In this chapter, I am concerned with the cursive scripts, mostly used in Persian miniature painting and also in photography, as we shall see later on. My aim is to analyze the use of text in the photograph as an ornamental and symbolic element and to explore how this use is related to calligraphy, miniature and Qajar painting. I will introduce some examples of Persian miniature painting and Qajar portraiture that will aid the understanding of some nineteenth-century Iranian portrait photographs. Two of the topics that I am more concerned with are calligraphic inscriptions within the photographic space and the kinds of cursive scripts used in the photograph. In order to achieve this, a brief introduction to the different types of script styles is required.

The Islamic art historian Yasin Hamid Safadi indicates that

the "six styles" known in Arabic as al-Aqlam al-Sittah, and in Persian and Turkish as Shis Qalam, are cursive scripts which were first raised to the status of major scripts when they were subjected to strict calligraphic rules by Ibn Muqlah (d. 940) (Safadi 1978: 52).

Persian calligraphers excelled in all styles of writing. The names of these classical cursive scripts are Thuluth, Naskhi, Muhaqqaq, Rayhani, Tawqi and Riqa. Four more scripts, Ghubar, Tumar, Tal'iq and Nastal'iq were later added to Ibn Muqlah's repertoire. Taliq and Nastal'iq are known as the hanging scripts. As stated by the art historian in Islamic art Sheila Blair, of all scripts, by far the most important in this period was Nastal'iq. She further writes, 
that Habiballah Faza'ili, the modern expert on Persian calligraphy, has estimated that 75 percent of everything written in Persian from the mid-fifteenth century was done in this script (Blair 2006: 418).

We will see shortly that in Persian miniature painting and Qajar portraiture, Thuluth and Nastal'iq scripts are the most widely used. In some nineteenth-century Iranian photographs, we can see the use of Naskh script as well. Therefore, I will just focus on these three scripts and will introduce them briefly, as Safadi has defined them.

Thuluth was first formulated in the seventh-century during the Umayyad caliphate, but did not develop fully until the late ninth-century. "The name means 'a third' - whether because of the proportion of straight lines and curves, or because the script was a third of the size of another popular contemporary script, the Tumar, is not known" (Safadi 1978: 52). Thuluth is still considered the most important of all the ornamental scripts. The first image (fig. 47) is a good example of Thuluth, being a detail in the hand of the most famous Ottoman calligraphers, Shaykh Hamdullah, who was active in Istanbul in the early sixteenth century. As stated by Safadi,

Naskhi was one of the earliest cursive scripts to evolve, but it gained popularity only after it had been redesigned by Ibn Muqlah in the tenth century. It was transformed by Ibn al-Bawwab and others into an elegant script worthy of the Koran, and ever since, more Korans have been written in Naskhi than in any other script. It appealed particularly to the ordinary man because it was relatively easy to read and write. It is nearly always written with short horizontal stems, and with almost equal vertical depth above and below the medial line. The curves are full and deep, the uprights straight and vertical, the words generally well spaced (Safadi 1978: 62).

The second image (fig. 48) is an example of Naskhi Koran copied also by the Ottoman calligrapher Shaykh Hamdullah al-Amasini in the early sixteenth century.

During the sixteenth-century in Persia, an important calligraphic development took place with the formulation of the Ta'liq (hanging) script from Riqa' and Tawqi'. The third image (fig. 49) is a composite page of Persian text in large ornamental Tal'iq and small Nastal'iq by Shah Mahmud alNishaburi in the early sixteenth century. From Ta'liq, an even lighter and more elegant form evolved, known as Nasta'liq. The next image (fig. 50) presents a page in Nasta'liq written by Mohammad Darwish alSamarqandi in Kashmir in 1624. As explained by Safadi, "derived from both Ta'liq and Nasta'liq was Shekaste (broken form), which is characterized by an exaggerated density in the super structured letters" (Safadi 1978: 84). The next image presents a page in densely structured Shekaste 
(fig. 51) written by Nawab Murid Khān in India, probably during the seventeenth century.

Persian painting and calligraphy (regardless of the type of script) are mixed together perfectly, the calligraphic inscriptions always being placed in the best possible places and with a harmonic understanding of space and design. This also would be a very important characteristic of text and photography, as we shall see with clear examples. Calligraphy flows through the painting and finds its proper place to become a perfectly harmonious work of art. This constitutes something like a poetic marriage of different elements (imagery and calligraphy), in both visual art mediums: photography and painting. The abstract calligraphic inscription not only does not disturb the perception of the final image, it also adds an extremely aesthetic dimension to it. Inscriptions were added traditionally in all kind of objects in Persia, as stated by Blair,

in the Islamic lands the earlier tradition of monumental writing not only continued but expanded. Inscriptions occur on objects of all media and materials, from the humblest, such as oil lamps and other unglazed ceramics, to the finest and most expensive, including rock crystals and jades. Inscriptions were added even in media where the technical limitations of the material make it extremely difficult to incorporate a running text, like silk textiles.... The demand for inscribed textiles was so great, however, that silk weavers in the Islamic countries soon overcame the confines of the technique, and by the tenth century Persian weavers had figured out how to incorporate long bands of inscriptions on their elaborated patterned silks woven on draw looms (Blair 1998: 4).

With this long and well-rooted tradition of placing inscriptions in every possible object, regardless of size or function, it is not striking that nineteenth-century Iranian photographers also used inscriptions within the photographic space.

\subsection{Text and nineteenth-century Iranian portrait studio photography: Type of script versus content and meaning of the inscription}

The main research focus of this section is whether the use, function and meaning of text or calligraphic inscriptions in nineteenth-century Iranian photography have been inherited from the Persian painting tradition. To establish parallels and differences is the aim of this chapter. Other questions that I pose in this section are whether the use of text in the photographic space is something unique, and therefore, defining of nineteenth-century 
Iranian photography or if it is to be found in nineteenth-century photography in other countries.

It is fundamental to remark here that when analyzing the text that is present in nineteenth-century Iranian photography, we find several degrees of elaboration in those inscriptions to the point that we have to be very cautious on how we use the words calligraphy or text, since in some cases the inscription is just a plain text that cannot be named calligraphy due to the lack of elaboration and the lack of decorative purpose, even if it has been written neatly or beautifully. As pointed out by Just Jan Witkam, photography was mainly an elite pastime. It is in that context that we must appreciate and judge the neat or beautiful texts on the photographs. In some cases, there is no practical purpose and therefore it is easier to see this as calligraphy. ${ }^{3}$ Nevertheless, what is common to all of them, and this is especially relevant for my research, is that they are implemented in the photographic space in a similar way as they were implemented in the Persian miniatures and, even more clearly, as in the Qajar portrait paintings. There are (at least) three possible ways of classifying the photographs selected for this chapter: by the type of script; by the content and meaning of the inscription; and by the way in which the inscription has been implemented on the photographic space (layout). Basically, I am trying to find an answer to three questions: how, what and where the inscriptions were written. For the first classification, I have defined three groups: Nasta'liq, Thuluth and Naskh. For the second classification I have defined two groups: factual information and poetic or symbolic meaning. The third classification includes two groups: framed/organized and freely written on the photographic space. The first and second classifications can also be identified and related to either decorative purpose (which includes both calligraphylike and symbolic or poetic meaning) or practical purpose (which includes both text and factual information). For the present book, I will classify the photographs according to the type of script versus meaning of the inscriptions, and I will reflect about the spatial implementation of the inscriptions within the photographic space individually with each image.

\section{Nasta'liq and poetry}

The first group that I have established taking into consideration the type of the script, Nasta'liq, is formed by images like the portrait of Crown Prince Mozaffar al-Din Mirzā (fig. 52), and we can see a particular use of text in the photographic space. There is an inscription in Nasta'liq script that is placed on four cartouches on each corner of the image. It is a piece of poetry about the young man depicted in this portrait: 


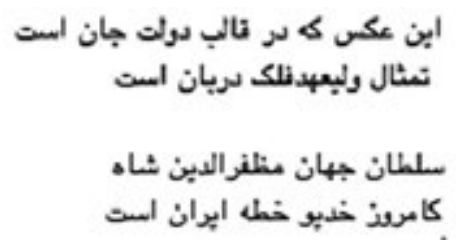

Remarkably, the inscription is a poem about the sitter that gives us factual information about him at the same time. The poem has been written for this photograph and this is an interesting element that we can find in other photographs selected for this chapter: a poem is written about the personality and/or occupation of the sitter and it is placed on the photographic surface. The inscription reads "The picture put within the mould/frame of the soul's state, it is the portrait of the prince, the protector of the world." This inscription was surely added some years later, as in the poem the sitter is mentioned as Shah, whereas in the photograph he was still a prince. This portrait presents the sitter in the typical pose used by court photographers, and we can find many examples like this one when going through the albums of Nāser al-Din Shah and his family held at Palace Golestān Library. The pose has been inherited from the Qajar portrait paintings of Fath Ali Shah and Nāser al-Din Shah, as I will show in the chapter of this book devoted to the pose in nineteenth-century Iranian portrait studio photography.

The way in which the inscription has been implemented within the photographic space, recalls the way in which inscriptions were implemented often in the pictorial space in Persian miniature painting, as it happens in Sultān-Hoseyn Mirzā Bayqarā, Herat, ca. 1500 (fig. 53, see full color section), which presents an unfinished drawing with a background of solid color, probably added when it was mounted in the Bahrām Mirzā Album. ${ }^{4}$ The inscriptions in Nasta'liq script are placed in "boxes" at each side of the painting and identify the subject as Sultān-Hoseyn (left top cartouche) as well as the artist - Ustād Behzād (top right cartouche). In the bottom center cartouche, we can read in Naskh script written with golden color and placed very much hidden inside a very intricate eslāmi structure, ${ }^{5}$ "Show me the answer to my letter". These three inscriptions (artist, sitter and text) read, in Persian:
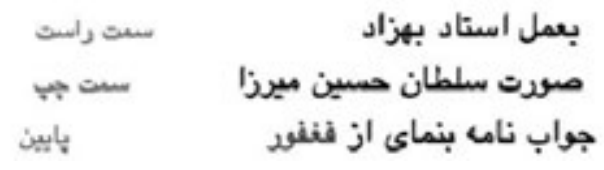

In Seated figure holding a cup, mid-seventeenth century (fig. 54, see full color section), we can read an inscription in Nasta'liq script, a beautiful 
piece of poetry by one of the great masters of Persian poetry, Omar Khayyām (1048-1122). ${ }^{6}$ The poem is a very popular one among Iranians:

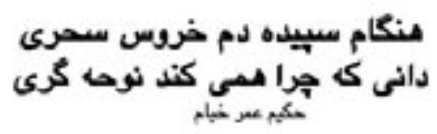

The translation into English reads: "Do you know why the rooster sings a dirge at dawn?". In the frame on the miniature and divided into twelve cartouches, we can read another poem whose author I have not managed to identify:

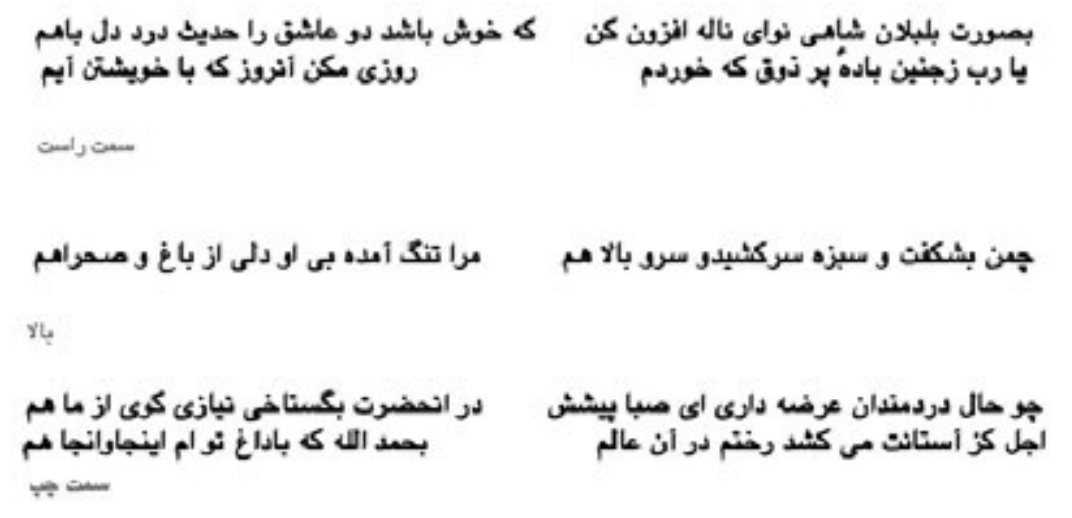

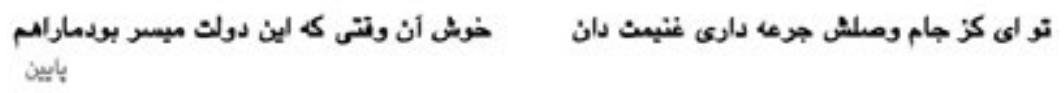

The next photograph (fig. 55) depicts the poet Habib Qā'āni. The inscription, in Nasta'liq script, in the upper left corner, is one of his poems of autobiographical content:

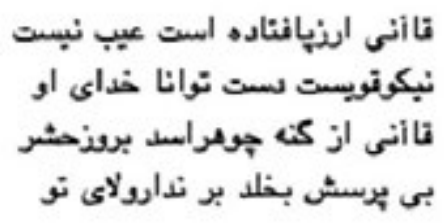

The text speaks about the weaknesses, lack of energy and fears of the poet and how they are taken in care by God. Again, the cushion behind the sitter's back, the water pipe, the traditional kneeling pose and the inscription result in an image that resembles fully that of miniature studios, such as Rezā-Abbāsi painting a picture of a European man, signed by Mo'in 
Mosavvar (fig. 56, see full color section), is a well-known work by the leading exponent of the "Isfahan style". Mu'in's master, the celebrated artist Rezā Abbāsi is shown working with deep concentration. The inscription has been written in Shekaste script, and it is quite difficult to read and decipher. This artwork is annotated with long and very detailed inscriptions that tell us when, why, and under what circumstances the drawing was made.

In Shiraz there was a family of photographers that was very active in the last part of nineteenth and the beginning of twentieth centuries. The first photographer of this family was Mirzā Hasan (1853-1915), who was active from around 1870. An interesting photograph taken by this photographer presents a group of poets from Shiraz (fig. 57) in 1894. Under and above each of them, we can read their names: four are kneeling in the traditional pose and eight are sitting on chairs. This photograph is also arranged in miniature style with inscriptions placed in cartouches above and under the image. In plain and clear Nasta'liq script we can read a poem:

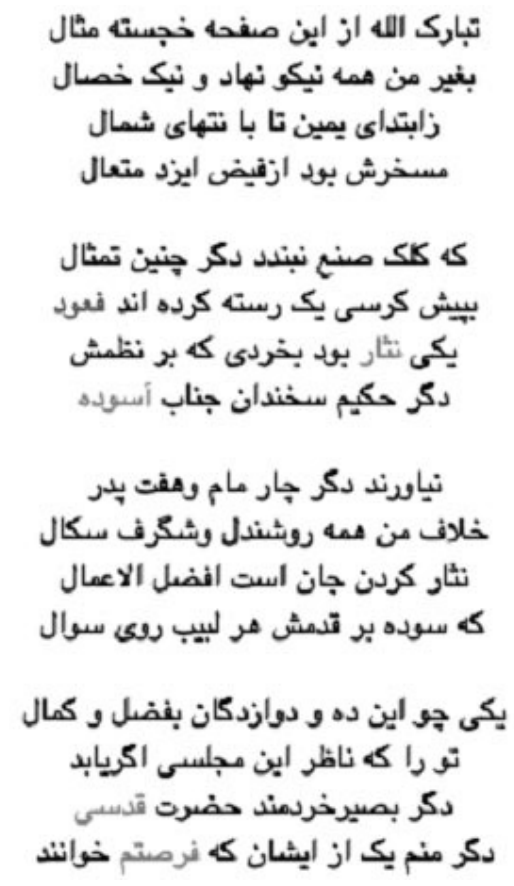




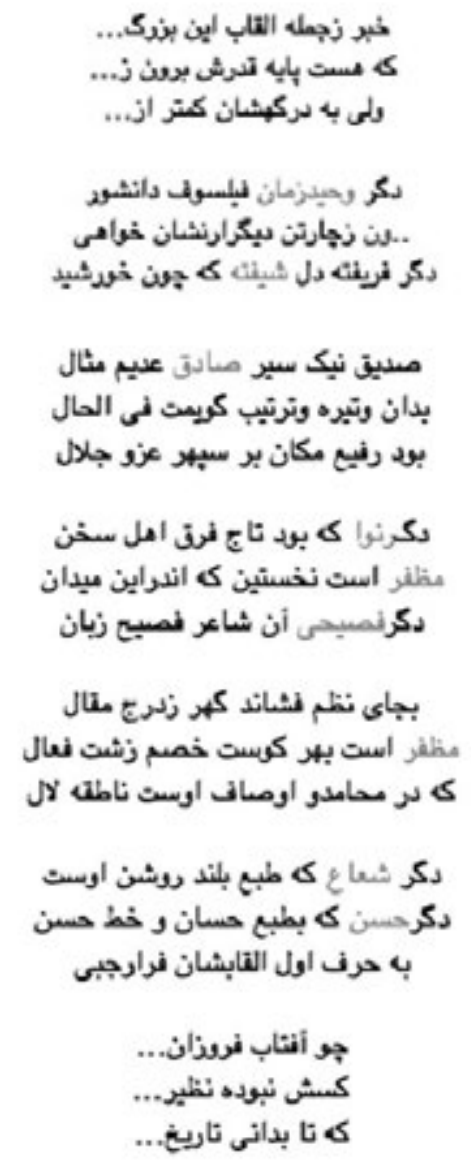

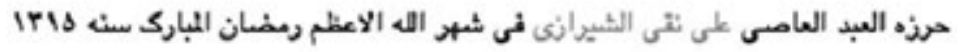

The Iranian poet Abd al-Āsi Ali Naqi al-Shirāzi is the author of this poem, whose content is a poetic exhaltation of the good personal qualities of each one of the poets depicted in the photograph. The Iranian photo historian and collector Mansour Sane states in his book Photography in Shiraz that "a photographer without any knowledge of poetry would be incomplete just in the same way a poet ignorant of images would be" (Sane 1991: 2). Iran is a land of poets and visual artists, and often both literary and artistic traditions are so intermingled that it is impossible to understand them properly as independent artistic expressions. Therefore, the aforementioned statement makes sense in this context, but it does not in a Western context. Poetry is deeply rooted in the Iranian culture's 
subconscious and impregnates with its metaphoric language all the visual arts. As Blair explains,

Persian verses became standard decoration on many other types of art made in Iran from the twelfth century onwards (...). Some verses were taken from well-known poets, others were composed for the occasion (Blair 1998: 98).

This agrees fully with the conclusion that I have reached after analyzing the text on several photographs. Persian verses were also used in textiles and even in carpets, like the Ardabil carpets, one hosted at the Victoria and Albert Museum in London and the other hosted at the Los Angeles County Museum of Art. ${ }^{7}$ Blair presents an interesting example of a silk dated to the twelfth century in the Boston Museum of Fine Arts that has a Persian quatrain. "Composed for the occasion, the verse is written in the first person as though the textile were speaking." She states further that,

Persian poetry became increasingly popular on objects from the fifteenth century onwards. The Persian verses were drawn from a wide repertory of classical poets, such as Daqiqi, Firdawsi, Sa'adi and Hafiz. The text also refers to the objects on which they are inscribed. (Blair 1998: 98)

In this image, a poem has been especially written about the persons depicted on the photograph and it is, therefore, also a good example to illustrate Blair's statement introduced above. The Iranian writer Mina Zandi Siegel has proposed a rendition of the poem for me and it reads:

Praise the Lord of this land, a byword for goodness, Wholly graceful and good-natured, unlike myself.

From the far South to the extreme North,

All has been under His Majesty's rule, by the grace of the Highest.

No artist's brush could create such an image,

A row of servants have humbled themselves near his throne.

One is Nessar, ${ }^{8}$ with the wisdom of his poetry.

The other, His Honor Asoudeh, ${ }^{9}$ the most learned and lucid,

The Four Mothers and Seven Fathers ${ }^{10}$ will not bring about such ..... again

But for me, all luminous of heart and profound of thought.

Sacrificing one's life being the most virtuous action,

So all the learned rubbed their imploring faces on his feet. 
If you, oh viewer of this group, would know

Those ten and twelve wise and learned,

One is the discerning, wise, His Excellency Ghodsi,

The other am I, who is called Forsat.

Knowledge of all the titles of this great...

The fame of his grandeur exceeds all limit,...

But yet in his court is less than...

One is Vahid-Zaman, philosopher and scholar.

And if you want to know the names of the other four,

One is Shifteh, ${ }^{11}$ his heart seduced, radiant as the sun,.....

The other, true Sadeq, with a good past, beyond compare,

Whose manner and education I shall tell you at length.

May he hold the loftiest place in Mighty and Glorious Heaven.

Another is Nava, who crowns the groups of the cultured,

The prime victor in this field.

Another is Fassihi, ${ }^{12}$ that poet of eloquent tongue,

Who speaks such verses that gems emerge from his speech.

He vanquishes every evil-doing foe,

For jeweled speech is one of his meritorious qualities.

Another one is Sho'a, ${ }^{13}$ whose lofty nature is brilliant, Another Hasan, ${ }^{14}$ the elegant calligrapher,

With matching nature peerless in time.

Like the blazing sun...

No one is their peer,...

History stands a witness...

Composed by Abd al-Āsi Ali Naqi al-Shirāzi, in the Great God's month of Ramadan, on the blessed date of 1315.

Abd al-Qāsem ebn al-Nuri took the next photograph as well (fig. 58), as we can read in the inscription, which is in Naskh script under the feet of the person depicted. The rest of the photograph is framed by one inscription in Nasta'liq script just as they are in miniatures. This is especially interesting since the inscriptions have been placed in clouds, exactly like in the illuminations. In the words of the Islamic art historian Norah Titley,

the sumptuous and meticulous art of illumination of manuscript title pages, headings, verse division, dedications, borders and book 
covers, had its origin, in the simple decoration of vowel marks and ornamentation of the circles separating the verses of Korans written in the seventh and eighth centuries by Arab calligraphers. By the fourteenth century, ornate palmettes and sunbursts decorated the borders of Korans and the arabesque, which developed from an origin as simple as that of the border decorations had become indivisible from Islamic decoration. (Titley 1983: 229)

The Persian illuminators with their strong sense of pattern and color and their creativity in design brought the art of illumination to a peak. As in miniature painting, every period and every atelier had its distinctive personal style of manuscript illumination. The designs of the illuminator were not confined to the text pages but were also incorporated in details within miniatures, on textiles, tents, architecture, carpets and in photographs, as we have just seen in the previous photograph. Lotus petal and flower design (fig. 59) from a page in Ferdawsi's Shāh-nāme is a beautiful example of illumination in the Persian Inju style of Shiraz and is dated mid-fourteenth century, which resembles fully those used in photography as well. The next example is a whirling arabesque design and illuminated page decoration (fig. 60) from Gharā'eb al-seghar by Navā'i made around 1520-30.

Coming back to our image, this is a photograph of a painting and it is hosted at the Golestān Palace Library, where there is one album (number 461) with 28 photographs taken by Abd al- Qāsem ebn al-Nuri, which includes this image. The text in Persian reads (first the inscription on the right side of the image, second on the top of the image, third on the left side and finally the inscription on the bottom):

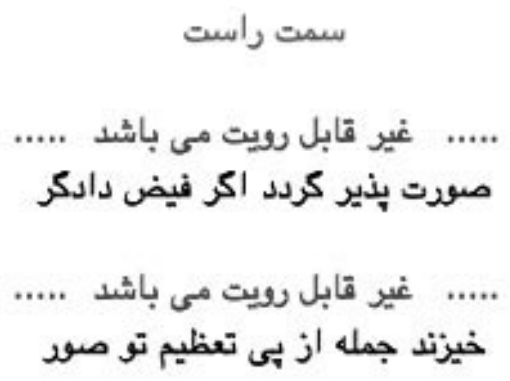




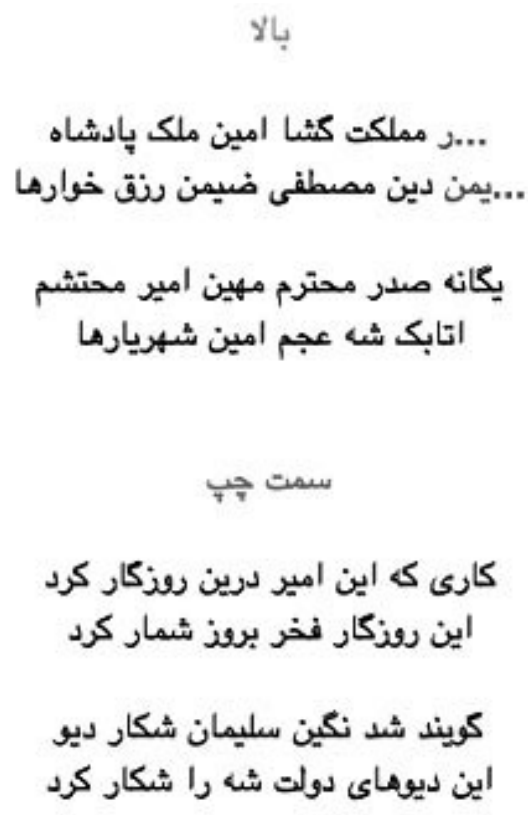

بابين

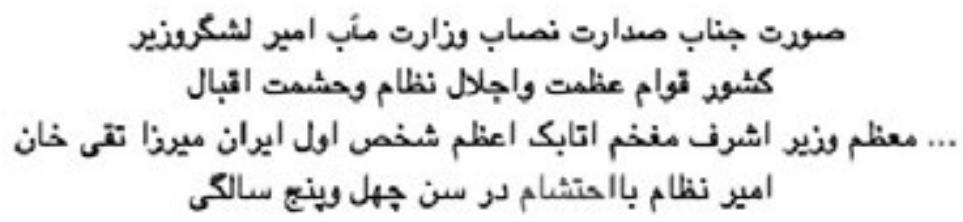

On the left, upper and right part of this frame, we can read a poem about the sitter, Amir Kabir (d. 1852), the prime minister of Nāser al-Din Shah. In the lower part of this frame, the photographer gives some biographical information about Amir Kabir, with his whole title, and indicates that the photograph was taken when he was 45 years old.

We can notice a parallel between the way of identifying the person depicted and the author in Iranian paintings and photographs. Who wrote the calligraphic inscriptions on the photographs? It could have been a calligrapher or illuminator, or maybe the photographer himself or even the sitter. Tahmasbpour argued (in the course of e-mail exchange in September 2008) that, often the inscriptions on the photograph was written by a calligrapher or illuminator. This is, again, an interesting parallel between Persian miniature paintings and photographs, since in the pictorial works the calligraphic inscriptions were also implemented by calligraphers or illuminators. 
Nevertheless, this topic deserves further research and it is actually one of the topics that I am researching currently.

Another photograph interesting for this study, which bears a poem by a famous Persian poet, is a portrait of the Iranian photographer Mirzā Mohammad-Rahim Akkāsbāshi (fig. 61), taken by the Iranian photographer Amir Seyyed Mohammad Rezā Khān al-Hoseyni. This image is interesting because we can find two different ways of implementing inscriptions within the photographic space: the first one is the traditional Persian way of using text/calligraphy within the pictorial space, the cursive flowing freely and harmoniously on the photographic space (post-photographic phase) and the second one using one piece of paper to frame the text (notice the Kodak piece of paper where the name of the photographer who took this photograph is written: Amir Seyyed Mohammad Rezā Khān alHoseyni), in the photographic space (pre-photographic phase). On the left side of the photograph just above the sitter's elbow we can read a poem by Sa'di but that has been signed by the sitter himself. This inscription was identified for me as one of Sa'di's poems by the Islamic Art Historian Markus Ritter in the course of an interview at Zürich University (November 2011), and the poem reads:

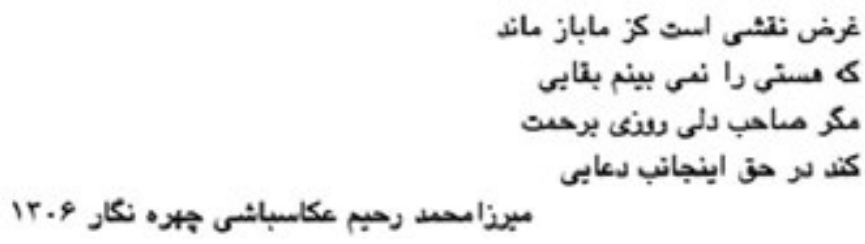

The intention is that an image of us remains/because I do not see perpetuity in existence/ perhaps a man of heart would some day pray for my sake.

As stated by Ritter, "these are the two last verses of the three-rhymed poem (qit'e) by Sa'di, written in the introduction of his Gulistan" (finished $656 / 1258$ ), inscriptions that he has studied in-depth in his research of Sa'di's verses in Safavid and earlier Islamic arquitecture. ${ }^{15}$

Remarkably, the signature has been introduced, as in other photographs, by the word 'amal and this agrees with Blair's statement about the generalized use of this word to introduce signatures on objects. She states that,

signatures on objects are typically introduced by the word 'amal ("work of"). The verb sana'a was used for higher-status or more meticulous work. Artisans who signed their names with 'amal on 
metal bowls and other objects, for example, used sana'a on astrolabes and other scientific instruments. (Blair 1998: 101)

The image has been mastered both in composition and atmosphere. The photograph is also remarkable for the pose/camera and clothes. The clothes are a mixture of Persian traditional clothes that present an elegant design of vest, shirt and belt that contrast with the Western-style coat. The composition is mastered through a triangle formed by the camera (looking leftwards), the chair (looking rightwards) and the head of the sitter. The elegant pose of the photographer together with his interesting face and appearance, complete a magnetic image that has been prepared with great detail and care.

\section{Thuluth: Titles of the sitters versus signatures of court photographers}

Most of the signatures of Iranian court photographers (and of Iranian photographers working at Dār al-Fonun) were written normally in Thuluth script. How did the court painters sign their works? How did court photographers sign theirs? Before I introduce in detail this topic, it is important to know when and how Iranian artists started signing their works. As the Islamic art historian and former curatorial assistant in the Islamic Department of the Metropolitan Museum in New York, Eleonor Sims states,

until about the end of the fifteenth century, Iranian figural painting in any medium, at any period, is virtually always anonymous; authentically signed paintings are very rare. In the late fifteenth century a change is noticeable: some painters begin to sign their pictures, just as scribes had done for some centuries in the Muslim world. When the image was intended to represent a particular person, he (or she) may have even been identified by a written inscription. In other words, starting late in the fifteenth century, paintings begin to be qualified, modulated, explained and - most significantly - specified by words: a fact that represents a profound change in certain norms with which literary Iranian society viewed itself. (Sims 2002: 58)

She further states that,

a better contemporary match between words and images occurs in another later Timurid phenomenon, the "portrait" that truly attempts to render some aspect of the physical reality of the person portrayed. Just as artists' signatures begin to become more frequent on paintings towards the end of the fifteenth century, painted portraits 
of important contemporary figures also begin to appear. (Sims 2002: 59)

So the tradition of signing works of art was already well established when court painters were active during the Qajar Era. In these painted portraits, next to the inscription revealing the identity of the artist, other inscriptions were also to be found.

A challenging example of the use of the Thuluth and Nasta'liq scripts in Qajar painting is found in the painting of Prince Mohammad Ali Mirzā by Jafar (fig. 62, see full color section). The Thuluth script is used in the upper right-hand corner in two cartouches: Navvab Muhammad Ali Mirzā (Shah) Qajar, fi shahr-e Rajab al-murajjab, Sanah 1236. The Nasta'liq script is seen under the throne: Raqam-i Jafar, chakir-i Dawlat. The upper inscription reveals the name of the sitter as Fath Ali Shah's eldest son, Mohammad Ali Mirzā, better known as Dawlatshāh, whereas the lower one informs us of the name of the artist. In this painting it is especially interesting to see in which way the calligraphic inscriptions identifying both sitter and painter have been placed and how. The symbol of the Lion and the Sun belonged to the regal attire and the imperial image of the Persian court in the Qajar Era. In this painting, both symbols have been integrated in quite an interesting way: the throne has lion-shaped arms and the Sun symbol (Khorshid Khānom in Persian) has been placed in the upper right corner above the cartouche where the name of the sitter is written. The paraphernalia in the way the identity of the sitter is revealed contrasts with the sober way in which the identity of the painter is revealed through a plain calligraphic inscription on the floor, right under the sitter's throne, as if it were his carpet!

All Qajar portraits selected here have in common that the calligraphic inscriptions give us the same kind of information: person depicted and author. The inscriptions in fig. 63 (see full color section) are in Nasta'liq script on the right-hand corner ("Fath Ali Shah al-Sultān-e Qajar, 1234) and on the Sun throne reads: "Is this the throne of the world-possessing Fath Ali Shah/ Or the heavenly thrown of the Lord of the Throne/This elephant of a king, golden-crowned/In whose justice the world is in need."16 In the stairs to the throne is written these are the stairs to the golden crown king/the king whose justice the world deserves. Portrait of Fath Ali Shah Seated, signed by Mehr Ali, 1813-14 (fig. 64, see full color section), presents inscriptions in two different scripts. In Thuluth script, to the right of the crown in a cartouche ("al-Sultan Fath 'Ali Shah Qajar") and in Nasta'liq script below in a cartouche, the text reads: "This is the likeness of the King of kings, who is exalted to the Heavens/ Fath 'Ali Shah is the ocean of the world". And also in Nasta'liq script in the lower left corner ("Raqam-e kamtarin gholām Mehr Ali sanah 1229", i.e. "the work of the humble slave Mehr Ali in the year 1229). ${ }^{17}$ In a well-known portrait of 
Fath Ali Shah, Fath Ali Shah in Armor, signed by Mehr Ali, 1814-15, we can see in the upper right corner, in Nasta'liq script ("Sultan Fath Ali Shah Qajar") and in the lower left we can read: "the work of the merest slave Mihr 'Ali in the year 1229". ${ }^{18}$ Again, this way of placing the inscription identifying sitter and painter, and the kind of script used for that, seems to be very consistent. There are other well known examples that the reader can find printed in different books devoted to the topic of Qajar painting. ${ }^{19}$ All the paintings analyzed here have in common that the name and the titles of the person depicted are in the upper position and the name of the artist in a lower place. It is striking that consistently among the paintings analyzed for this section, the inscription that reveals the identity of the sitter has been placed on the top right corner (quite close to the sitter's head) and the inscription that reveals the identity of the painter, his signature, has been placed exactly on the opposite side of the diagonal, meaning on the bottom left, in the furthest possible place to the first inscription. In some cases it is so hidden that it is very difficult to locate: under the chair where the poser is sitting, next to the edge of the carpet. Further, the majority of the Qajar portraits analyzed for this chapter use the Thuluth script for the name of the person depicted and the Nasta'liq script for the name of the artist. Since Thuluth is considered the most important of all ornamental scripts, the fact that the painter uses this script to identify the sitter may have the intention to show the social status of the person depicted. Also, the way in which the painter arranges this kind of calligraphic ornament and information in the pictorial space is very interesting and seems to follow some kind of aesthetic and/or symbolic rules. The name of the person depicted, in this case always Shahs, princes and noblemen of lesser rank, is placed in the upper part of the painting, whereas the name of the painter is placed in the lower corners of the painting. This also seems to follow Qajar court's rules of social status and hierarchy. So both the type of script and where it is placed seems to be directly linked to the hierarchical rules of Qajar society.

My hypothesis regarding the inconspicuous places where the signatures are normally placed in Qajar paintings is supported by Blair's research on signatures in all kinds of objects. She notes that "in bowls, for example, they are often found on the plain outside or under the foot. On a box, they can come between the straps or under the clasp" (Blair 1998: 100). She significantly states further that,

the inconspicuous location was deliberately chosen to show the humility of the artist, particularly in contrast to the lofty patron or recipient, whose name is usually inscribed earlier or in a more prominent place and often written in a different script. (Blair 1998: 100) 
This is what I have concluded in the previous paragraph after analyzing an important number of Qajar paintings. Blair continues that,

tiles show the same juxtaposition, and the artist is typically identified as "a low slave" in contrast to his lordly patron. This identification should be taken metaphorically: these workers were not necessarily slaves and were often quite well known individuals who worked in high-status professions. (Blair 1998: 101)

What happened in court photography? Did court photographers sign their works in a similar way to the court painters? Did they use the same formula of humility and self-deprecation?

The main production of photographic activity in the first decades was achieved within the walls of the Royal Photography Atelier (Akkāskhāne) and the atelier at Dār al-Fonun (the first studios outside of court appeared many decades later, at the very end of the nineteenth century). In the comparative chronology printed on the introduction to the history of Iranian photography of this book, we can locate the main court photographers and photographers at Dār al-Fonun. Some photographers working at the royal court were given the title "Akkāsbāshi" (Court Photographer), a parallel title to the one that it was given to their predecesors, "Naqqāshbāshi" (Court Painter).

The first studio photograph considered here (fig. 65), a portrait of Manuchehr Hasan Ali Khān Garusi (Amir Nezām) bears a signature written in Naskh script with elements of Thuluth. In this case, the inscription informs us that the photographer is Manuchehr Khān Akkāsbashi. This court photographer was active in the last part of the reign of Mozaffar alDin Mirzā in Tabriz (from 1882 onwards), and his photographs are signed with the formula Khān Ezzat Manuchehr (servant Manuchehr, which reminds us of the way the court painters signed their works previously). The second photograph (fig. 66) by the same photographer and also dated late 1880s, depicts Mozaffar al-Din Mirzā in Tabriz. Both photographs bear almost the same intricate and elaborated signature: in the upper part we can read Wali-'ahd (i.e. crown prince) under the Qajar emblem of the Lion and the Sun; in the middle, we read akskhāne-ye mobārake-ye hazrat-e vāla ruhenā-fadā (to name the royal photo studio from Mozaffar al-Din Mirzā in Tabriz); and in the bottom part we read Khān Ezzat Manuchehr. The pioneer of Iranian photo history, Yahyā Zokā, explains that in the Golestān Palace Library there are 83 photographs in two albums (Nos. 434 and 401) with photographs of the time of Mozaffar al-Din Mirzā in Tabriz. Further, and this is relevant for this research, in the last photographs from these albums, as Zokā explains, the word amal is used to introduce the name of the photographer, which is important since it agrees with research done by 
Sheila Blair about the use of the word amal to introduce the name of the author, the name of the artist, as explained in detail before in this chapter.

An extraordinary group portrait by the Iranian photographer Amir Qajar depicts several children of Fath Ali Khān in front of a local backdrop, their heads arranged in a pleasant and harmonic composition (fig. 67). A Persian textile is used here as studio backdrop. The signature is written once more in Thuluth script with some elements of Naskh, and reads Dār al-Khaläfe and Amir Qajar, therefore identifying the atelier and the photographer.

The next two images (figs. 68 and 69) are the work of the well-known court photographer Abdollāh Mirzā Qajar who had attended the Dār alFonun and, in 1869, traveled to Austria to study photography. He lived for one and a half years in Vienna and for three years in Salzburg. He got in touch through royal connections with the German/Austrian court photographer Fritz Luckhardt who sent him to the Salzburg polytechnic where all different aspects of photography were taught. There he learned photolithography, phototypy, zincography and some other minor printing techniques from Jourda, an Austrian professor at the Polytechnic Institute in Salzburg. When he returned to Iran, as explained by Zokā, he was made responsible for the department of photography at Dār al-Fonun. But due to the lack of printing newspapers at that time, he decided (or better said, was forced) to start his career as a professional photographer in 1884. Later on, under the reign of Mozaffar al-Din Shah, he was the head of the Imperial Printing Press. The two images considered here are all framed and the passe-partout bears an elaborated inscription identifying the photographer and where he produced the work, in this case, in Dār al-Fonun. The signature reads: "Special photographer to His Imperial Majesty" and then finishes with the same depreciative formula as the painters did: "his humble servant". Next to this, we can read "The Photographic Department of the Dār al-Fonun College". Notice that the inscription is only in Persian. In a later stage, this photographer added a French inscription as well, like it is the case in the next two images which bear, both of them, the same signature identifying photographer and the royal atelier and with the emblem of the Lion and the Sun of the Qajar Dynasty (figs. 70 and 71). But there are further differences between the name-stamp used in earlier photographs and in the later ones, since the royal emblem of the Lion and the Sun (Shir-o Khorshid) is different: in the earlier photographs the lion is lying down and in the more recent photographs the lion is standing up.

Similar ways of signing the photograph were used among different court photographers, as we can see in the next image composed of nine studio portraits (fig. 72), the three on the bottom using one of those elaborated signatures that identify the photographer as Mohammad Jafar Mirzā and the royal atelier, in Naskh script with Thuluth elements. 
I am currently engaged in a systematic study of the signatures of all Iranian court photographers and teachers at Dār al-Fonun, aiming at exploring further the use of different formulas to sign, the type of script used, and also whether the word amal is used systematically.

What about images of women in Qajar portraiture painting and photography? How were women depicted and which kind of inscriptions do the paintings bear, if at all?

Most of the portraits painted by artists during the Qajar era were men. Nevertheless, there are enough portraits of women to deserve a close analysis of them and focus on the use of calligraphic inscriptions in these artworks. After a period of research on this topic, I have found that no calligraphic inscriptions are to be found in those works of art except, and not always, the signature of the painter. Since they are idealizations of women, no further identification is found, and this seems to be the reason for the lack of further calligraphic inscriptions. Therefore, the treatment of the portraits of women and those of men is different when it comes to the presence and meaning of calligraphic inscriptions. In $A$ woman balancing on a knife (fig. 73, see full color section), we can find all the beauty attributes of Qajar women: her moon-like face, her joined eyebrows, her bow-shaped eyes and her small mouth. The acrobat's body is flattened against the picture plane and is performing some impossible acrobatic exercises. There is just one inscription placed between the face of the woman and the watermelon, the word Khätun, which means dame or lady. Here, as in many other such pictures that I have analyzed, not even the signature of the painter is to be found. This probably has to do with the fact that these artworks were executed merely for decorative purposes and that they were not considered as important and valuable as those of the men that mostly depicted Shahs and princes. For a painter, this kind of women portraits probably would not give any status, whereas the fact that he would paint a portrait of the ruler of the dynasty would immediately give him some extra credit. This is especially appealing because it illustrates the fact that women in Qajar portraiture were mere abstractions, idealizations and therefore, in any case are not or cannot be identified. This is a remarkable difference again in contrast to the portraits of men that present calligraphic inscriptions with good factual information about both the person depicted and the painter.

As for photography, the number of portrait photographs of women by Iranian photographers is almost non-exsitent compared to the number of portraits of men. The only examples that I have found of portraits of women that bear inscriptions were some belonging to the private albums that Nāser al-Din Shah made with photographs of most of his wives and many of his children. They are just informative inscriptions, with no artistic intention, that sometimes reveal the name of the woman depicted. A Persian word that is easy to find next to several of the photographs is mord, which means dead. 
Before I finish this section, I want to show a portrait that bears inscriptions in Thuluth to identify the sitter and his religious title. A portrait of hojjat al-eslām wal-muslemin Āqā Seyyed Mohammad Mojtahed Tabātabā'i (fig. 74), an important figure of the Constitutional Period ${ }^{20}$ is yet another example of portrait photography with inscriptions and has some peculiar elements that are well worthy studying.

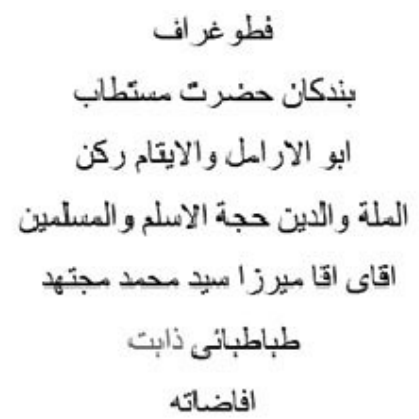

The inscription is written in clear Thuluth script and starts with a phrase that reads (in a very symbolic way) that the person depicted is a servant of the Mahdi (the 12th Imam for the Shia). ${ }^{21}$ The exact translation of the text written in this photograph by Witkam is:

Photograph/ (of) the most excellent person/ father of widows and orphans, pillar/ of the state and the religion, proof of Islam and the muslims/Mr. Agha Mirzā Sayyid Muhammad the mugtahid/ Tabatabai, may increase/ his overflowings. ${ }^{22}$

Reflecting on the actual physical implementation of the inscription within the photographic space, this image recalls (just formally), the way of implementing inscriptions within the pictorial space in Qajar painting (with a kind of cloud that frame the inscription).

\section{Naskh, Koranic verses (and philosophical thoughts)}

The third group is composed of images such as the one taken by the Iranian photographer Abd al-Qāsem ebn al-Nuri (active from around the 1880 s onwards) (fig. 75). It is one of the nineteenth-century Iranian photographs that show in a clearer way the relationship between calligraphy/text, poetry, painting and photography, since it presents several typical Iranian elements inherited from the Persian painting tradition. In the upper part of the photograph we can see three groups of inscriptions, all of them in Naskh script. Here we can appreciate that the script has been written in a much more elaborate way than in the previous examples, with a more 
noticeable deformation of the letters and with a more free understanding of the space (some words are placed above or under the main line of the inscription). The main inscription is:

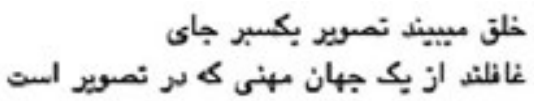

If I analyze the inscriptions in the portrait of this kneeling mullah, then in the right cartouche we can read "photo of Hojjatoleslam" and in the left cartouche "Fāzel Sharbiyāni Edamelboje", i.e. the person depicted in the photograph is being identified, exactly as in the Qajar portraits and in some miniatures, as noted above. The inscription in the upper center is a philosophical poem, a reflection about the importance of the meaning of the image beyond its mere form, its mere outer appearance. The inscription reads (free-translation): "the people see his image/ without noticing the deep meaning that underlies it". Finally, one can read in the lower inscription, also in Naskh script, "the work of the photographer Mohammad Abd alQāsem ebn al-Nuri, taken in the year 1305". Here, interestingly, the word 'amal has been used to introduce the signature on the photograph, as it is traditionally done on objects, as I have already mentioned before. This is a remarkable parallel in the way the inscriptions have been placed in all kinds of objects and in photography. The pose of the man depicted here, the traditional kneeling one inherited from the miniature portraits, together with the paraphernalia (cushions behind the back, the Persian carpet and the tasbi that the mullah is holding) result in an image that fully resembles the studies of Persian miniatures. The main inscription is the one that is especially relevant for my research because it has some deep philosophical message, which stresses the difference between form and meaning. As stated by the Islamic art historian Yves Porter,

the duality between surat (form) and ma'ni (meaning) can be related to the Sufi notion of zähir, "the exterior" and bātin, "the interior", as well as to the Zoroastrian complementary opposition between menok and getik. Every creature has a double nature: getik, the terrestrial, opaque, heavy, and menok, the ethereal, transparent, subtle one (Porter 2000: 113)).

Further, in words of the scholar Johann Christoph Bürgel,

for the mystic spectator, all earthly beauty points to the Divine, and by this very fact all the phenomena of creation transcend themselves, turn into symbols, which by their outward appearance (zahir, exterior, form) veil and, at the same time partly unveil, an inner 
meaning (batin, interior, $m a^{6} n i$, meaning), point to a higher layer of existence. (Bürgel 1975: 34-38)

The relationship between outward form and inner essence is treated directly in the writings of the great medieval Iranian scholar Ghazali (10591111 ) on the nature of beauty. In the words of the Islamic art historian Priscilla Soucek,

Ghazali discusses several types of beauty and the manner in which they are perceived by the senses in an ascending progression that moves from the beauty of man to that of the creation and finally focuses on how to define God's beauty. The faculty of sight and the related skill of visual imagination are important aspects of this process. The eye is attracted to beauty and takes pleasure from its perception (Soucek 2000: 102).

In the same way, another great Sufi poet, Mawlānā Jalāl al-Din Rumi (Konya, 1207-1273), acknowledges the power of images and stresses their inherent limitations. I have looked for books written by Iranian photographers in nineteenth-century, but in the first years after the invention of photography only books written by Western photographers were translated from French or English into Persian. In a later stage, the Iranian photographers started printing their own books written from their own perception of the new medium. A book that is especially interesting for this topic that deals with a philosophical and religious perception of the image, is Aksiyye Hashryye, a 56-page book written in the time of Nāser al-Din Shah by the photographer Mohammad-devne Ali Maskute al-Molk. ${ }^{23}$

The next photograph (fig. 76) also presents two inscriptions in elaborate Naskh script. The upper one is the same poem that was used in figure 75. I found this image in a different book from the one in which the first was found. In this second one, the author of the photograph is not identified by the author of the book or by any inscription in the photograph. But it could be that the photo is also mounted on a frame like the previous one and perhaps the inscription identifying the author is to be found there. In any case, I believe that the maker of this second photograph is the same as that of the first one, Abd al-Qāsem ebn al-Nuri, not only because he uses the same poem but also because of the way he uses the inscriptions. In the lower inscription we can read "photo of the dead Mirzā-ye Sharestāni, in 1315 Qamari", identifying in this way the sitter. The pose of the man depicted is not a traditional one but a typical Victorian sitting pose. The table also has been introduced in the studio and it is covered with an Iranian tablecloth. On top of it we can see several books with the intention to mark the higher education of the mullah depicted. One of the most interesting elements of this photograph is the folded curtain on the right side, an element that was 
introduced to Qajar portrait painting due to Western influence and later on also in photography, as we can see in this example.

The image of an unknown dervish (fig. 77) shows that the continuation of the tradition of illuminating paintings with poems did find its way into photography. Two different kinds of scripts have been used: in the inner frame the inscription is written in Naskh, which is the script that was normally used to write Koranic verses as is the case here, and the inscription in the outer frame has been written in Nastal'iq script for the inscription in the outer frame. Both inscriptions have been written in a very elaborate way. In the outer frame, a poem about the figure of the dervishes and their philosophy has been written.

Nos. 1-4. Upper outer frame

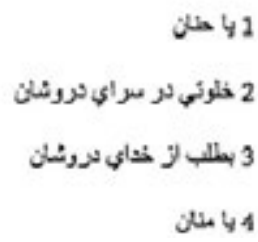

Nos. 5-8. Lower outer frame

5
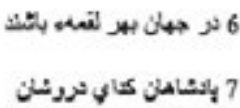

Nos, 9-10. Right outer frame

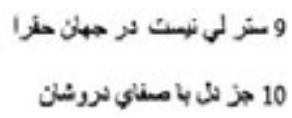

Nos. 11-12. Left outer frame

11 سر وجاتم الفاي الكه يود

12 سر وجاتث فأي سروثنان.

No. 13. Inner frame, right-bottom-left

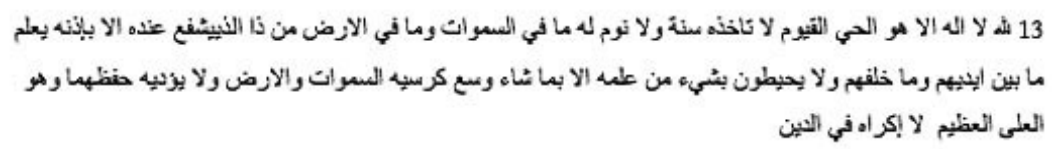

No. 14. Inne: frame, top 
Here, the photograph seems to illustrate the text, as in the miniatures. The inscription reads (outer frame): Pray for solace in the dervishes' abode / to the God of the dervishes / in the world Truth has no abode / other than in the pure hearts of the dervishes / For the tiniest morsels in this world / kings must beg the dervishes / Let my body and soul be sacrified / to him whose body and soul is sacrified to the dervishes. ${ }^{24}$ In the inner frame of the photograph, we can read several verses from the Koran, the one known as the Throne Verse (2:255 and beginning only of 2:256). The translation by Witkam reads:

2.225: Allah is He besides Whom there is no god, the Everliving, the Self-subsisting by Whom all subsist; slumber does not overtake Him nor sleep; whatever is in the heavens and whatever is in the earth is His; who is he that can intercede with Him but by His permission? He knows what is before them, and they cannot comprehend anything out of His knowledge except pleases Him, His knowledge extends over the heavens and the earth, and the preservation of them both tires Him not, and He is the Highest, the Greatest.

2.256: There is no compulsion in religion; .... (Throne Verse, in the Shakir translation).

Oh, 'Ali!, oh, Abliya! (=?); oh, Father of Hasan!; oh, Father of Turab! (=?), take me.

As explained to me by Witkam in the course of an e-mail exchange in February 2008, the Throne Verse is one of the most popular Koranic quotations. It is often seen in inscriptions in buildings or on objects (ceramics or the like). He noted that Blair in the index of her book Islamic Inscriptions has a considerable number of references to sura 2:255. It is by far the most frequent Koranic quotation she mentions. ${ }^{25}$ In the case of the Throne Verse, there is no practical purpose in its use on a photograph and therefore it is easier to see it as calligraphy than in other cases where the text gives us plain factual information.

As a conclusion it is important to stress that independently of which kind of information is given in the inscription (factual or interpretative), the language is always poetic. This is probably the most important conclusion of my research on this topic since it establishes a clear link between the use and function of text in painting and photography. Consistently, most of the inscriptions found in nineteenth-century Iranian photographs are poems or have been written in a poetic tone, even if they are not real poems.

The relation between image and written text is so well rooted in the cultural subconscious of the Iranian artist that nowadays it is very easy to find such examples in every field of Iranian visual arts. It is, indeed, one of the 
most important and defining aspects of Iranian contemporary art and it can be found in painting, animation, video-art and photography. In the visual arts, some artists find themselves looking back to their past, in search of inspiration. To be sure, history never repeats itself in the same way, but it rescues old themes from the past and presents them in new garb. This applies to Iranian photography as well. The work of the most internationally recognized Iranian photographer and video artist Shirin Neshat is a good example of this. She has lived in New York since 1972 and her work "Women of Allah" (1993-97), a photographic series of militant Muslim women that subverts the stereotype and examines the Islamic idea of martyrdom, consists of several photographs with handwritten inscriptions. ${ }^{26}$ The verses handwritten on the photographs emphasize Neshat's beliefs. Other Iranian artists, such as the Iranian graphic designer Rezā Abedini ${ }^{27}$ caught my attention with the use of parts of one Qajar photograph and calligraphic inscriptions mixed in perfect harmony with the image, in the way in which Persian miniatures and calligraphic inscriptions do. His work is a good combination of his creativity in producing personal graphic design and his individual skill in adapting the knowledge and achievements of Iran's artistic heritage, making it new and compelling. Even among sculptors there is a current that exemplifies the desire to move calligraphy into the three-dimensional world. Some Iranian artists create sculptural calligraphy, like the pioneer in this field Parviz Tanavoli. ${ }^{28}$

\section{Text and nineteenth-century photography in other countries in Asia}

I have already suggested at the beginning of this section that it important to ask if the use of calligraphy in Iranian photography is a particular and defining element of this culture, or if it is also used by other cultures like Chinese or Japanese. Calligraphy is regarded in China and Japan as the supreme artistic achievement. Painting, which uses the same basic materials of brush and ink on paper or occasionally silk, became the sister of calligraphy, while poetry, for its expression is linked inseparably to writing. ${ }^{29} \mathrm{I}$ have researched, mainly through printed books, nineteenth ${ }^{-c e n t u r y}$ Japanese and Chinese photography, and it seems that the Japanese photographers at least used calligraphic inscriptions within the photographic space. From around 1000 Japanese photographs analyzed (taken by Japanese photographers) from the nineteenth century and early twentieth century, I have found a few with some Japanese calligraphy on the surface of the photograph. The use of text or inscriptions in the photographic space may have been inspired by Japanese traditional painting in particular by the ukiyo-e, or woodprints. The term ukiyo-e, or "pictures of the floating world," refers to a style of genre painting and woodblock printing that appeared in Japan in the seventeenth century and that was practiced until the 
nineteenth century, more exactly the Edo Era (1603-1868). As the Japanese art historian Tadashi Kobayashi states,

the phrase "floating world," which was originally associated with a Buddhist world view and alluded to the ephemerality of man's existence, subsequently came to suggest a hedonistic preoccupation with the present moment, with the latest fashions, pursuits, and lifestyle of an urban culture, and implied a certain chicness. (Tadashi 1992: 65)

The three themes that recur most often in ukiyo-e painting are the beautiful women (bijin) and their world in the tea house and at home, the samurai, and the landscape. The influence of the ukiyo-e painting tradition on nineteenth-century Japanese photography is also evident in hand-colored photography, which not only adopts the paintings' color palette, but also copies the poses of the persons depicted and even the objects that they are holding. ${ }^{30}$ A married woman inspects her black teeth in a mirror (fig. 78), a typical ukiyo-e, was painted by Kitagawa Utamaro (1754-1806). On the top right corner we find a cartouche divided into three parts; in the two outer sections we can read some calligraphic inscriptions: in the right section the title of the series to which this ukiyo-e belongs is written in black ink (Fujin sogaku jittai, "Ten Women Type Physiognomies") and in red ink we can see a seal that reveals the identity of one of the owners of this artwork. On the left side of the cartouche written in black ink we can read somi (physiognomic seen) on the top, and on the bottom the name of the painter, Utamaro. This method of placing calligraphic inscriptions within the pictorial space is particular to the Japanese painting tradition.

The Japanese photographer Yokoyama Matsusaburo (1838-1884) also used text consistently within the photographic space, and he even chose to write both in red and black ink, like the painters did. ${ }^{31}$ The fact that other Japanese photographers such as Kojima Ryua also tended to add inscriptions within the photographic space, points to the fact that this combination of the two techniques, image and text, was an element particular to some indigenous Japanese photography, like it is the case in Iran. On the portrait of Nitta Tomi taken by Yokoyama in 1872 (fig. 79) we can read an inscription written in Kanji script with black ink. The first four signs reveal the date on which the photograph was taken, "ca. the 5th year of the Meiji Era", and the next three signs reveal that the technique used was albumin paper, "Japanese-lack paper". In red ink the photographer has written very detailed information about the process, the identity of the sitter and where the photograph was taken: "Nitta Tomi, sister of [illegible sign], the 7th year of the Meiji Era a photo-studio was opened next to the five-stock pagoda of the premises of the Asakusa-Temple". 32 
As pointed out by Helen Westgeest while viewing these images together, this way of placing the calligraphic inscriptions on a white strip was also done previously in the Ukiyo-es or Japanese woodprints. This indicates that the traditional Japanese painting tradition may have influenced the aesthetics used by some nineteenth-century Japanese photographers, like Yokoyama who was also an outstanding painter. Another portrait of the same woman, but taken by Yokoyama two years after, depicts the woman in the traditional kneeling pose (fig. 80). Here the calligraphic inscriptions have been placed on the left side of the image, again on a white strip and they have been written in red ink. One of the most interesting elements in this photograph is, again, the inscription placed on a white strip on the right top corner. The text has been written in Kanji script with red ink and gives us exhaustive information about the date, the technique used to produce the photograph and factual information about the person depicted. In the top right, Yokoyama informs us that this photograph constitutes the beginning of his work on women portraits and identifies the sitter as Nitta Tomi. Under this information, we find another inscription that informs us of the fact that Yokoyama opened a photo studio on the premises of the Asakusa-Temple. On the left, the inscription informs us of the date in which the photograph was taken, "ca. the 7th year of the Meiji Era" and where, "in Yokoyama's studio in Ikenohata".

The last photograph selected here from this photographer depicts Yamamoto Rempei, disciple of Matsusaburo (fig. 81). This image has been heavily overpainted with oil with a technique that he developed himself. As stated by the Japanese curator of the Tokyo Metropolitan Museum of Photography, Yokoe Fuminori,

he called this technique Shashin Abura-e or oil painting photograph, by which the film covering the photograph is peeled off and the photo is colored with oil pigments. This was probably the completion of a way of expression synthesizing both techniques of photography and oil painting, of which he had been in quest for many years. (Yokoe 1997: 182-83)

Portrait of Yamamoto Rimpei, is actually an example of his shashin abura$e$ or "photographic oil paintings" (the original is in color), as he has indicated in the lower part of the inscription in the top right white strip, in Kanji script: "the back of the photograph has been hand-colored". This agrees with Bennett's description of this technique, that involved peeling off the emulsion covering the face of a photograph and then painting the rear side with oil paints (Bennett 2006: 83). Under this inscription we can read, "the work of the master Yokoyama". On the bottom right white strip we find a very long and detailed inscription that informs us of the date on which Yokoyama started experimenting with this technique and how: "ca. 
the 13th year of the Meiji Era he discovered this technique and in the 15th year of the era the technique was refined. At that time, the photographer hired Mr Ryoichi Komamezawa as his assistant and they experimented with this technique together. His assistant started in the 17th year of the Meiji Era to.... [illegible]". The name of the sitter has been written in the left bottom corner: disciple Yamamoto Rimpei.

Another Japanese author who used calligraphy in his work was Kojima Ryua. The collage of Kojima Ryua and his family (fig. 82) taken in 1873 is astonishing and very avant-garde for its time. It is both aesthetically pleasing and intriguing. Ryua himself is placed on the left side of the final image, resting his elbow on his camera and looking at his wife and child who have been photographed in two different poses and then pasted together to complete this unique collage. A calligraphic inscription that reads "willow; frog" has been placed on a white strip that seems to have been painted to give the impression of a piece of wood, like the Ukiyo-es. One of its corners is broken and the fact that in another of his photographs we find the same white-wooden strip with broken corner, seems to point to the fact that it may have been an effect created by the author. This is also the case in the next image, a self-portrait of Kojima Ryua taken around 1870 (fig. 83) in which he is depicted in the traditional Japanese kneeling pose. The calligraphic inscription reads: "Ryua Kojima; photographer; born in Mino (today, province of Gifu); as a child he was named Gorosaku; willow; frog". The first three signs give factual information, but the last two "willow-frog" may have some poetic meaning (referring probably to a well-known Japanese fairy tale).

Recently, I have found some Indian photographs with inscriptions. A portrait of Nawwāb Rāj Begum Sāhibe of Oudh (fig. 84), taken by the Indian photographer Ahmed Ali Khān around 1855, presents an interesting and quite long inscription in Persian:

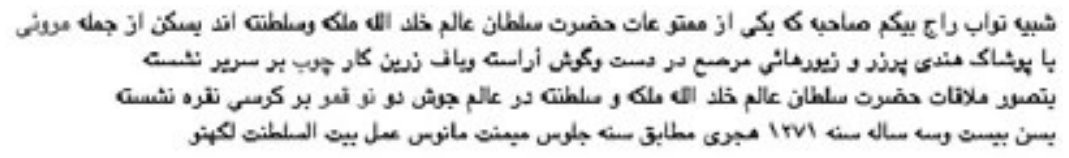

which reads, as translated by Witkam:

The image of Raja Begum Sahiba, who belongs to the most fortunate excellent sultans of the world, may God perpetuate his (her?) reign and power, and may he (she?) ... in Indian clothing full of gold and studded with gold ornaments, ornamented with jewels in the hand and the ear, (clothed) in gold woven textile, .... sitting on the throne (of sculpted wood?)/ imaging to meet the excellent sultan of the world, may God perpetuate his reign and his power in the world... seated on a silver throne/ at the age of twenty-three years 
in the year 1271 of the higra (1854-1855), coinciding with the year of the happy ascension to the unrivalled throne, (in) the abode of power Lucknow.

It is important to note that when comparing the use of text or calligraphic inscriptions in these three countries, the decorative tendency and elaborated ornament of the Iranian calligraphy contrasts with a more sober use of Japanese and Indian calligraphy. However, my research has been much more thorough in the Iranian case than in the other two countries.

To conclude, the use of text within the photographic space is one of the cultural components of a photograph analyzed here, as I have shown in this chapter through visual analysis of the role and meaning of the inscriptions in the photographic surface. Text/calligraphy and image always have been closely related in the Iranian visual culture tradition. The use and function of text or the calligraphic inscriptions in Iranian photography, whether for informative or as a philosophical purposes is mostly influenced and inherited from the Persian painting tradition, though it is not so uniquely Iranian.

The influence of the traditional use of calligraphy or text in painting and later on in nineteenth-century photography is apparent. The function of the calligraphic inscriptions used in Qajar painting has not only an aesthetic purpose but also an informative one. In this kind of paintings, the name of the person depicted is placed in the upper part of the picture, whereas the name of the author is placed in the lower part. This is all valid if we take into consideration male portraiture, but in the case of female portraiture, the situation is different since these artworks are in most cases unsigned and without any other kind of calligraphic inscriptions. The same happens in photography when taking into consideration the portraiture of women. The hierarchy implied by the way in which the text has been implemented in the pictorial space is not to be found in portraiture of men in photography. This is an important difference between the two mediums. The way in which the text or calligraphic inscription has been implemented within the pictorial and photographic space is also related: sometimes the text is placed within cartouches, other times it flows freely in the artwork's space. Regardless of the content or meaning of the script, the language used in the inscriptions placed on photographs is a poetic one.

Another important conclusion is that signatures of the photographers on the photographs are sometimes introduced by the word 'amal, as happens with most of the inscriptions placed on objects to introduce the name of the author, the artist. 


\section{Notes}

1 Sura is one of the 114 sections into which the Koran is divided. Suras are subdivided into ayat, "verses". Muslims believe that these suras were given to the last of Allah's prophets, Mohammad. Mohammad is said to have built on and perfected the teachings of Abraham, Moses and Jesus.

2 See: Abbott 1939; Lings 1977; Safadi 1978; Schimmel 1970; Schimmel 1990; Blair 1998 and 2006.

3 E-mail exchange in February 2009. I am grateful to Just Jan Witkam for his remarks concerning this matter and for his valuable help with the translation of several of the Persian and Arabic texts written in the photographs selected for this chapter.

4 Sims 2002: 270.

5 Eslami structure is a typical ornamental and decorative background used in Persian miniature painting.

6 Omar Khayyam (born in Nishapur, 1048-1122) was a Persian poet, mathematician, philosopher and astronomer. He is believed to have written about thousand four-line verses or quatrains (rubaai's). In the English-speaking world, he was introduced through The Rubaiyat of Omar Khayyam, translated by Edgard Fitzgerald (1809-1883).

7 For a detailed study of the Ardabil carpets and the inscriptions written on them, see: Stead, R. (1974), The Ardabil Carpets. Malibu: J. Paul Getty Museum, Malibu.

8 Sacrifice

9 Calm

10 The earth and the heavens.

11 Love-struck

12 Eloquent

13 Effulgence

14 Handsome

15 Ritter 2008.

16 This is actually a page of an album, a watercolor representation of Fath' Ali Shah seated on the Sun Throne (Takht-I Khurshid). Printed in Diba 1998: 177.

17 Printed in Diba 1998: 184.

18 To see this painting, please consult Diba 1998: 186.

19 See, for instance: Diba 1998; Falk 1973; and Sims 2002.

20 The Iranian Constitutional Revolution took place between 1905 and 1911. The Revolution led to the establishment of a parliament in Iran. The system of constitutional monarchy created by the decree of Mozaffar al-Din Shah that was established in Persia as a result of the Revolution ultimately came to an end in 1925 with the dissolution of the Qajar Dynasty and the ascension of Rezā Shah Pahlavi to the throne. Tabatabata'i was a very important religious constitutionalist. Further reading: Vanessa Martin, H.E. Chehabi (eds.) (2010), Iran's Constitutional Revolution: Popular Politics, Cultural Transformations and Transnational Connections, and History of the Iranian Constitutional Revolution: Tarikhe Mashrute-ye Iran, Volume I, translated into English by Evan Siegel (2006). Costa Mesa: Mazda Publications.

21 According to Twelver Shi'as, Imam Hujjat al-Mahdi (or Hujjat ibn Hasan ibn Ali) is the twelfth Imam and the Mahdi, the ultimate savior of humankind. Other Shi'a schools adhere to different Imam successions and do not, along with Sunnís, consider ibn-Al-Hasan the Mahdi. Shi'as believe that for several reasons, God concealed the twelfth and current Shi'a Imam, al-Mahdi, from humankind. They believe that al-Mahdi will reappear when the World has fallen into chaos and war and that he will bring justice and peace to the World. Further reading: Corbin, H. (1993), History of Islamic Philosophy, translated by Liadain Sherrard and Philip Sherrard. Kegan Paul International.

22 Words in grey here mean they are not legible. 
23 I am grateful to Mohammad Rezā Tahmasbpour for helping me with this matter.

24 Translation taken from Damandan 2004: 154.

25 Blair 1998. Witkam went through the index to find those references: $\mathrm{p}$ 69: common on mosques; $p$ 73: part of a limited repertoire of Koranic texts on buildings; $p$ 74: Fatimid inscription on walls of Cairo; $p$ 80: on a minaret in Tirmidh; p 137: inscription in wood in Beyshehir; p 139: on the Qala'un mosque in Cairo; p 147: on a walnut chest (to contain a Koran); pp. 156-57: on tiles; pp. 195-96; and pp. 213-215: as the Koranic verse used most on objects.

26 For further reading about the work of Shirin Neshat: Dabashi, H, "The Gun and the Gaze: Shirin Neshat's Photography" and Zaya, O., "Sounds of Desire, Zones of Contention (Islam, Women and The Veil)", in Shirin Neshat, Women of Allah. Milano: Marco Noire Editore (1997); Schmidt, B./Stammer, B. E. (2005), Shirin Neshat. Berlin: Steidl Verlag.

27 Abedini was awarded the Prince Claus Award in 2006.

28 Further reading about this topic in: Blair, S. (2006), "From Traditional Styles to Graphic Design and Calligraphic Art", in Islamic Calligraphy. Edinburg: Edinburg University Press: 589-627.

29 Shimizu and Rosenfield 1984.

30 Pérez González 2008.

31 For an analysis of the work of this photographer, see: Pérez González 2011.

32 I am very grateful to Jun Ueno (Japanisches Kulturinstitute in Cologne, Germany) for his translations of all the texts on the Japanese photographs selected here. 



\section{POSE, GESTURE AND OBJECTS HELD BY THE SITTER}

For Pilar Lombardo

Once I feel myself observed by the lens, everything changes:

I constitute myself in the process of posing, I instantaneously make another body for myself,

I transform myself in advance into an image. Roland Barthes (Barthes I98I: I0)

One might inquire into the origin of the traditional kneeling pose in early nineteenth- century Iranian photography. One can rule out that this pose has found its way into Iranian photography through the apparatus and art itself (as in the use the of chair, for example). Beyond the cultural habit of the time - sitting on floor mats - it seems that this particular position, along with the pose of holding various objects by sitters, is inherited from Persian miniature paintings. Another topic that I will research in this chapter is the difference of pose and objects held by men and women in painting and later in photography. In order to achieve this, I will undertake an exhaustive visual analysis of the pose and objects held by the sitters both in the Persian painting tradition and in nineteenth-century Iranian photography, with the aim of defining similarities and differences between the two techniques.

\subsection{Gesture, posture and pose}

The terms gesture and posture are closely related in meaning. What is a gesture and what is a posture?

The Oxford English Dictionary (2nd edition, 1989) defines gesture as a "movement of body or any part of it that is expressive of thought or feeling". In this sense, gesture includes any kind of bodily movement or posture (including facial expression) which is a message to the observer. The literary theorist Fernando Poyatos defines gesture as,

a conscious or unconscious body movement made mainly with the head, the face alone, or the limbs, learned or somatogenic, serving 
as a primary communicative tool, dependent or independent from verbal language; either simultaneous or alternating with it, and modified by the conditioning background (smiles, eye movements, a gesture of beckoning, a tic, etc). (Poyatos 1981: 375)

He defines posture as,

a conscious or unconscious general position of the body, more static than gesture, learned or somatogenic, either simultaneous or alternating with verbal language, modified by social norms and by the rest of the conditioning background, and used less as a communicative tool, although it may reveal affective states and social status (sitting, standing, joining both hands behind one's back while walking, etc). (Poyatos 1981: 375)

The topic of gesture and posture has been thoroughly researched. Since the Renaissance there have been many physiognomists, such as the Swiss J.C. Lavater (1741-1801), who have attempted to codify the facial expressions of emotion and character. He was certain that,

the wise physiognomist who studied and used the science of physiognomy with discernment could read the internal from the external, the character of humankind from the countenance and from its correct graphic representation. (Stemmler 1993: 151)

The notion that inner human character could be interpreted through facial expressions persisted throughout nineteenth-century portraiture in all visual media. The conviction that a clear correspondence existed between inner moods and outward appearances also informed scientific experiments on human gestures and facial expressions, such as the photographs of mental patients taken by Dr Hugh Welch Diamond in the 1850s, by the French doctor Guillaume Benjamin Duchenne de Boulogne $(1806-1975)^{1}$ or by the French physician and neurologist Jean-Martin Charcot (1825-1893). ${ }^{2}$ Also, as remarked by the English historian Sir Keith Thomas, "in the nineteenth century Charles Darwin's (1809-1882) The Expression of Emotions in Man and Animals gave new support to the view that physical expressions might be biologically inherited" (Thomas 1991: 2). Like Diamond, Duchanne and Charcot, Darwin's works emphasized facial expression as an infallible indicator of psychological states.

Most modern writings on the subject however start from the assumption that gesture is not a universal language but the product of social and cultural differences. In the words of Thomas, "there are many languages of gesture and many dialects" (Thomas 1991: 3). As the French sociologist Marcel Mauss states, for example, "it has been suspected for a long time 
that certain standing and sitting postures might be culturally significant" (Mauss 1979). Further, the anthropologist Gordon W. Hewes argues that "human postural habits have anatomical and physiological limitations, but there are a great many choices the determinants for which appear to be mostly cultural" (Hewes 1955: 231). The ways in which we sit, kneel or stand are determined not only by the human anatomy but foremost by culture. As pointed out by Hewes, "the peoples of the world differ in posture styles just as they do in styles of clothing, housing, cooking and music" (Hewes 1957: 123). He explains that,

postures and related motor-habits are intimately linked to many aspects of daily life: they affect the design of our clothing, footgear, furniture, dwellings, offices, vehicles, tools and machines.

Moreover, they speak an eloquent language in social intercourse.

Most of us look to postural cues as well as to facial expressions and speech itself, in our never-ending efforts to interpret or evaluate people's motives, moods or behaviour. (Hewes 1957: 123)

Here I would like to stress the difference in meaning of the terms posture and pose. The second one is more limited than the first. Pose is applied when considering photographs or paintings: the sitter's pose. Posture is a wider term used in a more general context.

In its general sense, posing can be considered a way in which the "subject" responds to the implied presence of the beholder. In the words of the Turkish photography historian Fulya Ertem, "it is by assuming a posture, an imaginary self, in front of any captivating gaze. When in front of the photographic camera, posing can be seen as a reaction to the camera's deadly capture" (Ertem 2006: 10). The French theorist Roland Barthes, extending the pose to inanimate things, also describes it as,

an instant, however brief, in which a real thing happened to be motionless in front of the eye. I project the present photograph's immobility upon the past shot, and it is this arrest which constitutes the pose. (Barthes 1981: 78)

Posing is thus a moment of immobility where the sitter turns him/herself into a frozen image. It can also be considered as a moment where the sitter tends to imitate a certain image $\mathrm{s} / \mathrm{he}$ has in his/her mind in order to project it onto her/his body and gesture. However, the American film theorist and art historian Kaja Silverman in The Treshold of the Visible World claims that,

posing is not imitative of a pre-existing image, it is imitative of photography itself, as the pose does not only arrest the body, 
"hyperbolising the devitalising effects of all photographic representation" but also resembles "three-dimensional photography".

(Silverman 1996: 202)

Much like Silverman, the American post-modernist critic Craig Owens says:

What do I do when I pose for a photograph? I freeze... as if anticipating the still I am about to become; mimicking its opacity, its stillness; inscribing, across the surface of my body, photography's mortification of the flesh. (Owens 1992: 210)

Silverman refers to the French psychoanalyst Jacques Lacan's description of the phenomenon of mimicry in his Four Fundamental Concepts of Psycho-analysis and argues that,

for Lacan, although mimicry is the behavior of certain species of insects, which seem to adopt the shape and natural color of their environment for protective reasons, mimicry is more an attempt to become part of a particular picture rather than an attempt to imitate a pre-existing image. (Silverman 1996: 201)

"Mimicry is thus a reproduction in three-dimensional space with solids and voids: sculpture-photography", as the Czech philosopher Vilém Flusser calls it in Towards a Philosophy of Photography (Flusser 2000: 50). For me the study of gesture and pose through photography is of more than purely antiquarian interest, since I believe that gesture formed an indispensable element in the social interaction of the past and it can offer a key to some of the fundamental values and assumptions underlying any given society, therefore, the study of the pose and gesture of the sitters in portrait photography gives us important clues to understand the mentality of that time. In the words of Thomas, "to interpret an account for a gesture is to unlock the whole social and cultural system of which it is a part" (Thomas 1991: 11).

The anthropologist Weston Labarre argues that,

many of these motor habits in one culture are open to grave misunderstanding in another. So much of the expression of emotion in our culture is open to serious misinterpretation in another. There is no "natural" language of emotional gesture. (Labarre 1947-8: 55)

Nevertheless, he also says, "in the language of gesture all over the world there are varying mixtures of the physiologically conditioned response and the purely cultural one, and it is frequently difficult to analyze and 
segregate the two" (Labarre 1947-48: 57). Some research has shown that there are different gestures for the same meaning in different cultures and it has often been suggested that teachers of foreign languages should consider gesture not only so that students learn to speak the language but also that misunderstanding of gestural usage be avoided. ${ }^{3}$ The emerging field of gesture studies is actually especially concerned with the exploration of the relationship between gesture and sign language, and how the gesture varies according to cultural and language differences. ${ }^{4}$

In this chapter, I will explore whether this cultural dependence of pose or gesture is visible in nineteenth-century Iranian portrait photography. I will analyze if there is a noticeable difference between the pose or gesture of the person depicted in Western portrait studio photography and Iranian portrait studio photography, and consequently a difference in meaning.

When analyzing photographs, one must assume that it is possible to distinguish between postures imposed upon the subjects by the photographer and those, which are habitual or indigenous. As Hewes states, "there are pictures in which the subjects have certainly been arranged in a line for the purposes of photographic composition, but in which seemingly indigenous postures also occur" (Hewes 1955: 234). In the cases in which the Western photographer imposes his wishes, in a probably unconscious way, he will at the same time impose typical Western poses that will probably change the natural native ones that the person depicted would take on. As the photography historian William C. Darrah concludes when considering cartes de visite from the nineteenth century,

there are four basic descriptive aspects of a portrait: pose, background, lighting and characterization, the latter being partly a result of the first three. There are only three types of studio poses: head or bust, seated and standing, although there are many variations of each. The seated figure may be half-length to full length. The standing figure is usually in full length. From 1860 to 1890, portraits were roughly equally distributed among the three posing types, although heads were somewhat more popular in the early 1860 s and again in the 1870s. (Darrah 1981: 26)

The seated pose was favored by many photographers because the subject was more relaxed and it was easier to imply activity. The popular standing full pose was fraught with difficulties. The subject was obliged to stand motionless for a minute or more while the final adjustments were made in exposing the negative. An iron head clamp, adjustable for height, with a tripod base, held the subject firmly in position. This classification is valid for Western photography, but for Iranian photography I would add another pose: kneeling, as another possible way of sitting. This pose is commonly found in Iranian studio portrait photography in the nineteenth century and, 
under the influence of Western poses on the studio, the seated pose is also to be found at a later stage. I will try to demonstrate the evolution of the pose from the ground to the chair, from kneeling to the sitting position in my visual analysis of Persian painting and of nineteenth-century portrait studio photographs. Therefore, it is relevant to briefly explain how chairs appeared, evolved and were imported from other countries. In order to do so, I will introduce the ideas and research of the American architect Galen Cranz concerning the origins and role of the chair in our lives and will reflect after that about its role in the studio.

All around the world, the chair and sitting on a chair has become a symbol of Westernization. Even if the chair was discovered in Asia as we shall see further below, it was in Europe that it took the main role, as far as furniture is concerned, in the life of common people. Conversely, as stated by Cranz,

when Gandhi wanted to make a point about the importance of retaining traditional culture, he chose to sit cross-legged on the floor, self-consciously rejecting the chair and the modernism that goes with it. In non-Western cultures, the specific connotations associated with chairs are different, but the chair is still used to communicate status differences. In the words of Crams, when it was introduced to China in the second century A.D., the Chinese called it the "barbarian (their word for anything foreign) bed". It connoted informal use because of its years of association with military camps, temporary travel furniture, and garden use. It was more like a cot, and for years was never used indoors. People sat on it tailor-fashion (crosslegged), showing contempt, indifference, or extreme confidence. Nine hundred years later, a new seating type evolved: the folding chair with a back. This chair then became acceptable and was used by all, but the language of dignity and honor retained the use of the term "mat" rather than "chair". (Cranz 2000: 29)

The word "chair" comes from the Greek. It is a contraction of cathedra, which is in turn a compound of kata, meaning "down", and hedra, from "to sit". A chair is a piece of furniture with a back, and usually four legs, on which one person sits. But so is a throne. However, the word "throne" has a different origin. As remarked by Cranz,

It comes from the Indo-European base dher, meaning "to hold or support". The throne supports, while the chair is a place to sit down. A throne suggests the palanquins on which a potentate might be carried, while the underlying meaning of a chair is quite different. Physically, almost anyone can sit down, whereas only a very privileged few can be carried. Neither thrones nor chairs originated 
in classical Greece; they are far older. Chair sitting was already a widespread practice in ancient Egypt of 2850 B.C. The oldest physical chairs we have come from the tomb of the young pharaoh Tutankhamen, who died in about 1352 B.C. (Cranz 2000: 31)

Chairs, stools and benches were in use in Egypt and Mesopotamia, therefore, at least 5,000 years ago. While commoners and slaves sat on stools or benches, the kings, priests and other exalted personages in ancient Egypt used chairs. The Chinese began using chairs fairly late in their history: 2,000 years ago they sat on the floor, as the Japanese and Koreans do today. In southern and Southeast Asia chairs have never become items of common use. As stated by Hewes, "even in the Middle East and North Africa the Islamic peoples seem to have returned to sitting on the floor, possibly because of the cultural prestige of the nomadic Arabs" (Hewes 1957: 127). No less widely practiced than chair-sitting is the deep squat. Ranking slightly behind chair-sitting and the deep squat is the cross-legged sitting posture that we call sitting in the "Turkish" or "tailor" fashion. Sitting on the heels with the knees resting on the floor is the formal sitting position for both men and women in Japan, and is the regular prayer position in the Islamic world and many other cultures in Eurasia. We shall see examples of all of these positions in paintings and photographs.

We need anthropologists to remind us that almost everything including how we hold our bodies should be understood in its cultural context. An Indian might squat to wait for the train or bus, or just while observing life pasing by; a Japanese woman might kneel to drink tea or to eat; and an Arab might sit crossed-legged to read a book. Hewes, as I have already noted, emphasized that postural variations are culturally determined. Sitting, like other postures, is predominantly regulated all around the world according to gender, age and social status. In mosques, Muslims sit and kneel on richly carpeted floors, that do more than protect the knees; all who enter a mosque (or home) take off their shoes, ostensibly so that no dirt is brought onto the carpets where people will put their hands and faces. I will come back later to this matter while analyzing the paintings and photographs selected for this chapter. In the words of Hewes, "among habitual chair-sitters over the world, there are a surprising variety of cultural differences in sitting posture, many of which can be classified on the basis of the way the legs or ankles are crossed" (Hewes 1957: 125). Here it is useful to show a part of the postural typology used in the compilation of data for Hewes' article (fig. 85). As Hewes explains, these drawings are for the most part based on photographs in the ethnographic literature.

However, from the corpus of photographs that I have analyzed for this chapter, both Western and Iranian, it will be evident that this variety of chair-sitting postures is not to be found in the photo studios where the typical Victorian sitting pose is more widely used: the two legs lying parallel 
next to each other (see posture number 30 and 31 in Hewes' drawings); even though, in Iranian photographs, due to the lack of experience of sitters at that time with chair sitting, some very peculiar leg-poses appear as we shall see later in this chapter while analyzing some photographs, resulting in a more varied and interesting repertoire than the uniform Western one. In this case the role of the photographer was definitive in imposing, or at least influencing, a definite chair-sitting pose in the photographer's studio. The most common sitting posture, though, in nineteenth-century Iranian photography is number 103 in Hewes' drawings, sitting on the heels with the knees resting on the floor.

\subsection{Pose and gesture in the Persian painting tradition}

In this section, I explore which are the traditional poses used in the Persian painting tradition. A fundamental topic that I consider is how has the use of the chair in Western portrait painting influenced the transition from the traditional kneeling pose to the sitting pose in Persian painting and later on in photography. Further, my aim is to solve the question of whether there is a difference in the poses in which men and women are depicted.

\section{Men in painting}

There are many examples to be found in Persian miniature painting that depict people in the Persian traditional pose, that is, sitting on their heels with the knees resting on the floor (Hewes' posture 103). Sultan-Husayn Mirzā Bayqara, a wonderful miniature from Herat, ca. 1500 (fig. 53, see full color section) introduced already in the previous chapter, presents the sitter sitting on his heels, one hand holding a handkerchief. Seated figure holding a cup, mid-seventeenth century, presents a figure in the same pose both because he is seated on his heels and because of the position and pose of the arms and hands (fig. 54, see full color section). Rezā Abbāsi painting a picture of a European man by Mo'in (pupil of Rezā Abbāsi (ca.1565-1635)), shows Riza as an old man, wearing spectacles and a turban. He is sitting on the ground with a low stand in front of him, but the picture is propped on a bent knee, as if to bring it closer to his face. His subject is a European man (fig. 56, see full color section).

There are also many examples of this kind of pose to be found in Qajar portraiture painting. Fath 'Ali Shah (d. 1834), the second of Qajar Rulers, is depicted on the next portrait seated on his heels (fig. 86, see full color section). As explained by the Islamic art historian Eleonor Sims, he is the most recognizable personage of any Iranian monarch up to the era of photography: 
his fine slender figure, his pale complexion and blazing black eyes under wide black brows, and especially his long and magnificent black beard, are instantly recognizable, whether they are on the tiniest of enameled gold pendants or the largest of oil-painted canvases or rock reliefs (Sims 2002: 275).

This painting is dated 1797 and is signed by Mirzā Bābā, Fath Ali Shah's chief painter from the very beginning of his reign. As remarked by Sims,

for the first of the large single-figure oil paintings, Mirzā Baba appears to have isolated the Shah from among his courtiers. Fath 'Ali Shah still kneels, in the old-fashioned position, on a carpet spread on a takht with a low wooden balustrade behind him. His posture is erect and he is holding a jeweled mace that, together with his level gaze, gives the sitter an effect of great majesty. The seventeenthcentury European prop of the draped curtain on one side of the picture is utilized, but the background is essentially "a neutral shadowed space that increases his majestic isolation". (Sims 2002: 275).

Mirzā Bābā repeated this kneeling image of the Shah several times, as did other painters, although later portraits made use of the standing pose or seated the Shah in a European armchair-throne, as we will see shortly. In the next portrait, also of Fath 'Ali Shah and already introduced in the previous chapter, we again find the traditional Persian pose, kneeling on a carpet with a cushion behind him, holding a mace (fig. 64). This portrait is the latest in a series of dated paintings depicting Fath Ali Shah seated on a carpet. The painting is signed by Mehr Ali and is dated 1813-14.

The sitting and the standing poses are also to be found among Qajar portraits. Fath Ali Shah Seated on a Chair Throne (fig. 87, see full color section), is attributed to Mehr $\mathrm{Ali}^{5}$, circa 1800-1806. Oddly enough, this painting has no calligraphic inscriptions. "The work is one of the three life-size paintings showing the ruler seated in a jewel-encrusted and enameled chair throne" (Diba 1999: 181). Diba goes on further to state that,

In conformity with the function of a state image intended for public display and designed to inspire a sense of awe in the viewer, Mihr 'Ali depicted Fath 'Ali Shah as impassive, rigidly posed, and ablaze with jewels. The image epitomizes poetic descriptions of the rulers' imperial aura and sunlike splendor, to which the sun-shaped roundel surmounting the throne back alludes. (Diba 1998: 183)

In addition to the throne, the crown, the sword and the royal armbands symbolize his royal nature. Notice that in all these portraits of Fath 'Ali 
Shah, he is invariably depicted looking to the front with a slight tilt to the left. See also figure 52 printed in the previous chapter for an example of this kind of sitting pose. Diba's book is the best source to see fine examples of sitters depicted in the standing pose.

In the following section, I will analyze the objects held by the sitters in Persian miniature painting and Qajar portrait painting. I want to explore if there is a difference in the objects held by women and men. When analyzing nineteenth-century Iranian portrait photographs, we can find several recurrent elements, such as the man holding a flower, as one of the more particular ones. The fact that the man is holding a flower is quite an unknown and bizarre element in Western portraiture. Flowers tend to be something more related to women than men, especially in that genre. But not in the Persian painting tradition as we shall see. It is actually quite easy to find portraits of men holding roses in various periods. A typical example among the many to be found is Youth with Flower (fig. 88) from the seventeenth century, a precisely drawn representation of a courtier or a dandy, which may have been a sketch for a larger painting. Iran often has been called "the land of the rose and the nightingale". Persian Sufi poets have used the rose extensively, almost obsessively. The symbol of the rose conveys allusions to concepts such as beauty, love, poetry, divine Unity, music and belovedness, while the nightingale symbolizes multiplicity and diversity.

Another interesting element is water, normally presented by way of a pond. See, for example, fig. 89, where a messenger offers to Sam (grandfather of Rustam) a painted picture of the new-born Rustam, seated crosslegged and garbed in a miniature version of his grandfather's clothing. ${ }^{6}$ This kind of miniatures with a pond placed in the bottom center of the image is very common and this kind of composition later on would also be used in photography, as we shall see below. Remarkably, and especially in photography, water has a close relationship to reflection and mirrors. Photography is often compared with a mirror in theories of photography. The motif of the mirror is one of the most fascinating ones used in Persian poetry, especially in mystical thinking. The meaning of the mirror in Persian literature has been analyzed in-depth by Johann Christoph Bürgel and Priscilla Soucek. Rumi is one of the Persian poets who has used the motif of the mirror more in his poetry. Annemarie Schimmel ${ }^{7}$ and Eva de Vitray-Meyerovitch ${ }^{8}$ have investigated the role of the mirror in the imagery of this poet.

There are, to be sure, many more motifs that bear a symbolic meaning in Persian miniature painting, but I have only referred to the two that are to be found in nineteenth-century Iranian portrait photography.

If we now consider Qajar portrait painting, the Qajar imperial attire and regalia consist of several key elements that can be easily identified. These elements have a uniquely Qajar flavor to them during Fath 'Ali Shah's 
reign. As we can see in figures $62,63,64,86$, and 87 they include crown, throne, sword, mace, dagger and jewels. The Qajar throne was also an essential element of Fath 'Ali Shah's imperial regalia. Crown and throne aside, as they are obviously the most symbolic of all the regalia, we can say that in general the arrangement and collection of elements chosen by Fath 'Ali Shah and his predecessor, Aqa Mohammad Khān Qajar (17421797), as part of their imperial image is important. In the words of the Iranian scholar Manoutchehr M. Eskandari-Qajar,

each element is, of course, symbolic, and each element works to complete the image that is to be projected. It is in the particular arrangement of the elements that Fath 'Ali Shah also achieved the unique look of Qajar imperial attire and regalia. (Eskandari-Qajar 2003: 84)

In addition to the above, a mace (gorz), a jeweled dagger, a studded belt with pendant and the Qajar hanging belt form the characteristic elements of Fath 'Ali Shah's regalia, as we have seen in the group of painted portraits presented. The sword and the mace remind us of the ruler's justice and the regalia and decoration reinforce an image of wealth. Some of these objects also became part of the regalia shown in photographic portraits in a later stage, as in the case of the sword. In this sense, Qajar painting came to influence the photographic portrait as far as the use of it was concerned, next to the possible aesthetical influence that I am studying in this book.

Diba states that,

there is considerable evidence that images, in myriad forms, sizes, and media, played an integral role in the nineteenth-century exercise of power, both at home and abroad. In addition, numerous intriguing references document the widespread use of figurative imagery in popular and court milieus throughout Qajar society for both religious and secular purposes. (Diba 1998: 31)

As remarked by Diba, the Islamic art historian B.W. Robinson's statement, "Persia in the nineteenth century was a land of paintings, as never before or since" (Robinson 1964: 96) may be taken literally. She argues further that,

Images in the form of mural paintings were embedded in the fabric of structures located throughout the country. They included portraits; historical, literary and mythological themes; genre, hunting, and battle scenes; and religious subjects. In fact, the entire Persian domain functioned as a lavish stage for images designed to convey the pageantry and splendour of Qajar rule. (Diba 1998: 31-32) 
In the same line of thought as Diba, Falk argues that,

the character of Qajar paintings is largely embodied in the subjects that were chosen. These must have always depended upon the choice made by the patron and, understandably, one of the first interests of a patron is himself, a fact amply illustrated by the greatest patron of Qajar painting, Fath`Ali Shah (1798-1834) (Falk 1972: $10)$.

One may wonder wether this construction of a royal Persian image in painting would have found its way also in other visual media such as photography. Ekhtiar reflects precisely on this interesting topic arguing that,

Members of the Qajar ruling elite soon realized that lithograph portraits and photographs of royal personages and the nobility were capable of serving the same purpose that life-size paintings had fulfilled earlier and began to regard lithographic portraits as a more efficient and economical vehicle for disseminating the royal image. (Ehktiar 1998: 62)

\section{Women in painting}

Most of the portraits painted by artists during the Qajar Era were of men. Nevertheless, there are enough portraits of women to deserve a close analysis. ${ }^{9}$ It is relevant for my study to analyze the pose of the women depicted in these paintings to see if there is any relationship between the pose and gesture of women in the Persian painting tradition and in nineteenth-century Iranian portrait photography. In all periods of history the prescriptions for the physical behavior of women have been different from those of men. This has been reflected clearly in Qajar portrait painting and also in photography, as we shall see shortly. According to the art historian S.J. Falk, "this subject, girls, apparently resulted from a desire for decoration that would suit the purpose of the building for which the painting was intended" (Falk 1972: 10). We can find images of women playing different instruments, dancing with castanets, and sometimes just resting or drinking. But without a doubt, the most impressive group of pictures is that which depicts female acrobats and tumblers who played a prominent role in the entertainment provided at court. These images provide the most striking images from the Persian painter's repertoire of females. Girls balancing on their hands and even on knives are especially interesting since those contortions of the human body have no precursors in earlier painting. A girl playing a sitar (fig. 90) by the painter Mohammad Sādiq and dated 1769-70 depicts a woman playing a sitar. As stated by Diba, 
the arched eyebrows, aquiline nose, narrow kohl-rimmed eyes, elongated body proportions, and stiff treatment of the wide trousers were typical elements used in this idealized representations of women. Those were, actually, the Zand painting canons. (Diba 1998: 157)

The lady's countenance and body correspond, indeed, to the classical canons of Persian beauty as interpreted in the Zand period: moon-faced visage, joined eyebrows, etc. The woman depicted here is dressed in the costume of the period, which so often consisted of huge patterned trousers made of thick carpet-like material, and a much lighter transparent chemise that was often open at the front. According to Diba,

the role and status of women entertainers in Middle East societies is a perplexing phenomenon. Performing, especially in front of men, was not regarded as a highly respectable profession, although its practitioners were not necessarily considered outcasts. (Diba 1998: 207)

These women performers in painting were also a favourite topic in other Middle Eastern countries and in North Africa. Sarah Graham-Brown explains that,

in many instances women entertainers were professionals brought into the harem to perform on special occasions, or sometimes they were actual members of the harem, usually concubines of the rulers, who were trained in the arts of singing, music, poetry and dancing. (Graham-Brown 1988: 174)

Ehktiar informs us that "the half-filled crystal decanter and porcelain tableware filled with piping-hot delicacies typically appear in representations of women during this period" (Ehktiar 1998: 207). As she explains further, the wine and apples are both attributes that act as visual equivalents for poetic metaphors: in Persian culture, apples represent love and fruitfulness, while wine is a favored metaphor for earthly and divine love. In $A$ woman balancing on a knife (fig. 73, see full color section) the acrobat's body is flattened against the picture plane, achieving impossible acrobatic poses in search of a harmonic balance. The watermelon in the right bottom corner of the painting gives the final image an interesting balance in composition. The wooden balustrade is also one of the typical elements found in these kinds of paintings as part of the studio setting. As is usual for Qajar paintings of beauties, the picture is neither signed nor dated (there is one word: Khātun, which means dame or lady), but its style and the young woman's clothes belong to the first quarter of the nineteenth century. Note that the 
women depicted on these paintings are always barefoot and their feet have been painted with henna. Like many other Qajar canvases showing women, this one seems to be one of a series of paintings that once decorated a palace. Diba argues,

although Qajar representations of women were rarely signed or dated (in clear contrast to those of men), these paintings present marked affinities with similar subjects executed by the painters Ahmad and Muhammad, providing a dating range from the late 1820 s to the early 1840 s. (Diba 1998: 211)

Such paintings of women were displayed in the public as well as private quarters of palaces and residences. Diba states further that,

These representations, in a society where women were secluded from the male gaze, understandably puzzled nineteenth-century European observers, who failed to grasp the abstract nature of these representations and mistook them for actual portraits. (Diba 1998:

211)

These female acrobats are not found in photography but the women musicians, especially playing the sitar are more common, as we will see in the next section. The women depicted in Qajar paintings hold musical instruments or, in some cases, little knives when performing some acrobatics, or a glass of wine or bottle, as we can see in figures 73 , see full color section, and 90. These elements are also present in photographic portraits of women, as I shall show with some examples.

In sum, as we have seen, there is a chronological evolution from the traditional Iranian pose to a more westernized pose, chiefly symbolized by the use of chairs in the painter's studio and, later, in the photographer's studio. The plane of the painting rises from a low one to an upper one to fully depict the person sitting on the chair. This transition happens over a longer period of time in painting than in the case of photography. The first chairs to be found in Qajar painting portraiture date from the beginning of the eighteenth century. Before this date, only the kneeling pose can be found. This traditional Persian pose widely used in miniature and Qajar painting, can be described as a person kneeling on the floor, on a carpet, and normally with a cushion at his/her back. The hands rest relaxed on the sitter's lap and quite often grapple some kind of typical object: tasbih (set of coral prayer beads), mace (in the case that the person depicted is one of the Qajar rulers), a book, a handkerchief, etc. Later on, after 1800, in Qajar portrait painting, only men were sitting on chairs or on a throne, if the person depicted is one of the Qajar rulers. Women were kneeling, standing or performing acrobatics. A possible explanation of this difference is that in 
the portraits of men, the sitters were real, belonging mostly to the highest levels of court society, whereas those of women were idealized portraits of anonymous women, more exactly of a prototype of women who were the court's entertainers. Around the same time, the standing pose can also be found, but is not as widely used as the sitting pose. There is clearly a different treatment of female and male portraits. Gesture reflects differences of gender as well as of class. Women portraits in the Qajar era were abstractions that represented anonymous women whereas those of men were always high-ranking society members that could be identified by the calligraphic inscription that is always found within the pictorial space. This conclusion agrees with the statement of the Iranian scholar Afsaneh Najmabadi that,

the subject of women in Qajar painting present us with a curious picture: we have an abundance of representations of women from the realm of male fantasy and pleasure, but very few representations of real women. (Najmabadi 1998: 76)

The analysis of the objects held by the sitter are rich in sociological input. While Persian miniature painting, due to its direct relation and dependence on Persian literature, is more prone to use elements that bear symbolic meaning, Qajar traditional portrait painting, as well as photographs, are more directed to stress the social status and power of the sitters. This consideration has a great impact on the treatment of the object held by the sitter. There is a clear difference between the objects held by men and women. Objects held by men are more related to the outer appearance of the sitter, more related to the public sphere of society, while the ones held by women are more related to the domestic sphere, a place governed by women. However in either case, through the objects held by the sitters, both photographers and sitters constructed their photographs showing a part of the reality of their life, what they were interested in and where they were coming from or their social status, as we shall see with examples in the next section.

\subsection{Pose and objects held by the sitter in nineteenth- century Iranian portrait photography}

In this section I explore which poses are used and which objects are held by the sitters present in traditional Persian paintings that may have been inherited by nineteenth-century Iranian studio portrait photography. Subsequently, I will discuss how Western aesthetics and studio paraphernalia have influenced the traditional pose of Iranian sitters in portrait studio photography. Due to this influence some hybrid poses may be found among Iranian photographs and my aim is to define them. The last topic 
that I research in this section is whether there is a difference in the poses used by men and women in photography, as was the case in Persian painting.

The two first photographs considered here share an almost identical pose: a man sitting on his heels with his knees resting on the floor (Hewes' posture 103), the typical Persian pose, with the hands almost in the same position, one of them holding an object: in fig. 75 the mullah (religious priest or leader) holding a tasbih (a set of coral prayer beads), as in traditional Persian painting (see figure 53, see full color section). The other hand rests on his lap. In fig. 55, the man is holding a water pipe with the right hand and his left hand rests in his lap in the same way as in the previous photograph. The parallel between the composition and aesthetics of these photographs and the paintings analyzed in the previous section is remarkable and leaves little doubt as to the influence of the paintings on the photographs. We can also find a remarkable amount of photographs of groups of people kneeling on the floor, like groups of musicians or jesters (see figs. 91 and 92). The first one depicts three men with one serpent and the calligraphic inscription at the center reveals them as a luti $b \bar{a} s h i^{10}$ and two märgirs (trainers of serpents). Next to this information the date appears on which the photograph was taken. The inscription on the right reveals the place where the photograph was taken (Akkāskhāne-ye Mobārake-ye Madrase-ye Majsus Nezām) and the inscription on the left reveals the name of the photographer (Dār al-Khalāfe-ye Nāseri Khān Ezzat Mohammad Hasan-e Qajar) as Mohammad Hassan Qajar. In the second image, a group of four musicians is depicted in front of the well-known Rezā Akkāsbāshi's backdrop with the Victorian house printed on it. Actually, all photographs by Rezā Akkāsbāshi are immediately recognizable by this backdrop and since the sitters are always Iranians, an odd and intriguing decontextualization of the subject with the atmosphere is also immediately noticeable. The inscription reveals the men as a group of musicians from Kashmir (the second part of the inscription is illegible). Notice that in this kind of images, the viewpoint of the photographer is also lower than normal. This points to the fact that the photographer could be kneeling also (or at least bending) on the floor and the camera would be much closer to the floor than when taking photographs of people standing up, such as in the next photograph (fig. 93), in which the Iranian photographer Ya'qub Akkāsbāshi from Tabriz is depicted, and we can notice that the level of his camera is much lower than the common one. Going back to the kneeling pose, sitting on the heels with the knees resting on the floor is also to be found in nineteenth-century photography in other countries in Asia, like in Japan (see figures 80 and 83 from the previous chapter) and India.

The four photographs that I have just discussed are only a few examples of the many of this kind to be found in nineteenth-century Iranian photography. We can also find many examples of photographs in which the 
person depicted is sitting on a chair. I would say that this change in pose is more a fashion in the photo studio, a direct influence of Western aesthetics, rather than a mirror of the social reality of the time. The uncomfortable and non-relaxed manner of several Iranian sitters shown in the photographs (see, for example, fig 94, where Anis al-Dowle, Nāser al-Din Shah's favorite, is depicted), seems to reinforce my hypothesis that the chair found its way into the Iranian studio earlier than into Iranian daily life (I will come back to this photograph later on in this section for further analysis). We can also see this in fig. 76, by Abd al-Qāsem ebn al-Nuri. This photograph was already analyzed in-depth in the previous chapter, especially regarding the inscriptions that are present on the emulsive surface of the photograph. Here the sitter is a mullah and is depicted seated in a chair in a photograph that is entirely reminiscent of the aesthetics and composition of Victorian studio photographs, in a rigid pose that contrasts with the more relaxed pose that we have seen in other images such as figures 55 and 75. The next portrait (fig. 95), taken by Rezā Akkāsbāshi, depicts a young man in the typical pose of the Qajar portraits of men holding a sword, sitting on a chair with a very self-conscious look, as was the case in the late Qajar portrait paintings of his ancestors. Actually the jeweled dagger, the studded belt with pendant and the Qajar hanging belt are all regalia and clothing present in the Qajar painting portraits as well. These are elements clearly inherited from the Qajar portraiture tradition and many such photographic portraits can be found (compare this portrait with figure 87). Notice the self-conscious look on the face of the young man, the raised eyebrow resulting in a quite proud pose. The calligraphic inscription below the portrait reveals the identity of the sitter as Jamin al-Dawle. As we have already seen in the previous section, Fath 'Ali Shah was responsible for the aesthetics and regalia used in Qajar painting portraiture and Nāser al-Din Shah played the same role but in the new medium of photography. He tried to show his power and that of his country through the photographs that were taken mostly by court photographers of him and his family. The photograph that we have just seen is a good example of this kind of court portraiture and we can see that it has a flavor of those kind of portraits painted in Fath Ali Shah's time. The sword and the conscious pose are two of the elements inherited from that painting tradition. Another good example is a hand-colored photograph of Nāser al-Din Shah (fig. 96, see full color section) taken and painted by the Italian photographer Luigi Montabone (d. 1877). He is wearing an astrakhan hat with a slanted top typical of the mid-Qajar period, decorated with the royal aigrette (jeqqe) and the clothes and especially the jewelry have been made obvious with the help of the colors. This image is a good example to illustrate the fact that the propagation of the Persian Royal Image was canalized not only by Iranian photographers working at court, but also by non-Iranian photographers related to the court. 
So these portraits display both elements from the Western portraiture tradition in photography (i.e. the Victorian model) and elements inherited from Qajar painting, resulting in what we can name a hybrid pose. The term hybrid gesticulation or pose, as the scholar David Efron has pointed out,

is used when the same individual may, if simultaneously exposed over a period of time to two or more gesturally different groups, adopt and combine certain gestural traits of both. (Efron 1972: 160)

So, a person that has been living for a long time in a foreign country and, therefore, has been exposed to different cultures, after some time will adopt some of the gestural and postural traits of her/his country of adoption and they will be present next to other poses and gestures typical of her/his own culture. The more different these two cultures would be, the more peculiar hybrid poses may appear. I would like to add that the fact that new furniture imported from the West is introduced into the lives, and into the photo studios, of people in so-called non-Western countries will lead to the appearance of new poses that will often be hybrid poses themselves. A very striking example is that of a person sitting on his heels or knees on a chair using the surface of the chair as if it were the floor. The pose is exactly the same, but the space where it appears has changed. Another peculiar example is that of climbing, squatting or kneeling on other pieces of studio furniture, like a balustrade or a column. In fig. 97, we can see a child who is sitting in a deep squat pose on a balustrade, in what seems to be a recreational reaction of the sitter to the absurd studio paraphernalia which seems to stress, even more, the absurdity of such imported studio furniture. Fig. 98 is also interesting, since most probably the photographer placed the flowerpot on the chair giving the chair a new use that was not originally intended by Europeans when they introduced the chair in the studio. Also in the work of European photographers active in Iran in the nineteenth century, we can track these kinds of hybrid images, like the photograph taken by the Italian photographer Montabone where the child is sitting on a chair but in a kneeling pose (fig. 99).

When we compare the photographs where the Iranian sitter is kneeling with those where the sitter is sitting, we can appreciate that the person depicted seems more relaxed in the ones with the traditional pose, resulting in a more natural pose. It appears to me that in the kneeling pose the hands of the sitter are more natural than when s/he is sitting on a chair or standing up. When they are sitting, the pose is very rigid: the legs lay heavy, one next to the other (no crossing of legs) and the hands lie quite still on each leg. Nevertheless, we can also find other kinds of hand poses, a direct influence of the typical portrait of the French photographer Nadar (18201910): one hand is placed under the jacket of the sitter giving him, 
somehow, a respectable appearance. In many photographs taken by Nāser al-Din Shah, this kind of pose is used. There is a parallel indigenous pose for the hands, also widely used in miniature painting and Qajar portraiture, in which one of them is placed under the belt.

In the following, I investigate if there are common elements used both in the Persian painting tradition and in nineteenth-century photography. I also study possible differences between the objects held by men and the objects held by women in photography as I have already done with painting in the previous section.

Flowers being held by men are a recurrent element to be found in nineteenth-century Iranian portrait photography. There are two kinds of portrait photographs that depict men holding flowers. The first are ordinary men holding flowers (see figs. 100 and 101), the second are mullahs or religious men (see fig. 102). In this kind of photographs the mullahs are normaly the ones who hold flowers in their hands, whereas the servants who are standing do not.

There is a third kind of image where men are depicted not holding the flowers but wearing them as part of their outfit! These men were jesters. Nāser al-Din Shah was fond of the company of jesters ${ }^{11}$ and there are many photographs of them in the Golestān Palace Library Photo-Archive. Many of these images depict jesters with funny, often ridiculous, ornamental elements that reveal their role as entertainers in Nāser al-Din Shah's court. Abd al-Qāsem Ghaffāri was a well-known jester at that time, whose head and shoulders are wrapped in flowers (see fig. 103). It seems that to decorate jesters with flowers was a favorite game among the Shah and his courtiers. Another image on this theme is the one that depicts A $\overline{g h a}$ Mohammad Khāje, eunuch of Nāser al-Din Shah's court and better known as Faqir al-Ghameh (see fig. 104). This image has more interesting elements in it. The first is the backdrop (it is the same, by the way, that was used in the previous photograph) that is clearly noticeable, the elegant chair that contrasts with the tile floor and the jester depicted on the photograph, who shows a contented pose and who wears quite a weird outfit. This seems to be a topic that was of interest only to Nāser al-Din Shah but that has no further connection to painting.

Many photographs of groups are organized around a small pond (e.g., figures 105 and 106). The use and function of those pools in photography may be related to their use and function in poetry and could then be explained by Schimmel's statement that

there are very few verses in the poetry of the greatest masters of Urdu, Turkish and Persian poetry that do not reflect the religious background of Islamic culture; it is, like the pools in the courtyards of the mosques, in which the grandeur of the huge building is mirrored, its beauty enhanced by the strange effects of tiny waves of 
verdure springing forth from the shallow water. (Schimmel 1975:

288)

This metaphoric element is probably well rooted in the Iranians' subconscious, with poetry and its images being so important to Iranians even today that its presence in photography as well could be easily understood.

Another interesting and recurrent element are pots of flowers in nineteenth-century photography, especially in Shiraz, in the studio paraphernalia, both outdoors and indoors. Shiraz, city of roses and nightingales, is an important city for poetry since some of the greatest Persian poets (such as Hafiz and Saadi) are buried there and their tombs have become shrines for Iranians. I find a stronger connection between miniature painting and photography in Shiraz, and therefore also between poetry and photography, than in other parts of Iran. The reason may be the special place of Shiraz in the Persian poetic tradition. We can see this in many images, such as the one presented here (fig. 107). In this photograph we can see a group of men, both religious and secular, kneeling, sitting or standing surrounded by many pots of flowers that are present even within the window frame next to two of the men depicted. The Iranian photographer from Shiraz Mirzā Habibollah Chehrehnegār (1896-1942), who was fond of using flowers and pots of flowers in his compositions, took this photograph. He was a son of Mirzā Fatollah Chehrehnegār (1877-1932). ${ }^{12}$ We already saw a photograph that depicts a child and a pot of flowers placed on the chair as part of the studio paraphernalia resulting in an interesting and different image (fig. 98). We will see further examples of this in chapter 5.

A recurrent element to be found in many photographs is the water pipe, which was simply a logical presence, being such an important part of Iranian daily life at that time. Other elements to be found with no other purpose than to give information about the person depicted are tasbih or books such as the Koran or of beloved poets. Some give us information about the person depicted through the pose and gesture without needing objects, like fig. 108, where a young man is depicted in the pose of the Muslim prayer, with hands opening up to the sky. Notice the small prayer carpet on the bottom left and the two books (most probably one Koran at least) and the Shi'a Muslim prayer's stone.

\section{Women in photography}

The topic of women is an interesting one and deserves some close attention and analysis. There is an interesting example to analyze, a full page of one of Nāser al-Din Shah's albums hosted in Golestān Palace Library, fig. 109. On this page we can see five photographs, all of them taken by Nāser alDin Shah himself, as well as some texts written under each image. The way that the photographs are arranged is quite interesting and gives us 
information about the structure and hierarchy of the imperial andarun or harem, in this case, Nāser al-Din Shah's harem and extensive family. In the center of the page a photograph of himself is placed, sitting on a chair and under it the text reads "my face". Circling this photograph, we can see three photographs of some of his wives: the one on the left side of the page is Turani, photographed ten days after her wedding, as we can read in the text written under the image; the photograph on the right side of the page depicts two women sitting on a bench, Bimesāl Khānum and Bigam Khānum as the text under them reveals. Under the frame of the page, we can also read that Nāser al-Din Shah has written, "my face at 51"; and there is more text that is illegible, at least for me. The last photograph is the one placed in the upper part of the page in which the eunuch Agha Mohammad Khājeh is depicted. It has been pasted into the album in a very strange way, the man rotated $90^{\circ}$ to the left. The reason for doing so is unclear to me at the moment; perhaps it is because it was the only way to fit this portrait on the page. Note that the poses of all the women are rather unnatural, sitting on chairs with legs crossed at the ankles, a pose that reminds us of those used when they sit cross-legged on the floor. It is also interesting to observe the way the hands are placed: the one on the right shows the woman with a hand placed on her heart (this means, according to the American scholar Carol M. Sparhawk in her article ContrastiveIdentification Feature of Persian Gesture ${ }^{13}$, "your servant". It is a widely used gesture among Iranians still today.) The other two photographs show the women with a pose that Nadar popularized, that of placing one hand on the chest under the jacket or shirt. On this single page, we can find an indigenous pose as well as a Western one. Note the dress of the women. As with court fashions in men's clothing, women's dress changed sometimes rather dramatically as the layers of long trousers shortened to a series of skirts, as noted by C.J. Wills, who worked in Persia from 1866 to 1881 as a doctor attached to the telegraph offices at Hamadan, Isfahan and Shiraz:

Their feet and legs were bare; their skirts were bouffes by a number of under-skirts such as are usually worn by the ballet on our operatic stage; but instead of these undergarments being white and gauzy, they were of silk and of all colors (Wills 1891: 50).

When taking into consideration the portrait photographs of women, we can immediately identify some elements borrowed from Qajar portraiture, not only in the pose of the woman depicted but also in the objects that she is holding. There are not many photographs of women to be found, when compared to the legacy of male portraiture photography that has reached our hands. Nāser al-Din Shah took photographs of most of his wives, most of them in formal poses, but also we can find others in more intimate 
poses. Since his photography was only meant to be seen by himself, it is of great interest, from both a historical and an aesthetic point of view. The existence of these photographs provides an interesting bridge between the perception and the reality of harems and that of Nāser al-Din Shah in particular. But what is especially revealing and important to point out is that this reality, like those of the Orientalist painters and photographers, is maybe staged too. Nevertheless, the actors are real and the photographer is himself the master of the harem. The reality depicted is a staged reality for the purpose of that picture alone and for the pleasure of the photographer alone. Not many of these images have been printed, but one of them is especially appealing as far as the pose is concerned: that of Anis al-Dowle, one of his favorites, in the reclining odalisque-like pose (fig. 94). This reclining pose, very much favored by Orientalist painters, is used here by Nāser al-Din Shah in the form of some kind of astonishing mirror representation in which this native photographer seems to represent his own people in the way that the Westerners perceive them. ${ }^{14}$ This phenomenon has been named "self-orientalizing" by the Iranian scholar "Ali Behdad, who says "it is the practice of seeing and representing oneself as Europe's Other" (Behdad 2001: 148). Nevertheless, it is important to keep in mind that the photographs of women analyzed here were taken exclusively by Nāser al-Din Shah. In this sense, I disagree with Behdad's conclusion further in his paper regarding this topic. He states that,

there is an "indigenous" tradition of photography in Iran, but this tradition, as I will discuss later, is not organic. By this I mean, it is indebted to, and mimetic of, Orientalism's aesthetic values and ideological assumptions more than to its Iranian and Islamic traditions. (Behdad 2001: 145)

This may be so when analyzing the work of Nāser al-Din Shah (and only in a couple of ambiguous photographs), but it is not so clear when taking into consideration the work of other court photographers or bazaar photographers who were more exposed to their Iranian visual traditions.

I have never seen printed images of fully naked Iranian women taken by Iranian photographers in books, but I have found in different books several printed photographs of women with transparent blouses that clearly reveal their breasts and bellies. Most of these images of women present a hybrid approach, usually represented by the chair in which she is sitting. In clear contrast to this, in all of the Qajar portrait paintings that I have studied, the women are either kneeling on the floor or standing. I have not found any chairs in those paintings. See, for instance, fig. 110, which is actually an album page where two photographs of women have been placed together. The two women are wives of Nāser al-Din Shah whom he photographed himself. I have seen many of these images of his wives that are placed in 
different albums kept at the Golestān Palace Library. All the women sit in the same richly carved rococo wooden chair and are photographed in exactly the same way, frontally and hieraticly. Often the feet are cut out, as in these two photographs, and there is not too much space above their heads. The woman sitting on the left is holding a sitar and reminds us of the typical Qajar painting portraits of women playing instruments (see fig. 90). In the photograph next to the previous one, the woman is depicted with a transparent blouse that clearly reveals her breasts and her belly (see the woman on the right side of fig. 110). This kind of chemise is the same style as the ones used in some Qajar painting portraits (see fig. 90), but the long thick trousers have been changed by the tutu that became fashionable in Nāser al-Din Shah's harem at a later stage. As stated by Najmabadi,

a figure that appears repeatedly in Qajar art is the bare-breasted woman. Allthough nude females as well as females whose breasts are visible through sheer clothing do appear in Safavid and Zand art, the bare-breasted woman, or woman with breasts emphatically displayed through style of dress or association with fetishistic objects, seem to be a heavily accented theme in Qajar painting. (Najmabadi 1998: 77)

One interesting detail is that in all the photographs of women that I have found, they always wear socks and shoes, whereas in the paintings the women are barefoot and the soles of their feet are painted with henna. Notice that the normally joined eyebrows that many of the women were fond of in this case presents a variant that shows two thick and long eyebrows with a black painted point between them. This might be a special fashion, but I have no factual information regarding this. Above both photographs there are two calligraphic inscriptions that reveal the identity of the women: Fateme Sultān Tārchi (Fatimeh The Tar Player) on the left and Zahrā Sultān on the right. When the woman depicted passed away, there was always a calligraphic inscription on the left side of her image that recorded this fact: mord, the Persian word for dead.

When women are holding objects, these are usually musical instruments. I have not found women holding books or religious objects (which does not mean that they do not exist! I have just not found them to date). I have not found photographs of women holding flowers either!

The Western photographer's representation of Iranian women was quite different from the Iranian one. It is interesting that the German photographer Ernst Hoeltzer (1855-1939) was concerned about offering an image of Iran based on real life, on observation from daily life; many of the photographs he staged in his studio involve images in which the people sit on the floor while eating, singing or playing instruments. A good example is the portrait of a group of women eating (fig. 111). (Notice that in this case 
the plane of the photographer has been lowered as well.) At the other end of the spectrum, we find the commercial (and very talented) photographer from Tiflis, Antoin Sevruguin (late 1830s-1933), who stressed the exotic side of this culture (but who also produced a remarkable corpus of photographs with an ethnographical approach), with images like fig. 112, which is kept at the Museum of Ethnology in Leiden. Next to the photograph there is a caption: Persian toilet. Also taken by Sevruguin is the portrait of an Iranian woman (fig. 113), depicted naked with her hand resting on a chair. These kinds of images of Middle Eastern women were quite usual in the second half of the nineteenth century and were especially constructed by Western photographers. The women who posed for such images were normally prostitutes, as the Algerian writer Malek Alloula states in The Colonial Harem. Referring to photography in North Africa he explains that

the photographer used paid models that he recruited almost exclusively on the margins of the society in which loss of social position, in the wake of the conquest and the subsequent overturning of traditional structures, affects men as well as women (invariably propelling the latter toward prostitution). (Alloula 1986: 17)

Graham-Brown maintains that,

many of these images of women, which hardened into clichés, were drawn from a pre-existing repertoire of themes already established by a genre of Orientalist painting which had developed, particularly in France and Germany, from the first half of the nineteenth century. (Graham-Brown 1988: 40)

Graham-Brown states further that,

in subject matter and construction, albeit not in aesthetic intention, it might be argued that Orientalist painting had a considerable influence on nineteenth-century studio photography of the Middle East. (Graham-Brown 1988: 40)

I will return to this and investigate this topic more in-depth in chapter 5 concerned with Western influences on nineteenth-century Iranian photography. A few examples from Iranian and Western photographers have shown us that it often happens that the analysis of images from the nineteenth century reveals more about the state of mind of the photographers in particular and society in general (biased perception of reality and the consequent biased representation of that reality, both by Western and Iranian photographers) than the objective reality of the social mesh or the photographs and the people represented on them. 
To summarize, in this chapter I have investigated photographs and paintings through one of their cultural components: the pose of the sitter and, as a part of the pose, the objects s/he holds. The analysis of the pose of the sitter revealed once again a cultural conditioning in the process of taking and producing photographs. Both the photographer and the sitter constructed photographs conditioned by the image that they wanted to give of themselves and they achieve that through the use of particular objects.

There is a clear influence of the pose used in the Persian painting tradition on the pose of nineteenth-century Iranian studio photography: the kneeling pose, the cushion behind the sitter's back, the pose of the hands, the objects that the sitter is holding, etc. We can find the same evolutionary phenomenon of the pose in the photographer's studio as we found in the painters' studio: rising from the floor to the chair level. Of course, in the case of photography, the process happens in a shorter period of time than in the case of painting. The fact that the sitter leaves the floor to climb on a chair seems to be an influence of the Western photo-studio's mode. There are hybrid poses to be found due to the double exposure of the sitter and photographer to the traditional Persian culture and the (new) Western influence. Such hybrid poses are found widely among Iranian photographers. The photographs of women were mostly taken by Nāser al-Din Shah and present them in a respectful mode, all sitting on highly decorated and elaborated chairs. Therefore, the influence of the Western sitting pose is especially interesting in the case of photographs of women and contrasts with the lack of chairs in Qajar painting portraiture of women. Indeed, the pose not only was used to stress social status, but also to express fantasy and ideals as well. The portrait of the women in painting in an idealized form is a clear indication of this claim. Portraits of men are in a more stern and serious pose than those of the women, who are posed in more inclined, and fanciful, or even in dancing or acrobatic poses. This hints at a bitter truth that men were real while women mostly were anonymous or even none-existing.

As far as the objects are concerned, the traditionally depicted objects on Persian miniature painting and Qajar portraiture (tasbih, flowers, water pipe, swords, cushion, etc) are also to be found in nineteenth-century Iranian photography. The women would normally hold musical instruments and the men religious objects, swords, flowers or water pipes.

\section{Notes}

1 Duchenne was a physician at the Paris hospital La Salpetriére and treated people suffering from epilepsy, neurological problems and insanity. His Mécanisme de la physionomie humaine (The Mechanism of Human Physiognomy), published in 1862, was accompanied by an atlas with 84 photographs of human subjects whose facial muscles were stimulated by electric currents. 
2 His L'iconographie photographique de La Salpetrière (Photographic Iconography of the Salpetrière Hospital) was a three-volume work that contained photographs of hysterics, published in 1880 .

3 See: Wylie, L. (1977), Beaux Gestes: A Guide to French Body Talk. Cambridge: The Undergraduate Press; Monahan, B. (1983), A Dictionary of Russian Gestures. New Jersey: Hermitage; Diadori, P. (1900), Senza Parole. 100 Gesti degli Italiani. Rome: Bonacci.

4 See: Kendon 2004. Adam Kendom is a leading authority on the subject and is the editor of the journal Gesture, an important referent to everybody interested in human communication.

5 As remarked by Diba, this attribution was first proposed by Robinson 1967: 336.

6 This page is an illustration of a chapter of Ferdowsi's Shäh-nāme. For an interesting analysis, see Sims 2002: 319.

7 Schimmel 1978.

8 De Vitray-Meyerovitch 1972.

9 For a good insight into this topic, see: Najmabadi, A. (1998), "Reading for Gender through Qajar Painting", in Diba 1998: 76-89.

10 Luti Bashi is a group of men that belong to a Zurkhāne, literally, the house of force. Members of the Zurkhāne followed a strict code of conduct. Imam Ali, the cousin and son-in-law of the Prophet, together with Rustam, the legendary pre-Islamic Iranian Hero, were inspirational figures for its members.

11 For an interesting research about the role of jesters in Nāser al-Din Shah's society, see: Martin 2006.

12 An Iranian photographer born in Shiraz and member of a family of several generations of photographers. The first photographer of this family was Mirzā Hassan Akkāsbashi (1854-1916). For a very good selection of his photographs and other family members and also biographical information, see: Sane 1990.

13 Sparhawk 1981: 449.

14 The word odalisque appears in a French form and originates from the Turkish odalik, meaning "chambermaid". During the nineteenth century odalisques became common fantasy figures in Orientalist painting. 


\section{ARRANGEMENT OF SPACE}

For Sandra Garabello and Ana Briongos

The function of "space" in Persian traditional painting, greatly influenced by Persian mystic culture, may have lent itself to nineteenth-century Iranian photography. I will devote this chapter to explore the understanding of space in Persian painting and the influence that this may have had on nineteenth-century Iranian photography, if at all. I will analyze the formal use of space both in Persian miniature painting and photography. The main research issues related to the arrangement of the space in Persian miniature painting are topics such as the non-linear perspective approach or the isometrical perspective (also called parallel perspective) to project a threedimensional space onto a two-dimensional picture plane; the existence of multiple centers of attention (diffuse composition); the grid layout structure; and the vertical composition/vertical perspective. I will introduce the kinds of compositions that can be defined on the basis of the arrangement of the elements in the pictorial or photographic space, and explore the ones that may be peculiar to nineteenth-century Iranian photography as influenced by the Persian painting tradition.

\subsection{Spatial characteristics of Persian miniature painting}

Space is perceived, understood, represented and inhabited in different ways in different cultures. This observation follows the same line of thought presented in the previous chapters of my book, and defends that artistic representation and composition is culture conditioned.

As Helen Westgeest states in her book Zen in the Fifties. Interaction in Art Between East and West, "Kitaro Nishida (1870-1945) ${ }^{1}$ described the traditional Japanese way of suggesting space as follows: 'The space in art from the Far East is not the space facing the self, but the space in which the self is situated" (Westgeest 1998: 20). Further, she remarks that "the Japanese artist Hajime Shimoyama confirmed this in an interview with the comment that space for Western artists exists primarily in front of him, whereas for the Japanese artist space surrounds him" (Westgeest 1998: 25). This difference, says Westgeest,

would seem to be reflected in the terms observation with respect to Western artists, and participation with respect to Japanese artists. 
She remarks also that, in the words of the French scholar of cultural geography Augustin Berque, the opposition between subject and object, between self and non-self, appears only at a certain level, while at another level both terms merge. The surroundings are, in his opinion even more important than the subject, a phenomenon, which he calls contextualism. He contrasts this with the Western approach, which he defines as: "This culture less easily assimilates itself to nature because, fundamentally, the subject's spontaneous self-definition, or particularity, acts in opposition to the definition, or naturalness, of its environment"” (Westgeest 1998: 25).

The analysis that I will present here points to the fact that Iranians also perceive space in a more active way, meaning here, that individuals become part of the whole picture, the whole surrounding space. I will come back to this later while analyzing photographs. The way that Iranian people are presented in nineteenth-century photographs of big groups of people depicted next to buildings is quite peculiar: people invade the whole structure of the building as we shall see later in this chapter, becoming part of the building's structure.

When looking at paintings and photographs made by artists from different cultures, we realize that there is a different understanding of space, a different treatment of photographic or pictorial space. If we take a representative series of Persian book paintings from a particular school and observe them with analytical attention, then it is straightforward to conclude that they obey certain conventions governing the depiction of space. The art of Persian miniature painting is an interesting historical manifestation of this fact. It is impossible to specify spatial characteristics, which are applicable to all Persian miniature paintings, since there are many different schools with their own peculiarities. However, there are a number of recurring aspects regarding the understanding of the space. To be sure, many of these spatial conventions differ greatly from those followed in Western painting, especially after the Italian Renaissance. In Western works since the Renaissance, a clear composition with one center of attention dominates, whereas in Oriental traditional miniature paintings (Indian, Iranian, Chinese, etc.) we clearly find different centers of attention. That is the first difference that we can notice and that is related to the grid structure of the Oriental miniatures.

The second topic that I will take into consideration is the isometric perspective used in Persian miniature paintings (inherited most probably from the Chinese) in contrast to the Western linear perspective. The latter issue deals with vertical composition and vertical perspective. These spatial elements actually can be grouped in two clusters: the first one being concerned with the fragmentation of the space into units (diffuse composition/ grid layout structure) and the second one being concerned with methods of 
suggesting perspective. I will devote some time to each one of these three sub-sections.

\section{Diffuse and scanned compositions/grid layout structure}

The French art historian Lucien Rudrauf has made a systematic study of compositional patterns. This study is sixty years old, but I still find it applicable as far as the definitions are concerned. He distinguishes two families of plastic composition: diffuse and scanned. However, I do not quite agree with his idea that the scanned composition is more interesting (or developed) from an aesthetic point of view. He calls that type of composition diffuse which, without being unrhythmic, does not follow any hierarchical principle in the distribution of its elements. In Rudrauf's words,

compositions of this kind are often made of a great number of details, none of which is marked with a predominant accent. The eye is not guided to go from one object to another. Attention scatters itself without hindrance over all parts of the plane, with nothing to lead it imperiously back to the center of radiation. Such pictures can be freely cut up into sections capable of having an independent life. Diffuse compositions ignore, intentionally or not, the effect of lighting which produces accents and contrasts incompatible with its nature. These kinds of compositions are often, if not always, freed from the laws of perspective (of linear perspective, as I emphasize). (Rudrauf 1949: 329)

The Persian miniature, as we shall see later in this chapter, offers typical examples of such diffuse composition. In Occidental art this is an exceptional phenomenon, most often encountered in earlier epochs, before the Italian Renaissance. But it does not disappear in the more evolved stage of spatial realism. The Netherlandish painters Jerome Bosch (1453-1516) and Pieter Brueghel the Elder (1525-1569) preferred it. In the words of Rudrauf, "its theoretical interest lies, in part, in the position of its essential characteristics in those of the other large class of plastic compositions: scanned" (Rudrauf 1949: 329). Rudrauf calls that type of composition scanned,

which spreads out before our eyes according to a spatial rhythm which is strongly hierarchical, allowing principal and secondary accents, marked with variable strength but always clearly perceptible. (Rudrauf 1949: 329)

In sum, there are two different kinds of composition, diffuse and scanned, the first being relevant for my study since it is the one that is present in 
Persian miniature painting and also, as I shall show with examples, achieved in nineteenth-century Iranian photography. Both mediums display a composition that presents multiple centers of attention.

During an interview with Westgeest ${ }^{2}$, we viewed some Persian miniature paintings and discussed the arrangement of the space in Persian miniatures and its possible influence on nineteenth-century Iranian photographs. She remarked on the resemblance of the formal structure of the miniatures and that of the grid that became popular at the beginning of the twentieth century in European art. The multiple centers of attention characteristic of Persian miniatures are supported or framed by a structure that resembles the grid layout structure, this late concept being a Western contemporary concept. I will briefly introduce this concept to further analyze it in Persian miniatures.

In the early part of the last century there began to appear in France and shortly after in Russia and Holland a structure that has remained emblematic of the modernist ambition within the visual arts ever since. As art critic Rosalind Krauss mentions, with the

surfacing [of] the pre-War cubist painting and [it] subsequently becoming even more stringent and manifest, the grid announces, among other things, modern art's will to silence its hostility to literature, to narrative, to discourse (Krauss 1979: 51).

Krauss continues that there are two ways in which the grid functions to declare the modernity of modern art. One is spatial; the other is temporal.

In the spatial sense, the grid states the absolute autonomy of the realm of art. Flattened, geometricized, ordered, it is anti-natural, anti-mimetic, anti-real. It is what art looks like when it turns its back on nature. In the flatness that results from its coordinates, the grid is the means of crowding out the dimensions of the real and replacing them with the lateral spread of a single surface. In the over-all regularity of its organization, it is the result not of imitation, but of aesthetic decree. Insofar as its order is that of pure relationship, the grid is a way of abrogating the claims of natural objects to have an order particular to themselves; the relationships in the aesthetic field are shown by the grid to be sui generis and, with respect to natural objects, to be both prior and final. The grid declares the space of art to be at once autonomous and autotelic. In the temporal dimension, the grid is an emblem of modernity by just being that: the form that is ubiquitous in the art of our century, while appearing nowhere at all, in the art of the last one. In that great set of chain reactions by which modernism was born out of the efforts of the nineteenth century, one final shift resulted in breaking the chain. By "discovering" 
the grid, Cubism, De Stijl, Mondrian, Malevich, etc., landed in a place that was out of reach of everything that went before. This is to say, they landed in the present, and everything else was declared to be the past (Krauss 1978: 3).

Krauss goes on to point out that,

one has to travel a long way back into the history of art to find previous examples of grids. One has to go to the fifteenth and sixteenth centuries, to treatises on perspective and to those exquisite studies by Ucello, Leonardo da Vinci or Dürer, where the perspective lattice is inscribed in the depicted world as the armature of its organization. But perspective studies are not really early instances of grids. Perspective was, after all, regarded as the science of the real for a long period of time, not the mode of withdrawal from it.

Perspective was the demonstration of the way reality and its representation could be mapped onto one another, the way the painted image and its real-world referent did in fact relate to one another the first being a form of knowledge about the second. Everything about the grid opposes that relationship, cuts it off from the very beginning. Unlike perspective, the grid does not map the space of a room or a landscape or a group of figures onto the surface of a painting. Indeed, if it maps anything, it maps the surface of the painting itself. (Krauss 1978: 4)

The grid has played a central role in the development and consolidation of the modern movement in twentieth-century graphic design, according to the graphic designer historian Jack H. Williamson. ${ }^{3}$ His article "The Grid: History, Use and Meaning", is an interesting analysis of the evolution of the grid in Western art. The article starts with the late medieval grid followed by the Renaissance and Cartesian grids, then the modern grid and finishes with the post-modern grid. In the words of Williamson,

for practical purposes, the process may be said to begin with Paul Cézanne's initial move away from Renaissance illusionism toward the abstraction and geometricization of nature and an emphasis on the flat field of the picture plane. This impulse continues through the faceting of the picture plane by synthetic cubism to produce an overall effect, and it peaks when Piet Mondrian (1872-1944) takes up the pictorial grid of synthetic cubism to explore and purify it in virtual isolation from other pictorial elements. Under cubism's influence, Mondrian's naturalistic subject matter became progressively abstracted and continued to employ vertical and horizontal bars, sometimes colored and usually not touching, on a white field. Often 
these bars appear to continue off the edge of the canvas, suggesting that the field extends infinitely in all directions although the viewer sees only that portion visible within the "window" of the canvas. (Williamson 1986: 22)

This is also the sensation that may be produced in the viewer by many Persian miniatures, like the ones that will be analyzed here, since they all share this sense that the scene goes on in all directions and off the page.

The grid shares, only structurally, the non-linear perspective approach of the Persian miniature painting tradition and its characteristics of non-realistic representation of the real world. There is an interesting corpus of literature on the "grid layout" for Persian miniatures, much of it determined by the text. It is interesting to note that these authors do not use the term "grid" to refer to this phenomenon. The grid structure that underlies every miniature is made more obvious through the way in which architecture has been used to divide space into blocks, as we will see with examples in the next section. The first attempt to make a rigorous study of the grid layout was done in the 1930s by co-authors Emmy Wellesz and Kurt Blauensteiner, in "Illustrationen zur einer Geschichte Timurs". ${ }^{4}$ They arrived at interesting conclusions after analyzing a manuscript of the Zafar$n \bar{a} m e^{5}$ dated 953 (1546) and designated as "The Praetorious Codex". The structural base of composition is best understood in the form of a diagram that was done by these two authors after their study (fig. 114). The Islamic art historian Grace Dunham Guest also did a classical and fundamental study in the 1940s on the use of space and composition in Persian miniatures, "Shiraz Painting in the Sixteenth Century". ${ }^{6}$ She conducted an indepth analysis of the "inner order" and excellence in composition found in the miniatures of the manuscript volume of the Khamse of Nezāmi ${ }^{7}$ held at the Freer and Sackler Gallery of Art in Washington. She explained that this inner order is based on a mathematically-controlled plotting of the page design as a whole. She states that the complete Shiraz canon of proportion, then, which evolved in the third decade of the sixteenth century appears in the diagram illustrated in figure 115. Dunham explains that,

greater liberties were taken with the "canon" towards the end of the [sixteenth] century when the "inner axes" were sometimes abandoned and the upright composition based on divisions of thirds adopted. (figure 116) (Dunham 1949)

Another, more recent, fundamental study of the understanding of space in Persian miniature painting was written in the 1970s by the Iranian archeologist and research director at the CNRS (Paris) Chahryar Adle, "Recherche sur le module at le tracé correcteur dans la miniature orientale". ${ }^{8}$ In this study he thoroughly analyzes some miniatures and draws a schema of 
designs for them, like the modular composition and "traces correcteurs" (fig. 117) of the scene of Shah Abbās attacking the Uzbek army from Fotuhät-e Hamāyun, from the school of Shiraz. Note the position of the hand of the man right in the center of the image, the vertical divisions of the page in three vertical identical parts regulated by the length of the text. This study illustrates precisely this peculiar understanding of the space in Persian painting.

\section{Linear perspective versus isometrical projection}

Isometry (like linear perspective) is a graphic method to project threedimensional space on a two-dimensional picture plane. With an isometrical perspective, the length and width of a cube are placed on the horizontal line of projection with an angle of 30 degrees (see fig. 118).

The three dimensions of a cube are projected onto the picture plane without optical distortion. Height, width and length are true to scale; they are rendered in equal measures. To be more precise, measurements do not change, but optically they distort: there are no $90^{\circ}$ corners (squares become rombus). This is different from linear perspective, in which edges that recede from the viewer are drawn shorter to stimulate the optical effect of things looking smaller in the distance. Because things do not get smaller in the distance in isometrical perspective, parallel lines remain parallel. The projection of three-dimensional space onto the two dimensional picture plane is a problem that has roots far back in history. In Europe, the problem was tackled by Renaissance artists such as Filippo Brunelleschi (1377-1446) and Leon Battista Alberti (1404-1472). Journalist and expert in Asian technology Jan Krikke notes that traditionally European art was based on optical representation. ${ }^{9}$ This method of representing linear perspective dominated European art until it was challenged in the twentieth century by the Cubists, who interpreted reality by juxtaposing several viewpoints on a single canvas. The discovery of the vanishing point, which means that the lines of projection meet at an imaginary point on the horizon, resulted in linear perspective: a perspective that is achieved by receding to the vanishing point. Linear perspective tries to achieve visual realism in paintings of three-dimensional environments. But not only in Europe a system to project space on the two-dimensional picture plane was developed. In China, axonometry was developed, which unlike linear perspective is not based on optical principles. In axonometry there is no vanishing point and, therefore, no optical distortion (see fig. 119, an illustration of the difference between axonometry as it is used in Chinese painting [left $]$ and linear perspective). ${ }^{10}$

In Chinese and Japanese painting, we can find examples of building interiors in which its structural elements, like pillars, will remain parallel as they are in reality and their size and geometry remains constant, even if at 
first sight observers may perceive them as divergent. The key features of axonometry are its high vantage point and the parallel lines of projection in the three principal directions: lines that are parallel in the three-dimensional space remain parallel in the two dimensional picture, in contrast to linear perspective in which lines along the z-axis in the three-dimensional space collapse to a single vanishing point at the horizon in the two-dimensional picture. Another characteristic of this kind of perspective is that objects that are distant have the same size as objects that are near; objects do not get smaller as they move away from the viewer. Axonometry was introduced to Europe in the seventeenth century by Jesuits returning from China, Krikke mentions. This scholar continues,

however, the wider acceptance of axonometry had to wait until it was given a mathematical foundation, by William Farish who provided axonometry with its geometrical basis. He formulated isometry, which means "equal measures" because the same scale is used for height, width and depth. (Krikke 1996)

An interesting book by the German art historian Hans Belting, Florenz und Bagdad. Eine westöstliche Geschichte des Blicks, offers a well documented and argumentative study of the Arabic origins of the Western linear perspective in art and constitutes a comparative study of the way of looking in the West and in the Islamic world. He shows differences and similitudes between the way of looking and thinking in both worlds. As Belting states,

Die heutige Globalisierung der Perspektive, die in dem westlichen Patent der weltweiten Medien TV und Presse Unterstützung findet, hat in der Kolonisation anderer Erdteile wie auch in ihrer Missionerung für das Christentum eine erstaunlich lange Vorgeschichte. In diesem gewaltsamen Export wurde die Perspective anderen Kulturen gegen deren eigene Sehgewohnheiten förmlich aufgezwungen. (Belting 2008: 54)

As observed by the art historian Peter Owen,

the same perspective system was used by Byzantine, Islamic, Chinese, Indian, and Persian artists, and can also be seen in early periods of Assyrian and Egyptian art and European Medieval painting. Children and "naïve" or outsider artists also rely on this system to express three-dimensional form. (Owen 1970: 204)

As noted by Westgeest ${ }^{11}$, this system of projection of three-dimensional space onto the two-dimensional picture plane was used in Persian 
miniature painting as well. I will come back to this topic when I undertake the visual analysis of those miniatures further below in this chapter.

\section{Vertical compositions/vertical perspective}

Around the fourteenth century the Shiraz School of miniature painting introduced a new system of vertical perspective, in which figures are shown one over the other, overlapping, and where such things as ponds and carpets appear as flat on the page. ${ }^{12}$ In Humay and Humayan Meeting in the Garden $^{13}$ (fig. 120, see full color section), we can see this way of placing the figures one over the other in this miniature that depicts two lovers who meet at night in a luxurious and enclosed garden. In this kind of vertical perspective, the objects most distant from the spectator are placed at the top; those closest at the bottom. After analyzing Persian miniatures, it seems that there is a tendency to use this kind of vertical perspective from the late fourteenth century onwards.

On the other hand, layering or vertical composition in the arrangement of the sitters in the pictorial space, has been used by several Persian painting schools. A well-known example of this is The Court of Fath 'Ali Shah, painted by an unknown artist around 1815 (fig. 121, see full color section). It is an image in miniature scale, which evokes the monumental imperial enthronement scenes. The watercolor is one of a series of reduced copies of life-size wall paintings in the Negarestan palace outside of Tehran, as stated by Diba. She argues further that

the original wall paintings represented an imaginary New Year's reception at the court of the monarch. The murals were completed in 1812-13 for the reception hall of the palace, by a team of artists led by 'Abdullah Khān. The copies (undated and unsigned, and executed in opaque watercolor, oil, and engraving) were produced sometime between the completion of the mural in 1812-13 and 1834, the year of Fath 'Ali Shah's death. (Diba 1998: 174)

The central image depicts Fath 'Ali Shah enthroned with twelve of his sons. ${ }^{14}$ Fath 'Ali Shah sits on an impressive jeweled throne with a sword on his lap and a water pipe in his hand. As Diba explains, his sons are all depicted standing (a symbol of respect) with their arms crossed. In the lower section ambassadors from France, Great Britain, Russia, the Ottoman Empire and the kingdoms of Sind and Arabia are depicted in meticulous detail. 


\subsection{The use of space in Persian miniature painting}

Having defined the different types of spatial composition, I will analyze a selected group of Persian miniatures that show all or some of the three spatial elements that I have just introduced and defined above.

One of the miniatures in which we can more clearly notice the isometrical perspective used to suggest the three-dimensional space, is Nighttime in a Palace (fig. 122, see full color section). We can notice that all lines remain parallel in the three dimensions of the space, not receding to a vanishing point, and all the figures depicted in this painting have the same size. The vertical composition here only seems to reinforce the suggestion of a three-dimensional space by isometrical perspective. In this dense image of urban life in sixteenth-century Iran, all kinds of people from different social and economic classes and ages are depicted, all engaged in different activities. In the bottom left corner of the painting, there is a group of male musicians playing different instruments. Right above them, a prince hosts a reception for noblemen on a tiled blue terrace. Notice the three servants bringing fruits and cones of sugar. There is also a group of women sitting on a balcony in the upper left part of the image and observing what is happening on the terrace while listening to the music being played by the musicians. Candles, oil lamps and other lighting sources are spread all over the space in the private houses, the markets (see an active market scene right in the center of the painting) and the mosque (see the right top corner). This is a fascinating painting where many different events are happening simultaneously in multiple centers of attention and with a narrative that gives the image a temporal and spatial dimension at the same time. The grid layout structure is also evident. The apparent lack of compositional organization in this picture is remarkable. Instead it appears to be a series of urban and genre-like architectural boxes comfortably fitted together.

Here it is important to note that the majority of the Persian miniatures that I have seen during this research are vertical. In this particular painting, it is especially clear that there is a combination of two spatial strategies to give the painting an alternative way of suggesting perspective: isometrical and vertical perspective. In the vertical perspective, the objects most distant from the viewer are placed at the top, whereas the objects closest to the viewer are placed at the bottom. This combination of isometrical and vertical perspectives is typical of Persian miniature painting and I have not found it, for instance, in Japanese or Chinese painting. Actually, it is relevant in order to understand the difference in the use of isometrical perspective in these countries that the origin of axonometry in China was found in the Chinese scroll paintings. A typical scroll painting has a size of approximately $40 \mathrm{cms}$ high by several meters wide. Thiadmer Riemersma explains that, 
for these scroll paintings, the Chinese painters needed a perspective that had no explicit vanishing points; every scene of the scroll painting would be seen individually, and a vanishing point that lies outside the viewpoint creates a disoriented view of the scene. The Chinese painters solved the problem by drawing lines along the zaxis as parallel lines in the scroll painting. This has the effect of placing the horizon at an imaginary line high above the painting. The axonometric projection is a technical term for a group of perspectives to which Chinese parallel perspective also belongs.

(Riemersma 2001: 3)

This is an important difference between the arrangement of the space and use of isometrical perspective used in China and Japan (horizontal format) and introduced here in contrast to Iran (vertical format). Notice that Japan also has kakemono (hanging vertical scroll) as opposed to makimono which is meant to be unrolled laterally on a flat surface. The kakemono is intended to be hung against a wall as part of the interior decoration and lacks, due to its format, the isometric perspective approach that was shown in the horizontal scrolls. Interestingly, what both pictorial traditions share and what makes them different from a Western spatial approach in painting, is that in Oriental painting the eyes scan parallel to the surface instead of looking from foreground to background as in the Western approach.

Wedding Celebration of Prince Homāy and Princess Homāyun (fig. 123, see full color section) painted by Joneyd Naqqāsh Sultāni in 1396, is another example where we find several of the spatial elements introduced above. It is an important work, since it plays an important role on the topic of signatures and paintings treated in chapter 2 . As noted by Blair,

the window-grille above the princess's head (the one sitting on her bed at the left side of the image), bears the signature of Junayad, "the royal painter", the first unquestionably genuine signature in Persian manuscript painting. (Blair \& Bloom 1994: 33)

Here the vertical perspective used to suggest three-dimensional space is again evident: the way in which the figures have been arranged to give the impression that the ones placed at the bottom are closest to the observer, whereas the ones placed at the top are most distant. In this case, the princess is the one that seems to be furthest from our view, inside of her room and sitting on her bed. In the words of Grabar, "a fascinating composition with dominant red colors in which all the episodes of a wedding, from sexual consummation to dancing, are either depicted or symbolized" (Grabar 2000: 55). Blair tells us that, 
the depiction of architecture is particularly elaborate, with geometric tile dadoes, floral arabesque archways, compartment carpets, and carved plaster grilles displayed in a dazzling array of brilliant blues, oranges and reds. This world of eternal lyricism in which flowers bloom and birds sing forever is one of the most characteristic features of Persian manuscript painting of the following century. (Blair 1994: 33)

The most interesting study for my own research that I have found on the understanding and use of space in Persian miniature painting is "The Use of Space in Timurid Painting" by the Islamic art historian Robert Hillenbrand. He focuses his study on four specific areas where the spatial understanding of space in Persian miniature painting is at its most intense: architecture, the preference for solid blocks of color or form, the margin and the use of empty space. I will just refer to the first two aspects, since they are the ones relevant for my own analysis of nineteenth-century Iranian photographs. In his words, "most strikingly of all, Timurid painting learned to suggest an architectural framework rather than to display it" (Hillenbrand 1992: 77). This idea can be clearly appreciated in the next miniature, the Shāh-name (The Book of the Kings) ${ }^{15}$ scene Ardashir and his slave-girl Golnār, which he analyzed. He points out, "it is the difference in plane within the architecture which helps structure the picture and above all integrate it with the text". The vertical divisions of the architecture reinforce those of the text columns, and the blocks of color operate in harmony with that aim. In this case, it is important to note that it is the choice of architectural division that has placed considerable emphasis on the sleeping personages. This element is also found at times in nineteenthcentury Iranian photography, text framing or surrounding the photograph. Another example of this kind of architectural arrangement is to be found in the Nezāmi's British Library Khamse scene Hārun al-Rashid in a Bathouse (fig. 124, see full color section). This miniature constitutes a good example of what a public bath at that time was like, where even the caliph leaves his own crown in a cupboard in the room where the men get undressed. This miniature is interesting as well because it shows a different organization of the space, as remarked by Grabar: "simple brick walls have replaced richly colorful decorated ones, and all the bathhouse employees are shown in their work clothes" (Grabar 2000: 115) .

In the classic study by D. H. Zain, Formal Values in Timurid painting, the author includes numerous schema of design that clearly show the grid layout and block schema that I am concerned with regarding Persian miniatures. Zain's work was brought to my attention reading Hillenbrand's article on the uses of space in Timurid painting. Three of the figures shown in Zain's study are design schemas of miniatures that I have selected for this chapter. One of them (fig. 125) is the schema of design of the 
miniature that I have presented. We can also appreciate here the isometric perspective that is clearly recognizable by the parallel lines in the z-axis that do not recede towards a vanishing point.

The most used contemporary fashion for composing an image on several levels is often reflected on the architectural forms themselves and those forms would allow many stories to happen at the same time, implying depth both in form and meaning. As Hillenbrand stated, "a more dramatic version of the same idea is found in the sharp zigzag movement of successive flights of stairs that are sometimes used in miniatures" (Hillenbrand 1992: 78). This is especially clear in The Seduction of Yusuf, the celebrated scene of Yusuf pursued by Zoleykā in the Cairo Saadi's ${ }^{16}$ Bustān of 893, painted in 1488 as it is written on the cartouche to the left of the iwan, and that is a painting which implies the passage of time as well as a sequence of spaces (fig. 126, see full color section). This miniature is signed by the great master Behzād on the architectural panel over the window in the room on the upper left. In this case, as Hillenbrand explains further,

the explosive impact of the encounter between the two major protagonists owes much of its intensity to the earlier temporal and spatial building-up. The artist has responded to the accumulated suspense and eventual dramatic climax of the literary text with an extraordinarily apt visual equivalent whereby the principals of each tale confront each other at the very top of the picture-pictorially speaking at the very last moment. Thus time is suggested by space.

(Hillenbrand 1992: 78)

He concludes this part of the story with the description of an architectural construct that is rich and laden with mystical overtones.

In Behzad's painting, the architectural forms are extremely rich, but they are also empty. As noted by Sims, "In the midst of this patterned elaboration, color and the absence of pattern draw the eye to the two figures and their relationship" (Sims 2002: 328). Notice here, once more, the perfectlydesigned page with the columns, where the text has been written, being the ones that decide the final composition of the painting with a grid layout. As stated by the Islamic art historian and curator Lisa Golembek,

the correspondence of text and painting in detail and in emphasis are static levels of relationship. There is yet in Behzad's painting a dynamic level in which the formal composition actively conveys meaning (Golembek 1972: 28).

The grid layout is perfectly noticeable in Zain's schema (fig. 127). Note as well the isometric perspective approach to suggest three-dimensional space. For instance, the balcony in the right top corner of the miniature shows 
clearly the parallel lines in each space direction and the same holds true for any other part of the structure of the building. The vertical composition is also shown here, like in all other miniatures selected for this section. Persian painters tended to use solid blocks of form and color to create their miniatures. Often these blocks are created by the structure of the building where the scene is taking place, in other occasions blocks may be created by rectilinear or multifold ponds, doors, balconies, floors, etc. In the words of Hillenbrand,

it is a prerequisite of their compositional role that they should be as monochrome as is consistent with their nature. Thus they establish a presence in the picture, something that is much more than mere decorative infill or background. They have an obvious spatial significance. (Hillenbrand 1992: 84)

In Funeral Procession, from Mantiq al-teyr ("The Conference of the Birds") by Farid al-Din Attār ${ }^{17}, 1483$ (fig. 128, see full color section), the ground is shown in several receding planes. The landscape, in fact, constitutes a true background to the depicted subjects. The tree that strays outside the frame-like margins is an element that was adopted by Persian miniaturists as an influence from the Chinese painting tradition. Contrary to what Rudrauf stated regarding diffuse composition, that the eye is not guided to go from one object to another (read before in this chapter), Grabar states in Mostly Miniatures, that,

if we go a little further in the analysis, we discover the curious fact that despite the apparently artificial compositions of the human figures, two details are rendered somewhat less unreal. One is the important clue of the gaze. All the miniatures of a certain quality are organized by a circuit of gazes that the protagonists launch at each other. It is a complex and passionate game of clues that, as in embroidery, organizes the relationships among the persons. (Grabar 2000: 133)

We can see this in this miniature, in which a complex composition is shown, and as he explains further,

heads and eyes compel a dynamic movement leading up to the snake in the tree, which is about to gobble up the eggs in the nest. The other trait are the witnesses, a whole world of figures who are there as if to bear witness to the truth of what is depicted; they are furnished with a formulary of gestures whose details it would be interesting to unravel. These two traits are familiar in Italian painting of the same centuries, but they have been miniaturized in Persian 
painting and demand a greater effort from the observer, just as the painter was obliged to work with a precision that did not allow for error. (Grabar 2000: 133-36)

This painting is a good example to see the funerary practices in the fifteenth century. As explained by Sims, a funeral procession arrives at the gate of the cemetery; inside workmen are preparing the grave of the man whose coffin is preceded by his mourning son, clothes torn from his upper body. He is placed in the vertical center of the picture, on the direct axis supplied by one corner of the platform where his father's grave is being dug. The secondary axis of the picture is the horizontal line of the cemetery wall, effectively dividing the two parts of the picture. Notice that, even if this miniature is mostly non-architectural, the isometric perspective is working: the octagonal fence that is depicted at the top left corner is shown with parallel lines in the three directions of space. Once again, Zain's schema shows the grid layout structure and we can see the parallel lines that I have just talked about in the octagonal fence (fig. 129).

Some experts in the field of Persian painting have tried to explain the fact that the Persian miniature painters did not use linear perspective to suggest a three-dimensional space. For instance, the art historian Sheila Canby says of Persian painting,

by favoring two-dimensionality and compositional harmony, they presented things as they should be, not necessarily as they are.

Within these parameters, Persian artists produced paintings over six centuries unrivalled in their perfect realization of an ideal world. (Canby 1993: 7)

She goes on to say that,

No matter what its period, a great Persian painting will exhibit a distinct sense of design and an understanding of how to arrange colors and forms on a flat surface to form a rhythmic whole. Despite the influence of European art from the seventeenth century onwards, Persian painters do not appear to have been convinced of the desirability of the illusionism that transforms two dimensions into the suggestion of three. Perhaps such visual tricks seemed innately dishonest. Finally, this art of highly developed surface values draws the viewer in, but does not trespass into his world. Before the nineteenth century the figures in Persian painting almost never look directly at the viewer. Later, when they do, they keep their emotions to themselves. Yet, the most gifted Persian artists could capture their sitters' character without invading their wall of reserve. (Canby 1993: 11-12) 
In conclusion, Persian miniatures do display a diffuse composition and grid structure layout. Often the proper structure of the buildings, the architectural structures that compose the painting, help stress this multiple-centered composition dividing the space into blocks. The third dimension is brought to life with the help of receding planes and with several scenes happening simultaneously, therefore achieving that multiple-center or diffuse composition, which is at the same time spatial and temporal.

The isometric system of projection to suggest perspective is used consistently in Persian miniature painting, one of the influences from Chinese traditional painting. Next to this, the vertical composition/vertical perspective is used consistently in Persian miniatures as well. The combination of these two strategies to suggest perspective is, in my opinion, a unique element found in this painting tradition.

\subsection{The use of space in nineteenth-century photography in Iran}

I will explore in this section the way in which space has been arranged in nineteenth-century Iranian photography (be it due to the photographers' taste, be it due to technical restrictions of the camera). An immediate question is whether isometrical perspective, diffuse composition, the grid layout structure and vertical composition/vertical perspective are to be found in nineteenth-century photography as they are in traditional Persian painting. As was the case in the previous chapters, another important question to be answered is whether this understanding of space is something peculiar to the Persian visual arts tradition or if it can be found in other countries. It is important to note that isometrical perspective is impossible in photography. As stated by the chief curator of photography at MOMA in the 1990s, Peter Galassi,

the ultimate origins of photography (both technical and aesthetic) lie in the fifteenth-century invention of linear perspective. The technical side of this statement is simple: photography is nothing more than a means for automatically producing pictures in linear perspective. The aesthetic side is more complex and is meaningful only in broader historical terms. (Galassi 1981: 12)

Therefore, as far as the topic on isometrical projection is concerned, there is no possible argumentation when related to photography: no matter who is behind the camera, an Italian, Iranian or Malawian photographer, the result will always be a photograph in true linear perspective, as a result of the monocular viewpoint, which is also the basis of Alberti's theory of linear perspective. I have established different categories of photographs in order to be able to study in depth the different spatial characteristics 
present in Persian traditional painting as well as in photography. I have named the first group diffuse compositions/grid structure and the second vertical composition/vertical perspective.

The first group that I have defined is diffuse composition/grid structure, a term that means, as I elaborated in the previous section, the presence of multiple centers of attention within the photographic space. In order to understand it fully and to be able to give enough examples of the composition used in nineteenth-century Iranian photography, I will broaden my scope and consider other kinds of photographs besides portrait studio photographs, since it is difficult to find those Persian elements of composition (diffuse compositions, grid layout structure and vertical composition) in them. I will start with a photograph taken by an unknown Iranian photographer in which a group of schoolboys are depicted together with their teachers from the school Nawbar in Tabriz. We can see that there is no special center of attention. On the contrary, the eye can scan the whole content of the picture freely and without a fixed path (fig. 130). See, for instance, the window on the right, full of people, in the same way that miniatures present different scenes, all with the same importance as far as information is concerned, as we have seen previously. These are examples of Rudrauf's diffuse composition. Further, we can also make an abstraction of the photograph and we get a grid structure as we did before with a miniature. There is an especially remarkable photograph of a group of schoolchildren gathered together to celebrate a special school event (fig. 131) in Moshiriyye's school in Yazd. The way in which the space has been depicted is interesting. See the left half of the image, where a group of teachers is depicted sitting around a huge table and the upper right part of the image in which a large group of schoolboys has been densely packed in a reduced space,almost ascending up to the ceiling. Here the monocular linear perspective of the table drives the eye from the front to the back. This photograph is, indeed, a good example to illustrate the fact that photography is a perfect technique to produce pictures in perfect linear perspective. But, at the same time, the general aspect of the image is that of miniatures, with their multiple centers of attention and grid layout structure. The Persian carpets that are hung on the walls, fully covering them, help to give the final image the appearance of a miniature. Notice the three men on the balcony in the top left of the image, looking downwards, as in many miniatures, at what is happening in the hall. Another example of a photograph where this miniature-like structure is clear is figure 132. These kinds of images are examples of what I introduced above about the "invasion" of space by people. Here it is important to remark that the possible parallels that I may establish between photography and miniatures are only valid from a pure formal point of view. The important temporal and spatial narrative dimension present in the miniatures I have analyzed in the previous sections, is something that the photographs do not have. Further, the fact that the miniature 
belongs to a book that has its precise place between the previous miniature and the following one is fundamental and needs to be pointed out in order to avoid confusion or to arrive at false conclusions.

The second group of photographs is vertical composition. An interesting photograph is one that depicts a group of seven men arranged in two rows, occupying two horizontal planes, and dividing the photographic space into two identical halves, in two independent spaces (fig. 133). The governor of Kerman is depicted sitting on a carpet on the lower row, on the left of the image, next to two colleagues. The carpet bends along the stair to become the carpet on which the other four men on the upper row are also sitting. The plane of the photographer has been lowered in order to get a frontal image where the whole group is packed within the photograph's horizontal frame. The formal parallelism in the vertical composition between this photograph and figure 121 (see full color section) is remarkable. This is interesting, since isometric projection suggests birdeye's perspective.

One extreme example of this vertical composition is an image that displays the most bizarre composition of a group of people - in this case four men - that I have found during my research (fig. 134). The original glass plate is partially broken, so we can only see in the print four heads of the five military men depicted. The heads of the four men have been arranged on a vertical line, fully covering the vertical photographic frame. The photograph was taken by the Iranian photographer Mirzā Mehdi ChehrehNamā, who ran a very well-known studio in Isfahan.

There are several photographs that I have found during my research that show an aesthetic approach similar to those of the miniatures. This effect is caused, as I will explain shortly, by the technical restrictions of the camera rather than by an aesthetical intention of the photographer. I will call this group optical illusions. Nāser al-Din Shah took the next two photographs considered here. The two women depicted in these images, seem to have been pasted onto the blurred backdrop, giving them the impression that they are partially floating in the photographic space. This probably happens due to the technical restrictions of the camera rather than due to an aesthetical effect intended by the photographer, but the perception of both of them is similar to those of the miniatures and this effect is reinforced by the carpet, clothing and pose of these women. Notice that here the presence of the carpet is an important element that conditions the perception of the space by the viewer of the final image, as was the case in the previous picture. The first one depicts Iran al-Moluk (fig. 135), daughter of Nāser al-Din Shah. The second depicts Bakhbaubashi (the one to the left), one of the wives of Nāser al-Din Shah (fig. 136), the receding stairs giving a true perspective to the final image. In both pictures there is a separation between the foreground and the background, therefore a linear perspective as I have already pointed out at the beginning of this section. 
Within this group, we could consider another sub-group of photographs, which show another peculiar element to be found in some nineteenthcentury Iranian photographs: the use of the middle horizon in the photographic space. As we know from the laws of composition in Western photography, one should not place the horizon exactly in the middle of the photograph. But if we analyze the next two photographs, we clearly see that this is exactly what happened: a row of kneeling mullahs (religious men) is placed in the upper half of the photographic space, just starting at the horizon line or the middle line of the photograph, leaving an empty and wide space in the lower half of the image (figs. 137 and 138). Actually this is just an optical illusion, since there is a carpet in both photographs that, as a result of the bad quality of the print that lost its sharpness, we cannot see clearly. Further, the placing of the horizon right in the middle of the photographs is most probably due to technical restrictions of the camera, because the photographer needed to lower his camera in order to take a frontal image of the group and therefore, the carpet or floor, would have taken a dominant role in the image. It is important to note that this way of arranging the space is only found in photography and therefore peculiar to this medium due to technical restrictions of the camera, since it is not found in Persian traditional painting, where the lower half of the image is especially important in its content and density of information. Next to this kind of image, there is another one that depicts men as if they were floating in the air. I have selected one photograph to illustrate this spatial illusion. A portrait of Hājji Hoseyn Quli Khān Nuri Mostowfi, Ministry of Foreign Affairs, taken by an anonymous Iranian photographer (fig. 139). Next to this kind of images, there is one that is interesting as a collage and because of the spatial arrangement of the three women depicted therein, all of them floating in the photographic space (fig. 140). This is actually the page of one of the albums of Nāser al-Din Shah's wives. Three full portraits of women have been cut out and pasted directly onto the album page and the final image presents a peculiar understanding of space since the three identical women are literally floating on the album page like the men in the previous two portraits. This kind of collage became quite popular amongst the Shah and his family, since they appear quite regularly in the albums' pages in the last years of his reign. An important difference between this last image and the previous photograph is that, in the collage, the photographer would be the one that decided to give the floating effect to the sitters, not the camera!

It has often been remarked that the lower part of a visual pattern demands more weight. As stated by Arnheim,

gravitation is probably at the root of this asymmetry in the vertical dimension, but how its effect on vision comes about is not known. The compensation, which keeps the lower part of a pattern from 
looking too light or too small, is needed everywhere, except for the structurally strong shapes, which resist the distortion of angles. It cannot be maintained, however, that general artistic practice makes patterns look heavier at the bottom - that is, lowers the center of gravity. True, in the landscape that man, the land animal, sees around himself, the lower part of the visual field is crowded with buildings, fields, trees, and events whereas the sky is relatively empty. A corresponding effect is sought in the arts wherever the realistic representation of solid bodies is intended. By lowering the center of gravity, the painter or sculptor adapts his work to the asymmetry of physical space. This practice, however, is not universal. It goes with certain styles only. For instance, modern art -because of its trend towards abstraction - has little use for this uneven distribution of masses. (Arnheim 1969: 20-21)

This is also true for some Iranian photographers active in the nineteenth century. For instance, in those images of a group of kneeling religious men, they actually seem to be levitating while being photographed and they do have, indeed, a very light appearance.

There is another group of photographs that can be considered as a subgroup of the one I am now analyzing. Plan-perpendicular shows the use of this way of understanding space. One of the peculiarities encountered in the Iranian style is the representation of sitters themselves in the perspective, above a patterned carpet that is shown in plan-perpendicular (straightfrom-above) view and has no particular relationship to the rest of the studio setting, as we can see in the photograph where a man sitting on a chair is depicted (fig. 141). This image of Mohammad Ebrahim Khān Me'mārbāshi, Minister of Defense and head of the Tehran department, presents as well an illusionary perception of the sitters, as if they were floating on the air. This element is also typical of the Indian photography of that time. We can see an obvious resemblance between this image and fig. 142 (see full color section), an 1885 album print taken by an unknown Indian photographer and painted partially with opaque watercolor where a musicloving landowner is depicted. The image shows him sitting, his face, hands and feet remaining photographic. Flatness of space is achieved through the way the carpet is painted, as in miniatures. Also the lack of shadows in the colors helps this non-perspective element of space. As the art historian and critic Judith Mara Gutman states in her book Through Indian Eyes. 19th and Early 20th Century Photography from India,

when photography was introduced to India in the nineteenth century, photographic expression followed the same pattern as paintings did. Photographers made photographs that emulated the space and subjects found in Indian paintings, using the patterns and forms that 
streamed through their aesthetic traditions; this ultimately changed the place, role, function, and representation of those patterns in photographs. Many photographs were composed with the same spatial arrangements that existed in paintings. (Gutman 1982: 69)

In sum, the grid layout typical of the Persian miniatures is also to be found in Iranian photographs that depict large groups of people spread over a more or less large space, be it the entrance of a school, a room in a school, a market, a theater, palace, etc. Nevertheless, this does not mean that the grid-like structure found in photographs was consciously displayed by Iranian photographers. People seem to completely inhabit the given space, and the final result (the photograph taken by the photographer who was in front of the scene without interacting with it), formally, resembles the grid layout structure and multiple centers of attention that I have analyzed in detail in the sections concerned with miniatures. Next to this, a vertical tendency towards organizing the sitters is also to be noted. The majority of the miniatures is vertical, whereas most of the group photographs of the kind analyzed here are horizontal, which could be explained in technical terms (but I say this very carefully as further research is needed in order to fully prove this hypothesis). Since the majority of the miniatures is used as a page in a book it seems that the artists find themselves with no choice but the vertical arrangement. In this respect the photographers do not feel such limitations and as a result the horizontal arrangements of sitters in the case of large groups of people are commonly found in the photographs of the period. It is important to note that the conclusions drawn here are exclusively from a formal approach. The placement of the horizon in the middle of the photographic space is something peculiar to some Iranian photographs and this, most probably, happens in this way due to technical restrictions of the camera rather than a self-conscious or unconscious aesthetical approach of the photographer to achieve this particular effect. Photographers, in this sense, did not arrange the space. The camera did that for them. They did frame the part of reality that they wanted to show and composed the final image within that frame.

I have shown through visual analysis of the paintings and photographs selected for this chapter that the understanding of space is one of the cultural components involved in the process of producing a painting or a photograph, even if later technical limitations of the camera definitely play a role in the final image. I have created a theoretic model to classify my corpus of paintings and photographs according to spatial components. For the paintings corpus I have defined three groups: diffuse composition/grid structure; isometrical perspective and vertical composition/vertical structure. For the photographic corpus I have defined two groups: diffuse composition/grid structure and vertical composition/vertical perspective. Persian miniatures employ diffuse composition and grid structure layout to 
achieve multiple-center or diffuse composition that is at the same time spatial and temporal. Furthermore, by using the isometric system of projection they provide a consistent usage of space, one of the many influences of Chinese traditional painting on Persian miniature painting. However, the combination of these two strategies to suggest space is, in my opinion, unique to the traditional Persian miniature.

\section{Notes}

1 Prominent Japanese philosopher, founder of what has been called the Kyoto School of Philosophy.

2 In Leiden, September 2008. I am very grateful to Helen Westgeest for her ideas and reading of the photographs and paintings selected for this chapter, especially regarding the topic of axonometry/isometrical perspective and grid structure layout.

3 Williamson 1986.

4 Wellesz 1936.

5 The Zafar-nameh is an epic poem written by the Persian poet Hamdollah Mostowfi (d. 1334). The epic history explores Iranian history from the Arab conquest to the Mongols.

6 Dunham 1949.

7 Nizami-ye Ganjavi (1140-1202), who is considered the greatest romantic epic poet in Persian literature, brought a coloquial and realistic style to the Persian epic. His Khamsa consisted of 5 poems written in the form of couplets: Makhzan al-Asrar( "Treasure of Secrets", 1177); Khosrov and Shirin (1180); Leyla and Majnun (1188); Haft Paikar ("Seven Beautiful Girls", 1196) and Iskandar-Nama (1203, usually divided into the Sharaf-Nama, which deals with Iskandar's conquests, and the Iqbal-Nama, which deals with his prophetic mission). For general information, see, Rypka, J.R. Rypka (1968), History of Iranian Literature. Dordrecht: 210-219.

8 Adle 1975. I am grateful to Oleg Grabar for directing me to this article and for his comments of this chapter.

9 The invention of linear perspective in Western art in the Renaissance was achieved through the discovery of the mathematical priciples that underly the concept of perspective by the Arab polymath Abu Ali Ibn al-Hasan Ibn al-Haitham (965-1040), known in the West as Alhazen. He made significant contributions to the principles of optics, astronomy, anatomy, visual perception and to science in general with his introduction to the scientific model. See: Saliba, G. (2007), Islamic Science and the Making of the European Renaissance, Cambridge; and "al-Haytam", in Onians, J. (2007), Neuroarthistory. From Aristotle and Pliny to Baxandall and Zeki, New Haven and London: Yale University Press: $38-41$

10 Taken from Krikke 1996.

11 Interview in Leiden, December 2008.

12 See: Talbot 1971.

13 Humay and Humayan is a medieval Persian romance written by the Persian poet Khwaju Kirmani (1280- 1352). For further information see "Humay and Humayan: A Medieval Persian Romance“, in Annali Instituto Italiano per il Medio e Estremo Oriente, Roma, 1990: 347-57.

14 For a detailed description of this image and identification of Fath 'Ali Shah's sons, see: Eskandari-Qajar, Manoutchehr, M. (2008): “The Message of the Negarestan Mural of Fath 'Ali Shah and His Sons: Snapshot of Court Protocol or Determinant of Dynastic Succession”, in Qajar Studies, Rotterdam/Gronsveld/Santa Barbara/Tehran: IQSA: 17-41. 
15 "The Book of the Kings" is the national epic of Iran written by the Persian master of poetry Abu al-Qasim Firdowsi (934-1025-26). He devoted 35 years to write the Shahname and this is he most studied of all Persian manuscripts, which was never finished.

16 Sheikh Saa'di (full name: Mosleh al-Din Moshref ibn Abdollāh), born in Shiraz (11841283-1291?) is one of the major Persian poets of the medieval period. He is recognized not only for the quality of his writting, but also for the depth of his sociological thoughts. His best known works are Bustān (The Orchard) completed in 1257 and Gulistan (The Rose Garden) in 1258. Bustān is entirely in verse (epic meter) and consists of stories to illustrate the good virtues recommended to Muslims and also includes reflections of the behavior of dervishes and their ecstatic practices.

17 Farid ad-Din Attar (1142-1220) was a Muslim scholar and Sufi mystic. "The Language of the Birds" is a book of poems of aproximately 4,500 lines. The poem uses a journey by a group of 30 birds, led by a hoopoe as an allegory of a Sufi sheikh or master leading his pupils to enlightenment. 



\title{
5 INTERACTIONS BETWEEN WESTERN AND IRANIAN PHOTOGRAPHY
}

\author{
For Kausar Turabi
}

Born originals, how does it come to pass that we die copies? Edward Young ${ }^{\mathrm{I}}$

\begin{abstract}
Nineteenth-century Iranian photography, with all its unique characteristics from Iranian culture and arts, is not free from the influence of the Western aesthetics of the period. The Victorian model, with its characteristics of hieratical and frontal pose, is the main referent of Western aesthetic models. Iranian court photographers, who were more exposed to this foreign influence, exhibit a sharp contrast to the local photographers who lived in smaller cities or towns, or worked in bazaars, far away from the court, and whose work I have analyzed in the previous chapters. It is also worth noticing that in spite of this contrast, Iranian photographers managed to create their own style suitable for the Iranian taste and culture. This style, a hybrid of two aesthetics, produced plenty of examples among the existing photographs of the period and even has found its way to modern photography.
\end{abstract}

\subsection{Schema of positions in portrait photography}

When defining the possible positions in portrait studio photography of two sitters belonging to two different cultures (here I will consider Iranian and non-Iranian, a person belonging to any Western culture in this particular example) by photographers belonging to the same two cultures, I have found four different possibilities: Western photographer (WPh) versus Western sitter (WS); Western photographer (WPh) versus Iranian sitter (IS); Iranian photographer (IPh) versus Western sitter (WS) and Iranian photographer (IPh) versus Iranian sitter (IS). Two of them belong to the category of photographing the self (here understanding the self as a culture, as one's own culture): WPh-WS and IPh-IS. The other two belong to the category of photographing the other: WPh-IS and IPh-WS. I have summarized the different possibilities of positions in studio portrait photography in the following diagram (graphic 1, see full color section): There are six 
possibilities that can be grouped in three different categories. The first one (blue lines) shows the pairs that compose the process of photographing and representing the self, one's own culture. The second one (red lines) shows the pairs that compose the process of photographing the other, the foreign culture. The pair WPh-IS has been studied in-depth in visual arts, especially in painting. To the best of my knowledge, to date the pair IPh-WS has not been taken into consideration for serious research. The third category (green lines) indicates the process of the self-portrait, the portrait that the photographer takes of himself, being at the same time the photographer and the sitter. Many male artists that went to the Near East and North Africa, were often photographed in oriental costume, smoking a narguileh and resting in the odalisque-like reclining pose. There are many wellknown examples of Western photographers portraying themselves dressed up in local clothes, like the British photographer Francis Fritz (1822-1898) posing in a Turkish summer dress (fig. 143). In contrast to this, numerous examples of self-portraits of Iranian photographers present a sober and self-conscious image of themselves, and most of the time their cameras are an important part of the photograph. A self-portrait of the Iranian photographer Abd al- Qāsem ebn al-Nuri (fig. 144) illustrates this nicely.

By analyzing all the possible permutations shown in my diagram, we can get an idea of the way in which both local and foreign sitters were represented in nineteenth-century photography. By comparing all these different kinds of photographs, we can obtain a lot of information about the way Western and Iranian photographers perceived and represented each other more than one hundred and fifty years ago. In the previous chapters of this book, I was mostly concerned with the pair Iranian photographerIranian sitter. In the present chapter, I will focus my study on the pair Western photographer-Iranian sitter. For any of the pairs presented above in the diagram, it is always important to remember that the two main persons involved in producing the final photograph, the photographer and the person depicted, have a role and aspiration in their preconception of the image to be achieved. Most of the time, the relationship between them would be an unbalanced one, because of their different social status, culture or even gender. For instance, if the sitter is Nāser al-Din Shah and the photographer a Westerner, then the Shah would have had a dominant role in the way that he is depicted in the final image; whereas the same photographer taking a photograph of an anonymous local Iranian, then would be the dominant one. By analyzing photographs, we can elucidate the kind of relationship that was established between the person depicted and the photographer at the time that the scene was frozen for eternity and, in more general terms, the way in which Westerners perceived Iranians and viceversa. 


\subsection{Western photographers versus local sitters: Photographing the Other}

In this section I will discuss the ways in which Western photographers represented Iranians in the nineteenth century as a particular case of representing other cultures in photography, and to establish differences or similitudes between the way Western photographers perceived and represented Iranians and the way Iranians perceived themselves.

Photography was invented in Europe and exported to the rest of the world as soon as the first photographer-travelers started heading for "exotic" foreign countries in the nineteenth century. The intersection of photography, printing, physical anthropology and colonial history produced hundreds of thousands of photographs and reproductions that represented the places and peoples of Asia as Westerners perceived them. In fact, they constitute an image world. This term was used by the American literary theorist, novelist and filmmaker Susan Sontag in her book On Photography. ${ }^{2}$ In her words,

in the real world, something is happening and no one knows what is going to happen. In the image-world, it has happened, and it will forever happen in that way. (Sontag 1979: 168)

There is a long list of scholars that has delved in the topic image world from different perspectives and has added further connotations to it. For example, according to the anthropologist Deborah Poole,

the image world encompasses the "complexity and multiplicity of this realm of images" and the flow of image objects and associated ideas "from place to place, person to person, culture to culture, and class to class". (Poole 1997: 7)

The French anthropologist Christaud M. Geary explains that,

image makers, the subjects of the images, publishers, distribution agencies and consumers were actively involved in the shaping of this image world, in which images cross political and cultural boundaries. The metaphor "image world" also implies a degree of independence from the world that the images depict. (Geary 2002: 19)

In the words of the art historian Anandi Ramamurthy,

some of the most dominant ideological and photographic constructions were developed during the nineteenth century and the camera 
joined the gun in the process of colonization. The camera was used to record and define those that were colonized according to the interests of the West. Europe was defined as "the norm" upon which other cultures should be judged. Whatever was different was disempowered by its very "Otherness". (Ramamurthy 2004: 223-224)

In general terms, the "other" is anyone apart from one's self. The existence of others is crucial in defining what is "normal" and in locating one's own place in the world.

\section{The other in photography}

In the last years of the nineteenth century a prominent role was played by the illustrated press which made use of photographs, particularly those taken by commercial photographers as the preferential means of spreading Asian "knowledge" concerning Asia and its people. The scarcity of actual knowledge concerning the Asian continent was countered by the enormous potential of the "discourse" produced by it, along a path followed by the colonial enterprise in line with the construction of a collective imagery skilfully nurtured by photography. In the words of the Italian art historian Silvana Palma written in her insightful article on nineteenth-century photography in Africa, "photography drew the line between the visible and the non-visible" (Palma 2005: 40). Paraphrasing Palma on her discourse, the identification of what was shown and what was omitted enables us today to measure the limits of Western "knowledge" of Asia. At the same time, it is also possible to measure the strength of a representation, which proves the ability of often imposing a misleading perception of Asian otherness.

As Palma states reflecting on this matter regarding Africa, but that also holds true for Asia,

Called on not only to describe and document events but also to interpret them, photographs contribute, through what they show, hide or invent, to the construction of the imagery not only of a social group but also of an entire age, shaped further by biased readings of contemporary viewers. Today they effectively make it possible to define the "mental landscape" that they helped to evoke, construct and reinforce in their day, thus creating, despite all their fragmentation and gaps in a nonetheless effective and significant manner, the ideological scaffolding that accompanied and supported the establishment of Western colonial power in Africa. They also guided relations between the rulers and the ruled. (Palma 2005: 61)

Reflecting further on this topic, the historian Christopher Lyman incisively noted, 
photographs were not viewed as metaphors of experience, but rather as sections of reality itself. If photographs showed gigantic trees and awe-inspiring mountains, then all the trees were gigantic and all the mountains were awe-inspiring. When photographs depicted Indians as "savages", Indians were confirmed as savages. (Lyman 1982: 29)

The visual anthropologist Christopher Pinney argues that,

much recent writing that seeks to historically contextualize photography's emergence during a period of colonial expansion has drawn on crucial insights from Edward Said to Michael Foucault and has tended to construct photographic imagery and practice as immovably within a "truth" that simplistically reflects a set of cultural and political dispositions held by the makers of those images. Perhaps the starkest of these contributions is that offered by the Algerian poet Malek Alloula in the Colonial harem (1987). By consciously eschewing the study of the actual political and historical consumption of images, Alloula spins an eloquent but untested hypothesis concerning the role of "photography" as the "fertilizer of the colonial vision (producing) stereotypes in the manner of great seabirds producing guano". (Pinney \& Peterson 2003: 2-3)

Such debates tend to invoke formal readings of images that are made to do the work of a pre-existing political hypothesis, continues Pinney. In Carlo Ginzburg' words "these are 'physiognomic' readings", in which the analyst "reads into them what he has already learned by other means, or what he believes he knows, and wants to "demonstrate"" (Ginzburg 1989: 34). Underpinning this approach, Ginzburg continues, is the conviction that "works of art, in a broad sense, furnish a mine of first-hand information that can explicate, without intermediaries, the mentally and emotive life of a distant age" (Ginzburg 1989: 35). This is, precisely, what the corpus of staged photographs taken by Western photographers in such "exotic" lands constitute and represent.

\section{Orientalism in photography}

Before considering the topic of Orientalism in photography, it is important to note here that the corpus of Oriental Studies is not reduced exclusively to Said's Orientalism. One does find the kind of approach in nineteenthcentury Western photography in Iran that Said has denominated as Orientalist. This does not mean, however, that this is the only kind of Western photography in the nineteenth century. ${ }^{3}$ In fact, one of the most important European photographers active in Iran at that time, the German 
Ernst Hoeltzer (1855-1939), produced a remarkable amount of photographs that are free from Orientalism as critized by Said. But Hoeltzer was an amateur photographer and this is, indeed, an important fact: usually the Western commercial photographers were the ones who used an orientalist approach in their work, in contrast to those who were amateurs and therefore free from the demand of the photographic market. So the photographic production was market-driven: the taste of the demand of the market did play a role in the kind of photography that was produced.

The concept and term Orientalism was coined by Edward Said, who examined the process by which the "Orient" was constructed in European thinking. Professional orientalists included scholars in various disciplines such as languages, history and philosophy. However, for Said,

the discourse of Orientalism was much more widespread and endemic in European thought. As well as a form of academic discourse, it was a style of thought based on the ontological and epistemological distinction between the "Orient" and the "Occident". (Said 1978: 1)

More widely, Said discusses Orientalism,

as the corporate institution, dealing with it by making statements about it, authorising views of it, describing it, by teaching it, settling it, ruling over it: in short, Orientalism as a Western style for dominating, restructuring, and having authority over the "Orient". (Said 1978: 3)

Orientalism signified a mode of knowing the other, but was a supreme example of the construction of the "Other", a form of authority. In Said's line of thought, the Orient is not an inert fact of nature, but a phenomenon constructed by generations of intellectuals, artists, commentators, writers, politicians and, more importantly, constructed by the naturalisation of a wide range of Orientalists' assumptions and stereotypes. The relationship between the Occident and the Orient is a relationship of power, domination and of varying degrees of a complex hegemony. Consequently, Orientalist discourse is more valuable for Said as a sign of the power exerted by the West over the Orient than a "true" discourse about the Orient. Interestingly, twenty-five years after Said's Orientalism, a whole field of study has developed to analyze and interpret the denigrating fantasies of the exotic "East" that sustained the colonial mind. But what about the fantasies of "the West" in the eyes of "the East"? These questions remain largely unexamined and, as the Anglo-Dutch writer and academic Ian Buruma and the Israeli philosopher and academic Avishai Margalit argue, woefully misunderstood. A book by these authors is Occidentalism. ${ }^{4}$ The 
term Occidentalism usually refers to stereotyped and sometimes dehumanizing views of the so-called Western world, including Europe, the United States and Australia. Iran constitutes but one of the many examples that illustrate the previous discourse, but it must be noted that this phenomenon never was as widespread as in other Middle Eastern countries and North Africa. In comparison to those countries, actually, it was quite irrelevant.

A good example to illustrate what I have just introduced above is The National Geographic Magazine published in April 1921, ${ }^{5}$ a volume devoted to Persia (fig. 145). It included two long articles: "Modern Persia and Its Capital" (47 illustrations, 47 pages) by F.L. Bird who, for five years, was an American college instructor in Tehran, and "Persian Caravan Sketches" (62 illustrations, 51 pages) by Harold F. Weston. When going through the magazine, it is especially striking to see the contrast between the photographs of Persian women that illustrate the two articles and those of the American women depicted in the forty-four pages devoted to advertisements at the front and back of the magazine. On page 372, there is a photograph whose caption reads "The almost blind leading the really blind in Persia" (fig. 146). Next to the caption, there is a short text that I reproduce here verbatim:

There are many blind persons in Persia, owing partly to the intense light rays of the sun. Tradition gives the following origin for the wearing of the veils by Mohammedan women: One day when the Prophet was seated with his favorite wife, Ayesha, a passing Arab admired her, expressed a wish to purchase her, and offered a camel in exchange. This experience so angered Mohammed that the custom of requiring women to wear veils resulted.

So, the caption talks about blinds and the text that comes along with it refers to them only in the first sentence. The four remaining sentences are devoted to the eternal Western obsession with the Muslim veil, something that is recurrently found in the two articles of this magazine. On the next page (fig. 147), there are two photographs in which different Persian women have been depicted fully covered with a chādor. Their respective captions read:

"Persian ladies leaving a public bath-house preceded by a domestic servant" (the short text that comes together with the caption reads: "Every Friday is 'bath day' in Persia, and a bath is obligatory before the faithful can worship. Frequently there is a public bath attached to the mosque" and "Persian women in chadars" (short text: "Both Christian and Mohammedan women wear the yashmak (veil) out of doors, but the chadar (chuddar), or enveloping garment, is peculiar to the followers of Mohammed"). 
Further, on page 392, there is a photograph of a Persian woman riding a donkey (fig. 148) whose caption reads: "A Persian woman apparelled for a pilgrimage" (short text: "The elaborate embroidered saddle-bag is a khorjin, in which both clothes and food are carried for the journey. The white veil over the face is the yashmak").

In contrast to this, the pages devoted to advertisements in which Western women are depicted deserve an in-depth analysis too. The page with an advertisement of the Motor Car Company (fig. 149) depicts a modern-dressed smiling woman holding a bouquet of flowers and waving to four young elegant women that are sitting on a modern black car, reflecting a quite emancipated attitude. The Persian woman riding the donkey contrasts deeply with the Western women represented in this advertisement. This is shocking especially because the title of the magazine is "Modern Persia and Its Capital" and the photographs selected do not show any kind of modernity or wealth that was also a part of the Persian reality in the nineteenth century. A couple of pages further we find an advertisement of the American Radiator Company (fig. 150) that depicts a fine and elegant Western young woman admiring a modern heating machine. After the two articles devoted to Persia, we find twenty-eight pages of advertisements. In one of them there is an advertisement by the Eastman Kodak Company (fig. 151) that depicts a smiling and independent young woman carrying a Kodak camera on her shoulder. With this kind of advertisement George Eastman and other companies began to direct camera advertising specifically to female customers. The modern clothes, the loose hair and the loneliness of this young woman contrast deeply with the fully dressed and covered Persian women and their omnipresent company of a man, servant or other women.

When analyzing the issue of The National Geographic Magazine devoted to Persia and its people, the photograph's caption emerges as playing an important role. This is because it has a clear influence on constructing the otherness of the people living in "exotic" countries. In fact, images employ a complex amplitude of levels and modes of communication. In addition to codes of a more specifically visual nature, socio-cultural and linguistic codes where the "written text" supports the image, are used to shape its interpretation, as we have seen clearly while analyzing the magazine. As stated by the scholar Clive Scott,

the distinguishing characteristic of the caption is that it is already a step away from the image towards its assimilation by, and interpretation through, language. The caption is spoken; it is an intervention, a response forestalling the response of the viewer. (Scott 1999: 49)

As art-historian and critic Rosalind Krauss claims, 
it is clear that although the photograph registers reality and isolates the fragments, which are to be made visible, the space isolated from the image is not always significant by itself. It therefore requires a double trace provided by the written text. (Krauss 1985: 131)

Moreover, Sontag states that,

the caption adds a further frame, which in reality proves to be a boundary: it creates an additional space, which guides the interpretation, influencing perception to such an extent that it can reverse its interpretation. And so the same image can be taken equally well to portray an ally or a traitor, a peasant or a brigand, thus confirming that images can be read in different and even conflicting ways depending on the context in which they are inserted, which also determines their possible uses. (Sontag 1979: 62)

Captions helped to create and stress the orientalist perception of countries like Iran in the Western mind and they were a complement to the photographs that definitely resulted in them being classified as "types". Captions play an important role in making the conception of the other, in the process of "othering".

There are some scholars who have argued that Western photographers did not only shape reality through the prism of Orientalism, but that there are also examples of local photographers, like Nāser al-Din Shah himself, whose work was influenced by the Western orientalist painting tradition and subsequently by Orientalist photography. As I already mentioned briefly in chapter 3, this phenomenon has been named "self-orientalizing" by Behdad, who says that,

by this term he means the practice of seeing and representing oneself as Europe's Other. Having internalized the discourse and practices of Orientalism, Nāser al-Din Shah depicts himself and his wives in the same stereotypical way as European artists represented

Middle Eastern women and the oriental despot. (Behdad 2001: 148)

A portrait of Anis al-Dowle, one of Nāser al-Din Shah's favorites, taken by himself (fig. 94) already introduced in chapter 3 of this book, is reminiscent of the reclining odalisques typical of Orientalists painters, the example that Behdad has used to illustrate the concept of self-orientalism. ${ }^{6}$ Another example that could be used to illustrate this is a photograph taken by Rezā Akkāsbāshi in which two women (Shirazi-ye Kuchak and Farangi) are depicted drinking (maybe) wine and hugging a man identified as Āghā Salmān (fig. 152). Nevertheless, I have never seen any other examples of this kind of image so nothing can be concluded on this delicate 
topic. Behdad's statement is, in that sense, debatable. Behdad further discussed the topic of "self-orientalism", and states that:

a general aesthetic transformation took place in how the West represented the Orient and how the Orient represented itself. This aesthetic transformation, though governed by new rules and techniques, constantly returned to and repeated the subjects, aesthetic consciousness, and formal sensibilities of the previous mode of artistic representation, i.e., painting. (Behdad 2001: 142)

If we follow his thoughts on this topic, we may conclude that Orientalist paintings not only influenced Western photography in the nineteenth century, but also influenced local photography. "Orientalism, therefore," says Behdad,

should not be viewed as a unilateral artistic, intellectual, and political force but instead as a particular system of ideas, aesthetic expressions, and intellectual practices that was internalized by "Orientals". (Behdad 2001: 148)

This paradoxical situation also has been pointed out by Pinney who asks himself what the consequences are, for instance, of the documented fact that "collectors of North African, Near and Middle Eastern descent dominate the market for orientalist art?", as has been claimed by the art historian Roger Benjamin. ${ }^{7}$ Pinney goes on to argue that "those paintings, which Said and Linda Nochlin ${ }^{8}$ have argued projected an image of largely negative alterity, are now eagerly consumed by those whose reality these images so distorted" (Pinney 2003:2-3). Benjamin's research on those who market these paintings, indicates that a nostalgic invocation of "indigenous identity through images of the pre-colonial past' is involved, together with a new sense of positive empowerment expressed through the acquisition and thus redefinition of western cultural documents" (Benjamin 1997: 34-35). A paradoxical situation in which everybody is implicated: the photographer, the person depicted, the observer and the collector. Nāser alDin Shah was a pioneer in displaying his own private and inner world. There are few sovereigns like him who have expressed their thoughts through artistic media like illustrations, photography, private letters and diaries. It is debatable that by using a precise example (Anis al-Dowle in a reclining odalisque-like pose) we can extend this approach to all his work. There is a remarkable amount of photographs that Nāser al-Din Shah left of all his wives and most of them were depicted sitting on chairs in a frontal pose, just like those typical of the Victorian portraiture. Even if Nāser al-Din Shah would have internalized such Orientalist discourse, we cannot be completely sure of what his real intentions were. 
In clear contrast to the aforementioned representations of Iranian women in photography, it is striking to note that in most of the portraits of parents holding children in their arms or laps in nineteenth-century Iranian photography that I have gathered, usually the men are holding the children (see figs. 21 and 22)! This contrasts with the fact that, in real life, the main occupation of the women may well have been taking care of children and holding them in their laps most of the day. Actually, the only photograph that I have found were you can somehow note the presence of a woman holding a child is an ambiguous presence indeed (fig. 153): a couple of boys have been depicted, the youngest one being held by two ghost-like hands that are hidden behind the chadored chair in which he is sitting. A striking image that makes the restricted presence of women in portrait photography in nineteenth century in Iran even more obvious. I have also seen several photographs of court eunuchs holding court children in their arms, like one photograph taken in the Bodouir studio (fig. 154), in which two eunuchs are holding two babies and two other children are sitting on a bench.

In sum, Qajar Persia was not an exception in having some orientalist traits in the representation of foreign societies in nineteenth-century Western photography. This orientalism could be found both in single photographs and in publications were photographs had a main role in the construction of the image of the country, of the image-world of Persia. Nevertheless, there was also an important corpus of photographic material from a documentary standpoint that was completely free of any orientalist connotation and that constitutes precious research material for historians, sociologists and anthroplogists, as we shall see further on in this chapter.

\subsection{Interaction between Western and Iranian photographers}

In this section I will introduce the Western photographers that were active in Persia in the nineteenth century and focus only on the ones whose influence on Iranian photographers may have been important. An important topic to explore is in which way they could have influenced the aesthetics of local photographers. Especially relevant is a discussion of how this influence might have changed the four topics explored in the previous chapters: visual laterality, text/calligraphy, pose and space. In order to achieve this, it is essential to know who the Iranian photographers working with Western photographers were. There were two possible agents through which this interaction could take place: the first were Western photographers who traveled and/or lived in Iran (some of whom came to work as photographers in the court of Nāser al-Din Shah); the second were Iranian photographers who traveled and/or lived in Europe (some of whom, like Abdollāh Mirzā 
Qajar, went to Europe precisely to learn photographic technique). Both will be discussed.

\section{Western photographers in Iran}

Jules Richard being the first Western photographer to work as a teacher in Iran, he may have been an influential photographer for Iranians, as I have already mentioned in the brief historical introduction.

There were around thirty Western photographers active in Iran in the nineteenth century, but for my research the most relevant ones are the French Francois Carhlian, the Italian Luigi Montabone and the Georgian Antoin Sevruguin. The reason for this is that they were the ones whose work most influenced the aesthetic of local photographers. To prove this is the aim of the present section.

The French photographer Carlhian was active in Iran in 1858. There is an interesting album hosted at the Musée National des Arts AsiatiquesGuimet, where photographs taken by Carlhian, the Italian photographers Pesce and Gianuzzi are shown together with some watercolors collected by the French colonel Brongiart. He became a teacher at the Dār al-Fonun and he did some experiments with cyanotype. Most likely Rezā Akkāsbāshi learned this technique from him. Carlhian was probably responsible for the introduction of Western props and paraphernalia in the Iranian photographer's studio, as well as for the typical Victorian pose: frontal and hieratic.

The Italian photographer Luigi Montabone introduced hand-colored photography in Iran. The photographs taken during his Italian mission were exhibited at the international exhibition in Paris in 1867 with big success. He produced the already mentioned and well-known album titled Ricordo del Viaggio in Persia della Missione Italiana 1862. In the words of Tahmasbpour,

the aesthetics and style introduced by Montabone had a profound influence on Iranian photographers working at the imperial court.

To date, no earlier examples of colored photographs in the Golestān Palace other than the photographs of Montabone are identified and so we can safely argue that Montabone's photographs mark a revolution in Iranian photography. (Tahmasbpour 2007: 17)

A good example of this kind of photograph is the one that depicts two Iranian military men whose clothes have been finely hand-painted with watercolors (fig. 155, see full color section). As Tahmasbpour states, the Iranian photographers that were active in hand-coloring were Rezā Akkāsbāshi, Mirzā Ahmad Akkās, Mirzā Ebrāhim Khān Akkāsbāshi and Abdollāh Mirzā Qajar. Tahmasbpour further states that, "besides, the vignetting used for the portraits taken of the Shah were novel too and were 
copied by Iranian photographers in the ensuing years" (Tahmasbpour 2007: 17). There is a hand-colored and vignetted portrait that Montabone took of Nāser al-Din Shah (fig. 156, see full color section) that is a good example of the two techniques that Montabone introduced in Iran. Many Iranian photographers adopted the vignetting technique, among others Rezā Akkāsbāshi, Mirzā Hoseyn Ali Akkās, Mirzā Ahmad Akkās, Āqā Yosuf Akkās, Manucher Khān Akkās, Abdollāh Mirzā Qajar (fig. 157) and Amir Jalil al-Dowle Qajar (fig. 158). One of the Iranian photographers who was most likely influenced by Montabone was Rezā Akkāsbāshi. There is one photograph taken by Montabone in which a group of Iranian sitters from the court are depicted (fig. 159). Among them we can find Rezā Akkāsbāshi standing (the third one from the left), portrayed in 1862 when he was already active as a photographer in the court. Actually his attitude, among all the men depicted, is the most conscious and theatrical one: he is the one who is completely aware of the camera and is playing both with the camera and the photographer. In this photograph we can guess the relationship that these two photographers may have had. This copy of this photograph is placed in an album hosted at the Golestān Palace Library, but in that one Nāser al-Din Shah identified and wrote the name of the persons depicted in Farsi, and also wrote: "Taken by the Italian photographer at Niavaran".

It is widely accepted among photo historians that Hoeltzer and Sevruguin are two of the more prolific and interesting photographers that were active in Iran in the nineteenth century. Both have left a remarkable photographic legacy yet to be studied in a systematic way. Hoeltzer's work may have been (consciously or not) nourished by both his cultural background and Persian visual arts aesthetics, due to the fact that he lived in Iran for a long time. Surprisingly, the Iranian photo historian Parisa Damandan claims that "his knowledge of Iranian culture and history was so limited that it stuns any educated person of our age" (Damandan 2004: 21). Even if he lived in Iran for a long time, the fact that he was an amateur photographer who basically worked for his own interest and enjoyment, make the hypothesis that his work was not influential to Iranian photographers very plausible. Nevertheless, as a consequence of 30 years in Iran, his work is remarkable especially for its anthropological approach.

Sevruguin was a well-known professional and commercial Orientalist photographer. His work's aesthetics were remarkable. His photography finds itself halfway between staged portrait and ethnographic photography. As the Iranian photo historian Rezā Sheikh points out,

Sevruguin's prowess as a stage director with a painter's instincts was best revealed within the confines of his studio. To assure better light he often photographed in his house's courtyard or the military procession grounds near his studio. (Sheikh 1999: 56) 
Sevruguin's work was very well known by Western travelers and was often used in their travelogues. In some cases, the writer would acknowledge the author of the photographs but in other cases would not. One of the most shocking examples is the April 1921 National Geographic Magazine, Modern Persia and its Capital, that I analyzed in the previous section, and where many pictures taken by Sevruguin appeared with another author's name (Faye Fischer). Unfortunately, in those days copyright was still science fiction. His work seems to be influenced by the Russian realist painters like Ilya Yefimovich Repin (1844-1930) and the English photographer Julia Margaret Cameron (1815-1879). The pose, facial expression and treatment of light in Cameron's portraits resemble Sevruguin's portraits of dervishes (figs. 160 and 161). In none of these photographs does the sitter look directly into the camera. All the men portrayed here seem to be in deep inner thought, with a clear mystical appearance in all of them that has been masterly achieved through the use of light and the staging of the sitter's attitude.

The next photograph by Sevruguin (fig. 162) nicely illustrates the pictorialist approach of this painter photographer. Taken around 1880, the composition of this image is no doubt very avant-guarde for its time and is very different from the archetypical Victorian portrait: frontal, hieratic and still. Looked at from a distance it shows a perfect balance between light and composition, a perfect diagonal and turning movement of the body that recalls the paintings of Ingres, all of which help to create an atmosphere of harmony. To make it even more interesting, the eyes of the sitter, which are turned away from the observer, are reflected in the mirror in front of him. Only people who are familiar with Persian culture will recognize the person depicted in the picture as a luti, a member of a traditional Iranian wrestling and athletic club known as zurkhāne. Apparently, lutis shave their heads when preparing for the annual passion play to commemorate the Shi'i imam Hussein, who died a martyr's death at the hands of the Sunni caliph Yazid in 680 AD. In an act of self-mutilation known as ghame-zani or tigh-zani, they inflict heavily bleeding wounds on their shaved heads, re-enacting the sufferings of Imam Hoseyn. Later on, while doing research on the archives of nineteenth-century Western photography in Iran at the Museum of Ethnology in Berlin, I was surprised to find a second image (fig. 163), a preliminary stage of the first one, that shares the three most important and characteristic elements with the first picture: it is also taken from the back, with a mirror, and the Persian style of haircut. However, it is obvious that the composition and the light bear no comparison to the first photograph, the previous one. These two photographs prove that Sevruguin was indeed a stage director in his own studio.

Type photography was a genre practiced by Sevruguin and in the collection we can find many images (like fig. 164). Here I would like to mention the research conducted by the German Iranologist and curator Frederike 
Voigt. She states that this kind of photography of types influenced the traditional tile painting in nineteenth century in Iran, with Sevruguin's photographs serving as a model for those tiles. ${ }^{9}$ There is one photograph where an Iranian woman is depicted in a squatting position with a straightforward title written under the photograph: Persian Toilet (fig. 112, already analyzed from another point of view in chapter 3). Another appealing photograph is that of a naked Iranian woman (fig. 113, also analyzed in chapter 3). These two photographs, emblematic of "Otherness", are at the Ethnology Museum of Leiden, which hosts a well-preserved collection of Sevruguin. These two images reveal Sevruguin's Orientalist approach better than others. Nude women are a recurrent topic in studio portraits of the nineteenth century, no matter in what country. This matter deserves closer attention because the photographer is non-Iranian and the woman an Iranian lady. The Algerian writer Malek Alloula has written the most remarkable analysis of postcards of "exotic" women that were sent to the Western public. In his book The Colonial Harem ${ }^{10}$, he collected, arranged and annotated picture postcards of Algerian women produced and sent by the French during the first three decades of the last century:

the mundane use of the postcards - short messages to family and friends - make the portrayals of Algerian women all the more insidious. Who were those women posing for these kinds of images? Were they the pure fantasy of the photographer's mind? .... The photographer comes up with more complacent counterparts to these inaccessible Algerian women. (Alloula 1986: 17)

Thus, as the photo historian and curator Nissan N. Perez stated,

genre photographers faced another problem with the lack of availability of models and the unwillingness of the local population, owing to their religious taboos or simple prejudices, to be photographed. Many of the women photographed in evocative poses were no doubt prostitutes. Other models appear to be blind and unaware of what was happening around them. (Perez 1988: 107)

Perez uses a striking example of a literally blind Nubian woman with exposed breasts taken by the Turkish brothers and photographers of Armenian origin Abdollāh Frères (fig. 165). Further, he presents two photographs by the French photographer Félix Bonfils of the same person identified in one as the chief rabbi of Jerusalem and in the other as a cotton carder. ${ }^{11}$ Alloula also presents a similar example in his book in a set of three postcards in which the same model, wearing the same outfit, photographed by the same photographer at the same location, represents in turn a "young Bedouin woman", a "young woman from the South" and a "young kabyl woman"! 12 
One of the peculiarities that I find more revealing of the nineteenth-century Western mind when faced with "exotic" women from North African and Asiatic countries, is the ambiguity between modest reserve and whispered beckoning, between the veil that reminds us of the seclusion of the female in those countries and naked parts of their bodies, which is almost always the breast. There are many examples of this kind of dichotomic images that play between hiding and revealing. I have selected two of them here: the first one is titled Moorish Bust and belongs to the series of postcards "Scenes and Types" (fig. 166). The second one is a postcard full of fantastic surrealism (fig. 167). The caption of the photograph reads: "Arabian woman with the Yachmak". I have found some examples of this kind in nineteenth-century Iranian photography, even if more discrete, interestingly in the work of Nāser al-Din Shah (see, for example, figs. 110 and 168), where two of his wives have been depicted with fully covered heads, but with exposed belly or/and breasts. I have seen quite a significant number of photographs where his wives wear a transparent blouse that fully reveals the breast underneath it: see figure 110. It is important to note that the Shah was the only photographer that took that kind of photographs; they were only meant to be enjoyed by himself and his wives. I believe that there is some kind of ludic component in those images: he did not produce the photographs for the market; they were just meant to be items of private contemplation, to his own enjoyment.

W. Ordén, as I briefly noted in the introduction to the history of photography in Iran, was one of the most mysterious and elusive photographers active in Central Asia at the end of the nineteenth century. His work produced in the Khānates of Khiva, Bukhara and Khokand is well-known, but to date, it was not known that he also traveled through Persia at the end of the nineteenthcentury and that he took many photographs of landscapes, architecture and people there. He must have been very fond of collages, since there are many in his collection and some of them depict Persian types (figs. 169 and 170). An extreme case of this, not depicting Persian types, but good to illustrate my argument, is a set of multiple collages of a rich variety of Central Asian types (figs. 171). More interesting for us is the collage the Oriental Princes at their Dignitaries (fig. 172), found in another collection (Anahita Gallery, Santa Fe), in which we can see in a central position a portrait of Nāser al-Din Shah surrounded by several important high-ranked men of the court.

After having analyzed the Ordén Collection of the nineteenth-century photographs from Central Asia and Persia hosted at the Ethnology Museum in Vienna (amounting to a total of 700), I perceive his viewpoint to be quite an anthropological one: by the care that he displays in arranging the collages of types and the information given of each one of them individually; by the repetition of certain subjects/topics, such as the cemeteries and also foreign populations (communities) of people in each city; 
by the number of art objects and artefacts and the care arranging the image. It seems to me that he was making a great effort to give as much visual information as possible (and therefore, his photographs remain a wealth of information about the material culture of the countries that he visited), complemented by captions rich in factual information about the people, places and objects depicted. His work constitutes a good example to illustrate what I stated at the beginning of this section, namely the fact that some Western photographers have left a rich legacy of photographs with a documentary, ethnological and/or anthropological approach.

It is very unlikely that his work had an influence of any kind on Iranian photographers, since no other document referring to him has been found anywhere yet. Further research is highly desirable. I am currently researching on this photographer, jointly with the american photo historian Heather S. Sonntag, expert on $19^{\text {th }}$ century Central Asian photography. The result of this joint work will be a travelling exhibition and catalogue.

In retrospect, I can conclude that Western photographers active in Iran in the nineteenth century, produced more photography with an ethnographical or anthropological approach (or documentary photography) than staged Orientalist photography that was basically produced by Sevruguin. The market for those Orientalist photographs never was as established and developed in Iran as it was in other Middle Eastern countries or North African countries, such as Algeria.

\section{Iranian photographers in Europe}

Several Iranian photographers traveled to Europe to learn the photographic technique with Western teachers. Rezā Akkāsbāshi traveled to Vienna in 1873, on a mission with Nāser al-Din Shah during his first trip to Europe, but he surely got Western influences already before this trip, since in 1863 , he was already being trained as a photographer in the court of Nāser alDin Shah under the guidance of the French photographer Carlhian. Abdollāh Mirzā Qajar attended the Dār al-Fonun and in 1869, traveled to Europe to study photography. He lived for a year and a half in Paris and for three years in Salzburg. Both of these photographers were court photographers and the influence that Western photographers had on the aesthetics of their work is noticeable in contrast to that of other more local (or bazaar) Iranian photographers: the pose (especially of the hands and head), the use of Western studio paraphernalia, the hand-coloring of photographs and the vignetting technique. Actually, one of the most aesthetically pleasing photographs that I have seen from nineteenth-century Iranian photographers is a lithograph hand-over-painted by Abdollāh Mirzā Qajar (fig. 173, see full color section), where we can see a very young Nāser al-Din Shah. Certainly, Nāser al-Din Shah was himself one of the Iranian photographers who was more exposed to Western aesthetics. He traveled to Paris several 
times and met the French photographer Gaspar Felix Tournachon (18201910), better known as Nadar, who took at least one portrait of the Shah around 1873 (online). As we can read in the Shah's travelogue The Diary of H.M. the Shah of Persia during his tour through Europe in A.D. 1873,

Nadar, a talented Parisian photographer, had an audience and took our photograph. He used to make flights in hot air balloons; but has now dropped that fancy, and occupies himself with photography. He is a pleasant and corpulent man. (Nāser al-Din Shah 1873: 237)

I have also seen a portrait taken by Nadar of Farrokh Khān Amin al-Molk (later known as Amin al-Dowle), who went to Paris in 1857 as an envoy of the Persian court (see Gosling, Niegel, Nadar, Secker \& Warburg, London, p. 117) to sign the first treaty between Persia and Germany. The influence of this photographer on the photographic work of the Shah is clear (especially the hand-pose used consistently by Nadar: one hand under the coat or jacket). See, for instance, figure 109 introduced in chapter 3, in which he and all the women depicted there show the same Nadar-pose. In contrast to this, we do not find this kind of pose at all in the work of Abdollāh Mirzā Qajar, although we do find it in Rezā Akkāsbāshi (see fig. 174).

The Shah was potrayed also by several European photographers during his travels through Europe in 1873, notably by the well-known Austrian female photographer Adele Perlmutter-Heilperin (active in Vienna after 1862). ${ }^{13}$ On the back of the picture (fig. 175) we can see both the stamp and signature of Adele's studio and the date, 1874. She was the most successful female photographer in Vienna at that time and one of the most famous portraits of her was taken by the Austrian photographer Fritz Luckhardt (1843-1984) ${ }^{14}$, who was to become the mentor of the Iranian court photographer Abdollāh Mirzā Qajar during his 5-year long stay in Austria to pursue his studies.

Another important Iranian photographer was Ali Khān Vali Hākem, whose work I shall analyze further on this chapter. Ali Khān Vali's photograph album documenting his career as governor at various places in Azerbaijan (Northwest Persia) between 1879 and 1896, is of the highest quality and character. Although the earliest photographs in the album are portraits of Nāser al-Din Shah taken in 1862-3, it would appear that the rest of the photographs date from Ali Khān's 1879 posting to Maragha, and the following years. The last date in the text is 1895-96. It contains no less than 1,400 photographs on 439 pages, that include representations of Shi'ite saints, portraits of Nāser al-Din Shah, Ali Khān's family, and all kinds of people and places he encountered during his career as governor. The photographs are captioned in almost all cases. Moreover, page after page is covered with a continuous narrative of his career, written around 
the photographs. In the work of this photographer we can clearly find elements that are borrowed from the Victorian portrait, but also elements that come from the Persian cultural background of the photographer. I will present some of his work in the next section, devoted to the topic of hybridity.

\section{Court photographers versus bazaar photographers. Art and craft}

It would be interesting to see if there was a noticeable difference in the aesthetic approach in photography between the Iranian court photographers and professional studio photographers living in big cities, on the one hand, and those who lived in smaller cities or towns or worked in bazaars, far away from the court, as I believe is the case. My current hypothesis (that will have to be tested with further research) is that the aesthetics of these court photographers, who were more exposed to the leading Western model of representation in photography (the Victorian model), was remarkable different from those photographers exposed to the age-old master-apprentice system, what I name here bazaar photographers. The aim of this future research would be to try to show with images if this hypothesis holds true, and to reflect on an interaction between the traditional Iranian learning system based on guilds and the new system directly influenced by Western academic models. As stated by Maryam Ekhtiar in her insightful article "From Workshop and Bazaar to Academy", for centuries in Iran, "art" was considered indistinguishable from "handicraft"

Traditionally, the activities of artisans and craftsmen in Iran were tied to the operation of guilds (asnāf) and workshops (kārkhāne). Whether employed by the royal workshops and guilds (asnäf-e sha$b i$ ) or by the local bazaars, artists and craftsmen worked and trained within the system. The kitābkhāne, or royal library workshop, had functioned within the parameters of the Royal Household and was considered one of its domestic departments. Despite Iran's increasing interaction with Russia and Europe during the eighteenth and early nineteenth centuries, the practices of the royal ateliers at this time still bore a striking resemblance to those of earlier periods. (Ehktiar 1998: 51)

Islamic art historian Sheila Canby argues that,

while individual artists, occasionally with the help of an assistant, designed and executed the actual illustrations in Persian manuscripts, the complete production of an illustrated book could involve many people, all of whom would be employed within the library or book-making atelier of a major, often royal patron. The director of 
the project would decide which episodes of the narrative should be illustrated. If the borders were to be flecked with gold, specialist gold-sprinklers would perform their task while the paper was still wet. Then, once the sheets were burnished, the scribe would copy the text, leaving space for paintings and illuminations as instructed by the director. The painter(s) would next proceed, followed by illuminators and gilders, whose intricate decorations adorned the frontispieces, end-pages and chapter-headings. These artists were also responsible for ruling and framing the lines that demarcated text from paintings and separated lines of poetry. (Canby 1993: 19)

European photographers became teachers of the Iranian court photographers, as I have already explained in the historical overview at the beginning of the book. Analyzing photographs taken by court photographers, like Rezā Akkāsbāshi, and contrasting them with the previous ones, we can see a clear Western influence, more specifically that of the Victorian portrait tradition in photography: hieratic, still and with the typical studio paraphernalia (background, chairs, columns and carpet). Next to this Western influence, court photography was also influenced by Qajar painting, as has been researched by scholars such as Diba, especially concerning the objects held by the sitter and the pose (including attitude towards the camera, normally a self-conscious one).

Apparently, court painting was more rooted in tradition following the guild-working models, whereas court photography was more exposed, in general, to Western models from its very beginning and for self-explanatory reasons: it could be that photography, being a Western discovery, was immediately accepted and admired by the Persian kings and was therefore accepted without any reserves with regard to the way of learning and teaching that came with the photographic practice. On the other hand, it would be important to explore if bazaar photographers (or photographers not related to the court) approached photography with the more traditional guild system. This belief is reinforced by the fact that classic Iranian historical texts about photography and Iranian photographers, such as "The beginning of the craft of photography and stereotyping in Iran" written by Iqbal Yaghma' ${ }^{16}{ }^{16}$, which considers photography as a craft in the very title. Actually, an important question to take into consideration is how Iranians received a modern Western invention such as photography, and how it became accepted. In my search for the roots and early uses of photography in Iran, the first thing I had to consider was the name that the Iranians gave to this new medium: Aks. As stated by Afshar,

the word aks has long been used in Persian in the general sense of the reflection in water, mirrors, etc. As he states further, the terms aks and $A k k \bar{a} s$ (photographer) also have a more technical use in two 
sixteenth-century texts dealing with miniatures and illustrations. Both passages refer to the same artist, Mawlana Kepek of Heart. The first is an introduction to an album in the Topkapi Museum (dated 1576-7) published under the tittle of Bustan-I Khatt: the other rare talent of the era was Mawlana Kepek, the $A k k \bar{a} s$ of Heart, who made aks (stencils) of pictures and line drawings, and in the making of colored stencils and gold sprinkling and the use of different colors and artistic designs (tarrahi) and calligraphy copying (muthan$n a$ ) has excelled all human beings. (Afshar 1992B: 267-268)

It seems that Iranians used a word that was already in their language to name the new invention. This contrasts with the fact that the English word photography that comes from the Greek photos, meaning "light", and graphia, meaning "drawing" or "writing", was invented exclusively for the new medium. Interestingly in Japan something similar happened to what happened in Iran: as stated by the Japanese critic and art historian Kohtaro Iizawa,

the Japanese gave to the new medium the word shashin, which is derived from the characters for "reproduce" and "true", meaning, in other words, the process of making a true reproduction, or "true copy". The word shashin was used in Japan even before the arrival of photography. It was used in the Chinese school of painting, which had a great influence on Japanese artists, especially with regard to the techniques of portraiture. (Iazawa 1994: 38)

\section{Female photographers}

What about female photographers? As already mentioned in the historical introduction, we know of three Western women active in Persia in the nineteenth century, the French Dieulafoy ${ }^{17}$ (active from 1881), the English Bishop-Bird ${ }^{18}$ (active 1890) and Bell ${ }^{19}$ (active in Iran from 1892). All of them were traveler-amateur photographers and their work did not have any influence on local photographers. Dieulafoy married Marcel Dieulafoy in 1870 and joined him in the army of the Loire during the Franco-Prussian war of 1870 . From that time, she adopted a masculine costume and short haircut in her extensive travels. When Marcel obtained an assignment in Persia, she decided to accompany him. She covered the whole Persian itinerary of the voyage (1881-82) on horseback. She managed to penetrate into the andaruns and provided us with vivid descriptions of the lives of secluded women of all ranks. Besides the main monuments and archeological remains, she photographed and processed on the spot many portraits of men, women and various social groups. All drawings and engravings 
illustrating her travel accounts and Marcel Dieulafoy's publications were made from these photographs.

The first Iranian women to acquire the technique of photography were most probably some of Nāser al-Din Shah's wives, who approached the new medium as an entertainment. They especially enjoyed the dark room's work. Asraf al-Saltane (1901-1953) was one of the Iranian pioneer female photographers. She was born in Kermanshah but moved to Tehran when she married Mohammad Hasan Khān E'temād al-Saltane, one of Nāser alDin Shah's ministers. In the family of Mo'ire al-Mamālek, there were also some female photographers. Asraf al-Soltane did not have children and used her time mostly to learn history, medicine, French and the technique of photography with Shahzade Soltān Mohammad Mirzā Wallet. After the death of her husband, she married again and moved to Mashhad. She was a very unusual woman for that time, who lead a life devoted to learning and experiencing things that were not the norm among Iranian women at the turn of the twentieth century. Eight years after her death, the Iranian historian Soltān Ahmad Dowlatshā'i Yomhan-Dowle wrote about her life and work, and that constitutes the best known source of information about this pioneer female photographer. ${ }^{20}$

There were two well-known Iranian female photographers active in the nineteenth century, Fāteme Soltān Khānom (wife of Mirzā Hasan Ali Akkās) and Osrat Khānom (wife of Āqā Yosuf Akkāsbāshi). They were sisters and the wives of two Iranian photographers, as was almost always the case with female photographers in the nineteenth century. As Rosenblum explains, most frequently, a woman would help her spouse in the photography business and then take it over after his death. ${ }^{21}$ Rosenblum further describes that as the techniques for producing portrait photographs changed, women were called upon for retouching as well as coloring. This skill, taught in schools, remained women's work well into the twentieth century, perhaps because, as one writer put it in the mid1880 s, a woman skilled in retouching "would have secured higher wages if she had been a man". ${ }^{22}$ Nāser al-Din Shah's wives were helping him to put together the albums of photographs that he took at court, mostly portraits of his wives and children.

The wife and daughter of Sevruguin are also among the first female photographers that were active in Iran in the late nineteenth-century and early twentieth century. They were both working at Sevruguin's studio and took it over after his death, in accordance with Rosenblum's claim.

In Shiraz, two daughters of Mirzā Hasan Chehrehnegār known as Aziz-e Jahān and Habib-e Zamān, opened the first studio in this city specialized in portraits of women. They became serious professional photographers.

Iranian female photographers in the nineteenth century is a fascinating topic that has to date been underresearched. It is especially important to undertake such a research since female photographers mainly took pictures 
of women, and such a research will probably give new insights into the topic of the representation of women in nineteenth-century photography. The leading photo historian Khadije Mohammadi Nameghi has done extensive research on the topic of photographing women in the Qajar Era and her work is an important referent to anybody wanting to undertake further research on this topic (see bibliography for references to her published work). An article about the topic of photographing women in the Qajar Period and through the 1930s and about female photographers (by Khadijeh Mohammadi Nameghi and Carmen Pérez González) will be published in a special issue of the journal History of Photography devoted to Iranian photography in the nineteenth and early twentieth century (January 2013, see bibliography).

\section{Evolution of visual laterality, relation text-image, pose and space}

Among the topics considered in the four previous chapters of this book, the ones in which Western influence may be most noticeable or relevant are "visual laterality" and "pose".

The visual-laterality phenomenon may have changed in the course of the nineteenth and twentieth centuries. My research points to the fact that there are more exceptions to the visual-laterality composition (mirror-like) of Iranian photographs towards the beginning of the twentieth century, when Western influences may have been stronger and more noticeable. Nevertheless, to date I cannot conclude anything solid about this, and it remains an open research topic.

As for pose, the most important Western influence on the traditional Iranian pose was caused by the use of the chair in the studio paraphernalia. The change of pose from the traditional kneeling pose to a more westernized sitting position is clearly noticeable in nineteenth-century Iranian photography. Next to this, the court photographers, such as Rezā Akkāsbāshi or Abdollāh Mirzā Qajar, were by far more influenced by the Western studio paraphernalia than bazaar or local photographers: in the individual portraits taken by court photographers we find more sitters on chairs than in the case of non-court photographers, whose photographs show normally kneeling sitters. This difference disappears, interestingly, when we consider group portrait photographs: in this case, the sitters are almost always kneeling! The reason for this may be that there were not enough chairs in the photographer's studio. See, for instance, Rezā Akkāsbāshi's photographs of kneeling mullahs (figs. 137 and 138) from the previous chapter. Probably the traditional poses of the hands (like the modest one, holding hands and resting them on the sitter's lap, or holding with one hand a tasbi or some other traditional object, see figure 75) were influenced, and changed, into some other more westernized poses, like the one that Nadar made popular: one hand under the coat. One of the typical 
Victorian hand-poses that also entered the Iranian photographer's studio is that of the hands resting in parallel on each one of the legs (see figure 103). Another traditional pose inherited, as I have already pointed out in chapter 3, from the Qajar portraiture tradition is the one of a man sitting on a chair and holding a sword (see figures 14, 62, 95 and 96, see full color section).

Even if Iranian photographers adopted the props and studio paraphernalia typical of the Victorian-style studios, they usually adapted those elements in a more local way. For example, the background: there are local backgrounds used by some Iranian photographers that are more patterned than the Western realist ones. There are even photographers who use a carpet as background.

In sum, Carlhian, Montabone and Sevruguin were the most influential Western photographers in Iran. Carhlian was responsible for the introduction of the Victorian pose (hieratical and frontal) and studio paraphernalia among Iranian court photographers; Montabone introduced hand-colored photography and the technique of vignetting; and Sevruguin's pictorialism in photography was also a fundamental referent for those Iranian photographers more exposed to foreign influences, as court or successful professional photographers who ran studios in Tehran or other big cities.

\subsection{Hybridity versus Appropriation}

Due to the double cultural influence that some of the nineteenth-century Iranian photographers had during their active life as photographers, their work presents, as I shall show shortly with several photographs, a combination of elements belonging to each of the two cultures. I have spent some time trying to find an adequate term to define this property of the photographs produced by these Iranian photographers. It was difficult to find a good term to name the phenomenon: hybridity, acculturation, interculturality, assemblage and appropriation were the terms considered during that process. For a long time I considered the term "hybridity" as the one to clearly explain the concept. Nevertheless, I disregardered it later in favor of "appropriation". In the following pages I discuss the reasons for taking that decision. Iranian photographers made elements found in nineteenthcentury Western photography their own: they not only adopted studio paraphernalia but also the attitude and pose of the sitter.

Hybridity is one of the most widely employed and most disputed terms in postcolonial theory. It refers to the creation of new transcultural forms within the contact zone made by colonization. The term hybridity has been most recently associated with the work of the Indian theorist of postcolonialism Homi K. Bhabha, whose analysis of colonizer and colonized relations stress their interdependence and the mutual construction of their subjectivities. Bhabha states that all cultural statements and systems are 
constructed in a space that he calls "the third space of enunciation". Cultural identity always emerges in this contradictory and ambivalent space, which in Bhabha's opinion makes the claim to a hierarchical "purity" of cultures untenable. For him, the recognition of this ambivalent space of cultural identity may help us overcome the exoticism of cultural diversity in favor of the recognition of an empowering hybridity. Within this, cultural difference may operate. As Bhabha said:

It is significant that the productive capacities of this Third Space have a colonial or postcolonial provenance. For a willingness to descend into that alien territory (...) may open the way to conceptualizing an international culture, based not on the exoticism of multiculturalism or the diversity of cultures, but on the inscription and articulation of culture's hybridity. (Bhabha 1994: 38)

Here it is important to remark that some scholars, such as the art historian John Clark, have incisively noted that sometimes postcolonialist discourses were built on virtual ignorance of the local archives it would be thought they had consulted. ${ }^{23} \mathrm{He}$ further states that,

according to the Scottish writer and historian William Dalrymple, in all the output of Subaltern Studies not one PhD has been written from the Mutinity Papers ${ }^{24}$, the basic archival collection, nor a major study systematically explored its contents. ${ }^{25}$

The use of the term hybridity has been widely criticized, since it usually implies negating and neglecting the imbalance and inequality of the power relations it references. By stressing the transformative cultural, linguistic and political impacts on both the colonized and the colonizer, it has been regarded as replicating assimilationist policies by masking or "whitewashing" cultural differences. ${ }^{26}$ The idea of hybridity also underlines other attempts to stress the mutuality of cultures in the colonial and postcolonial process in expressions of syncreticity, cultural synergy ${ }^{27}$ and transculturation. As explained by scholars on postcolonial theory Bill Ascroft, Gareth Griffiths and Helen Tiffin,

The criticism of the term referred to above stems from the perception that theories which stress mutuality necessarily downplay oppositionality, and increase continuing post-colonial dependence. There is, however, nothing in the idea of hybridity as such that suggests that mutuality negates the hierarchical nature of the imperial process or that it involves the idea of an equal exchange. (Ascroft, Griffiths \& Tiffin 1998: 119) 
This is actually the way in which some proponents of decolonization and anticolonialism have interpreted its current usage in colonial discourse theory. It has also been subject to critique as part of a general dissatisfaction with colonial discourse theory, including the critics Chandra Talpade Mohanty, Benita Parry and Aijaz Ahmad. ${ }^{28}$ These critiques stress the textualist and idealist basis of such analysis and point out the fact that they neglect specific local differences, which agrees with Clark's arguments as well. As argued by Clark,
hybridity is the notion of a redeployment of practices and discourse, even whole constructions of the self, into the interstitial space be- tween cultures has a long presence in varying shapes and media- tions of the "other". It requires mutual acceptance and sometimes adherence to values and practices, involving reciprocal tolerance and sometimes reciprocal formal acknowledgment. The hybrid is dependent on neither colonial nor post-colonial situations and may indeed have been historically subversive of the hegemonies of both. (Clark 2007: 2)

The art historian Frederik N. Bohrer used Bhabha's ideas on hybridity and applied them to photography. He takes Sevruguin and his life as an example of cultural "between-ness", since he was influenced and knew both cultures well due to his early movements back and forth between Tehran and Tblisi, between the Iranian capital and an area newly under Russian rule. He talks about the conditions of photographic hybridity. ${ }^{29}$ Behdad has been critical of Bohrer's use of New Historical/Postcolonial language to describe early photography as a self-fashioning and hybrid phenomenon. He takes Sevruguin and also Nāser al-Din Shah as examples for his argumentation. In the words of Behdad,

Qajar photography, as a Western mode of representation, borrowed its images from the large body of Orientalist discourses and artistic practices. Neither Sevruguin nor Nāser al-Din Shah could have captured "the complexities and contradictions of a multicultural society", as Bohrer claims. (Behdad 2001: 148)

I do fully agree with Behdad's statement, these photographers could not have captured the complexities and contradictions of a multicultural society. But, their work (probably in an unconscious way) does reflect the double exposure of the photographer to Western and Iranian culture. Therefore, the photographs are, to my understanding, the only ones that can be classified under the term hybrids. The historian G.R. Garthwaite has strongly criticized the author's methodologies of the book Sevruguin and the Persian Image (among them Bohrer and Behdad). He states that 
historians value this kind of photography as texts that need contextualization from other contemporary sources, without which the photographs cannot be fully understood or appreciated.

Decontextualization is but one of the negative consequences of Said's orientalism and, as stated further in his article, the use of "hybridity" as analytical categories, says more about late twentiethcentury academic interests than late nineteenth-century Iran.

(Garthwaite 2000: 409)

This fully agrees with Clark's arguments that I have introduced on the previous page. After having introduced this discourse on hybridity, it is clear that one must be careful with using the term hybridity. To make my position clear, I will define aesthetic hybridity (maybe better hybrid aesthetic) as a cultural practice that presents, next to each other, elements that come from two different cultures and that share space in a work of art, in this case, in a photograph. Nevertheless, the use of this word was not accurate for this particular phenomenon and after some time I adopted "appropriation" because it better reflects the meaning of that phenomenon. ${ }^{30}$

Etymologically the word "appropriation" derives from the Latin ad meaning "to", with the notion of "rendering to", and proprius, "own or personal", yielding in combination, appropriare, "to make one's own". Appropriation is active, subjective and motivated. Following the definition of the word appropriation by the art historian Robert S. Nelson in Critic Terms for Art History, it seems more adequate to use the term "appopriation" to define what happened with nineteenth-century Iranian photography in the process of its being influenced by Western photography. As the art historians Robert S. Nelson and Richard Shiff explain,

Its application to art and art history is relatively recent and pertains to the art work's adoption of preexisting elements. Such actions have been less successfully described as "borrowings", as if what is taken is ever repaid, or as "influences", that elusive agency, by which someone or something infects, informs, provokes, or guides the production or reception of the artwork (...) Michel Foucault critized the concept of influence, in particular, as belonging to a constellation of terms, which if poorly understood theoretically, nevertheless function to affirm and maintain the continuity and integrity of history, tradition and discourse. In regard to art history itself, Michel Baxandall also argued that influence occludes actor and agency. In contrast, the term "appropriation" locates both in the person of the maker or receiver. The difference between the two is the same as the grammatical distinction between the passive and the active voices. (Nelson \& Shiff 2003: 161-162) 
In conclusion, I will undertake a visual analysis of a group of photographs, both by Iranian and Western photographers, which present this phenomenon of appropriation of foreign elements in their work, and therefore their work displays a mixed aesthetic approach. As I have mentioned already, there is always the possibility that the persons depicted chose the pose themselves. In these cases they often picked traditional poses, such as kneeling. Therefore, elements belonging to the two cultures can be traced in the photographs, and they can have been caused both by the photographer or by the person depicted. The first is caused by the mixed cultural influence on the photographer and the second by the unconscious gestual reaction of the body of the sitters that also can be conditioned by culture. The photographs that I will analyze in this section show elements inherited from the Victorian portrait tradition next to others from the Iranian cultural background of the photographer and/or the sitter. I have grouped the photographs selected for this section in three categories: appropriation of the objects held by the sitters (objects); appropriation of the use and role of the studio props and paraphernalia, especially the chair (chair); and finally appropriation of studio props that provoke a decontextualization of the subject, a tension between an unexpected sitter and an artificial atmosphere best represented by the backdrop and studio props (tension). An artificial and strange environment has been created: a Western environment in an Iranian cultural context.

To start with the first group, objects, I have selected two images, one by a Western photographer and the second one by an Iranian photographer. In the first image (fig. 102), taken by Hoeltzer and already introduced in chapter 3, we can see a group studio portrait of five men. The three men sitting are mullahs and are wearing traditional garments. The two men standing are probably servants. All of them are wearing a jobbe (gown) under the $a b \bar{a}$ (a form of outer garment that is open at the front and sleeveless with large armholes). Men and women of all classes wore these two pieces of clothes. The type of material (silk, wool, camel hair) and its weight varied according to the time of the year. The three men sitting are wearing the typical turban that completes the outfits of the mullahs. This photograph is revealing as far as aesthetic hybridity is concerned as we see a mixture of the Victorian portrait (frontal, hieratic) and the aesthetics of the Persian miniatures represented by the flowers held by two of the men depicted. The pose of the three men holding flowers in their hands recalls that of figure studies in miniature paintings where this pose was often used (see figs. 100 and 101, chapter 3). This element is unusual for this painting tradition and cannot be found in Western painting. The next picture was taken by Mirzā Mehdi Khān Chehre-Namā), an Iranian photographer who was working successfully in Isfahan at around the same time as Hoeltzer. He composed the pictures in exactly the same way: the same Victorian portrait aesthetic mixed with that of the miniature represented by the flowers. If we 
compare both pictures, we would not actually be able to tell which one was taken by Hoeltzer or which one by Mirzā! This is apparent if we compare the previous image with one taken by this Iranian photographer (fig. 176).

There are numerous examples that illustrate the second group, chairs, like a photo taken by Montabone, in which a hybrid pose caused by the use of the chair is to be found. In Viceré di Tebriz coi suoi ministri (fig. 99) we can see a boy who is kneeling on a chair as if it were the floor. This is the kind of image that is produced, as I have stated above, by the person depicted. As David Efron states in Gesture, Race and Culture,

"Hybrid" gesticulation indicates that the same individual may, if simultaneously exposed over a period of time to two or more gesturally different groups, adopt and combine certain gestural traits of both groups. (Efron 1972: 160)

In this case, a foreign element in the studio (chair) is used with a native posture (kneeling). There are many examples of this kind of hybrid postures, like figure 97 already introduced in chapter 3, which depicts a child squatting on a balustrade, therefore giving this studio prop a different role from the one it had originally: a mere decorative element of the studio. The chair is an interesting element used as part of the studio paraphernalia and I have found many examples of photographs where the chair has been given a particular use very different from the one that it was meant for: sitting or just as a point to hold your balance. Seyyed Ali Darvandi is depicted in the next photograph (fig. 177) taken by the Iranian photographer Ali Khān Hākem Vali. He is sitting on the floor and using the chair only to rest his elbow. The fact that the main function of the chair is for people to sit on makes the image quite bizarre (for Western eyes) since the man is completely ignoring the function of the object and uses it in his own way. Also taken by Hākem Vali is the next image that presents Mirzā Mohammad Sādeq Sāhebnaqsh in exactly the same pose as in the previous one (fig. 178). Another peculiar use of the chair in Iranian photographs is as a table, placing, for example, a pot of flowers on top of it as if it were a decorative object on top of a table. See the next two photographs by Hākem Vali that show this interesting new function of the chair in the photographer's studio. In the first one, Mirzā Ali Khān Sartip (fig. 179) is depicted and in the second one Ali Āghā Akkās (also a photographer) (fig. 180). I have seen the same two pots of flowers being photographed by Hākem Vali over and over again. There are many other examples of this kind taken by other Iranian photographers.

A photograph that I have already introduced in chapter 2, is one that depicts a scholar sitting on a chair with a book on his lap (fig. 76). The studio paraphernalia and pose is typical of the Victorian portrait: carpet, 
curtain a table with books.... But the inscriptions in the upper left corner of the image is the Persian element that finally gives the image a hybrid aesthetic and specific representation. The inscription in the upper part of the photograph is a philosophical poem, a reflection about the importance of the meaning of the image beyond its mere form and outer appearance. In this image, the sitting pose is used instead of the traditional Persian way of kneeling or sitting on the floor. Some of the photographs selected for the second chapter of this book (text and photography) show this same mixed aesthetic.

The last group, tension, includes images, such as the next two photographs, that are shocking images of two prisoners (Hajji Mirza Ahmade Kermani and Hajji Mohamad Ali Saya-he Mahalati ) posing in a photographer's studio (figs. 181 and 182), precisely that of Mohammad Hasan Qajar. The subject is totally out of context, the background and studio paraphernalia look ridiculous next to the hard look and position of the prisoner. Further examples of this kind are those taken by the court photographer Rezā Akkāsbāshi. After analyzing many photographs taken by this photographer, I can now recognize the authorship of his photographs simply by looking at the backdrop, which shows a landscape with a typical Victorian house (like in fig. 92, introduced in chapter 3). The interesting decontextualization that is to be found widely not only among Iranian photographers but also in the work of other Asian and African photographers is where a native person is depicted in front of a painted background with a landscape that does not belong to the real context of the person depicted. A sort of spatial and temporal dislocation is achieved through this decontextualization between the backdrop and the sitter. Sometimes it was not the topic of the backdrop's painting, but the mere use that the backdrop was given. In many photographs taken by nineteenth-century Iranian photographers we can notice that the photograph has not been framed "properly", meaning here, that one of the functions of the backdrop (to make "more" credible a staged photograph in the studio) has been ignored, be it by technical restrictions of the camera or on purpose by the photographers. Nevertheless, there are clear examples of the second possibility, like a stereographic portrait of Mozaffar al-Din Shah (fig. 183): the Shah is depicted sitting on a chair and is smiling at the camera, the photographer stands far away from him and takes the picture from behind a fence so that the Shah, the backdrop and the whole montage completely lose their original function. The Western backdrops contrast with a more local kind of backdrops that in some cases were patterned (with abstract designs, often a carpet) that introduced an element of indeterminance (see figs. 184 and 67). It is interesting to note the striking parallel between the kind of images just analyzed and those produced by the Malian photographer Seydou Keïta in the 1960s. He also used patterned and abstract backdrops that contrast with the realist backdrops used by Victorian photographers. This 
practice is also found in nineteenth-century African photography and Indian photography. ${ }^{31}$

In retrospect, Western and Iranian photographers both constructed photographs based on their own perception, their own reading (i.e. interpretation or/and manipulation) of the reality that surrounded them. However, Western photographers displayed an ethnographical approach in their work that was (normally) free of the Orientalist taste, and next to that, Sevruguin also produced a remarkable corpus of the so-called Orientalist photography. The photographs taken by Western photographers have been deconstructed through their cultural components, like I did in the previous chapters with the Iranian ones: the direction of writing, the lack of inscriptions on the photographic surface, the pose of the sitter (sitting, frontal, hieratic), and understanding the space are the cultural components.

In reality, the aesthetics of Iranian photographers were the product of travels that Western and Iranian photographers undertook in both directions. Carlhian, Montabone and Sevruguin were the most influential Western photographers, at least regarding court photographers. Carhlian introduced the Victorian portrait's aesthetics and studio paraphernalia, and the cyanotype process to Iranian court photographers; Montabone introduced handcolored photography and the technique of vignetting; and Sevruguin added a pictorialist approach to Iranian photography. Rezā Akkāsbāshi and Abdollāh Mirzā Qajar, both court photographers, traveled to Europe and were also influenced by Western teachers in the court. Also, next to the Western influences in the court, there were the ones from Western photographers who were visited by Iranian photographers in Europe, notably the French Nadar. These travels not only provided exchanges and refinements but also made the Western photographers witnesses to the formation of a new modern concept that Iranians formed of their own life and their own desires. Thus, these photographs turned out to become a brilliant unadulterated document as to the way Iranians recorded their passage from tradition to modernity, especially as regards to life in the court.

Indeed, as a mediator between the two cultures, these Iranian court photographers, not only brought the aesthetics of their European counterparts home, but they propagated the royal Persian image abroad through the lenses of their cameras, a commodity as valuable as spices brought to Europe by Marco Polo.

\section{Notes}

1 Edward Young, eighteenth-century poet and playwrigh (1683-1765), Conjectures on Original Composition. In a Letter to the Author of Sir Charles Grandison, London, A. Millar and R. and J. Dodsley, 1759.

2 Sontag 1979: 153-180. 
3 It is important to remark here that whenever I use the term Orientalism, I will exclusively refer to Said's Orientalism, but this does not meant that I view the whole corpus of Oriental Studies or Western photographic corpus through Said's prism.

4 Buruma and Margalit 2005.

5 The National Geographic Magazine, published by the National Geographic Society, Washington, D.C., April 1921.

6 The word odalisque appears in a French form, and originates from the Turkish odalik, meaning "chambermaid", from oda, "chamber" or "room". During the nineteenth century odalisques became common fantasy figures in the artistic movement known as Orientalism.

7 See: Benjamin 1997: 32-40.

8 See: Nochlin 1983.

9 For further reading on this topic and interesting examples see: Voigt, F. (2002), Qadscharische Bildfliesen im Etnologischen Museum Berlin. Berlin: Staatliche Mussen zu Berlin.

10 Alloula 1986.

11 To see the examples: Perez 1988: 107.

12 To see the examples: Alloula 1986: 62, 63 and 65.

13 Adele Perlmutter-Heilperin co-owned the studio with her two brothers. The studio prospered and around 1890, the Atelier was named Photographer to the Imperial Court. Also in 1890, Perlmutter- Heilperin turned over management of the studio to one of her brothers.

14 Luckhardt, who at that time was the First Secretary of the Viennese Photographic Association, was born in Germany, but after a short stay in Paris and England, he settled in Vienna in 1865 and opened his own studio in 1867 as an elegant society photographer. For more information on this photographer, see: Auer, A. (1997), Die vergessene Briefe und Schriften. Niépce, Daguerre, Talbot, Photographische Gesellschaft in Wien (PhGW): 50-51.

15 The only instance in which "art" in any way approximated an academic discipline before the mid-nineteenth century had been in the education of kings and princes within the royal household. Maryam Ekhtiar, "From Workshop and Bazaar to Academy. Art Training and Production in Qajar Iran", in Ehktiar 1998: 63.

16 Afshar 1992B: 262.

17 Dieulafoy, J. (1887), La Perse, la Chaldée, la Susiane. Paris: Phebus. The whole travelogue (but not all images) have been reprinted in two volumes: Une amazone en Orient (2010) and L'Orient sous le voile (edition 2011). Paris: Phebus.

18 Bird, I. (1891), Journeys in Persia and Kurdistan. Travels on Horseback in 1890, Long Rider's Guild Press. Reprinted in two volumes in 2004.

19 Bell, G. L. (1894), Safar Nameh. Persian Pictures. A Book of Travel. London: Richard Bentley and Son: 96-111. This travelogue has been published in a modern edition in: Bell, G. and Lukitz, L. (2005). Persian Pictures, Anthem Studies in Travel.

20 As summarized and translated from Zokā 1997: 178-180.

21 Rosenblum 1994: 42.

22 Manson, G. J. (1883), “Work for Women in Photography”, Philadelphia Photographer 20: 37. Taken from Rosenblum 1994: 48.

23 Clark, J. (2007), Hybridity in Asian Art Now: conference outline: 2.

24 The Mutinity Papers is a corpus of historical documents written in Urdu and Persian about the 1857 Indian mutinity or the "first war of independence", when Indian soldiers of the British army rebelled against their colonial masters. They are held at the National Archive in Delhi.

25 After Clark (2007): see Dalrymple, W. (2006), The Last Mughal; The Fall of a Dynasty, Delhi, 1857. London: Bloomsbury: 13-14. 
26 Ashcroft, Griffiths and Tiffin 1998: 119.

27 A term used to emphasize that post-colonial cultures are the product of a number of forces variously contributing to a new and complex cultural formation.

28 See, after Ashcroft (1998): Mohanty, C.T. (1984), "Under Western eyes: Feminist scholarship and colonial discourse", Boundary 2: 71-92; Parry, B. (1987), "Problems in current discourse theory", Oxford Literary Review 9: 27-58, and Parry, B. (1994), "Resistance theory/theorising resistance: Two cheers for nativism", Colonial Discourse/Postcolonial Theory. Manchester and NY: Manchester University Press; Ahmad, A. (1992), In Theory: Classes, Nations, Literatures. London: Verso.

29 Bohrer 1999: 33-53.

30 I am very grateful to Kitty Zijlmans for her ideas and insight on the topic of hybridity and appropriation.

31 For an interesting article about the widespread use of props and backdrops in popular postcolonial photography and the way it expresses a resistance to the documentary claims of photography and a foregrounding of critics of modernity, see: Appadurai, A. (1997), "The Subaltern Backdrop", in Afterimage 24 (5): 4-7. 



\section{CONCLUSION}

Nineteenth-century Western photographers constructed other culture's realities as much as Iranian photographers constructed their own. Both groups of photographers produced their own constructed realities of the same "reality" and the result of each process of construction was deeply influenced by the cultural background of the photographer. Studios were nothing more than mere theaters where, both sitters and photographers, could eternally freeze the image that they wanted others and themselves to see. The Western creations were done, only in part, in line with Orientalist photography that was fashionable at that time and practiced in other "exotic" countries such as Algeria or Egypt. The Iranian photographs were influenced both by the Iranian pictorial tradition and by the Western (i.e. Victorian) model. Nevertheless, regardless of their nationality, photographers did not fail to submit to fashion when producing for the tourist market, for which the cultural origins of the photographer were of little importance. These elaborated representations never failed to reflect the ideology of their epoch. Iran was not a commercial country at all as far as its photographic material is concerned; therefore commercial photography has almost NO relevance regarding the amount of photographic material produced in Iran in the nineteenth century, and it can be almost reduced exclusively to the work of Antoin Sevruguin. Iran was not on the route of the steamers going from Europe to Japan and this was one of the reasons why commercial photography did not flourish there as it did massively in other Asian countries.

For my dissertation (the materia prima for this book), I conducted a thorough visual analysis of photographic material and developed a model to visually analyze and compare corpuses of photographs and paintings. This model aims to strip images of their cultural components in a multilayered process in the same way, but in the reversed direction, as the images were constructed: images present different elements in a multilayered form and these elements can be analyzed one after the other as if we were peeling off an onion. Further, what I mean by "reversed direction" is that I analyzed the images to define the elements present in the photographs in the contrary direction (temporal and probably also spatial) of the one in which the photographs were taken. The set of cultural components through which I have deconstructed nineteenth-century Iranian photographs is composed of: the direction of the script which leads to a tendency in nineteenthcentury Iranian photographers to produce mirror-like images of those produced by their Western colleagues; the use of text within the photographic space; the pose of the sitter; and the understanding of the space. This 
constitutes a particular cultural-components-set of Iranian photography in the nineteenth-century. Mirror-like compositions are directly related to the direction of writing of the script; use of text and pose are directly related to the Iranian painting tradition. Space remains the least convincing component for a comparative analysis between painting and photography, since the technical restrictions of the camera seem to play a dominant role in the understanding of the space in photography. If we would conduct the same research with a Japanese, Chinese or Indian photographic corpus, we may find a comparable cultural-component recipe.

The model developed here can be summarized as follows: define the photographic corpus; define the corpus of paintings ; conduct a visual analysis of both corpuses to establish differences and similarities between them; define the cultural components found after visual analysis of the photographic and painting material (these cultural components can include some of the ones already defined for Iranian photography, but the final cultural set will probably be different); and lastly, establish categories or groups of photographs that represent the cultural components defined in the previous section. The model could be used also to compare two corpuses of photographs (not necessarily involving paintings): for example, a corpus of photographs taken by Spanish photographers in South America and a second corpus of photographs taken by South American photographers in their own countries, in the nineteenth century. Regardless of the corpuses compared, this method is based on very large corpuses of graphic material.

The cultural-components-set found and defined after pursuing an indepth visual analysis of the corpuses selected for this dissertation and the interaction between the different disciplines, can be summarized through the next diagram (graphic 2, see full color section):

The basic steps for applying the model are:

1 Build up corpuses of graphic material, gathering as many images as possible from archives, printed books, etc.

2 Cross-visual analyze corpuses of graphic material.

3 Establish hypotheses.

4 Theoretical perspective: once the topics (classification of the images in groups) to study are defined, we have to delve in a historical theoretical perspective for each one of them, in order to make an analysis of the state-of-the-field related to each particular hypothesis (theoretical support of each hypothesis).

5 Establish categories after having tested the hypotheses both theoretically and empirically.

In each chapter, I have analyzed the photographs from one of the four perspectives defined (visual laterality; use of text; pose; and space). To 
conclude this book, I would like to come back to a few photographs, which have already been introduced from a multi-perspective point of view, to show that the above listed elements are not isolated phenomena but all share space within the photograph.

The portrait of a kneeling mullah (fig. 75) summarized the different aspects of the Persian visual art tradition present in nineteenth-century Iranian photography: the use of inscriptions; the philosophical understanding of images as powerful tools but in compliance with their inherent features (such as with Sufi philosophy); the poetic tone of the text; the use of traditional objects (tasbi); the traditional kneeling pose of the sitter; and the use of an ornamental frame. Another photograph that presents several characteristic elements found in Persian miniatures is the portrait of the poet Gha'ani (fig. 55): the use of inscriptions; traditional kneeling pose; objects held (water pipe); studio paraphernalia (cushion); and an elaborated passe-partout. The third photograph selected here is the group portrait of the poets in Shiraz (fig. 57): the use of inscriptions (poem); traditional kneeling pose of some of the sitters; objects held (tasbi, flowers); and the omnipresent pots of flowers.

Most of the photographs analyzed in this book present at least two of the Persian elements mentioned above, revealing a different aesthetic approach to the dominant, Victorian model of photography that was in vogue in the nineteenth century. The research conducted in this book has shown that different aesthetic models of representation existed in the nineteenth century, related to their specific socio-political and cultural context, such as in this case Iran. 



\section{AFTERWORD}

Here, I would like to introduce briefly the areas which I am researching currently. The work that I have presented in this book is merely a preliminary research, from an art historical standpoint, of a small part of the fascinating and to date still underresearched field of Iranian photography, or more precisely, of the aesthetics of Iranian photographers in the nineteenth century. As a result of what I think is the logical evolution to my research, I have taken the decision to detach myself from the restrictions of conducting a comparative research between painting and photography. This approach was fundamental for me when I started this research in 2004. No study had been done before on this topic in the field of photography and turning my eyes to painting was both very educative and inspiring, and I would say, the most obvious thing to do. The topics that I shall be working on in the future are:

1 Visual Laterality. I am currently gathering graphic material from different fields of the visual arts (photography, painting, graphic design, film, etc) for a projected book that will explore this topic from a wide intermedial perspective. I am building up two corpuses of graphic material (one from Iran and the other from Spain) for a comparative analysis.

2 The Written Image: Text and Photography. I am working on the conceptual design of a book about the topic of text and photography in nineteenth-century Asia, but with a stronger focus on Iranian photography and expanding the topic to other countries, aiming for a comparative analysis of the content and spatial implementation of the inscriptions within the photographic space.

3 Methodological issues. Through the research for my $\mathrm{PhD}$ thesis I have developed a method of comparative analysis that seems to be useful for art historians, to locate, define and prove the cultural conditioning in the production of images (and of photographs in this particular example). Due to the unexpected interest that this approach has caused in some of the readers of my dissertation (supervisors, reading committee members and some colleagues), I have decided to keep exploring these theoretical and methodological issues. In addition to applying this method of research to other photographic and painting corpuses, I will keep refining the method by applying it further to my two aforementioned research topics (visual laterality and the written image). In the 
future, I intend to elaborate the theoretical definition of this methodology.

4 Lives and work of the Iranian photographers considered in this book are a continuous source of interest for further research. Currently, I am actively researching signatures and Iranian court photographers. 


\section{BIBLIOGRAPHY}

\section{General photography}

Arnheim, R. (1974), 'On the Nature of Photography', in Critical Inquiry, 149-161.

Barthes, R. (1981), Camera Lucida: Reflections on Photography. New York: Hill and Wang.

Batchen, G. (1997), Burning with Desire: The Conception of Photography. Cambridge: MIT Press.

Belting, H. (2001), Bild-Anthropologie. München: Wilhelm Fink Verlag.

Berger, J. (1972), Ways of Seeing. London: Penguin.

Burgin, V. (ed.) (1982), Thinking Photography. London: Macmillan.

Burgin, V. (1986), 'Something about Photography Theory', in The New Art History, edited by A. L. Ress and Frances Borzello, New Jersey: Humanities Press International.

Darrah, W.C. (1981), Cartes de Visite in the Nineteenth Century. Pennsylvania: Darrah-Smith Books.

Elkins, J. (ed.) (2007), Photography Theory. New York \& London: Routledge.

Flusser, V. (2000), Towards a Philosophy of Photography. London: Reaktion Books.

Frizot, M. (1989), Neue Geschichte der Fotografie. Cologne: Könneman.

Gernsheim, H. (1982), The Origins of Photography. New York: Thames and Hudson.

Henisch \& Henisch (1994), The Photographic Experience 1839-1914: Images and Attitudes. Pennsylvania: Pennsylvania University Press.

Kelsey, R. \& Stimson, B. (2008), The Meaning of Photography. New Haven and London: Yale University Press.

Newhall, B. (1982), The History of Photography from 1839 to the Present Day. New York: The Museum of Modern Art.

Pollack, P. (1969), The Picture History of Photography from the Earliest Beginnings to the Present Day. New York: Abrams.

Rosenblum, N. (1994), A History of Women Photographers. Paris, London, New York: Abbeville Press Publishers.

Rosenblum, N. (1997, 3rd edition), A World History of Photography. New York: Abbeville Press Publishers.

Sontag, S. (1979), On Photography. New York: Picador.

Tagg, J. (1988), The Burden of Representation: Essays on Photographies and Histories. Minneapolis: University of Minnesota Press.

Trachtenberg, A. (ed.) (1980), Classic Essays on Photography. New Haven: Leete's Island Books.

Warner Marien, M. (2002), Photography. A Cultural Story. London: Laurance King Publishing.

Weaver, M. (1989), Art of Photography, 1839-1989. New Haven: Yale University Press.

Wells, L. (ed.) (2004, 3rd edition), Photography: A Critical Introduction. London \& New York: Routledge.

\section{Photography in Iran}

Adle, Ch. (1983), 'Notes et documents sur la photographie Iranniene et son histoire', in Studia Iranica 12: 249-281.

Adle, Ch. (1994), 'Daguerreotype', in Encyclopedia Iranica, edited by Ehshan Yarshater, Costa Mesa: Mazda, 7: 577-578. 
Adle, Ch. (1997), 'De la pinture à la photographie: naissance de la daguerréotypie iranienne', in Images, 36: 6-11.

Adle, Ch. (2000), 'Iranian Cinema: Acquaintance with cinema and the first steps of filming and filmmaking in Iran, 1277 to ca. 1285 AS / 1899 to ca. 1907 AD (second version)', in Tavoos Quarterly, 5\&6, Autumn 2000-Winter 2001

Ashfar, I. (1992), A Treasury of Early Iranian Photography. Tehran: Na Shre Farang-e Iran Publishers (Persian).

Afshar, I. (1992B), 'Some remarks on the early history of photography in Iran', in Qajar Iran. Political, Social and Cultural Change, 1800-1925, edited by Edmund Bosworth and Carole Hillenbrand for Edinburg University Press: 261-290.

Assemi, M. (1975), Ernst Hoeltzer. Persien vor 113 Jahren. Tehran: Offset Press Inc.

Barjesteh van Waalwijk van Doorn, L.A.F. \& G.M. Vogelsang-Eastwood (eds.) (1999), Sevruguin Iran/ Iran az negah Sevruguin. Tehran \& Rotterdam: Barjesteh/Zaman Publishers Combination.

Barjesteh van Waalwijk van Doorn, L.A.F. (eds.) (2004), The Montabone Album. Ricordi del viaggio in Persia della Missione Italiana 1862. Rotterdam, Gronsveld, Santa Barbara \& Tehran: IQSA.

Behdad, A. (2001), 'The Powerful Art of Qajar Photography: Orientalism and Self-orientalizing in Nineteenth Century Iran', in Iranian Studies 34: 141-152.

Bohrer N. F. (ed.) (1999), Sevruguin and the Persian Image. Photographs of Iran, 1870-1930. Washington: Smithsonian Inst. Publishers.

Bonnetti, F. \& Prandi, A. (eds.) (2010), La Persia Qajar. Fotografi Italiani in Iran 1848-1864. Rome: Peliti Associati.

Brusius, M. (2010), 'Album Wilkinson', in Bonnetti, F. \& Prandi, A. (eds.) La Persia Qajar. Fotografi Italiani in Iran 1848-1864. Roma: Peliti Associati, 2010, 178-179.

Brusius, M. (forthcoming 2013), 'The back and forth of photography. An album of photographs by Italian travellers in 19th Century Persia', Metropolitan Museum Journal, 47.

City Photography Museum (2008), Mohammad Hassan Mirzā. The Last Crown Prince Qajar. Tehran: City Photography Museum Editions (Persian).

Damandan, P. (1999), Chehrehnegaran-i- Isfahan. A View of the History of Photography. Isfahan: Cultural Research Bureau (Persian).

Damandan, P. (2004), Thousand Sights of Live. Photographs of Ernst Hoeltzer from Nāser al-Din Shah's Age. Tehran: Cultural Heritage Organization.

Garthwaite, G.R. (2000), review of 'Sevruguin and the Persian Image: Photographs of Iran, 18701930', in Visual Resources 16: 407-412.

Jalali, B. (1998), Visible Treasure. A Collection of Photographs from Album Khānneh Golestān Museum. Tehran: Cultural Heritage Organization (Persian).

Khounigh, E. (2003), Tabriz in Photographs. Tabriz: Danyal Publication (Persian).

Mahboob, E. \& Nemati, B. (2005), A Selection of Historical Photos in Documentation Center of Astan-e Quds-e Razavi, Vol. 1. Mashhad (Persian).

Nelson, R. S., \& Shiff, R. (2003), Critical Terms for Art History. Chicago \& London: University of Chicago Press.

Pérez González, C. (2007), 'Sevruguin and the Persian Tonsure', Omslag 7 (29):12; on-line: http://media.leidenuniv.nl/legacy/omslag_2_2007.pdf

Pérez González, C. (2007), 'Defining a model of representation for nineteenth-century Iranian portrait photography', PhotoResearcher 10: 17-22.

Pérez González, C. (2008), 'Nineteenth-Century Iranian Portrait Photography', Aksnameh: 2-17 (in Persian).

Pérez González, C. (2012), 'Lateral organisation in nineteenth-century studio photographs is influenced by the direction of writing: A comparison of Iranian and Spanish photographs', Laterality: Asymmetries of Body, Brain and Cognition, Available online: 07 Nov 2011: DOI:10.1080/1357650X.2011.586701. 
Safi, Gh. (1983), Iranian Personalities and Places. Qajar Era, Vol. 1. Tehran: Tehran University Publications (Persian).

Safi, Gh. (1984), Iranian Personalities and Places. Qajar Era, Vol. 1. Tehran: Tehran University Publications (Persian).

Safi, Gh. (1989), The Historical Persian Postcards. Tehran: Gostaresh-e-Honar (Persian).

Safi, Gh. (1992), Historical Photographs of Iran. Tehran: Tehran University Publications (Persian).

Sane, M. (1990), Emerging of Photography in Shiraz. Tehran: Soroush Publications (Persian).

Sane, M. (2004, 2nd edition). In Memory of Shiraz. The Pictures of Old Shiraz. Tehran: Manssur Sane Publishers. (Persian).

Sattari, M. (2006), Yesterday Children. 100 Years of Child Photography. Tehran: City Museum Publishers (Persian).

Scarce, J. (1976), 'Isfahan in Camera - 19th Century Persia Through the Photographs of Ernst Hoeltzer', in AARP: 1-23.

Semsar, M. (2004), Golestān Palace Photo Archive, Catalogue of Qajar selected Photographs. Tehran (Persian).

Sheikh, R. (2004), 'The Rise of the King Citizen: Iranian Portrait Photography, 1850-1950', in Parisa Damandan, Portrait Photographs From Isfahan: Faces of Transition, 1920-1950. Tehran: Saqi Books, 231-253.

Sheikh, R. (2010), 'National Identity and Photographs of the Constitutional Revolution', in Vanessa Martin, H.E. Chehabi (eds.), Iran's Constitutional Revolution: Popular Politics, Cultural Transformations and Transnational Connections: 249-77.

Sheikh, R. \& Pérez González, C. (eds.) (2013), special issue of the journal History of Photography, 19th-century and early 20th-century Iranian photography.

Stein, D. (1984), 'Early Photography in Iran', in History of Photography 7: 257-292.

Tahmaspour, M.R. (2001), Nāser ol-Din Shah, The Photographer King. Tehran: Iran History Publications (Persian).

Tahmasbpour, M.R. (2006), Italians and Photography in Iran. Tehran: Nasre Ghoo (Persian).

Tahmasbpour, M.R. (2007), Rezā Akasbashi. Tehran: Sasemane Fahrhangi Honari ShardariMohavanat Honari (Persian).

Tahmasbpour, M.R. (2010), Of Silver and Light. Tehran: Nasre-Tahrikhe Iran (Persian).

The National Geographic Magazine (1921), Modern Persia and Its capital. Washington.

Torabi, N. (2003), Introduction to the history of photography in Khorasan. Tehran: Kalhor Publication (Persian).

Vogelsang-Eastwood, G.M. (1999), Sevruguin's Iran. Late Nineteenth Century Photographs of Iran from the National Museum of Ethnology in Leiden. Tehran \& Rotterdam: IQSA.

Vuurman, C. \& Martens, T. (1995), Perzië en Hotz. Beelden uit de fotocollectie-Hotz in de Leidse Universiteitsbibliotheek. Leiden.

Vuurman, C. (2004), "Luigi Montabone and Western Photography in Persia", Barjesteh van Waalwijk van Doorn, L.A.F. (eds.), The Montabone Album, Rotterdam, Gronsveld, Santa Barbara \& Tehran: IQSA, 23-29.

Vuurman, C. (2007), "Dimitri Iwanowitsch Ermakov: Photography across the Persian Border", in Qajar Studies: The Journal of the International Qajar studies Association, Vol. VII: 93-108. Rotterdam, Gronsveld, Santa Barbara \& Tehran: IQSA.

Vuurman, C., Pérez González, C. \& Sheikh, R. (2008), 'Eyes on Persia: Late Nineteenth-Century Persia in the Hotz Collection, Leiden University Library', in Qajar Studies: The Journal of the International Qajar studies Association, VIII, 43-78, Rotterdam, Gronsveld, Santa Barbara \& Tehran: IQSA.

Vuurman, C. (2011), Nineteenth-Century Persia in the Photographs of Albert Hotz. Images from the Hotz Photograph Collection of Leiden University Library, the Netherlands. Rotterdam \& Gronsveld: IQSA \& Barjesteh van Waalwijk van Doorn \& Co. 
Zokā, Y. (1997), The History of Photography and Pioneer Photographers in Iran. Tehran: Sherkate Entesharat Elemi wa Fahrhangui (Persian).

NOTE: a detailed bibliography of all Iranian and Western sources on the topic of nineteenth-century Iranian photography by photo historians Khadijeh Mohammadi Nameghi, Francesca Bonnetti and Alberto Prandi, will be published in early 2013 in the special issue of History of Photography already mentioned above in this list of references.

\section{Persian miniature painting and Qajar painting}

Blair, S. \& Bloom, J. (1994), The Art and Architecture of Islam 1250-1800. New Haven and London: Yale University Press.

Binyon L., Wilkinson, J.V.S. \& Basil, G. (1933), Persian Miniature Painting. New York: Dover Publications Inc.

Canby, S. R. (1993), Persian Painting. New York: Thames and Hudson.

Diba, L. (1998), Royal Persian Paintings. The Qajar Epoch 1785-1925. New York: I. B. Tauris Publishers in association with Brooklyn Museum of Art.

Dunham Guest, G. (1949), Shiraz Painting in the Sixteenth Century. Washington: Smithsonian Institution Publication.

Falk, S.J. (1972), Qajar paintings. Persian Oil Paintings of the $18^{\text {th }}$ and $19^{\text {th }}$ centuries. London: Faber and Faber Limited and Sotheby Parke-Bernet Publications.

Grabar, O. (2000), Mostly Miniatures. An Introduction to Persian Painting. Princeton \& Oxford: Princeton University Press.

Hillenbrand, R. (2000) (ed.), Persian Painting. From the Mongols to the Qajars. Studies in honour of Basi W. Robinson. London \& New York: I.B.Tauris Publishers.

Kubicková, V. (1960), Persische Miniaturen. Prague: Artia.

Robinson, B.W. (1967), Persian Miniature Painting from Collections in the British Isles. London: Victoria \& Albert Museum.

Sims, E. (2002), Peerless Images. Persian painting and its sources. New Haven and London: Yale University Press.

Talbot Rice, D. (1971), Islamic Painting. A Survey. Edinburgh: Edinburgh University Press.

Titley, N.M. (1983), Persian Miniature Painting and Its Influence on the Art of Turkey and India. London: The British Library Collections.

\section{Chapter 1}

Adair, H. \& Bartley, S.H. (1958), 'Nearness as a Function of Lateral Orientation in Pictures', in Perceptual and Motor Skills 8: 135.

Arnheim, R. (1965), Art and Visual Perception. A Psychology of the Creative Eye. The New Version. Berkeley and Los Angeles: University of California Press.

Arnheim, R. (1969), Visual Thinking. Berkeley and Los Angeles: University of California Press.

Banich, M.T., Heller, W. \& Levy, J. (1989), 'Aesthetic Preference and Picture Asymmetries', in Cortex 25: 187-195.

Barjesteh van Waalwijk van Doorn, L.A.F. (eds.) (2008), Qajar Studies: The Journal of the International Qajar studies Association, VIII, Rotterdam, Gronsveld, Santa Barbara \& Tehran: IQSA.

Beaumont, J. G. (1985), 'Lateral Organization and Aesthetic Preference: The Importance of Peripheral Visual Asymmetries', in Neuropsicology 23: 103-113.

Bennett J. (1970), 'The Difference between Right and Left', in American Philosophical Quarterly 7: $175-191$.

Buswell, G.T. (1935), How People Look at Pictures. Chicago: Chicago University Press. 
Chatterjee A., Maher L. \& Heilman K. (1995), 'Spatial Characteristics of Thematic Role Representations', in Neuropsychologia 33: 643-648.

Chokron, S. \& De Agostini, M. (2000), 'Reading Habits Influence Aesthetic Preference', in Cognitive Brain Research 10: 45-49.

Corballis, M. \& Beale, I. (1970), 'Bilateral Symmetry and behaviour', Psychological Review 77: 451-464.

Corballis, M. \& Beale, I. (1971), 'On Telling Left from Right', Scientific American. 224: 96-104.

Christman, S. \& Pinger, K. (1997), 'Lateral Biases in Aesthetic Preferences: Pictorial Dimensions and Neural Mechanisms', in Laterality 2 (2): 155-175.

Dean, A. (1946, 4th edition), Fundamentals of Play Directing. New York: Rinehart \& Company Inc.

Fagard, J. \& Dahmen, R. (2003), 'The Effects of Reading-Writing Direction on theAsymmetry of Space Perception and Directional Tendencies: A Comparison Between French and Tunisian Children', in Laterality, 8 (1): 39-52.

Freimuth, M. \& Wapner, S. (1979), 'The Influence of Lateral Organization on the Evaluation of Paintings', in British Journal of Psychology, 70: 211-218

Fritsch, V. (1964), Links und Rechts in Wissenschaft und Leben. Stuttgart: Urban Bücher.

Gaffron, M. (1950), 'Right and Left in Pictures', Art Quarterly, 13: 312-313.

Gaffron, M. (1956), 'Some New Dimensions in the Phenomenal Analysis of Visual Experience', in Journal of Personality, 24: 285-307.

Gaffron, M. (1962), 'Phenomenal Properties and Perceptual Organizations', in S. Koch (Ed.), Psychology: a Study of a Science, 4. 'Biologically Oriented Fields'. New York: McGraw Hill: 562-608.

Gardner, M. (2005, 3rd revised edition), The New Ambidextrous Universe: Symmetry and Asymmetry from Mirror Reflections to Superstrings. Dover: Dover Publications.

Gazzaniga, M.S. (1967), 'The Split Brain in Man', Scientific American, 217: 24-29.

Geschwind, N. (1967), 'The Organization of Language and the Brain'. Science, 170: 940-944.

Geschwind, N. (1969), 'Language and the Brain': 76-83.

Gilbert C. and Bakan P. (1973), 'Visual Asymmetry in Perception of Faces', Neuropsychology, 11: 355 .

Gordon, I.E. \& Gardner D. (1974), 'Responses to Altered Pictures', in British Journal of Psychology 65: 243.

Gross C. \& Bornstein M. (1978), 'Left and Right in Science and Art', in Leonardo, 11: 29-38.

Gur, R.E. (1975), 'Conjugate Lateral Eye Movements as an Index of Hemispheric Activation', in Journal of Personality and Social Psychology 31: 751.

Gutman, J.M. (1982), Through Indian Eyes. 19th and Early 20th Century Photography From India. New York: Oxford University Press.

Harris L.J., Cárdenas R.A., Spradlin Jr., M.P. \& Almerigi, J.B. (2006), 'Lateral Preferences for Holding a Doll, a Book and a Package: Relation to Attentional Bias on a Chimeric Faces Test', Poster Presentation, Annual Meeting of the Human Behavior and Evolution Society, Philadelphia, June 7-11.

Harris L.J., Spradlin Jr., M.P. \& Almerigi, J.B. (2007), 'Mother's and Father's Lateral Biases for Holding their Newborn Infants: A Study of Images From the World Wide Web', in Laterality 12: 64-86.

Heath, R. L., Rouhana, A. \& Abi Ghanem, D. (2005 A), 'Asymmetric Bias in Perception of Facial Affect Among Roman and Arabic Script Readers', in Laterality, 10 (1): 51-64.

Heath, R. L., Mahmasani, O., Rouhana, A. \& Nassif, N. (2005 B), 'Comparison of Aesthetic Preferences Among Roman and Arabic Script Readers', in Laterality, 10 (5): 399-411.

Hufschmidt H.J. (1980), 'Das Recht-Link Profil im kulturhistorischen Längsschnitt. Ein Dominanzproblem', in Archiv für Psychiatrie und Nervenkrankheiten 229 (1): 17-43. 
Hufschmidt H.J. (1985), 'Zeichnung, Schreibrichtung und Blickfelddominanz. Ein experimentelle und kulturhistorische Studie', in European Archives of Psychiatry and Neurological Sciences 235 (2): 76-81.

Jaynes, J. (1977), The Origin of Consciousness in the Breakdown of the Bicameral Mind. Boston \& New York: Houghton Mifflin.

Keller, R. (1942), 'The Right-Left Problem in Art' in Ciba Symposia, 3 (11).

Kinsbourne M. (1974), 'Direction of Gaze and Distribution of Cerebral Thought Processes', in Neuropsychologia, 12: 279.

Labar, M. (1973), 'Turning the Left Cheek Examined with Modern Photography', in Nature, 245: 338.

Levy, J. (1976), 'Lateral Dominance and Aesthetic Preference', in Neuropsychologia, 14: 431445.

Mayo, B. (1988), 'The Inconguity of Counterparts', in Philosophy of Science, 25: 109-115.

McManus, I.C. \& Humphrey, N.K. (1973), 'Turning the Left Cheek', in Nature, 243: 27.

McManus, I.C., Edmondson, D., \& Rodger, J. (1985), 'Balance in Pictures', in British Journal of Psychology, 76: 311-324.

McManus, I.C. (2004), Right Hand, Left Hand. The Origins of Asymmetry in Brains, Bodies, Atoms and Cultures. Boston: Harvard University Press.

Nakanishi, A. (1980), Writing Systems of the World: Alphabets, Syllabaries,Pictograms. Singapore: Turtle Publishing.

Nashat, G. (2004), 'Marriage and the Harem in the Qajar Era', in Journal of the International Qajar Studies Association. Tehran, Santa Barbara, Rotterdam: IQSA: 61-89.

Noton, D. and Stark, L. (1971), 'Scanpaths in Saccadic Eye Movements While Viewing and Recognizing Patterns', in Vision Research 11 (9): 929-942.

Onians, J. (2007), Neuroarthistory. From Aristotle and Pliny to Baxandall and Zeki. New Haven and London: Yale University Press.

Onians, J. (2008), 'Neuroarthistory: Making more sense of art', in Valiz, Zijlmans, K. \& van Damme, W., (eds.), World Art Studies: Exploring Concepts and Approaches. Amsterdam: Valiz: 265-286.

Pears, D.F. (1992), 'The Incongruity of Counterparts', in Mind, 61: 78-81.

Pérez González, C. (2012), 'Lateral Organization in Nineteenth- Century Studio Photographs is Influenced by the Direction of Writing: A Comparison of Iranian and Spanish Photographs', in Laterality: Asymmetries of Body, Brain and Cognition. Psychology Press (published online 07 Nov 2011, DOI: 10.1080/1357650X.2011.586701; published in journal: forthcoming 2012).

Pollatsky A., Bolozky S., Well A., \& Rayner K. (1981), 'Asymmetries in the Perceptual Span for Israeli Readers', in Brain and Language, 14: 174-180.

Remnant P. (1963), 'Incongruent Counterparts and absolute Space', in Mind, 72: 393-399.

Ramón y Cajal, S. (1899), Textura del sistema nervioso del hombre y los vertebrados, Madrid: Moya.

Ross, B.M. (1966), 'Minimal Familiarity and Left-Right Judgments of Paintings', in Perceptual and Motor Skills, 22: 105.

Salk, L. (1961), 'The importance of the Heartbeat Rhythm to Human Nature: Theoretical, Clinical and Experimental Observations', in Proceedings of the Third World Congress of Psychaitry. Toronto: University of Toronto Press: 740-746.

Schapiro, M. (1970), 'On Some Problems in the Semiotics of Visual Art: Field and Vehicle in Image-Signs', in Sign, Language and Culture, Greimas AJ, Mouton: 487-502.

Schott, G.D. \& Schott J.M. (2004), 'Mirror Writing, Left-handedness, and Leftward Scripts', in Archives of Neurology, 61: 1849-1851.

Schott, G.D. \& Schott, J.M. (2005), 'In reply' of 'Etiology of Mirror Writing in Japanese', in Archives of Neurology, 62: 835. 
Schott, G.D. (2007), 'Mirror Writing: Neurological Reflections on an Unusual Phenomenon', in Journal of Neurology, Neurosurgery and Pschiatry, 78: 5-13.

Skoyles, J. R. (1988), 'Right Hemispheric Reading in the Ancient World', in The Alphabet and the Brain: Lateralization of Writing, Berlin, Springer Verlag: 363-380.

Skoyles, J. R. (1992), 'Mirror Script', in Nature, 377: 25-26.

Swartz, P. \& Hewitt, D. (1970), 'Lateral Organization in Pictures and Aesthetic Preference', in Perceptual and Motor Skills, 30: 991.

Tashiro, K., Matsumoto, A., Moriwaka, F., Shima, K. \& Hamada, T. (2005), 'Etiology of Mirror Writing in Japanese', in Archives of Neurology, 62: 834-835.

Todd, B. and Butterworth, G. (1998), 'Her Heart is in the Right Place: An Investigation of the "Heartbeat Hypothesis" as an Explanation of the Left Side Cradling Preference in a Mother with Dextrocardia', in Early Development and Parenting 7: 229-233.

Trevor-Roper, P. (1985), 'The Evolution and Vicissitudes of Directional Scanning'. Ophthalmological Society of the United Kingdom, 104: 719-727.

Tyler, C.W. (1988), 'Painters Centre One Eye in Portraits', in Nature, 392: 877-878.

Vaid, J. \& Singh, M. (1989), 'Asymmetries in the Perception of Facial Affect: Is There an Influence of Reading Habits?', in Neuropsychologia, 27 (10): 1277-1287.

Van Cleve, J., Frederick, R., eds. (1991), The Philosophy of Right and Left: Incongruent Counterparts and the Nature of Space. Dordrecht: Kluwer Academic Publishers.

Van der Meer, H.Ch. (1958), Die Links-Rechts Polarisation des phänomenalen Raumes. Groningen: J.B. Wolters.

Van der Meer, A. \& Husby, T. (2006), 'Handedness as a Major Determinant of Functional Cradling Bias', in Laterality 11: 263-276.

Vauclair, J. \& Donnot, J. (2005), 'Infant Holding Biases and Their Relations to Hemispheric Specialization', in Neuropsychologia 43: 564-571.

Wölfflin, H. (1941), 'Über das Recht und Links im Bilde', in Gedanken zur Kunstgeshichte. Basilea: Schwabe: 82-96.

Yarbus A.L. (1967), Eye Movements and Vision. New York: Plenum.

Zangemeister, W.H., Sherman, K. \& Stark, L. (1995), 'Evidence for a Global Scanpath Strategy in Viewing Abstract Compared with Realistic Images', in Neuropsychologia, 33 (8): 10091025.

Zeki, S. (1999), Inner Vision. An Exploration of Art and the Brain. Oxford: Oxford University Press.

Zijlmans, K. \& van Damme, W., eds. (2008), World Art Studies: Exploring Concepts and Approaches. Amsterdam: Valiz.

\section{Chapter 2}

Abbott, N. (1939), The Rise of North Arabic Script. Chicago: Chicago University Press.

Abbott, N. (1941), 'Arabic Paleography', in Ars Islamica 6: 65-104.

Ahmad, Q. (1959), Calligraphers and Painters: A Treatise by Ahmad Qadi, Son of Munshi, translated by V. Minorsky with an introduction by B.N. Zakhoder. Washington: Freer and Sackler Gallery of Art Occasional Papers, 3 (2).

Blair, S. (1998), Islamic Inscriptions. Edinburg: Edinburg University Press.

Blair, S. (2006), Islamic Calligraphy. Edinburg: Edinburg University Press.

Bennett, T. (1996), Early Japanese Image. Tokyo: Charles E. Tuttle Publishing Co.

Bennet, T. (2006), Photography in Japan: 1853-1912. Tokyo, Rutland, Vermont, Singapore: Tuttle Publishing.

Burgin, V. (1986), 'Seeing Sense', in The End of Art Theory: Criticism and Post-Modernity. New York: Humanities Press.

Bürgel, J.C. \& Allemann, F. (1975), Symbolik des Islam: Tafelband. Stuttgart: Hiersemann.

Caffin, H.C. (1971), Photography as Fine Art. New York: Morgan \& Morgan. 
Corbin, H. (1960), Terre céleste et corps de résurrection. De l'Iran mazdéen a l'Iran shi'ite. Paris: Buchet/Chastel-Correa.

Dabashi, H. et al. (1997), Shirin Neshat. Women of Allah. Milano: Marco Noire Editore.

Damandan, P. (2004), Portrait Photographs from Isfahan. Faces in Transition, 1920-1950. London: Saqi Books, \& Prince Claus Fund Library.

Delank, C. (1997), 'Samurai, Geisha und der Grosse Buddha. Japan in der Photographie 18601900', in Alles Wahrheit! Alles Luge! Photographie und Wirklichkeit im 19. Jahrhundert, Bodo von Dewitz und Roland Scotti eds. Cologne: Verlag der Kunst.

Diba, L. (1998), 'Images of Power and the Power of Images. Intention and Response in Early Qajar Painting (1785-1834)', in Royal Persian Paintings. The Qajar Epoch 1785-1925. New York: I.B. Tauris Publishers.

Dower, J. (1980), A Century of Japanese Photography. London, Melbourne, Sydney, Auckland and Johanesburg: Hutchinson Publishers.

Edwards C.C. (1940-42), 'Calligraphers and Artists: A Persian Work of the late 19th Century', in BSOAS, X: 199-211.

Fernandes, J. (2004), 'Text and Photography in Contemporary Art: Two Examples', in EXIT 16 Writing Pictures: 108-112.

Floor, W.M. (1975), 'The Guilds in Iran: An Overwiev from the Earliest Beginning till 1972', in Zeitschrift der Deutschen Morgenlandischen Gesellschaft, 125: 99-116.

Floor, W.M. (1989), 'Asnaf', in Encyclopaedia Iranica (2): 772-78.

Fu, S., Lowry, G. D., \& Yonemura, A. (1986), From Concept to Context. Approaches to Asian and Islamic Calligraphy. Washington: Freer Gallery of Art.

Hanaway, W.L. \& Spooner, B., (2007), Reading "Nasta'liq". Persian and Urdu Hands from 1500 to the present. Costa Mensa: Mazda Publisher Inc.

Hughes, A. \& Noble, A. (2003), Phototextualities: Intersections of Photography and Narrative. Alburquerque: University of New Mexico Press.

Junkerman, J. (2003), The History of Japanese Photography. Houston: Houston Museum of Art.

Keyvani, M. (1982), Artisans and Guild Life in the Later Safavid Period: Contributions to the Social-Economic History of Persia. Berlin: Klaus Schwarz.

Lings, M. (1977), The Koranic Art of Calligraphy and Illumination. London: World of Islam Festival Trust.

Mitchell, W.J.T. (1994), Picture Theory: Essays on Verbal and Visual Representation. Chicago: University of Chicago Press.

Mynorsky V. (1959), Calligraphers and Painters. Washington DC: Smithsonian Institute.

Ozawa, T. (1981), 'The History of Early Photography in Japan', in History of Photography, 5 (4): 285-303.

Pérez González, C. (2011), 'Yokoyama Matsusaburo (1838-1884), a pioneer experimental photographer', in Photoresearcher 15, 2-12.

Pérez González, C. (2008), 'Hand-coloured Photography in Asia: Japan, India and Iran', in Jubilee. 30 Years ESHPh. Vienna: Fotohof Edition: 100-109.

Porter, Y. (2000), 'From the "Theory of the Two Qalams" to the "Seven Principles of Painting": Theory, Terminology, and Prcatice in Persian Classical Painting', in Muqarnas: 109-118.

Robinson B.W. (1964), 'The Court Painters of Fath' Ali Shah', in Eretz-Israel 7: 94-105.

Ritter, M. (2008), 'Monumental Epigraphy in Iran: Paired panels with square Kufic script and Sa'di verses in Safavid and earlier Islamic arquitecture', in Eurasian Studies 8 (1-2): 19-37.

Rosenthal, F. (1961), 'Significants Uses of Arabic Writing', in Ars Orientalis 4: 15-23.

Safadi, Y.H. (1978), Islamic Calligraphy. London: Thames and Hudson Limited.

Schmidt, B., \& Stammer, B. E. (2005), Shirin Neshat. Berlin: Steidl Verlag.

Schimmel, A. (1970), Islamic Calligraphy. Leiden: E.J. Brill.

Schimmel, A. (1990), Calligraphy and Islamic Culture. New York: Tauris.

Schwartz, H. (1985), Art and Photography: Forerunners and influences. Chicago: W.E. Parker. Scott, C. (1999), The Spoken Image. London: Reaktion Books. 
Shimizu, Y. and Rosenfield, J.M. (1984), Masters of Japanese Calligraphy: Eight Through Nineteenth Centuries. New York: Asia Society galleries and Japan House Gallery.

Slemmons, R. (2004), 'Between Language and Perception', in EXIT 16 Writing Pictures: 38-48.

Soucek, P. (2000), 'The Theory and Practice of Portraiture in the Persian Tradition', in Muqarnas, 17: 97-108.

Soudavar, A. \& Beach, M.C. (1992), Arts of the Persian Courts: Selections from the Art and History Trust Collections. Houston: Rizzoli.

Tadashi K. (1992), Ukiyo-e. An introduction to Japanese woodblock prints. Tokyo, New York and London: Kodansha International.

Winkel, M. (1991), Souvenirs from Japan. Japanese Photography at the Turn of the Century. London: Bamboo Publishing Ltd.

Woodall, J. (1997), Portraiture: Facing the Subject. Manchester: Manchester University Press.

Worswick, C. (1978), Imperial China: Photographs 1850-1912. Washington: Penwick Publishing, Inc.

Yarshater, E. (1962), 'Some Common Characteristics of Persian Poetry and Art', in Studia Islamica 16: 61-72.

Yokoe, F. (1997), The Advent of Photography in Japan. Tokyo: Tokyo Metropolitan Museum of Photography.

\section{Chapter 3}

Alloula, M. (1986), The Colonial Harem. Minneapolis: University of Minnesota Press.

Barasch, M. (1987), Giotto and the Language of Gesture. Cambridge: Cambridge University Press.

Barthes, R. (1973), Mythologies. London: Granada.

Bazin, A. (1967), 'The Ontology of the Photographic Image' in What is Cinema? Berkeley \& Los Angeles: University of California Press.

Behdad, A. (2001), 'The Powerful Art of Qajar Photography: Orientalism and (Self)-Orientalizing in Nineteenth-Century Iran', in Iranian Studies, 34 (1-4): 141-152.

Benjamin, W. (1970), 'The Work of Art in the Age of Mechanical Reproduction', in Illuminations. London: Cape.

Berger Jr., H. (1994), 'Fictions of the Pose: Facing the Gaze in Early Modern Portraiture', in Representations, 46: 87-120.

Bhabha, H. (1994), 'Of Mimicry and Man: The Ambivalence of Colonial Discourse', in The Location of Culture. London \& New York: Routledge: 85-92.

Bremmer, J. \& Rodenburg, H. (1991), A Cultural History of Gesture. From Antiquity to the Present Day. Cambridge: Polity Press.

Bürgel, J.C. (1988), The Feather of Simurgh. The "Licit Magic" of the Arts in Medieval Islam. New York and London: New York University Press.

Caffin, H.C. (1971), Photography as Fine Art. New York: Morgan \& Morgan.

Corbin, H. (1958), L'imagination créatrice dans le soufisme d'Ibn Arabi. Paris: publisher.

Corbin, H. (1960), Terre céleste et corps de résurrection. De l'Iran mazdéen a l'Iran shi'ite. Paris: Buchet/Chastel-Correa.

Cranz, G. (2000), The Chair: Rethinking Culture, Body and Design. New York and London: WW Norton and Company Inc.

Darrah, C.W. (1981), Cartes de Visite in Nineteenth Century Photography. Pennsylvania: DarrahSmith Books.

De Vitray-Meyerovitch, E. (1972), Mystique et poesie en Islam. Djalal-ud-Din Rumi et l'ordre des dervisches tourners. Paris: Desclée de Brouwer.

Efron. D. (1972), Gesture, Race and Culture. The Hague: Mouton.

Ekhtiar, M. (1998), "From Workshop and Bazaar to Academy: Art Training and Production in Qajar Iran”, in Diba 1998: 50-65. 
Ertem, F. (2006), 'The Pose in Early Portrait Photography: Questioning Attempts to Appropriate the Past', in Image and Narrative, Online magazineoftheVisualNarrative, 14. www.imageandnarrative.be/painting/fulya.htm

Eskandari-Qajar, M.M. (2003), 'Qajar Imperial Attire: The Making of Persia's Lion and Sun King, Fath 'Ali Shah Qajar', in Qajar Studies. Journal of the International Qajar Studies Association, III. Rotterdam, Santa Barbara \& Tehran: IQSA: 71-93.

Gombrich, E.H. (1970), 'The Mask and the Face: The Perception of Physiognomic Likeness in Life and in the Art', in E.H. Gombrich, J. Hochberg and M. Black, Art, Perception and Reality. Baltimore and London: The Johns Hopkins University Press.

Gombrich, E.H. (1982), 'Image and Code: Scope and Limits of Conventionalism in Pictorial Representation', in The Image and the Eye. Further Studies in the Psychology of Pictorial representation. New York: Cornell University Press: 278-297.

Gombrich, E.H. (1982), 'Ritualized Gesture and Expression in Art', in The Image and the Eye. New York: Cornell University Press.

Graham-Brown, S. (1988), Images of Women: The Portrayal of Women in Photography of the Middle East 1860-1950. New York: Columbia University Press.

Heller, T.C., Sosna, M. and Wellbery, D. eds. (1986), Reconstructing Individualism. An Individuality and the Self in Western Thought. Standford University Press.

Hewes, G.W. (1955), 'World Distribution of Certain Postural Habits', in American Anthropologist, 57: 231-44.

Hewes, G.W. (1957), 'The Anthropology of Posture', in Scientific American, 196 (2): 122-32.

Holsbach, S. (2006), Von Ausdruck zur Pose: Theatralität und Weiblichkeit in der Fotografie des 19. Jahrhunderts. Berlin: Reimer Verlag.

Jones, A. (1998), 'The Eternal Return: Self-Portrait Photography as a Technology of Embodiment', in Signs: Journal of Women in Culture and Society, 27 (4). Chicago: Chicago University Press.

Kelsey, R. \& Stimson, eds. (2008), The Meaning of Photography. New Haven and London: Clark Studies in the Visual Arts, Yale University Press.

Kendom, A. (1981), Nonverbal Communication: Interaction and Gesture. The Hague, Paris, New York: Mouton Publishers.

Kendon, A. (2004), Gesture. Cambridge: Cambridge University Press.

Labarre, W. (1947-8), 'The Cultural Basis of Emotions and Gestures', in Journal of Personality, 16: 49-68.

Lacan, C. (1977), The Four Fundamental Concepts of Psychoanalysis. London: The Hogarth Press and the Institute of Psychoanalysis.

Lingwood, J. ed. (1986), Staging the Self. Self-Portrait Photography 1840s-1980s. Plymouth: Plymouth Arts Centre.

Martin, V. (2006), 'The Jester and the Shadow of God: Nasser od-Din Shah and his Fools', in Entertainment in Qajar Persia. Rotterdam, Gronsveld, Santa Barbara \& Tehran: IQSA: 99111.

Mauss, M. (1979), 'The Techniques of the Body', in Sociology and Psychology. London: 97-123.

Mead, M. and Frances C.M. (1951), Growth and Culture. A photographic study of Balinese childhood. New York: Putnam.

Mitchell, W.J.T. (1987), Iconology. Image, Text, Ideology. Chicago \& London: Chicago University Press.

Morris, D. et al. (1979), Gestures: Their Origins and Distribution. New York: Stein \& Day.

Najmabadi, A. (1998), 'Reading for Gender Through Qajar Painting', in Diba, 1998: 76-89.

Nashat, G. (2004), 'Marriage and the Harem in the Qajar Era', in Journal of The International Qajar Studies Association. Tehran, Santa Barbara, Rotterdam: IQSA Publishers.

Owens, C. (1992), 'Posing' in Beyond Recognition: Representation, Power, and Culture. Ed. Scott B., Barbara K., Lynne T. \& Jane, W. Introduction by Simon Watney. Berkeley, Los Angeles and Oxford: University of California Press. 
Panofski, E. (1962), Studies on Iconology. New York: Harper Torchbooks.

Porter, Y. (2000), 'From the Theory of the Two Qalams to the Seven Principles of Painting: Theory, Terminology, and Practice in Persian Classical Painting', in Muqarnas, 17, Leiden: 109-118.

Poyatos, F. (1981), 'Gesture Inventories: Fieldwork Methodology and Problems', in Kendon, Adam, Nonverbal Communication, Interaction, and Gesture, The Hague, Paris \& New York: Mouton Publishers: 371-399.

Scarce, J. (1981), 'Persian Art Through the Eyes of British Travelers', in British Society for Middle Eastern Studies, 8: 38-50.

Schimmel, A. (1975), Mystical Dimensions of Islam. Chapel Hill: University of North Carolina Press.

Schimmel, A. (1978), The Triumphal Sun. A study of the works of Jalaloddin Rumi. London: East West Publications.

Segall, M. et al. (1966), The Influence of Culture on Visual Perception. Indianapolis: Bobbs Merrill Co.

Sekula, A. (1992), 'The Body and the Archive' in The Context of Meaning: Critical Histories of Photography. London: Richard Bolton Mit Press.

Silverman, K. (1996), The Threshold of the Visible World. New York and London: Routledge.

Silverman, K. (1997), 'Den Blickregime begegnen', in Christian Kravagna (Hgr), Privileg Blick. Kritik der Visuellen Kultur: 41-64.

Sims, E. (2002), Peerless Images. New Haven and London: Yale University Press.

Singer, C. \& Baldrige, C.L. (1936), Half the world is Isfahan. Oxford: Oxford University Press.

Sobieszek, A.R. (1999), Ghost in the Shell: Photography and the Human Soul 1850-2000, Essays on Camera Portraiture. Los Angeles: Los Angeles Country Museum of Art.

Sparhawk, C.M. (1981), 'Contrastive-Identification Feature of Persian Gesture', in Kendon, A., Nonverbal Communication, Interaction and Gesture. The Hague, Paris \& New York: Mouton Publishers: 412-458.

Stemmler, J.K. (1993), 'The Physiognomical Portraits of Johann Casper Lavater', in The Art Bulletin, 75 (1): 151-168.

Terakado, H. (1973), 'Sitting on the Floor Versus Sitting on a Chair', in Journal of Human Ergology, 2 (1): 91-92.

Wills, C.J. (1891), In the Land of the Lion and Sun or Modern Persia being experiences of life in Persia from 1866 to 1881 . London: Ward, Lock \& Bowden.

\section{Chapter 4}

Adle, C. (1975), 'Recherche sur le module et le trace correcteur dans la miniature orientale', in Le mond iranien at l'islam, III. Geneve: Droz Ed.: 81-105.

Arnheim, R. (1969), Art and Visual Perception. A Psychology of the Creative Eye. Berkeley and Los Angeles: University of California Press.

Belting, H. (2008), Florenz und Bagdad. Eine westöstliche Geschichte des Blicks. München: Verlag C.H. Beck.

Blochet, E. (1926), Les enlumiers des manuscrits orientaux-turcs, arabes, persans- de la Biliothèque Nationale. Paris: Editions de la gazette des beaux arts.

Bronstein, L. (1935), 'Space Forms in Persian Miniature Composition', in Bulletin of the American Institute for Persian Art and Archeology, IV: 111-9.

Bronstein, L. (1994), Space in Persian Painting. New Brunswick: Transaction Publishers.

Byrne, D. (1984), 'Manuscript Ruling and Pictorial Design in the Work of the Limbourgs, The Bedford Master, and the Boucicault Master', in Art Bulletin LXVI (1): 118-36.

Dunham Guest, G. (1949), 'Shiraz Painting in the Sixteenth Century', in Oriental Studies, 4. Washington: Smithsonian Institution. 
Galassi, P. (1981), Before Photography. Painting and the Invention of Photography. New York: The Museum of Modern Art.

Golombek, L. (1972), 'Toward a Classification of Islamic Painting', in Richard Ettinghausen eds. Islamic Art in the Metropolitan Museum. New York: Metropolitan Museum of Art: 23-43.

Gutman, J.M. (1982), Through Indian Eyes. 19th and Early 20th Century Photography From India. New York: Oxford University Press.

Hillenbrand, R. (1992), 'The Uses of Space in Timurid Painting', in Timurid Art and Culture. Iran and Central Asia in the 15th Century, L. Golombek \& M. Subtelny eds. Leiden: E. J. Brill.

Krauss, R. (1979), 'Grids', in October. MIT press: 51-64.

Krauss, R. (1978), Grids, You Say. New York: The Pace Gallery.

Krikke, J. (1996), ‘A Chinese Perspective for Cyberspace', in IIAS 9. Leiden.

Krikke, J. (1998), The Corridor of Space. China, Modernists, and the Cybernetic Century. Amsterdam: Olive Press.

Krikke, J. (2000), 'Axonometry: A Matter of Perspective', in IEEE computer Graphics and Application.

Owen, P. (1970), 'Painting', in The Appreciation of the Art, Vol. 5. London: Oxford University Press.

Riemersma, T. (2001), 'Axonometric Projections: A Technical Overview', in Graphics, Programming and Theory, online publication:

http://www.gamedev.net/page/resources/_technical/graphics-programming-and-theory/axonometric-projections-a-technical-overview-r1269

Rudrauf, L. (1949), 'The Annunciation: Study of a Plastic Theme and its Variation in Painting and Sculpture', in The Journal of Aesthetics and Art Criticism, 103: 325-348.

Soucek, P. (1972), 'Nizami on Painters and Painting', in Richard Ettighausen Islamic Art in the Metropolitan Museum of Art. New York: Metropolitan Museum of Art: 9-22.

Westgeest, H. (1996), Zen in the fifties. Interaction in Art Between East and East. Amsterdam: Waanders Publishers.

Wellesz, E. \& Blauensteiner, K. (1936), 'Illustrationen zur eine Geschichte Timurs', in Wiener Beiträge zur Kunst-und Kulturgeschichte Asiens, Jahrbuch des Vereins des Freunde Asiatischer Kunst und Kultur. Vienna, X: 20-34.

Williamson, J.H. (1986), 'The Grid: History, Use and Meaning', in Design Issues, III (2): 15-30.

Zain, D.H. (1989), Formal Values in Timurid Painting. Kuala Lumpur: Penerbitan Fargoes.

\section{Chapter 5}

Ahmad, A. (1992), In Theory: Classes, Nations, Literatures. London: Verso.

Alloula, M. (1986), The Colonial Harem. Minneapolis and London: University of Minesota Press.

Ashcroft, B., Griffiths, G. \& Tiffin, H. (1998), Key Concepts in Post-Colonial Studies. London \& New York: Routledge.

Bhabha, H.K. (1994), The Location of Culture. London: Routledge.

Behdad, A. (2001), 'The Powerful Art of Qajar Photography: Orientalism and (Self)-Orientalizing in Nineteenth-Century Iran', in Iranian Studies, 34 (1-4): 141-152.

Benjamin, R. (1997), 'Post-Colonial Taste: Non-Western Markets for Orientalist Art', in Orientalism. Delacroix to Klee. New South Wales: 32-40.

Berger, J. (1972), Ways of Seeing. London: Penguin.

Bird L., I. (1891), Journey in Persia and Kurdistan, Vol. 1, London: J. Murray.

Briggs, A. (1989), A Victorian Portrait. Victorian Life and Values as Seen Through the Work of Studio Photographers. London: Cassel Publishers Limited.

Buruma, I., \& Margalit, A. (2005), Occidentalism. London: Penguin. 
Damandan, P. (2004), Thousands Sights of Life. Photographs of Ernst Hoeltzer From Nāser alDin Shah's Age. Tehran: Iran Cultural Heritage Organization Documentation Center.

Dieulafoy, J. (1989), Une amazone en Orient: Du Caucase a Ispahan, 1881-1882. D'Ailleurs, (French Edition) : Phebus.

Efron, D. (1972), Gesture, Race and Culture. London: Mouton Publishers.

Ekhtiar, M. (1998), "From Workshop and Bazaar to Academy: Art Training and Production in Qajar Iran", in Diba 1998: 50-65.

Galerie Gmurzynska (1988), Dimitri Jermakow, ca. 1845-ca.1916, ein Pionier der Photoreportage. Cologne: Druk-\& Verlagshaus Wienand.

Garthwaite, G.R. (2000), 'Review of Sevruguin and the Persian Image: Photographs of Iran, 1870-1930', in Visual Resources 16: 407-412.

Geary, C.M. (2002), In and Out of Focus. Images from Central Africa, 1885-1960. London: Philip Wilson Publishers.

Ginzburg, C. (1989), 'From Aby Warburg to E.H. Gombrich: A Problem of Method', in Clues, Myths, and the Historical Method. Baltimore: John Hopkins University Press.

Green-Lewis, J. (1996), Framing the Victorians. Photography and the Culture of Realism. Ithaca and London: Cornell University Press.

Herder, H. (2001), 'Ermakov as photographer and traveler', in L.A. Ferydoun Barjesteh van Waalwijk van Doorn et al., Journal of the International Qajar Association, 1. Rotterdam/ Santa Barbara/Tehran: IQSA Publishers: 57-62.

Hill, S. \& Gertrude B. (1868-1926), (1976). A selection from the photographic archive of an archaeologist and traveler. Department of Archaeology: University of Newcastle-upon-Tyne.

Iiazawa, K. (1994), 'The Shock of the Real. Early Photography in Japan', in Robert Stearns Photography and Beyond in Japan. Space, Time and Memory, Tokyo: Hara Museum of Contemporary Art: 38 .

Jansen, M., Vanzan, M.A., Vuurman-Achour, C. \& Tahmasbpour, M.R. (2004), The Montabone Album. Rotterdam, Gronsveld, Santa Barbara \& Tehran: IQSA \& Barjesteh van Waalwijk van Doorn \& Co's..

Krauss, R. (1985), The Originality of the Avant-Garde and Other Modernist Myths. Cambridge: MIT Press.

Lacan, J. (1968), The Language of the Self: The Function of Language in Psychoanalysis, translated with notes and commentary by Anthony Wilden. Baltimore: Johns Hopkins University Press.

Lyman, C. (1982), The Vanishing Race and Other Illusions: Photographs of Indians by Edward S. Curtis. New York: Pantheon Books.

Mohanty, C.T. (1984), 'Under Western eyes: feminist scholarship and colonial discourse', Boundary 2.

National Geographic Magazine (1921), Modern Persia and Its Capital, April.

Nāser al-Din Shah (1995), The Diary of H.M. the Shah of Persia during his tour through Europe in A.D. 1873, translated from the Persian by J.W. Redhouse, new introduction by Carole Hillenbrand. Costa Mesa: Mazda Publishers Inc.

Nelson, R.S. \& Shiff, R. (2003, 2nd edition), Critical Terms for Art History. Chicago and London: University of Chicago Press.

Nochlin, L. (1983), 'The Imaginary Orient', in Art in America: 121-131.

Palma, S. (2005), 'The Seen, the Unseen, the Invented. Misrepresentations of African "Otherness" in the Making of a Colony. Eritrea, 1885-1896', in Cahiers d'Études africaines, XLV (1), 177: 39-69.

Parry, B. (1987), 'Problems in current discourse theory', Oxford Literary Review 9.

Parry, B. (1994), 'Resistance theory/theorising resistance: two cheers for nativism', Colonial Discourse/Postcolonial Theory. Manchester and New York: Manchester University Press.

Perez, N.N. (1988), Focus East. Early Photography in the Near East. 1839-1885. New York: Harry N. Abrams Inc. Publishers. 
Piamontese, A. (1972), 'The Photograph Album of Italian Diplomatic Mission to Persia, Summer 1962', in East and West, New Series 22 (3-4): 255-272.

Pinney, C. \& Peterson, N., eds. (2003), Photography's Other Histories. Durham and London: Duke University Press.

Poole, D. (1997), Vision, Race and Modernity. A Visual Economy of the Andean Image World. Princeton: Princeton University Press.

Qa'im-Maqami, J. (1977), Wurud-I san'at-I 'Akkāsi ba-Iran (Introduction to the craft of photography in Iran), in Yadgar-nama-yi Habib Yaghma'I (H.Y. Memorial Volume). Tehran: 279-82.

Ramamurthy, A. (2004, 3rd edition), 'Spectacles and Illusions: Photography and Commodity Culture', in Liz Wells ed. Photography: A Critical Introduction. London and New York: Routledge.

Said, E. (1978), Orientalism: Western Conceptions of the Orient. London: Penguin.

Sartre, J.P. (1957), Being and Nothingness: An Essay on Phenomenological Ontology, translated by Hazel E. Barnes. London: Methuen.

Scott, C. (1999), The Spoken Image. London: Reaktion Books.

Sheikh, R. (1999), 'Portfolio of a Nation' in Sevruguin and the Persian Image. Photographs of Iran, 1870-1930. Washington: Bohrer Editors.

Tahmasbpour, M.R. (2005), 'The first miracles of light', in Hamshari. Tehran (Persian)

Tahmasbpour, M.R. (2007), Rezā Akasbashi. Tehran: Sasemane Fahrhangi Honari ShardariMohavanat Honari (Persian).

Thomas, A. (1977), Time in a Frame. Photography and the Nineteenth-Century Mind. New York: Schocken Books.

Trachtenberg, A. (1989), Reading American Photographs. Images as history, Mathew Brady to Walker Ewans. New York: Hill and Wang.

Voigt, F. (2002), Qadscharische Bildfliesen im Etnologischen Museum Berlin. Berlin: Staatliche Museen zu Berlin.

Vuurman, C.J.M. \& Martens, T. (1995): Perzië en Hotz. Beelden uit de fotocollectie-Hotz in de Leidse Universiteitsbibliotheek. Leiden: Leidse Universiteitsbibliothek.

Vuurman-Achour, C.J.M. (2007), 'Dimitri Iwanowitsch Ermakov: Photography across the Persian border', in L.A. Ferydoun Barjesteh van Waalwijk van Doorn et al., Journal of the International Qajar Association. Rotterdam, Santa Barbara, Tehran: IQSA: 92-107.

Witkam, J.J. (1998), 'Albert Hotz and his photographs of Iran. An Introduction to the Leiden Collection', in Kambiz Eslami (ed.), Iran and Iranian Studies. Essays in honor of Iraj Afshar. Princeton, NJ: Zagros Press: 276-288.

Young, E. (1759), Conjectures on Original Composition. In a Letter to the Author of Sir Charles Grandison. London: A. Millar and R. and J. Dodsley.

Young, R.J.C. (1995), Colonial Desire: Hybridity in Theory, Culture and Race. London: Routledge. 


\title{
APPENDIX: PHOTO-CHRONOLOGY
}

\author{
General Photo-chronology
}

Iranian Photo-chronology ${ }^{1}$

1835 Publication of the first litographic newspaper in Iran by Mirzā Salih Shirazi.

1839 Daguerre reproduces images by the action of light on silver-coated copperplate. The french government purchases rights to the process and makes it available to the French people.

- Talbot announces to the British Royal academy his reproduction of images on paper by the action of light.

1841 Talbot patents the calotype process.

1842 Introduction of daguerreotype process in Iran. Nikolav Pavlov takes his first daguerreotypes by mid-December 1842.

\section{4}

Jules Richard (1816-1891) becomes the first Western photographer to work in the Persian Court.

1847 Claude Félix Abel Niepce de Saint-Victor proposes using a glass plate coated with albumen and silver halides as a negative.

1849 Gustave Le Gray introduces the waxed-paper process in France.

1850 Frederick Scott Archer, a British sculptor, invents the wet-plate process.

- Blanquart-Evrard announces the process for making photographic prints on paper coated with albumen.

1851 A special department for photography is opened in 1851 at Dār alFonun (Academy), Iran's first institution of higher learning based on Western models. 
- Luigi Pesce (active 1848-1861), an Italian colonel and master of the calotype process, arrives in Iran.

- Fochetti arrives in Iran, a master in the wet-collodion process.

- August Karl Kriz (1814-1886) experiments in Iran with photography on paper.

1853 Tintype process is invented in France.

1854 Collodion positive images (“Ambrotypes") are introduced.

- French photographer A.A.E. Disdéri patents small-format "carte-devisite".

1857 Francois Carlhian and Henry de Coulibeouf Blocqueville arrive with the French Mission.

1860 While photographing the Turcoman revolt in Khurasan, the equipment of Carlhièe and Blocqueville is smashed to pieces and Blocqueville is taken prisoner.

1862 French physicist Louis Ducos du Hauron describes methods of producing photographic images in color.

- Luigi Montabone (d. 1877) comes with the Italian mission. He introduces the hand-coloring technique in Iran.

- Angelo Piamontese's article "The Photograph Album of the Italian Mission to Persia (Summer 1862)”' is published.

1863 The eldest treatise describing the act of photography and how to develop pictures and make copies is written by Mohammad Kāzim B. Ahmad Mahallāti by order of Nāser al-Din Shah.

- The earliest information known to date about the introduction of photography in Iran: the third volume of the "Mer'at al-buldān-e Nāseri", written by I'timād al-Saltane (Sāni al-Dawle) is published.

- Abbās Ali Beik starts working at court, supervises Akskhāne and helps Rezā Akkāsbāshi to develop photographs.

1864 Walter B. Woodburry, in England, patents the Woodburytype. 
- Rezā Akkāsbāshi (1843-1889) is granted the title Akkāsbāshi (Chief Photographer) in recognition of his mastery of photography.

1869 Nāser al-Din Shah starts taking pictures and learns the technique with Jules Richard and Francois Carlhièe.

- Abdollāh Mirzā Qajar (1849-1908) travels to Europe to study photography.

1870 Mirzā Hasan Akkāsbāshi (1854-1916) starts working as a photographer in his hometown Shiraz.

1871 The dry-plate silver bromide process is announced by Richard Leach Maddox; it is not perfected until 1878.

- The German ingenieur Ernst Hoeltzer starts taking photographs in Isfahan, where he lives for 30 years.

1873 Platinum-printing method is invented in England.

1877 Mirzā Hoseyn Ali Akkās starts working at court and eventually becomes the head of Akskhāne. He was active for over 20 years.

1878 "Fann-e Akkāsi", "The Art of Photography" was published in Tehran (translation made by Antovan Khān for Mozaffar al-Din Shah).

1880 First halftone reproduction of a photograph appears in a NY newspaper.

- Antoin Sevruguin starts working in Iran.

- "Qavā'ed-e aks va telegrāf", "Principles of Photography and Telegraphy” is written by Hasan B. Ali Reza Lāhiji Najafi.

- Abd al-Qāsem ebn al-Nuri starts working at court.

1881 Frederic E. Ives invents halftone photoengraving process, making it possible to reproduce photographic and other images in the same operation as the printing of text.

- Jane Dieulafoy journeys through Iran and takes many photographs of landscapes, people and architecture.

1882 Manucher Khān Akkās starts working in Tabriz. 
1884 Abdollāh Mirzā Qajar starts his career as a professional photographer after coming back from Europe.

1886 Mirzā Mohammad Rezā Akkās (1869-1903) starts working as a photographer in Shiraz.

1888 Introduction of George Eastman's Kodak camera.

- "Al-Ma'āthir wa-l-āthār"” by E'temād al-Saltane is published (this is the second source of information written about the introduction of photography in Iran, as stated by Afshar).

1889 George Eastman applies for patent on transparent roll film.

1890 The Dutch amateur photographer and businessman Albert Hotz takes photographs in Iran during a trip of several months in the country. He also collects photographs of other photographers like Hoeltzer and Sevruguin.

- Isabella Lucy Bishop-Bird journeys in Iran and takes photographs of the landscape and people.

- Aghayanes Armeni starts working and opens a studio outside of the court.

- Mohammad Hasan Qajar starts working at court.

- Mirzā Jahāngir Khān Akkās starts working at court.

1895 Another treatise on photography is written by Nawwāb Mushin Mirzā.

1896 Mr Iqbāl Yaghmā'i's article "The beginnings of the craft of photography and stereotyping in Iran" is published (it is the best source of information about Abdollāh Mirzā Qajar).

1904 Mirzā Fatollāh Chehrehnegār (1878-1942), starts taking photographs in Shiraz.

1911 Gertrude Bell is actively taking photographs in Iran.

1918 Mirzā Habib Allāh Chehrehnegār (1897-1943) starts taking photographs in Shiraz. 


\section{Note}

1 The article "Some Remarks on the Early History of Photography in Iran" by Iraj Afshar has been fundamental for this chronology. 



\section{About the author}

Carmen Pérez González was born in 1969 in Valencia (Spain). She studied Astrophysics at Barcelona University and was awarded her M.A. in 1993. As a photographer, she has published the catalogue of a solo exhibition about women workers in Asia taken during a two-and-a-half year's journey through Asia (Museo Príncipe Felipe, Valencia, Spain), as well as several portfolios. For several years, she worked as a cultural manager, organizing exhibitions, at the Science Museum in Barcelona (Spain) and at the Department of Culture of the Embassy of Spain in Prague (Czech Republic). In October 2005, she was awarded her $A B D$ ("All But Dissertation") in Fine Arts (Photography) at Barcelona University and in February 2007, she was admitted as an external PhD researcher at the Department of Art History, Leiden University. She defended her $\mathrm{PhD}$ Thesis, "A Comparative Visual Analysis of Nineteenth-Century Iranian Portrait Studio Photography and Persian Painting" in February 2010 and was awarded the ICAS Best Book Prize (PhD Thesis, Asian Studies, Humanities) at ASS/ICAS 2011 in Hawaii. She has published several articles about nineteenth-century photography in Iran, India, Japan and Egypt in academic magazines and books. She is currently working as a curatorial research fellow at the "Museum für Ostasiatische Kunst" in Cologne where she is preparing an exhibition (and catalogue in English and German) with a selection of 350 photographs from its collection of nineteenth-century photographs from different Asian countries (From Istanbul to Yokohama: The Camera Meets Asia, 1839-1900), due for April 2013. 



\title{
Index
}

\author{
A \\ Abbās Ali Beyk $35 \quad$ D \\ Abd al-Qāsem ebn al-Nuri 36, 82, 83, \\ 92-94, 121, 156, 211, 257, 263, 264, \\ 291 \\ Abdollāh Mirzā Qajar 32, 36, 90, \\ $166,167,171,172,177,185,211$, \\ $212,260,261,262,285,298,327$ \\ Aesthetic preferences 9, 62, 64, 66, \\ 199 \\ Aghayanz Armeni 36 \\ Aks 28, 174, 175, 211 \\ Akskhāne Mobārake-ye Homāyuni, (the \\ Royal Photographic Atelier) 27, 30, \\ 121, 126, 163, 164, 272, 289 \\ Albert Hotz 197, 208, 212 \\ Ali Khān Amin Hazrat 34 \\ Ali Khān Vali Hākem 37, 172, 308, \\ 309 \\ Amal 85, 89, 90, 91, 93, 101 \\ Amir Khān Jalil al-Dawle Qajar 36, \\ 260 \\ Anis al-Dowle 30, 121, 126, 163, \\ $164,272,289$ \\ Antonio Gianuzzi 28, 29, 30, 166 \\ Antoin Sevruguin 31, 33, 34, 36, 128, \\ 166-169, 171, 176, 178, 180, 185, \\ 189, 196, 197, 207, 208, 211, 212, \\ 281, 300, 301, 302 \\ Daguerreotype 27, 30, 38, 47, 195, \\ 209, 232 \\ Dār al-Fonun 23, 27-29, 34-36, 38, \\ $86,89,90,91,166,171,209$ \\ Diffuse composition 21, 24, 131-133, \\ 144, 146, 147, 151, 152 \\ Direction of writing 9, 21, 23, 41, 42, \\ $43,52,58,59,67,68,185,190,196$, \\ 200, 227 \\ Direction of script 23,66 \\ E \\ Ernst Hoeltzer 9, 31, 39, 127, 160, \\ 167, 182, 183, 196, 197, 207, 212, \\ 275,280 \\ F \\ Fáteme Soltān Khānom 176 \\ Ferdowsi Studio 275 \\ Fochetti 28, 210 \\ Francois Carlhian 28, 29, 34, 166, \\ $171,178,185,210$ \\ Franz Stolze 33 \\ Friedrich Sarre 33 \\ G \\ Gertrude Lowthian Bell 33, 207, 212 \\ Appropriation 21, 178, 181, 182, 187 \\ Gholām-Hoseyn Derakhshān 264 \\ Grid 21, 24, 131-136, 140, 142, 143, \\ 145-147, 151, 152, 206 \\ August Karl Krziz 28 \\ Aziz-e Jahān 176 \\ B \\ Boudoir Studio 298 \\ Habib-e Zamān 176 \\ Handedness 42, 48, 57, 58, 59, 62, \\ 64, 67, 69, 200, 201 \\ C \\ Henry René d'Allemagne 34 \\ Comparative analysis 9, 10, 190, 193 \\ Hybridity $173,178-182,186,187,208$
}


I

Image world $157,165,208$

Iraj Afshar 13, 17, 26-28, 38, 78, 208, 213, 229, 240

Isabella Lucy Bishop-Bird 33, 212

Isometrical projection 137,146

$\mathrm{J}$

Jacques Jean Marie de Morgan 33

Jane Dieulafoy 33, 211

Joseph Papaziant 36

Jules Richard 27, 166, 209, 211

$\mathrm{K}$

Ketāb-e 'aks 28

L

Linear perspective 132-133, 137-138, 145-148, 152, 284

Luigi Montabone 28, 29, 121, 166, 197, 210, 274, 299, 318, 326, 327,

Luigi Pesce 28, 210

M

Malak Ghāsem Mirzā 30

Manucher Khān Akkās 35, 167, 211, 259

Mirzā Ahmad Khān Sāne al-Saltane 35

Mirzā Fatollāh Cheherhnegār 37, 212

Mirzā Habibollāh Chehrehnegār 37, 124, 273, 278

Mirzā Hasan Akkasbāshi 37, 79, 130, 211

Mirzā Jafar Akkasbāshi 262

Mirzā Jahāngir Khān Akkās 36, 212

Mirzā Ahmad Chehreh-Namā 278

Mirzā Mehdi Chehreh-Namā 148, 182, 286, 307

Mirzā Mohammad Rezā Akkāsbāshi 37

Mirzā Seyed Ali 35

Mirror writing 57, 58, 59, 62, 67, 200, 201
Mixed aesthetics 21

Mohammad Hasan Qajar 36, 120, $212,274,310$

Mohammad Jafar Mirzā 90, 299

Mohammad Shah 27, 34

Movassaq Karimi 297

Mozaffar al-Din Shah 36, 77, 89, 90, $102,184,211,255,259,261,311$

$\mathrm{N}$

Naskh 73, 74, 76, 77, 82, 89, 90, 9295, 253

Nāser al-Din Shah 23, 27, 28, 29, 30, $34,35,36,38,49,77,84,91,94$, $121,123,124,125,126,127,129$, 130, 148, 149, 156, 163, 164, 165, $167,170,171,172,176,180,196$, 207, 210, 211, 241, 262, 272, 279, 280, 287, 289, 304, 307, 318, 327

Nasta'liq 74, 76-79, 82, 87, 88, 202, 253, 254

National Geographic Magazine (Persia) 31, 161, 162, 168, 186, 197, 207, 291-296

Neuro-aesthetics 55

Neuroarthistory $\quad 55,56,68,152,200$

Nikolai Pavlov 27, 209

Non-linear perspective $24,131,136$

$\mathrm{O}$

Occidentalism 160, 161, 206

Orientalism 25, 126, 159, 160, 163, 164, 165, 181, 186, 196, 203, 206, 208

Osrat Khānom 176

$\mathrm{R}$

Reading habits $41,51,54,62,63,65$, 66, 67, 69, 199, 201

Rezā Akkāsbāshi 29, 30, 34, 35, 37, 46, 120, 121, 163, 166, 167, 171, 172, 174, 177, 184, 185, 210, 211, 229, 231, 234, 238, 241, 271, 272, 288, 297, 306 
$S$

Self-orientalism 163, 164

Scanned composition 133

Sven Hedin 34

$\mathrm{T}$

Thuluth 73, 74, 76, 86-90, 92

V

Visual Laterality $10,14,21,22,23$, $25,41,42,43,45,46,47,49,51$, $54,55,57,63,66,67,165,177,190$, 193

Visual brain $55,56,57,251$

Vertical composition 21, 24, 131, 132, $139,140,144,146,147,148,151$

Vertical perspective $24,131,132$, $139,140,141,146,147,151$
Victorian portrait $164,168,173,174$, 182, 183, 185, 206

W

W. Ordén 31, 32, 170, 221-225, 232 , 304-306

World Art Studies 10, 22, 25, 55, 68, 200, 201

Written image 71, 193

Y

Yahyā Zokā 13, 38, 89

Ya'qub Akkāsbāshi 120, 271

Yokoyama Matsusaburo 98, 99, 202, 265, 266

Yusof Khān Akkās 35 


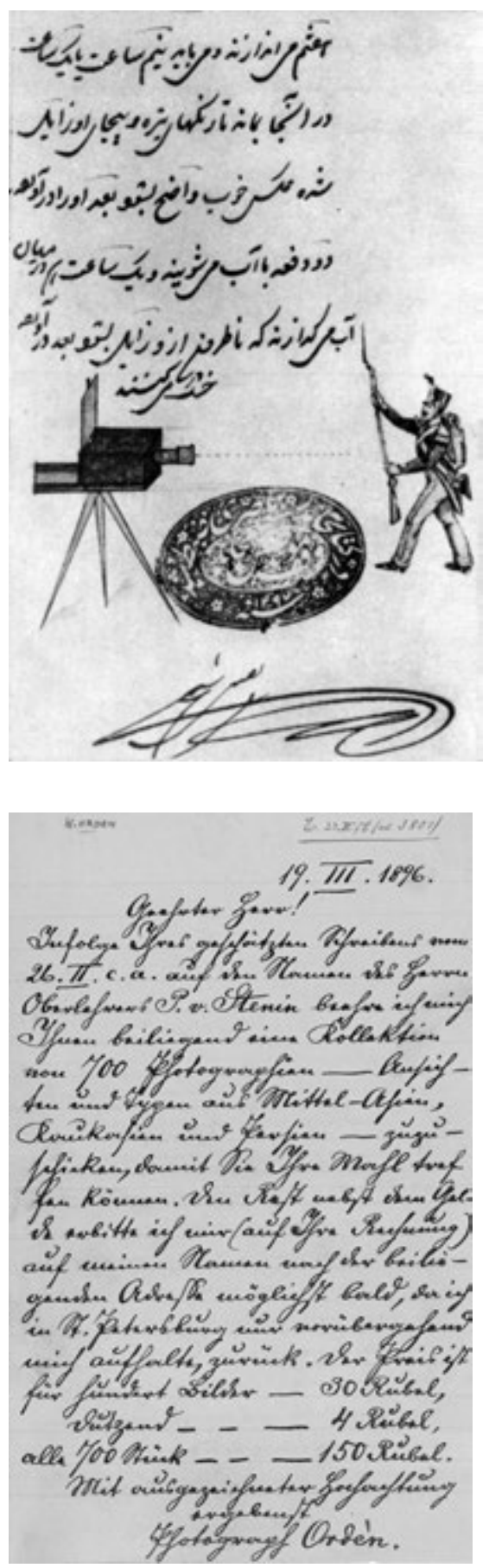

Figure I Unknown Iranian author, booklet on photography, c. 1859 , taken from Zokā 1997: 292.

Figure II Letter 1, signed W. Ordén, 19th March 1986, Museum für Völkerkunde, Vienna. 

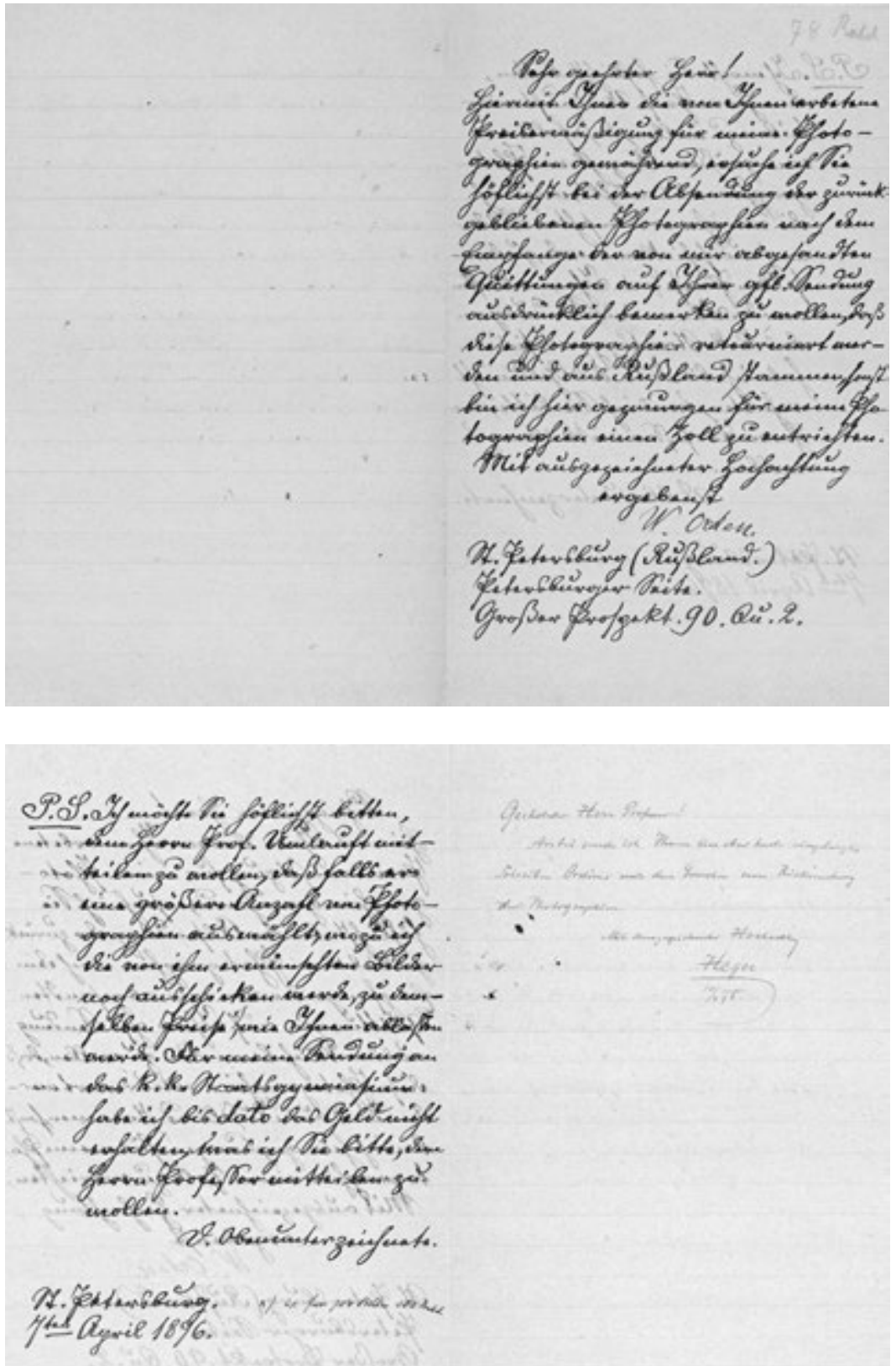

Figure III Letter 2, signed W. Ordén, 7th April 1896, Museum für Völkerkunde, Vienna. 


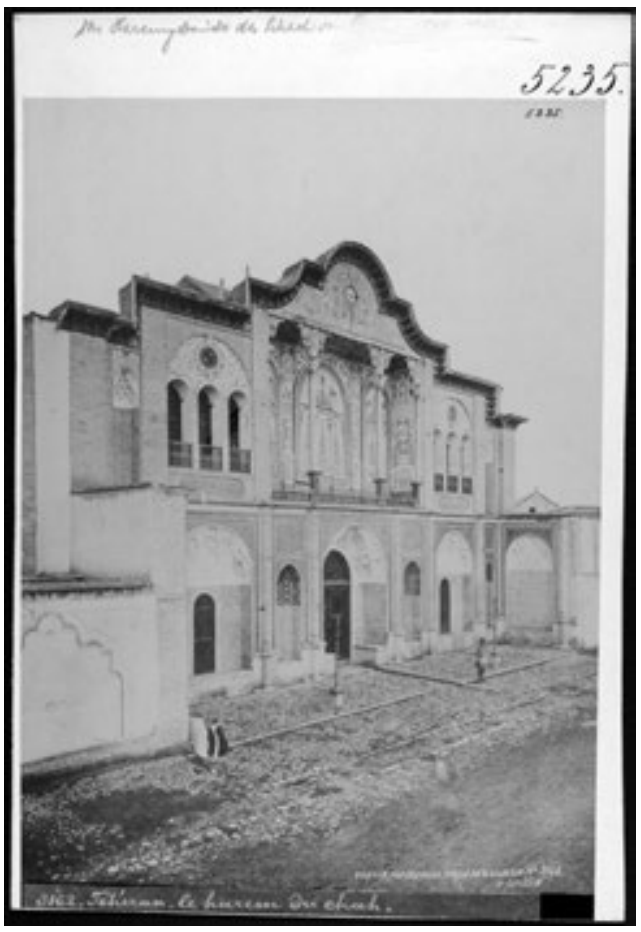

Figure IV W. Ordén, $N^{\circ} 3162$ Tehran. The Shah's Harem, c. 1886, albumen print, $14.5 \times 21 \mathrm{~cm}$, Museum für Völkerkunde, Vienna, VF-5232.

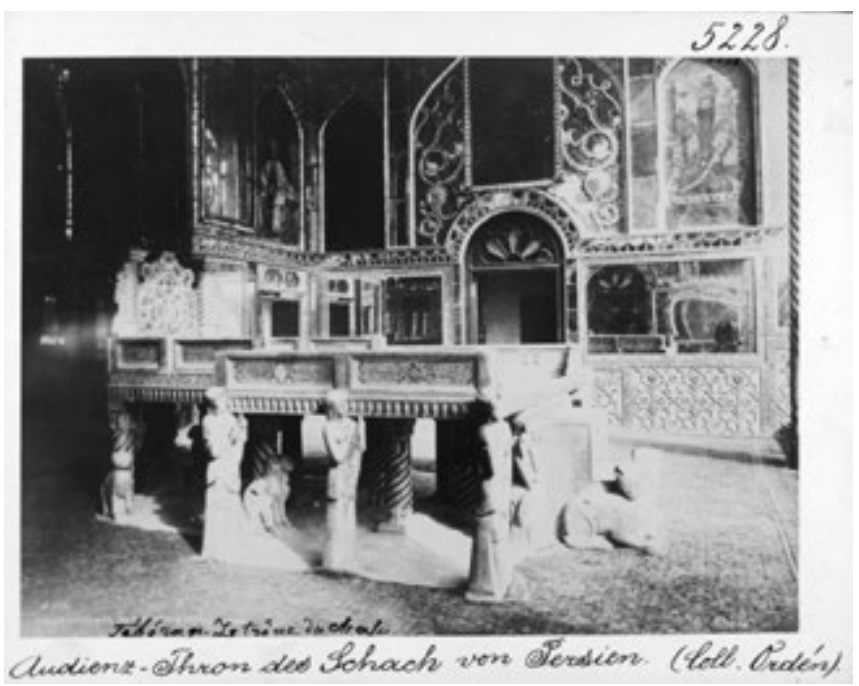

Figure V W. Ordén, $N^{\circ} 3176$, Tehran. The Shah's Throne, c. 1886, albumen print, $18.8 \times 14 \mathrm{~cm}$, Museum für Völkerkunde, Vienna, VF-5228. 


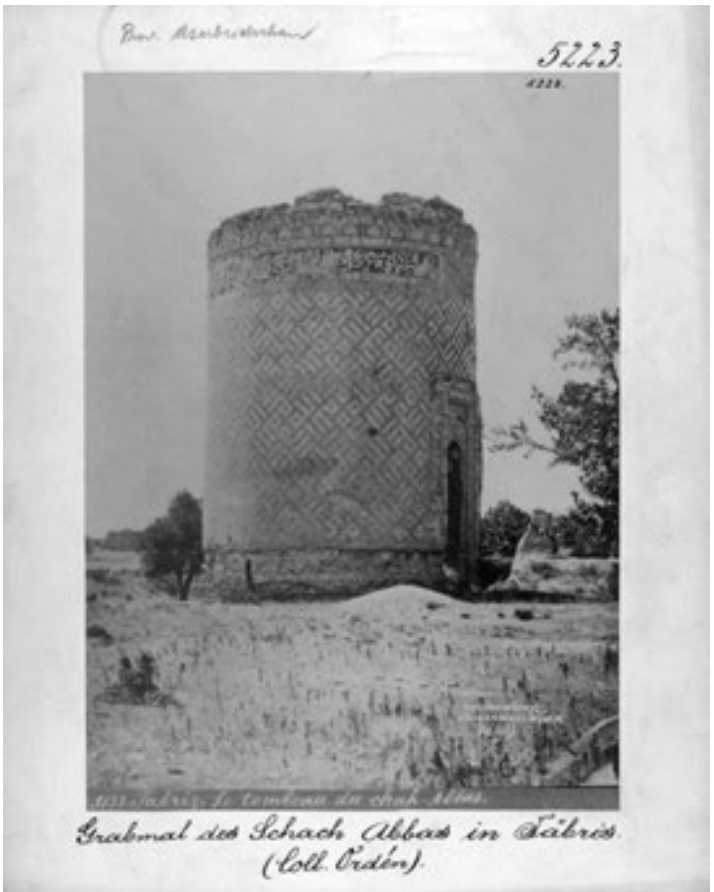

Figure VI W. Ordén, $N^{\circ}$ 3133, Tabriz. The Tomb of Shah Abbās, c. 1886, albumen print, $20.3 \times 14.7 \mathrm{~cm}$, Museum für Völkerkunde, Vienna, VF-5223.

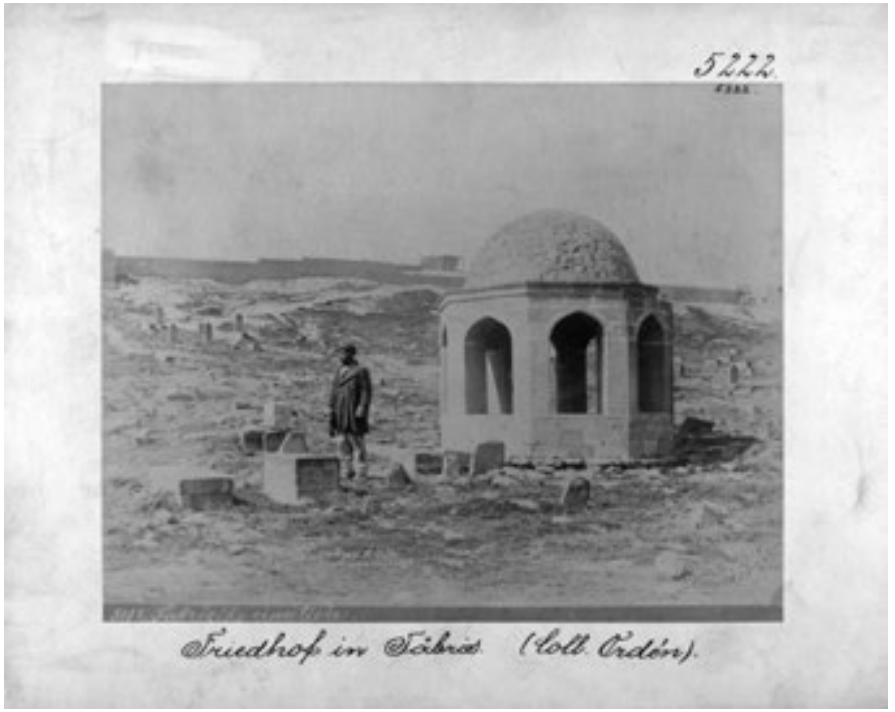

Figure VII W. Ordén, $N^{\circ}$ 3139, Tabriz. Cemetery, c. 1886, albumen print, $18.8 \times 15$ cm, Museum für Völkerkunde, Vienna, VF-5222. 


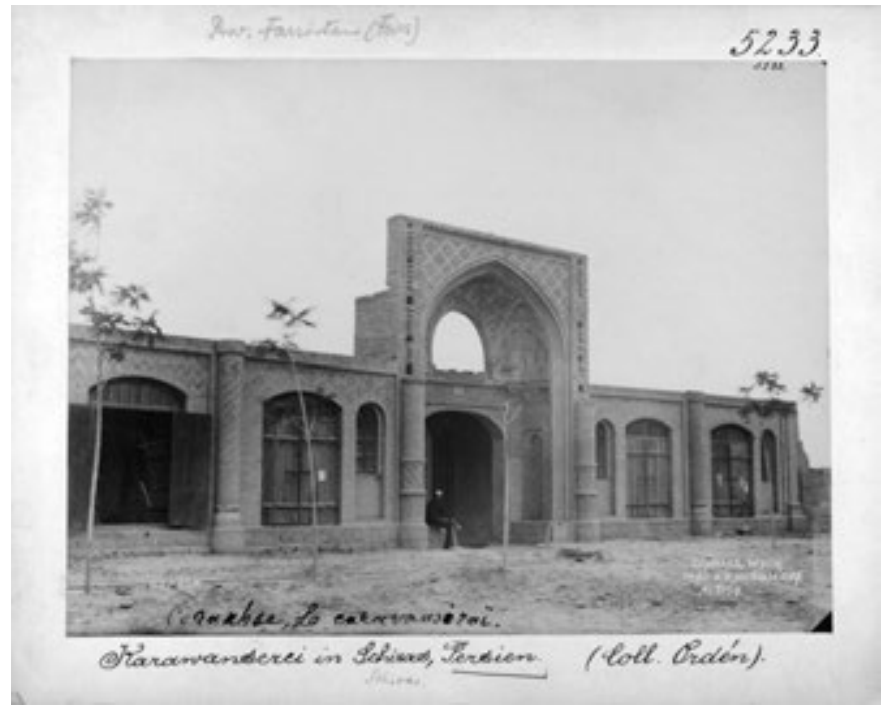

Figure VIII W. Ordén, $N^{\circ}$ 3150, Caravanserei Shiraz, c. 1886, albumen print, 21.4 x $16.3 \mathrm{~cm}$, Museum für Völkerkunde, Vienna, VF- 5233.

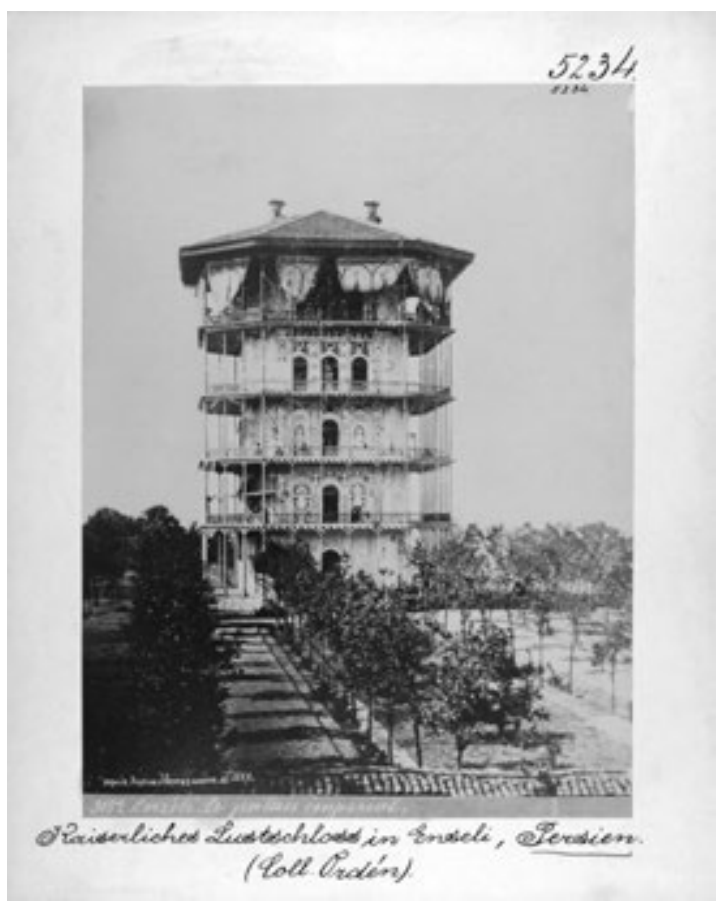

Figure IX W. Ordén, $N^{\circ}$ 3159, Enzali. The Imperial Palace, c. 1886, albumen print, $20.2 \times 15.2 \mathrm{~cm}$, Museum für Völkerkunde, Vienna, VF-5234. 


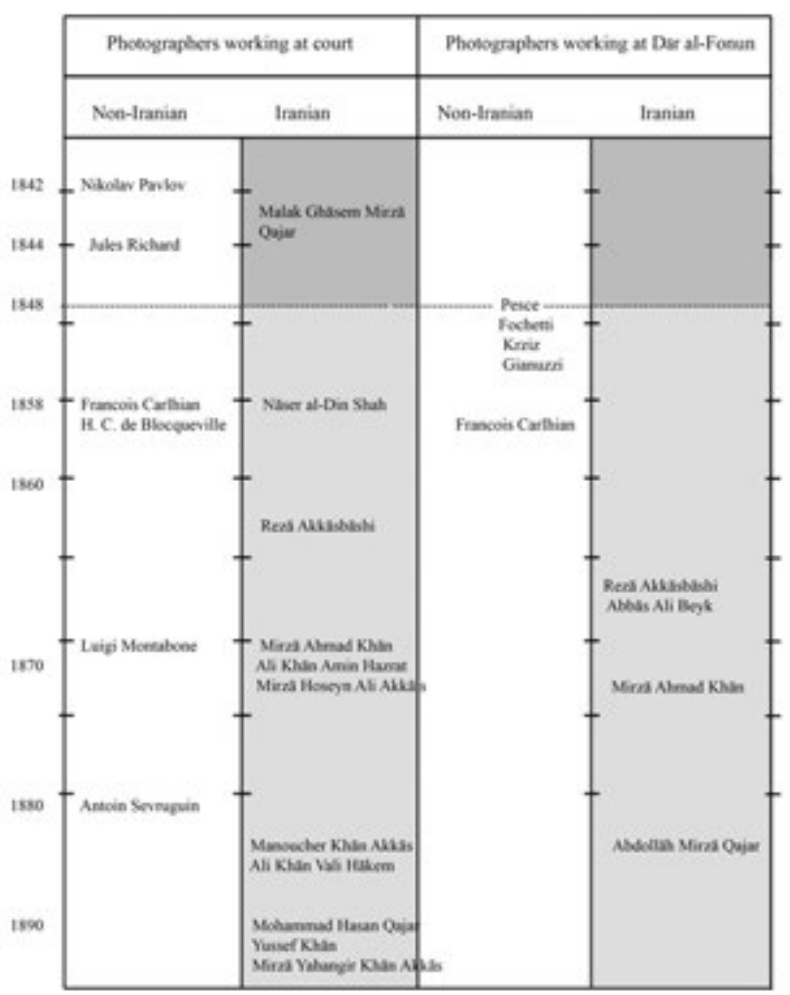

Figure $\mathbf{X}$ Chronology of Western and Iranian photographers working at court and Dār al-Fonun, by Carmen Pérez González.

\begin{tabular}{|c|c|}
\hline & $A B C D E F$ \\
\hline$I X 1$ & GHIJKL \\
\hline goq & MNOH \\
\hline & stuv \\
\hline
\end{tabular}

(a)

(b)

(c)

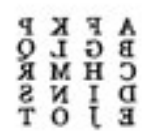

(d)

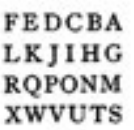

(g)

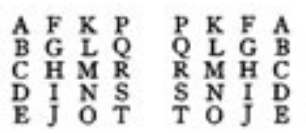

(c)

(f)

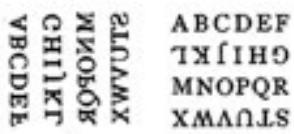

(h) (D)

Figure 1a Nakanishi, Akira, Writing Systems of the World. Alphabet, Syllabaries, Pictograms, Tokyo, 1980: 112. 


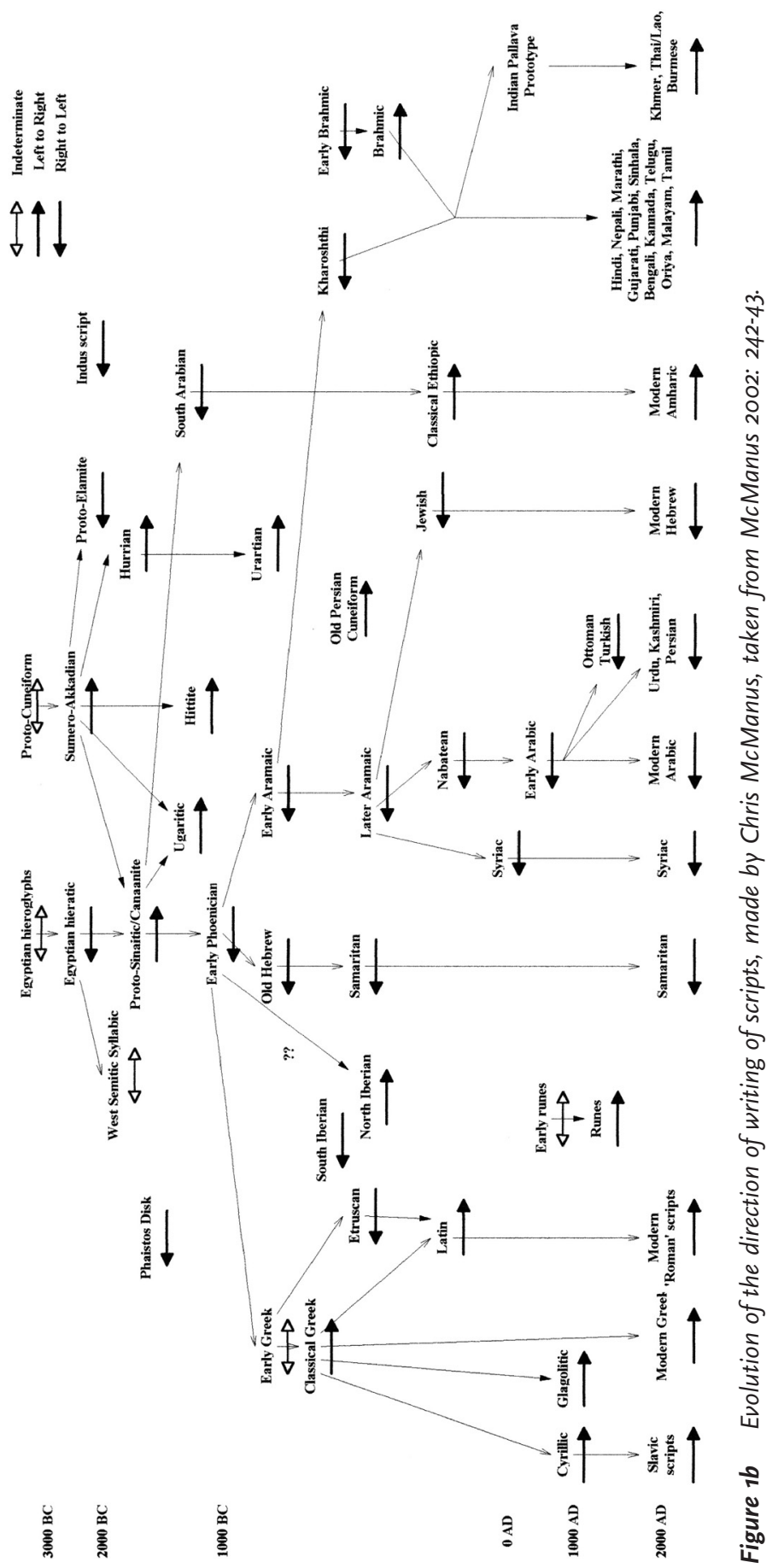




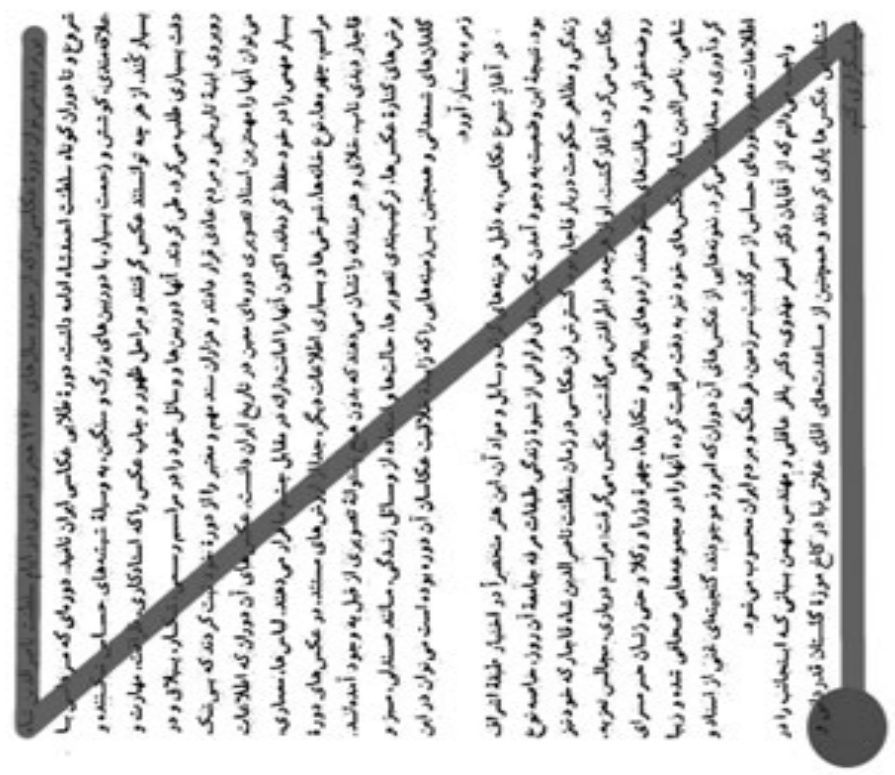

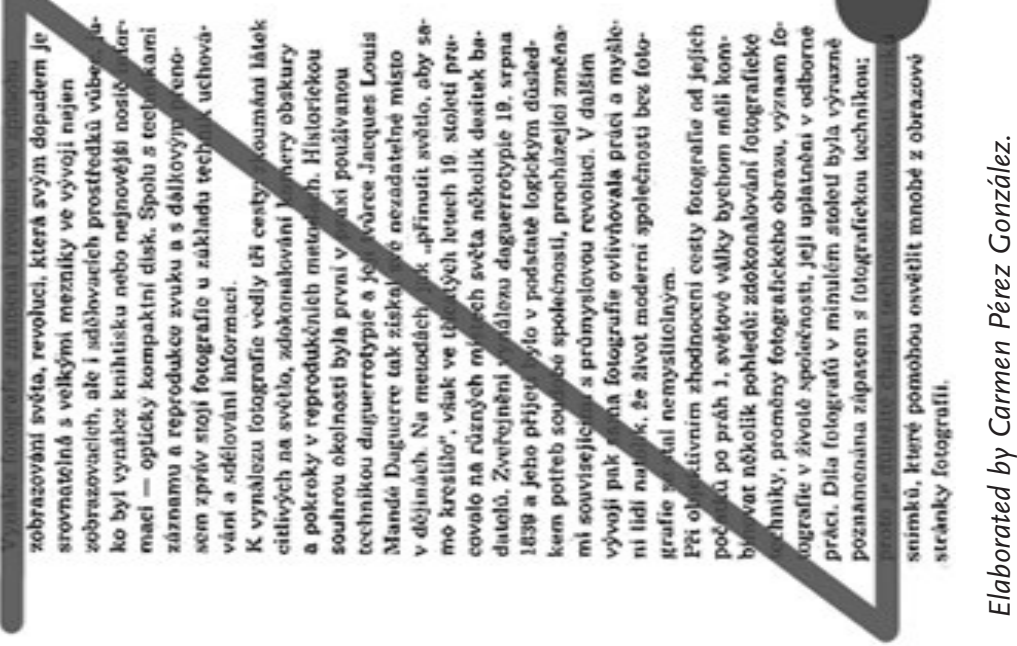

童 


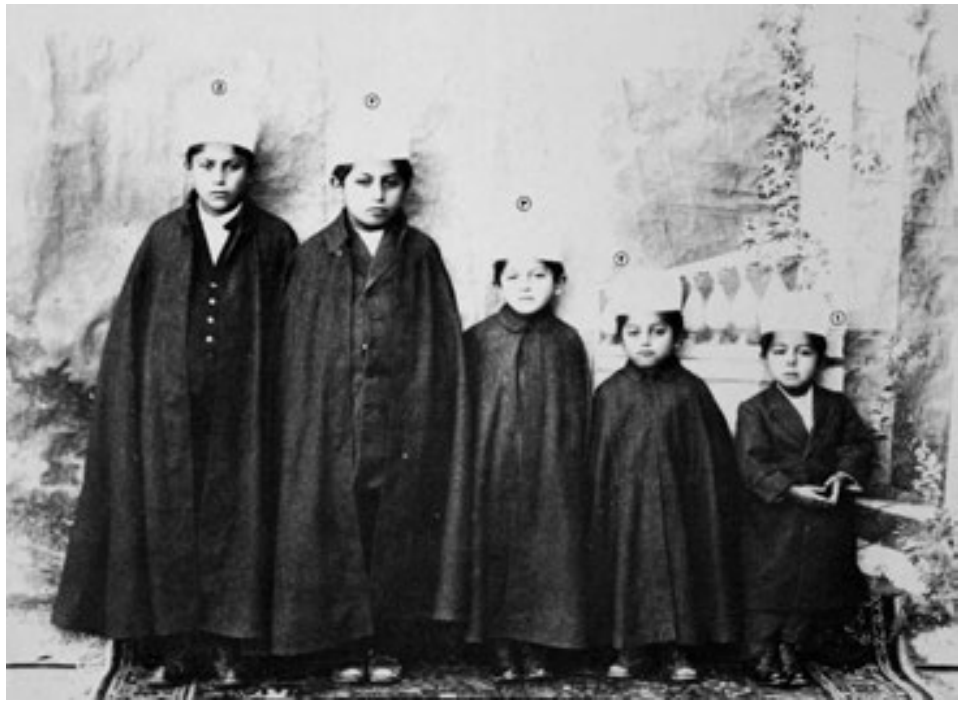

Figure 3 Anonymous Iranian photographer, a group of Bakhtiari children, c. 1880, albumen print, particular collection of Iraj Afshar, taken from Afshar 1992: 317.

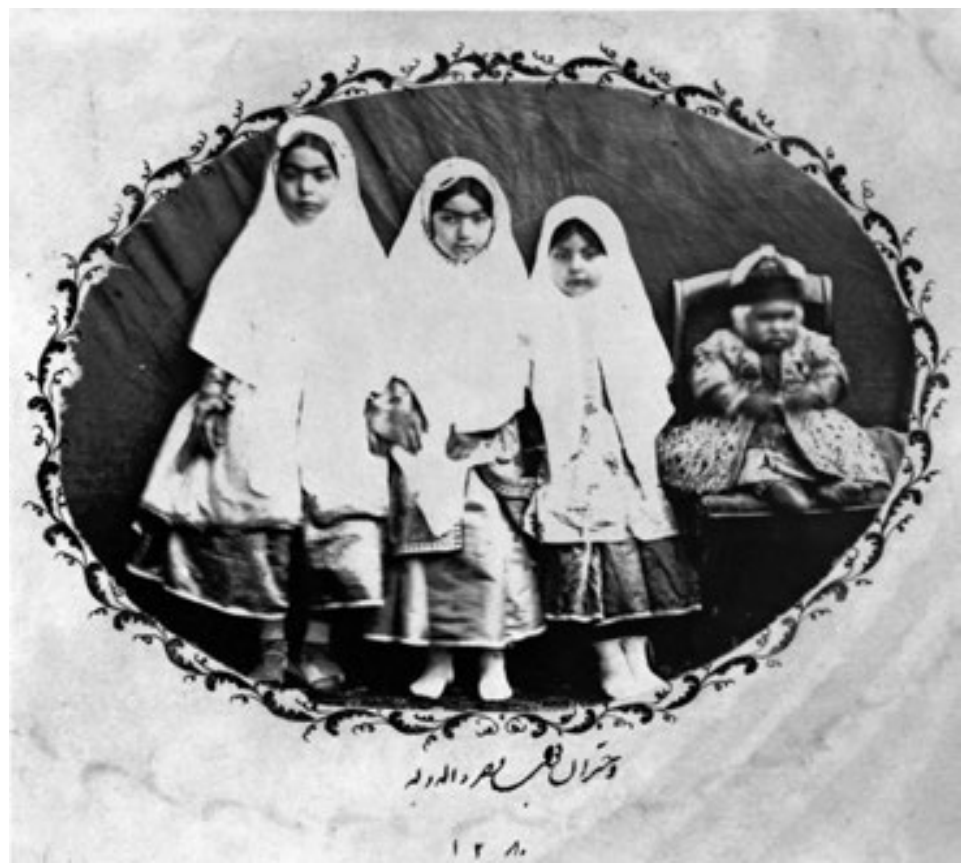

Figure 4 Rezā Akkāsbāshi, Prince Firuz Mirzā children, 1866, albumen print, 16 x $11.5 \mathrm{~cm}$, Golestān Palace Library, Tehran, Album 133, Photo 91. 


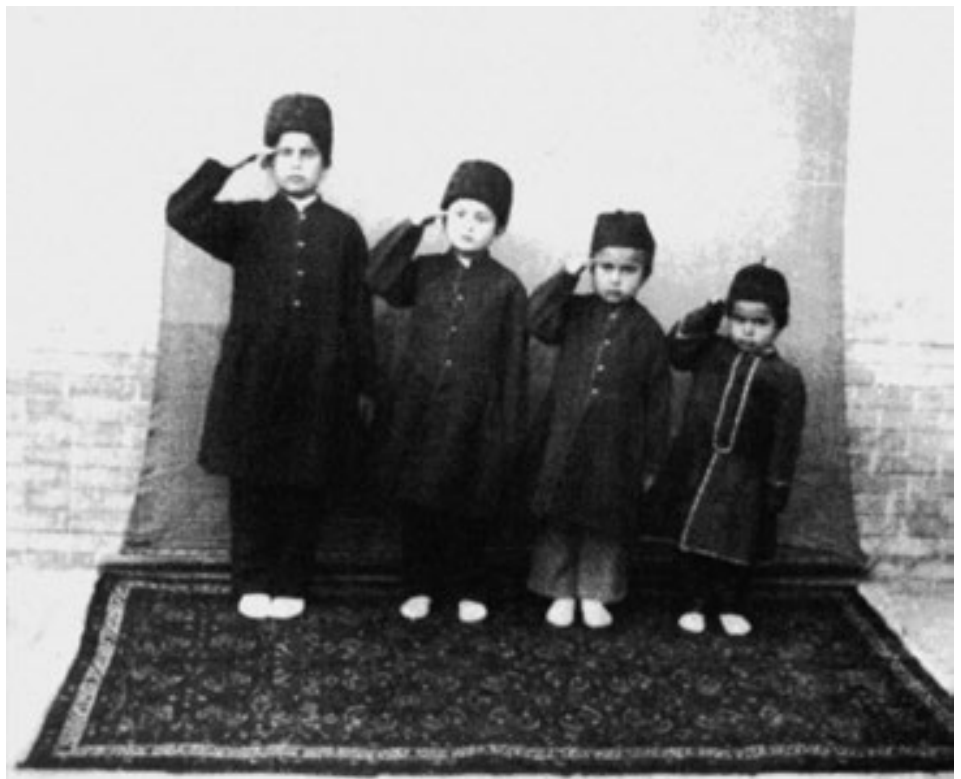

Figure 5 Attr. Rezā Akkāsbāshi, sons of Mohandes-e Mamālek, c. 1866, albumen print, Golestān Palace Library, Tehran, Album 191.

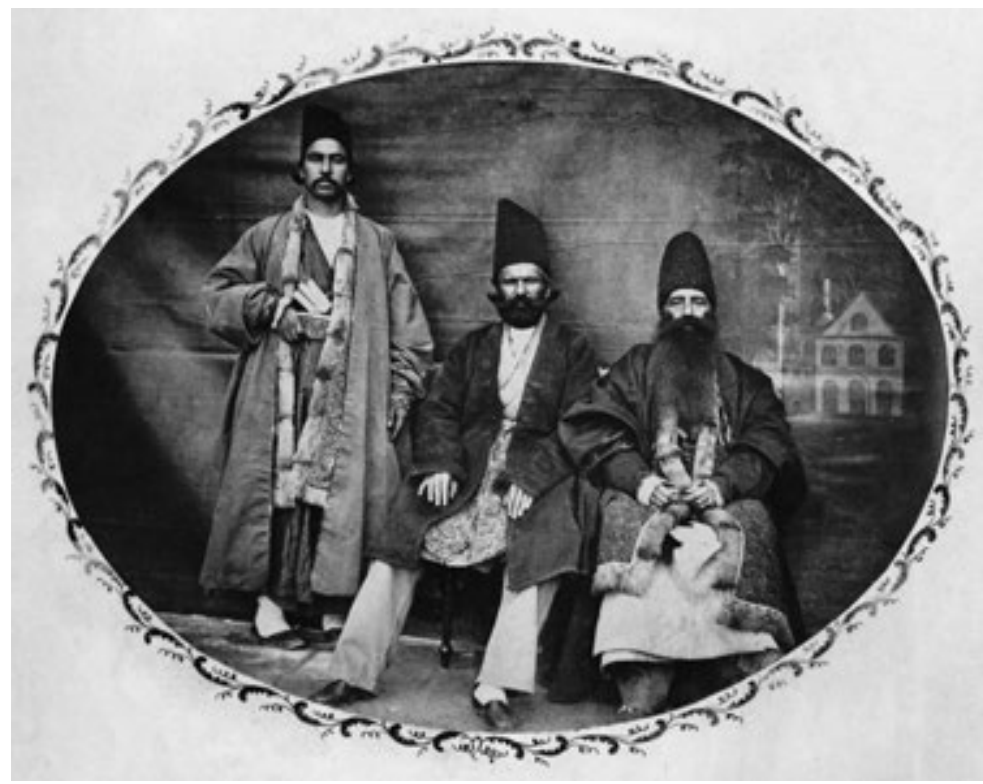

Figure 6 Rezā Akkāsbāshi, Ismail, Asad al-Khān and Nāser al-Manushi, 1866, albumen print, $20.5 \times 15.4 \mathrm{~cm}$, Golestān Palace Library, Tehran, Album 188, Photo 19. 


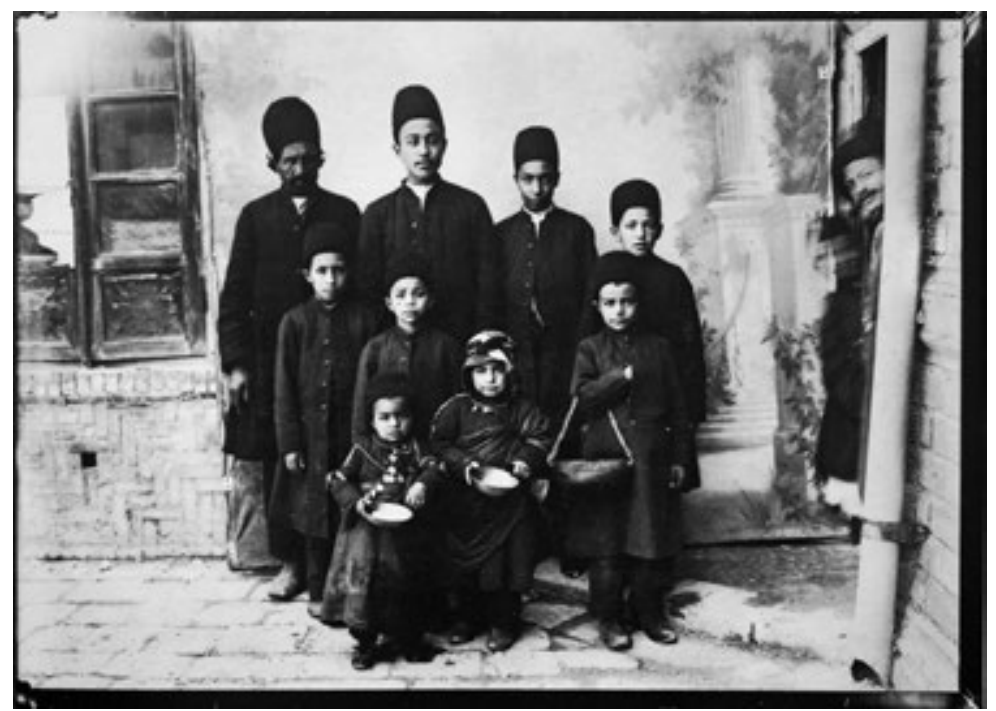

Figure 7 Anonymous Iranian photographer, group portrait, c. 1880, taken from Jalali 1998: 166 .

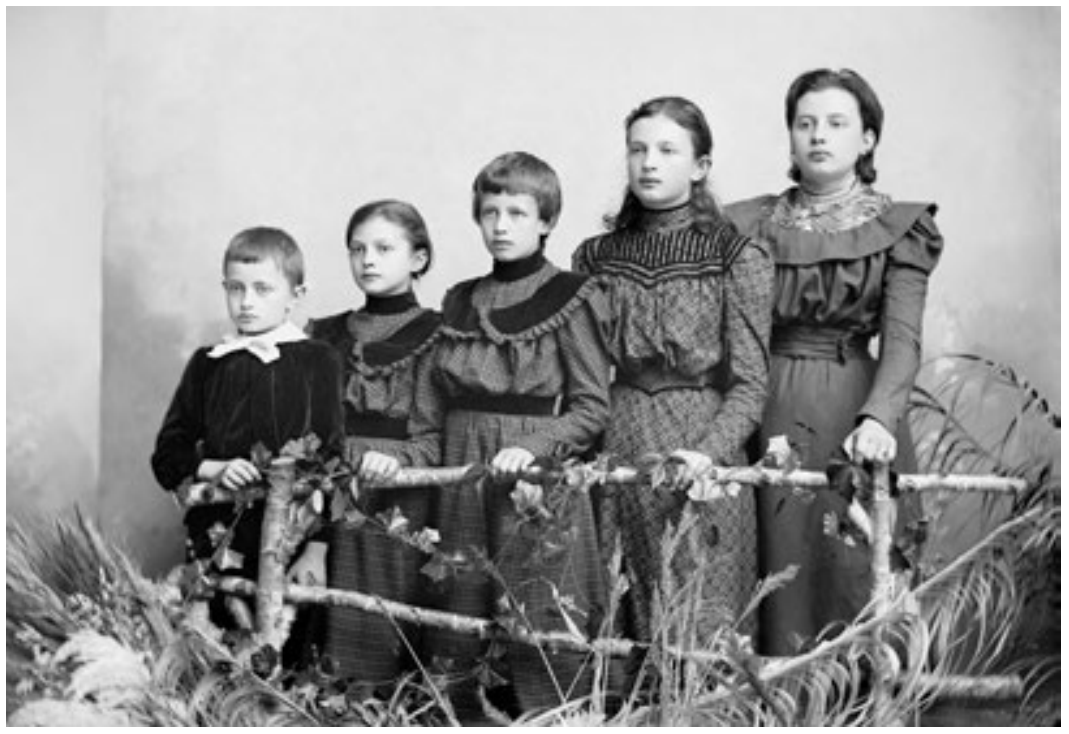

Figure 8 Ignác Schächtl, group of children, c. 1890, albumen print, Tábor, Czech Republic. Hosted at Photo-Museum Tábor, Czech Republic. 


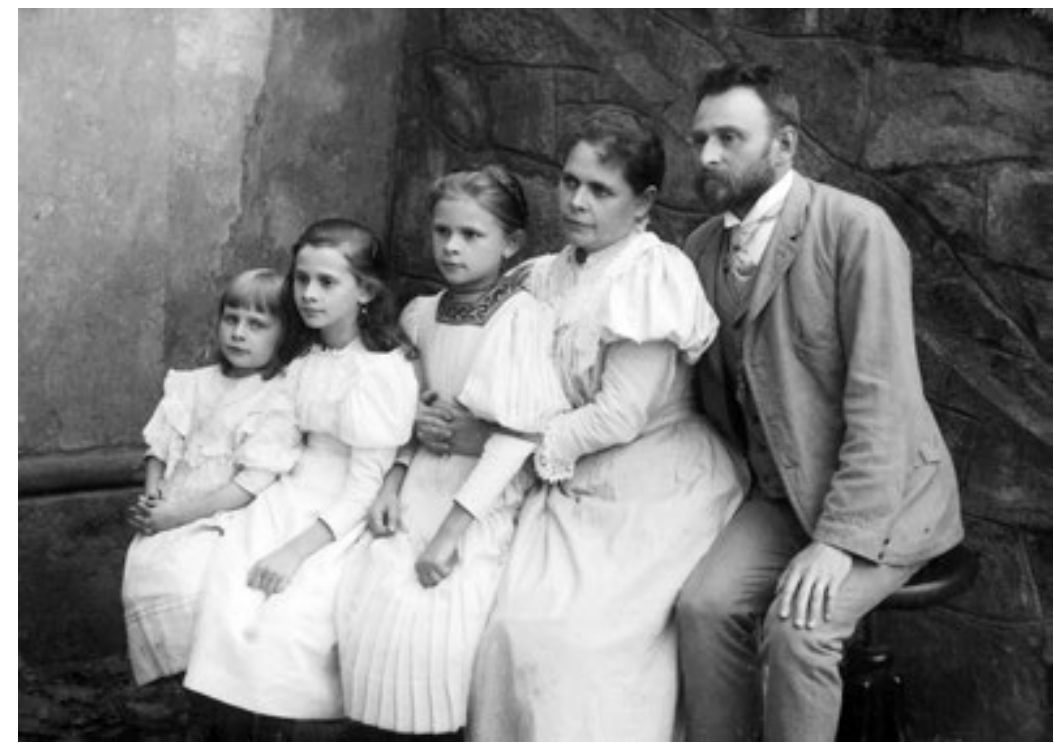

Figure 9 JosefJindrich Sechtl, Novak Family, 1911, albumen print, Bozejov, Czech Republic. Hosted at Photo-Museum Tábor, Czech Republic.

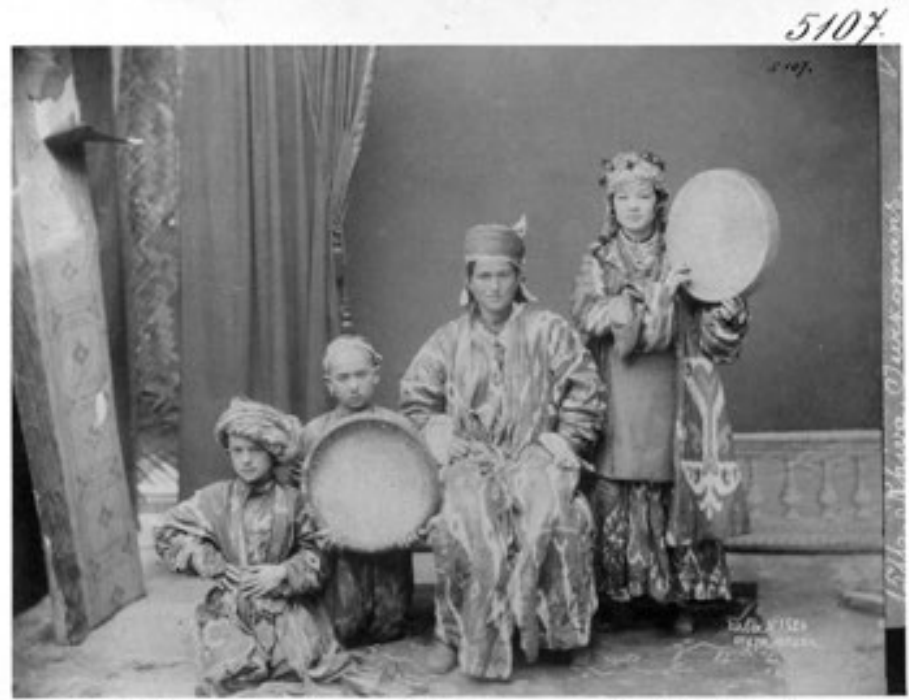

Surkmenen aud Orhina (Loll. Ordén)

Figure 10 W. Ordén, Khiva women with their children, c. 1886, albumen print, $14.7 \times 20.3 \mathrm{~cm}$, Museum für Völkerkunde, Vienna, VF5107. 

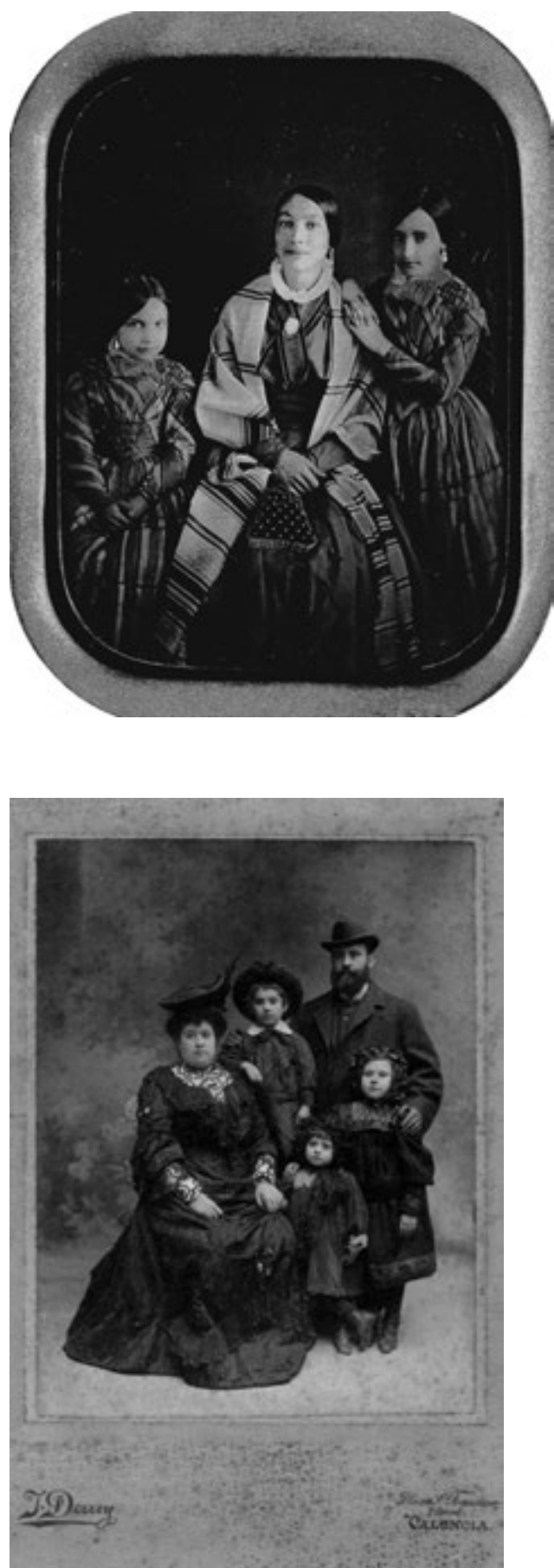

Figure 11 Lorichón, Grupo de señora y dos niñas.

Daguerreotype, 1850, Archivo Museu de la Ciencia i la Tècnica de Catalunya, Barcelona.
Figure 12 Julio Derrey, El relojero Juan Bautista Carbonell y familia (Valencia), 1890, albumen print, $22.6 \times 16.8 \mathrm{~cm}$, Juan José Prósper Díaz Collection. 


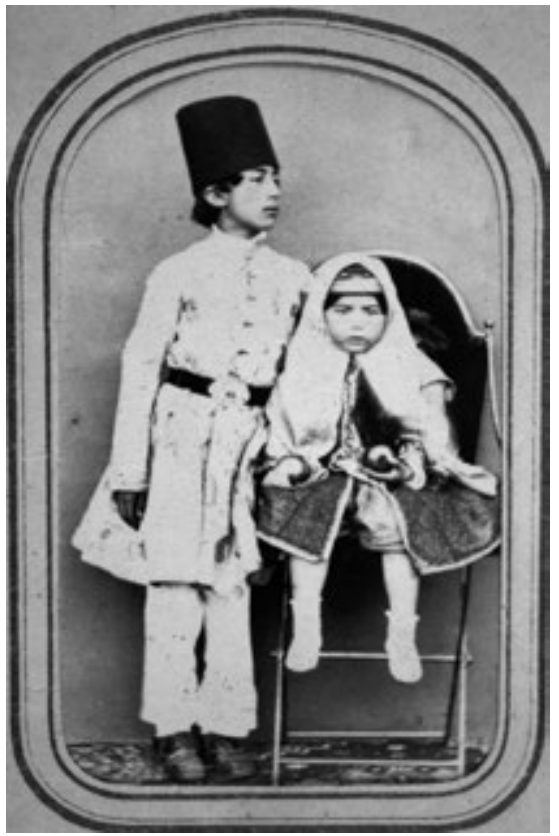

Figure 13 Unknown Iranian photographer, two children, c. 1890, albumen print, Golestān Palace Library, Tehran, Album 269, photo 25-2.

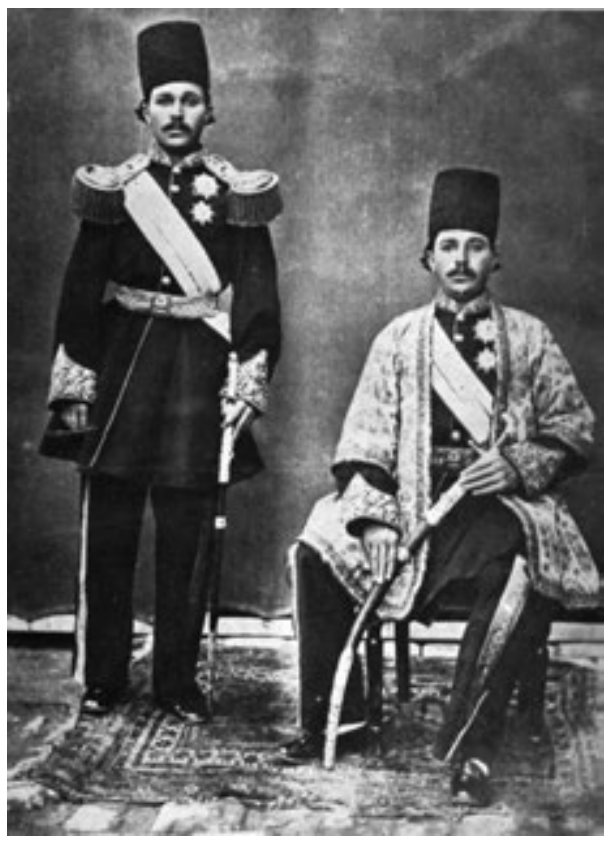

Figure 14 Attr. Rezā Akkāsbāshi, doble exposure of Bahā al-Molk, albumen print, c. 1864, Golestān Palace Library, Tehran, taken from Zokā 1997: 229. 


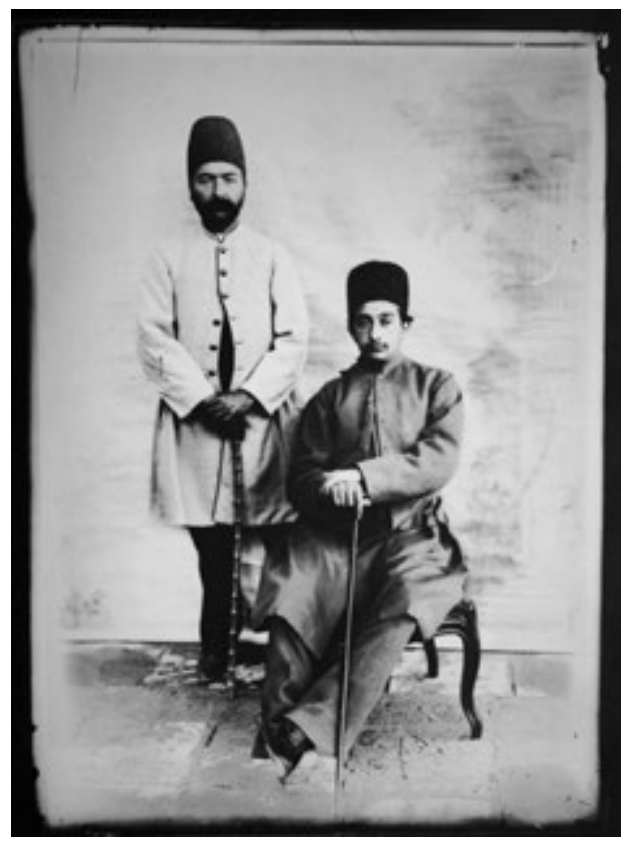

Figure 15 Anonymous Iranian photographer, Sālār al-Dowle (sitting), date unknown, albumen print, Golestān Library Palace, Tehran, glass negative number 2338, Album 83, taken from Jalali 1998: 62.

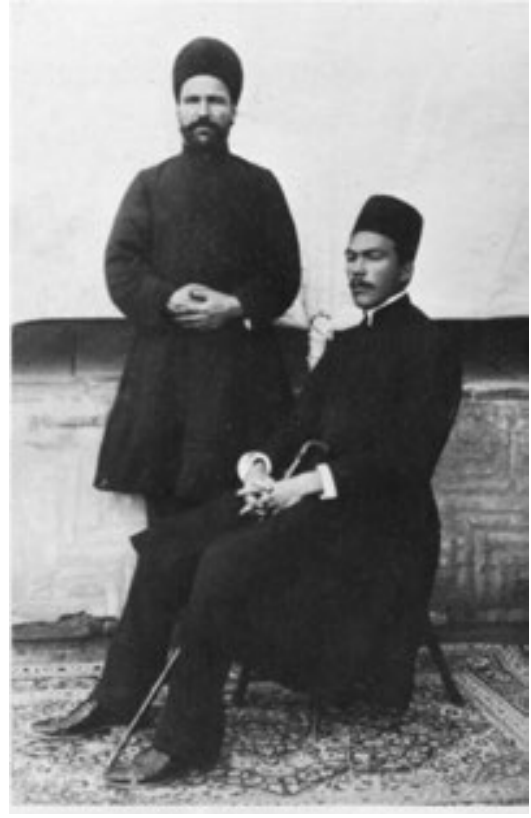

Figure 16 Unknown photographer, untitled, date unknown, albumen print, Golestān Palace Library, Tehran. 

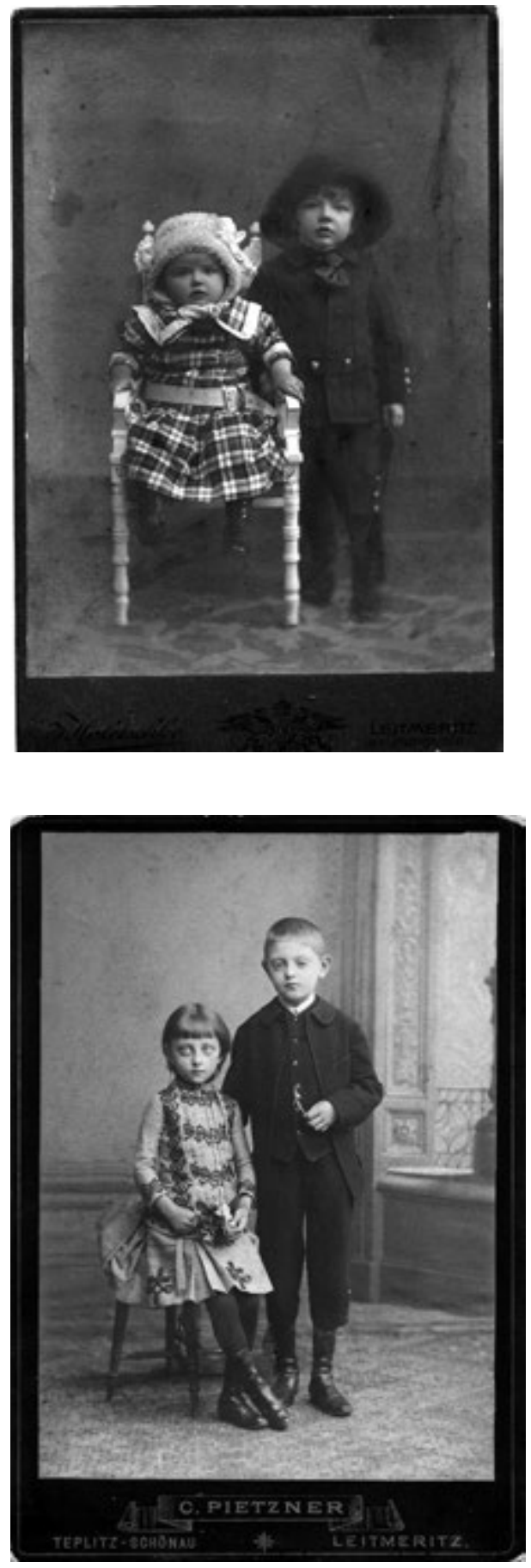

Figure 17 Fot. Atelier L. Ranges Holetschke, brother and sister, c. 1907, albumen print, $16.5 \times 10.6 \mathrm{~cm}$, Carmen Pérez González Collection.

Figure 18 C. Pietzner, brother and sister, c. 1890s, albumen print, $16.4 \times 11.3 \mathrm{~cm}$, Carmen Pérez González Collection. 


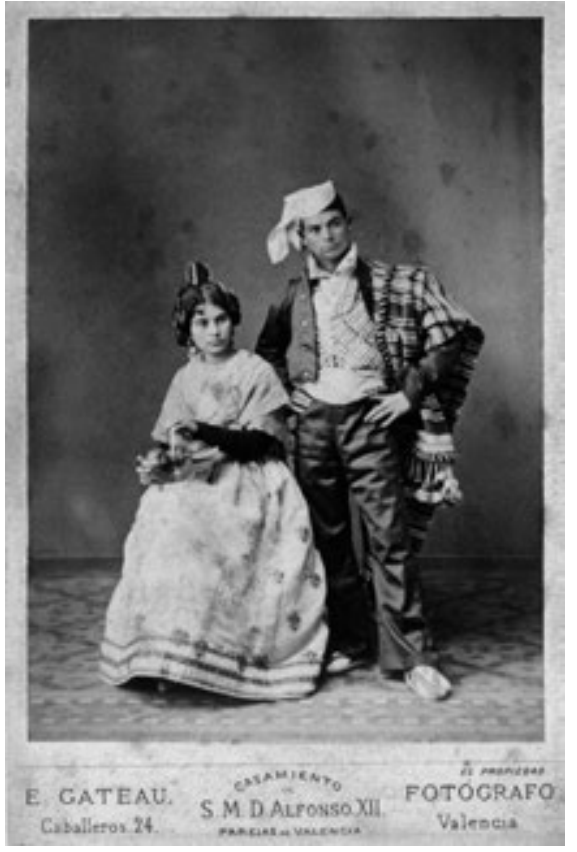

Figure 19 E. Gateau, Pareja de Valencia, 1878, albumen print, $9.6 \times 13.5 \mathrm{~cm}$, Juan José Díaz Prósper Collection.

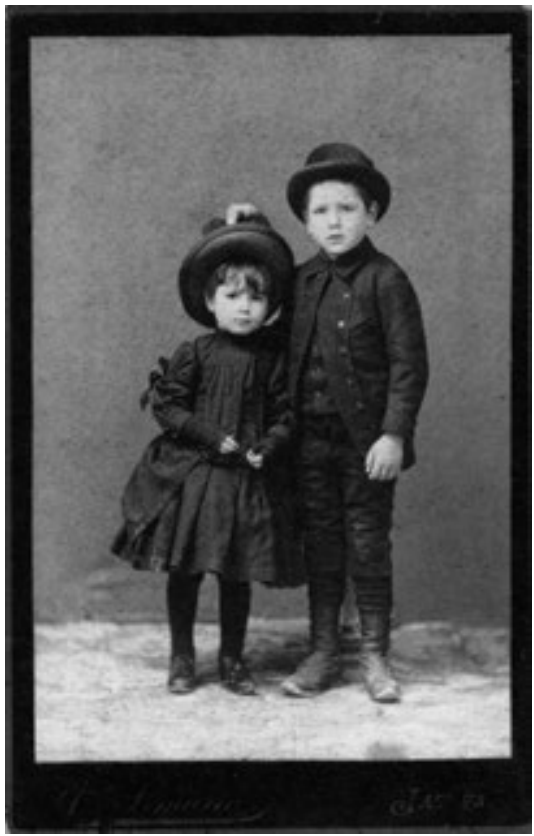

Figure 20 Vicente Simarro, Niño y niña (Játiva), c. 1870, albumen print, $10.8 \times 7.6 \mathrm{~cm}$, Juan José Díaz Prósper Collection. 


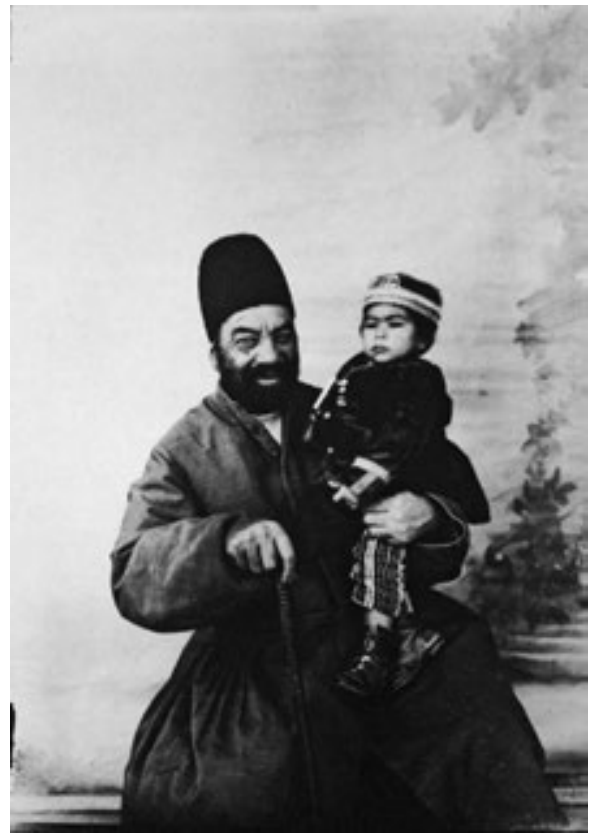

Figure 21 Unknown Iranian photographer, A Servant holding Mohammad Khān, date unknown, albumen print, Golestān Palace Library, Tehran, glass negative number: 2989 , Album 54.

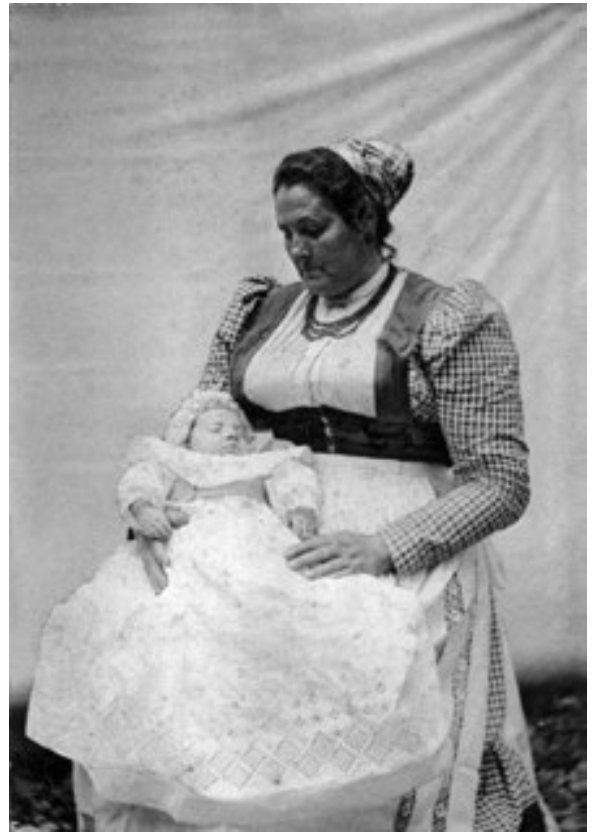

Figure 23 Unknown Spanish photographer, Nodrissa, 1890, albumen print, $11.5 \times$ $16.8 \mathrm{~cm}$, Juan José Díaz Prósper Collection. 


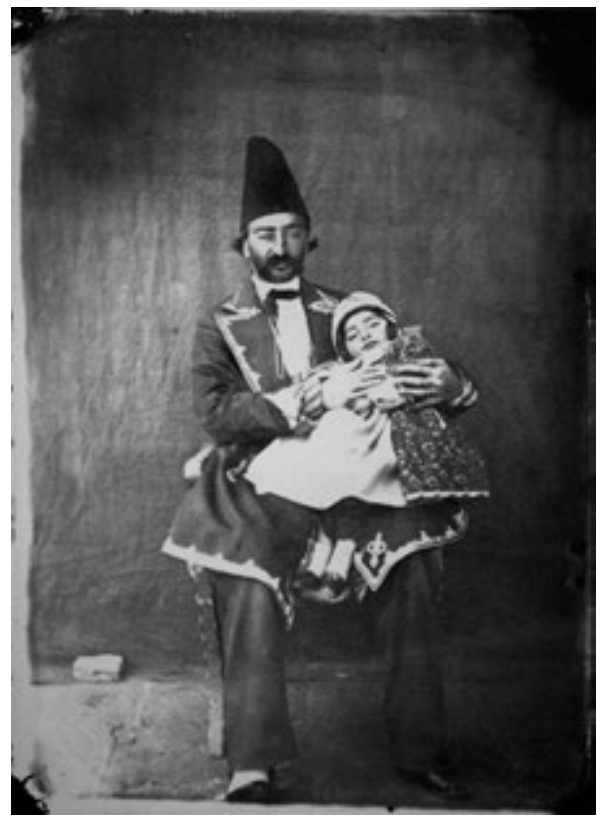

Figure 22 Rezā Akkāsbāshi, Eyn al-Molk, c. 1865, albumen print, $16 \times 11.9 \mathrm{~cm}$, Golestān Palace Library, Tehran, Album 133, Photo 19.

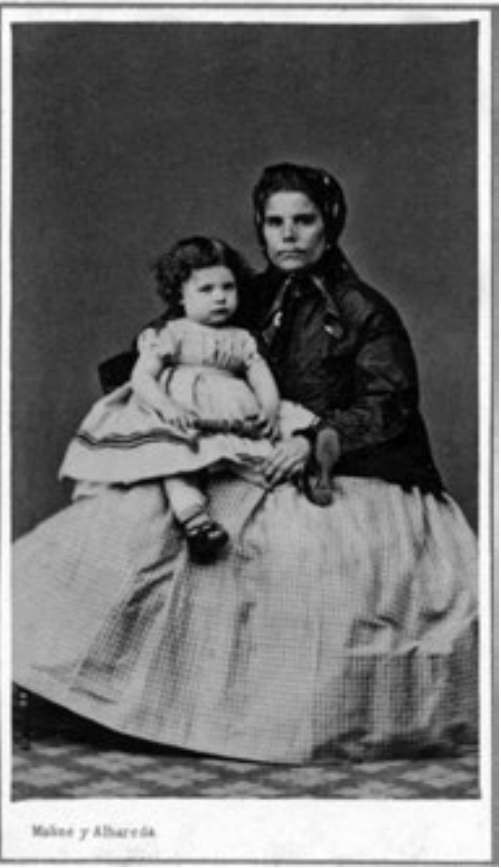

Figure 24 Moliné y Albareda, without title, c. 1865, albumen print, $6 \times 10 \mathrm{~cm}$, Juan José Díaz Prósper Collection. 


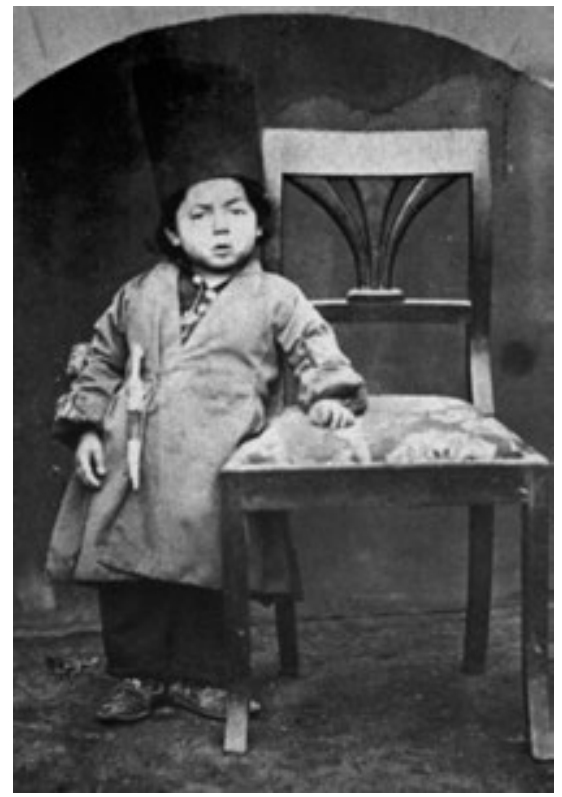

Figure 25 Anonymous Iranian photographer, Mirzā Hoseyn Khān Ehteshām, date unknown, albumen print, Iraj Afshar Collection, taken from Afshar 1992: 319.

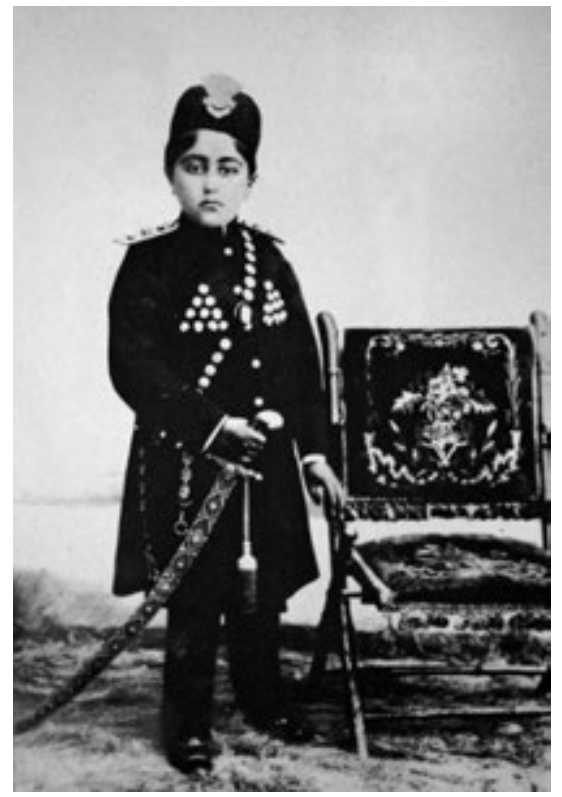

Figure 26 Unknown photographer, Sultan Ahmad Mirzā Qajar, c. 1903, albumen print, taken from Afshar 1992: 33 . 


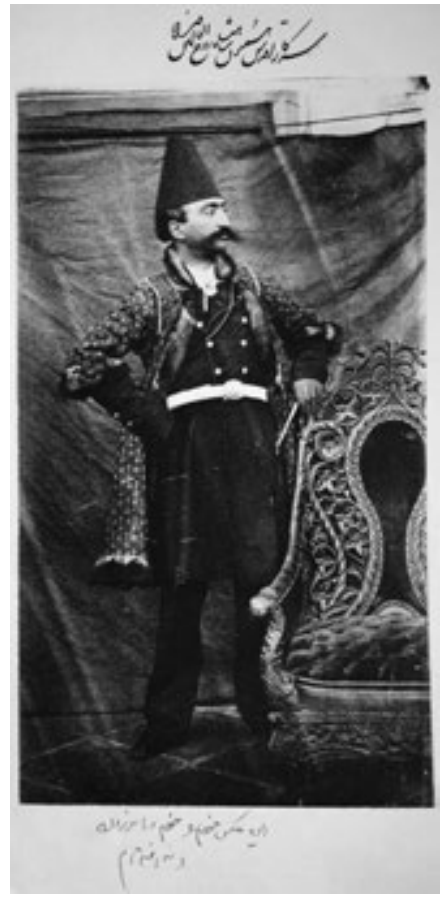

Figure 27 Nāser al-Din Shah, Nāser al-Din Shah, c. 1866 , albumen print, $17.4 \times 9.8 \mathrm{~cm}$, Golestān Palace Library, Tehran, Album 133, Photo 6.

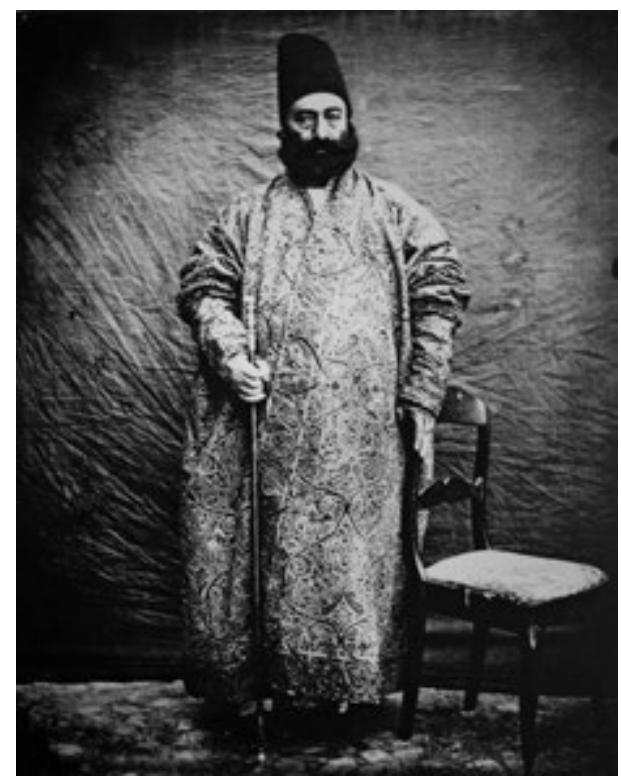

Figure 28 Rezā Akkāsbāshi, Hājji Ali Khān E'temād al-Saltane, c. 1866, albumen print, $18.3 \times 13.8 \mathrm{~cm}$, Golestān Palace Library, Tehran, Album 188, Photo 21. 


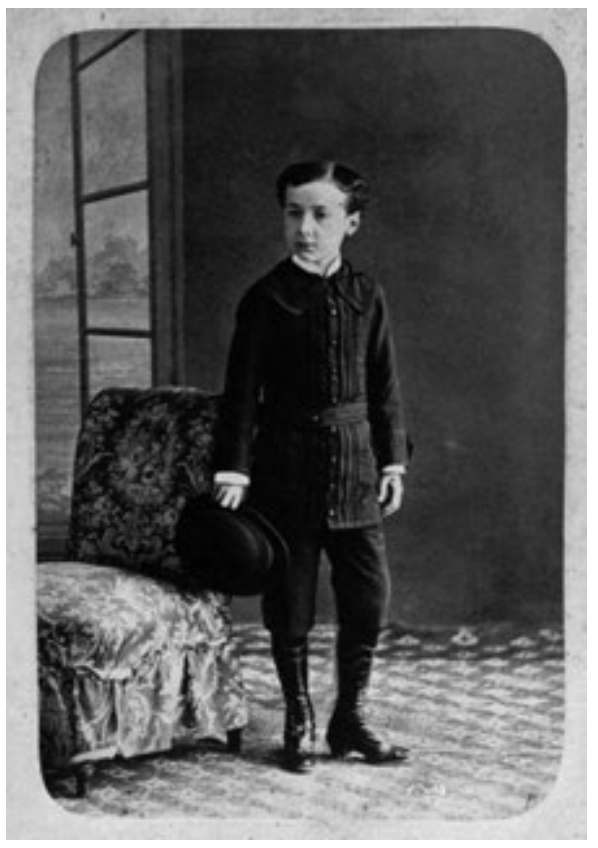

Figure 29 Juan Ramón Sabater, Antonio Alloza (Castellón), c. $1880,13.4 \times 8.9$ $\mathrm{cm}$, Juan José Díaz Prósper Collection.

Figure 30 Atelier Elite, untitled, c. 1910s, albumen print, $11.8 \times 5 \mathrm{~cm}$, Carmen Pérez González Collection.

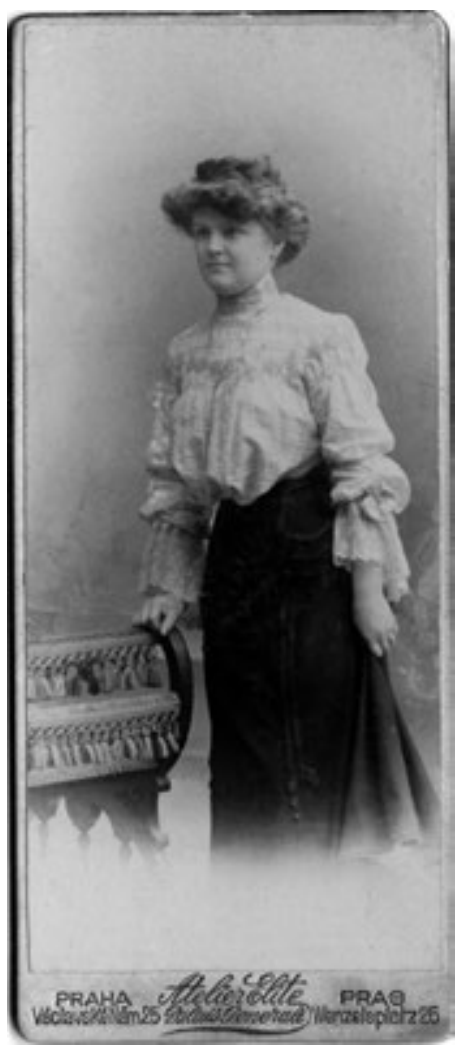


Figure 31 Hans Heinrich, untitled, before October 1911 (back inscription), albumen print, $11.8 \times 4.8 \mathrm{~cm}$, Orianenburg, Carmen Pérez González Collection.
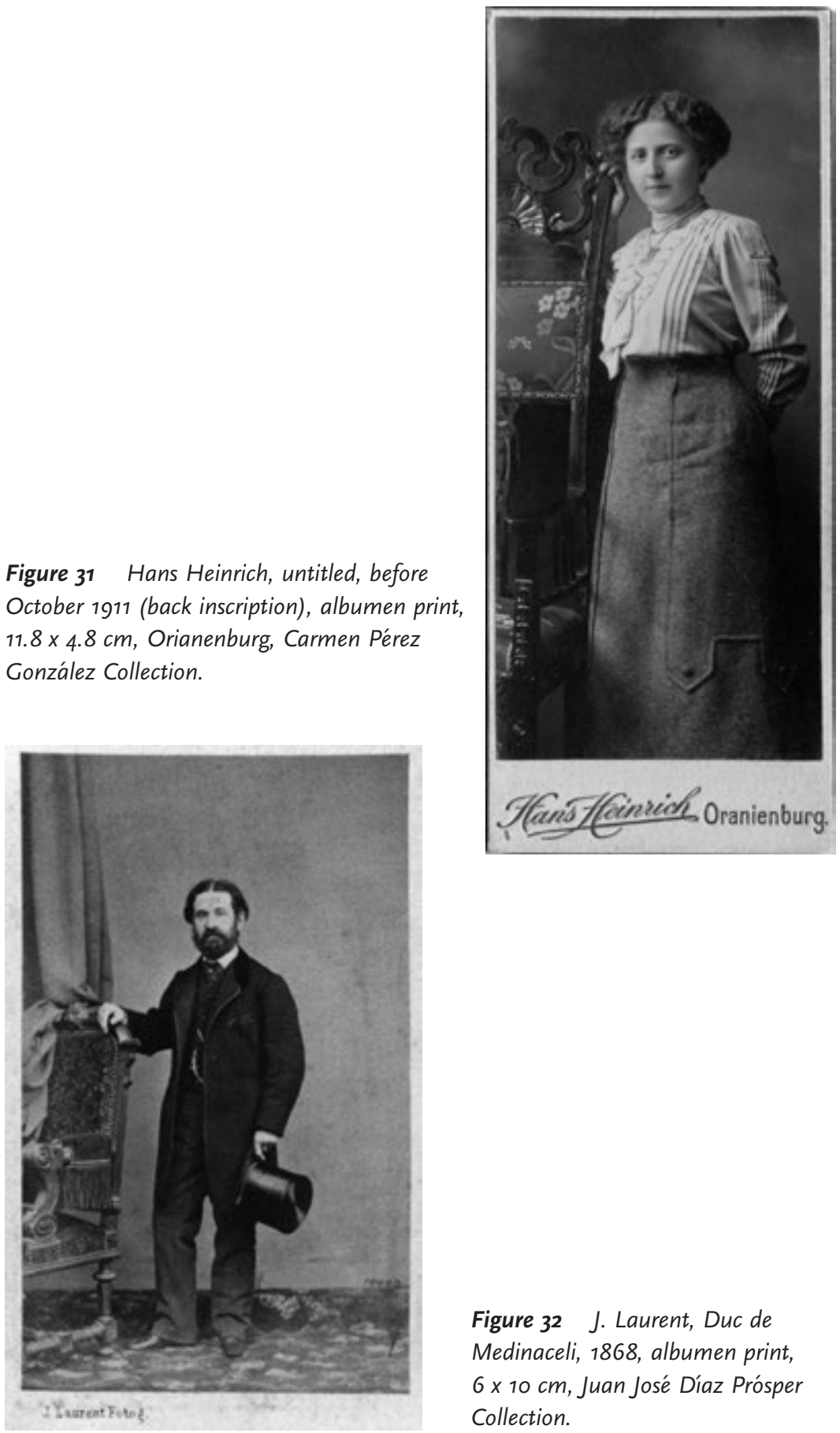

Figure 32 J. Laurent, Duc de Medinaceli, 1868, albumen print, $6 \times 10 \mathrm{~cm}$, Juan José Díaz Prósper Collection. 

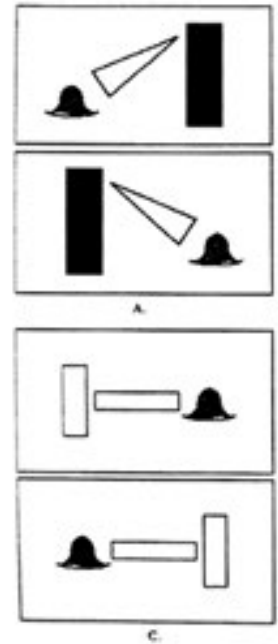
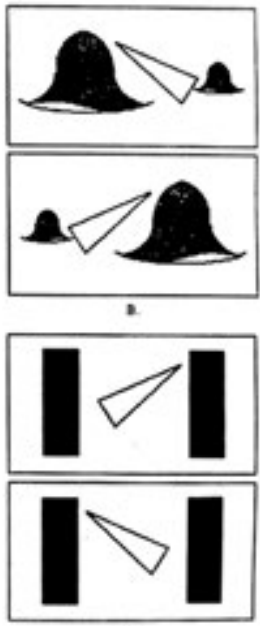

a.

Figure 33 Examples of stimuli. A: top=right-biased weight, left-biased interest, and left-to-right directionality, bottom=left-biased weight, right-biased interest, and rightto-left directionality. B: top=left-biased weight, balanced interest, and right-to-left directionality, bottom=right-biased weight, balanced interest, and left-to-right directionality. C: top=absent weight, right-biased interest, and absent directionality, bottom $=a b s e n t$ weight, left-biased interest, and absent directionality. D: top=balanced weight, absent interest, and left-to-right directionality, bottom=balanced weight, absent interest, and right-to-left directionality. Taken from Christman and Pinger, 1997: 159.

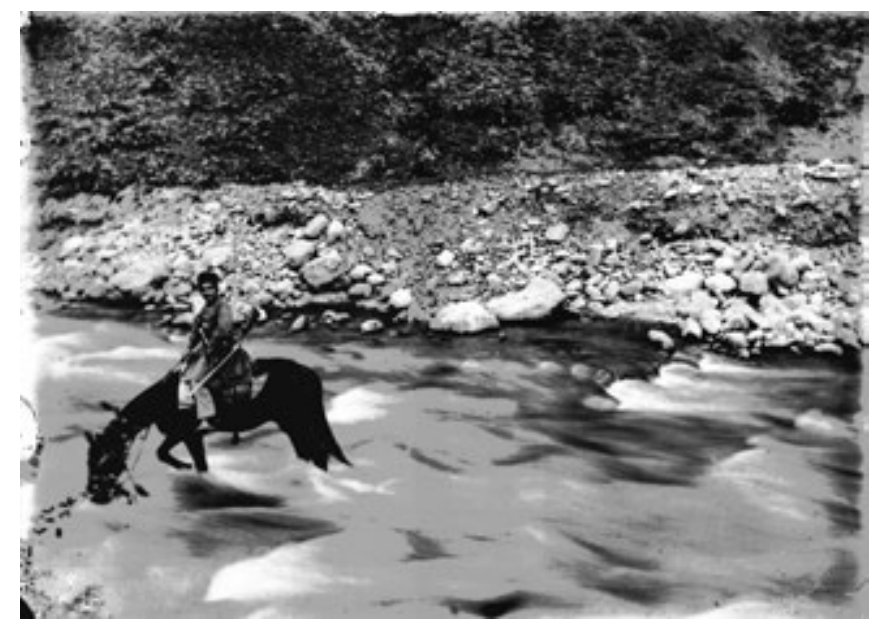

Figure 34 Unknown Iranian photographer, untitled, date unknown, albumen print, taken from Jalali, 1998: 140-141. 


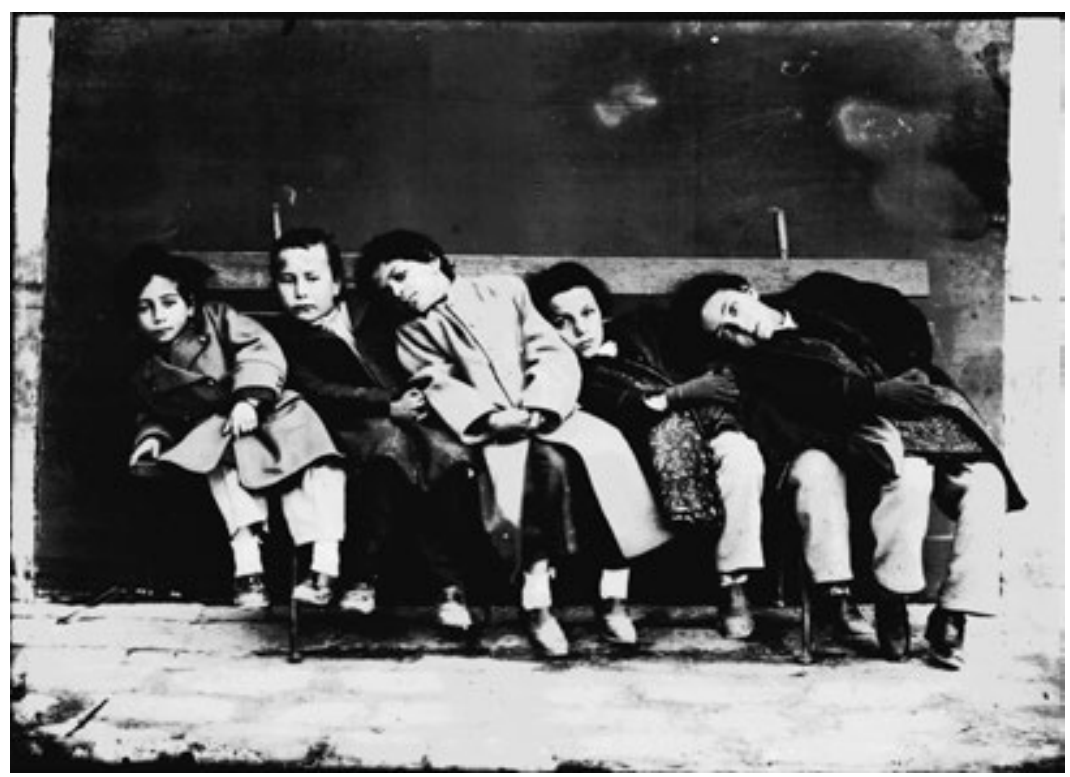

Figure 35 Unknown Iranian photographer, untitled, date unknown, albumen print, taken from Jalali, 1998: 52-53.

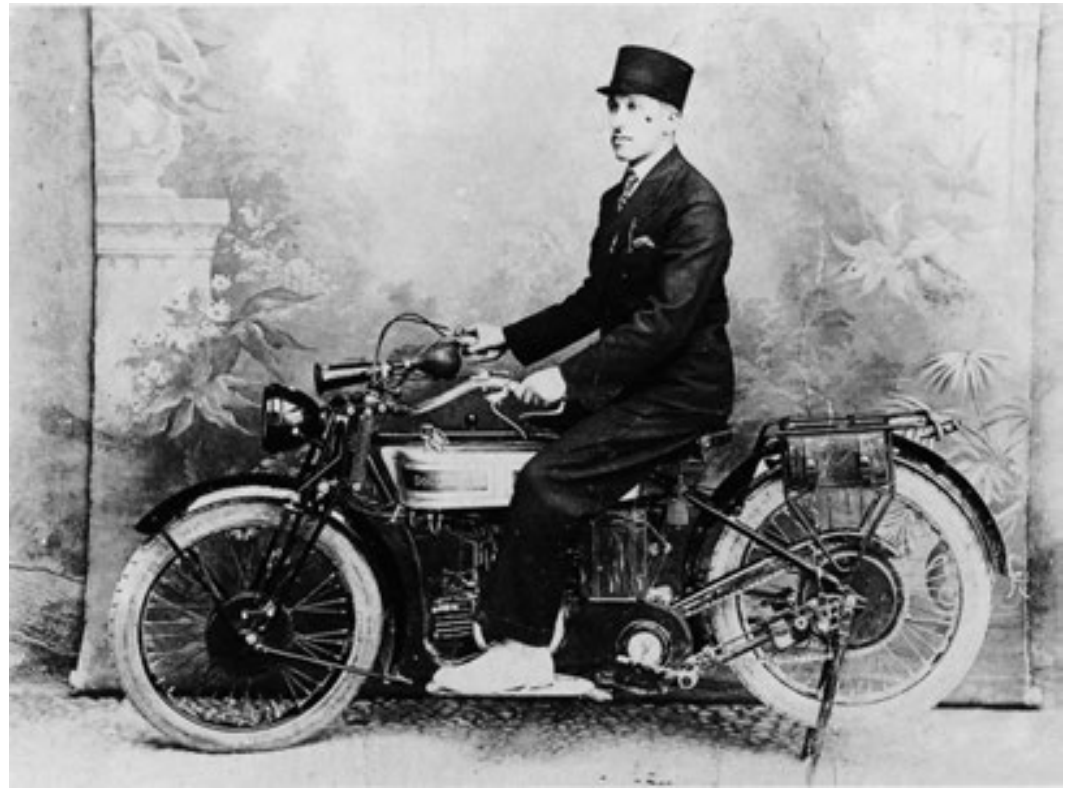

Figure 36 Unknown Iranian photographer, untitled, date unknown, albumen print, private collection. 


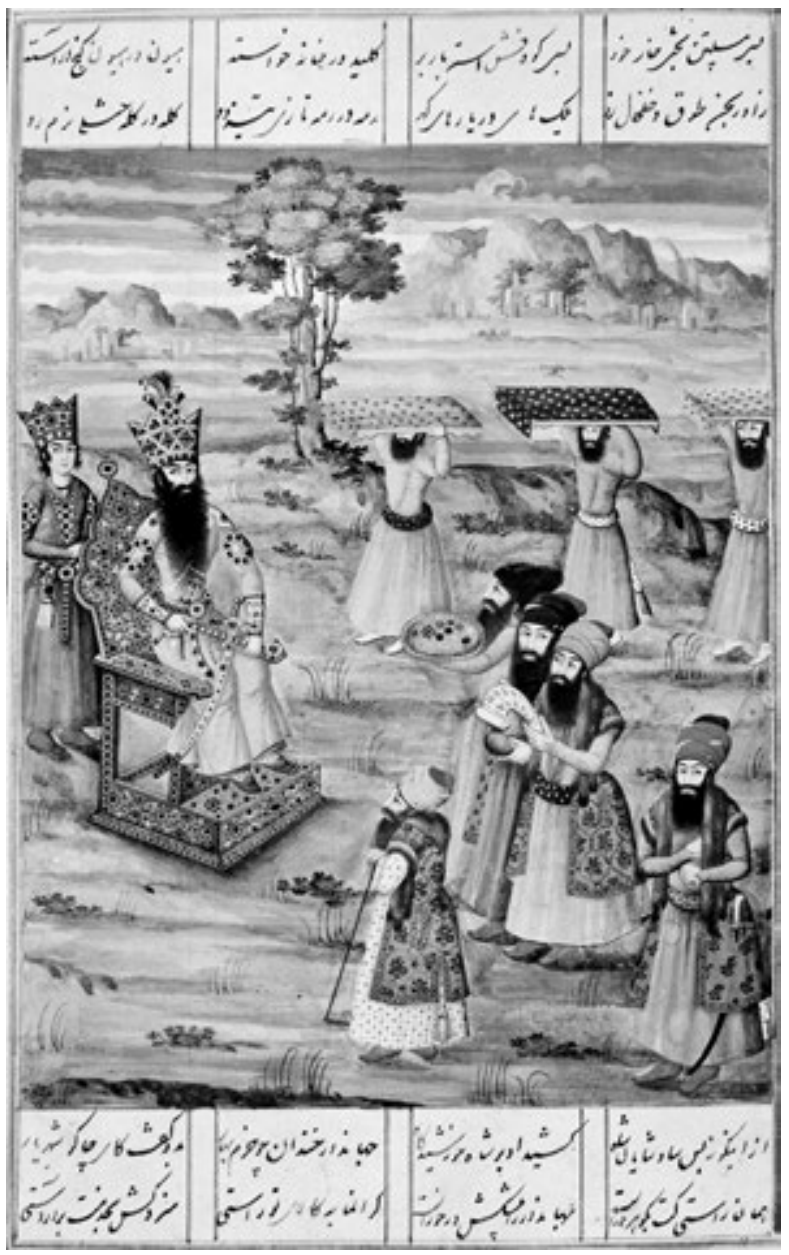

Figure 37 Fath Ali Shah Received by Mirzā Rezā Qoli Monshi al-Molk in Sawdasht. Folio G1a from a manuscript of the Shähanshähnäme, Iran, c. 1810-18, opaque watercolor, ink, and gold on paper, $39 \times 26 \mathrm{cms}$, Österreichische Nationalbibliothek, Vienna. 


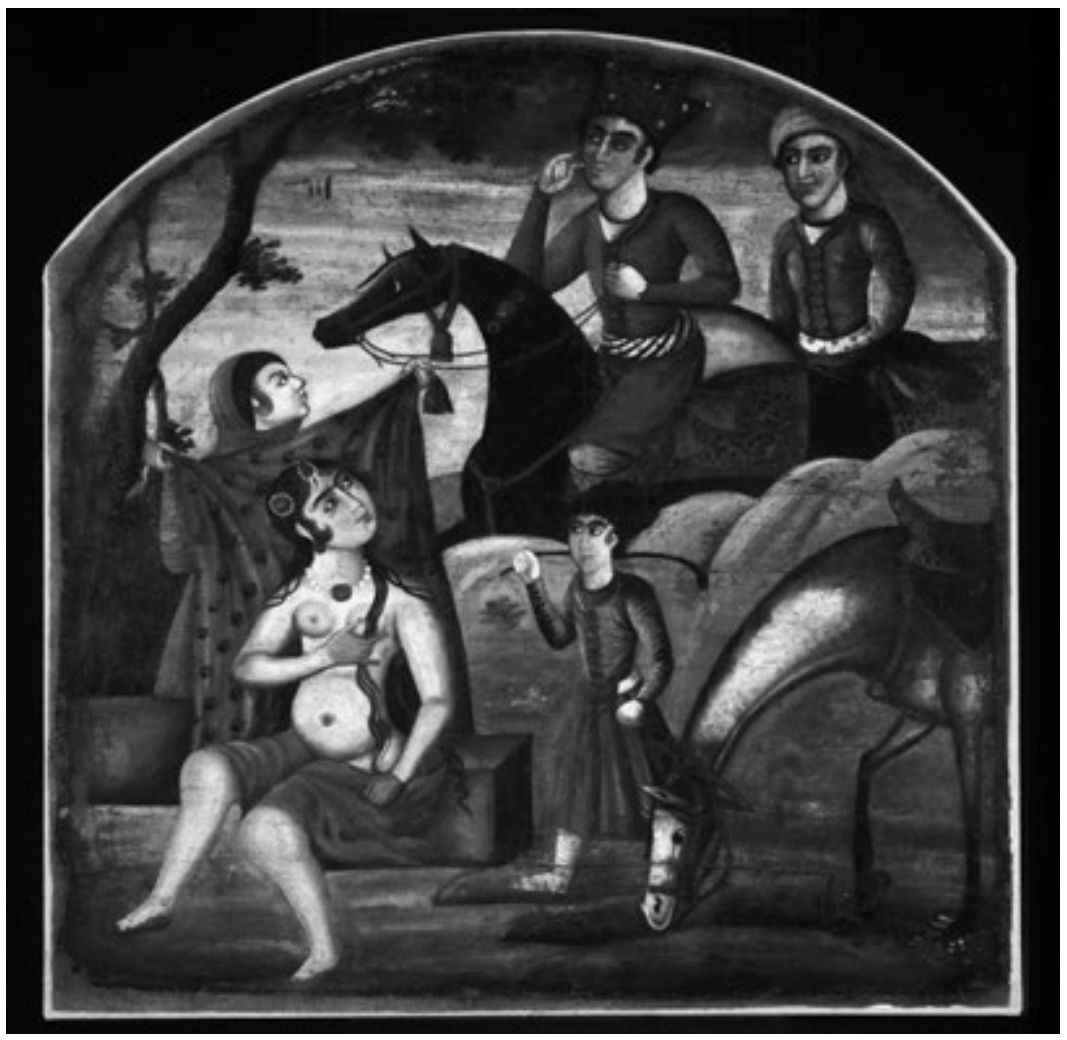

Figure 38 Khosrow Discovers Shirin Bathing, Brooklyn Museum of Art, Bequest of Irma B. Wikilson, 1997, 108. 


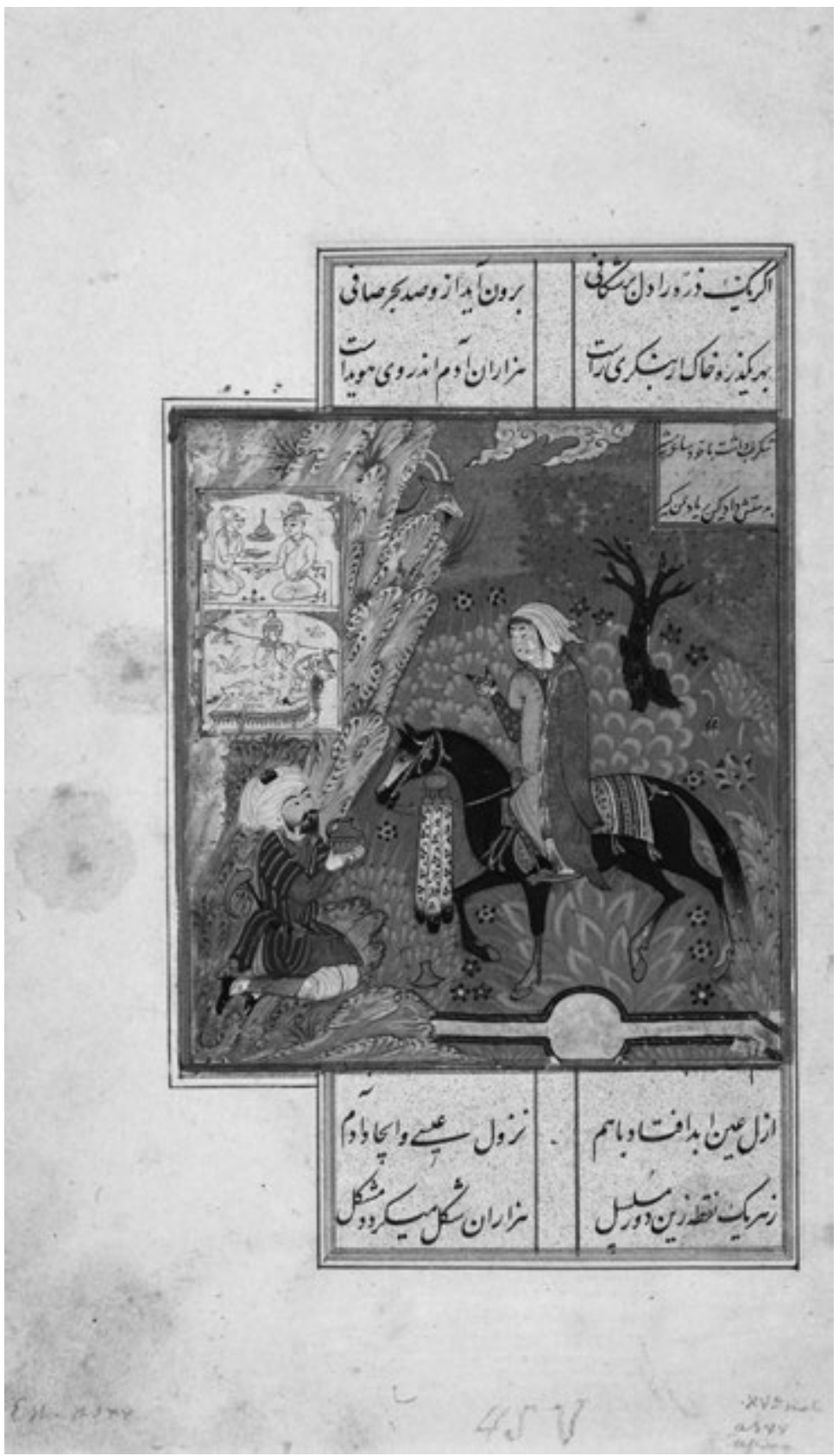

Figure 39 Shirin Presents a Jug of Milk to Farhäd. Artist unknown. Iran, late 15thearly 16th century. Opaque watercolour, ink, and gold on paper, $24.7 \times 14.5 \mathrm{~cm}$, Arthur M. Sackler Gallery, Smithsonian Institution, S86.0179. 


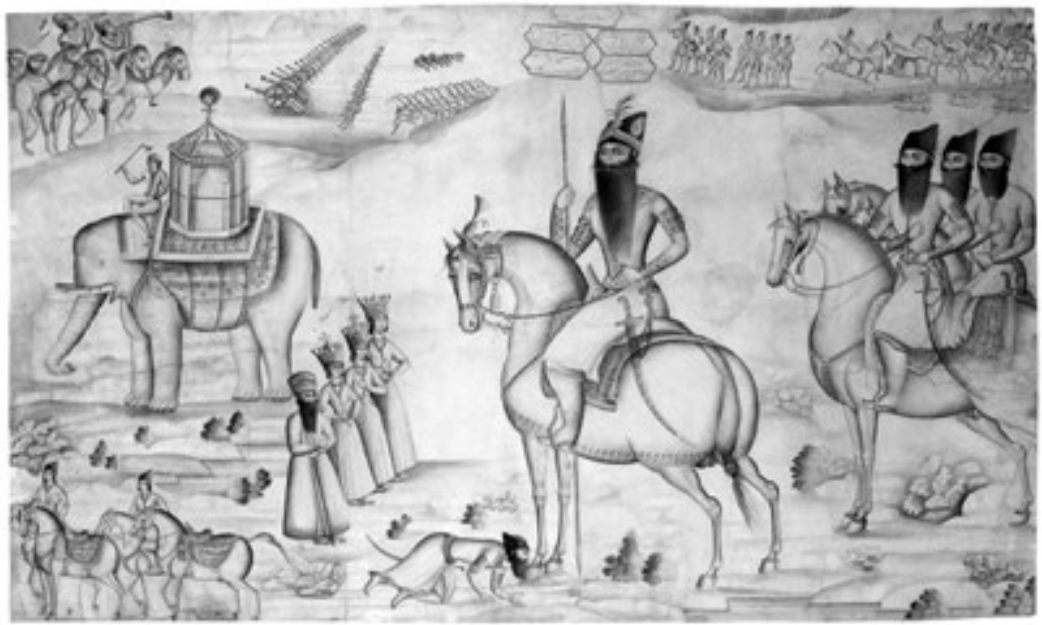

Figure 40 Artist unknown, Military Review with Fath Ali Shah and Prince Hoseyn Ali Mirzā, Shiraz, Ink on paper, $53 \times 96 \mathrm{~cm}$, The State Hermitage Museum, Saint Petersburg, Inv. No. VR-1047. Photograph (C) The State Hermitage Museum. Photo by Vladimir Terebenin, Leonard Kheifets, Yuri Molodkovets.

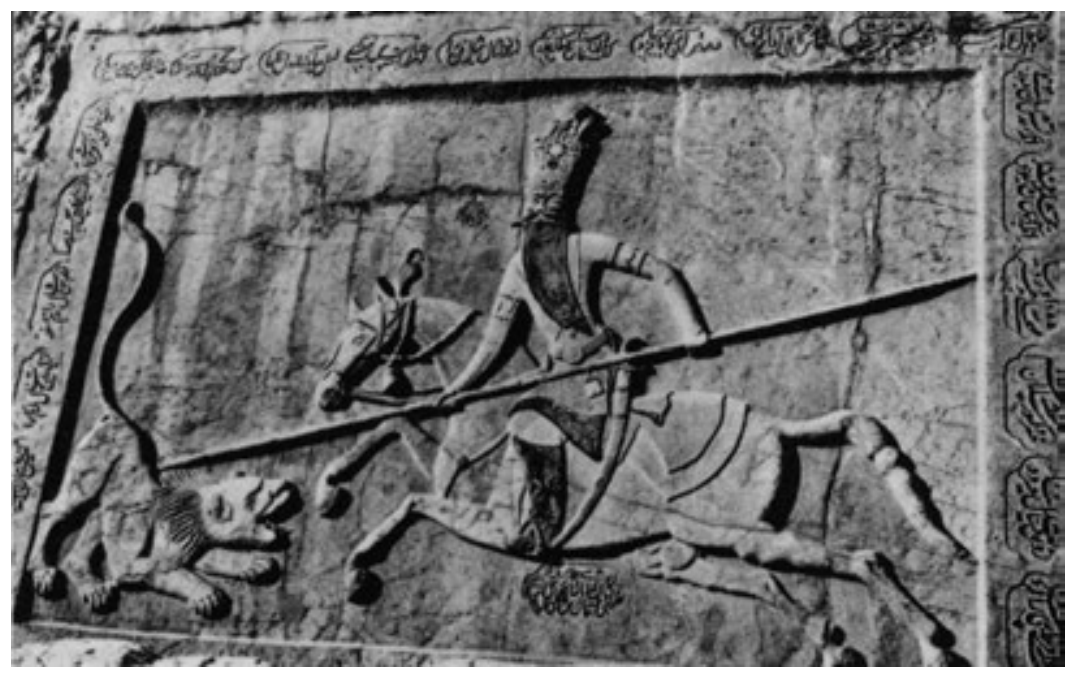

Figure 41 Abdollāh Khān, Fath Ali Shah at the Hunt, Rayy, circa 1820-30, taken from Diba 1998: 41. 


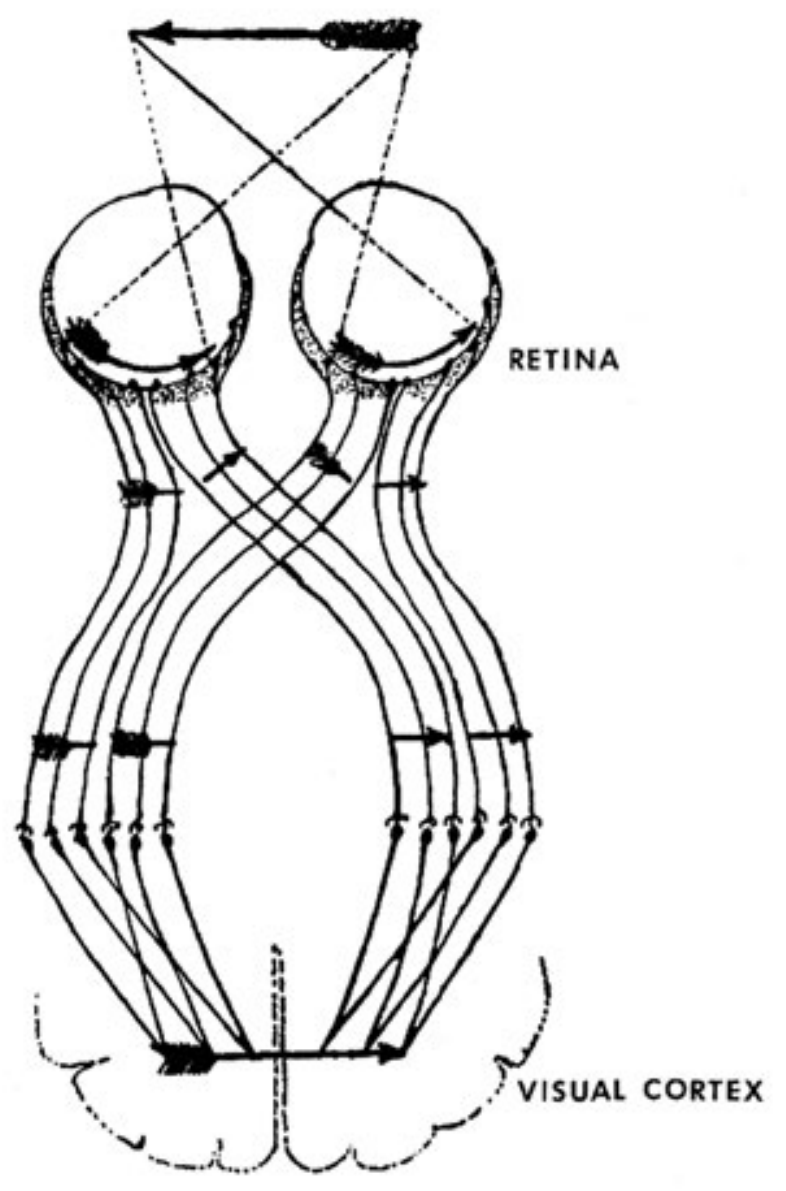

Figure 42 Note that the optics of the eye reverses the image of the arrow in the retinae. The nerve fibres from each retina separate so that messages from the left half of each retina travel to the visual cortex of the left hemisphere, and the messages from the right halves travel to the visual cortex of the right hemisphere. Thus when the center of the arrow is fixated (as shown) information in the left half of space (the arrow head) goes to the right cortex, and information in the right half of space (the feathers) goes to the left cortex. Note further that the two cortical representations are not mirror-reversed with respect to each other. Taken from Ramón y Cajal 1899. 

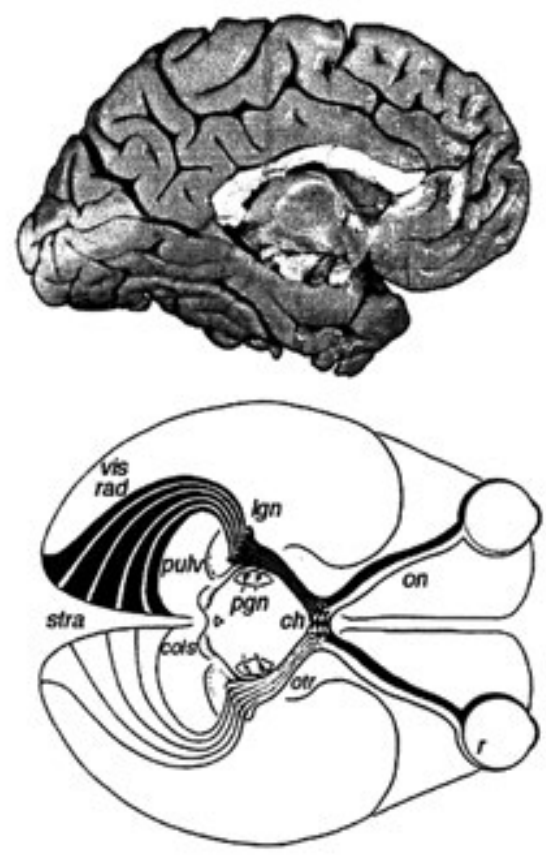

Figure 43 The fibres from the retina terminate at the back of the brain, in a part known as the primary visual cortex (area $V_{1}$ ), shown in yellow on the medial side of the left hemisphere of the brain. Taken from Zeki 1999: 15.
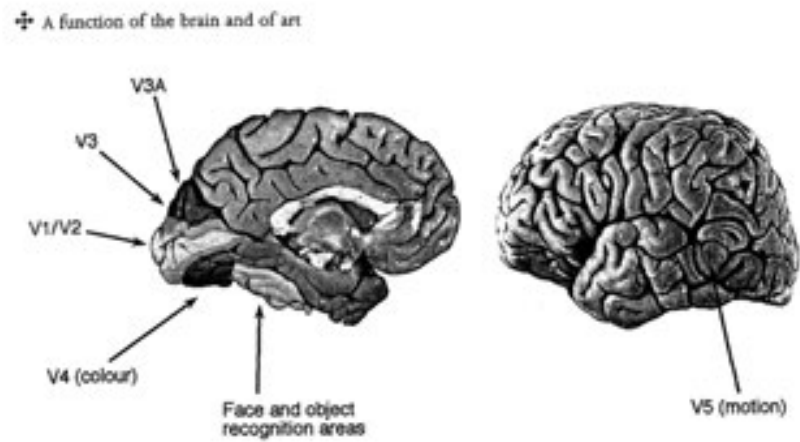

Figure 44 The visual brain consists of multiple functionally specialised areas, which receive their visual input largely from $V_{1}$ (yellow) and an area surrounding it known as $V_{2}$ (green). These are the best charted visual areas, but not the only ones. Other visual areas are being continually discovered. Taken from Zeki 1999: 16. 

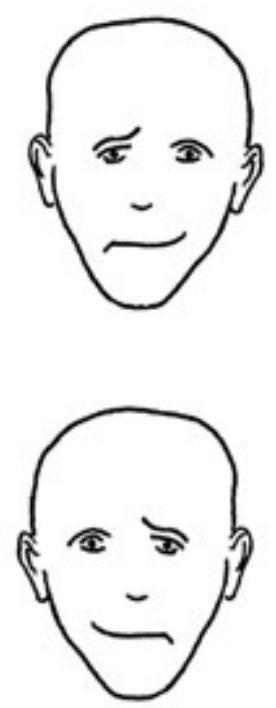

Figure 45 Stare at the nose of each face. Which looks happier? J. Jaynes found that most right-handers choose the bottom face with the smile in their left visual field, presumably because the smiling side is processed by the right hemisphere on central fixation, taken from Jaynes 2000: 120.

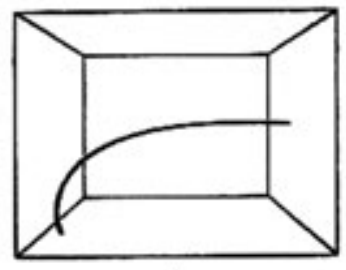

A

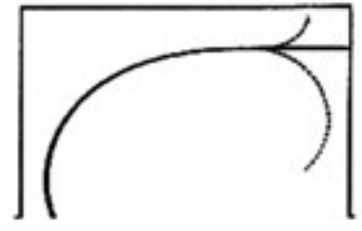

B

Figure 46 Taken Gaffron 1950.

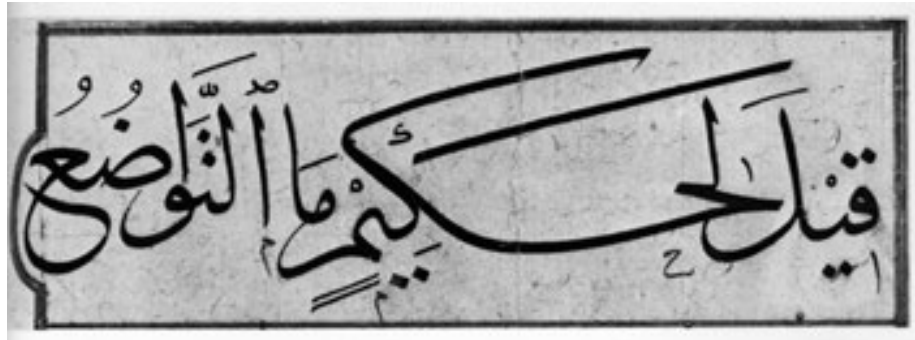

Figure 47 Detail in the hand of the most famous Ottoman calligrapher, Shaykh Hamdullah, Istanbul, early sixteenth-century, Istanbul Museum of Islamic Art, taken from Safadi 1978: 53. 


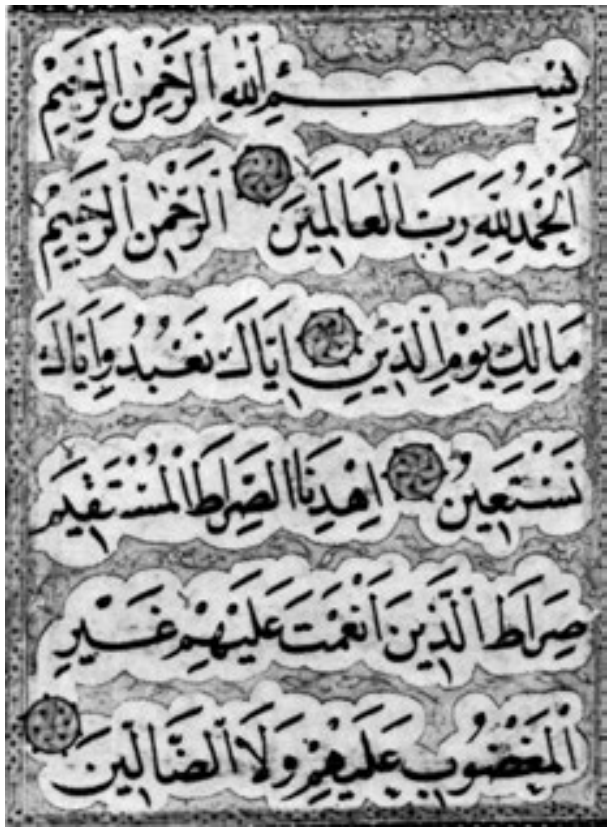

Figure 48 Naskhi Qur'an copied by the Ottoman calligrapher Shaykh Hamdollah al-Amasini the early sixteenth-century, Agha Khan Collection, Geneva, taken from Safadi 1978: 64 .

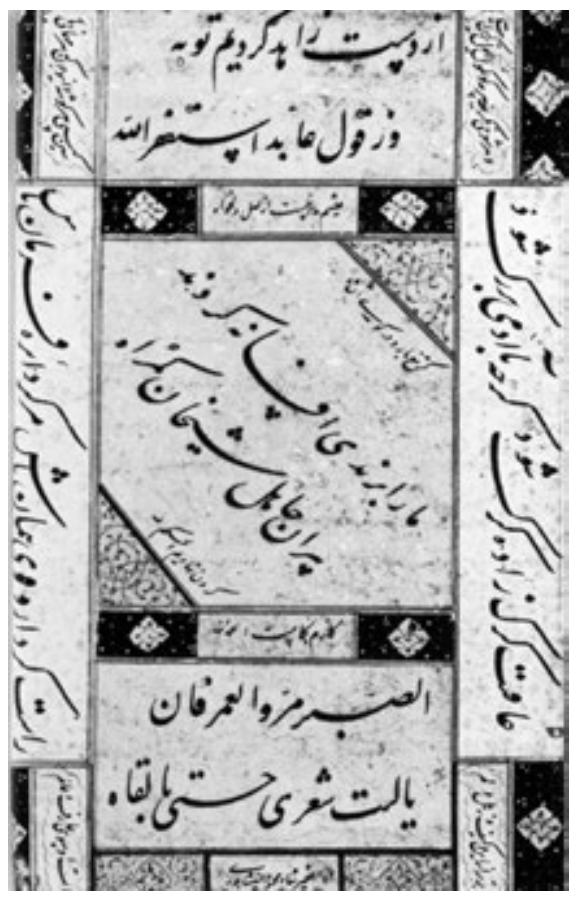

Figure 49 Composite page of Persian text in large ornamental Ta'liq and small Nasta'liq by Shah Mahmud al-Nishaburi, Persia, early 16th century, taken from Safadi 1978: 87 . 


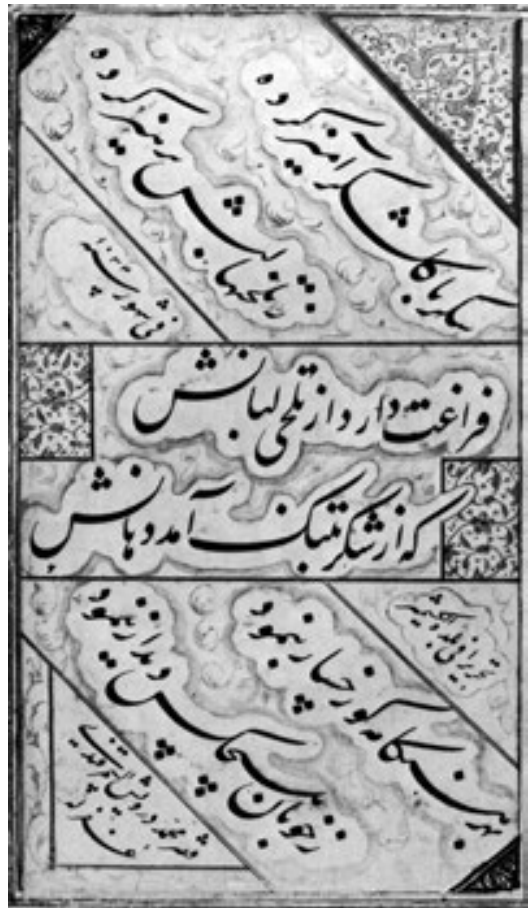

Figure 50 Compartments of various shapes dividing sections of Persian verse in free-flowing Nasta'liq. Page written by Mohammad Darwish al-Samarqandi in Kashmir in 1624, British Museum, London.

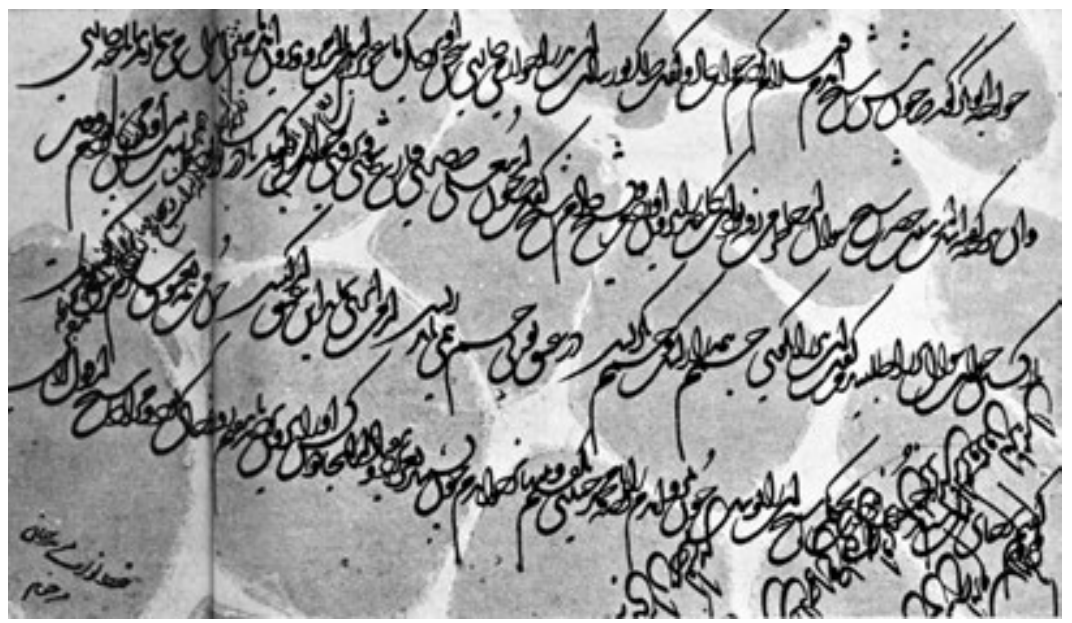

Figure 51 Shekaste, written by Nawāb Morid Khān in India, probably during the seventeenth century, Staatliche Museen, Berlin. 


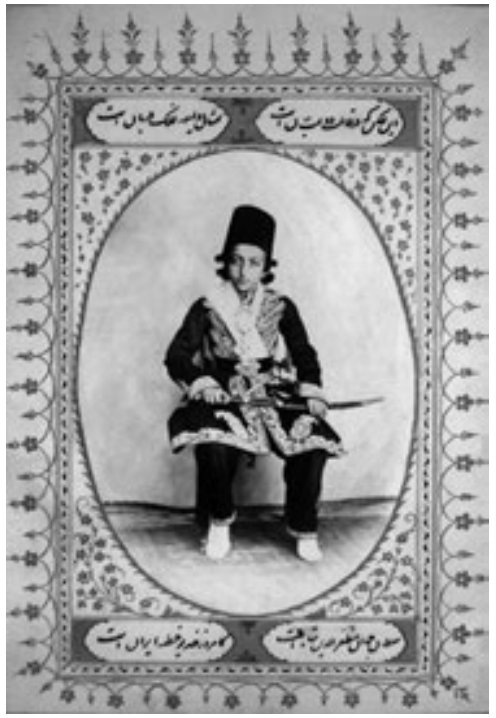

Figure 52 Anonymous Iranian photographer, Crown Prince Mozaffar al-Din Mirzā, c.1864-66, Archive of the Institute for Iranian Contemporary Historical Studies, Tehran.

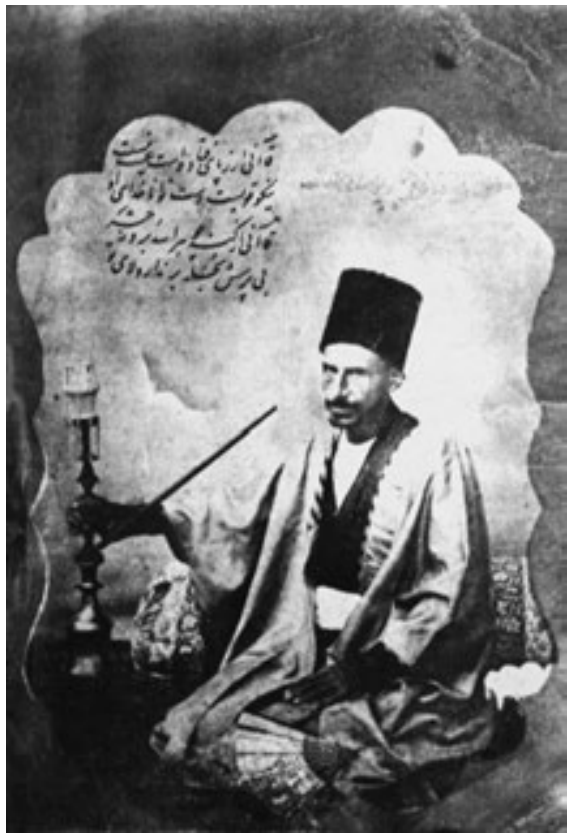

Figure 55 Anonymous Iranian photographer, Habib Q̄ā'āni, a poet, date unknown, albumen print, taken from Afshar 1992: 164 . 


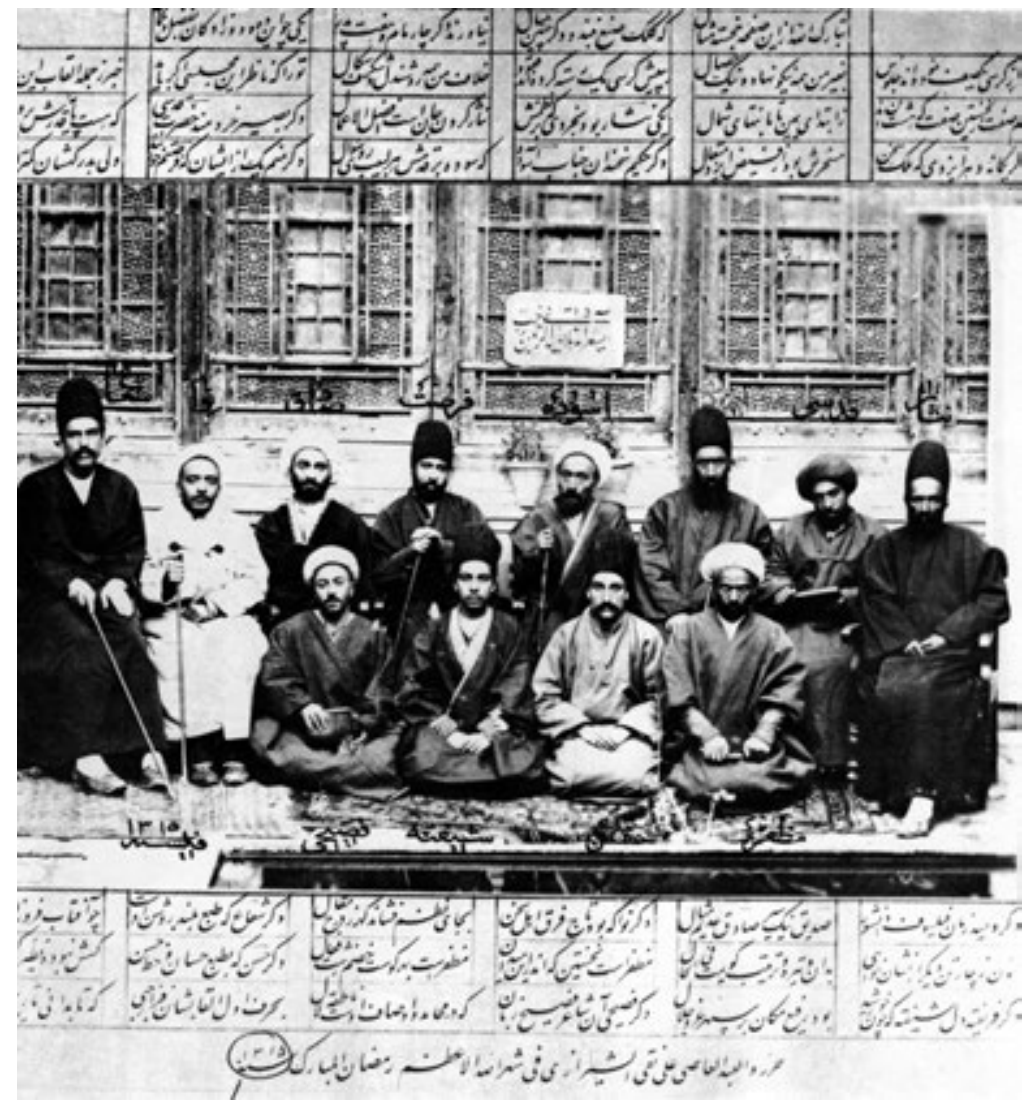

Figure 57 Mirzā Hasan Akkāsbāshi, Poets in Shiraz, c. 1895, albumen print, Collection Mansour Sane, Shiraz. 


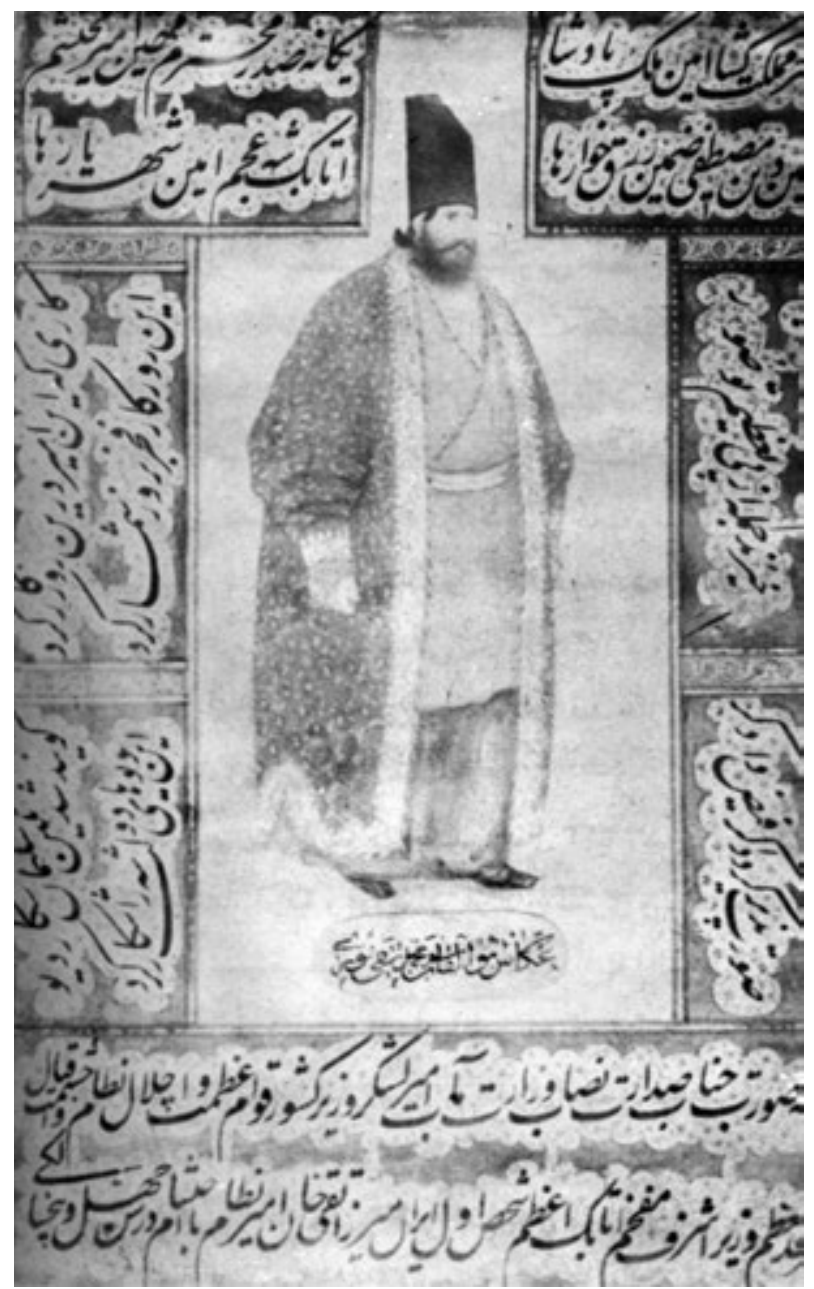

Figure 58 Abd al-Q̄āsem ebn al-Nuri, portrait of Amir Kabir, 1889, albumen print, private collection, taken form Zokā 1997: 118.

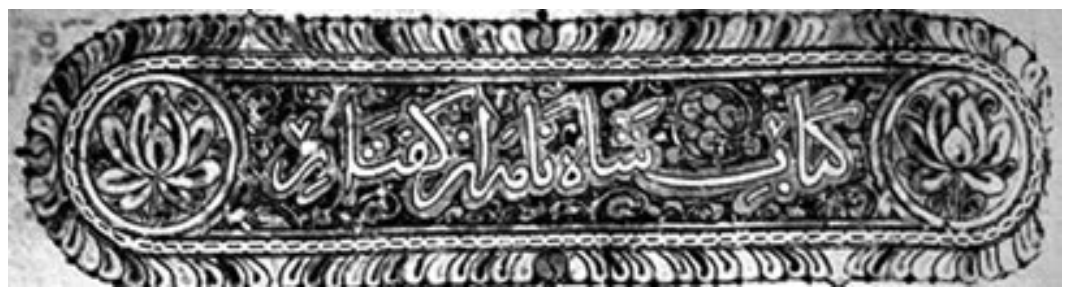

Figure 59 Lotus petal and flower design, Ferdowsi's Shāh-nāme, $37.5 \times 29 \mathrm{~cm}$, Persian, Inju style, Shiraz, 1331, Topkapi Sarayi, Hazine 1479 (5a). 


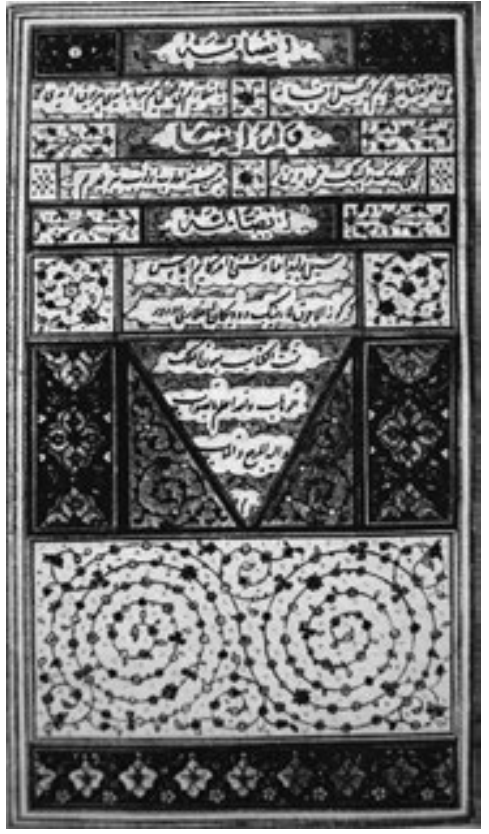

Figure Go Whirling arabesque design and illuminated page decorations, Gharā'eb alseghar by Navā'i. $108 \times 8 \mathrm{~cm}$. Ottoman Turkish, ca. 1520-30. Or. 13061 (224a).

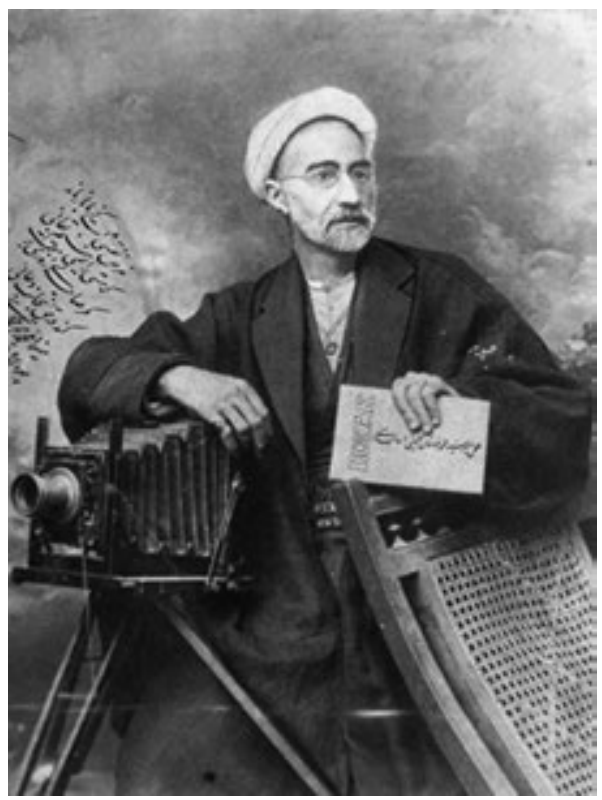

Figure G1 Amir Seyped Mohammad Rezā Khān al-Hoseyni (Ferdowsi Photography Studio), Shiraz, Mirzā Mohammad-Rahim Akkāsbāshi, date unknown, albumen print, Archive of the Institute for Iranian Contemporary Historical Studies, Tehran. 

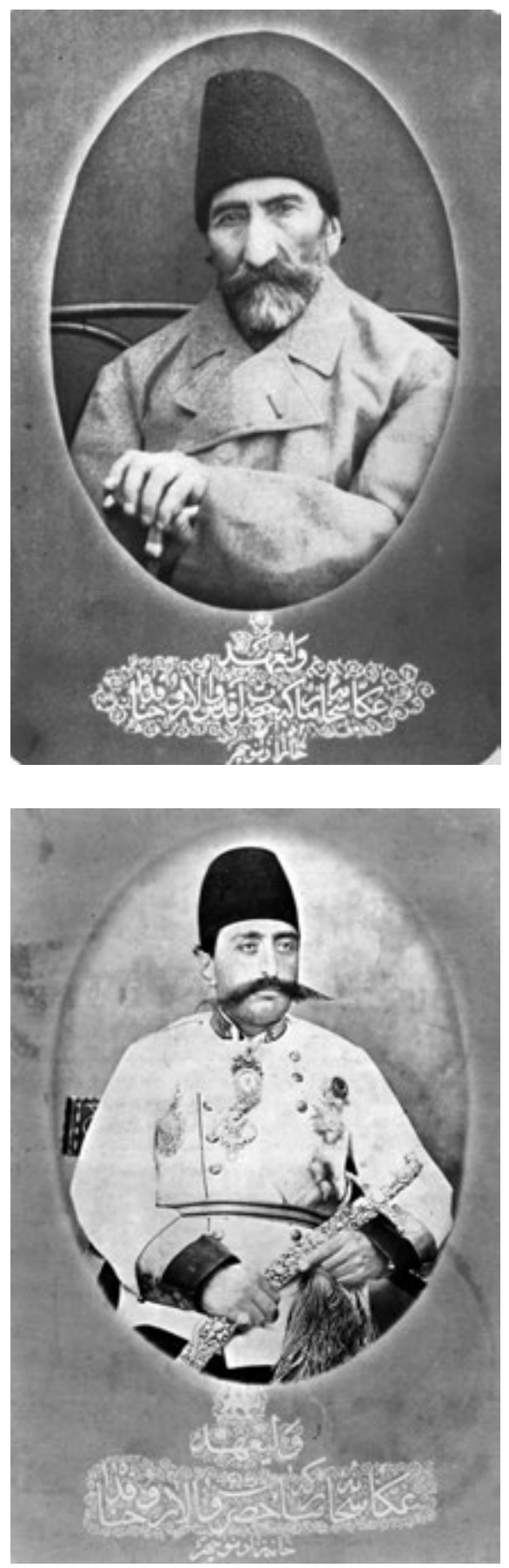

Figure $6_{5}$ Manucher Khān Akkās, Manuchehr Hasan Ali Khān Garusi (Amir Nezām), c. 1886, albumen print, private collector, taken from Zokā 1997: 195.

Figure 66 Manucher Khān Akkās, Mozaffar al-Din Mirzā, prince in Tabriz, c. 1886, albumen print, private collector, taken from Zokā 1997: 194. 

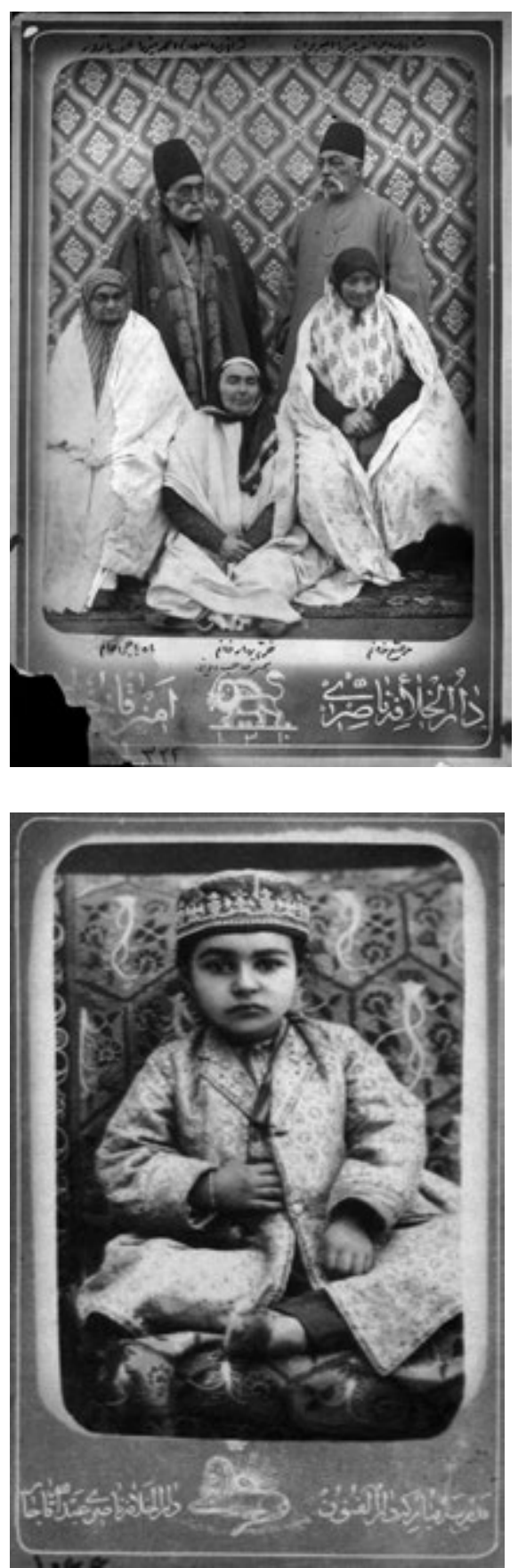

Figure 67 Amir Qajar, Several children of Fath Ali Shah, date unknown, albumen print, Golestān Palace Library, Tehran.
Figure 68 Abdollāh Mirzā Qajar, daughter of the prince Hajj Bahā alDowle, c. 189os, albumen print, size, Golestān Palace Library, Tehran. 


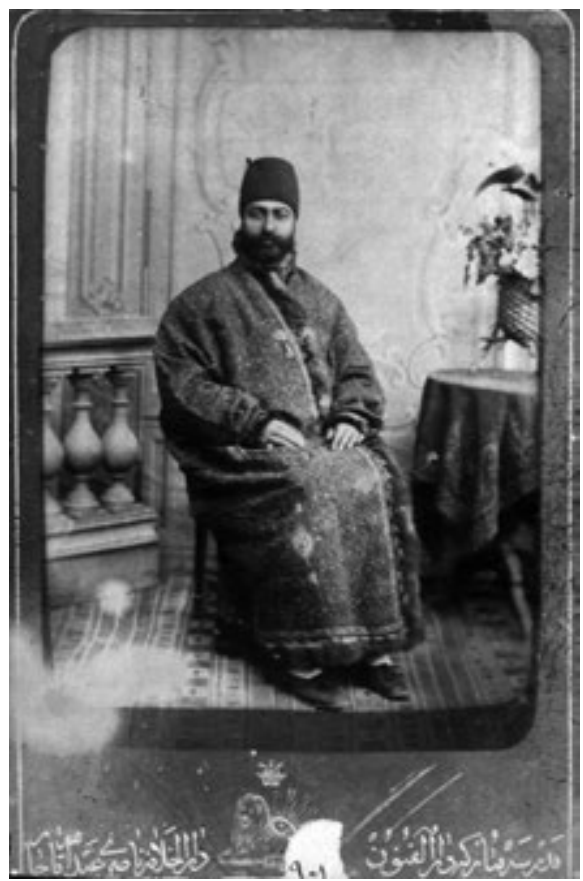

Figure 69 Abdollāh Mirzā Q̨ajar, Mirzā Hoseyn Khān Mo'tamen alMolk, c. 189os, albumen print, size, Golestān Palace Library, Tehran.

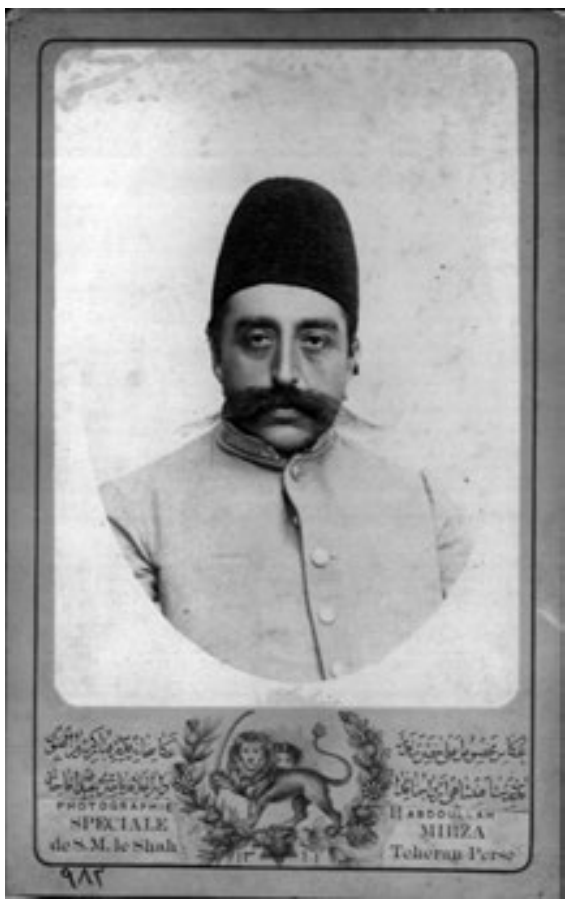

Figure 70 Abdollāh Mirzā Qajar, Mozaffar al-Din Shah, c. 1896, albumen print, Golestān Palace Library, Tehran. 


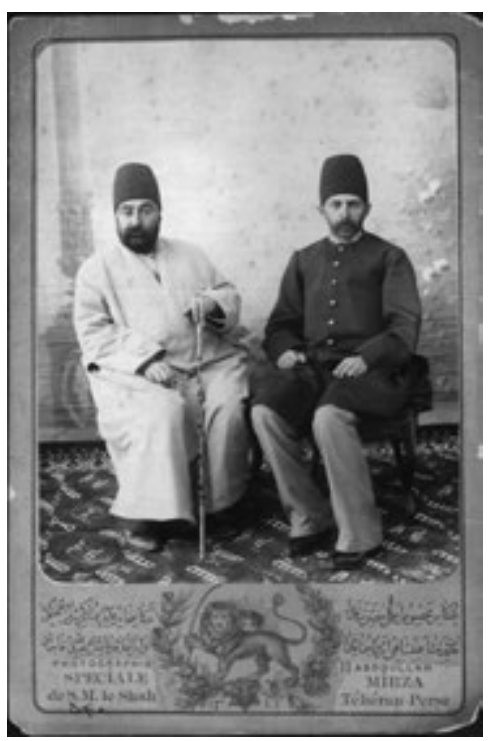

Figure 71 Abdollāh Mirzā Qajar, Abdollāh Hoseyn Mirzā Farmān Farmā and Seyped Ahmad Monshibāshi Atabak, c. 1893, albumen print, Golestān Palace Library, Tehran.

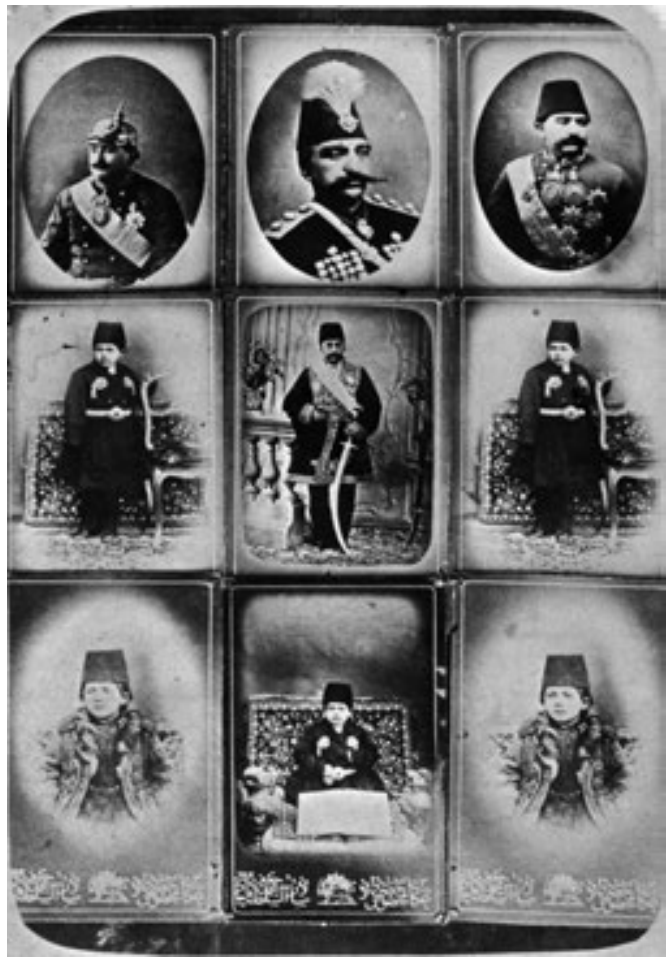

Figure 72 Mirzā Jafar Akkāsbashi, Nāser al-Din Shah and his sons, c. 1888, albumen print, taken from Zokā 1997: 87. 

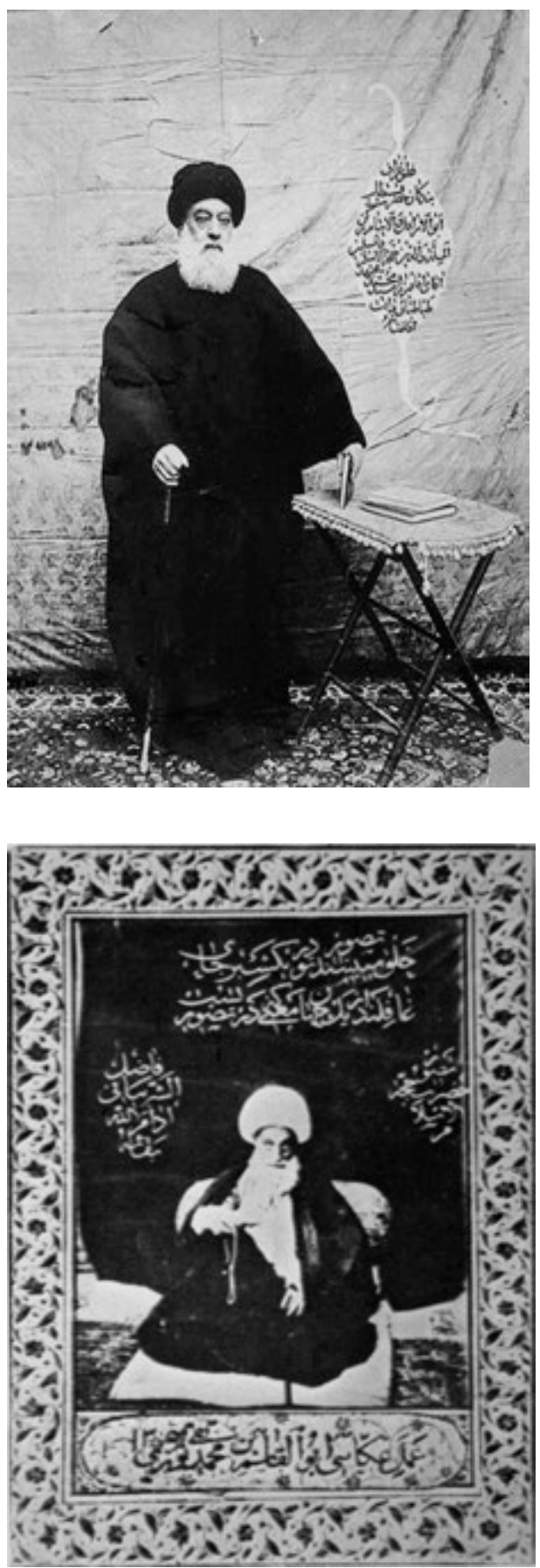

Figure 74 Unknown Iranian photographer, Āqā Seyped Mohammad Mojtahed Tabātabā'i, c. 1915, albumen print, private collection.
Figure 75 Abd al-Q̄āsem ebn al-Nuri, Fāzel Sharbiyāni Edamelboje, c. 1889, albumen print, size, Golestān Palace Library, Tehran, taken form Zokā 1997: 118. 


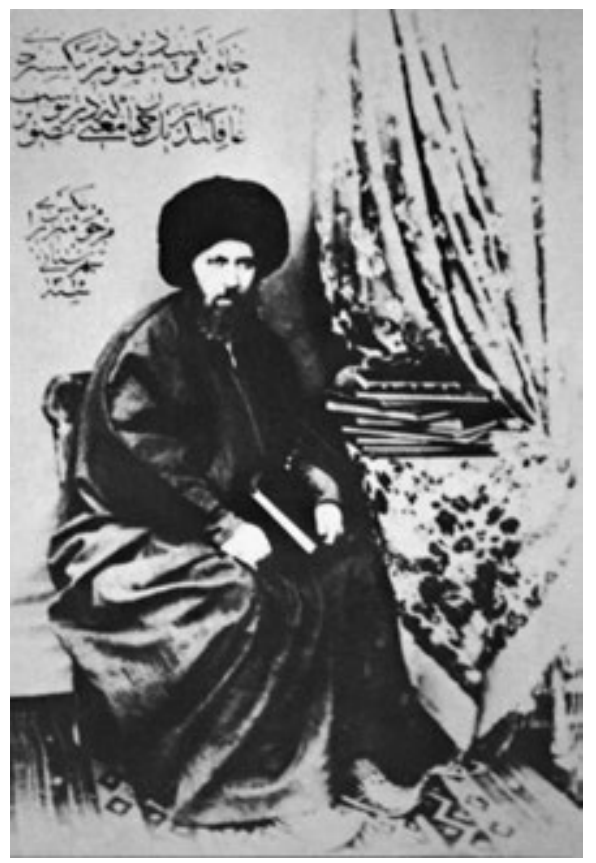

Figure 76 Abd al-Q̄āsem ebn al-Nuri, Mirzā-ye Sharestāni, c. 1897, Golestān Palace Library, Tehran, taken form Afshar 1992: 164.

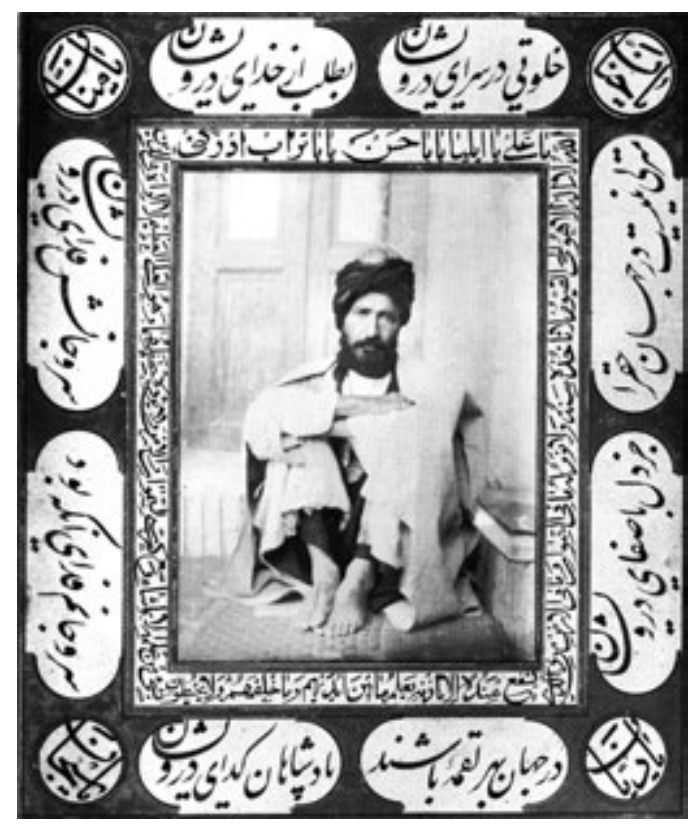

Figure 77 Gholām-Hoseyn Derakhshān, dervish, c. 1930s, albumen print, Parisa Damandan Collection. 

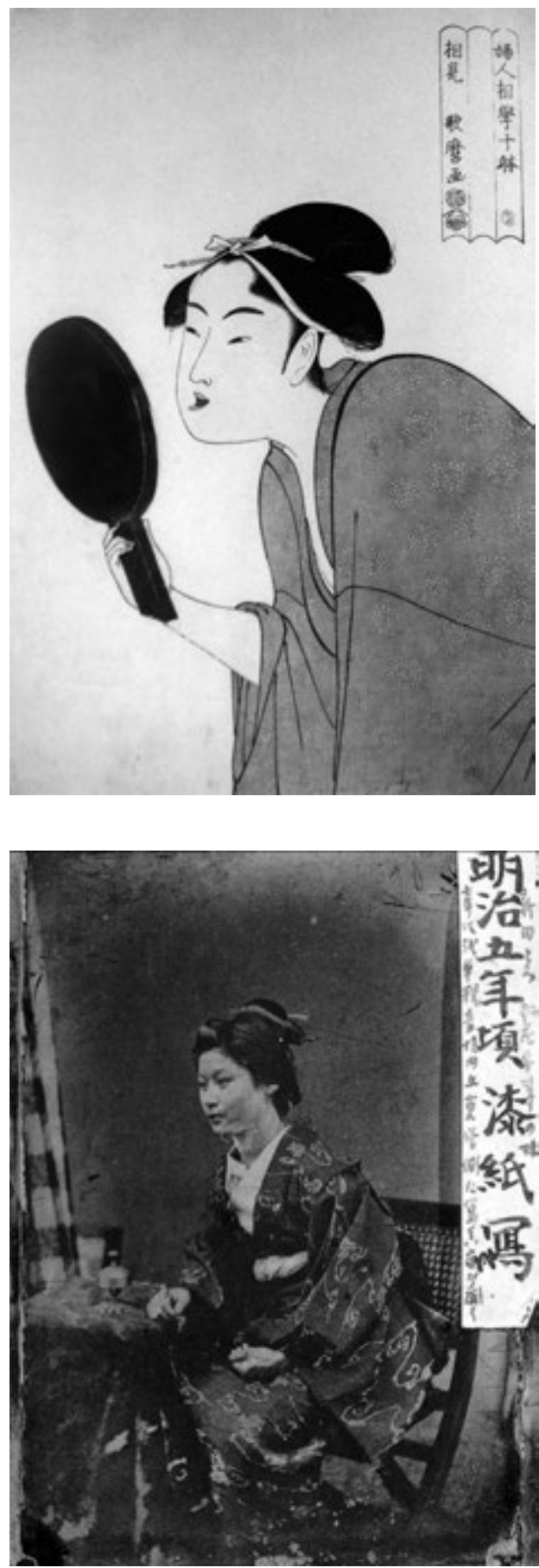

Figure 78 Kitagawa Utamaro, A Married Woman Inspects Her Black Teeth in a Mirror, Ukiyo-e painting, Museum für Ostasiatisches Kunst, Cologne.

\section{Figure 79 Yokoyama}

Matsusaburo, Portrait of Nitta Tomi, c. 1874, albumen print, 10 $x$ 7,2 cm, Yokoyama Family Collection. 

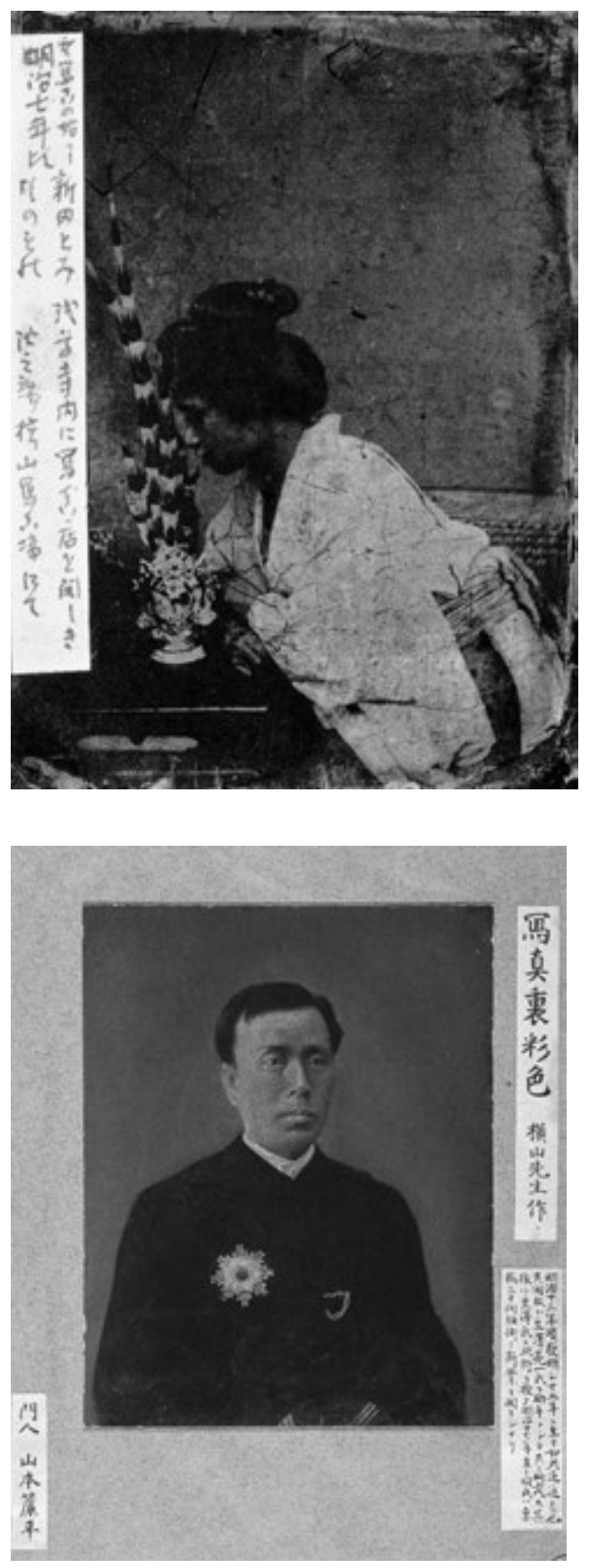

Figure 80 Yokoyama Matsusaburo, Portrait of Nitta Tomi, c. 1872, albumen print, $10 \times 7,2 \mathrm{~cm}$, Yokoyama Family Collection.
Figure 81 Yokoyama Matsusaburo, Portrait Yamamoto Rempei, disciple of Yokoyama Matsusaburo, c. 1874 , albumen print and oil painting, Yokoyama Family Collection. 


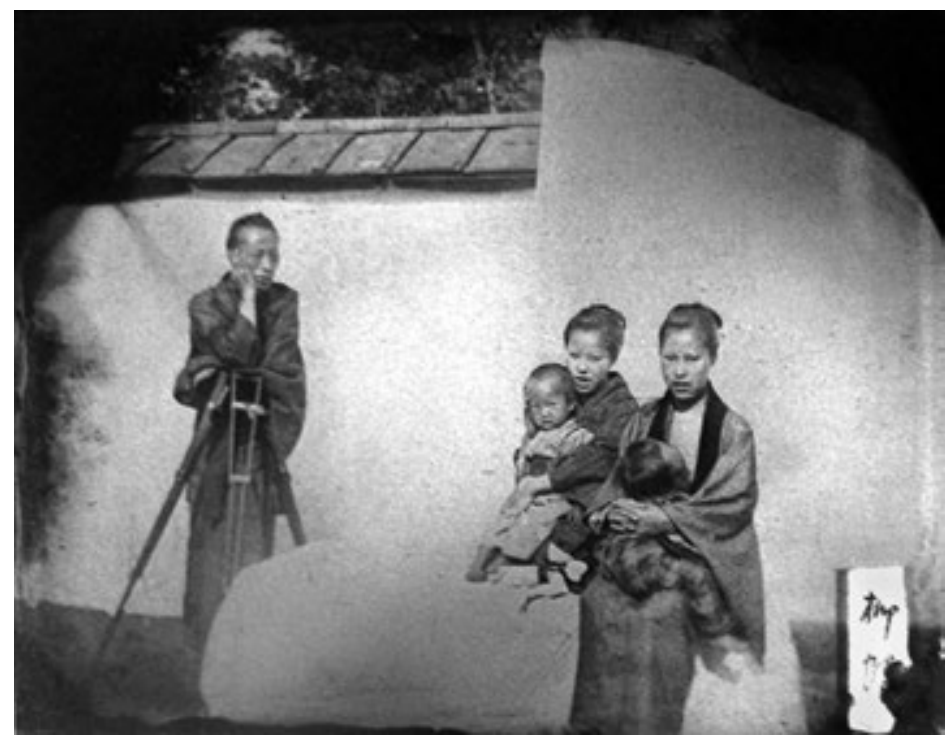

Figure 82 Kojima Ryua, collage of Kojima Ryua and his family, c. 1873, private collection.

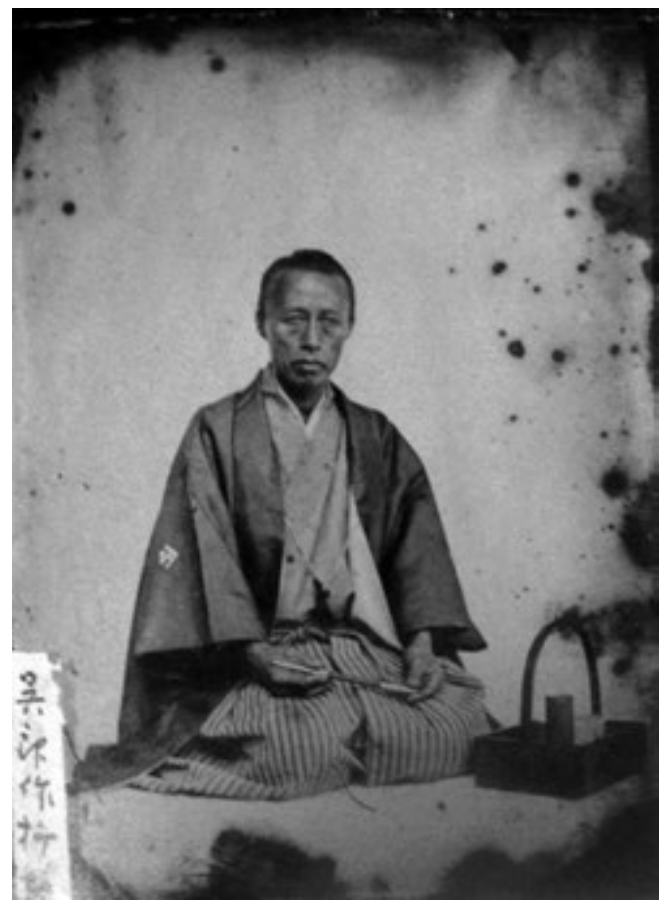

Figure 83 Kojima Ryua, self portrait, 1870 s, private collection. 


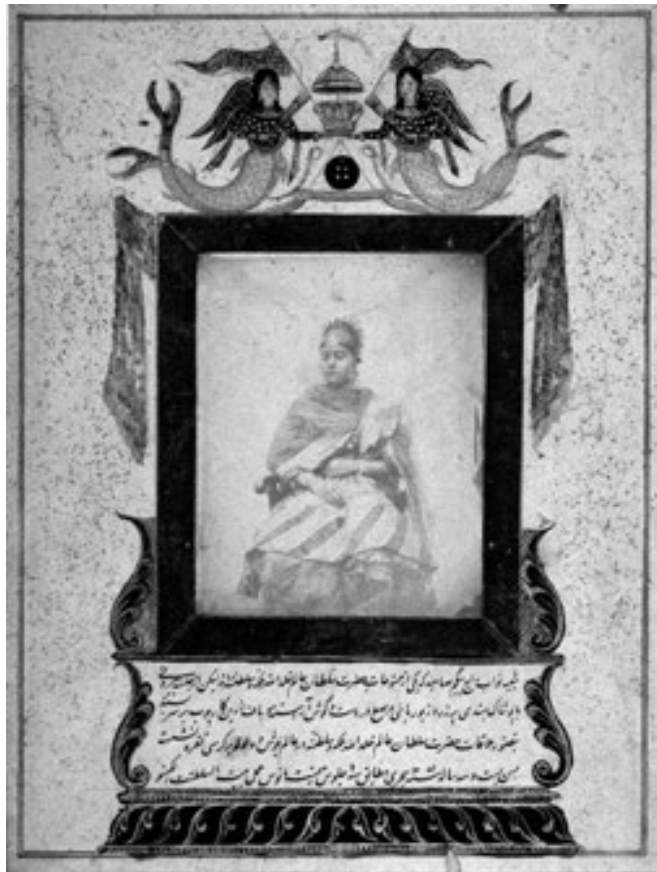

Figure 84 Ahmad Ali Khan, Portrait of Nawāb Raj Begum Sähibah of Oudh, c. 1855 . Salt print, $12.2 \times 9.8 \mathrm{~cm}$, overall $29.8 \times 21.4 \mathrm{~cm}$, British Library OIOC Photo 500 (3).

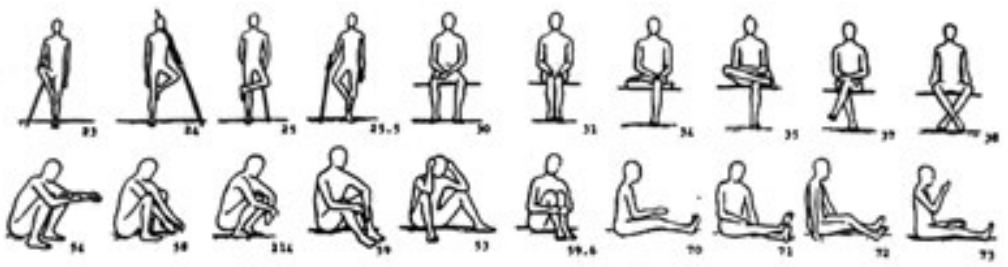

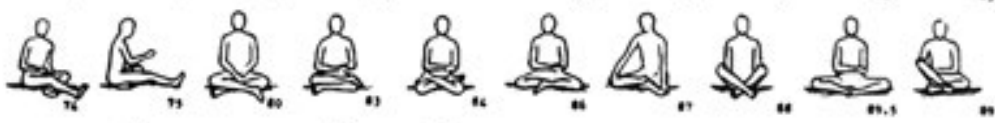

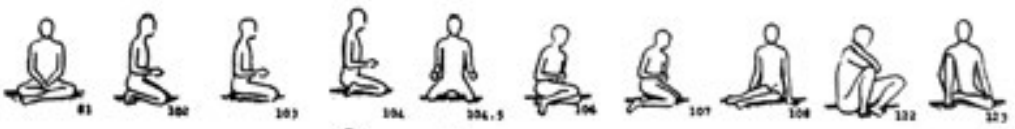

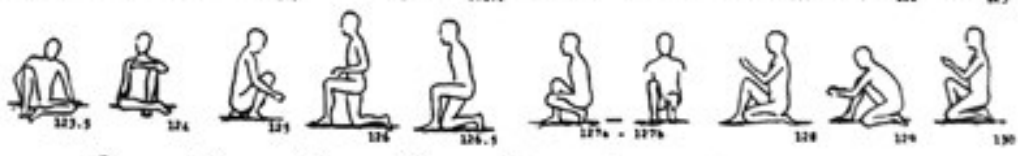

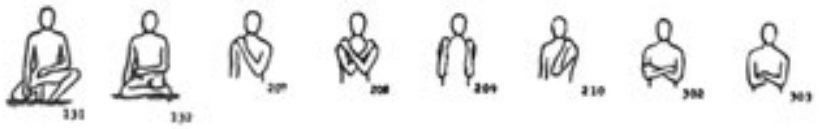

Figure 85 Postural diagram by Hewes, taken from Hewes 1957: 125. 


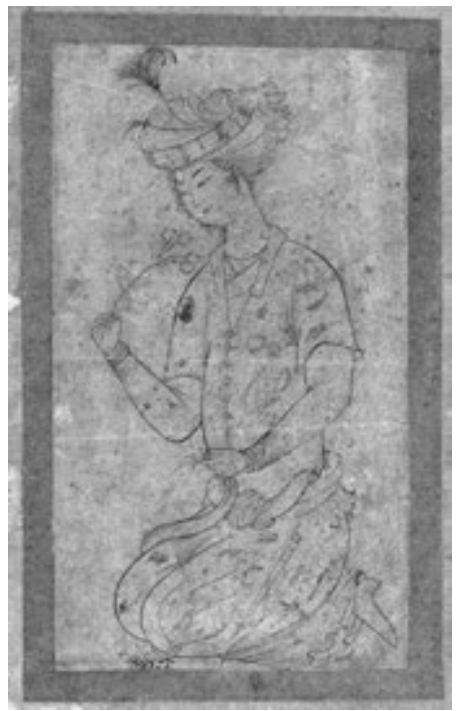

Figure 88 Youth with flower, Safavid Period, 1630 , ink on paper, $H \times W: 15.1 \times 8.5$ $\mathrm{cm}$ (5 15/16 33 3/8 in), Freer Gallery of Art, Smithsonian Institution, Washington, D.C.:

Purchase 1953.22

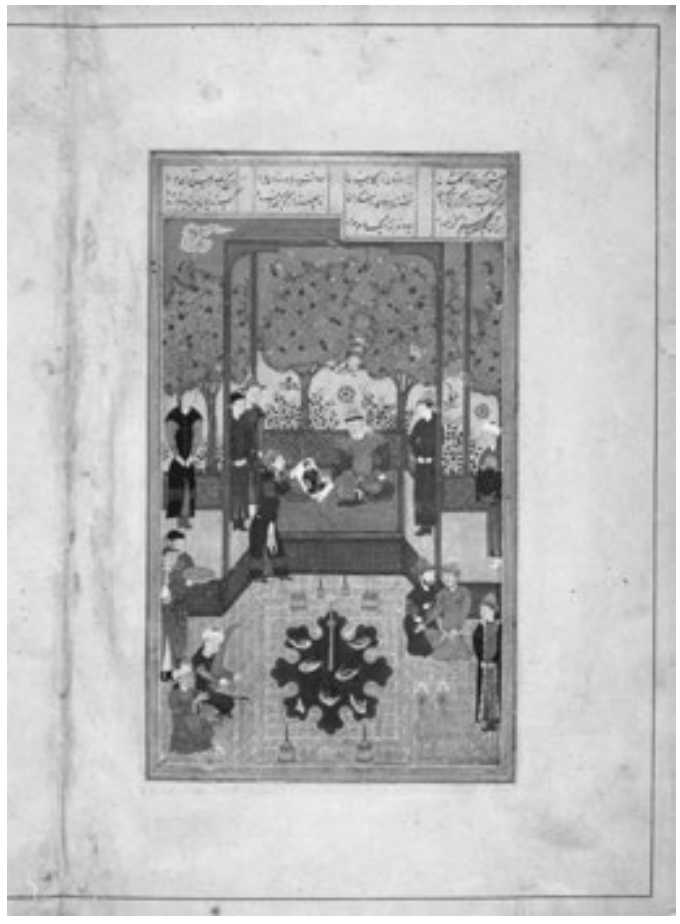

Figure 89 The Silken Image of Rustam Shown to his Granfather Sam, Painting from Muhammad Juki's manuscript of Ferdawsi's Shäh-nāme, Herat, ca. 1440, Royal Asiatic Society, London, MS 239, fol. 3ov. 


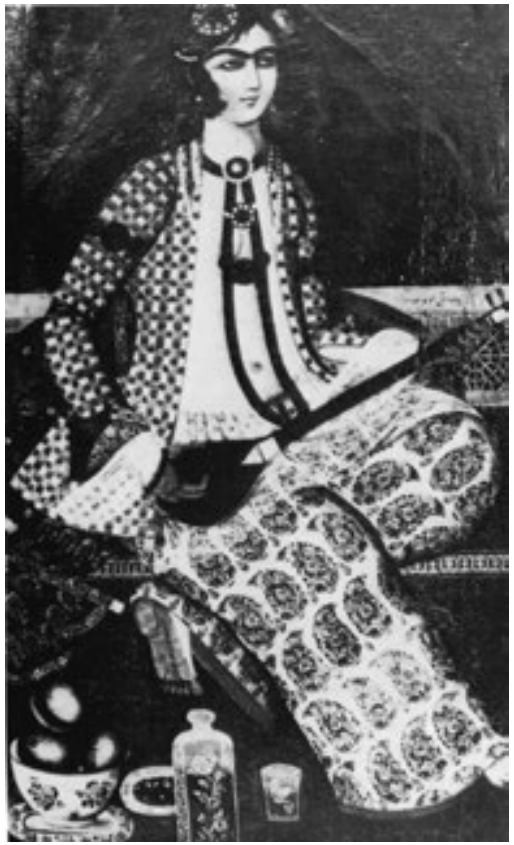

Figure go Mohammad Sädiq (signed Yā Sādiq al-Va'd), Shiraz, 1769/70, A Girl Playing a Mandolin, oil on canvas, formely collection of M. Forugi, Tehran.

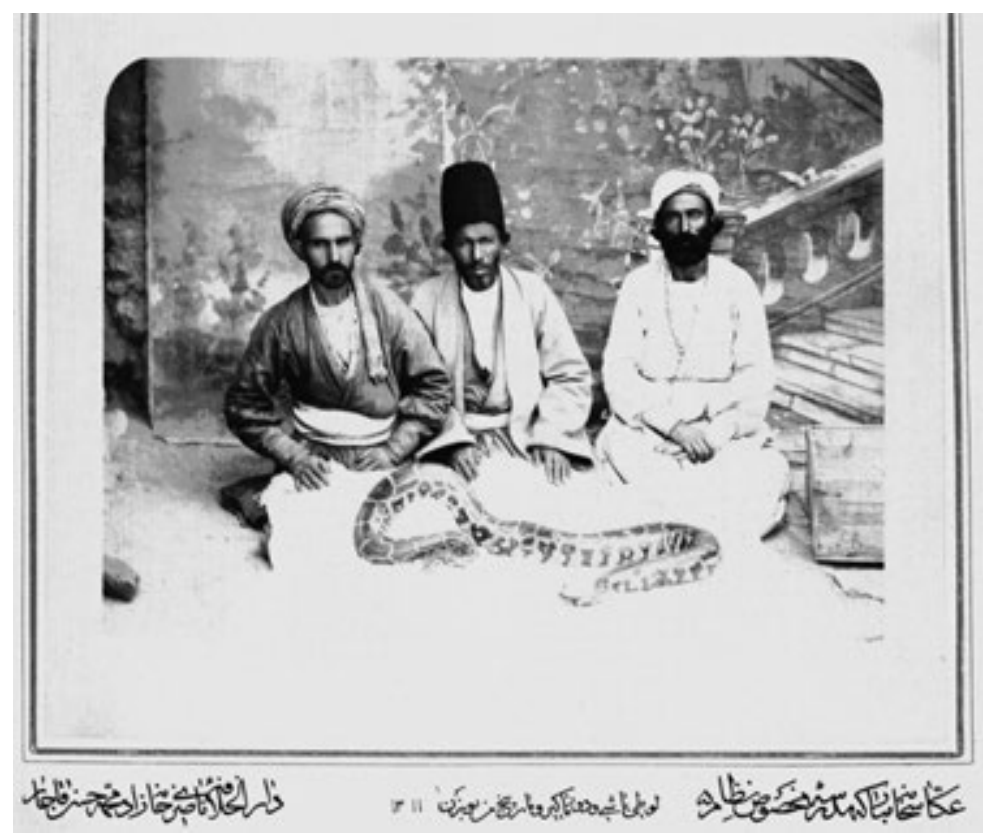

Figure 91 Mohammad Hassan Qajar, luti bāshi and two mārgirs, c. 1893, albumen print, $20.7 \times 18.3 \mathrm{~cm}$, Golestān Palace Library, Tehran, Album 1357, Photo 2. 


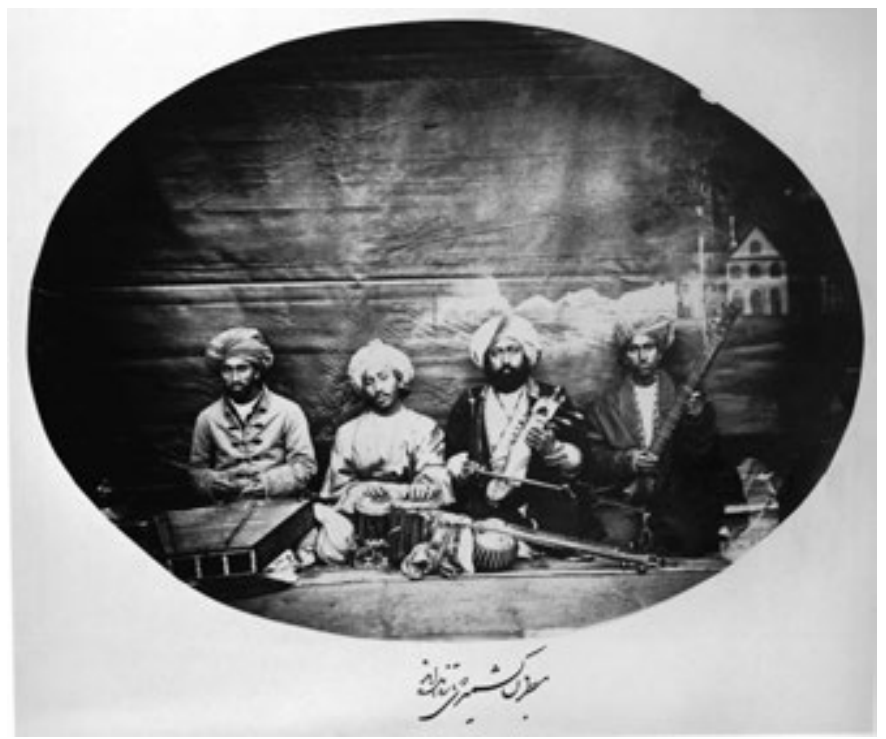

Figure 92 Rezā Akkāsbāshi, group of musicians from Kashimir, c. 1865, albumen print, $20.8 \times 15.5 \mathrm{~cm}$, Golestān Palace Library, Tehran, Album 133, Photo 66.

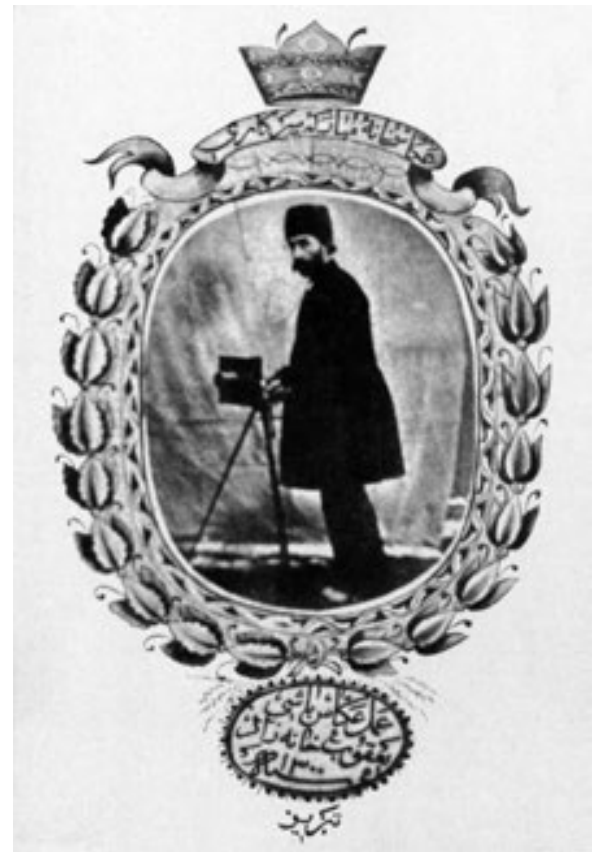

Figure 93 Ya'qub Akkāsbāshi, self portrait, c. 1882, albumen print, private collection. 


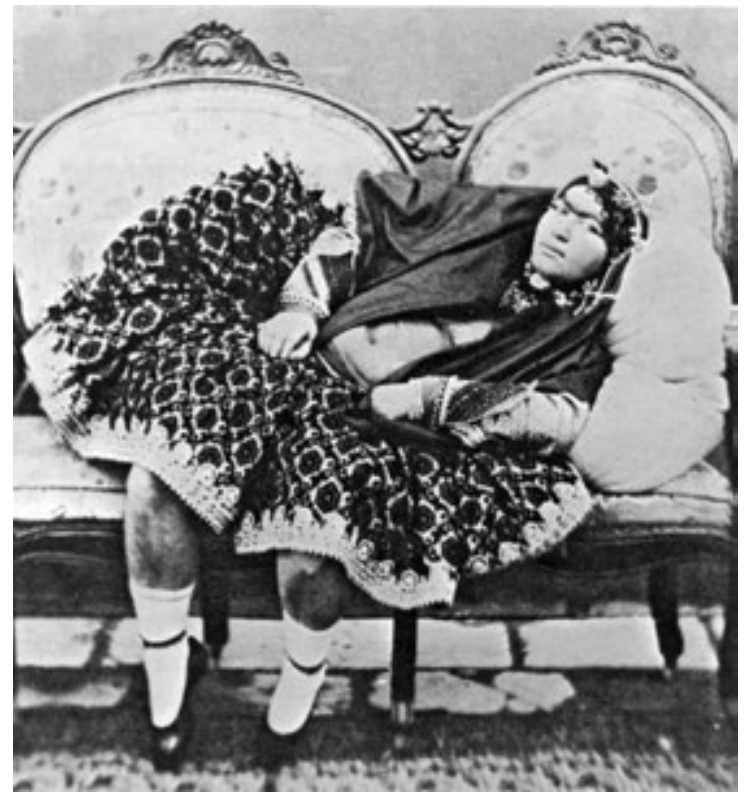

Figure 94 Nāser al-Din Shah, Anis al-Dowle, c. 1871, albumen print, $7.2 \times 6.7 \mathrm{~cm}$, Golestān Palace Library, Tehran.

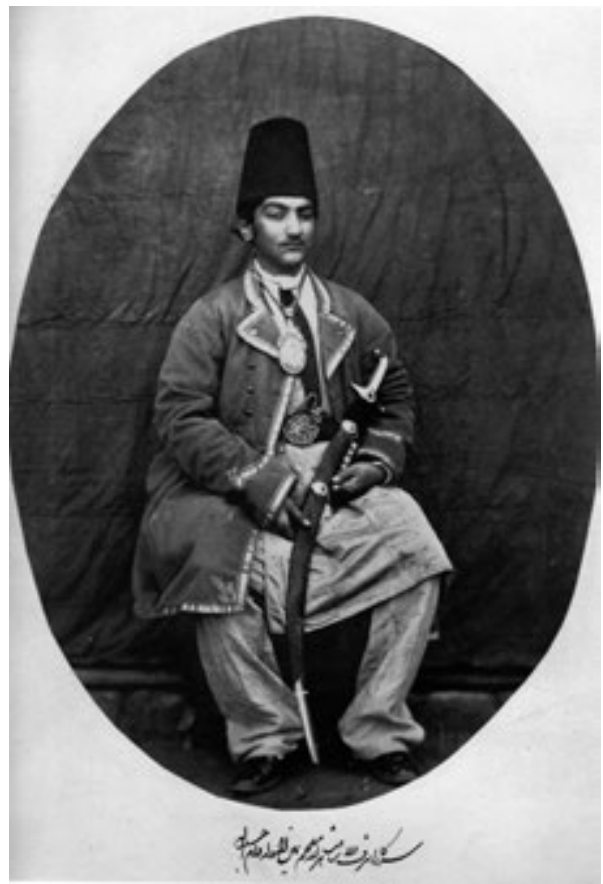

Figure 95 Rezā Akkāsbāshi, Jamin al-Dawle, c. 1865, albumen print, $20.4 \times 15.4 \mathrm{~cm}$, Golestān Palace Library, Tehran, Album 133, Photo 9. 

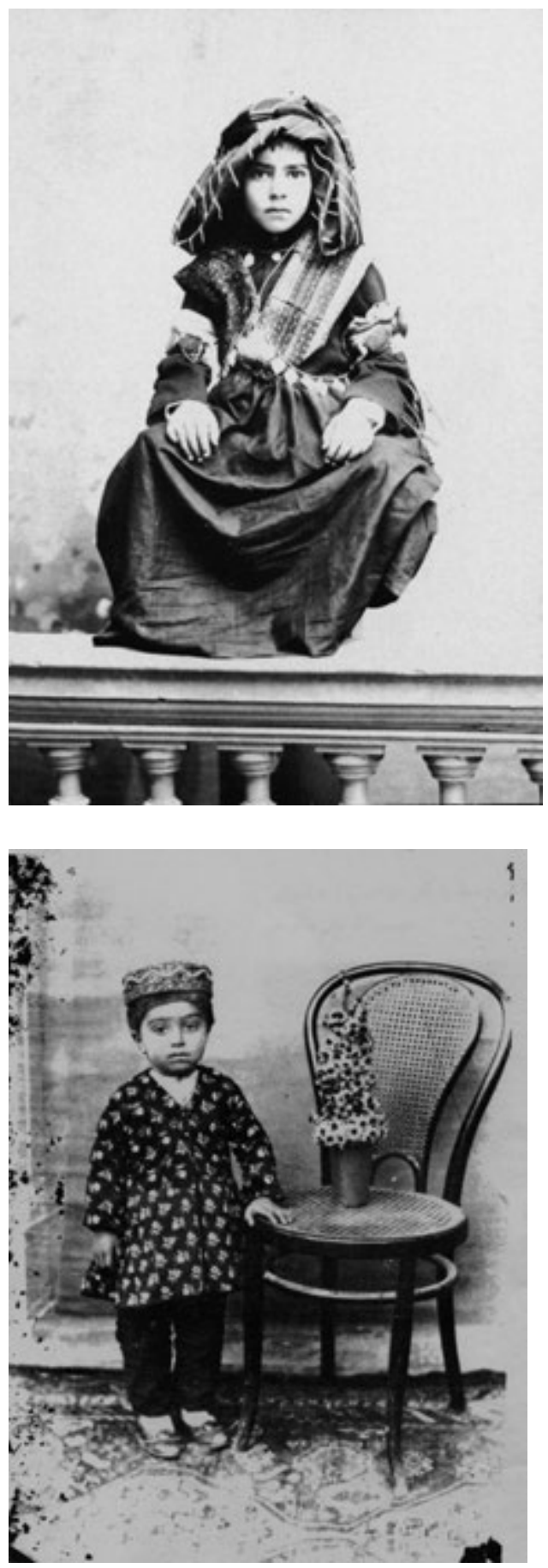

Figure 97 Unknown photographer, Child squatting on balustrade, c. 1880s, albumen print, private collection.
Figure 98 Mirzā Habibollāh Chehrehnegār, Child with chair and flower pot in Shiraz,

c. 1910s-20s, albumen print, private collection. 


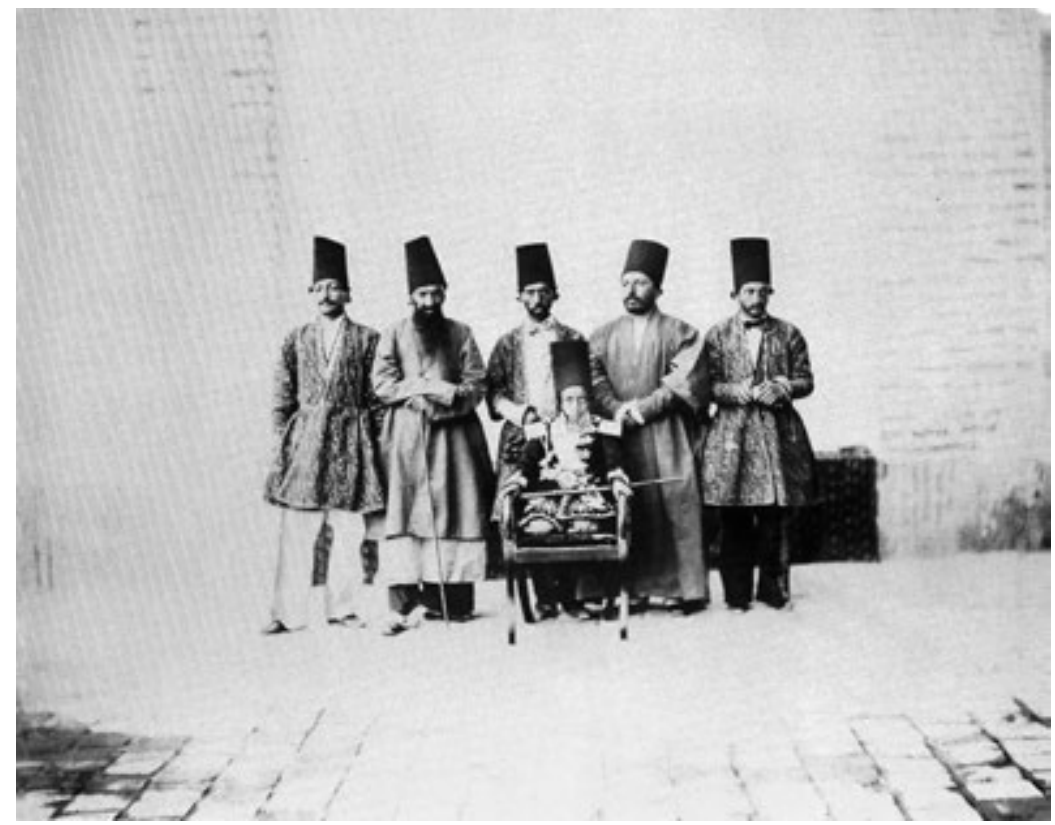

Figure 99 Luigi Montabone, the crown-prinze Mozzafar al-Din Mirzā Qajar with his most important advisers, c. 1862, albumen print, $21.3 \times 26.6 \mathrm{~cm}$, Royal Collections, The Hague, The Netherlands, inv. Nr. FA o603-17.

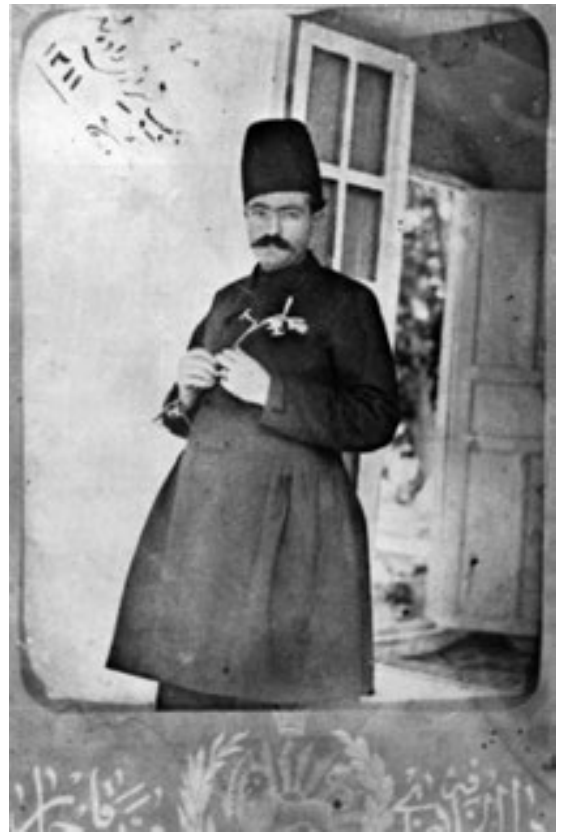

Figure 100 Mohammad Hassan Qajar, A man holding a flower, c. 1893 , albumen print, taken from Zokā 1997: 120 . 


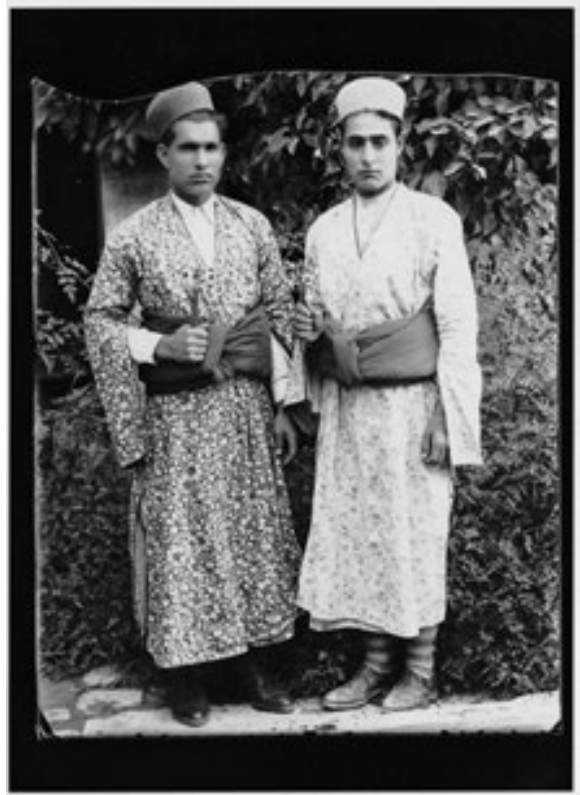

Figure 101 Ferdowsi Studio, men holding flowers, two qashqais, c. 1931, Shiraz, Archive of the Institute for Iranian Contemporary Historical Studies.

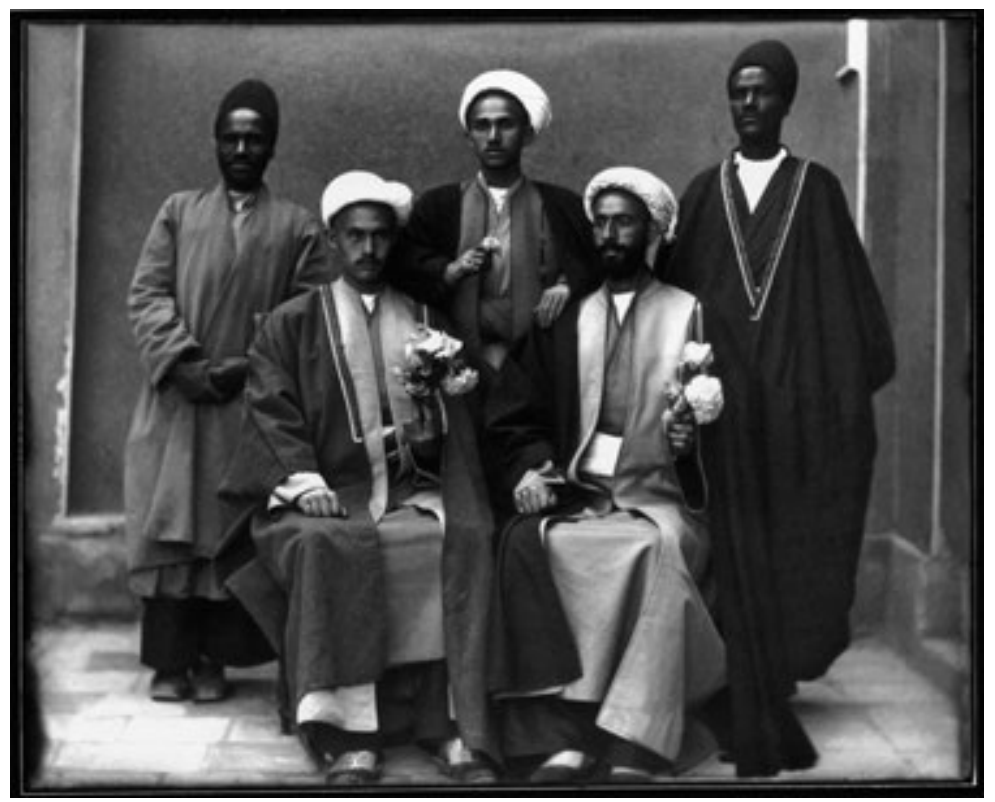

Figure 102 Ernst Hoeltzer, three mullahs with flowers, c. 1880, albumen print, Parisa Damandan Collection. 

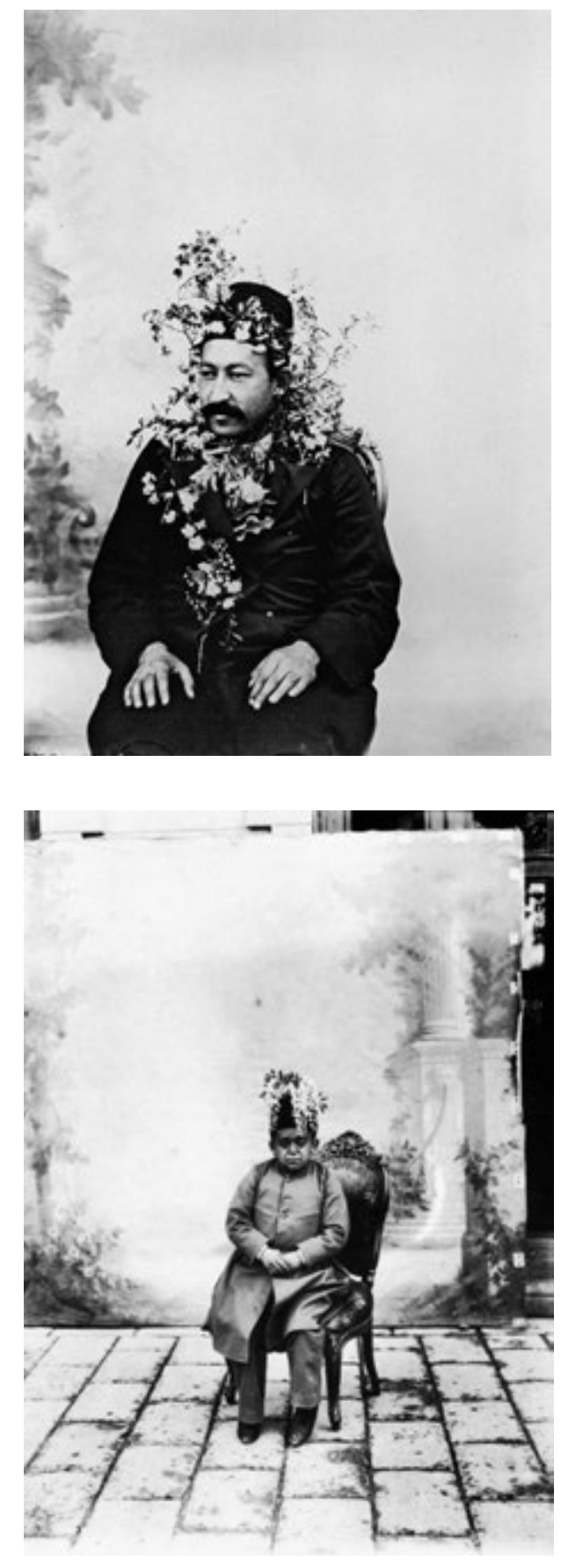

Figure 103 Photographer unknown, Abd al-Qāsem Chaffāri, date unknown, albumen print, Golestān Palace Library, Tehran.

Figure 104 Unknown photographer, Āghā Mohammad Khāje (eunuc) better known as Faqir al-Ghameh, date unknown, albumen print, Golestān Palace Library, Tehran. 


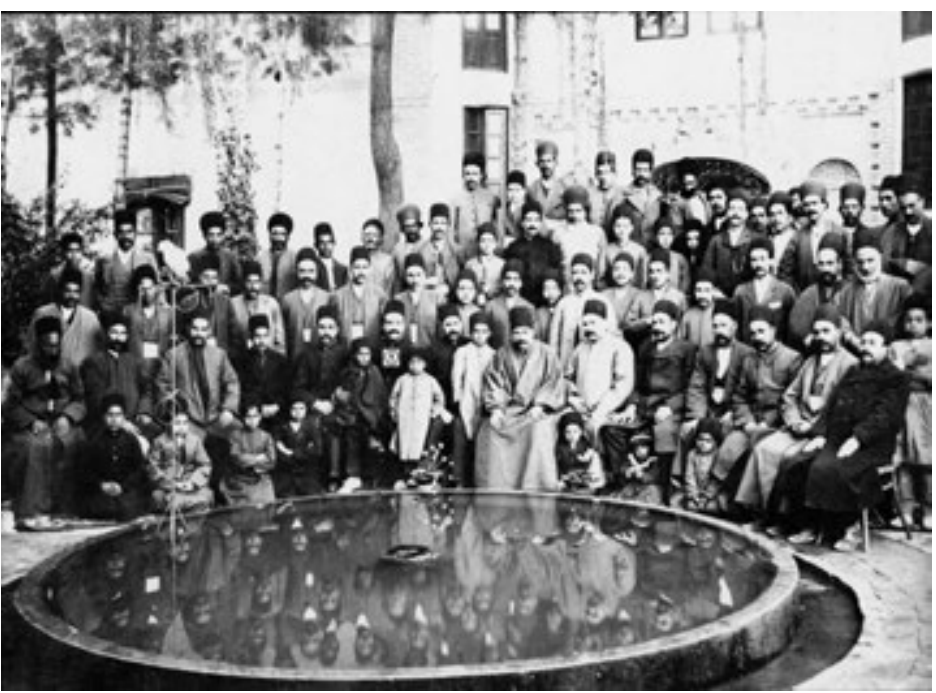

Figure 105 Unknown photographer, Pond of water, c. 1890s, albumen print, taken from Afshar 1992: 256.

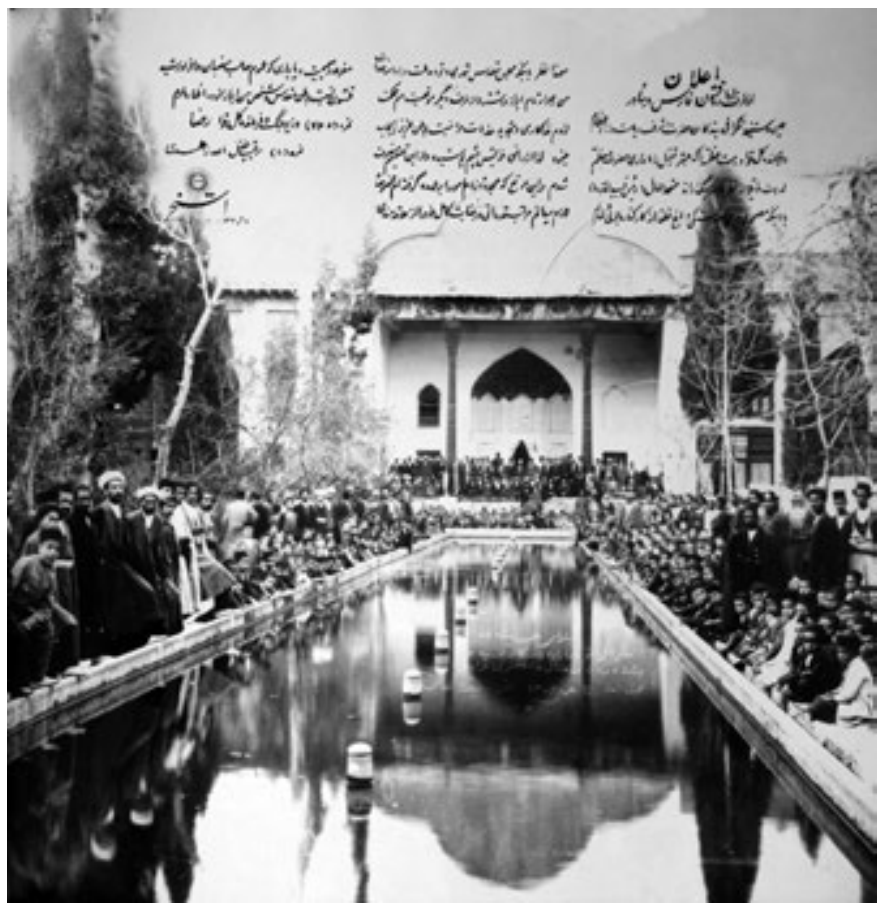

Figure 106 Unknown photographer, Pond of water, c. 1890s, albumen print, taken from Sane 2004: 66. 


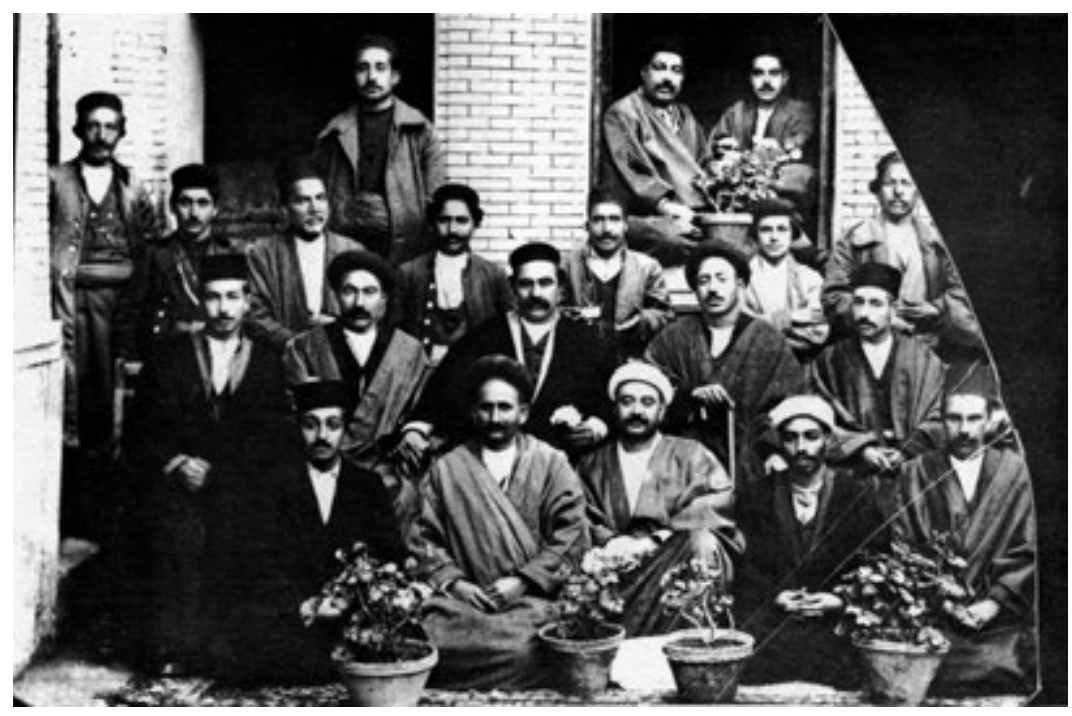

Figure 107 Mirzā Habibollāh Chehrehnegār, Group of men with pots of flowers, in Shiraz, c. 1918, Mansour Sane Collection.

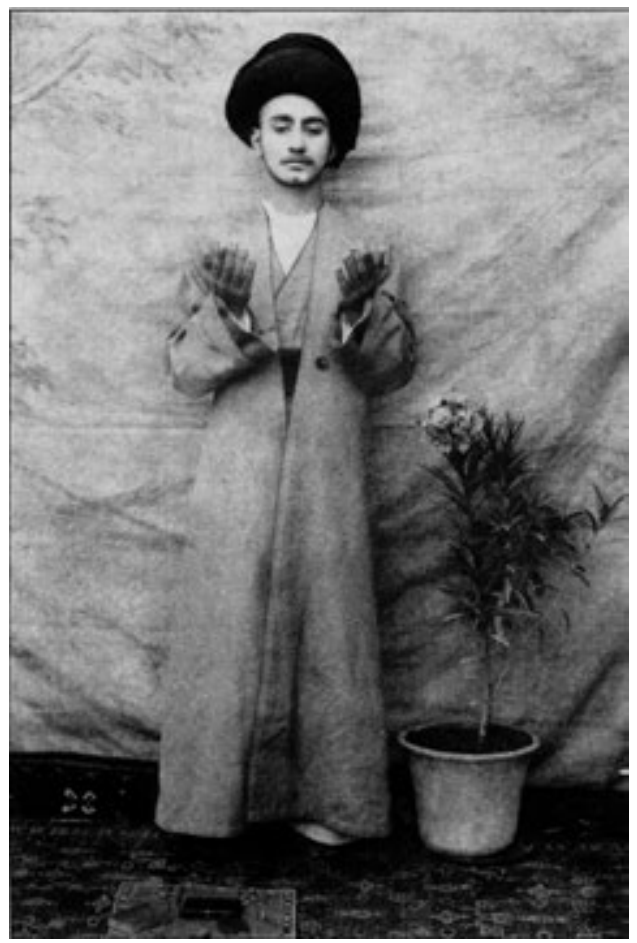

Figure 108 Mirzā Ahmad

Khan Chehreh-Namā, man praying, date unknown, albumen print, Parisa Damandan Collection. 


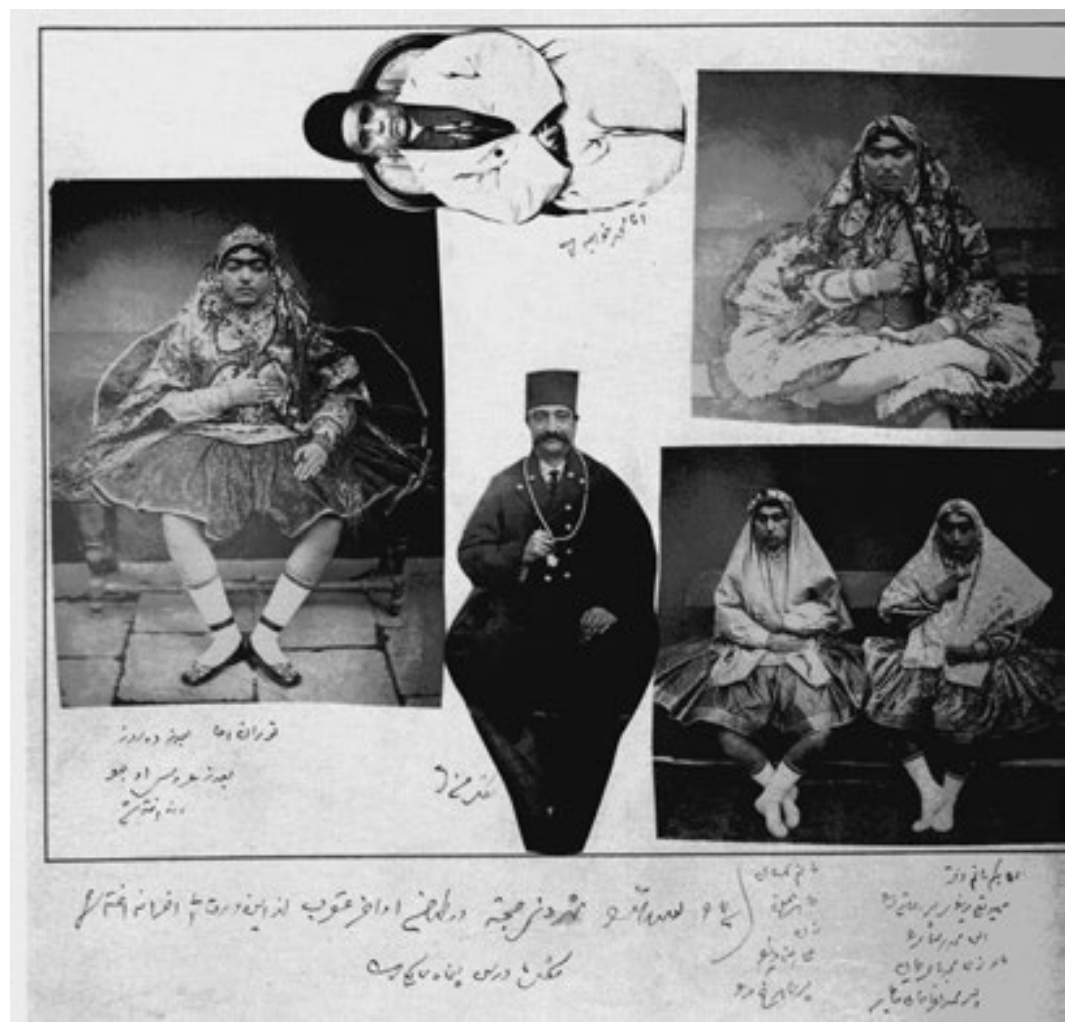

Figure 109 Nāser al-Din Shah, page of an album, c. 1879, albumen print, Golestān Palace Library, Tehran.

Photographs clockwise (starting photograph on the left side):

Nāser al-Din Shah, Turān Agha, c. 1879, $14 \times 10 \mathrm{~cm}$, Album 289, Photo 4-2. Nāser al-Din Shah, Mohammad Khān Khäje, c. 1879, $10.2 \times 5$ cm, Album 289, Photo 4-1.

Nāser al-Din Shah, Shah's wife, c. 1879, $14 \times 10 \mathrm{~cm}$, Album 289, Photo 4-4. Nāser al-Din Shah, Bigam Khānom and Bi-Mesāl Khānom, c. 1879, $11 \times 10.5 \mathrm{~cm}$, Album 289, Photo 4-5.

Nāser al-Din Shah, Nāser al-Din Shah, self-portrait, c. 1879, $13 \times 5.7 \mathrm{~cm}$, Album 289, Photo 4-3. 


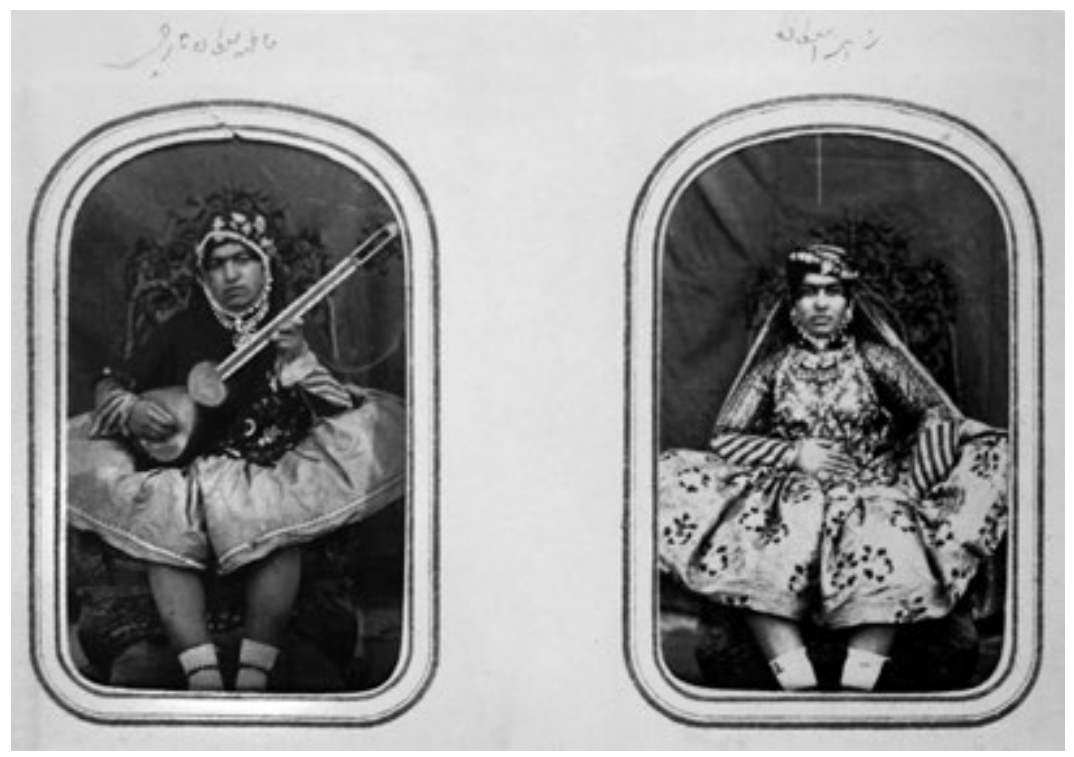

Figure 110 Nāser al-Din Shah, Fāteme Sultān Tarchi and Zahrā Sultān, c. 1865, albumen print, $10.8 \times 5.8 \mathrm{~cm}$ and $9.5 \times 5.8 \mathrm{~cm}$, Golestān Palace Library, Tehran, Album 362, Photos 17-2 and 17-1.

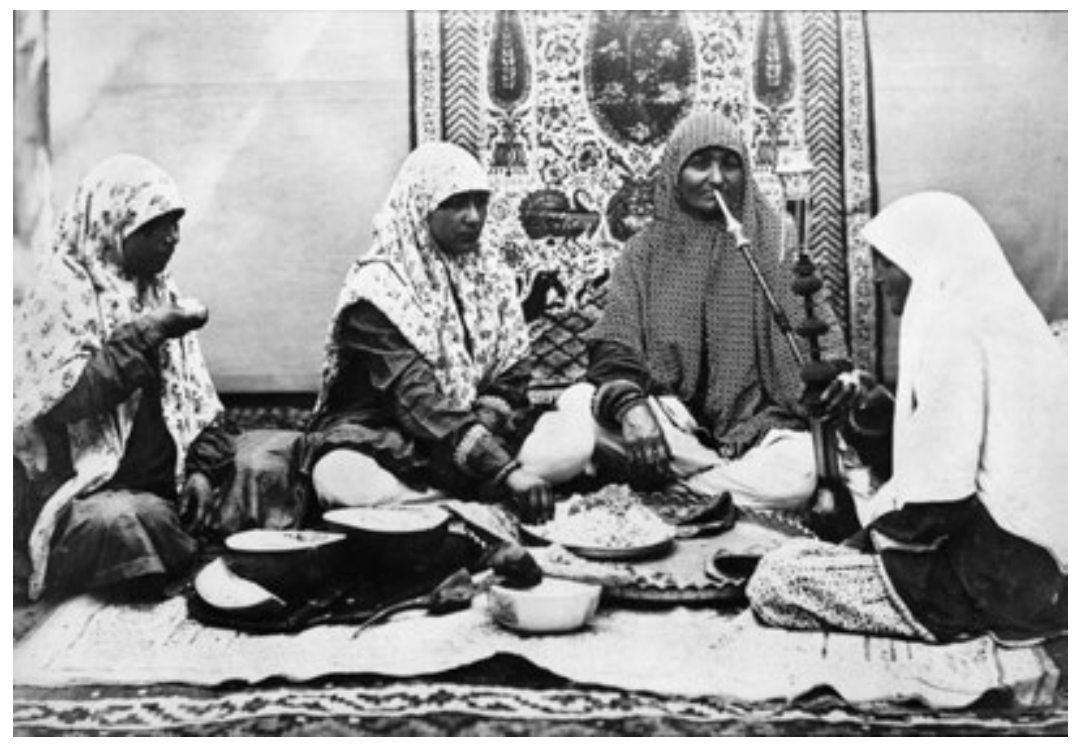

Figure 111 Ernst Hoeltzer, women eating pilav and melon, c. 1880s, albumen print, Hotz photo-collection hosted at the University Library in Leiden, Hotz Album 11: 60 . 


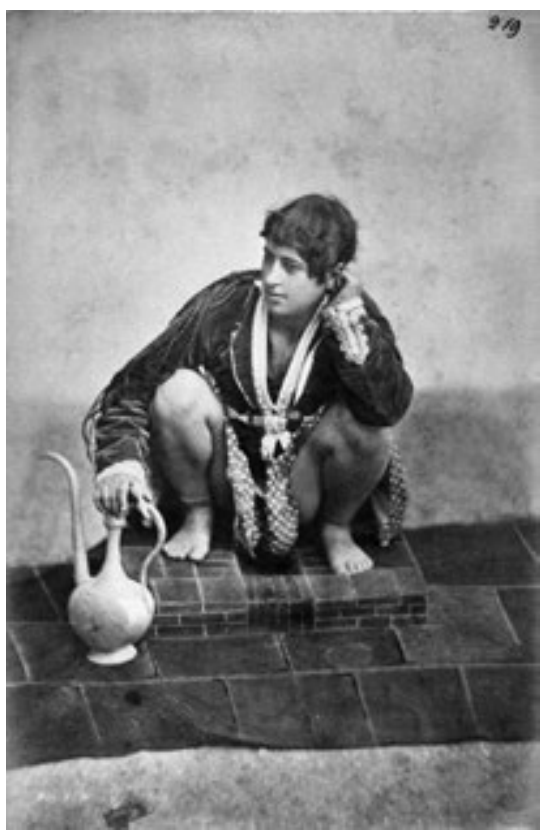

Figure 112 Antoin Sevruguin, Persian toilet, c. 1890 s, albumen print, Museum of Ethnology, Leiden.

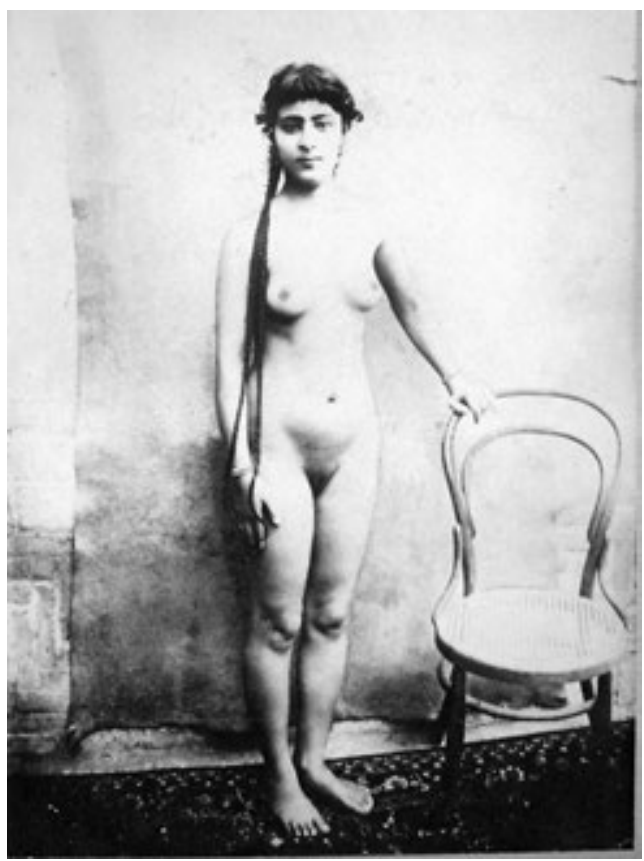

Figure 113 Antoin Sevruguin, naked woman, c. 1890s, albumen print, Museum of Ethnology, Leiden. 


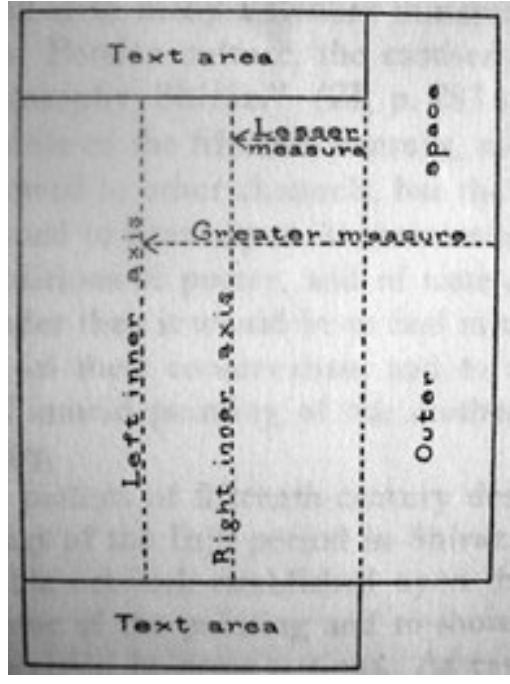

Figure 114 Plot of Praetorius Codex Miniatures, by Emmy Wellesz and Kurt Blauensteiner, in "Illustration zur einer Geschicte Timurs".

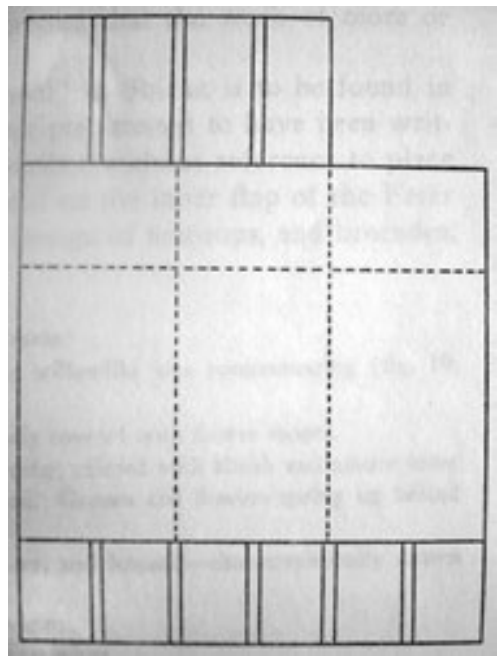

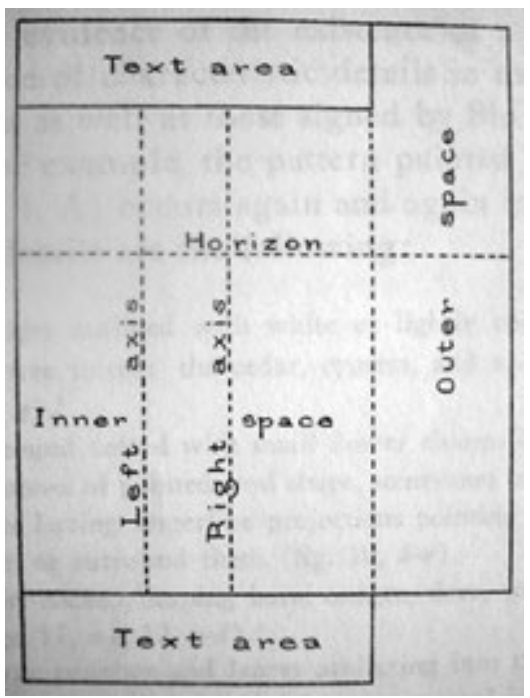

Figure 115 Shiraz canon, by Grace Dunham Guest 1949: 29.

Figure 116 Modified Shiraz canon, by Grace Dunham Guest 1949: 29. 


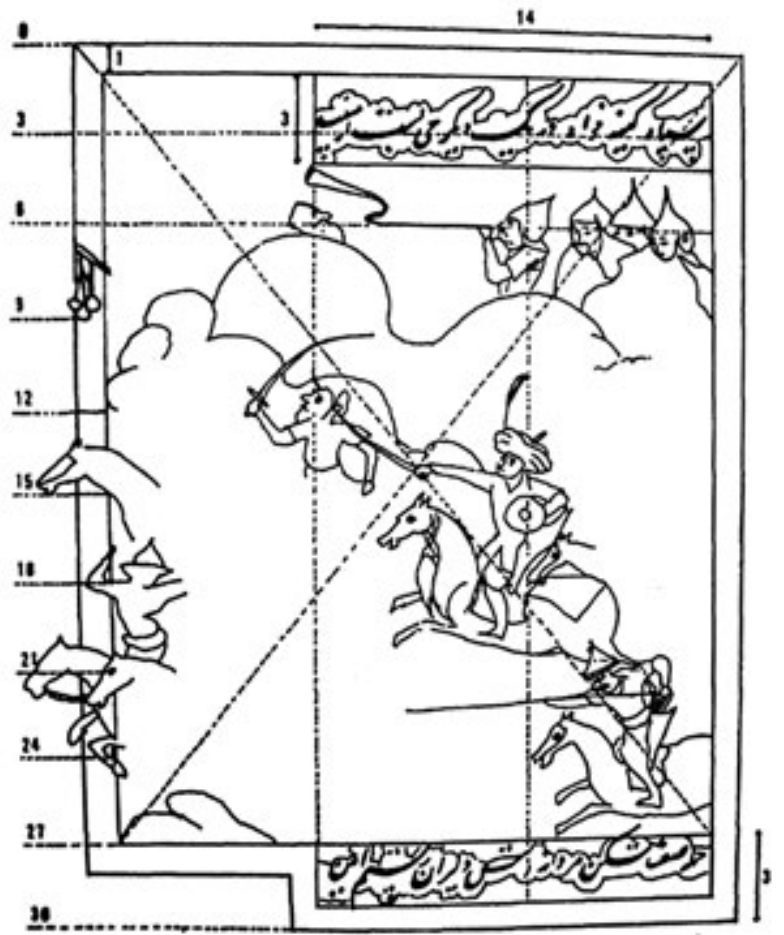

Figure 117 Plot by Charyhar Adle. Modular composition and "trace correcteur" of Shah Abbās attacking the Uzbek army, from Fotuhāt-e Hamāyun, 1600-05, fol. 88r. taken from Adle 1975: 90.

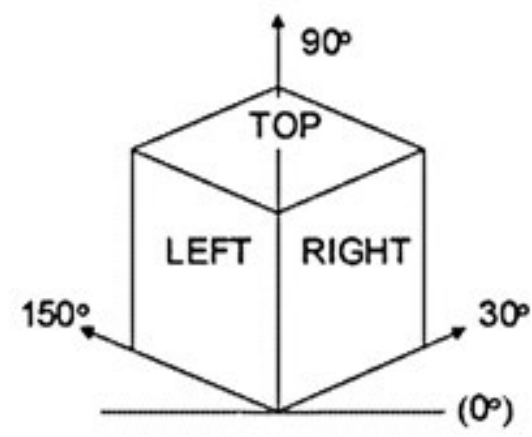

Figure 118 Illustration of William Farish's isometrical perspective, taken from Krikke 1996. 

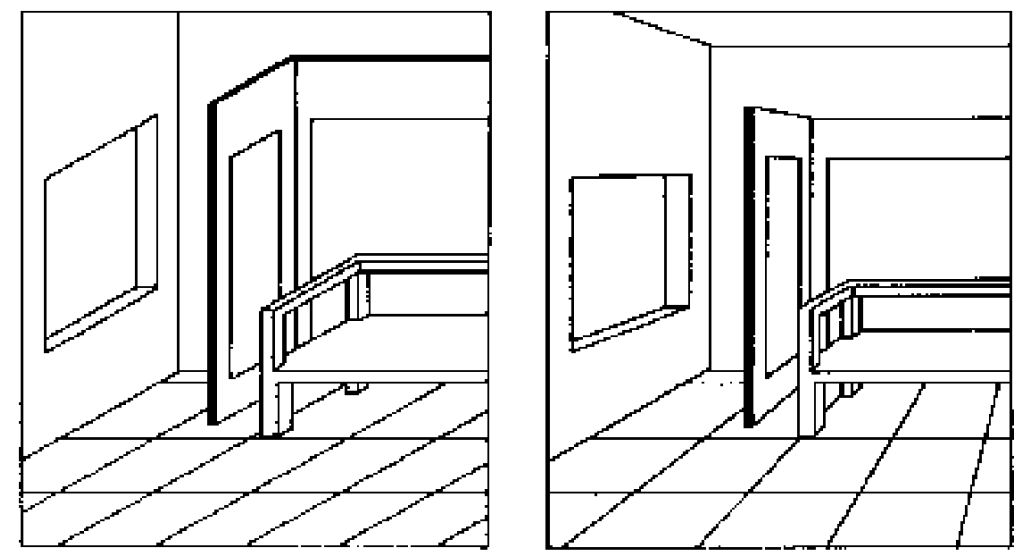

Figure 119 Illustration of the difference between axonometry as it is used in Chinese painting (left) and linear perspective (right). Taken from Krikke 1996.

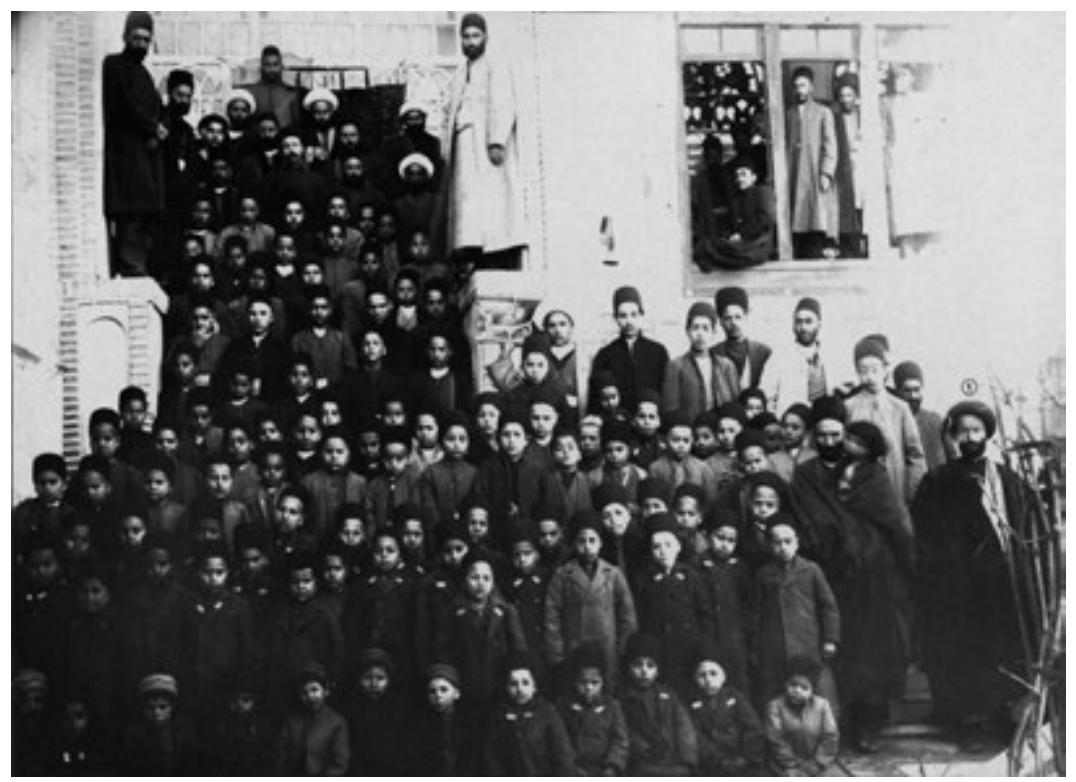

Figure 130 Unknown Iranian photographer, Group of students from Nawbar school, Tabriz, c. 189os, taken from Afshar 1992: 307. 


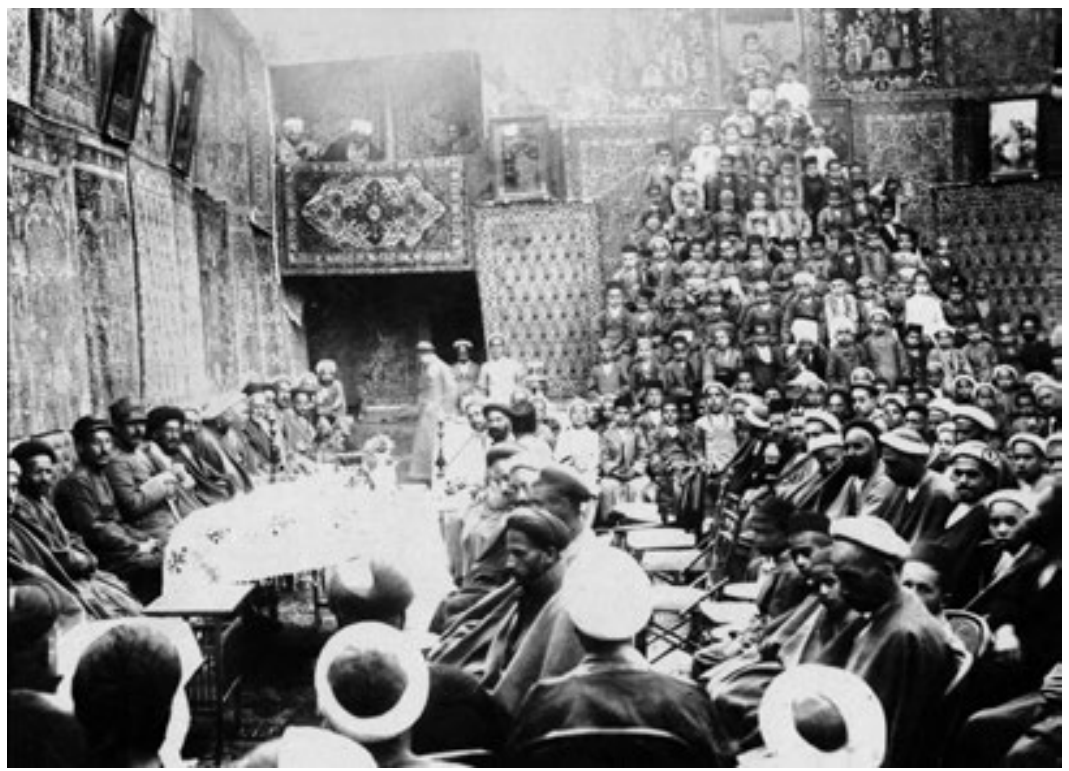

Figure 131 Unknown Iranian photographer, Moshiriype school, c. 1880s, Yazd, albumen print, private collection.

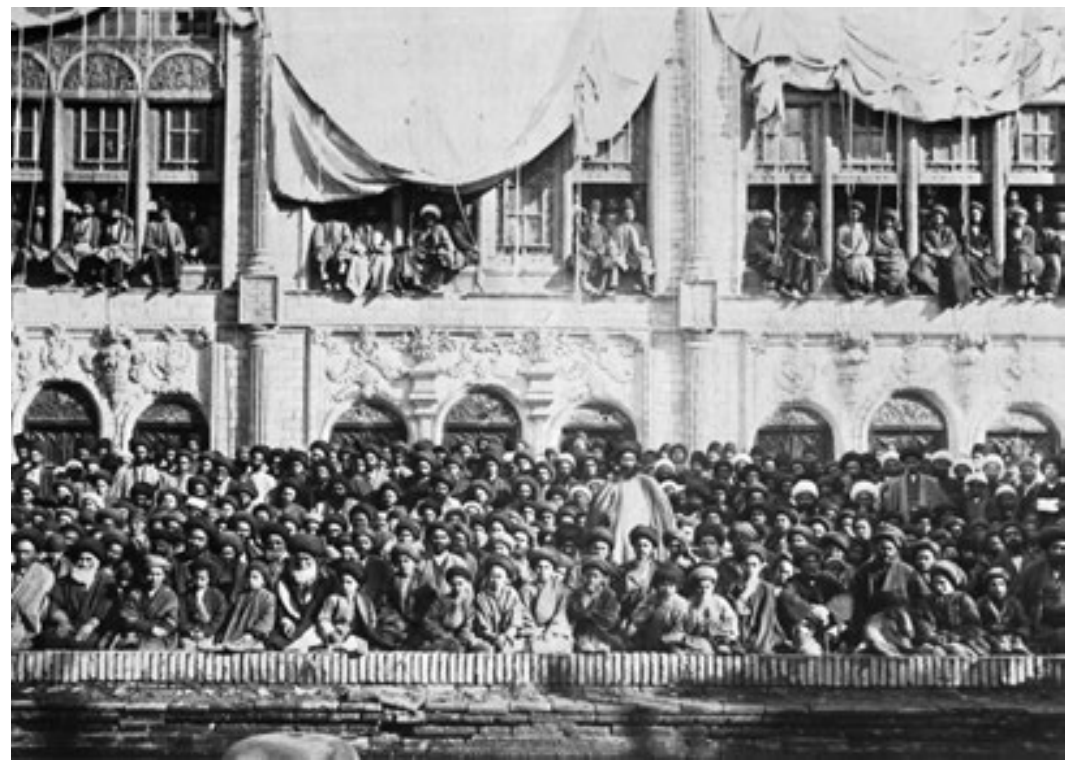

Figure 132 Abdollāh Mirzā Qajar, celebrations of the birthday of Fāteme at the house of one minister, c. 1894, $25 \times 17.5 \mathrm{~cm}$, taken from Zokā 1997: plate 60. 


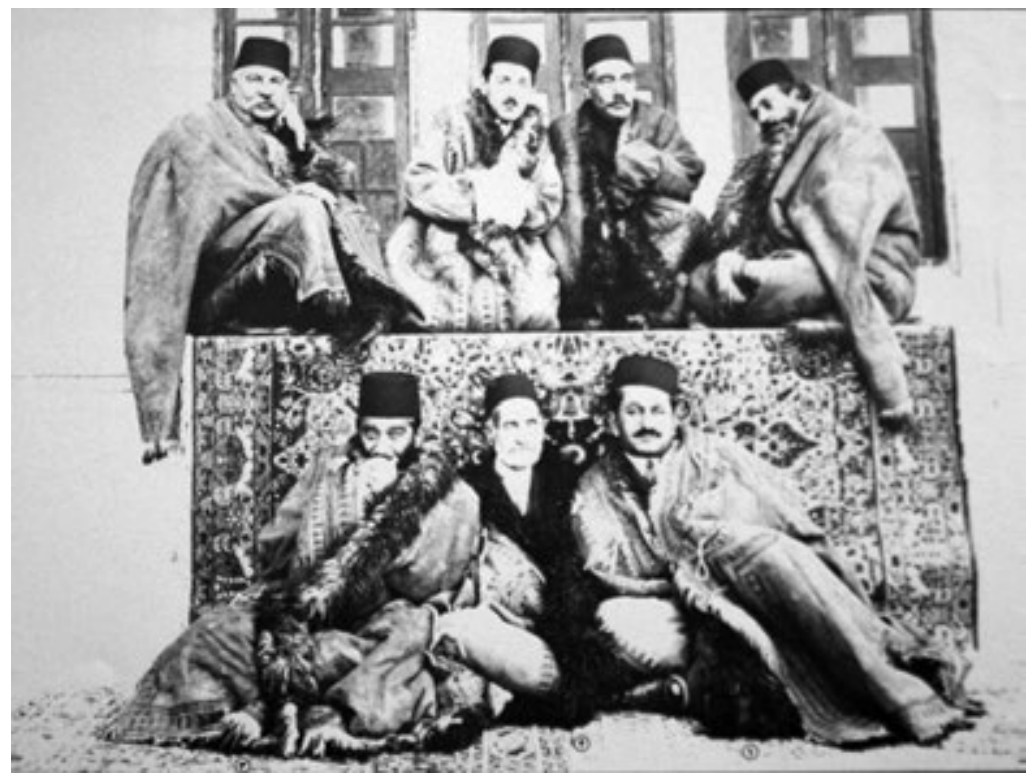

Figure 133 Unknown photographer, Governor of Kerman with friends and colleagues, date unknown, taken from Afshar 1992: 206.

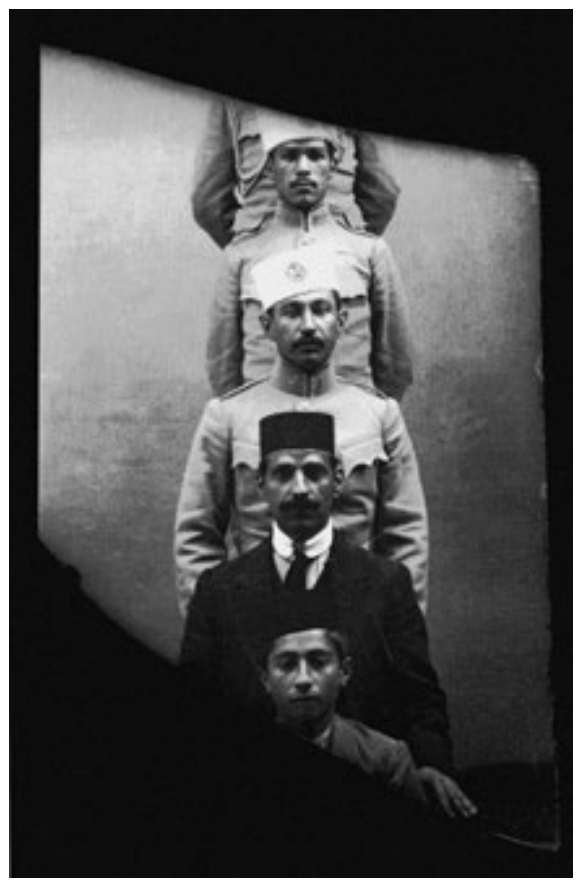

Figure 134 Mirzā Mehdi Khān Chereh-Namā, military men, c. 1920s, Parisa Damandan Collection. 


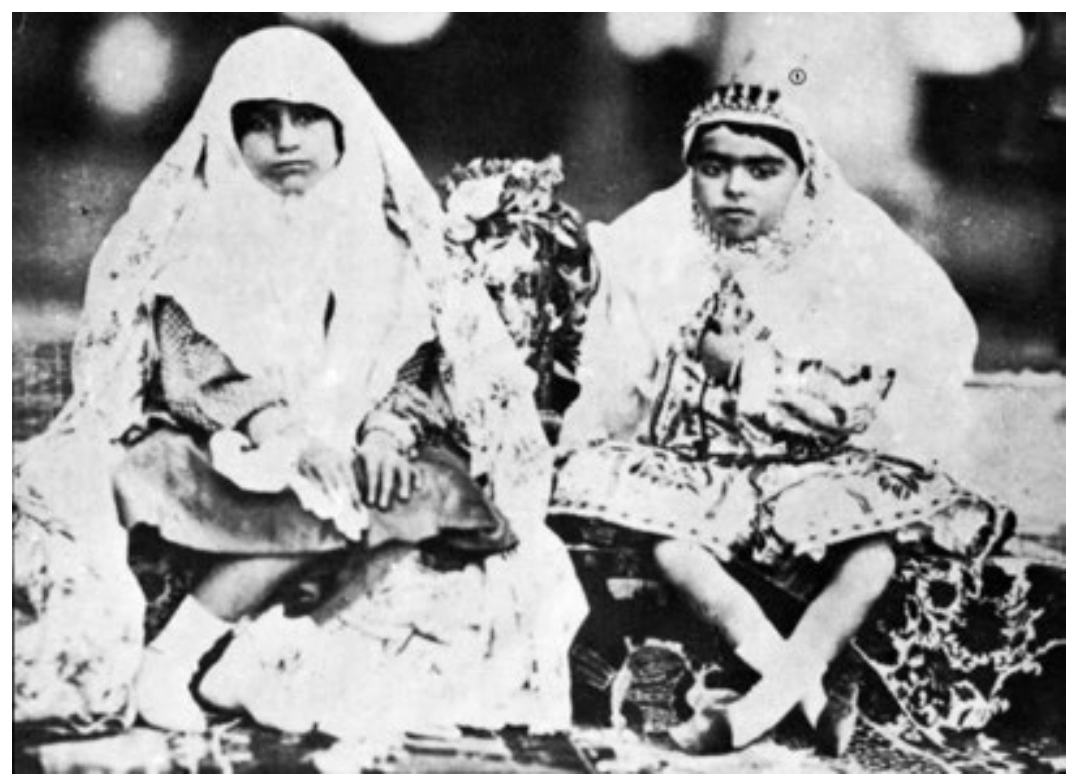

Figure 135 Nāser al-Din Shah, Iran al-Moluk, one of Nāser al-Din Shah's daughters wives (the woman on the left side), date unknown, Golestān Palace Library, Album 286, Tehran, taken from Afshar 1992: 205.

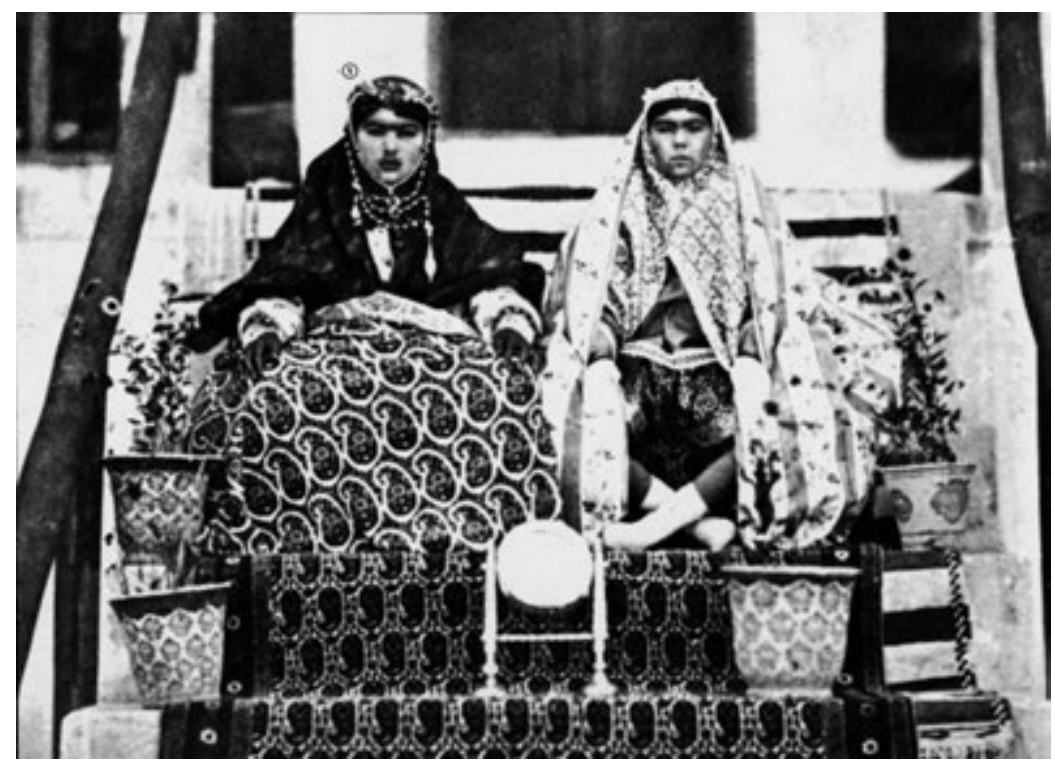

Figure $136 \mathrm{Nāser}$ al-Din Shah, One of Nāser al-Din Shah's wives (the woman on the left side), c. 1870s, Golestān Palace Library, Album 286, Tehran, taken from Afshar 1992: 55 . 


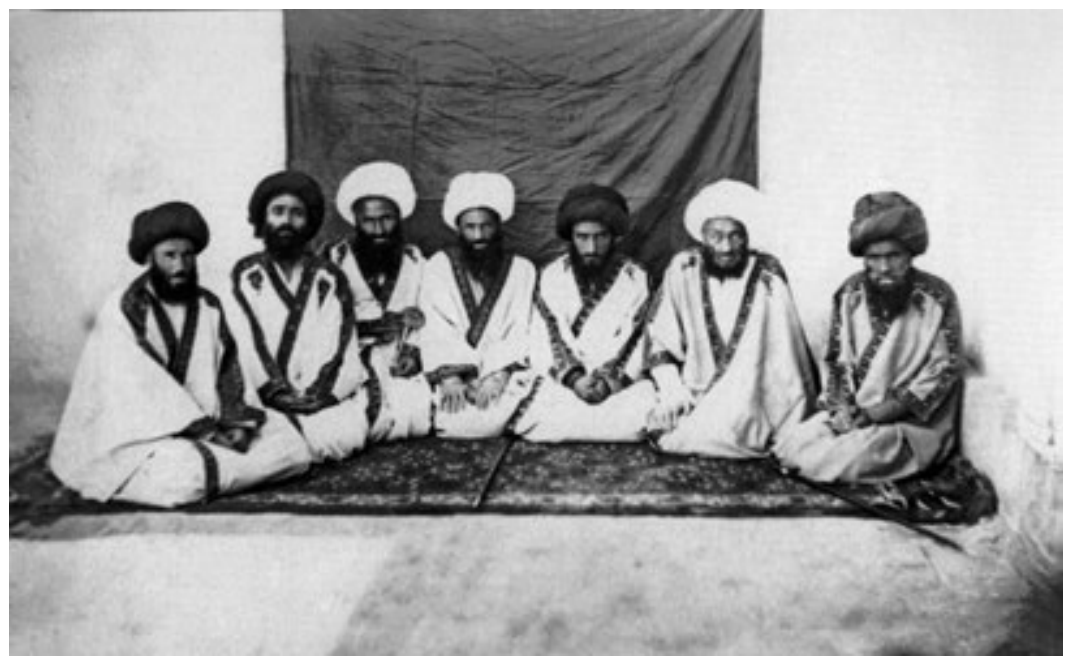

Figure 137 Rezā Akkāsbāshi, group of mullahs, date unknown, albumen print, taken from Tahmasbpour 2007: 13.

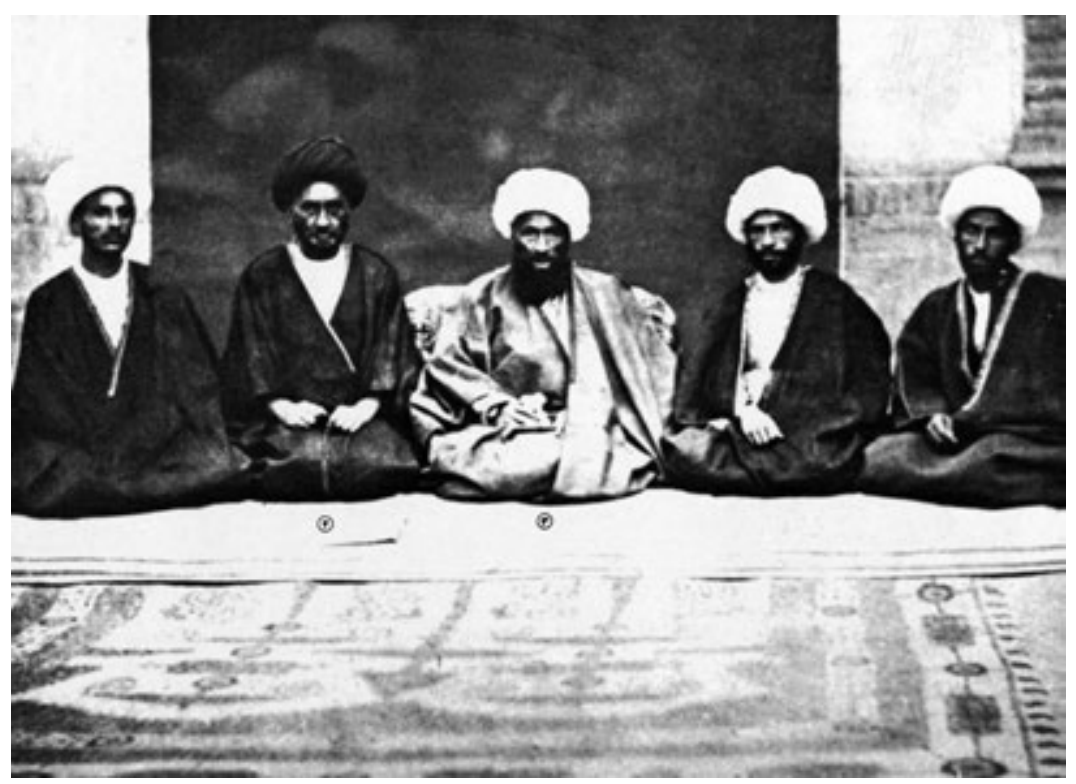

Figure 138 Rezā Akkāsbāshi, group of mullahs, date unknown, albumen print, Museum of Photography, Tehran. 


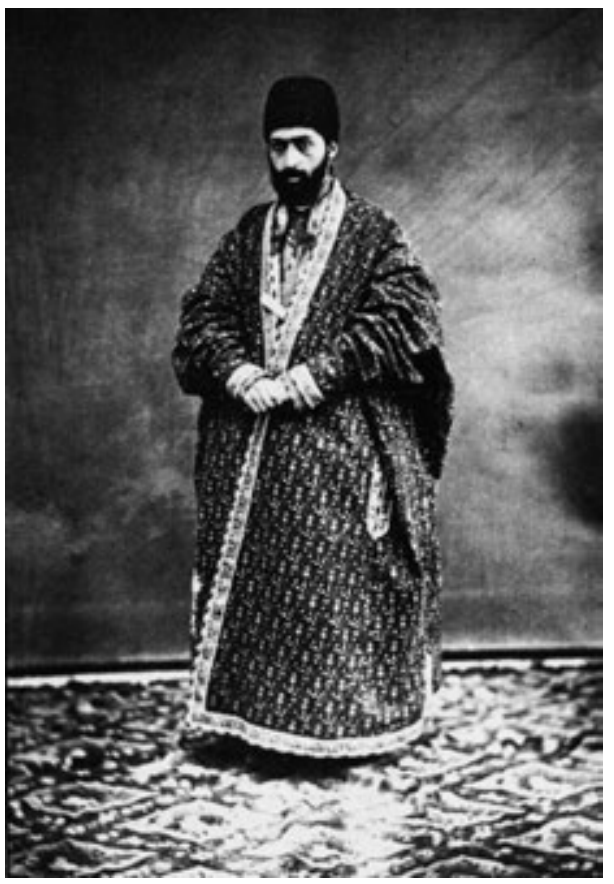

Figure 139 Unknown photographer, Hājji Hoseyn Quli Khān Nuri Mostowfi, Ministry of Foreign Affairs, date unknown, albumen print, taken from Afshar 1992: 120.

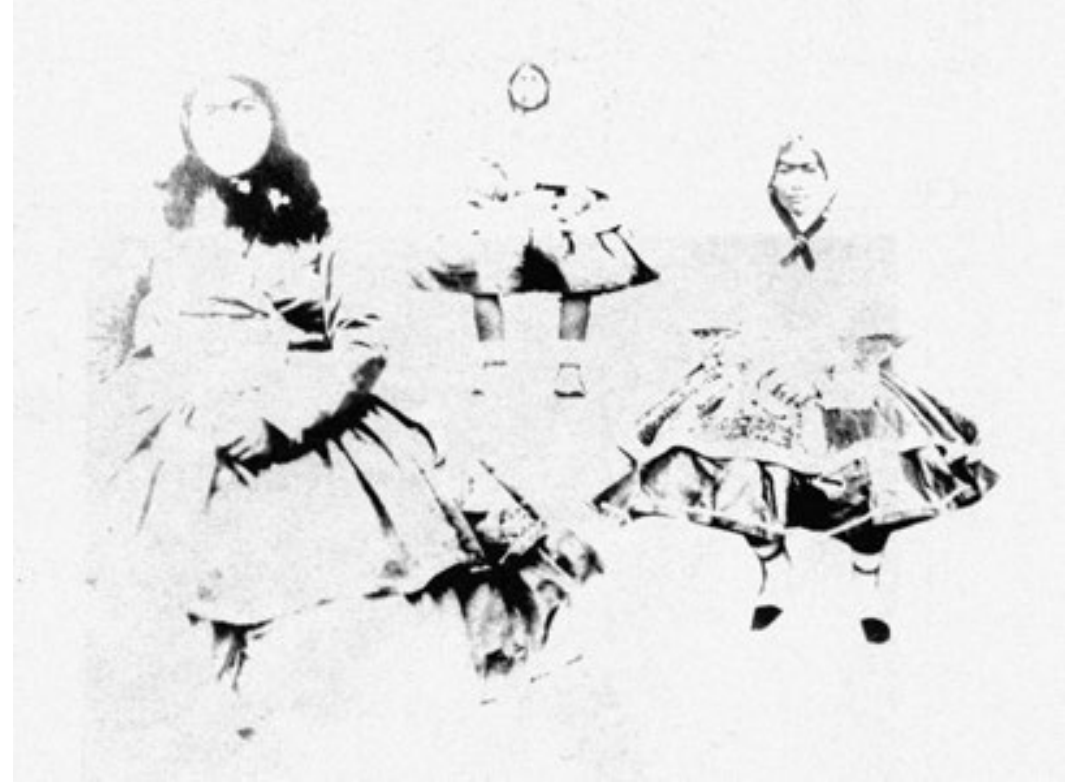

Figure 140 Nāser al-Din Shah, Anis al-Dowle and Shirazi Kuchak, wives of the Shah, between 1865-1875, Album 289, page 28, Golestān Palace Library, Tehran. 


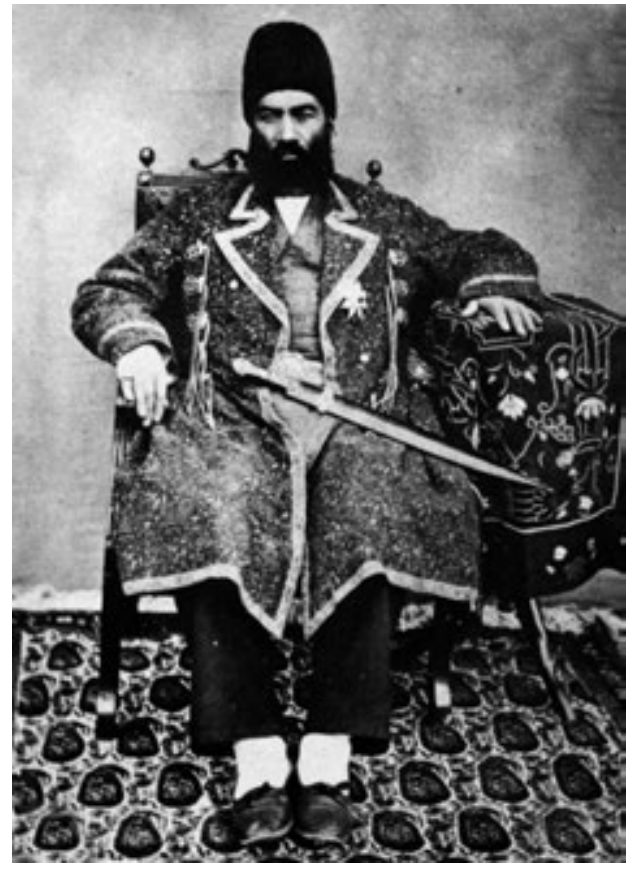

Figure 141 Unknown Iranian photographer, Mohammad Ebrahim Khān Me'mārbāshi, c. 1886, taken from Afshar 1992: 60.

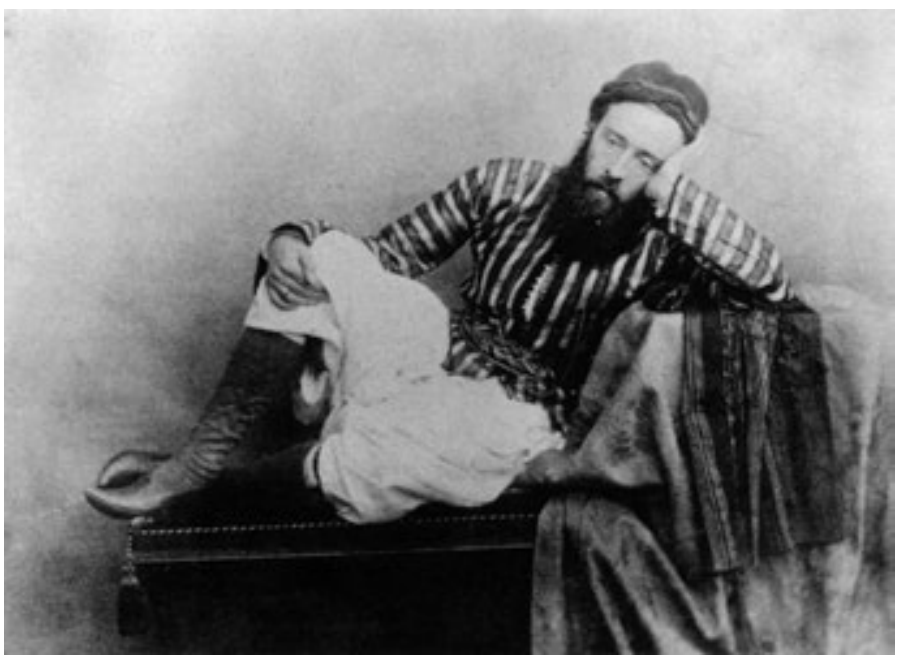

Figure 143 Francis Fritz, Self-portrait in Turkish Summer Costume (sic), 1857, albumen print, Permanent loan from the Jerusalem Foundation, The Israel Museum, Jerusalem, L76.27/01. 

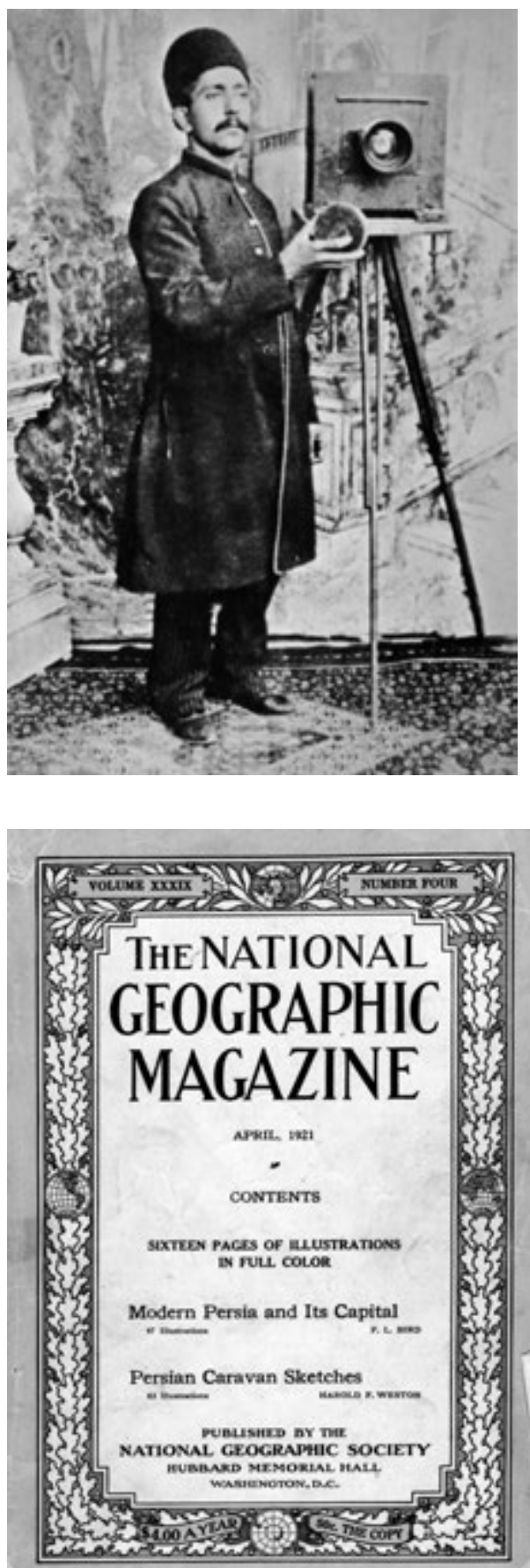

Figure 144 Abd al-Q̄āsem ebn al-Nuri, self-portrait, c. 1900s, Golestān Palace Library, Tehran, taken from Zokā 1997: 117.

Figure 145 The National Geographic Magazine, April 1921, Washington, cover. 


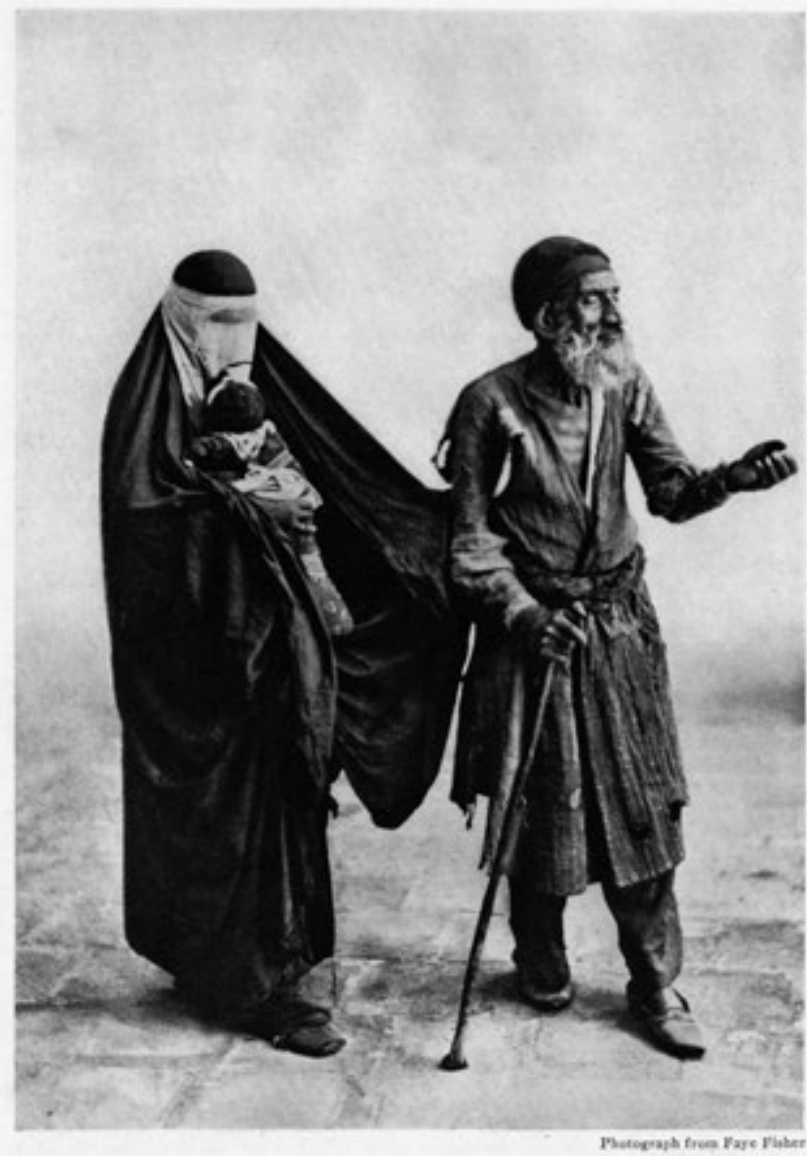

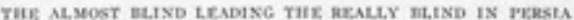

There are many blind permons in Persia, ewing partly to the intense Eght rays of the sun. Tradition gives the following oricin for the wearing of veils by Mobammedan women: Oae day when the Prephet was seated with his favorite wife. Ayesha, a passing Arab admired her, expressed a wish to purclase her, and offered a camel in exchange. This experience so angered Sohammed that the custeen of requiring women to wear veils resulted.

Figure 146 The National Geographic Magazine, April 1921, Washington: 352. 


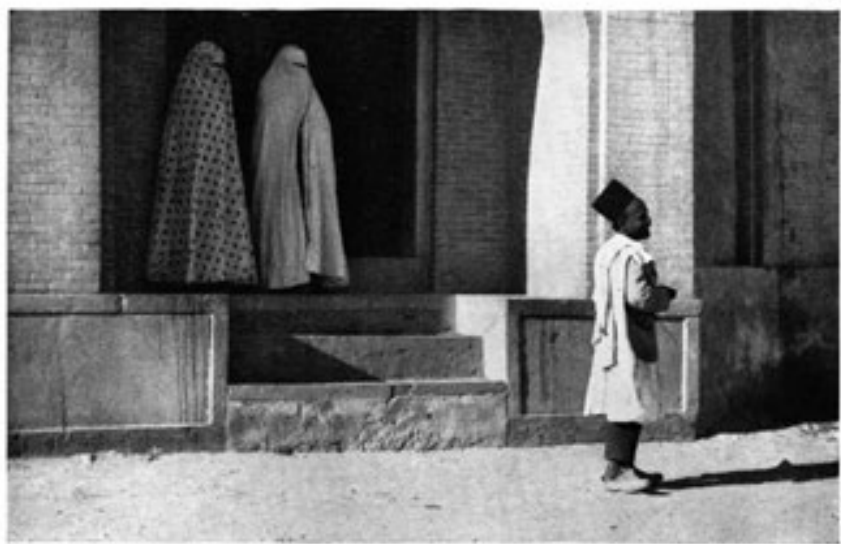

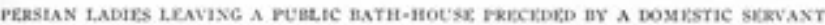
Every Friday is "lath day" in Persia, and a bath is obligatory before the faithful cas worship. Frequently there is a peltlic bath attached to the movege.

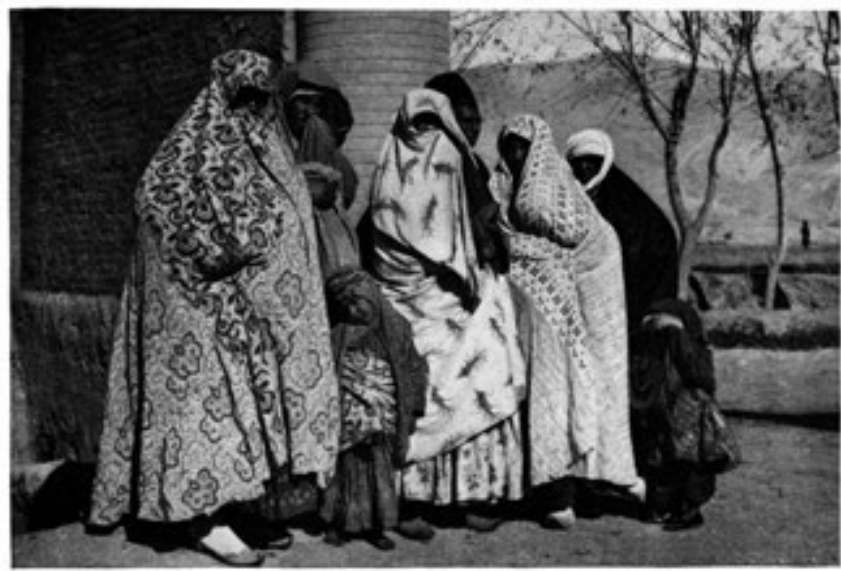

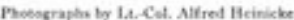

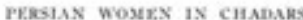

Both Christian and Molammedan women wrar the voshmek (veil) ont of doors, bug the glagdar (chuddar), or enveloping garment, is peculiar to the followers of Mohammed

Figure 147 The National Geographic Magazine, April 1921, Washington: 353. 


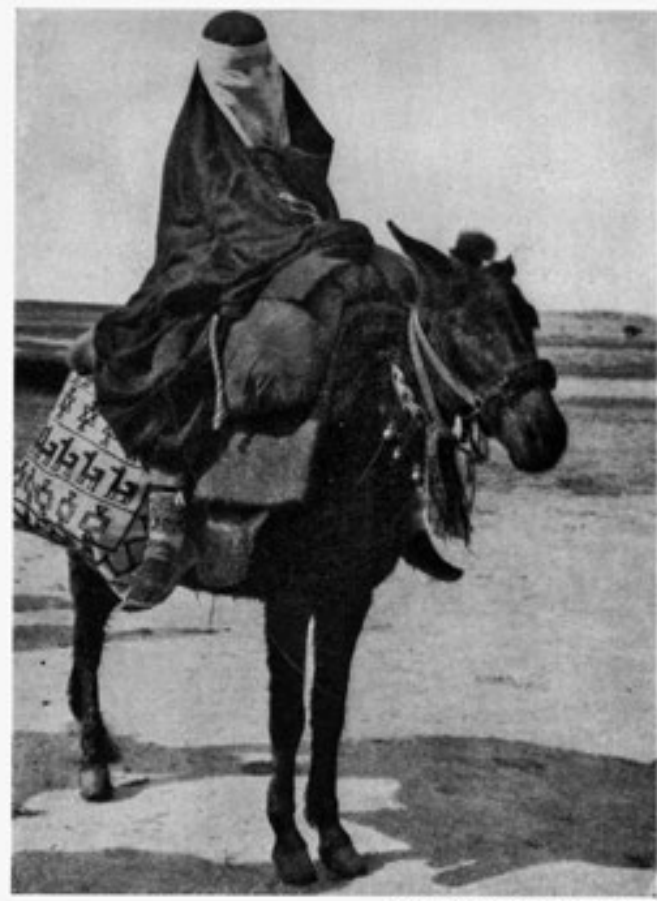

Photograpal by Roland Corbol.

A PERSIAN WOMAN APPARELID JOR A PILGRTMAG:

The elaborately embroidered saddle-bag is a khorjon, in which both elothes and food are carried for the journey. The white veil over lier face is the yostrual.

The railroad and the motor car have not yet won the competition with the camel and the donkey; and while modern schools are increasing in number and quality, the old Makhtab Khaneh, with the Arabic Koran as the text-book in the primer class, is still a national institution.

While Teheran is the seat of an experiment in representative government, most of the surrounding villages are a part of an oriental feublal system, as the property of the crown or the wealthy land-owning nobles, In these dreary, insanitary, adobe villages, still centers the Persian jeasant life, an existence entirely aloof from the modern world, dominated by bigotry and conservatism, and not yet ameliorated by medical science or enlightened education.

From their central. ized abodes the peas. ants go each day to till the surrounding fields with tools and methods similar to those employed by their forebears. And within this same limited area rove rough, untutored nomads, self-dependent, prosperous in terms of flocks and herds, desiring no better shelter than the black wool tenting woven by their virile, unsecluded wives and daughters, but unconcerned with the affairs of state.

From the more progressive centers of Teheran and other important Persian cities waves of reflected en. lightenment are mowing in slowly widening concentric circles to reduce the divergence in present-day Persian life.

The rise of the pres. ent Kajar Dynasty was a final attempt to restore a conservative oriental despotism in the midst of a swiftly progressing modern world. and under the long, benevolent rule of Naser-ed-din Shah, who maintained order and obedience throughout the length and breadth of his kingdom, this anachronism gave strange promise of success; but the failure of his successors disclosed the futility of competing with antiquated equipment in the modern economic and political struggle.

The progressive element among the Persians realized their weakness, and in 1906 demanded and secured a constitu.

Figure 148 The National Geographic Magazine, April 1921, Washington: 392. 


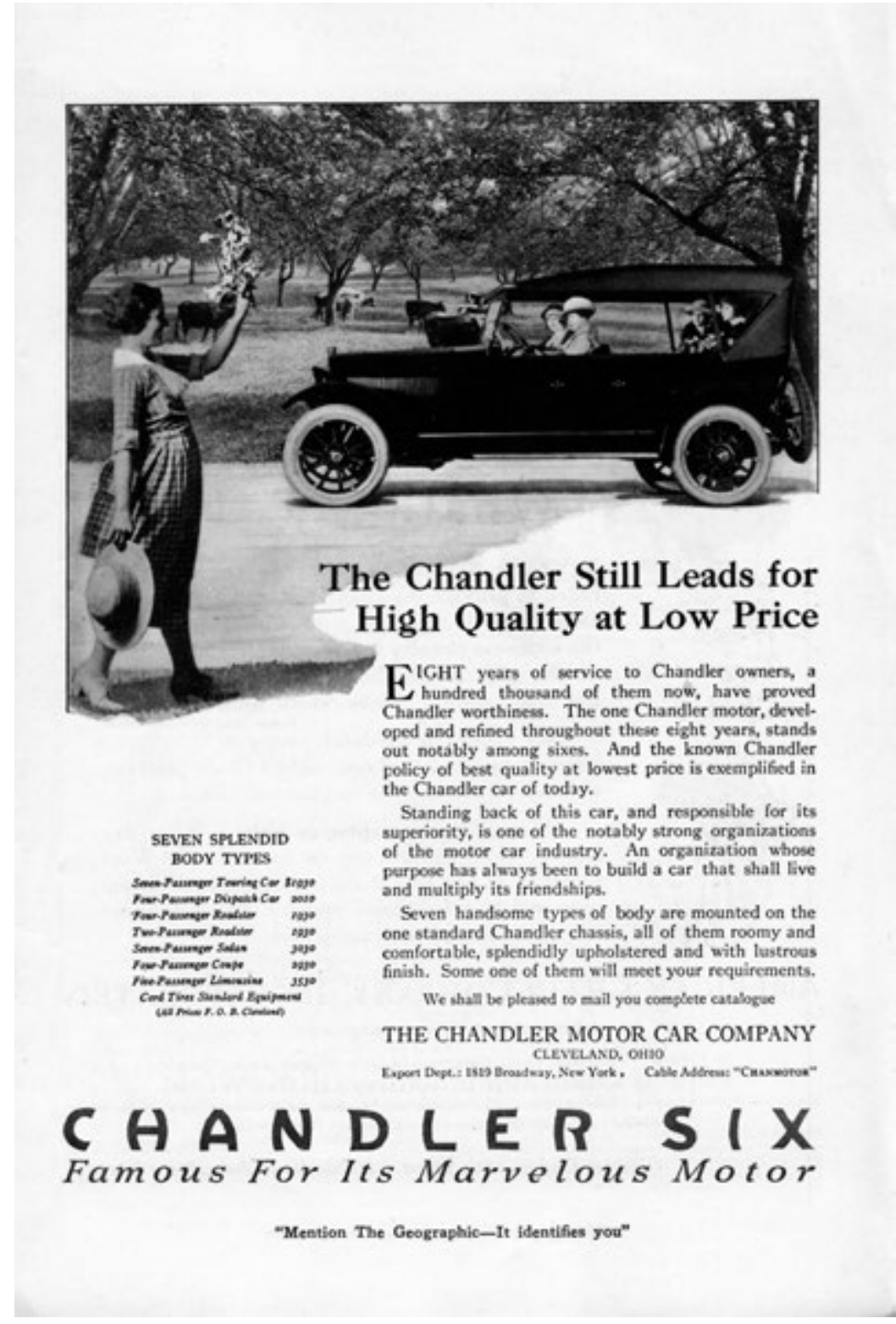

Figure 149 The National Geographic Magazine, April 1921, Washington, advertisement. 


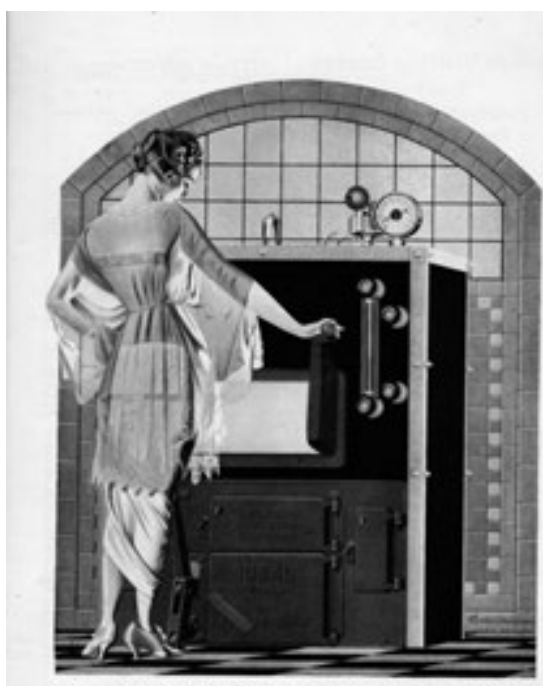

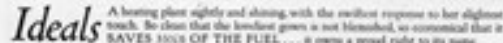

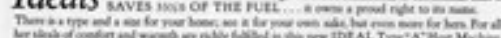

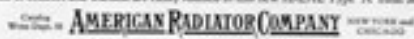
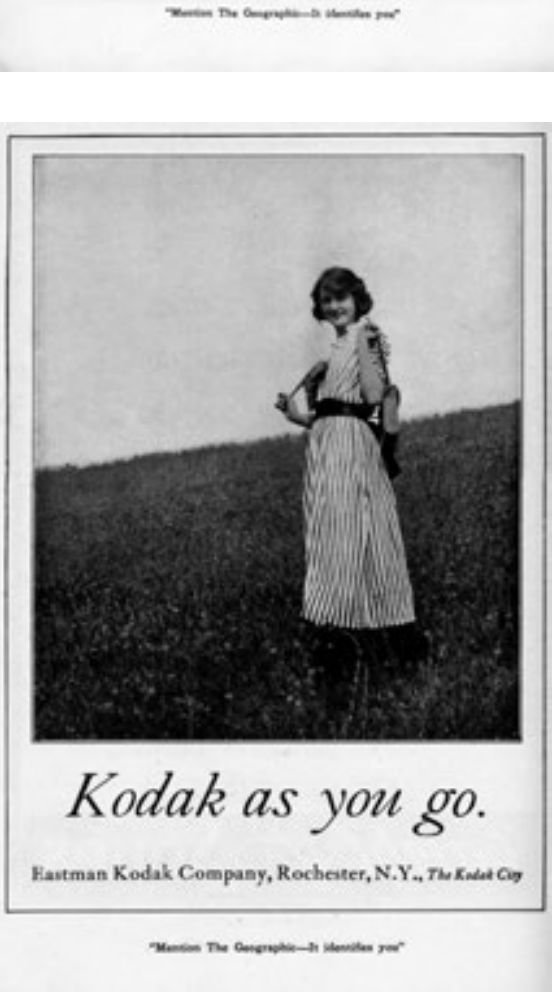

Figure 150 The National Geographic Magazine, April 1921, Washington, advertisement.

Figure 151 The National Geographic Magazine, April 1921, Washington, advertisement. 


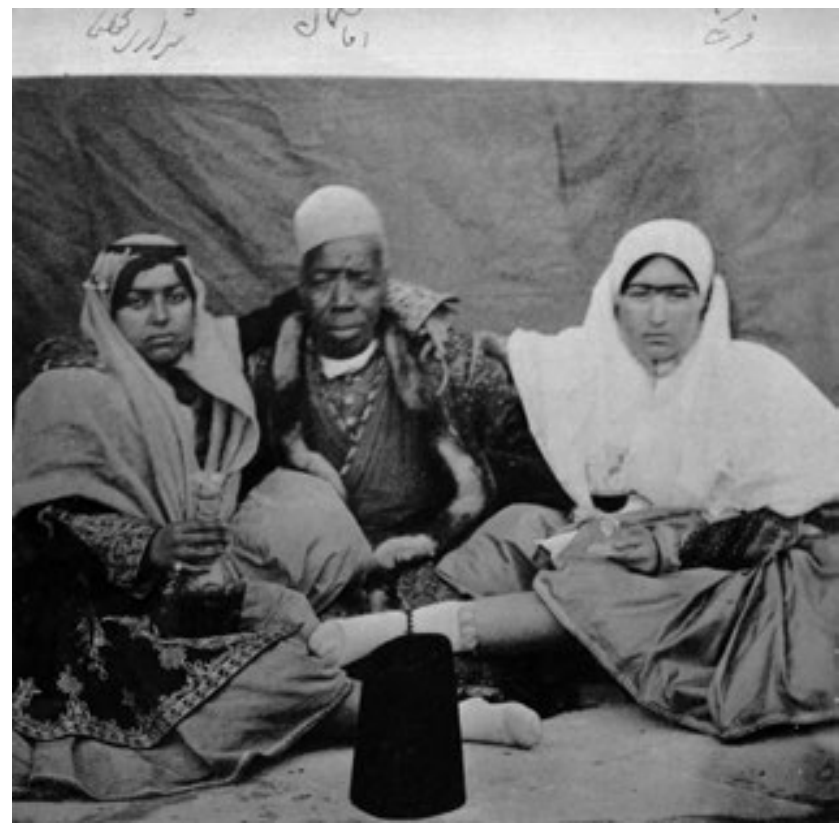

Figure 152 Rezā Akkāsbāshi, Shirazi-ye Kuchak and Farangi with Aghā Salmān, Golestān Palace Library, Tehran.

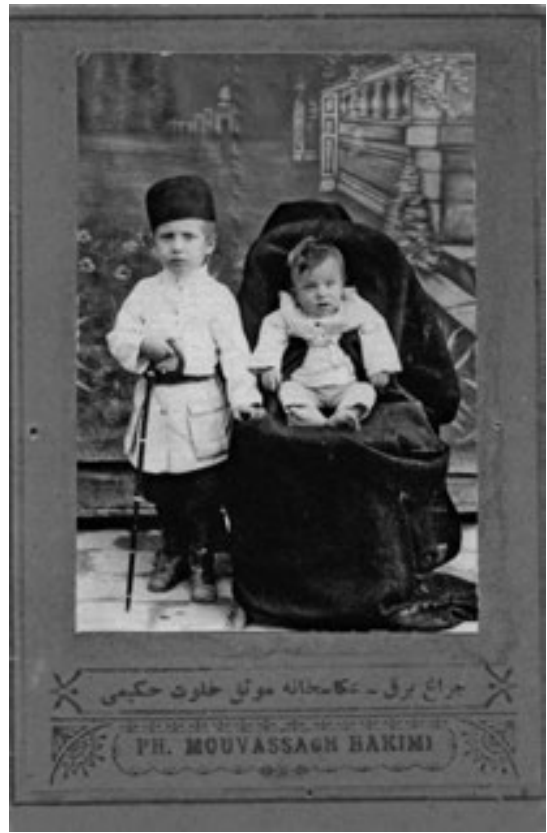

Figure 153 Movassaq Karimi, portrait of two small children, unknown dates, Museum of Photography, Tehran. 


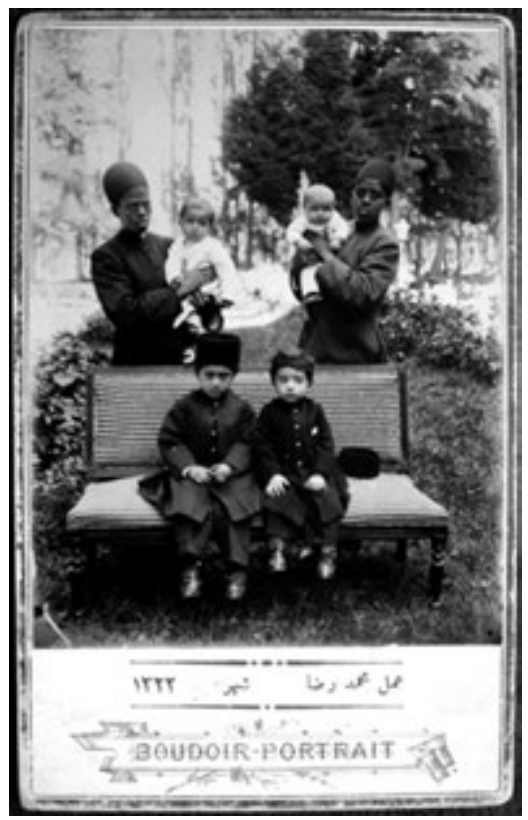

Figure 154 Boudoir studio, untitled, 1904, Bahman Bayani Collection, Tehran.

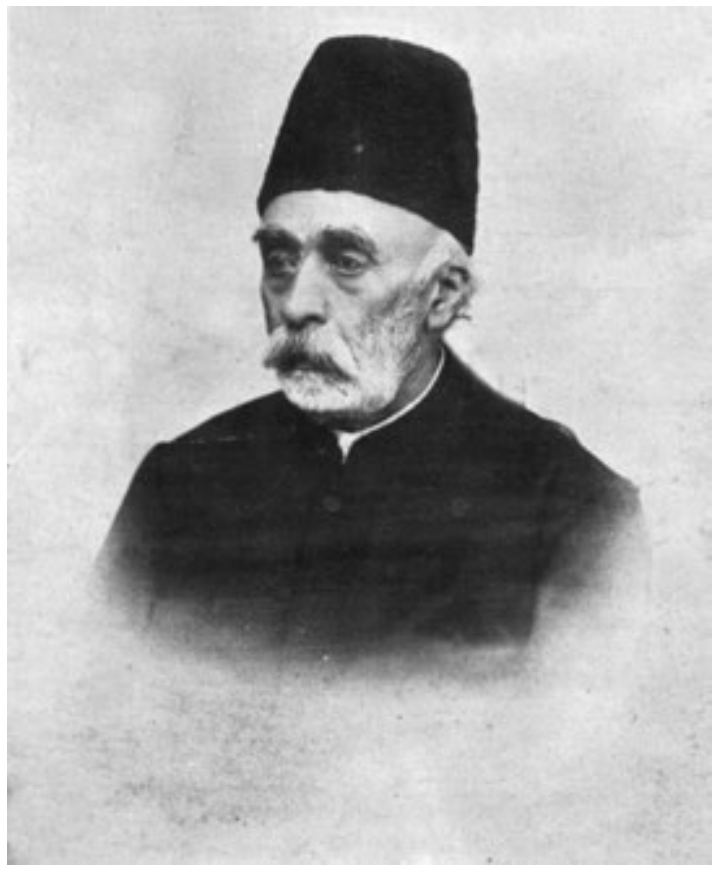

Figure 157 Abdollāh Mirzā Qajar, Ja'far Qoli Khān, c. 1902, private collection, taken from Zokā 1997: 82 


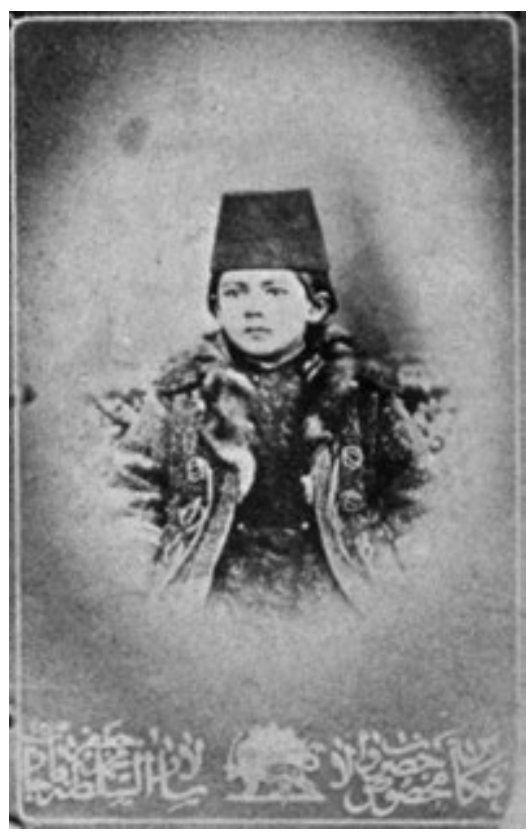

Figure 158 Mohammad Jafar Mirzā, Nosrat al-Din Mirzā as a child, c. 1887 , private collection, taken from Zokā 1997: 87.

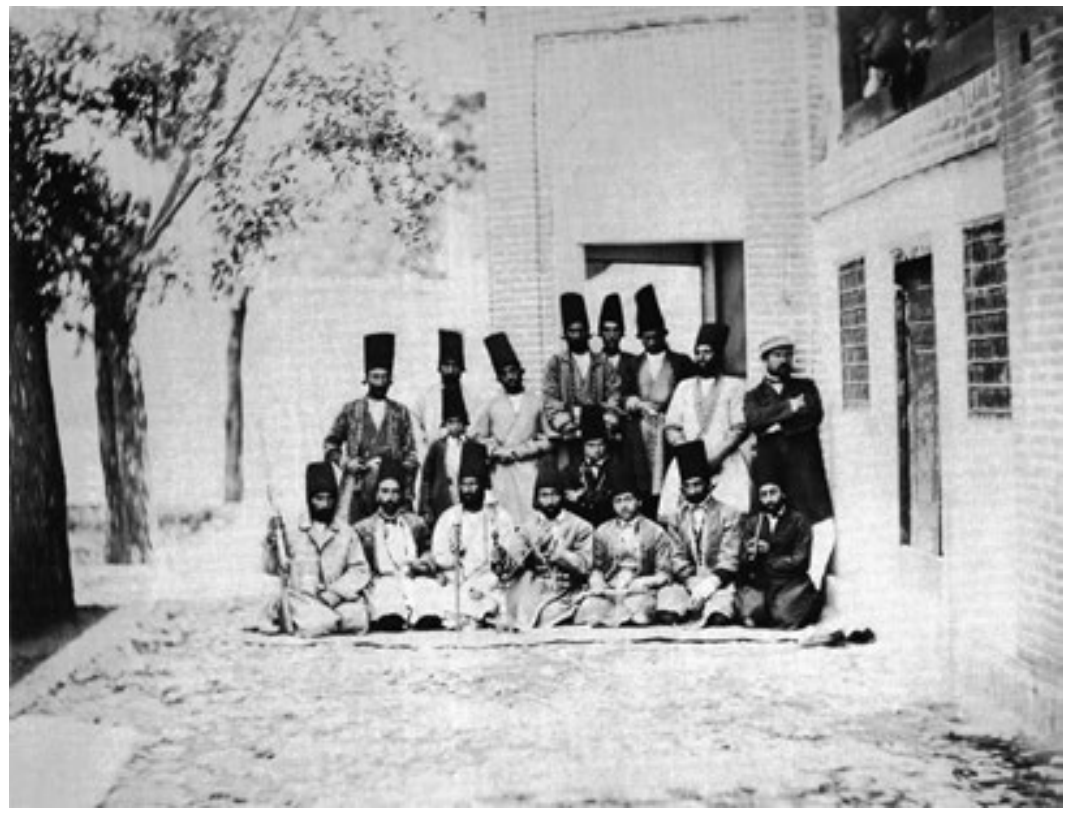

Figure 159 Luigi Montabone, Grandi personaggi di corte, c. 1862, albumen print, $24.1 \times 29.4 \mathrm{~cm}$, Royal Collections, The Hague, The Netherlands, inv. Nr. FA 0603-53. 


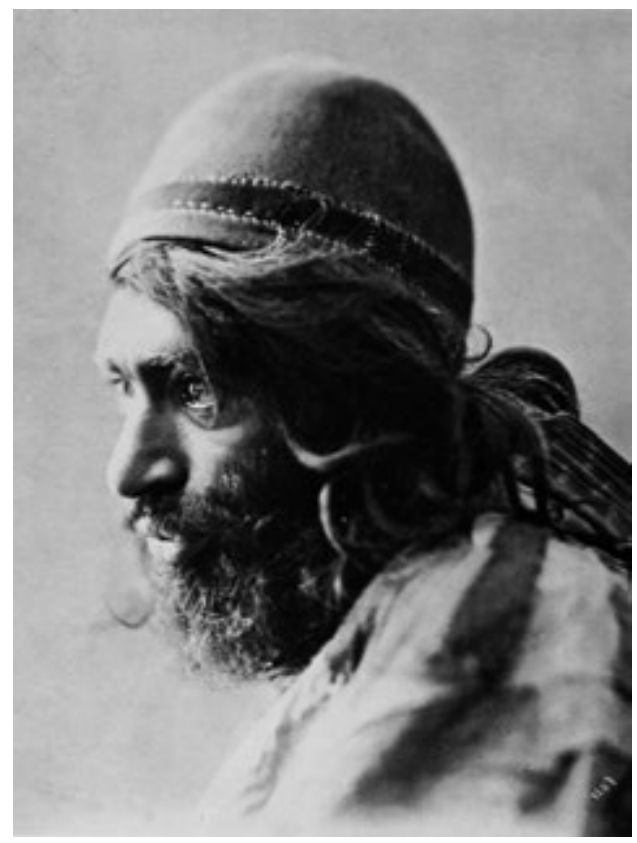

Figure 160 Antoin Sevruguin, dervish, c. 1880s, albumen print, private collection.

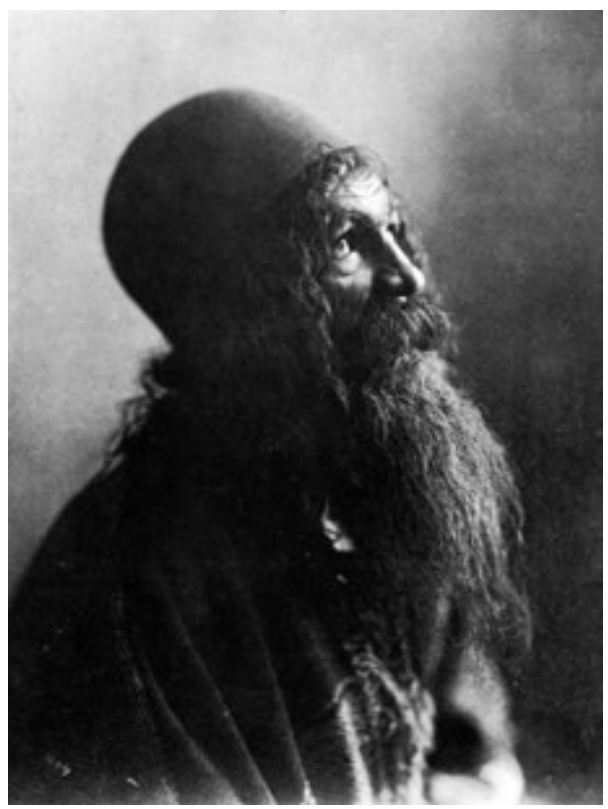

Figure 161 Antoin Sevruguin, dervish, c. 1880s, albumen print, private collection. 


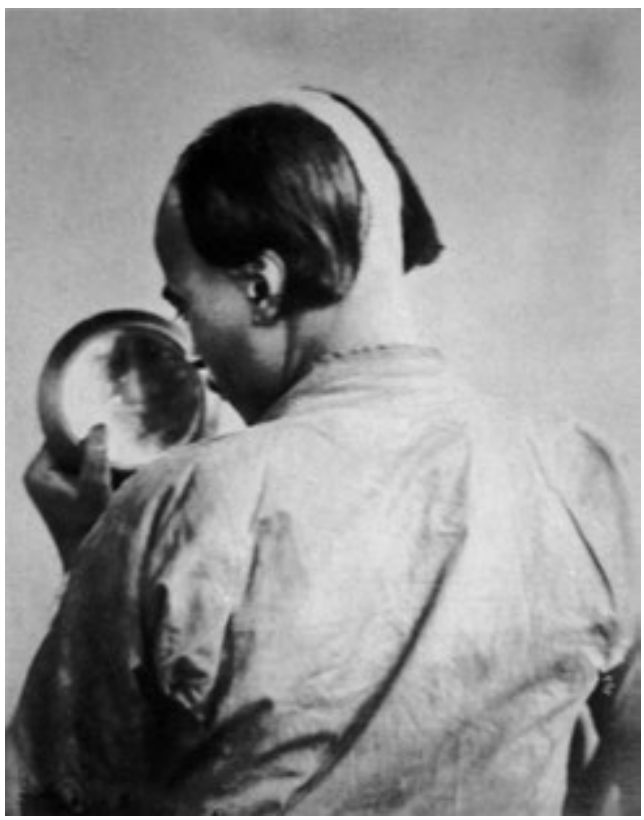

Figure 162 Antoin Sevruguin, The Persian Tonsure, c. 1880s, albumen print, Leiden University Library, Hotz 15:32.

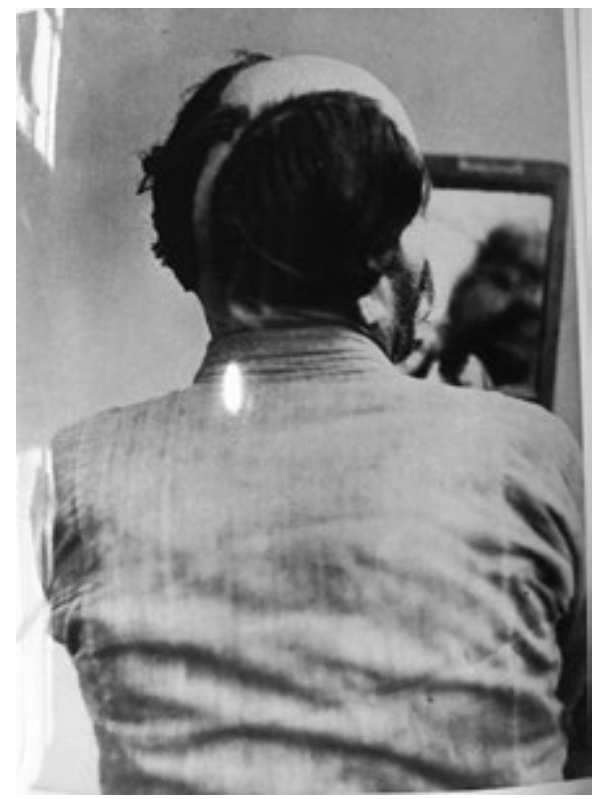

Figure ${ }_{163}$ Antoin Sevruguin, The Persian Tonsure, c. 1880s, albumen print, Ethnology Museum in Berlin. 


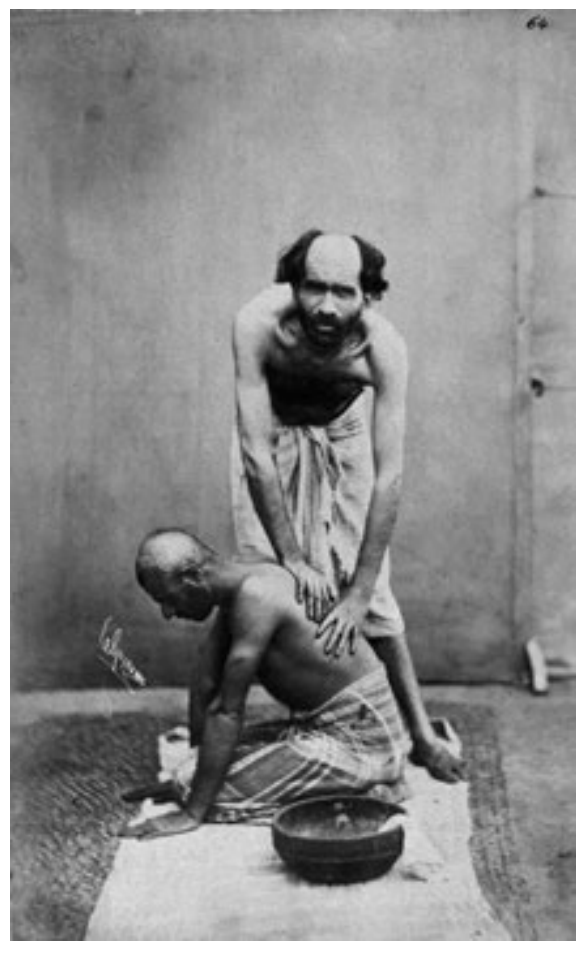

Figure 164 Antoin Sevruguin, massage, c. 1880 , albumen print, Museum of Ethnology, Zurich.

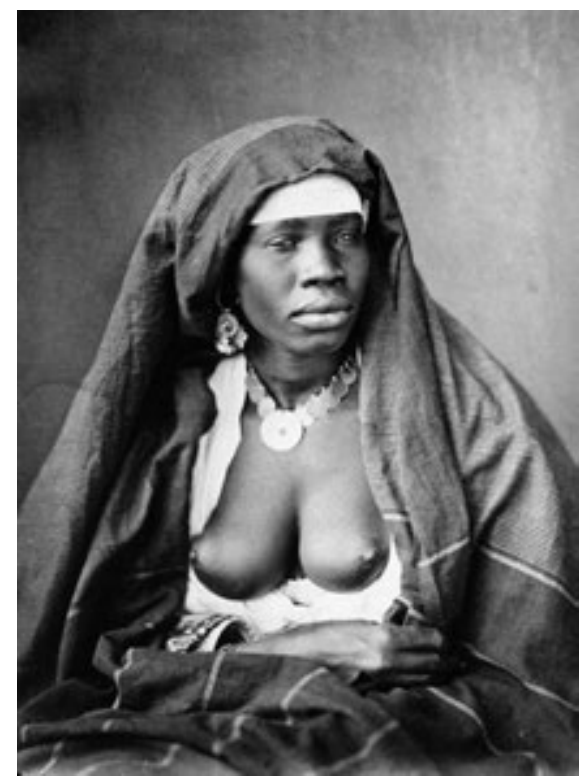

Figure 165 Abdullah Frères, untitled, c. 1880, taken from Pérez 1997: 106. 

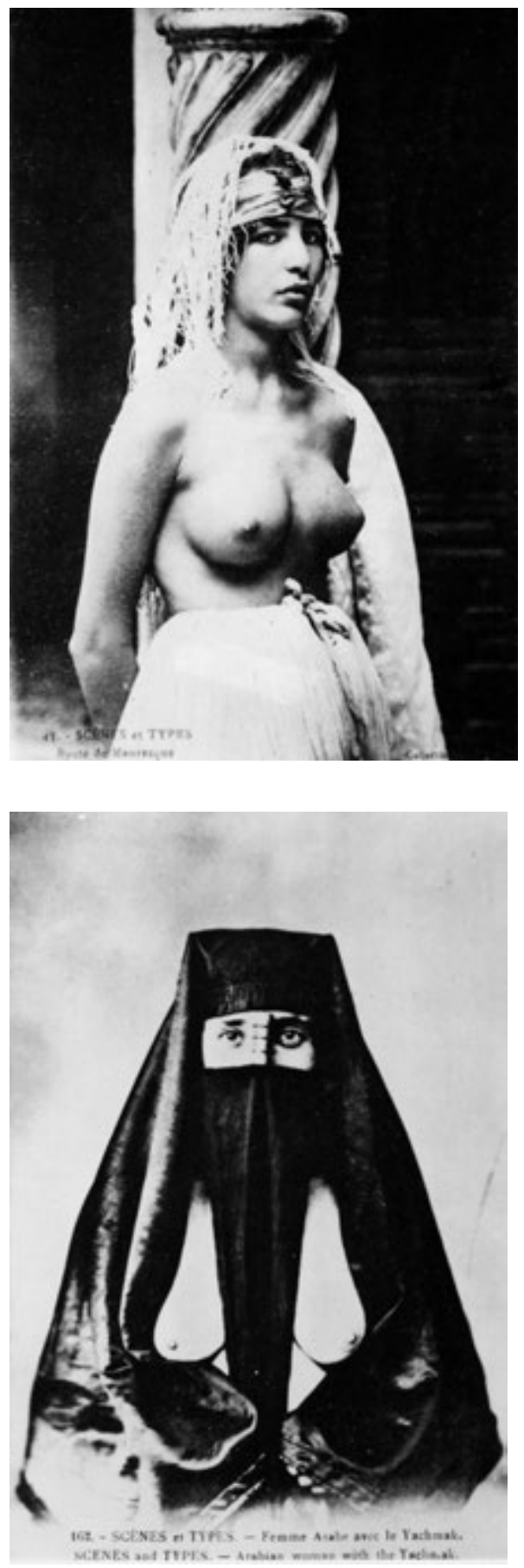

Figure 166 Scenes and types, Nr. 62, Moorish bust, postcard, taken from Alloula 1986: 123.
Figure ${ }^{167}$ Scenes and types, Nr. 162, Arabian woman with the Yachmak, postcard, taken from Alloula 1986: 126. 


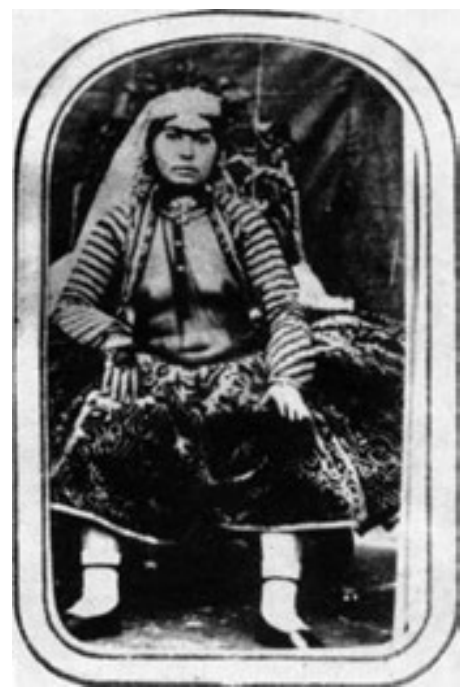

Figure 168 Nāser al-Din Shah, One of Nāser al-Din Shah's wife, date unknown, albumen print, Golestān Palace Library, Tehran, taken from Tahmasbour 2001: 45.

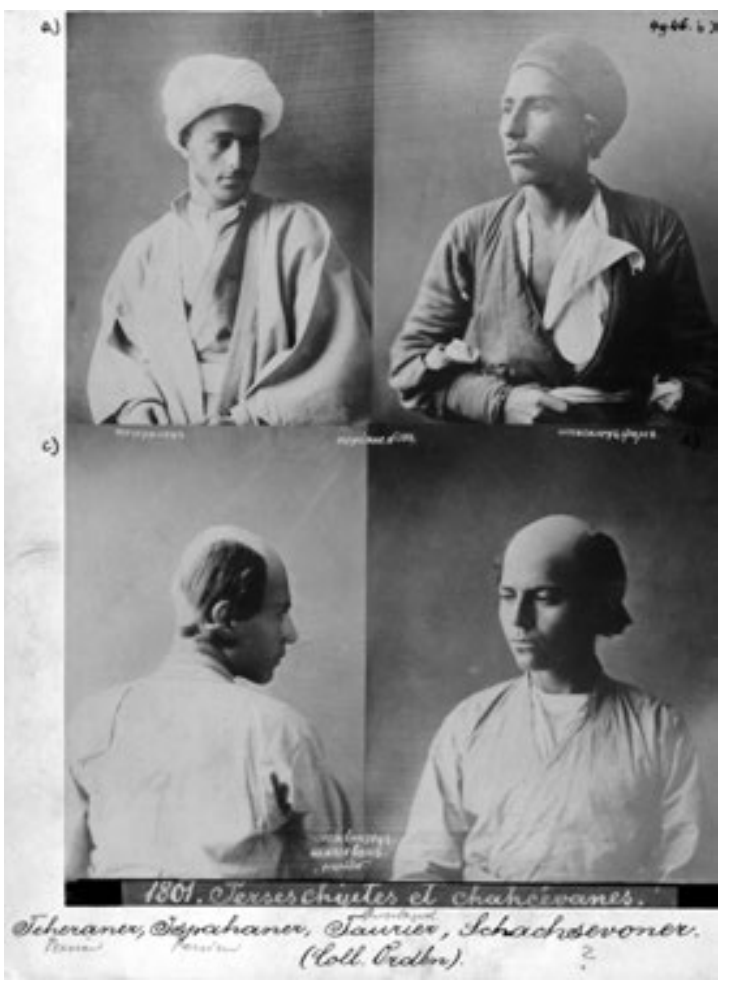

Figure 169 W. Ordén, $N^{\circ}$ 1801, Persian Shia, c. 1886, albumen print, $21 \times 16.4 \mathrm{~cm}$, Museum für Völkerkunde, Vienna, VF-4946. 


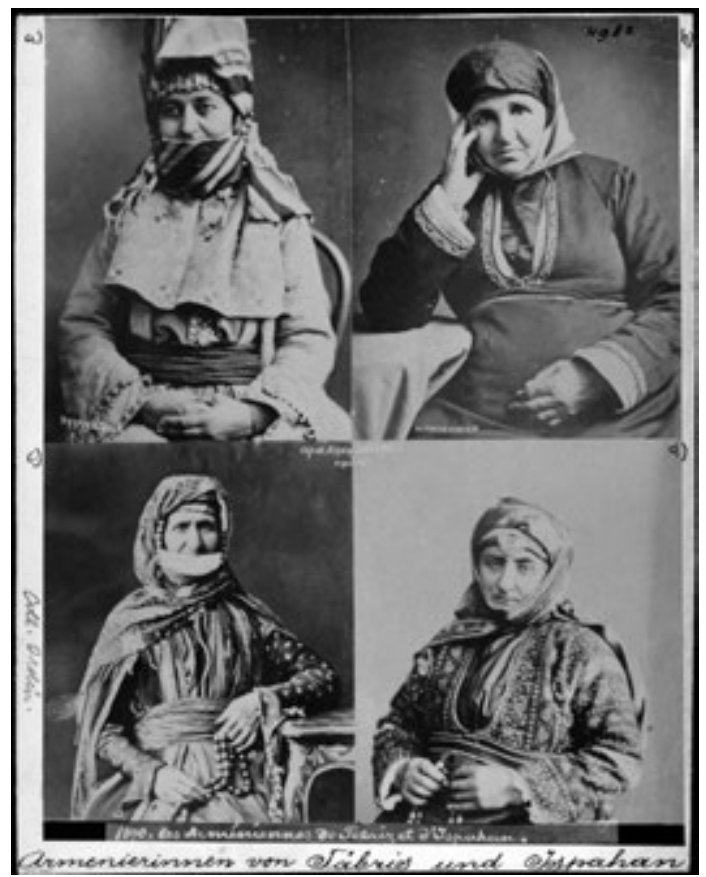

Figure 170 W. Ordén, $N^{\circ}$ 1890, The Armenians of Tabriz and Isphahan, c. 1886, albumen print, $21.5 \times 16.5 \mathrm{~cm}$, Museum für Völkerkunde, Vienna, VF-4983

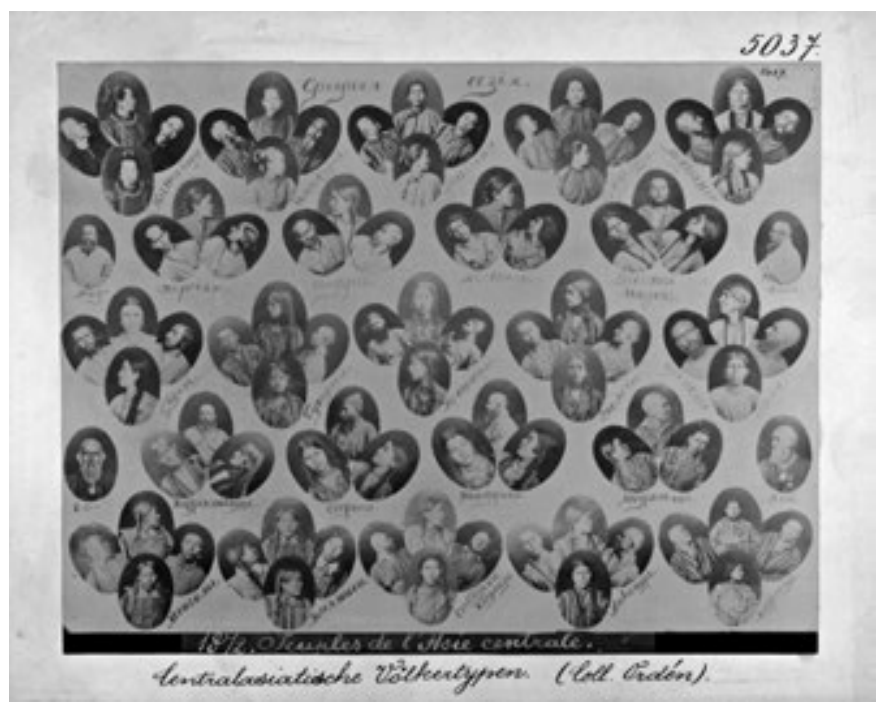

Figure 171 W. Ordén, $N^{\circ}$ 1872, Central Asia Types, c. 1886, albumen print, $21.5 \times 16.8 \mathrm{~cm}$, Museum für Völkerkunde, Vienna, VF-5037. 


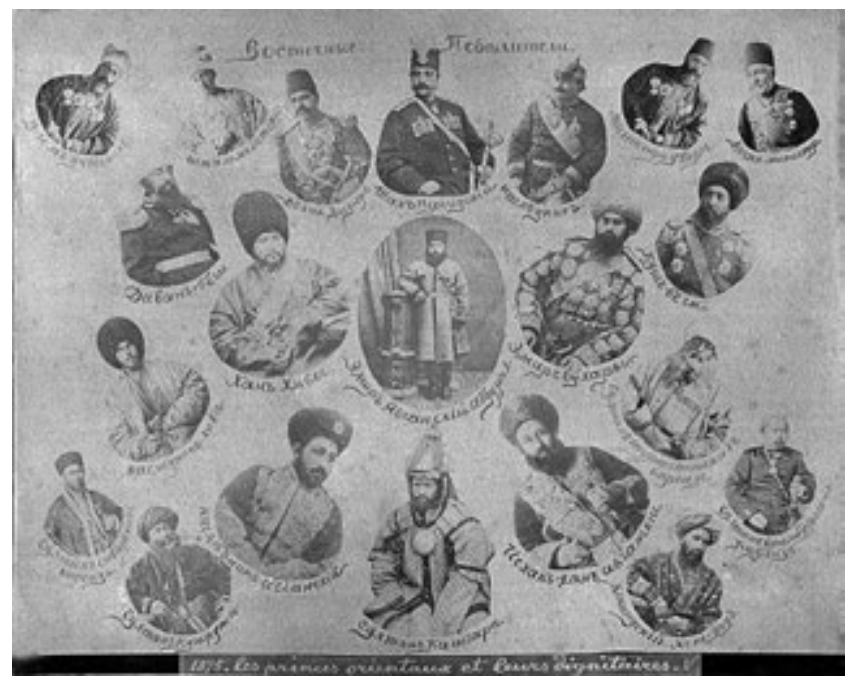

Figure $172 W$. Ordén, $N^{\circ} 1875$, The oriental princes and their dignataries, c.1886, albumen print, Anahita Gallery, Santa Fe, AG 2076.

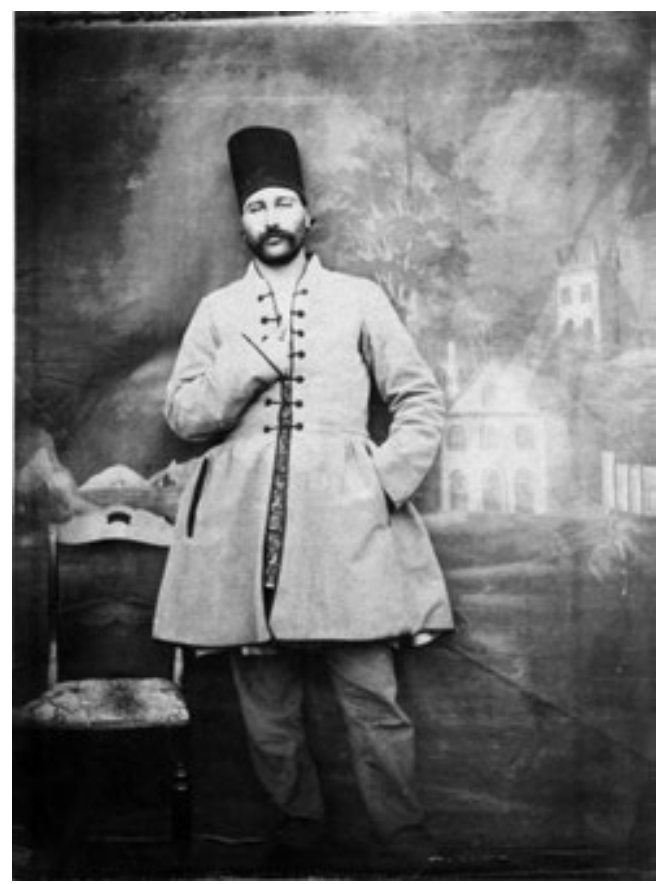

Figure 174 Rezā Akkāsbāshi, Sahhāfbāshi, date unknown, albumen print, $17.9 \times 13.4 \mathrm{~cm}$, Golestān Palace Library, Tehran, Album 189, Photo 29. 

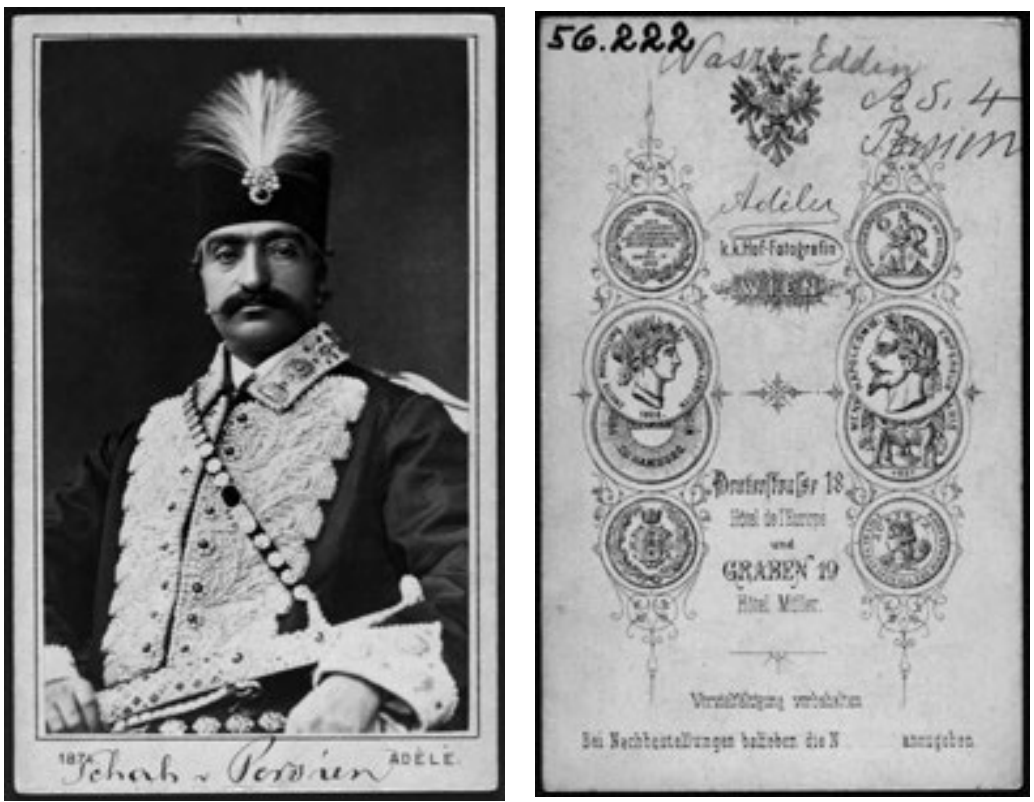

Figure 175 Adele Perlmutter, Nāser al-Din Shah, 1873, albumen print, $10.5 \times 6.5 \mathrm{~cm}$, Museum für Völkerkunde, Vienna, VF 56222.

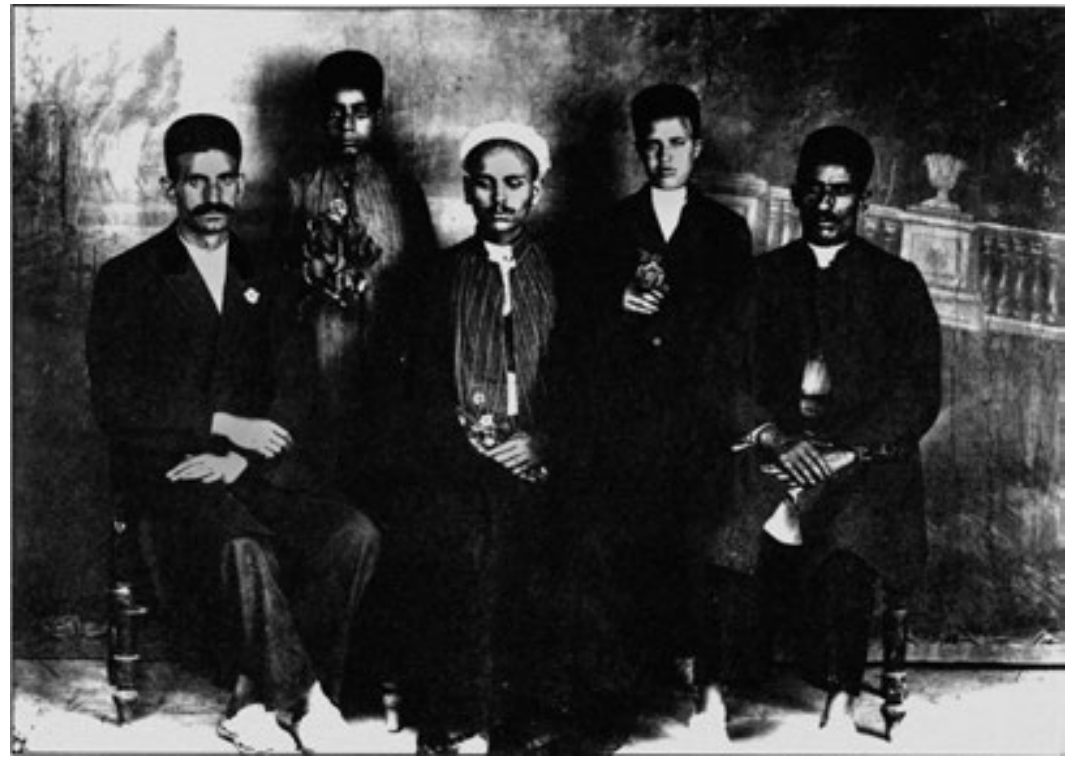

Figure 176 Mirzā Mehdi Khān Chehreh-Namā, group portrait, c. 1910s, albumen print, $9 \times 12 \mathrm{~cm}$, Parisa Damandan Collection. 


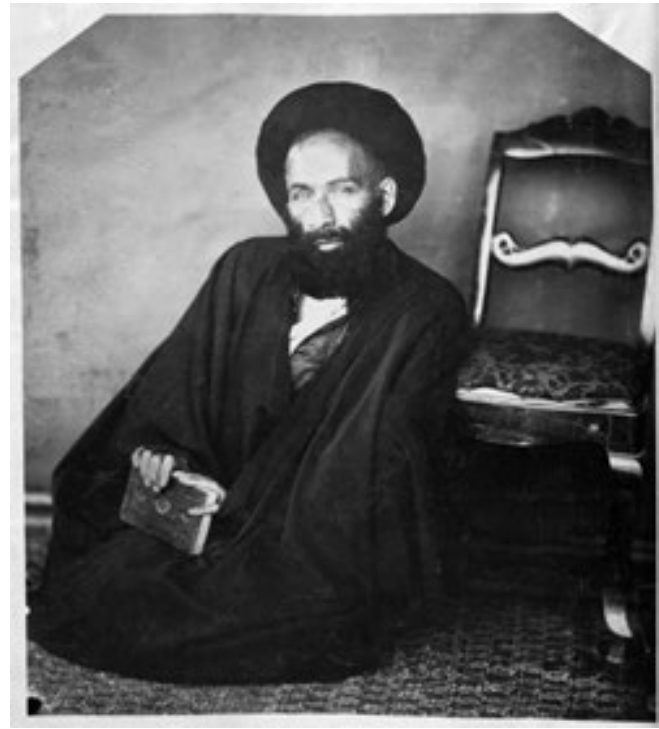

Figure 177 Ali Khān Vali Hākem, Seyped Ali Darvandi, c. 1880-90, albumen print, courtesy of Special Collections, Fine Arts Library, Harvard University.

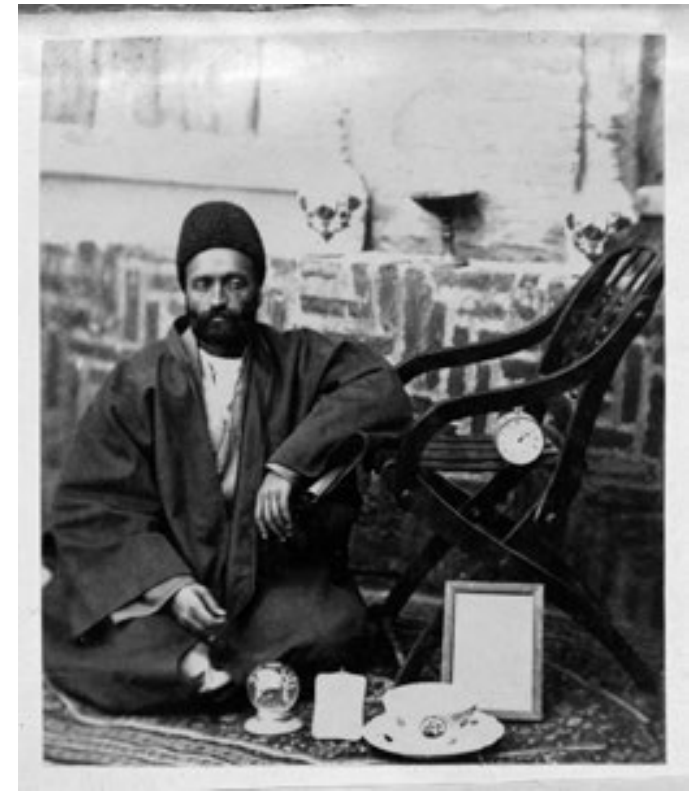

Figure 178 Ali Khān Vali Hākem, Mirzā Mohammad Sādeq Sāhebnaqsh, c. 1880-90, albumen print, courtesy of Special Collections, Fine Arts Library, Harvard University. 


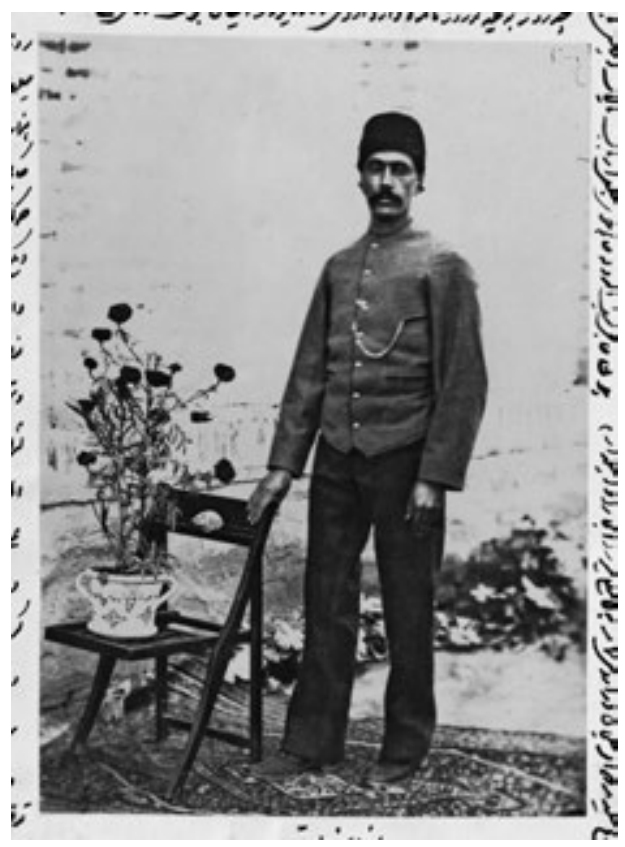

Figure 179 Ali Khān Vali Hākem, Mirzā Ali Khān Sartip, c. 1880-90, albumen print, courtesy of Special Collections, Fine Arts Library, Harvard University.

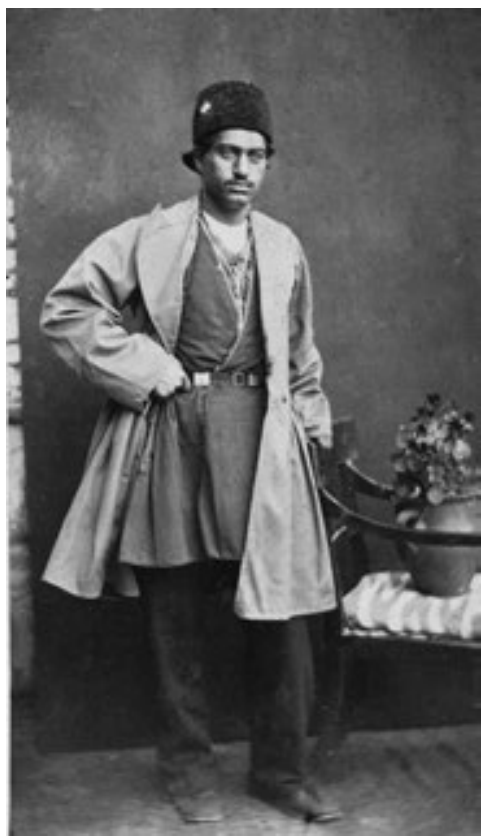

Figure 180 Ali Khān Vali Hākem, Ali Āqā Akkās, c. 1880-90, albumen print, courtesy of Special Collections, Fine Arts Library, Harvard University. 


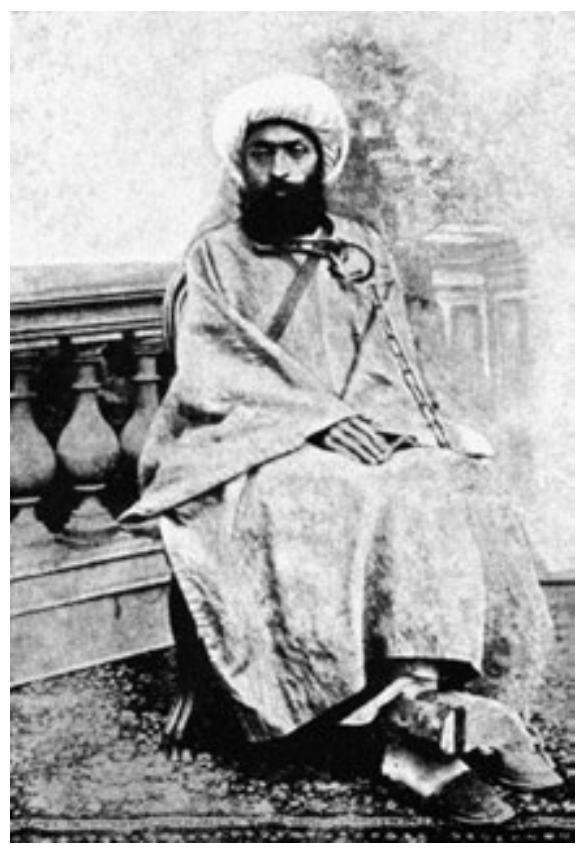

Figure 181 Mohammad Hasan Qajar, Hajji Mirzā Ahmad Kermāni, c. 1890 , albumen print, taken from Afshar 1992: 106.

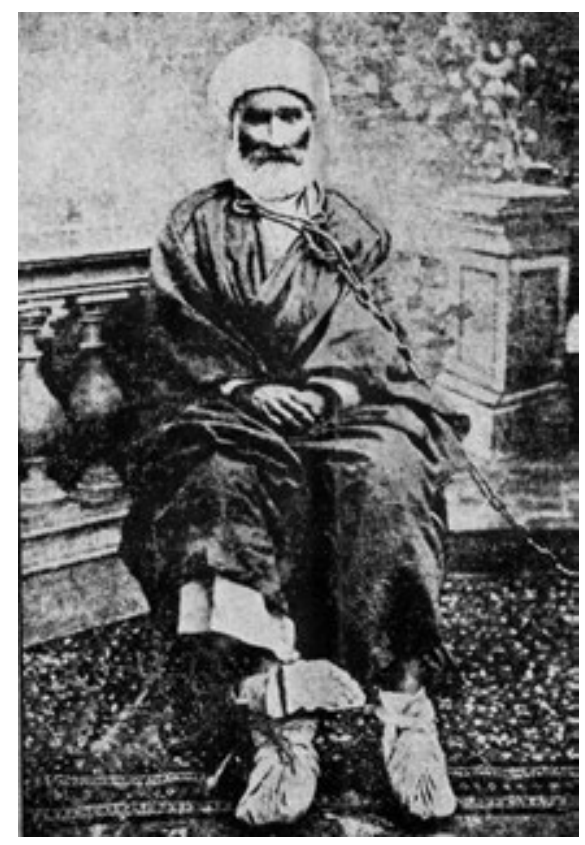

Figure 182 Mohammad Hasan Qajar, Hajji Mohammad Ali Sayyāh Mahalāti, c. 1890, albumen print, taken from Afshar 1992: 106. 

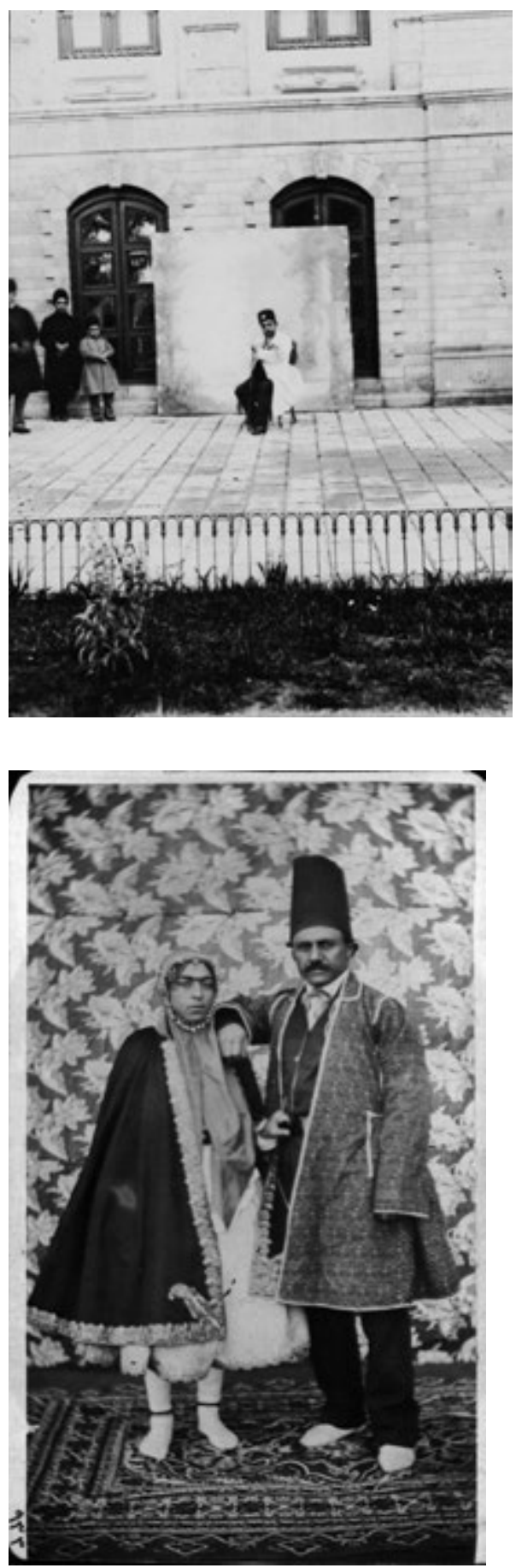

Figure 183 Unknown court photographer, Mozaffar al-Din Shah, c. 1900, albumen print, Golestān Palace Library, Tehran.
Figure 184 Unknown photographer, couple in studio, date unknown, albumen print, University Library, Tehran. 



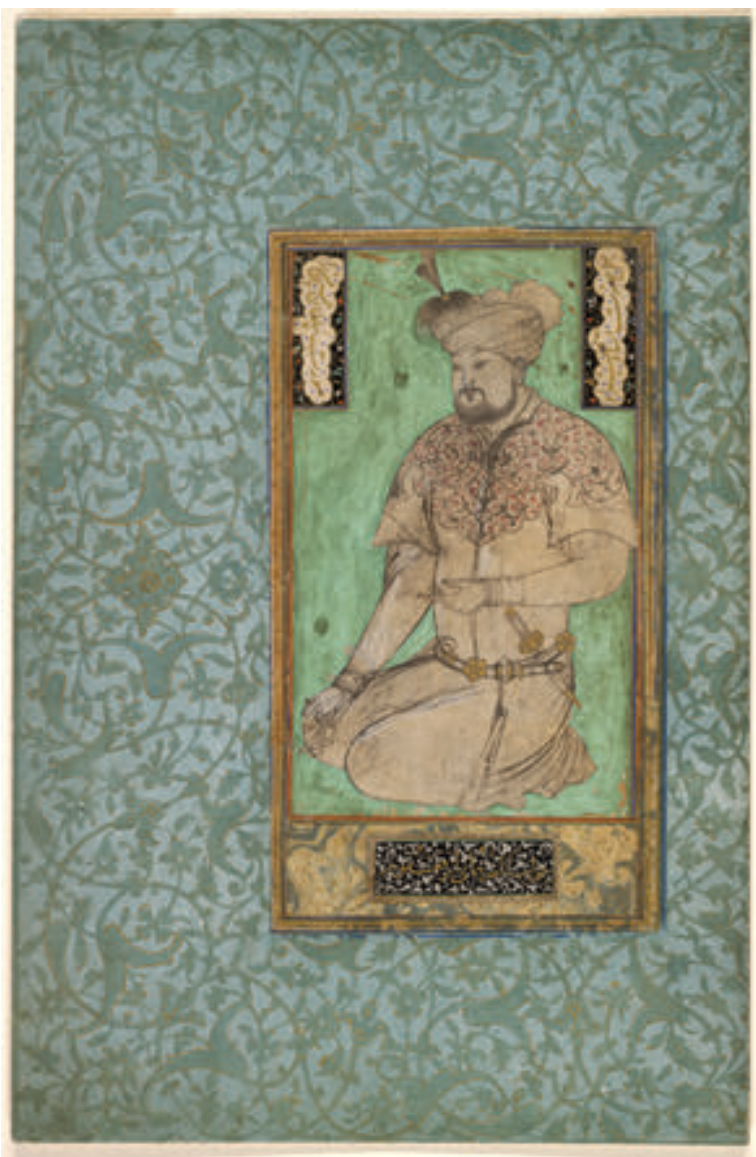

Figure 53 Attributed to Bihzad, portrait, Sultān-Hoseyn Mirzā. Folio from a manuscript, c. 1500-1525. Ink, color and gold paper; folio: $34.3 \times 37.2 \mathrm{~cm}$, Arthur M. Sackler Museum. Gift from John Goelet, formerly in the collection of Louis J. Cartier, 1858.59. Photo: Imaging Department @ President and Fellows of Harvard College. 


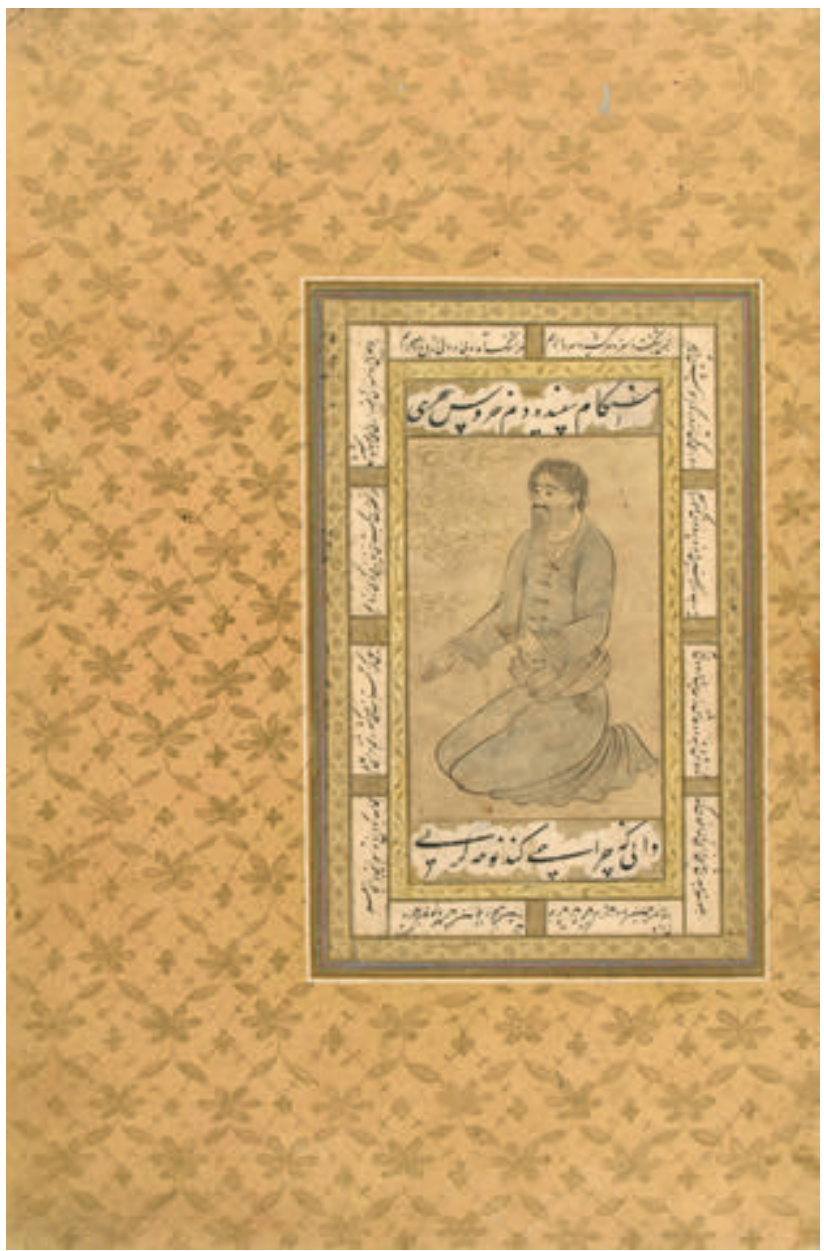

Figure 54 Seated figure holding a cup, mid 17th century, colour wash and ink on paper, $H \times W: 35.9 \times 23.5 \mathrm{~cm}$ (14 1/8 $\times 9 \frac{1}{4}$ in), Arthur M. Sackler Gallery, Smithsonian Institution, Washington, D.C.: Bequest of Adrienne Minassian, S1998.17. 


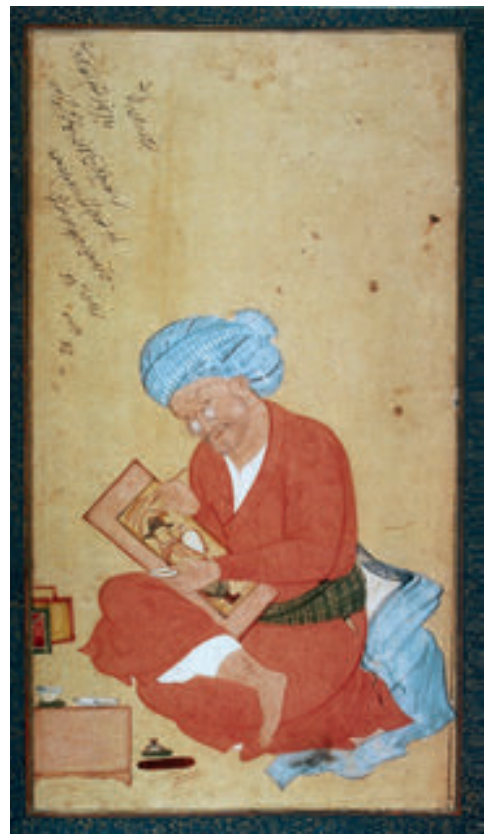

Figure 56 Mo'in Mosavvar, RezāAbbāsi painting a picture of a European man, started 1635 and finished 1673, Robert Garret Collection of Islamic Manuscripts, No 96 G, Manuscripts Division, Department of Rare Books and Special Collections, Princeton University Library, H: 18,8 cm x W: 10,4 cm.

Figure 62 Prince Mohammad Ali Mirzā Dowlatshāh, Jafar, oil on canvas, $1820, H \times W$ (overall): $208 \times 107$ $\mathrm{cm}(817 / 8 \times 421 / 8 \mathrm{in})$, The Art and History Collection, courtesy of the Arthur M. Sackler Gallery, Smithsonian Institution, LTS2003.1.9.

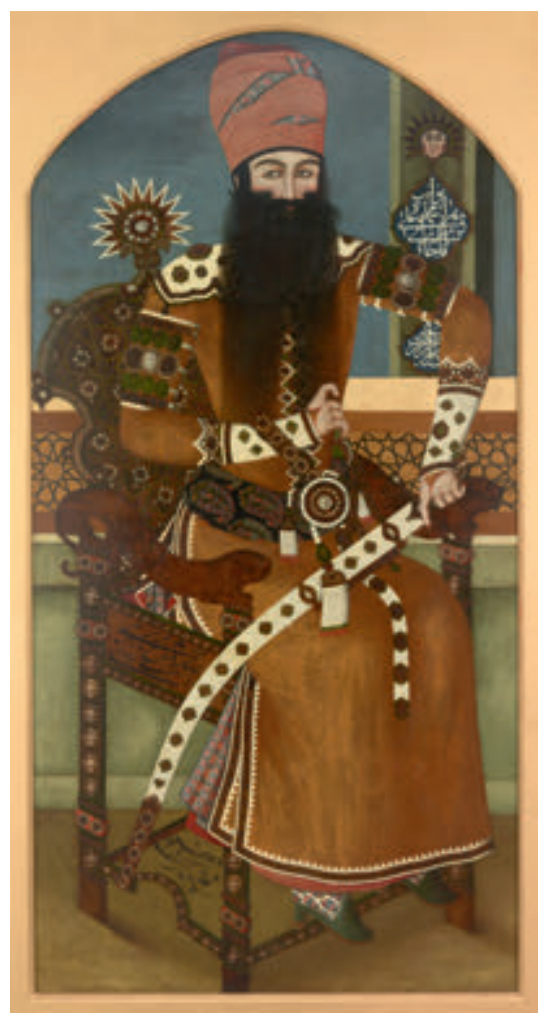




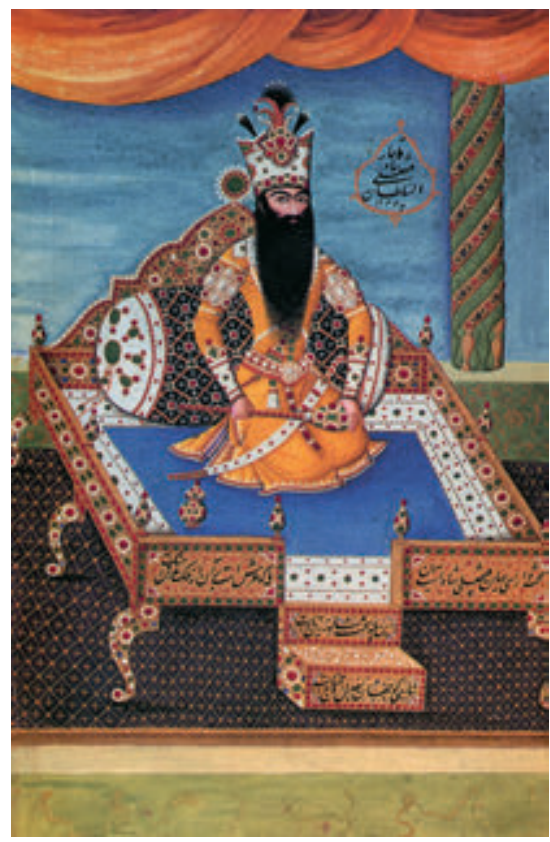

Figure $6_{3}$ Artist unknown, Fath Ali Shah seated on the Sun Throne, Tehran, 18th century, Collection of Prince Sadruddin Agha Khan, Geneva.

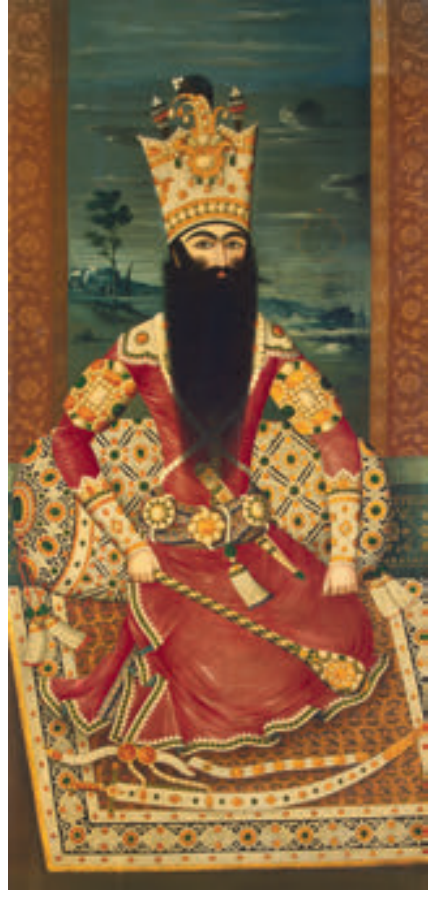

Figure $6_{4}$ Signed by Mehr Ali, Portrait of Fath Ali Shah Seated, 1813-14, oil on canvas, $253 \times 118 \mathrm{~cm}$, State Hermitage Museum, St Petersburg, VR-1108. Photograph (C) The State Hermitage Museum. Photo by Vladimir Terebenin, Leonard Kheifets, Yuri Molodkovets. 

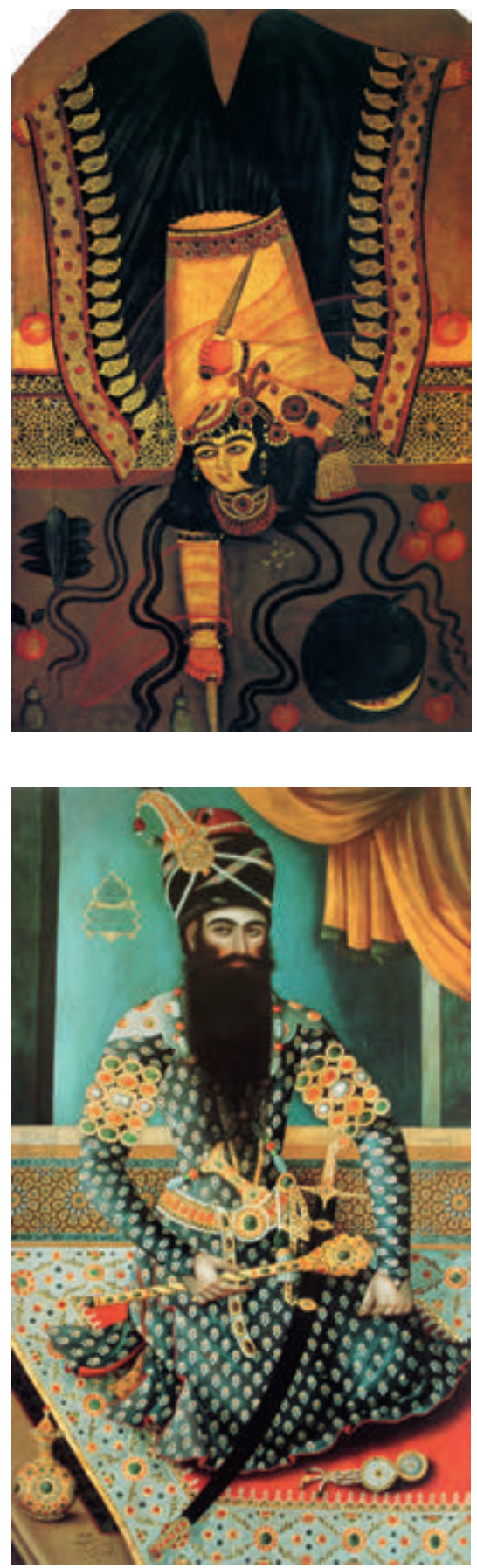

Figure 73 A girl acrobat balancing on a knife, c. 1840, Shirin painter, 127 × $80 \mathrm{~cm}$, Amery Collection (Museum of Art in Tehran), taken from Falk 1973: plate 43.

Figure 86 Fath Ali Shah, oil on canvas. Tehran 1798-99. London, Oriental and India Office Library Collections, Foster 116. 


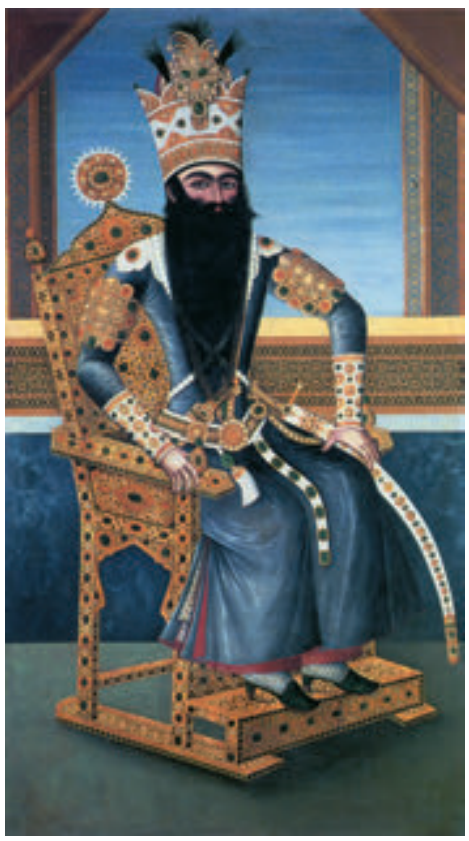

Figure 87 Attributed to Mehr Ali, Fath Ali Shah Seated on a Chair Throne, Tehran, circa 1800-1806, Oil on canvas: $227,5 \times 131 \mathrm{~cm}$, Musée du Louvre, Paris, Section Islamique, on loan from the Musée National de Versailles, $M V G_{3} 8$.

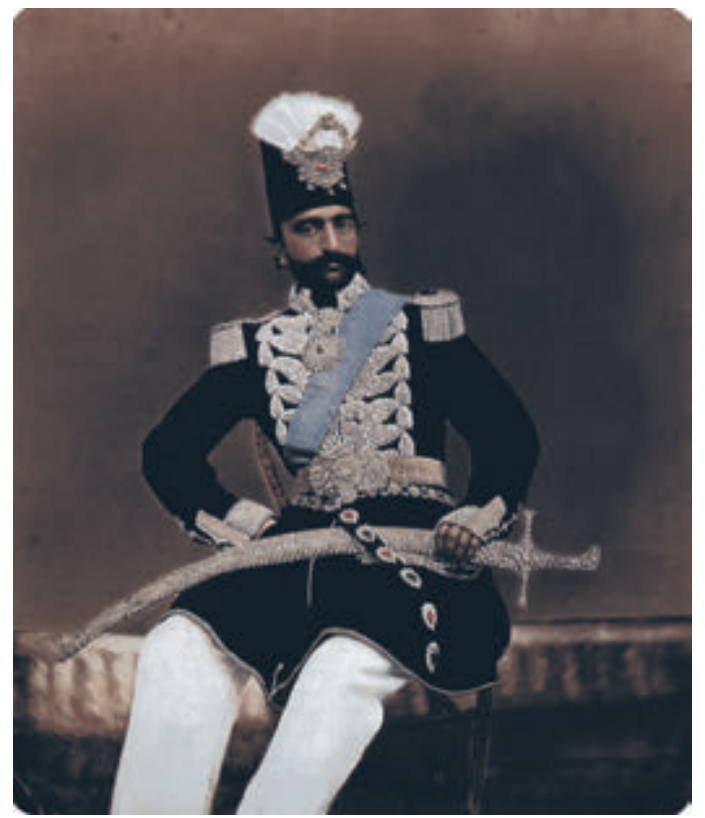

Figure 96 Luigi Montabone, portrait of Nāser al-Din Shah, three quarter length, sitting with sword, c. 1862, hand-colored albumen, $30.1 \times 24.0 \mathrm{~cm}$, Royal Collections, The Hague, The Netherlands, inv. Nr. 0603-03 


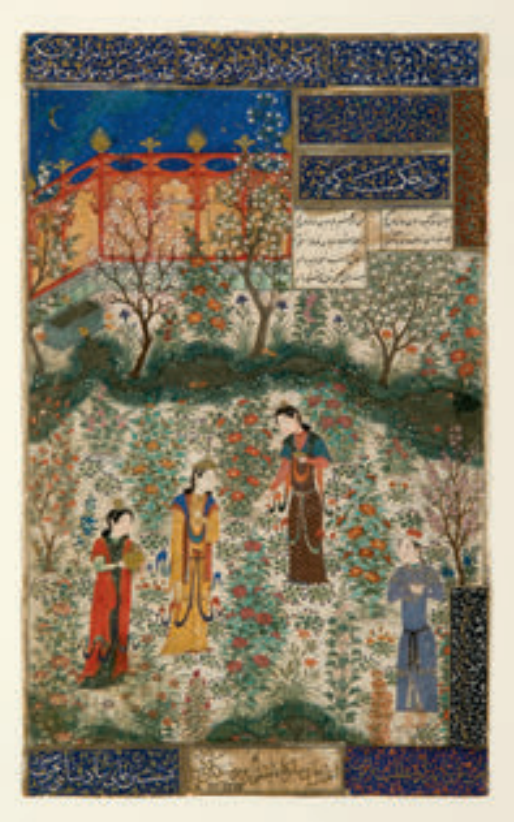

Figure 120 Humāy and Humāyun Meeting in a Garden, ca. 1430-40, Miniature from a manuscript of the Khamse of Khwāju Kirmāni, Musée des Arts Décoratifs, Paris, Inv. 3727.

Photograph (C) Musée des Arts Décoratifs. Photograph by Jean Tholance.
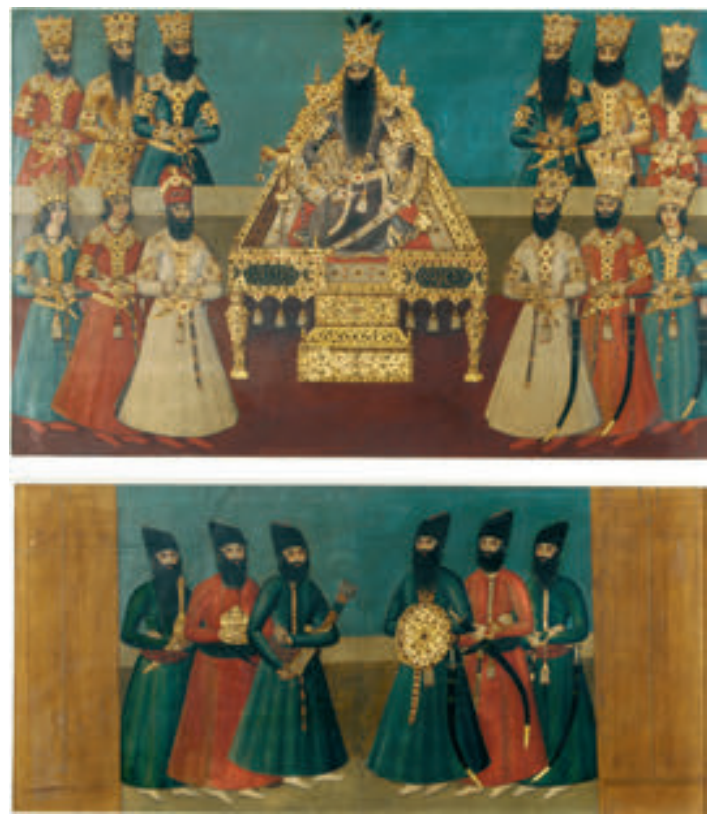

Figure 121 Artist unknown, The court of Fath Ali Shah, c. 1815, Opaque watercolor and gold on paper. Central panel Go $\times 52 \mathrm{~cm}$, the Art Q History Trust, courtesy of the Arthur M. Sackler Gallery, Smithsonian Institution, LTS 1997.5.1-3. 


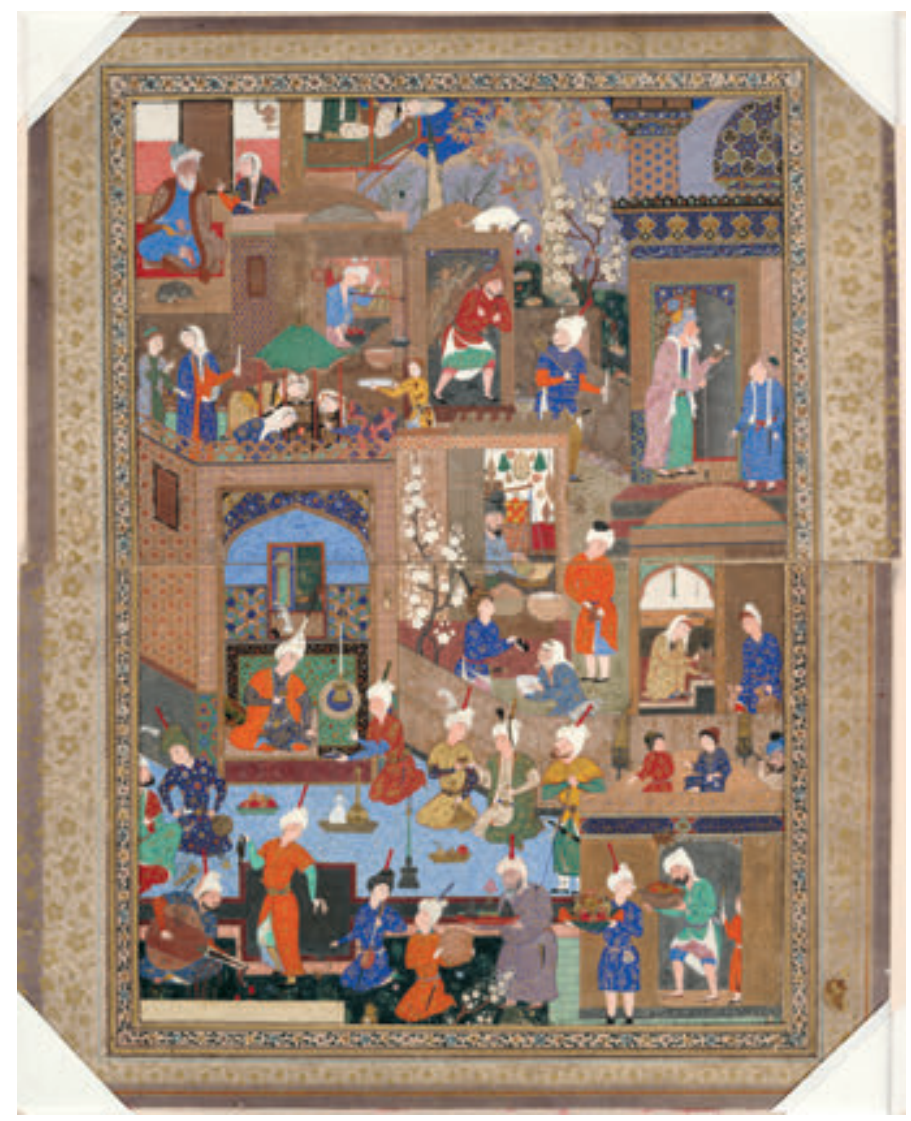

Figure 122 Unknown artist, Nighttime in a Palace, probably a folio from a manuscript, c. 1540, opaque watercolor, gold and silver on paper; image: $28.6 \times 20 \mathrm{~cm}$ (11 1/4 $x 77 / 8$ in.), Harvard Art Museums/ Arthur M. Sackler Museum.

Gift of John Goelet, formerly in the collection of Louis J. Cartier, 1958.76. Photo: Katya Kallsen@President and Fellows of Harvard College. 


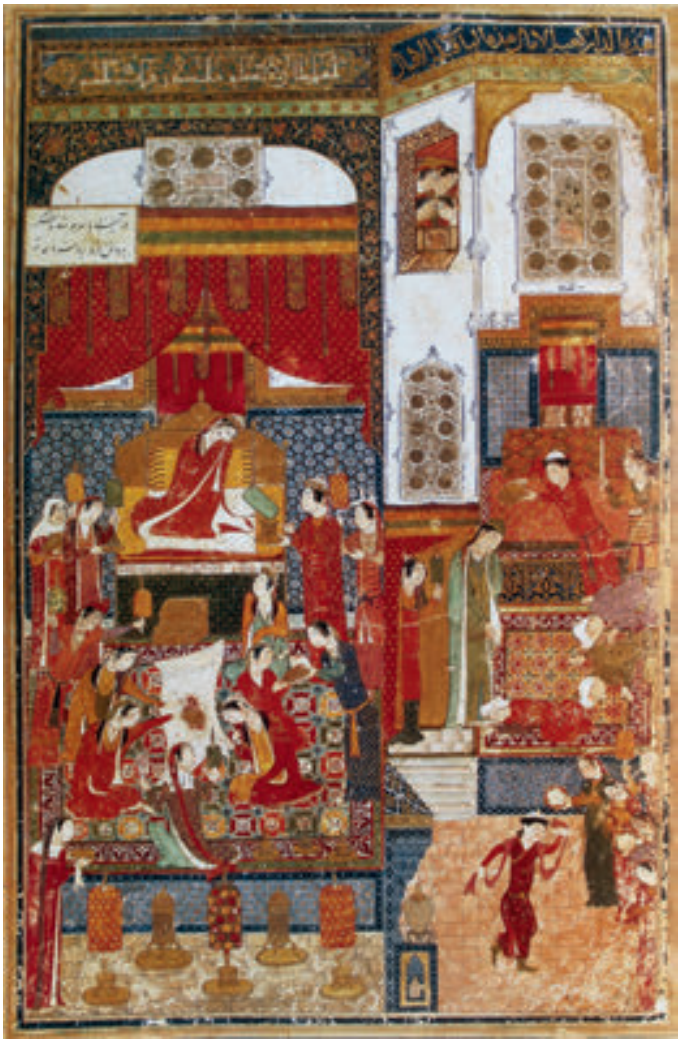

Figure 123 Joneyd Naqqāsh Sultāni, Wedding Celebration of Prince Homāy and Princess Homāyun, from Divān by Khwāju Kirmāni, 1396, British Library, London, (fol. 45v; Add. 18113). 


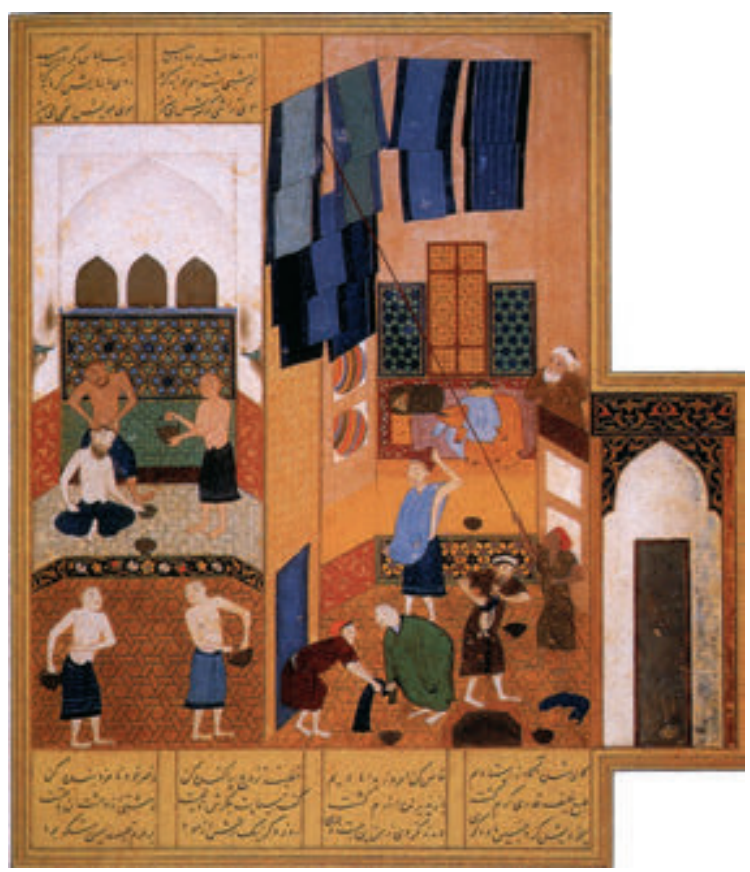

Figure 124 Behzād, Hārun al-Rashid in a Bathhouse, from a Khamse by Nezāmi, The British Library, 1494, London (fol. 27 v; Or. 6810).

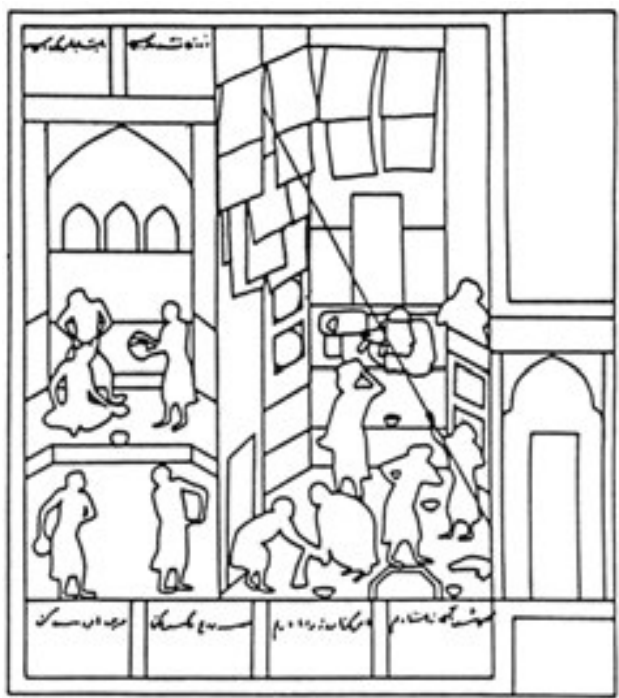

Figure 125 Design schema of fig. 124, after Zain. 

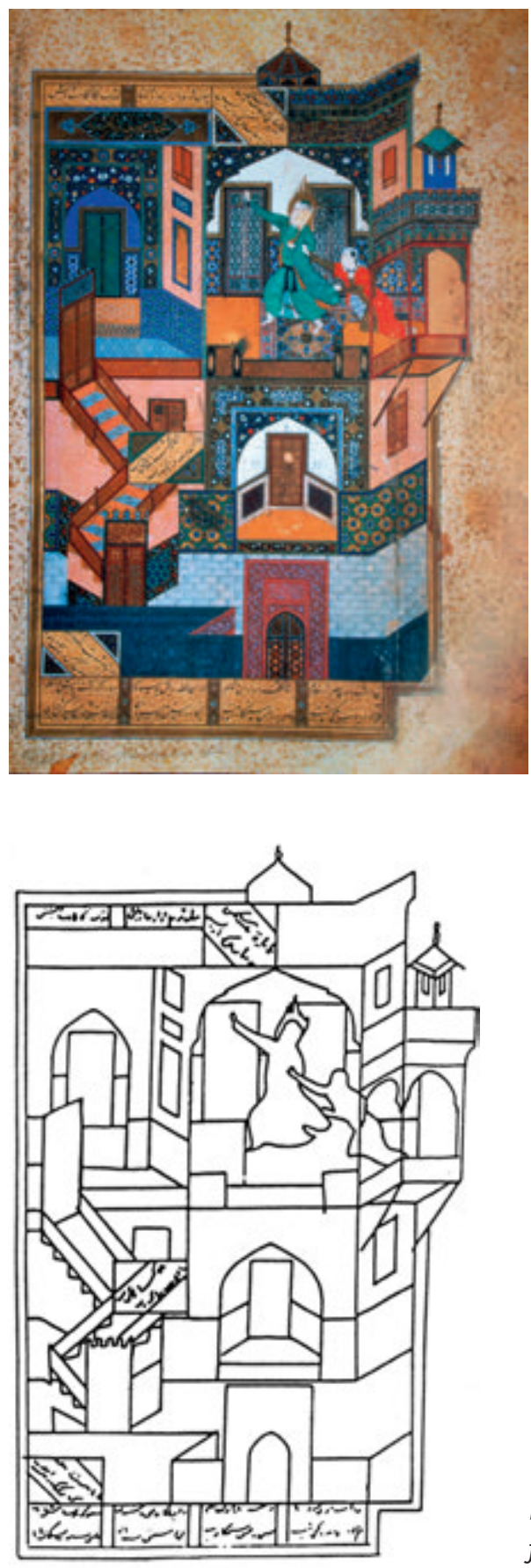

Figure 126 Behzād, Zoleykhā attempts to seduce Yusof, from a Bustān by Sa'di, Cairo, National Library (General Egyptian Book Organization), Abad Farsi, 908, fol. $52 \mathrm{v}$, Heart, $\mathrm{H}: 25.4 \mathrm{~cm}$; $W: 15.8 \mathrm{~cm}$.
Figure 127 Design schema of fig. 126, after Zain. 

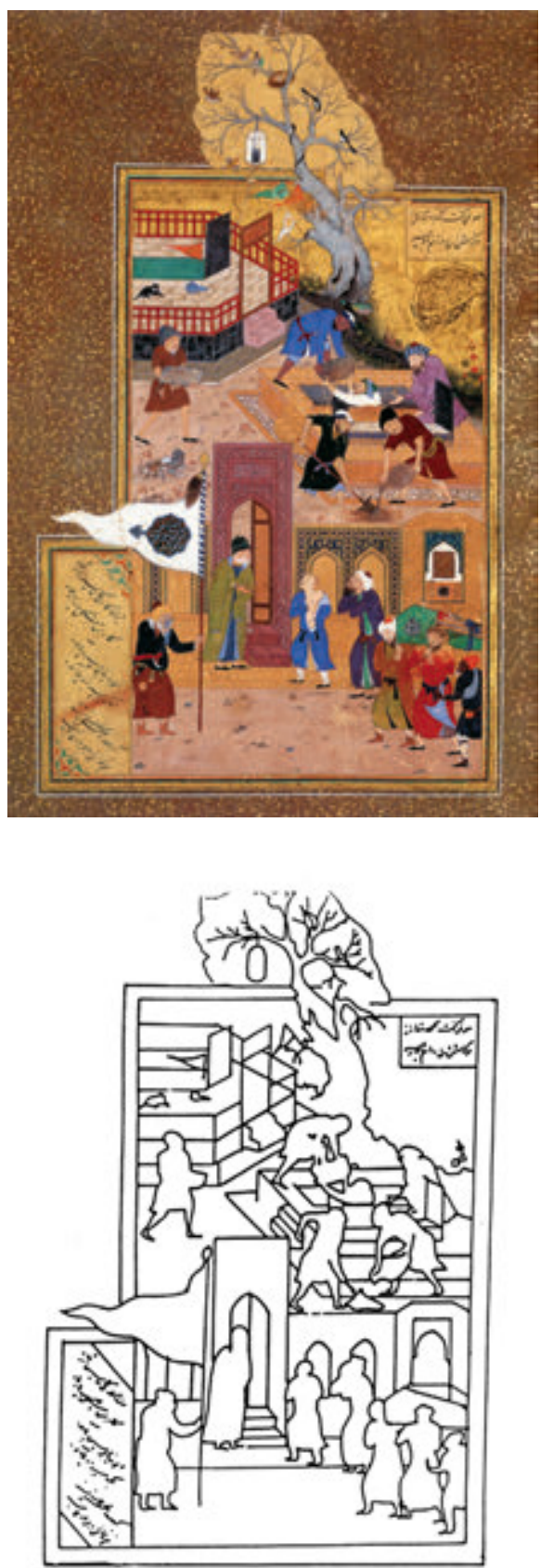

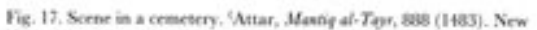
Veek, Metropolitas Mturven of Ant. 63.210.35, fol. 33a. Schrma of design. (Alier Zain)
Figure 128 Funeral Procession, attributed to Behzād, from Mantiq al-teyr (The Language of the Birds) by Attar, 1483, The Metropolitan Museum of Art, NY, Fletcher Fund, 1963 (fol. 35; 63.210.35).
Figure 129 Design schema of fig. 128, after Zain. 


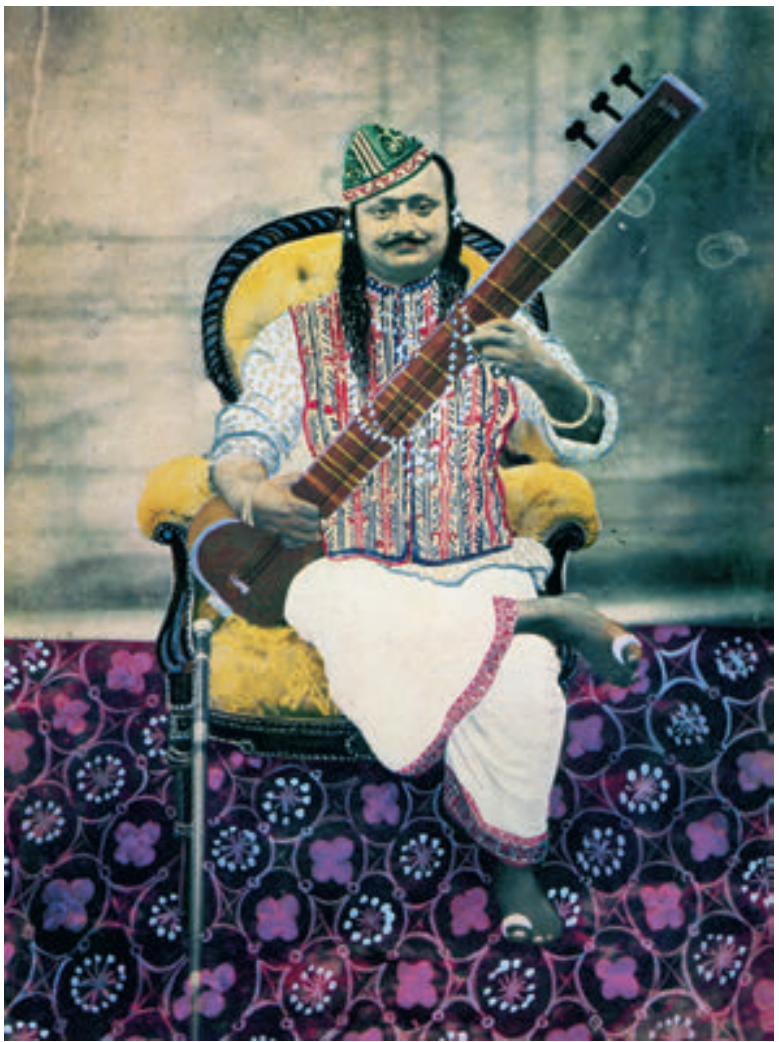

Figure 142 Photographer and painter unknown, Landowner who loves music, ca. 1885, albumen, opaque watercolour, 22kt. Gold; Alkazi Collection of Photography, New Delhi, India.

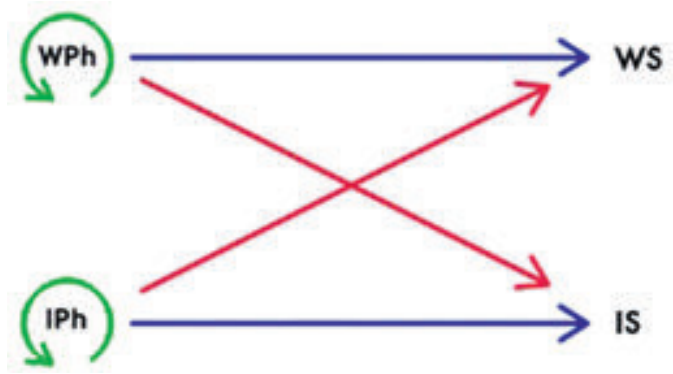

Graphic 1 Schema of positions sitter versus photographer in studio portrait photography. Elaborated by the author. 


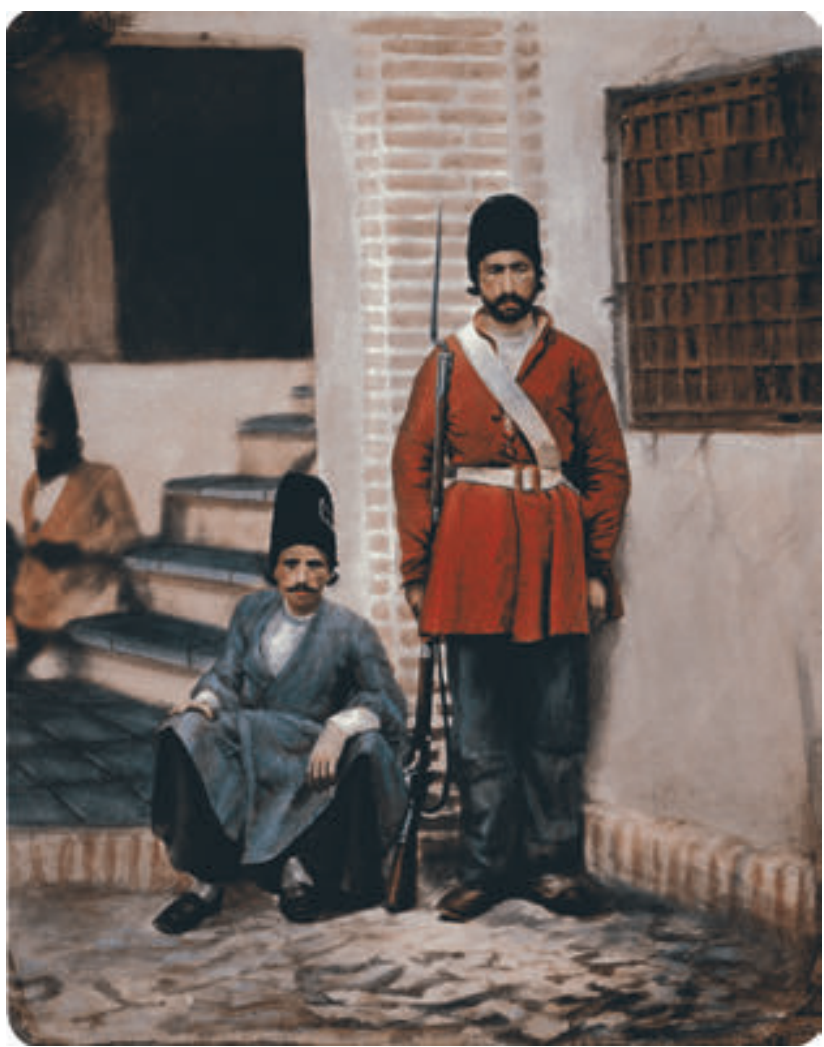

Figure 155 Luigi Montabone, Soldati Persiani, c. 1862, hand-colored albumin print, $25.0 \times 20.0 \mathrm{~cm}$, Royal Collections, The Hague, The Netherlands, inv. FA Nr. 0603-54. 

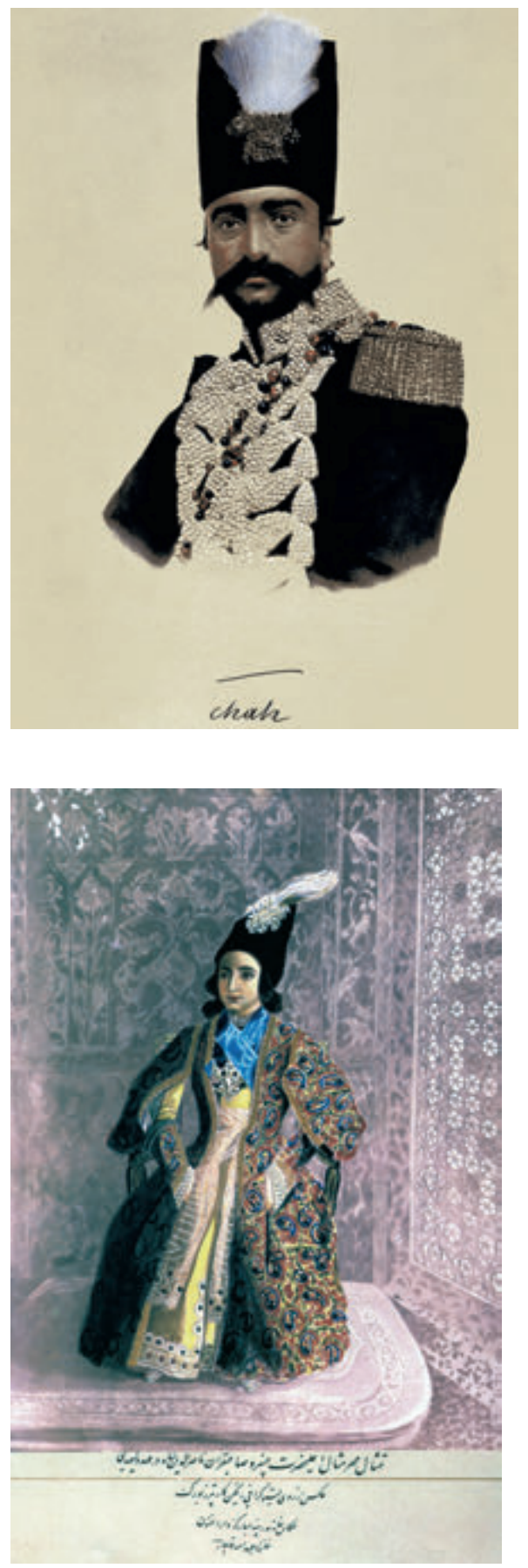

Figure 156 Luigi Montabone, Nāser al-Din Shah, c. 1862, hand-colored albumen print, sheet: $36.7 \times 27.6 \mathrm{~cm}$, image only: $19.3 \times 11.5 \mathrm{~cm}$, Royal Collections, The Hague, The Netherlands, inv. Nr. FA o603-02.

Figure 173 Abdollāh Mirzā Qajar, Nāser al-Din Mirza, c. 1886 , albumen print, $24.1 \times 18.5 \mathrm{~cm}$, lithography hand-overpainted (from an earlier photograph), Golestān Palace Library, Tehran, Album 1142, Photo 7. 


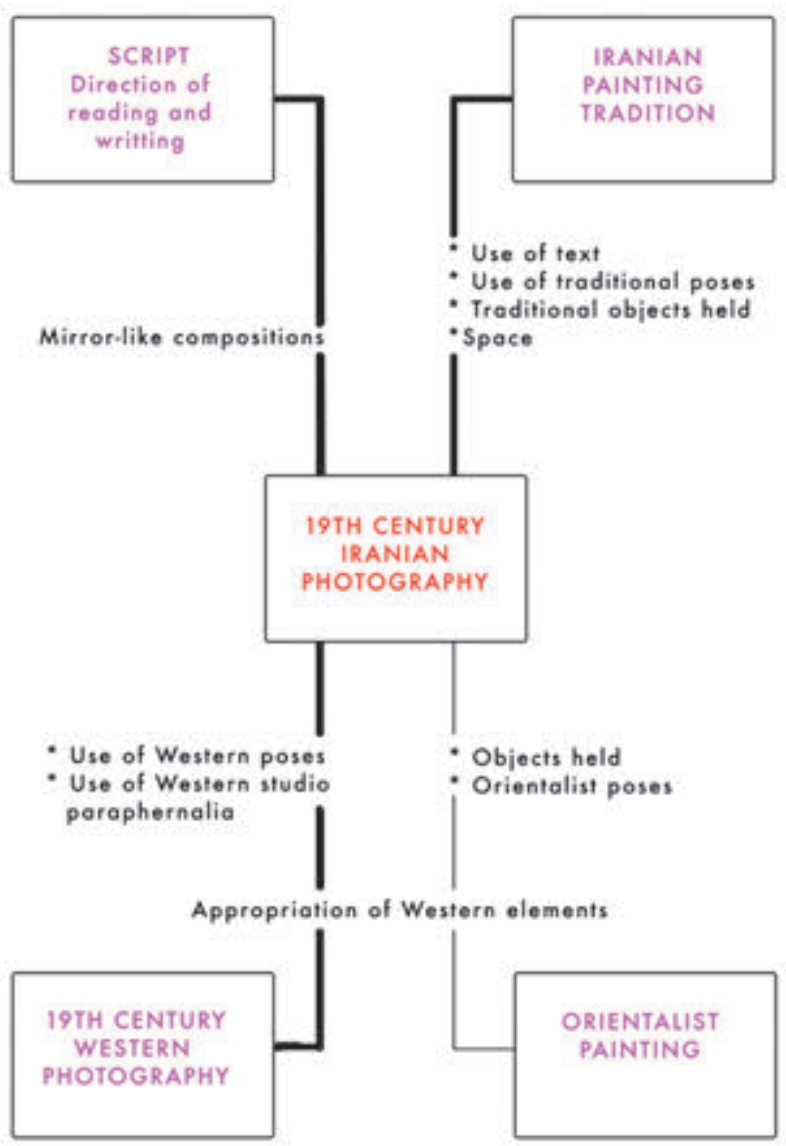

Graphic 2 Schema 


\title{
Backlist Iranian Studies Series:
}

J.C. Bürgel \& C. van Ruymbeke (eds.)

Nizami: A Key to the Treasure of the Hakim

ISBN 9789087280970

\section{J. Coumans}

The Rubáiyát of Omar Khayyám. An Updated Bibliography

ISBN 9789087280963

F. Lewis \& S. Sharma (eds.)

The Necklace of the Pleiades. 24 Essays on Persian Literature, Culture and Religion

ISBN 9789087280918

\section{A. Sedighi \\ Agreement Restrictions in Persian \\ ISBN 9789087280932}

\section{A.A. Seyed-Gohrab \\ Courtly Riddles. Enigmatic Embellishments in Early Persian Poetry \\ ISBN 9789087280871}

\section{A.A. Seyed-Gohrab \\ The Great 'Umar Khayyām. A Global Reception of the Rubáiyát \\ ISBN 9789087281571}

\author{
A.A. Seyed-Gohrab \& S.R.M. McGlinn (eds.) \\ One Word - Yak Kaleme. 19th-Century Persian Treatise Introducing \\ Western Codified Law \\ ISBN 9789087280895
}
A.A. Seyed-Gohrab \& S.R.M. McGlinn (eds.)
Safina Revealed. A Compendium of Persian Literature in 14th-Century Tabriz
ISBN 9789087280888
A.A. Seyed-Gohrab, F. Doufikar-Aerts \& S. McGlinn (eds.)
Embodiments of Evil: Gog and Magog. Interdisciplinary Studies of the
'Other' in Literature \& Internet Texts
ISBN 9789087280901 
S. Tabatabai

Father of Persian Verse. Rudaki and his Poetry

ISBN 9789087280925

\section{Forthcoming titles in the Iranian Studies Series:}

J.T.P. de Bruijn, The Journey of the Faithful to the Place of Return. A Persian Allegory on the Development of the Human Soul by Sanâ'i of Ghazna, Founding Father of Persian Sufism

J.T.L. Cheung, The Nartic Epic Tradition. Remnants of Iranian Lore from the Caucasus

S.R.M. McGlinn, Abdul-Baha's Sermon on the Art of Governance

R. Rahmoni \& G. van den Berg, The Epic of Barzu as Narrated by Jura Kamal

K. Talattof \& A.A. Seyed-Gohrab (eds.), Conflict and Development in Iranian Film 